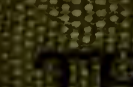

檪

DIE PRINOIPLES AND

- PRACIICE OP 2.

DRUUNT G

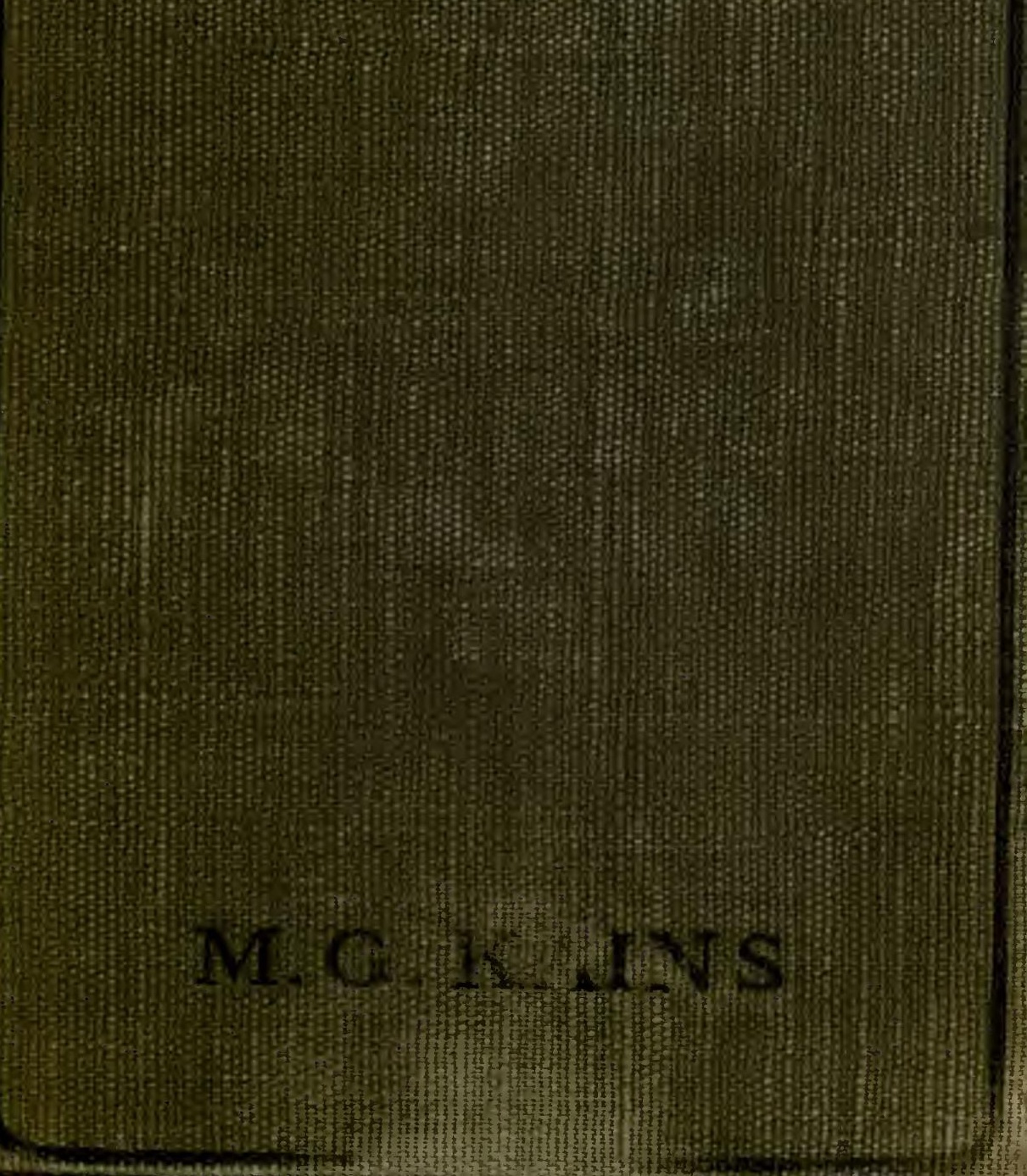




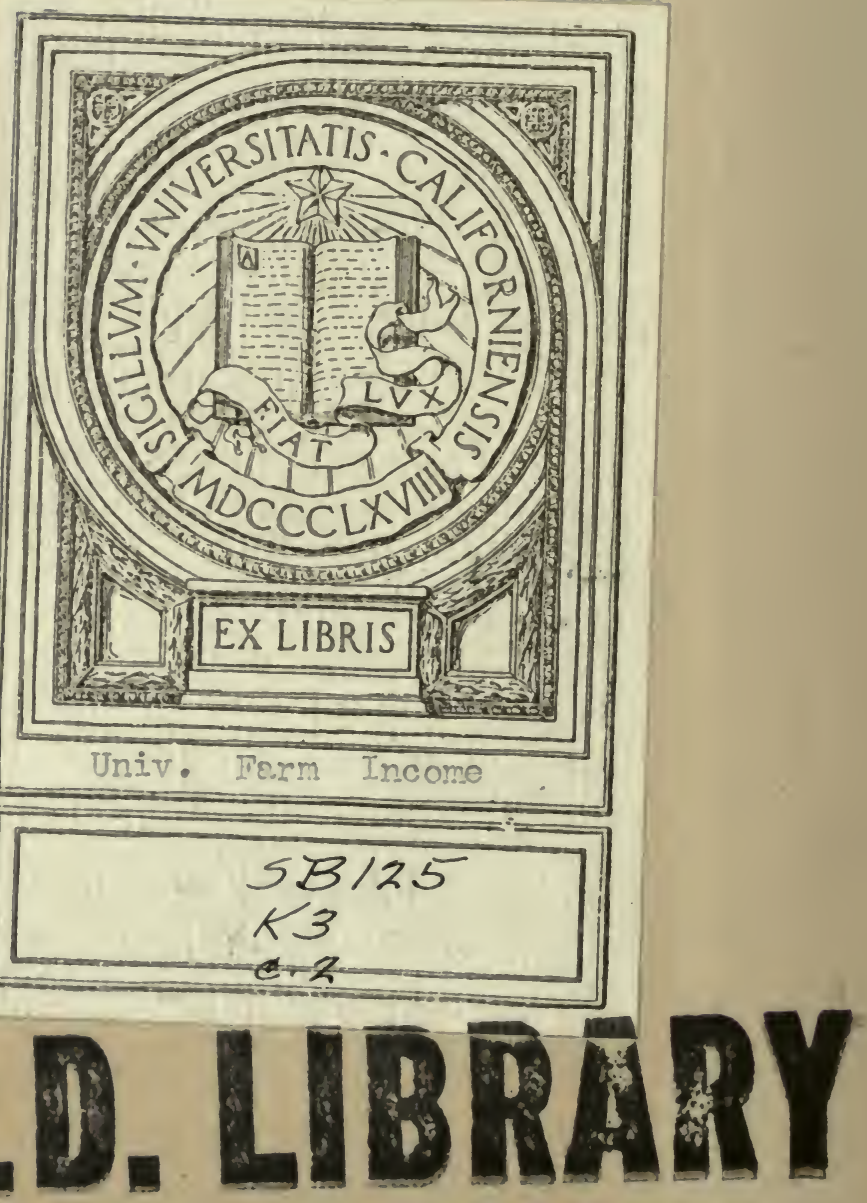




\section{THE PRINCIPLES AND PRACTICE OF PRUNING}




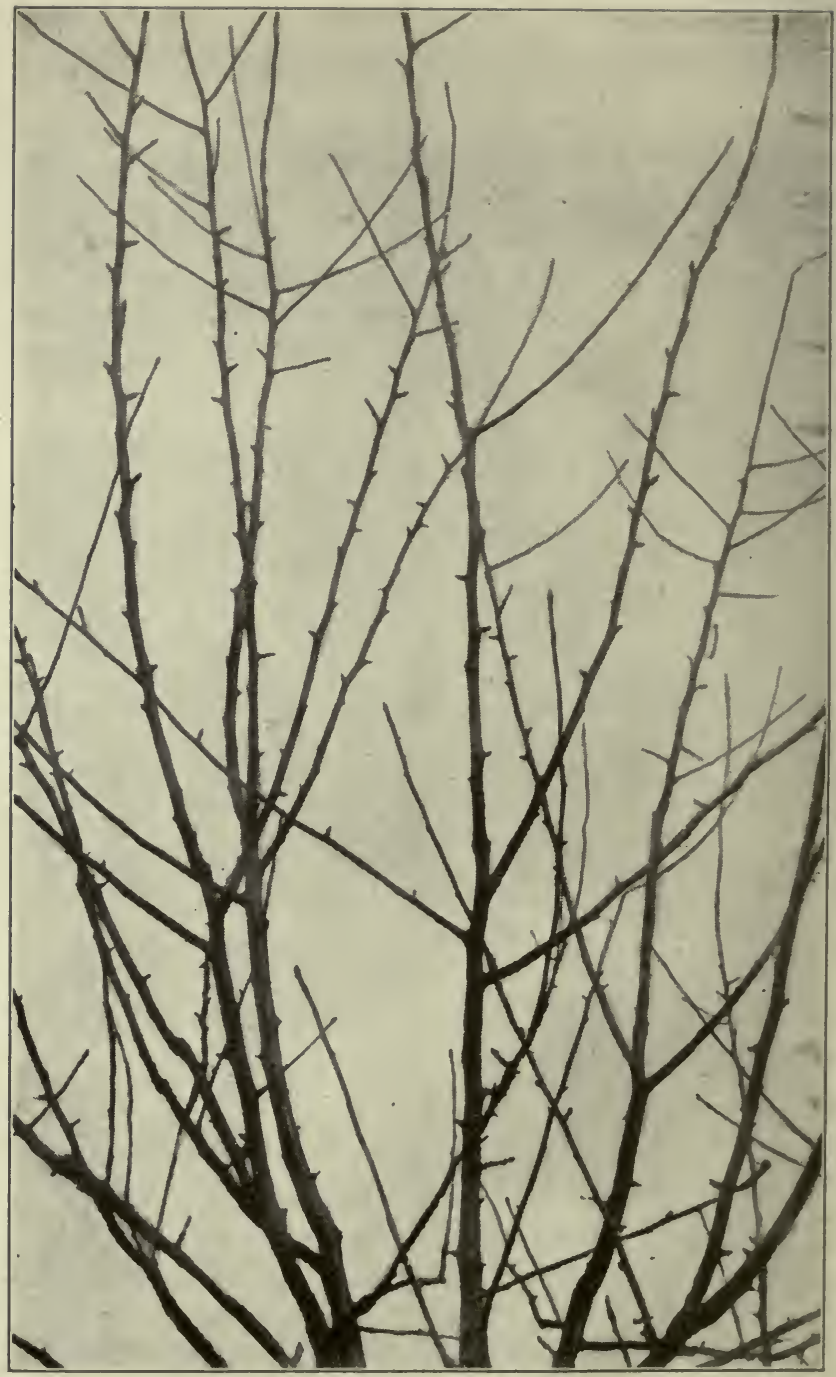

CLOSE VIEW OF FRUIT SPURS OF TREE SHOWN IN FIG. 173

This shows the tendency of unheaded shoots to develop large numbers of fruit spurs. Notice that a spur has developed from nearly every node on the two-vear wood, and this in the top of a young tree of a variety normally slow to come into bearing. 


\section{The Principles and Practice of PRUNING}

Je weniger wir zu schneiden haben am Baum, desto gesunder bleibt er und desto schöner entwickeln sich Früchte. - Karl Koopmann.

[Translation.- The less a tree is cut, the sounder it will be, and the better its fruits.]

\section{By}

M. G. K A I.N S

Lecturer on Horticulture,

Columbia University

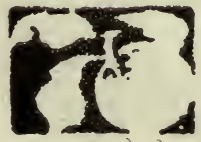

NEW YORK

ORANGE JUDD COMPANY

1920 
Copyright, 1917 , by

ORANGE JUDD COMPANY

All Rights Reserved

Uniritane?

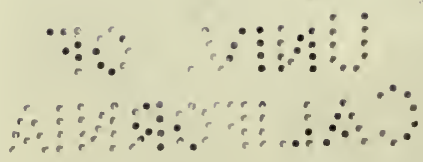

Printed in U. S. A. - 
To tije memory

of

ftlp Grandatjer

in whose well=managed plantation

IJ gained my fírst pruning experience

and discobered mp love for

fruit growing 


\section{If Trees Could Talk}

\section{Frank L. Brace in Tree Talk}

If trees could talk, the tales they'd tell

Would surely be worth listening to.

The trees that form the shady dell,

Where lovers their fond vows renew;

The trees that guard the home, the street

Where children play and elders rest;

What varied tales would they repeat

Of hopes deferred or hearts oppressed

Of happy lives divinely blest.

If trees could talk, how oft we'd hear Of gross mistreatment, lack of care, Borne patiently for many a year, While thoughtless mortals unaware Of how trees suffer, why they fail, Put forth no effort to repel

The foes that constantly assail.

Sad tales like this we know full well, A myriad suffering trees would tell.

If trees could talk, methinks their words

Would sound a protest loud and stern For loss of their good friends, the birds, And make a plea for their return.

Trees need the birds and so do we.

In the incessant fight to stay

The foes that so persistently

On flowers and fruit and foliage prey, Our allies, vigilant, are they.

Trees cannot talk, and yet, to him

Who truly loves these friends of man, Their every leaf and flower and limb

Is vocal. Since the world began

The trees have been our steadfast friends, And our well-being constantly

Upon their life and growth depends.

How faithful then our care should be,

How fondly should we love the tree. 


\section{PREFACE}

AEW practices in the handling of plants, especially of fruit trees and bushes, attract so much interest as those of pruning. The methods are so varied, the results so diverse and the apparently contradictory opinions of growers so tenaciously held that this subject is always one of the surest to arouse discussion and hold attention at horticultural society meetings and wherever demonstrations are given by agricultural colleges and schools and by farm bureaus.

During the past two decades the principles of plant physiology have been more satisfactorily applied to plant production and crop management than ever before in the history of agriculture. Especially during the latter half of this period have experiment station and other workers been devoting annually increasing attention and time to pruning investigations in their efforts to discover new truths and to prove not only disputed and undecided points, but to test many beliefs and rules of thumb which have been accepted as true, but which increasing knowledge of plant physiology has led these investigators to challenge. Much has been discovered, much verified and much disproved. But the reports of these investigations are necessarily so scattered that very few fruit growers have access to them, and students of agricultural colleges and schools, even if they know how to search, lack the time to hunt through the libraries of their respective institutions to find this literature. Many bulletins and reports are out of print, so none can be had. Hence the demand for a book which shall present the really important features of these investigations as well as set 
forth the fundamental principles based upon the laws of plant growth.

The writings on these pruning investigations have been quoted freely, the original investigator's own words being used in preference to mine. This I feel simple justice both to investigator and reader, because in any re-statement something is sure to be lost. The reader will herein find only slight condensations of the investigators' original text. Among the writers so quoted are: Professors Lewis of Oregon, Bioletti of California, Blake of New Jersey, Whitten and Chandler of Missouri, Keffer of Tennessee, Drinkard of Virginia, Howe and Gladwin of New York, Selby of Ohio, Newman of South Carolina, and Collins of the United States Department of Agriculture.

In the preparation of this volume $I$ have found the Experiment Station Record, published by the United States Department of Agriculture, of immeasurable help in searching for literature on pruning by means of its abstracts and voluminous indexes. From it occasional brief passages, mainly concerning foreign investigations, have been copied, with credit to the original sources of information instead of to the Record itself.

My special thanks are due to Professor W. G. Brierley of the University of Minnesota for photographs of pruning tools (Figures 107, 108, 110, 114, 116 and 118) and the legends which accompany them; to Mr. B. F. IVilliamson of New York, who made almost all of the pen and ink drawings, either from rough sketches or from the original sources in bulletins, reports, etc.: and to $\mathrm{Mr}$. E. T. Kirk of the Pennsylvania State College for photographs of local subjects, mostly gathered in the college orchard and on the campus. The other photos, except as specified under "Acknowledgments," were "snapped" by my own camera, mainly at State College, Pa., and developed by Mr. Kirk, 
I have had too long experience in editing books and articles to suppose that this volume is physically perfect. I therefore request that readers kindly note any least error and notify either the publishers or me, so that correction may be made in future editions. In the hope, however, that these errors will be few and that the book will meet the need of those for whom it has been written, I commend it to all who may have occasion to use pruning tools.

M. G. KAINS.

Port Washington, L. I. 



\section{ACKNOWLEDGMENTS}

The following individuals and institutions have supplied illustrations referred to by the figure numbers opposite their names.

Prof. W. G. Brierley, University of Minnesota at St. Paul

$107,108,110,114,116,118$

California Experiment Station at Berkeley

$257,258,265,282$ to 286,288 to 290

Colorado Experiment Station at Fort Collins___._-_-_._-_._2, 136a Connecticut Experiment Station at Storrs

25 to $27,209,215,216,302$

Cornell Experiment Station at Ithaca, N. Y.

211 to 213,183 (redrawn by B. F. Williamson)

Prof. A. W. Cowell, Pennsylvania State College at State College,

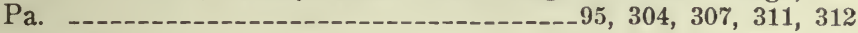

Credit lost

Farmers' Bulletins of the United States Department of Agri-

culture $181,188,190,248,254$ to 256,259 to $262,264,266$, 274,276 to 281,287

N. R. Graves of Rochester, N. Y. 298 to 300

Idaho Experiment Station at Moscow 75 to $77,92,93$

Indiana Experiment Station at Lafayette

$61,73,132$ to $134,178,179$

Iowa Experiment Station at Ames-_-_-_-_-_-_-_-_-_ 70

E. D. Kains of Wyomissing, $\mathrm{Pa}$. -..._-_._._. $64,65,96,310$

Kentucky Experiment Station at Lexington_-_-_-_-_-_-_-_269 to 273

Maryland Experiment Station at College Park_-_-_-_-_-_._-_2, 102

A. F. Mason of State College, Pa.

Massachusetts Experiment Station at Amherst_-_-_-_._-_-_-_-_ 313

Missouri Experiment Station at Columbia

$98,120,214,217$ to 225,294

New Jersey Experiment Station at New Brunswick

$121,122,125,128$ to 131,195 to 198,200

New York Experiment Station at Geneva

North Carolina Experiment Station at Raleigh_._-_-_-_-_-_-_-- 33

Ohio Experiment Station at Wooster

$-4,315$ to 324 
Oregon Experiment Station at Corvallis, 'Frontispiece, 23, 124, 145 to 152,154 to $177,180,182,184$ to $187,189,191$ to 193 , 202,235 to 237

Rhode Island Experiment Station at Kingston_-137 to 144, 240, 244 Tennessee Experiment Station at Knoxville-_-_-_-_-_-_-_234 to 266 United States Department of Agriculture at Washington, D. C.

$301,303,305,306,308,30$ !)

Vermont Experiment Station at Burlington_-_-_-_-_71, 205 to 208

Washington Experiment Station at Pullman-_-_-_-_-_-_-_---- 247

West Virginia Experiment Station at Morgantown

$153,238,239,242,243,245,246,250$ to 253

W. R. White of State College, Pa. -...- 96

B. F. Williamson of New York City

$10,12,13,15,17,19,106,109,113,135,136 \mathrm{a} .263$

Wisconsin Experiment Station at Madison

$11,66,67,123,127,136,194,314$ 


\section{CONTENTS}

CHAPTER I

Introduction .

CHAPTER II

Plant Physiology as Related to Pruning . • $\quad 6$

CHAPTER III

The Philosophy of Pruning. .
CHAPTER IV

Buds . . . . . . . . . . . . 48

CHAPTER V

Pruning Principles .

CHAPTER VI

How Wounds Heal

CHAPTER VII

Prevention and Repair of Mechanical Injuries . 138 ,

CHAPTER VIII

Dressings for Wounds . . . . • . 154

CHAPTER IX

Pruning Nursery Stock .
CHAPTER X

Pruning Young Trees . . . . . . 186

CHAPTER XI

Pruning Mature Trees xiii 
xiv

CONTENTS

CHAPTER XII

Page

Care of Top-Worked Trees

CHAPTER XIII

Bush Fruit Pruning

CHAPTER XIV

Grape Pruning and Training

. 294

CHAPTER XV

Pruning Ornamental Trees and Shrubs.

. 354

CHAPTER XVI

Dwarf Tree Pruning and Training .

. 364

CHAPTER XVII

Odd Methods of Pruning and Training .

. 371

CHAPTER XVIII

Practical Tree Surgery .

CHAPTER XIX

Rejuvenation of Neglected Trees

.405 


\section{LIST OF ILLUSTRATIONS}

Fig.

Close View of Fruit Spurs of Tree-Frontispiece

1 Renovating an Old Neglected Apple Tree . 2

2 Wrongly Cut Limb with Decay Hole . . . 3

3 Tree Too High-Headed . . . . 4

4 First Crop of Apples After Renovation of Old Trees .. . . . . . 5

5 Meristematic Cell from Root Tip of Maize $\quad 6$

6 Chlorenchyma Cell Showing Starch Grains and Chloroplasts . • . . . . 7

7 Root Hair Greatly Magnified . $\quad$. 9

8 Root Tip Much Magnified . $\quad$ • $\quad$ • 9

9 Rootlet Seen in Cross Section . . . 10

10 How Nursery Trees Are Dug . • . 11

11 Last Year's (Black) and This Spring's (Light)

Roots; Also Buds of Spruce . . . 12

12 Epidermal Cells and Stomata from a Leaf - 15

13 Three Sections of Oak Branch Showing Various Tissues . . . . . . 17

14 Cross Section of Stem $\quad$ • $\quad$ • $\quad$ • 19

15 Fibro-Vascular Bundle . . . . 21

16 Contrasting Growths of Mazzard Cherry . 22

17 Diagram of Cut Edge of Leaf . • . 23

18 Comparison of Growth . . . . . 24

19 Cross Section of a Leaf . • • • 25

20 Side View of an Apple Seedling . . . . 27

21 Seedling Apple Seen from Above . • . 28

22 "Leggy" Peach Trees" . . . . . 32

23. Result of Close Planting and Poor Pruning • 34

24 How Not to Manage Trees . . . . 35

25 White Pine Plantation, Before Thinning . 37

26 White Pine Plantation After Thinning . . 38 
Fig.

27 Seedling Chestnut 103 Years Old .

28 How Branches Are Buried .

29 Apple Twigs of Various Ages

30 Dehorning with a Vengeance

31 New Growth on "Dehorned" Peach Tree

32 Nothing Wrong with the Roots

33 Fruiting Habit of Fig

34 Apple Branch Estimated 20 Years Old

35 Fruiting Spurs of Apple

36 Blooming Twig of Apple

56

37 Peach Spur

38 Annual Growth of Peach

39 European Plum

40 Tapanese Plum

41 Blossom Buds of Sour Cherry

42 Sweet Cherry Twig in Two Sections '. . 63

43 Swect Cherry . . . . . . . 64

44 Sour Cherry . $\quad . \quad . \quad . \quad . \quad .65$

45 Four-Year Sweet Cherry Twig . . . 65

46 Fruit and Leaf Buds of Peach . . . 66

47 Peach Twigs That Have Borne Fruit . . 66

48 Japanese Plum . . . . . . . 67

49 Currant Branches of Various Ages . . 67

50 Gooseberry Branches, Young and Old * . 68

51 Grape Cane One Year Old . . . . . . 69

52 Red Currant Bloom Cluster . . . . . 71

53 Gooseberry . $\quad . \quad$. $\quad . \quad . \quad .71$

54 Fruiting Branch of Blackberry . . . 73

55 Red Raspberry Fruiting Branch . . . 75

56 Black Raspberry Fruiting Laterals and Cane . 77

57 Characteristic Grape Shoot of a Labrusca Variety

58 How Quince Bears Bloom . . . . . 79

59 Quince Method of Fruiting . . . . 80

60 "Der End of Der Limit" in Pruning . . 82

61 The Tree Butcher's Method . . . 84 
62 Upright Limb Replaces Horizontal One . 84

63 Leader Renewed in Broken Tree . . . 86

64 One of the Worst Foes of Trees Is the "Line Man". . . . 88

65 Tree's Attempt to Offset Butchering . . 88

66 Yearling Growth Cut Back . . . . 90

67 How Crooked Branches Are Made . .91

68 One Way Horizontal Branches Are Killed . 93

69 Poorly "Pruned" Pear . . . . . 94

70 Twenty-Year-Old Catalpa Plantation . . 96

71 Typical Pasture-Grown White Pine . . 98

72 Branches of Low-Headed Trees Tend to Ascend at Acute Angles . . . . . 100

73 Badly Developed Tree Head . . . 104

74 Effects of Ringing Young Trees . . . 108

75 Shoot Growth from Stubs Left in May . . 111

76 Shoot Growth from Winter-Pruned Stubs . 112

77 Effects of August Pruning . . . . 113

78 How Bark Becomes Rough by Splitting and Healing

79 Cross Sections of White Pine $(2 \times 4)$ Scantlings Showing Branches Buried by Tissue . 122

80 Cross Section of Pine Scantling . . . 123

81 Dead Limbs Being Buried . . . . 123

82 History of a Stub in Six Chapters . . 124

83 Hoping Still . . . . . . 125

84 More Than Three-Fourths of the Trunk Lost

by Decay and Breakage . . . . 125

85 Flicker's Nest . . . . . . 126

86 Cannon Ball in Oak Tree . . . . . 127

87 Heart Decaying . . . . . . 128

88 Cuts Made Heading-In Twigs . . . 129

89 Wrong Way to Cut Off Big Limbs : . 130

90 Proper Way to Start Cutting Off Large Limb - 131

91 Second Cut Properly Made in Sawing Off

Large Limbs 
Fig.

92 Wrong Way to Make a Cut in Removing a Large Limb

93 Right Way to Make Pruning Cut .

94 Sad Effects of Sleet Storm

95 Label Wire Makes Girdled Limb Bloom Prematurely

96 A Wire Girdled This Cherry Tree .

97 Bench Supported by Living Tree.

98 How to Handle Young Forked Tree

99 History of a Crotch Split .

100 Triple Y-Crotch

101 Saving a Y-Crotch

102 Splitting of Peach Tree Where the Top Was Improperly Formed with a Y-Crotch

103 One Wrong Way to Mend Y-Crotch

104 Living Wood Brace Between Trunk and Limb of Norway Maple. Well-Branched I.ow-Headed Peach Pole Shears for Outside Branch Pruning Pole Shear Pruners, Sliding Handle Type Pruning Shears of Various Styles

110 Good, Bad and Indifferent Hand Shears .

\section{Common Pruning Saws}

112 Pruning Knives of Various Styles .

113 Collection of Pruning Knives

114 Principal Styles of Double-Handled Lopping Shears

115 Good, Bad and Indifferent Pruning Saws

116 Types of Hand Saws for Tree Pruning .

117 Students' Combination Saws

118 Pole Saws Are All Awkward in Use, Make

Ragged Cuts and Are Undesirable

119 Where New Roots Start 
Fig.

122 After Pruning Tree in Fig. 121

123 How Top of Newly Set Tree May Be Pruned . 171

124 Effect of Wind on Unstaked Trees

125) Peach of Poor Form . . . . . . 173

126 After Pruning . . . . . . . . . . . . .

127 Young Trees Properly Heeled in for Temporary Storage . . . . . 174

128 Yearling Peach Before Pruning . . . 175

129 Same Tree as in Fig. 128 After Being Pruned 175

130 Undesirable Form . . . . . 176

131 Desirable Form of Growth Made by Tree Headed About 2 Feet When Set . . 176

132 Developing Tops on Second-Class Trees . 177

133 Well-Branched Nursery Tree . . . 178

134 Where to Cut . $\quad . \quad$. $\quad . \quad$. 179

135 How to Plant a Tree . . • . . 179

136 Air Space Among Roots of Badly Planted Tree 180

137 Tree Set Obliquely Against Wind . 180

138 Tree Grown from Untrimmed Nursery Stock 181

138a Tree from "Stringfellowed" Roots . . 181

139 Tree Grown from Stub-Pruned Roots . . 182

140 Tree Grown from Untrimmed Nursery Plant . 182

141 Head on Tree Where Roots Were Cut Back . 183

142 At Planting Time the Branches Were Cut Back 183

143 Tree Grown from a "Whip" with the Leader Left . . . . . . 184

144 Head Formed by "Whip" with Leader Cut Back 184

145 Badly Formed Tree Head . $\quad . \quad$. 186

146 Main Branches Barren Because of Neglect . 187

147 Old Bartlett Fruit Spurs Which Bloom Yearly but Seldom Bear Fruit . . . 188

148 Young Yellow Newtown Tree Before August

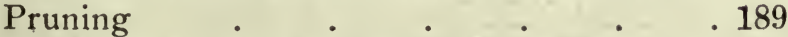

149 After August Pruning Young Yellow Newtown 189

150 Vigorous Shoot Produced from Old Bartlett Pear Spur 
Fig.

151 Heavy Heading Back Develops Wood .

152 Typical Leader Tree.

153 Three Decks of Frame Limbs

154 Modified Leader

155 Modified Leader

156 Good Modified Leader

157 Modified Leader

158 Example of Unequal Growth

159 Good Vegretative Response from Thinning Bartlett Pear Spurs . . . . . 19j

160 Five-Year-Old Wagener Apple Tree . . 196

161 Heading Back Makes Growth . . . . 197

162 Good Effect of July Pruning . . . . 198

163 Good Example of Proper Balance Between Branches

164 Balanced and Unbalanced Pruning . . 200

165 Reinvigorated Top of Old Pear Tree . . 201

166 Moderate Pruning Stimulated Shoot Formation 202

167 Pear Spurs Which Have Borne Well in Previous Years . . . . . . . 203

168 Too Much Shading by U'pper Branches Killed This Twig

169 Abundance of Fruit Spurs in the Light . . 205

170 Partial Dehorning Failed . . . . 204;

171 Heavy Pruning Makes for IVood • . . 207

172 Vigorous Growths Follow Thinning . . 208

173 Fruit Spurs Due to Good Pruning . . 209

174 Typical Five-Year Winter Nelis Pear . . 210

175 Fruit.Spurs Form on Last Year's Shoots . 211

176 Five-Year Newtown Pruned . . . 212

177 Five-Year Apple Pruned Previous Summer . 213

178 Well-Formed Apple Tree Head . . . 214

179 Splendid Distribution of Frame Branches on

Four-Year Apple Tree . . . . 215

180 Far Too Many Fruit Spurs . . . . . 216

181 Plan of Tree at Planting Time . . . . 217 
Fig.

183 Fire-Blight Handling Kit . . . . . 219

184 Poor Type Cherry . . . . . . 220

185 Three-Year Lambert Cherry Before Early July Pruning

186 Three-Year-Old Lambert Cherry Tree After Pruning in Early July

187 Old Prune Tree After Removal of Dead Wood and Severe Thinning of the Living Spurs . 222

188 Five-Branched Tree at end of First Season . 223

189 Neglect Following Dehorning

190 Plan of Tree Top After One Season's Growth in Orchard . . . . . . 22\%

191 English Walnut . . . . . . 225

192 Splendid Type of Low-Headed, Spreading English Walnut

193 Portable Brush Incinerator: . . . . 227

194 Well Pruned and Open Headed . . . . 228

195 Good Yearling Peach $\quad$. . . . . . 229

196 Peach Trunk, $1 \quad$. $\quad . \quad$. $\quad . \quad$. $\quad .229$

197 Peach Trunk, 2 . . . . . . 230

198 One-Year Peach from Nursery . . . . . 231

199 Good Tree Protector . . . . . . . 231

200 One-Year Peach from Nursery . . . . 232

201 Inviting Disaster . . . . . . 241

202 Unpardonable "Pruning" . . . . . . 242

203 Cross Section of Trunk Shown in Fig. 204 . 243

204 How Trees Bury Stubs . . . . 244

205 Winter Injured Rhode Island Greening Apple

Tree Before Pruning in Early June . . 245

206 Pruned Apple $\quad$. $\quad . \quad$. $\quad . \quad$. . . 246

207 August . . . . . . . . . 246

208 September Showing . . . . . . . 246

209 Healthy Pear Bark Showing Lenticels . . 247

210 Fungi Attack Injured Bark . . . . 248

211 Pear Stub Admits Blight . . , . 248 
Fig.

212. Blight Spread from Pruning Wound

213 Cankered Limb Showing Blight Exudations

214 Frost-Killed Peach Wood Variously Handled

215 Winter Injury of Peach

216 Winter Injuries .

217 Poor Growth of Peach Tree Not Pruned After

Severe Winter Injury

218 Peach Trees Cut Back with Varying Degrees of Severity

219 Tree Headed Back More Severely Than It Should Be and Too Many Branches Left . 257

220 Properly Cut Back Peach . . . . 258

221 Unsatisfactory Growth of Peach Not Pruned

Back Severely Enough After Winter Injury . 259

222 Peach in Foreground Shows Good Growth . 260

223 One Season's Growth of Eight-Year Peach . 261

224 Old Mixon Free Peach with Spreading Head . 262

225 Peach Tree with Very Dense New Growth . 263

226 Greensboro Five Years Old . . . 264

227 Greensboro Peach, Five Years Old . . 265

228 Greensboro, Five Years Old, Not Summer

Pruned . . . . . 266

229 Greensboro, Five Years Old, Pruned in August 267

230 Greensboro, Five Years Old, Pruned in July. . 268

231. Five-Year Belle of Georgia Pruned in Early June

232 Five-Year Belle of Georgia Not Summer-

Pruned . . . . . . 270

233 Greensboro Tree, Seven Years Old, Not Sum-

mer Pruned. . . . . . . 271

234 Fourteen-Year Greensboro Summer-Pruned . 272

235 New Growth on Top-Worked Apple . . 275

236 One Season's Growth on Top-Worked Apple . 276

237 New Growth at End of Second Season on Top-

Worked Apple Tree

238 Red Raspberry Canes Before Pruning . . 280 
Red Raspberry Canes After Pruning .

240 Bramble Canes in Position for Covering with

Earth for the Winter . . . . . 282

241 Red Raspberry Cane Improperly Pruned . . 283

242 Black Raspberry Before Pruning . . . 284

243 Black Raspberry After Pruning . . . 285

244 Loganberry Plants with Fruiting Canes Supported on Wire Trellis . . . . . . 286

245 Blackberry Canes Before Pruning . . 287

246 Blackberry Canes After Pruning . . . 288

247 Styles of Bramble Cane Supports . . . 289

248 Popular Styles of Blackberry Training . . 290

249 Blackberry Cane and Main Branch . . 291

250 Unpruned Currant Planted One Year . . . 292

251 One-Year Planted Currant, Pruned Same as Fig. 250

252 Gooseberry Before Pruning . $\quad . \quad 292$

253 Gooseberry After Pruning . . . . . 294

254 Vines Growing in Vineyard the First Year . 295

255 Grapevine Showing Method of Pruning Roots

Ready for Planting . . . . . 296

256 Rotundifolia (Muscadine) . . . . . 297

257 Unit of Short Pruning . . . . . . 298

258 Unit of Long Pruning of Grapevine . . 299

259 Vines Headed Back for Various Systems of Pruning . . . . . . . . 300

260 Pruned and Unpruned Vine at Various Stages of the Renewal System . . . . 301

261 Umbrella Trellis . . . . . . 302

262 Fan System, Vine at Various Ages . . 303

263 Wire Hook for Holding Vine to Trellis . . 304

264 Post and Stake Methods of Grape Training . 305

265 Head Pruning: Fan-Shaped Head, Fruit

Canes Tied to Horizontal Trellis . . 306

266 Diagram of Ordinary Trellis _ . . . 307 
r.1.

267 Recurving the Canes as in the Fan System Usually Tends to Promote Fruitfulness . 3^s

268 Unpruned Vine Trained According to the Fan System

269 The Kniffin System. Before Pruning Grapevine 314 270 The Kniffin System of Training the Vine

Shown in Fig. 271 . . . . . . 315

271 End of Munson Row . . . . . 317

272 Munson System of Training, Vine Unpruned . 318

273 Munson System of Grape Training . . 319

274 Pruned and Unpruned Vinc, "Umbrella"

Kniffin System

275 Various Methods of Vine Pruning Popular in

New. York

276 Vine in Its Fourth Year

322

325

277 Hudson Horizontal System

326

278 Caywood System of Grape Training . . 327

279 Parrales System of Training Vines . . 328

280 Muscadine (Rotundifolia) Grapevine . . 329

281 Cross-Wire System Showing Pruned Vine . 3:30

282 Sultanina Vine Showing Effect of Tying Fruit

Canes in Vertical Position

283 Rooted Vine Pruned

$33:$

284 Treatment of an Average Vine During Second Season.

285 Grape Spur

286 Three-Year-Old Vines After Pruning

287 Grapevines of Various Ages

. 338

288 Forms of Grapevine Head 'Training

289 Treatment of Average Vine in 'Third Season or

Vigorous One in Second

290 Forms of Head Pruning of Grapes

291 Horse Chestnut Co-Terminal Bloom Bud Expanding

292 Shade Tree Headed Too Low . . . 357

293 Huge Wound Well Made . 
Fig.

294 How to Force Peach Buds to Determine Their Condition

295 Golden Bell-Forsythia 360

296 Co-Terminal Method of Bloom BearingWeigelia

297 Red Bud

298 Dwarf Fruit Trees Artistically Handled in Amateur Garden . . . . . 372

299 Dwarf Pear Trees Trained in Simple Way . 374 300 Peach and Pear Trees Trained to Wire Trellis 376 301 Treated Injuries Normally Heal . . . 382 302 Mutilated to Lay a Curb . . . . 383 303 Cement Fillings and Guy Chain Attuchment . 385 304 Good Healing Over Properly Placed Bolt Head 387 305 Long Cavities Excavated Through Several Openings

306 Excavated, Bolted and Cemented Cavities

308 Cement Filling Types and Successive Steps 392 309 Proper Method of Fastening Guy Chains and Bolts 393

310 Isn't This Ghastly?

311 Roping a Tree Preparatory to Bolting .

312 Students at Work in Tree Surgery .

313 Methods of Fastening IVires to Trees . .

314 Neglected Tree Hard to Spray and Harvest 397 398 399 404

315 Old Peach Tree Before Rejuvenation . 405

316 Old Peach After Cutting Back Severely .

317 Old Peach Tree Rejuvenated

318 Orchard Before Renewal or Renovation .

319 Caught Red Handed! .

320 Trees After Cutting .

321 First Season's Growth After Pruning .

322 Isolated Apple Tree Pefore Pruning

323 Isolated Apple Tree After Being Pruned 



\section{INTRODUCTION}

1. Pruning defined.-Pruning is the horticultural process of cutting off excess or undesirable living, dying or dead branches, twigs, roots or other plant parts, especially of fruit trees, vines and shrubs, to benefit the parts that remain. It naturally divides into three classes, dependent upon the aim of the pruner; namely: 1 , pruning for profit, as in the case of fruit trees and bushes, the object being to secure finer or more specimens ; 2 , pruning for ornament, in which case the form of the specimen is altered for a real or a fancied improvement; 3 , pruning to save the life of the specimen-repair pruning or tree surgery, as it is today popularly called. In the present volume the main object is pruning for profit, but the principles and the practice underlying the other two classes are discussed, so the reader may have a good general or working knowledge of each.

The practice, which is as old as human history, is referred to specifically in Leviticus (xxv, 3,4), in which the children of Israel are told to prune their vineyards and gather the fruit during six years, but in the seventh year to let the vines go unpruned. In five other passages in the old Testament figurative reference is also made to pruning and "pruning hooks." In spite of the ancient origin of the practices and the efforts of many investigators during the intervening centuries, we have by no means reached the limit of knowledge, but can claim to have discovered and demonstrated only a few important principles and useful practices. These are, however, understood by comparatively few of the people who grow plants, and even by many of the self-called pruning ex- 
perts, as evidenced by the ill effects observed in countless fruit and shade trees and illustrated by many of the halftones shown in this volume.

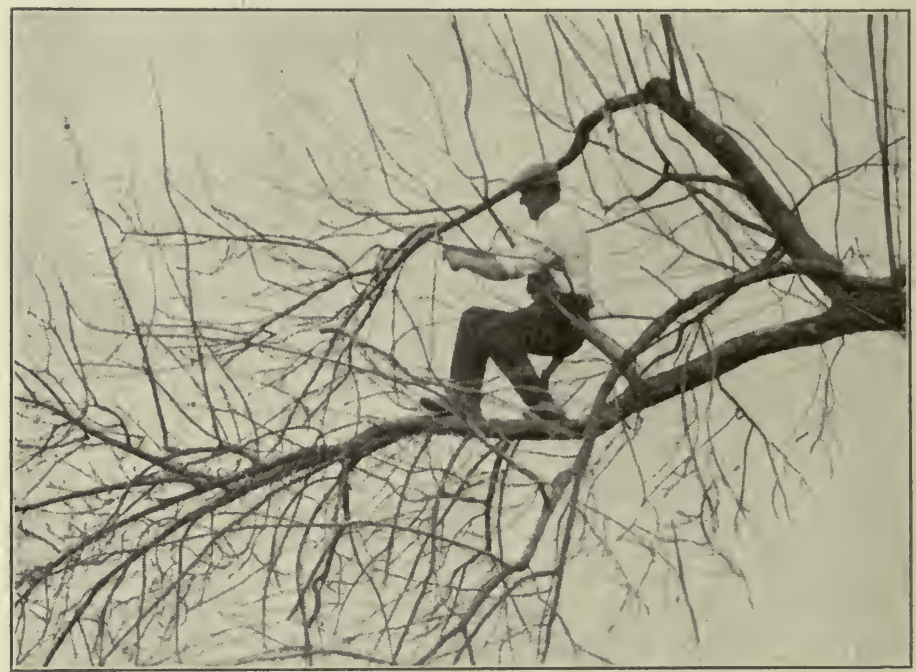

FIG. 1-RENOVATING AN OLD, NEGLECTED APPLE TREE

Notice the upright growths which started as water sprouts, but which have developed into fruiting branches with many short and stubby fruit spurs.

Pruning demands knowledge of plant physiology. Unless the pruner has at least a working knowledge of how plants grow he will be unable to prune intelligently to secure desired results. On the contrary, he may, and probably will, do far more immediate or ultimate harm than good. Simply to top off limbs with an ax (Fig. 61) or improperly to remove others with a saw (Fig. 201) is not pruning, but usually a species of tree butchery or vivisection; for the tree is almost sure to suffer and sooner or later die from the effects. Again, without having a definite, desired end and intelligently working within the scope of the underlying physiological principles, the specimen treated may develop nothing but disease, death, 
decay and disappointment. Therefore, a sketch of plant physiology as it bears upon pruning is given so the reader may better understand the reasons for the pruning principles and practices which follow in subsequent chapters.

2. Pruning systems and ideals.-With every kind of fruit, even the strawberry, there are various systems and ideals of pruning and training. These, so far as the woody fruit plants are c on c e r n ed, differ mainly in the form which it is designed to give the plant and in the management of the annual growths. Some differences are due to variations among the varieties or species, others to the aims sought, still others to the environmental conditions or the fashion of the locality, and many are merely a matter of the grower's whim or caprice (Chapter XVII). Unquestionably the best system is that which is most nearly and readily adapted to the conditions in the individual

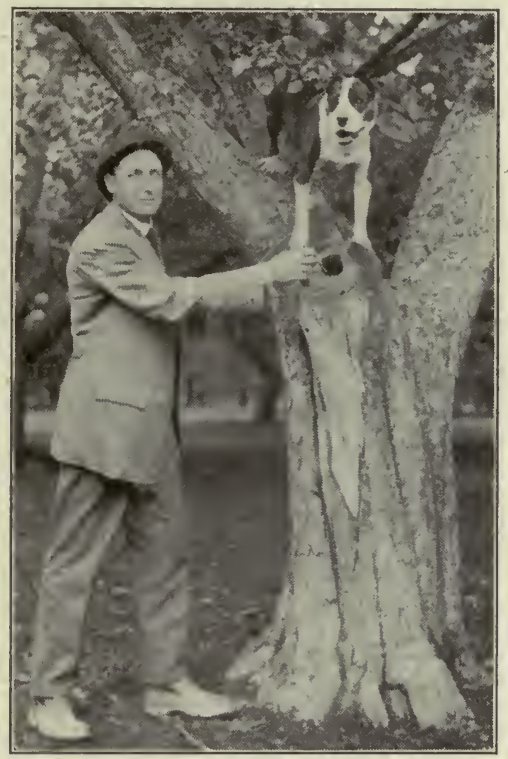

FIG. 2-WRONGLY CUT LIMB WITH DECAY HOLE

The dog has chased a squirrel up in the tree and has jumped up to his present position. plantation. Whatever the system, unless it considers the nature of the plant to be pruned, it is faulty, to say the least.

In no branch of horticultural work is it more important for the operator to have a clear mental picture or ideal 
for which to strive as in pruning. Fruit plants are so open to accidents of cultivation, storm, disease and insect attack that it is often impossible to secure, much less maintain, an absolutely ideal specimen, yet the ideal fruit plant, each for its variety or species, must be held tena-

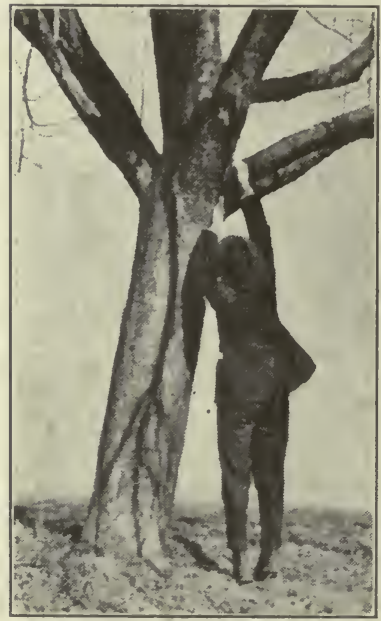

FIG. 3-TREE TOO HIGHHEADED

This $\operatorname{man}$ is 5 feet 10 inches tall. He is reaching over 7 feet. Note also that branches start mainly from one point-undesirable. ciously in the pruner's mind, or his mechanical skill will count for naught, and the plants he prunes will necessarily be uneven in appearance, development, prolificacy or some other important point or points. With a clear ideal constantly held while at work he may constantly approach even approximate realization of his desires, and will be able to counteract undesirable tendencies and to direct the energies of the plant in the right direction. With no plants is this more important than with young ones. This fact is well illustrated by many popular proverbs; for instance, "As the twig is bent, so the tree inclines."

3. Defective pruning may result in one or more of four general classes of undesirable ways: 1 . The average annual crop may be small because of insufficient fruit huds, delayed bearing, irregularity of development, or imperfect utilization of vigor. 2. The quality of the fruit may be inferior because of over-bearing. especially of weak plants, irregular distribution of the fruit, and consequently more or less irregular ripening and injurious contact of the fruits with each other, with twigs, branches 
of the plants bearing them, with the soil or other objects. 3. Shortened life of the plants because of pruning and other wounds, growth of water sprouts and suckers, or to occasional or periodical over-bearing. 4. Excessive cost of plantation maintenance-tillage practices, pruning and thinning, pest control or harvesting and grading.

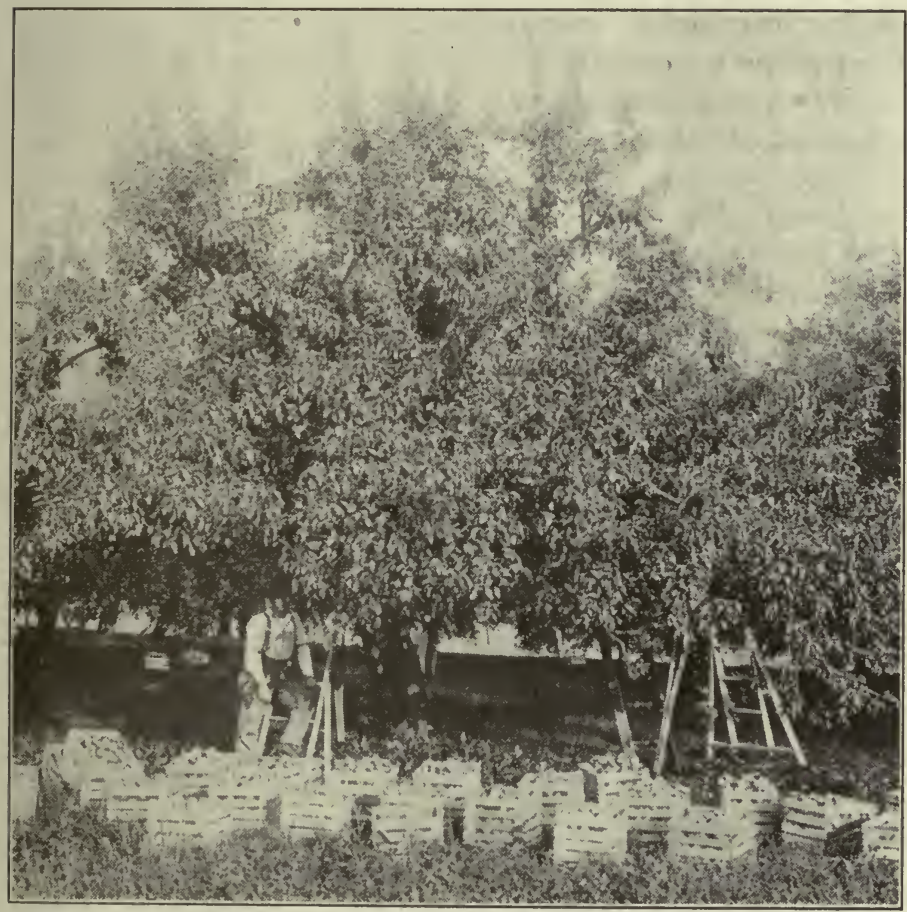

FIG. 4-FIRST CROP OF APPLES AFTER RENOVATION OF OLD TREES 


\section{PLANT PHYSIOLOGY AS RELATED TO PRUNING}

4. Plant cells and their functions.-Knowledge of the "living machinery" upon which fruit and ornamental plant growers depend for profit or beauty depends primarily upon knowledge of the minute structure and the functions of plant eells. It is not necessary in the present

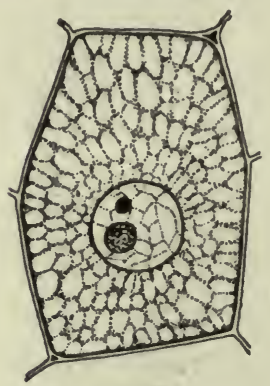

FIG. 5

MERISTEMATIC CELL FROM ROOT TIP OF MAIZE discussion, however, to go into the matter as deenly as does the plant physiologist, even though in practically all physiological processes plant cells form "the important substratum of all vital activity."

5. Cell.- "One of the structural elements of living bodies, by which the multiplication of growth is affected. In plants the cell usually appears as a closed sac surrounded by a firm wall of cellulose and containing the essential element, protoplasm, and usually a nucleus, the active agent in celldivision" (Crozier).

6. Protoplasm.- "The viscid, contractile, semi-liquid, more or less granular substance that forms the principal portion of an animal or vegetable cell" (Standard Dictionary). "The physical basis of life" (Huxley).

7. The water supply has much to do with the activities of protoplasm and cells and the organisms which these compose. Unquestionably it more definitely sets the bounds of plant growth as to habitats, localities and regions than does any other environmental, physical factor; for, unless the plant can secure a sufficient and practically 
constant supply of water during its growing season, the soil, however rich in plant food, might as well be sterile. Succulent plants and plant tissues in active growth contain relatively little fiber, mineral and other solid material, but 75 per cent or more of water. Thick-walled, protective and woody tissues contain relatively less, as may also the succulent parts during periods of drouths.

8. Dual function of water.-Water acts in the double capacity of (1) a plant food solvent and transporting agent, and (2) a crude plant food itself, as in the manufacture of starches, sugars, cellulose, etc. During the growing period, therefore, ordinary plants must be in constant touch with water in greater or lesser supply. Their forms, functions and development are also affected by the volume, the distribution and the mineral content of the available water.

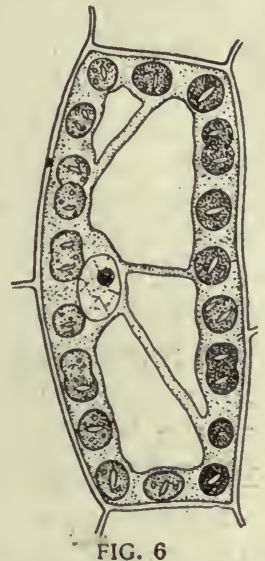

CHLORENCHYMA CELL SHOWING STARCH GRAINS AND

CHLOROPLASTS

Water maintains rigidity in succulent plants and in those growing parts whose cells have not become firm enough to maintain their normal form when the supply of water becomes reduced. This function produces what is termed hydrostatic rigidity, since it enables succulent plants to support considerable weights of branches and other plant parts. Should the water supply become reduced, such plants would droop or wilt more or less seriously. Hence, ample water is a prime requisite of successful development. The supply may be reduced by. other means than simply lack of water in the soil.

"Booth reports an instance in which peaches on Marianna plum stocks grew fairly" well for two years, though from the start the peaches grew more rapidly than the plums, so the peach trunks were at two years twice as large at the union as below. During the second season the weather was very hot and dry, and the peach trees, 
after wilting for several days, but reviving during the night, finally dried out and died, evidently because sufficient moisture was not furnished by the slow-growing Marianna roots to meet the demand from the peach leaves during a period of excessive transpiration." *

9. Water is absorbed by the root system of the great majority of higher plants, especially those used in agriculture and horticulture. This system is of various forms, textures and distributions in the soil, but these differences are not necessarily linked with noticeable differences in the quantities of available water. Root systems may be divided into two general classes, namely: (1) The taproot style, which penetrates the soil more or less vertically downward (parsnip, hickory), with branch roots developed at irregular intervals; (2) the fibrous-root style, which reveals little, if any, main root axis, but has many more or less uniformly sized small roots starting from near the base of the stem (wheat; currant).

10. Root hairs and their function.-Roots and rootlets, no matter how minutely they divide, are both the holdfast organs whereby plants maintain their positions in the soil, and the pipe lines whereby the upper parts of plants are supplied with water taken from the soil. Nevertheless they are of secondary importance to the root hairs with respect to the water supply. The root hairs are single cells which push out from the epidermis of rootlets, not at the immediate and elongating tip, but just in the rear of this part, an area that has ceased to extend, but has not developed thick or hard-walled epidermal cells. Their function is to secure water and crude plant foodmainly of a mineral nature-from the soil. Always they occupy positions within a few inches of the extreme tips of the rootlets. As the tips push forward new root hairs are formed in front of the older ones and the oldest disappear, to be replaced by thicker-walled tissues incapable of absorbing either water or mineral matter from the soil. Root hairs can be easily studied by sprouting seeds and

- Kains, Plant Propagation, Greenhouse and Nursery Practice, Page 189. 
allowing the seedlings to grow a few days between sheets of white blotting paper. When so grown they are more or less straight, but when grown in the soil they are much contorted because of the contact of soil particles.

11. Root hairs are usually most numerous on plants growing in soil that is dry, and least in that which is saturated with water. Also, when the water supply de-

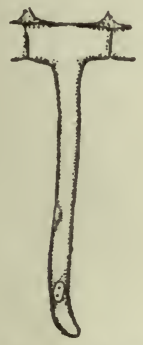

FIG. 7-ROOT HAIR GREATLY MAGNIFIED

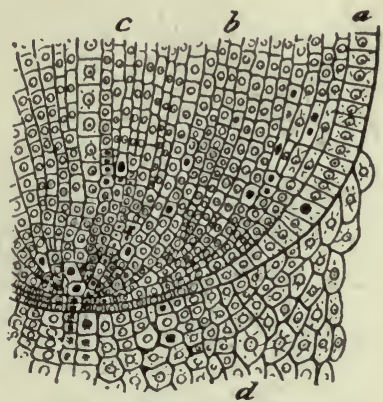

FIG. 8-ROOT TIP MUCH MAGNIFIED

$a$, epidermis; $b$, cortex; $c$, plerome; $d$, root cap.

minishes they become more numerous; and when it becomes wet, less abundant. Plants grown in wet soil and then transplanted to soil much drier will suffer severely unless watered. Often they will die because they cannot develop root hairs fast enough to supply the loss of moisture by transpiration from the leaves.

This finds a specially important application in the pruning of nursery stock at transplanting time; the tops of the plants must be cut back to balance the unavoidable loss of roots due to digging. (Chapter IX.) It may be proved very simply by the following experiment: Sow some cabbage or lettuce seeds in a flat filled with soil of uniform quality. When the plants have two or three leaves and are large enough to prick out, divide the most 
uniform ones into three groups and transplant in flats filled with soil also of uniform quality. Keep the plants of one set very moist, those in another set very dry and those in the third set moderately moist. In three or four weeks transplant the plants to the open ground, treating

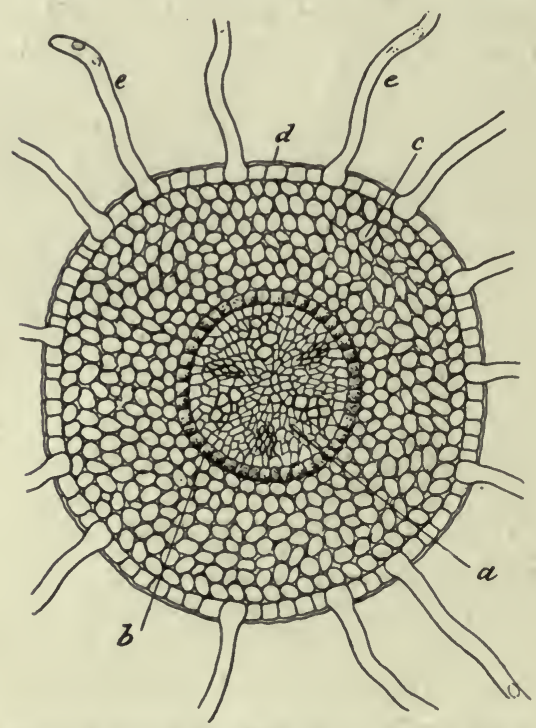

FIG. 9-ROOTLET SEEN IN CROSS SECTION $a$, xylem and phloem; $b$, central cylinder; $c$, endodermis; $d$, cortex; $e$, root hairs. those of each lot in three ways, thus: Transplant some with the least possible loss of any parts, others after removing 75 per cent of the leaf surface and the third lot after the destruction of about half the root and the leaf area. If the open ground conditions are fairly uniform, it will usually be found that the plants kept wet in the flat will suffer most. those kept dry least. and those deprived of considerable leaf surface in each lot will suffer less than those from which none of the leaf area is removed. Don't BELIEVE this statement simply because it is printed in this book. Try it. Prove it. 'Then you will understand why nursery stock should have the tops cut back to balance the loss of root digging.

12. The extent of the root system is usually greater in agricultural plants than that of the trunk, branches and leaves combined. Thus the plants are able to draw water from an enormous area of soil particles, propor- 
tionately the greater as the fineness of the particles and the quantity of organic matter in the soil increase. An idea of the extent of the root systems of cultivated plants may be gained from the statement that a full-grown sunflower will fill almost a full cubic yard of soil with its root system. Such an enormous water-absorbing area is necessary because other parts of the plant (in agricultural plants, at least,) are not fitted or at best are poorly fitted for absorbing water.

Even leaves which are supposed to absorb water when wilted by rain and dew are much less able to do this than is popularly supposed. Yes, 1 e a ves wilted by hot weather quickly become turgid after a shower, but this is far less due to the water on surfaces than to the reduction of transpiration in the cooler, moister air and to the increased supply of water which the roots can draw upon. Leaves of some plants, however, are able to take up water much more readily than others, but these are such as do not concern the subject of pruning.
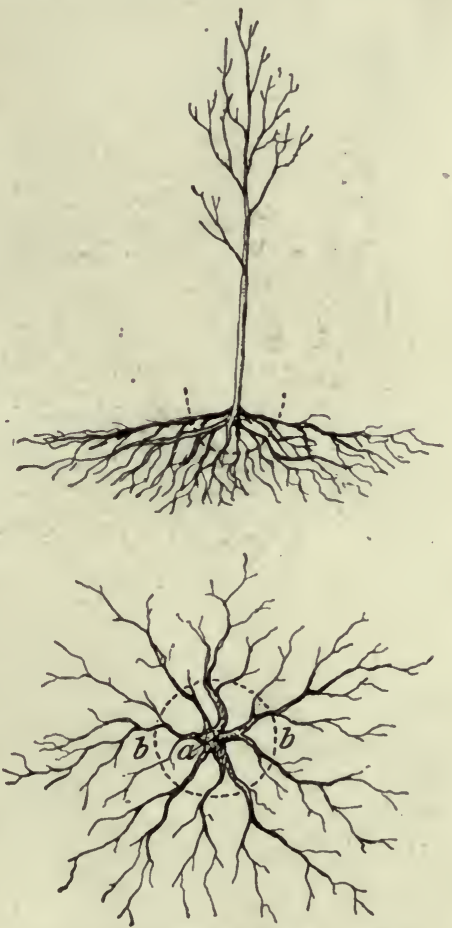

FIG. 10-HOW NURSERY TREES ARE DUG

Dotted line shows diagrammatically where roots are cut; $a$, what the purchaser gets; $b$, what is left in the soil.

13. Osmosis and diffusion of water account for passage of water from the soil through the root hairs and upward 


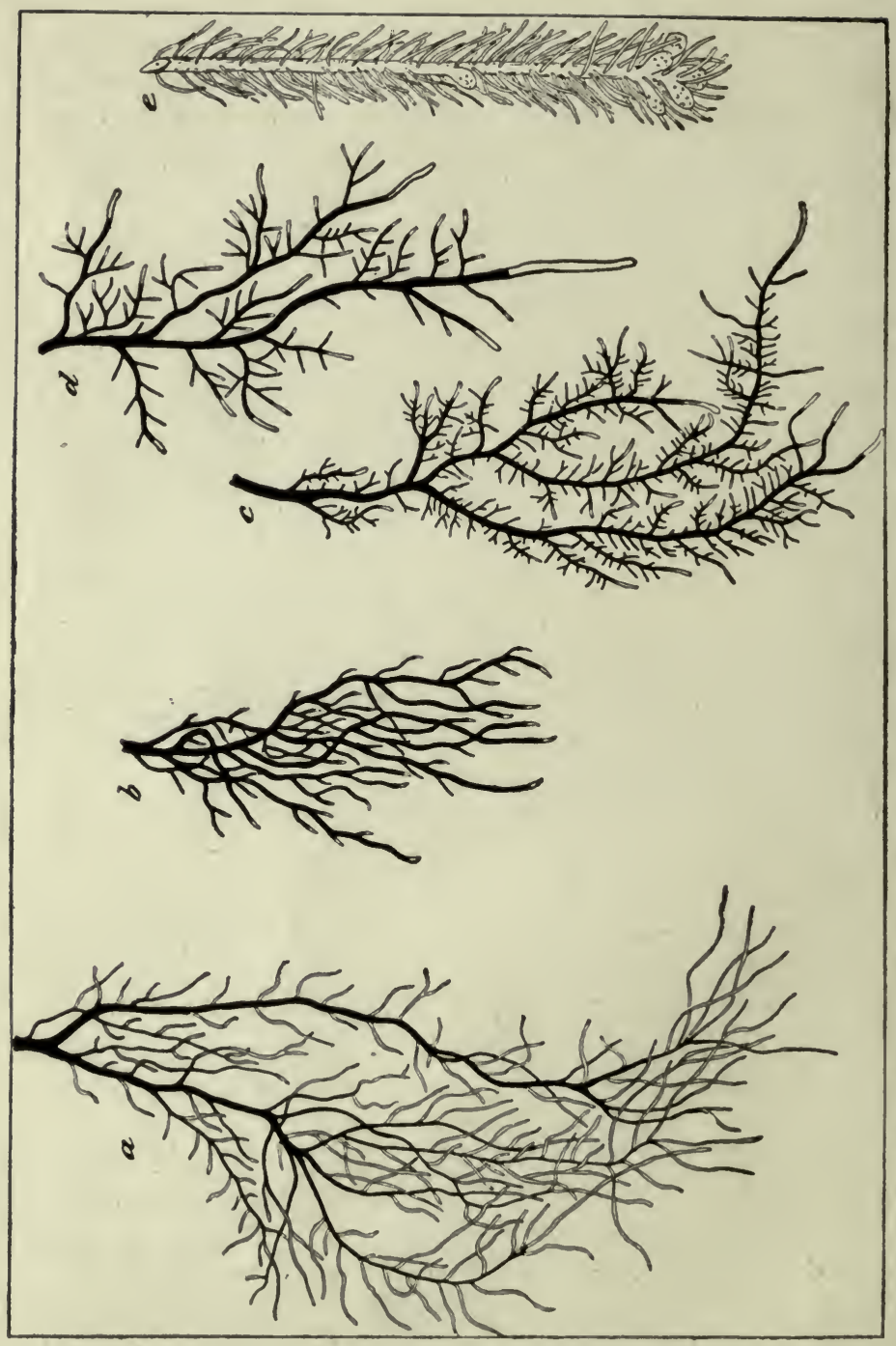

z

×

o. $\frac{2}{5}$ in

$\omega$ ㄴํㅇ

Iㄴㄴㄴ

$\leftarrow$ \%

응ํํㄹํㄴ

z 는

ह

ㄴ)

$<\ldots z$

त ले

n.

$\propto 5$

เป

$>0$

市

3

I $=$

$\pm \bar{E}$

j)

4. i 
in plants. The movements are due to the tendency of liquids of different densities to equalize, the weaker moving toward and diluting the stronger, and vice versa. Root hairs contain cell sap, which, besides protoplasm, contains also usually a stronger solution of salts than does the soil water. Hence the flow of water is from the soil through the root-hair wall and from the root hairs to other cells more and more remote from the water-absorbing surfaces-the interior cells of the roots, the stems, the leaves, etc.

The effect of this flow or hydrostatic pressure, called turgor, is the principal cause of normal stiffness of succulent vegetative parts of plants. Its opposite effect (wilting or plasmolysis) may be due to lack of sufficient water to maintain turgor or to a soil water solution stronger than that in the plant tissues, the result in this latter case being the passage of water from the plant into the soil water. So far as pruning is concerned, the strength of the solution is of minor importance, but unless there is an inflow of water from the soil to the roots sufficient to maintain transpiration, wilting will be a more or less serious phenomenon, in some cases even resulting in death.

14. Root or sap pressure is the term given to the osmotic power of the roots. It may be observed when transpiration is not too rapid to offset its effects. The most common phenomenon which proves this sap pressure is the so-called "bleeding" of grapevines, maples, box elders, birches and other plants cut in spring about the time that growth normally starts. If the cutting is done earlier the adjacent cells become dry and shriveled so the sap cannot exude. In other cases the wounded surfaces may develop corky layers, may become clogged with glutinous or solid material, or special growths (tyloses) which come from adjacent cells and clog those cells or tubes from which the major part of the bleeding 
occurs. It may be said, parenthetically, that this bleeding may produce ill effects instanced as follows:

15. Vine bleeding.-C. C. Newman has demonstrated the evil effect of late spring pruning of muscadine grapevines.*

Two vines growing side by side were pruned, one November 15 and the other February 15. The vine pruned in November did not bleed at all as the spring advanced and produced a wonderful crop of fine fruit. The vine pruned in February began to bleed as soon as the weather turned warm, slowly at first, but bleeding more freely as the spring advanced. Drops of sap could be seen steadily dripping from the end of each vine that had been cut. The vine pruned in February was 10 days later in putting out leaves than the one pruned in November. The growth was very feeble and it set very little fruit, most of the canes dying during the summer.

To form some idea as to the amount of sap that would flow from a vine that had been pruned too late in the season, a third vine was pruned in November, and on March 20 one cane, $1 / 2$ inch in diameter, was cut on the same vine and a rubber tube fastened over it so as to conduct the sap to a large glass jug, the mouth of which was closed with a cork, through which the rubber tube passed. The vine began to bleed freely from the cane cut March 20, but the canes cut in November did not bleed at all. A careful record was kept of the sap collected, and in four weeks from the time the cane began to bleed, 23 pounds of sap had been collected from this one cane. The loss of sap through this cane affected the entire vine, and its growth was checked considerably.

16. Transpiration is the passage into the air of water in vapor form from leaves and other green and growing parts of plants. Thus a very great part of the water absorbed by the root hairs finds its way into the air. Certain plants (eucalyptus trees), because of their ability to transpire immense quantities of water, are used to remove excess water from soils that cannot readily be drained in any other way. As instances among agricultural plants it may be mentioned that experiments with a little tree have shown that (proportionately) an apple tree 30 years old would probably transpire 250 pounds of water a day, or about 20 tons during the growing season. At this rate an apple orchard with trees set $40 \times 40$ feet-

- S. C. Bulletin 132, Page 7. 
27 trees to the acre-would transpire 540 tons in a season! Such facts, estimations and deductions as these indicate the importance of water conservation in trees and shrubs by pruning and in the soil by cultural practices.

17. The transpiration apparatus.-Water escapes from plant tissue into the air mainly through minute openings (stomata) in the epidermis of leaves and growing shoots. Lenticels in the bark of older shoots and branches perform a similar function. Some water may also escape more or less directly through the epidermis of delicate and very young leaves and shoots before the cutinization of this epidermis.

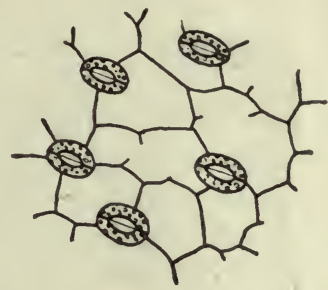

FIG. 12-EPIDERMAL CELLS AND STOMATA FROM A LEAF

18. Stomata (singular, stoma).- - Openings in the epidermis of plants for the admission of air and the liberation of water; breathing pore" (Crozier).

19. How stomata operate.-Stomata are doors through the epidermis to the chambers and contorted corridors which constitute the aerating, intercellular spaces of leaf and other green tissue. They open and close according to the intricate action of growth factors, which operate mostly in the tissues, though external factors-light, temperature, motion and humidity of the air, water content of the soil, etc.-may also operate to a greater or lesser extent. Since the protoplasm in every cell of the transpiring tissue is rich in water, and since every cell borders an intercellular space, the air in the intercellular parts becomes heavy with water vapor. When the stomata are open and the external air conditions favor it, the outward passage of this water-saturated air is rapid. Plants in nature check transpiration in many ways, such as development of hairs or wax on their cuticles, by thickened cuticles, placing their stomata in cavities, reducing the 
number of stomata in given areas, developing water-holding tissues, reducing the amount of surface exposed to the air, and so on. Artificially, transpiration may be reduced by preventing the development of excessive leaf area, as when nitrogenous plant food is withheld, and by pruning off unnecessary branches and twigs and even individual leaves.

Instances of water loss effects during dry spells are the wilting and drying up of certain herbaceous annuals, the premature defoliation of deciduous perennials, the partial or total defoliation of fruit trees followed by the development of new growth subsequent to a wet spell in early autumn. Such instances indicate that short water supply during the growing season tends to maturity of all parts, especially fruits and seeds, the former of which are often altered in texture and even chemical composition.

20. Transportation of water and plant food.-In all plants with which this volume deals there are "vessels" or conduits which greatly facilitate the transpiration of liquids. These are of two classes. (1) Some of these, the large and numerous xylem vessels (25) on the inner side of the cambium, lead from the water-absorbing areas to the transpiring areas. Through them the greater part of the copious "transpiration stream" ascends. From them also more or less water diffuses to cells which need it, and which have enough tension to draw it. This stream also carries mineral nutrients from part to part upward. (2) Other of these vessels (sieve tubes), smaller ones than those just mentioned, are outside the cambium. They lead from the chlorophyll-containing parts of the water-transpiring areas to all regions of the plant where growth and food storage are taking place and pass by diffusion through the cell walls where such activities are occurring. These smaller conduits carry the "elaborated" plant foods made from water and carbon dioxide in the process of photosynthesis (29). 
In the first case the sap will continue to ascend for a considerable time after the stem has been girdled; in the second the stem will increase considerably in girth, the process requiring several weeks or months, dependent upon the kind of plant, the size of the stem and other factors. The following instances will prove interesting at this oint.

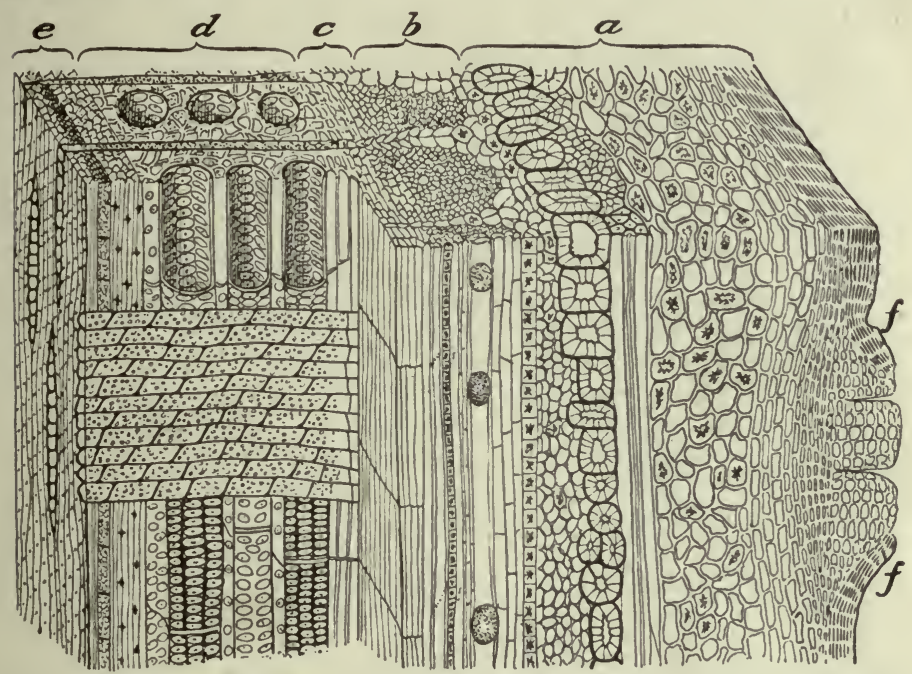

FIG. 13-THREE SECTIONS OF OAK BRANCH SHOWING VARIOUS TISSUES

Upper surface, cross section; front face (from $f$ to middle) longitudinal section; extreme left, tangential section showing ends of medullary rays; left center, cross section showing medullary ray; $a$, cortex; $b$, bast; $c$, cambium; $d$, spring-formed wood; $e$, autumn-formed wood of previous year; $f$, lenticel.

21. Tenacity of life in trees.-The fact that the course of the crude sap in exogenous plants is upward through the sap-wood is well illustrated by the tenacity of life in trees that have been deprived of their bark completely around their trunks to considerable heights. For instance, trees are often girdled by mice and rabbits to a height of several inches or even a foot, so that it is thought necessary to resort to bridge or repair grafting (128) to help the healing process. More remarkable, however, is the instance recorder by I. Simpson in the Gardeners' Chronicle--the peeling of standing oaks to the height of 20 to 40 feet and the subsequent leafing out of these trees and the continuance of these leaves even to the end of the season. 
The reasons for the peeling practice are that timber merchants believe timber so peeled keeps in better condition than when peelerl after felling. It costs much more to peel the trees standing than felled. Peeling begins as soon as the sap begins to rise, and is continued till the trees come into leaf, when the bark cannot be detached. Many of the trees are completely stripped of their bark from bottom to top, except the topmost branches, yet large unbarked tops continue to swell their buds and come into full leaf, while the peeled trunks up to the heads are barkless and apparently as dry as a board for perhaps 20 to 40 feet below. On some of the trees the leaves fade before the summer is over, but on others they continue till the end of the season.

Cases similar to these came under the writer's observation at the close of the Spanish-American war, when $450 \mathrm{U}$. S. army mules were turned loose at Washington on the "Potomac Flats," where they stripped the bark as high as they could reach from about 100 Carolina poplars. The trees continued green till the close of the season, but, with a few notable exceptions, failed to leaf out the following spring. These exceptions all had retained strips of uninjured bark from base to branches in positions beyond the reach of the mules so that food elaborated by the leaves could return to the roots and thus maintain the life of the trees.

In the orchard of the author's boyhood an Onondaga pear tree through some accident became "barked" from the ground to the first branches and for fully three-fourths of its girth, yet it bore excellent fruit for many years thereafter.

22. The reason why.-In commenting on such cases as these A. C. Forbes in a later issue of the Gardencrs' Chronicle says in substance: The partial development of the annual shoots in trees deprived of their bark is only one of several interesting facts to be seen in trees in a more or less unnatural condition. The growth of the shoots on the barked trees is in no way more remarkable than it would be had the bark remained on.

The generally accepted view of tree growth is that the watery sap rises through the outer rings of the stem into the leaves, there becomes greatly.changed, and passes from the leaves through special vessels in the bast or inner bark downward to the cambium and other growing and storage tissues. The removal of the bark, therefore, if not carried too far, does not interfere directly with the growth and support of the leaves but prevents the food which they prepare being put to its proper use by the destruction of the downward conducting channels and the cambium layer. The continuation of growth in the annual shoots under such circumstances depends upon the capability of the stem to retain its water-conducting power, and the amount of reserve material contained in the roots, which are thus enabled to carry on their absorptive functions.

In the case of trees barked up to their smallest branches and twigs, the water-conducting power of the upper parts of the stem 
is soon lost, or reduced below the needs of the leaves, - owing to outer influences, such as sun and wind carrying off most of the sap by evaporation before it reaches the growing shoots. Where large branches are ringed at their bases, however, so that at least a part of the bark of the crown remains connected with the roots, their growth proceeds for many years with little or no decrease of vigor or health and ceases only when the decay of the barked portion cuts off the supply of sap.

The growth of the roots of trees barked at the surface of the ground usually continues for one or two years after barking, though whether this is due entirely to the store of reserve materials in the fleshy part of the cortical tissue, or partly to root grafting from neighboring trees, it is difficult to say.

According to some authorities, the rise of sap is confined to one or two-year-oll rings in certain species, while in others as many as five or six are concerned in the business. In the latter the sap ascent would probably be continued for s?veral years longer than in the former, - hile the resistance offered by the wood to cecay would also exercise its influence. In resinous conifers the saturation of the wood on the outside of the barked stem with resin, which occurs when the cells and cell-walls lose their water, ac's as a protection against the cracking and drying of the stem by atmospheric conditions, and its infection by fungi.

23. Felled trees develop sprouts.-Another interesting feature of the vitality of woody tissue is the throwing out of arventitious shoots or "water-branches" by the tree trunks felled in winter and left lying with the bark on. Elm, oak, poplar, willow, etc., on damp ground, continue growing in this way for two or three years, and the dwarf shoots on young larch stems and branches left on the ground also develop and keep green for a month or two. Of course such growths are dependent entirely upon the reserve

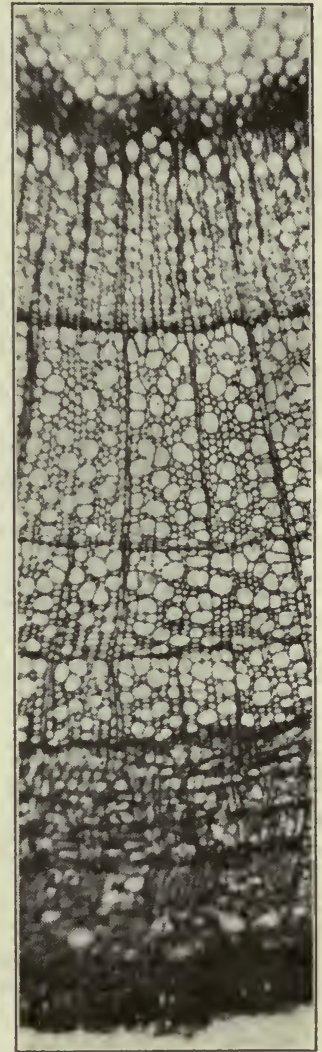

FIG. 14-CROSS SECTION OF STEM

$\mathrm{T}$ h is microphotograph shows how the stem of a tulin tree (Liriodendron tulipifera) looks. Notice the ar's of the annular rings, the spoke-like medullary rays, the bark (below) and the pith (above). This stem is four years old. 
materials in the sap-wood and the inner bark. The increase in the wood ring, which accompanies them, is almost nil. These growths, however, are of economic importance, since they are the means of removing the starchy compounds from the timber-compounds which indirectly do much to hasten decay. It may be that the reputation of winter-felled timber is partly due to this fact.

24. "Phloem, that portion of a fibro-vascular bundle in plants containing the bast and sieve tissue. In exogens it is always sharply defined from the remaining portion (xylem, 25) by a layer of cambium. The inner bark is derived from the phloem, the wood from the xylem. The elaborated plant food from the leaves passes down and is distributed by the phloem.

25. "Xylem, or woody portion of a fibro-vascular bundle which contains the larger continuous air-holding vessels and the walls of whose cells are often thickened and lignified. The xylem is separated from the phloem by the cambium, when there is any, and it usually occupies the side of the bundle toward the center of the stem. Water with the mineral compounds in solution passes up through the xylem to the leaves." *

26. Fibro-vascular bundles.-The conducting tissue discussed above is arranged in fibro-vascular bundles. In monocotyledonous plants (sorghum, corn) these bundles are distributed irregularly through softer tissue (parenchyma). Because of this irregular distribution, and also because there is no cambium within the bundles. monocotyledonous plants usually have neither true bark, cambium rings nor annual rings of wood. In dicotyledonous plants. on the other hand, the fibro-vascular bundles have a cambium which separates the xylem from the phloem. In dicotyledonous plants, which form a wood-ring. the primary tissue of the bundles forms a layer in which the outer part contains the phloem and the inner the xylem. Since the cambium is between these two sets of tissue, new xylem and phloem are developed as growth proceeds:

\footnotetext{
- Kains, Plant Propagation, Greenhoute and Nursery Practice, Page 146.
} 
and, as the tissues become old, they gradually cease to function in water and food conduction. Thus in trees and shrubs the interior tissues serve only to strengthen the stems. In other words, the "heart wood" is dead.

The earliest formed of the vascular bundles are arranged in a more or less circular series; those formed later are developed from the cambium between them. litimately such large numbers of these bundles may be formed that in woody and semi-woody dicotyledonous plants they may form a cylinder of wood, though the individual bundles may be partially or wholly separated from each other by thin plates of wood called medullary rays
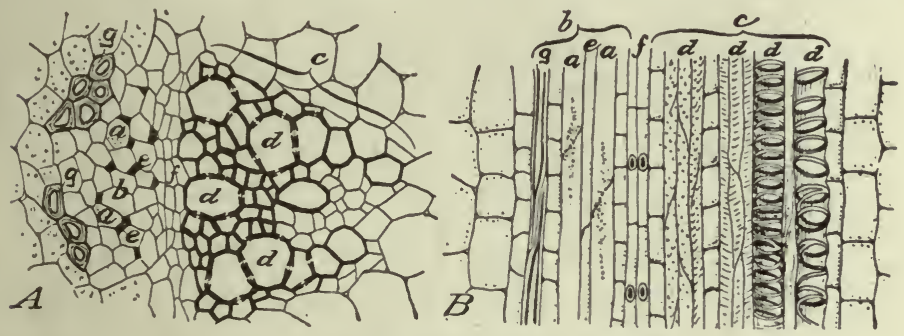

FIG. 15-FIBRO-VASCULAR BUNDLE

$A$, cross section, phloem showing sieve tubes, $a$, companion cell, $e$, sclerenchyma and $g$, parenchyma, $b$, xylem, $c$, showing vessels, $d$, between the two cam. bium, $f ; B$, longitudinal section. Outside cells parenchyma. Letters in $A$ apply to various tissues.

(Fig. 14). Since the cambium in such plants produces new xylem on its interior, it is steadily moved annually or seasonally farther outward from the center of the stem; since new phloem is developed on the outer side of the cambium, both the wood and the bark increase in thickness and the stems, as a whole, increase in girth; and since the xylem developed in the early part of the season is thinner walled than that produced later when growth is not so active, the characteristic annual or annular rings so readily seen in cross sections of dicotyledonous woody plants are formed. 
27. Leaf venation.-As has been stated, the xylem parts of the vascular bundles lead from the absorbing areas of the roots to the transpiring areas, and the phloem parts from the transpiring areas to parts where growth

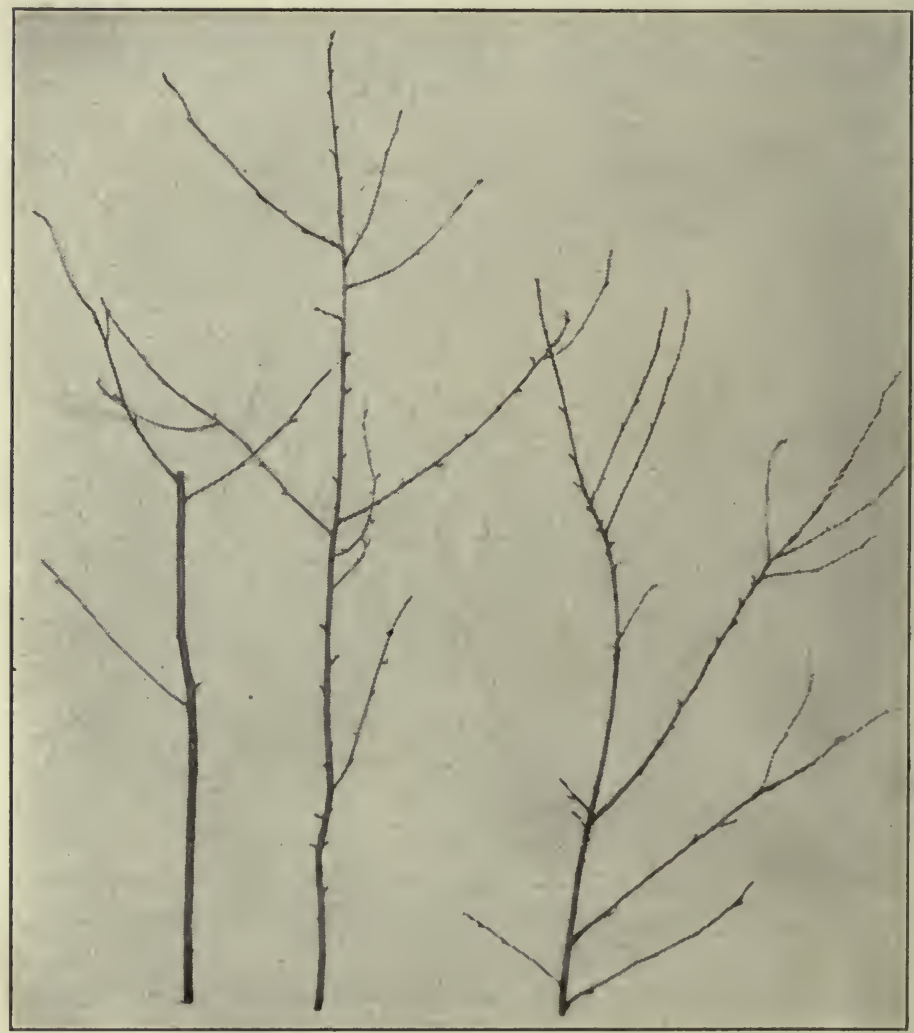

FIG. 16-CONTRASTING GROWTHS OF MAZZARD CHERRY

The specimen at the left shows one year's growth in a thicket where the tree "pulled" for light. The two lowest branches and a little stub are dead. The middie specimen is the upper part of the first, three years old at its base. Note how it continued to extend until it reached favorable light, where it developed branches. The specimen on the right is as old as the middie piece-three years. Note how much shorter and how much more branchy it is. It grew in the open ground, where it had no competitors except grass for light and air. 
or storage is occurring. It remains only to be mentioned that each rootlet and each leaf are more or less directly connected by vascular bundles in more or less definite number, depending upon the species. In leaves these bundles constitute the "ribs" or veins which serve both as conduits and as stiffeners of the leaves themselves.

28. Chlorophyll, the green colforing matter of plants, is the most intimate link which bindslife to the sun. It is the laboratory in which is made the earth's supply of organic matter, including all fucl. Though sometimes obscured

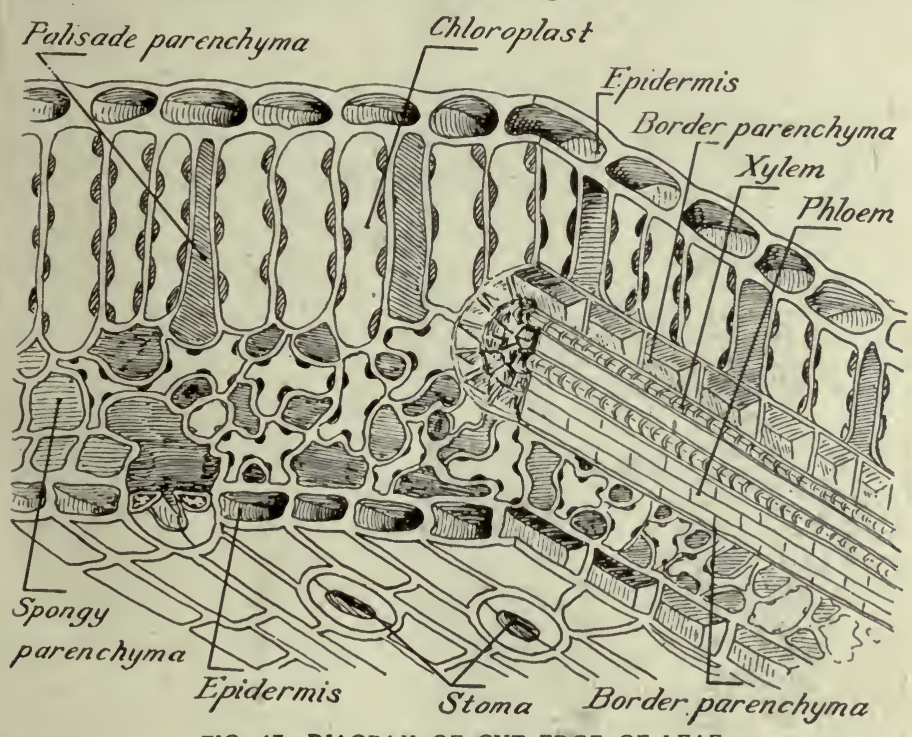

FIG. 17-DIAGRAM OF CUT EDGE OF LEAF

Note the various tissues. (After Stevens, Plant Anatomy.)

by other colors, it is characteristic of all higher plants, algr and mosses, but is absent in fungi. Plants containing it may grow in partial shade or in the full glare of the sun, but never in total darkness. The relation of light to chlorophyll is clearly indicated by the sizes and forms of the leaf blades, the arrangement of leaves upon their 


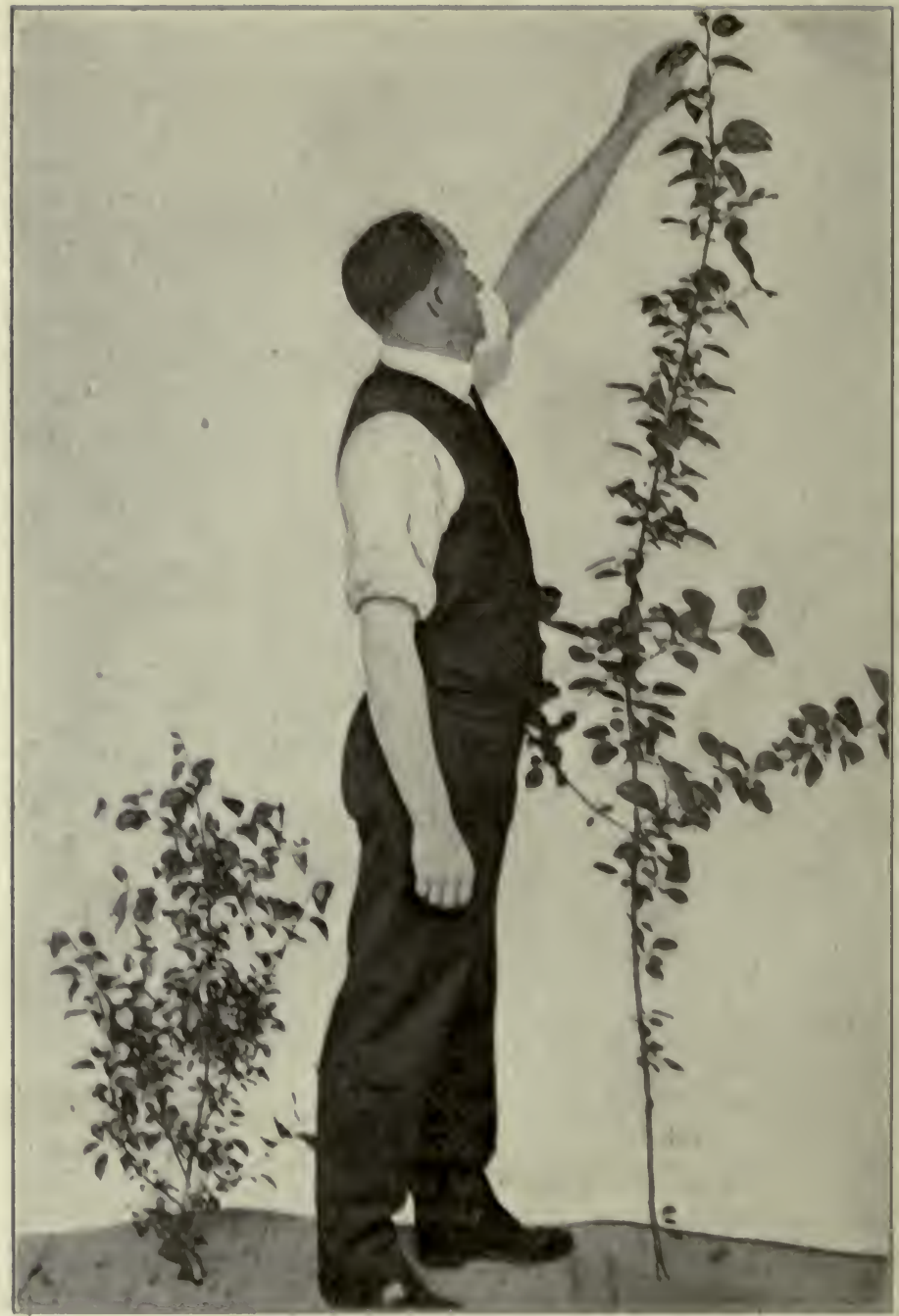

FIG. IS-COMPARISON OF GROWTH

These two apple irees are the same age-three yeara. The one on the left in a cediling which grew in the open ground with no competition but that of the grass: the one on the righe is araft sprout which arew in a clase thloket, and beceuse of lack of light a well an its varietal nature and pmbahly strong roose power, has "pulled" toward the light. Note the difference in number of branches. 
branches and the arrangement of the branches (Fig. 20). Plants growing alone in the open develop leaves uniformly on all sides (Fig. 20), those growing in groups lack leaves where other plants compete with them for light (Figs. 18, 22, 23). The same is true of branches and twigs in trees. Hence the importance of pruning so as to admit ample light to supply leaves on the interior twigs and branches of trees and shrubs; for when such parts are poorly lighted they cannot function properly. In many cases-for instance, interior twigs on young (three to five-year-old) peach trees improperly pruned-they die for lack of light.

29. Photosynthesis is the process whereby the chlorophyll is able, in the presence of light, to construct organic foods from the crude materials contained in the soil water and the air. Though light, carbon dioxide and water are essential, the process is influenced by temperature and other factors unnecessary to discuss. The intensity and the quality of light bear a more or less complex relation to food manufacture. When the temperature is favorable, the capacity of plants to produce finished plant food is proportional to the intensity of the light up to the limit of the available carbon dioxide and water. In sup-

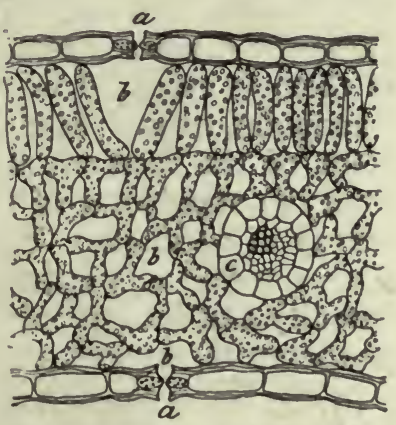

FIG. 19-CROSS SECTION OF A LEAF

Upper and lower epidermis with stomata, $a$; air chambers, $b$, or intercellular spaces; cross section of leat vein, $c$, in the parenchyma or soft, thin-celled tissue. port of this statement instances may be suggested of plants which stand the full glare of the sun and of others whose maximum is reached in partial shade. Too strong emphasis, however, must not be placed on this intensity factor, because increased transpiration of water 
may tend to dry the active tissues, close the stomata and otherwise reduce photosynthesis.

It has been estimated that a vigorous Concord grapevine in good vineyard practice may expose to the light a leaf surface of 10 to 12 square yards. Such an area has been estimated as manufacturing about a pound of organic matter in a day during the active growing season. From this calculation a hazy idea may be formed of the work done by a vineyard or an orchard between, say, April and October, and a hint may be gained as to the importance of pruning and training so as to enhance the process of photosynthesis, especially in fruit-bearing plants.

30. Growth and growth relations.-Though growth and growth relations have been touched upon indirectly in the previous chapter, it is necessary that certain of their phases be discussed separately, becąuse a true conception of them is essential in pruning. From the agricultural standpoint, growth is measured by yicld: from the standpoint of the forester, usually by size or development; from the standpoint of the ornamental horticulturist, by beauty of specimen. These ends are all affected by various internal and external factors, such as (1) vitality, heredity and food supply and (2) environment, moisture, temperature, oxygen, character of food and light.

31. Proof of growth.-Popularly, growth is evidenced in flowering plants by increased weight and size, by development from the seedling stage to maturity and the quick production of stems, leaves, flowers and fruits. It is dependent upon the formation and enlargement of cells and may lead to strongly marked changes in both internal structure and external form. The most evident of these changes are (1) differentiation, due to structural changes either within a single cell or a group of cells; and (2) extension or increased length, sften accompanied by greater girth. 


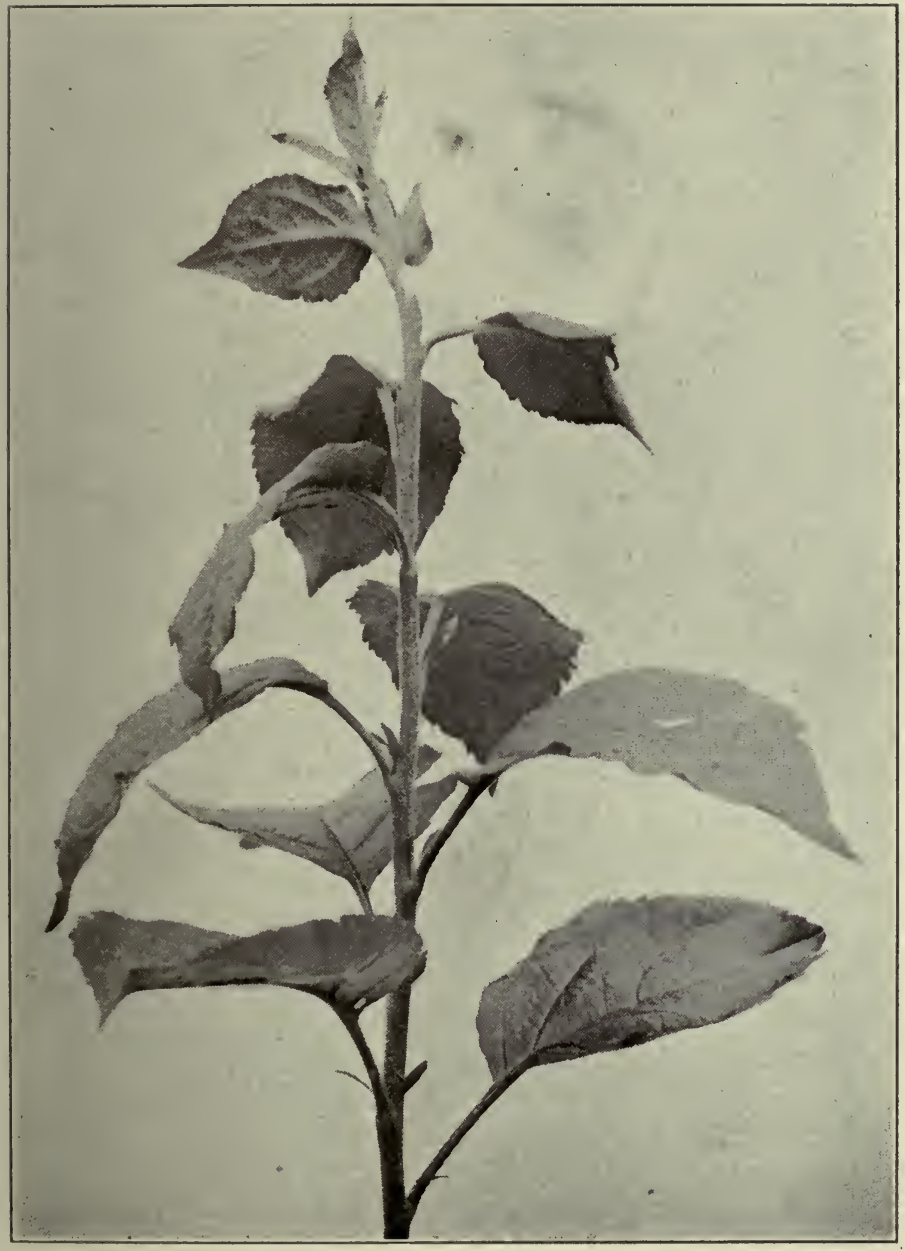

FIG. 20-SIDE VIEW OF AN APPLE SEEDLING

Note how the leaves are arranged on the stem. Each extends outward at a different angle from the one above and below it. Thus it takes advantage of its opportunity to get light. Note view from above in Fig. 21. 
32. The tip of the stem and of the branch in flowering plants is the point from which extension takes place. Since any wood bud may become the starting point of a new branch or stem, this statement is general. Dissection

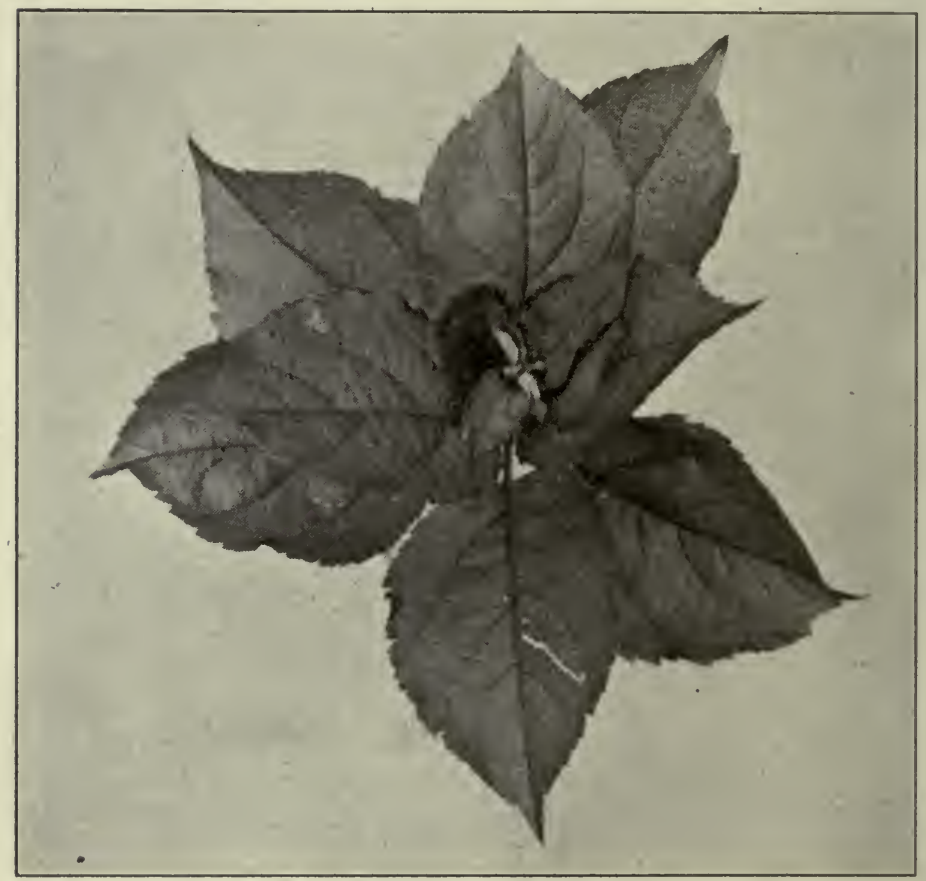

FIG. 21-SEEDLING APPLE SEEN FROM ABOVE

Here the tree shown in Fig. 20 shows how the leaves apparently make an almost perfect rosette. Thus they get the fullest advantage of the light. Note the spaces almost opposite each other where it seems as if a leaf were missing. These "jogs" were caused by the nearness of other seedlings in the nursery row; there was not the same chance to get light as in the other directions.

has shown that extension is dependent upon no one cell, but that a rather indefinite cell area, which constitutes the primary meristem, is the originating tissue. Here division rapidly takes place, while immediately in the rear of the dividing cells is the area of extension. 
33. Leaf formation takes place immediately in rear of the stem apex. In some plants (apple) the leaves occur in spiral order, in others opposite (lilac), in still others alternately (elm) and so on. Incipiently, they are tiny swellings, but soon they flatten and grow more rapidly than does the stem apex, over which they curve more or less to form a bud. In few trees does this leafy axis continue to extend during the growing season. Where extension occurs each leaf is left behind in the spiral, the whorl or other natural formation as the tip moves forward. New points of growth are usually differentiated later as buds in the axils of the leaves; and when the leaves fall at the end of the growing season these buds become

34. Resting buds.-In most trees and shrubs, at least in temperate and cold climates, the shoot axis terminates in late summer or early fall in a bud which is said to remain dormant until the following spring, so also do the axillary buds. This dormancy is not total, since there is some slight growth activity, except perhaps during the coldest weather $(54,55)$. The resting buds are very short leaf axes covered by bud scales (specialized leaves) which serve as protectors of the more important internal parts. While the buds are said in the fall and the winter to be resting or dormant, they may have been ready for the "rest" as early as July. They do not, however, usually appear to be resting until the leaves fall. In spring with the return to conditions favorable to growth activity the resting buds : apidly unfold, either a leafy shoot (quince, diervilla) a flower (peach, golden bell-Forsythia, Fig. 296), a cluster of flowers (cherry, spice bush-Lindera) or a cluster containing both leaves and flowers (apple, thornCratcogus).

35. The types of stem extension from resting buds, though diverse, may be grouped in two classes, though these may present numerous cases of over-lapping. 
(1) Rapid extension of resting buds into shoots which bear no other parts than those already in the buds themselves. In this group belong many north temperate trees and shrubs, among which beech and pine may be taken as typical, the former having a segmented, the latter an unsegmented shoot. In spring the beech bud gradually swells, and at first presents a fairly general extension of the internodes. Soon the bud has doubled its original length, at which time the method of extension may best be noted. Beginning at the basal node, it will be seen that each internode in turn becomes successively most active, so that the terminal internodes are the last to extend rapidly. The pine shows a similar development except that, having an unsegmented stem, the most actively extending part moves gradually forward in a more uniform manner than in the case of the beech. Apples and pears present much the same method as the beech.

(2) Some trees and shrubs, such as willow and lilac, normally develop more leaves than those wintered over in the resting bud, so that the total number of nodes and internodes at the end of the growing season is larger than the numbers represented in the buds. The peach may sometimes develop leaves, nodes and internodes in this way, though it perhaps generally develops as described under class one. This phenomenon is probably more common in young trees than in older ones. For instance, old trees of the cottonwood or necklace poplar (Populus monilifera) may develop no more leaves, nodes and internodes, than were contained in the resting bud; young ones may develop three, four or even more times as many. From such instances it is concluded that conditions, such as age, environment and character of season, may account for the differences.

The secondary growth of shoots, especially of fruit trees, must not be confounded with the normal phenomena discussed above. Such growth usually occurs during a 
moist, late summer or early autumn following a more or less protracted drouth. It may also be due to excess of nitrogenous plant food and an ample water supply in the soil. Such growths are usually undesirable because they are developed from buds which should continue dormant until the following spring and also because they usually do not have sufficient time to ripen fully before winter sets in. Consequently much of the growths so produced must be pruned off, to the greater or lesser loss of wood that if grown in normal time would be valuable for fruit production or other purpose.

Hence cultural practices, such as tillage, drainage, fertilizing, cover and inter-cropping, have a direct bearing upon pruning, because these affect more or less definitely the production of wood. In many kinds of trees, especially apple and pear, leaves appear to be borne in clusters on very short twigs called spurs. This phenomenon is due to the suppression of the internodes and the consequent shortening of the axis. Sometimes the reverse of this case occurs on a spur, as when a bud, which might be expected to continue the slow extension of a spur, suddenly elongates into a slender twig such as shown in Fig. 36.

36. The relation of leaves to light intensity is one of the most commonly observed of plant growth phenomena. Everyone who has had anything to do with plants, especially those grown in dwellings, knows that leaves and leafy shoots "turn toward the light." This is the more marked as the room is poorly illuminated; the plant parts capable of doing so soon bend toward the window or other light source. Similar effects may be seen in the open. The explanation for this phenomenon is that the parts which thus change position do so in order that the chlorophyll may secure the maximum illumination and thus function to best advantage.

Broad-leaved plants generally form a more or less complete mosaic of green. Especially good examples of this 
are Boston ivy and grapevines; the leaves completely hide the flowers, fruit, woody parts and the supports. Among trees, Norway and sugar maples, especially the former, are very striking because, when, say, 30 or more years old uninjured specimens growing by themselves show a perfect envelope of leaves covering bare branches and trunk beneath. In neglected fruit trees similar though much less marked development may be observed.

To carry the illustration and the lesson it teaches still further, the same effects may be noted in trees and shrubs that grow in close groups, whether in a state of nature or in a plantation. This has two very striking applications, one in the forest, the other in the fruit plantation.

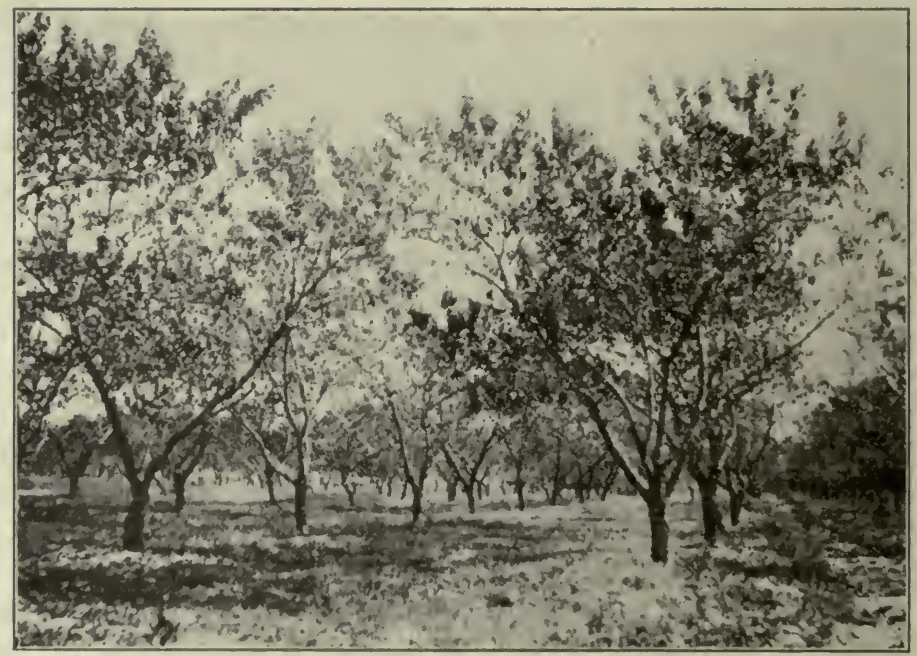

FIG. 22- "LEGGY" PEACH TREES

Adequate spacing and judicious pruning would have made these more stocky. They are far too tall and too likely to be injured by wind.

Trees which grow close together in the forest produce so much shade that their lower branches, being deprived of light, die and ultimately fall off, and only the tops 
continue leafy. (Figs. 25, 26, 27.) The result is the long, bare trunks which characterize forest trees, whereas the same species growing in the open would have short, branchy trunks. From the lumberman's point of view, the former are the more desirable, but they are produced at too great a risk of decay by means of fungi and bacteria, which may enter through decaying stubs of limbs. In the other striking application, namely, the fruit plantation, similar results follow the too close

37. Spacing of trees and shrubs.-Just as in the forest, trees planted too closely together grow inordinately tall. (Fig. 25, 27.) Their lower twigs and limbs die because improperly lighted, and the orchardist is put to serious expense in pruning, spraying, thinning and harvesting. Nowhere is this so conspicuous as in neglected, closely set orchards. (Fig. 22.) Often orchards which so far as the health of the trees is concerned might be renovated cannot be so worked over because too much wood would have to be removed to bring the tops down to workable heights, or too many trees would have to be cut out to leave profitable numbers in given areas. 


\section{CHAPTER III}

\section{THE PHILOSOPHY OF PRUNING*}

38. Good and bad effects of pruning.-Every owner of a fruit tree expects to prune, or at least, he considers the advisability of the operation. There is the greatest difference of opinion as to the merits of particular styles and methods of pruning, and perhaps equal difference as

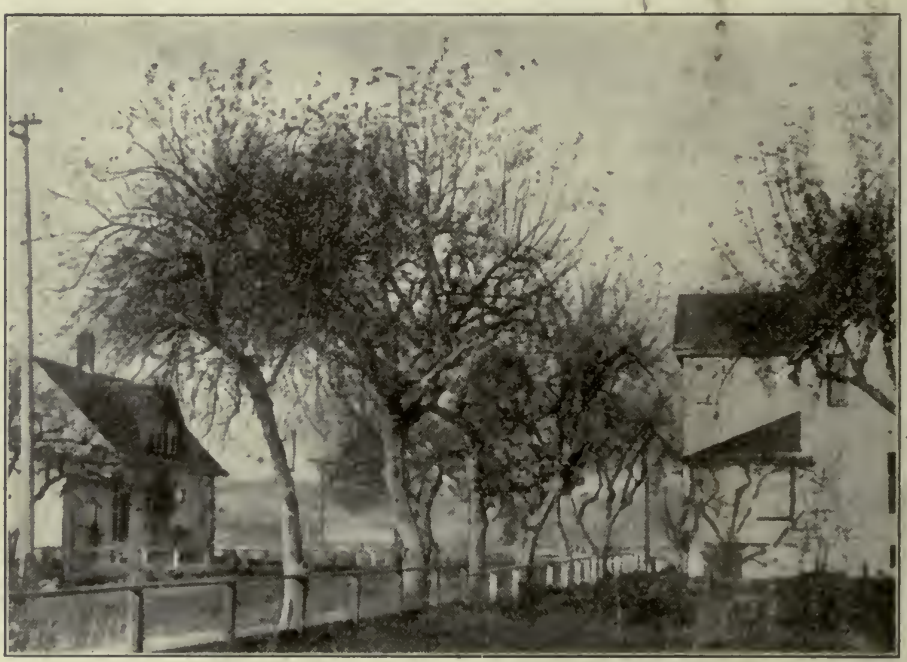

FIG. 23-RESULT OF CLOSE PLANTING AND POOR PRUNING

These tree heads are practicaliy out of reach, hence spraying and thinning are out of the question and harvesting so costly as to "eat up the profits."

to the effect of the operation on the life and health of the tree. Perhaps every fruit grower has observed evil effects to result from pruning, and many of these observers have reasoned therefrom that pruning is itself injurious, or at

* This chapter, except the parts in brackets, is the somewhat condensed answer which 1. H. Bailey gave the Peninsular Horticultural Society to the question, "Does Pruning Devitalize Plants?" 
least hazardous. I cannot, of course, uphold or explain away the examples of injury which follow pruning. They are patent even to the casual observer, but we must not exalt individual instances, however numerous, into proofs of the perniciousness of pruning.

There should be at this day sufficient study and experience to enable us to pass upon the merits of the practice as a whole. It is urgent, also, that the subject be discussed, for however much of correct teaching may be

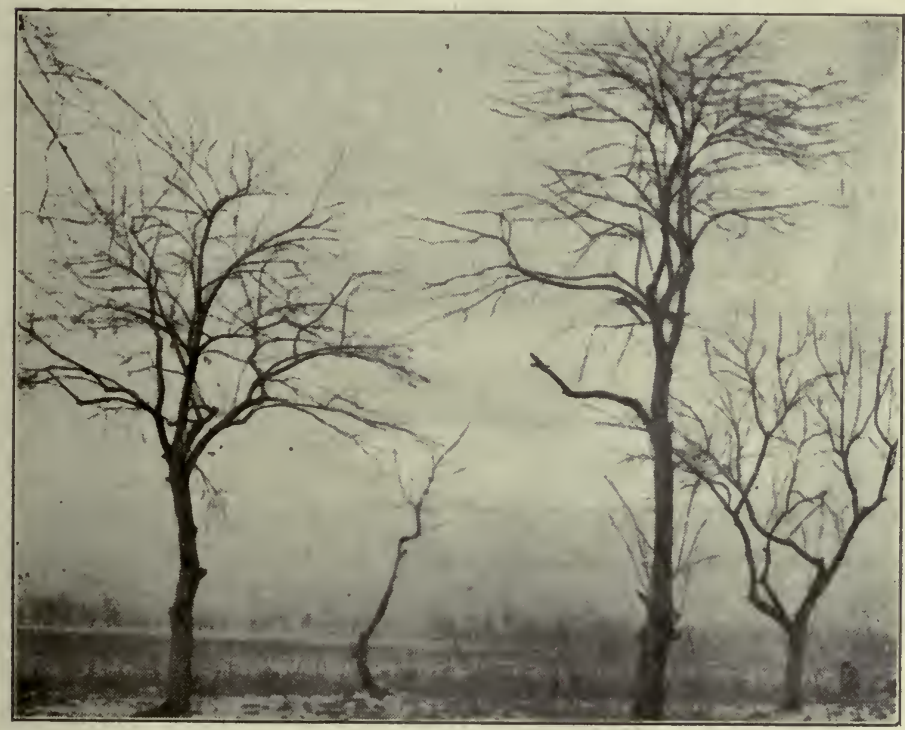

FIG. 24-HOW NOT TO MANAGE TREES

Trees neglected and vivisected like these cannot be made to pay either as investments or as objects of beauty.

promulgated, there is a constantly recurring wave of error and prejudice. For myself, I am convinced that pruning, even when somewhat heroic, is not a devitalizing practice. In support of this conviction I shall present arguments from three sources-philosophy, plant physi- 
ology and common experience. I do not purpose to discuss mechanical injuries to the trees, as a result of wounds, for we all know that such injuries are a result of careless or injudicious pruning. My proposition is this: Does it injure a plant to remove a part of it? Is the entire growth necessary to a plant's health and longevity?

39. The argument from philosophy.-There is an intense struggle for existence among all organisms. The world is now full, and there can probably be no permanent increase in the sum total of animals and plants. If one species increases, another must decrease. Changes in the numbers of individuals are, therefore, largely matters of readjustment between different types. Each kind is held down to a certain equilibrium in relation to other kinds. It is easy to see that any species of animal or plant could completely occupy the surface of the globe, if it could multiply to the full extent of its powers. Not only do some species compete with others, but the individuals of the same species compete with each other for standing room. The greater the number of thistles in a given field, the less is the opportunity for another thistle plant to gain a foothold.

Now, a tree is essentially a collection or colony of individual plants. Every branch, even every joint of the branch, is endeavoring to do what every other branch does-to bear leaves, flowers and seeds. Every branch competes with every other branch; and there are more germs of branches-that is, more buds-than there can be branches upon any tree. So it comes that no two branches of a tree are exactly alike, but are what their position or condition makes them to be. Some are strong and some are weak. That is, there is no definite or proper size or shape for any branch, as there is for the various parts of an animal or a flower. The limbs and organs of an animal are not competitors but co-partners, each performing some function or office which another does not, 
and they all obtain a definite maturity of size and shape. But a branch never attains its full size until it ceases to grow and thereby begins to die. Branches are not organs, but competing individuals.

If all these statements are true, then three conclusions follow: a, there is struggle for existence among the branches of a tree (Fig: 25 ), and some of the contestants perish; b, the destruction of these branches must conduce to the betterment of the remaining ones; c, all the branches of a tree are not necessary to it, but some of them may be a detriment to it. In other words, pruning is a necessity.

40. An instance from nature.-Two years ago a wild, black cherry tree came up near my door.*

'The first year, it sent up a single straight 19inch shoot, which produced 27 buds and one branchlet 8 inches long.

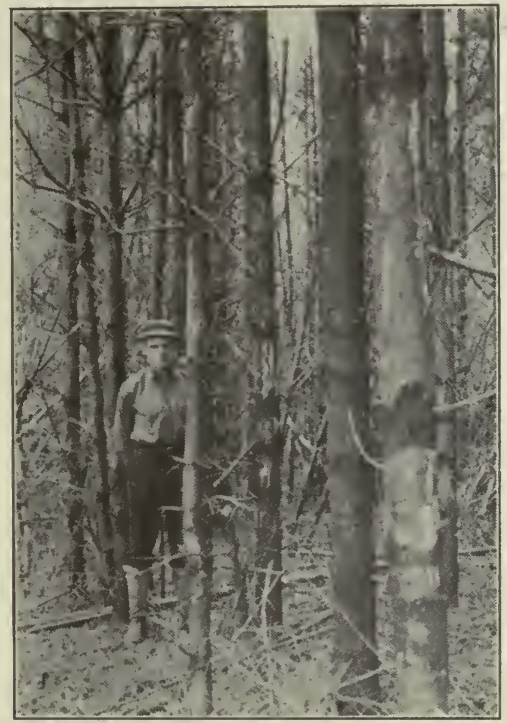

FIG. 25-WHITE PINE PIANTATION, BEFORE THINNING

Note how branches have died from lack of light. Compare with Fig. 26.

This branchlet bore 12 buds. At the end of the first season, therefore, the little tree had produced a total of 39 buds, one branchlet and 27 inches of growth. The second year, 19 of these 39 buds produced branches, and 20 did not start. These 19 branches made a total growth of 231

* The reader will find it interesting to study some little seedling tree in the way the tree here discussed has been studied. 
inches and produced 370 buds. The terminal branch or shoot grew 36 inches long.

Here, then, is a little tree two years old and $41 / 2$ feet

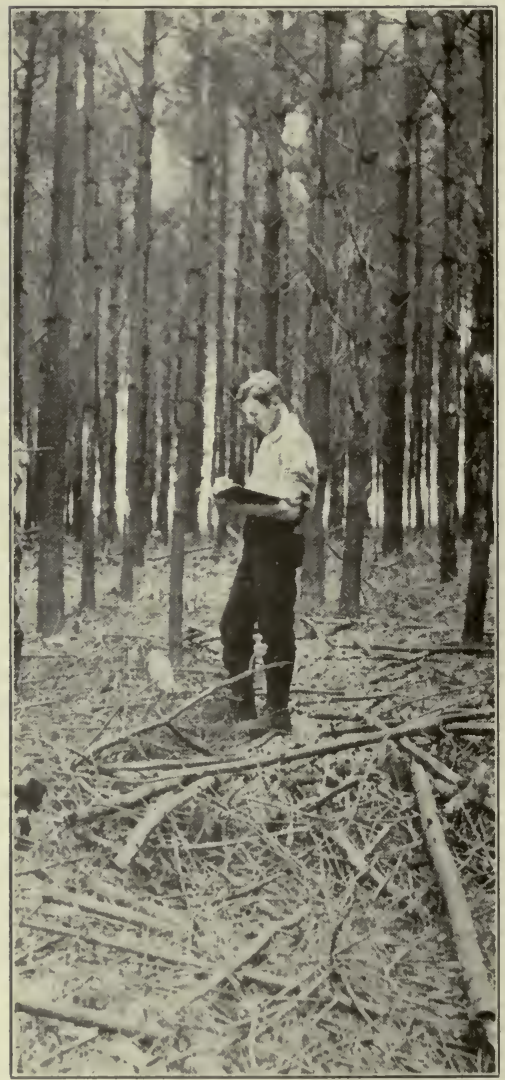

FIG. 26-WHITE PINE PLANTATION AFTER THINNING

Compare with Fig..25. Note piles of brush and the trunks pruned of dead branches high which has made an effort to bear 409 branches. It is plain that more than 90 per cent of these efforts must be futile. Many of the buds will not start, but the tree now has a total of 27 branches and subdivisions as a result of its first year's growth, if it makes a proportional number this year from the growth [of last year], it will bear 216 branches at the close of this season and will have made a total effort of about 3,500 branchgerms or buds. This little tree will undergo a severe pruning in the coming years, alt'lough a knife does not touch it.

But the natural thinning of the top will continue in geometrical ratio as long as the tree grows; and after a time this pruning will become more severe, for larger branches will be sacrificed. Probably less than a fifth of the buds upon any tree ever 
make branches, and less than a fifth of the branches persist. The greater part of these branches die beforc they come to bearing age, no doubt, but some of them perish after they have attained a considerable size. A forest tree grows a tall, straight bole because the side branches are lopped off (Fig. 27), and the more vigorous this pruning, the taller and stronger the tree becomes.

Another black cherry tree, two years old, found in the woods, bore buds at regular intervals - about two dozen of them. The second year the terminal bud sent out a shoot, and 13 lateral buds gave rise to branches. Of these 13 lateral branches only three stand any chance of living in the dense shade of the forest. In fact, four or five of the lowest twigs were dead when the [observation] was made; showing that the struggle

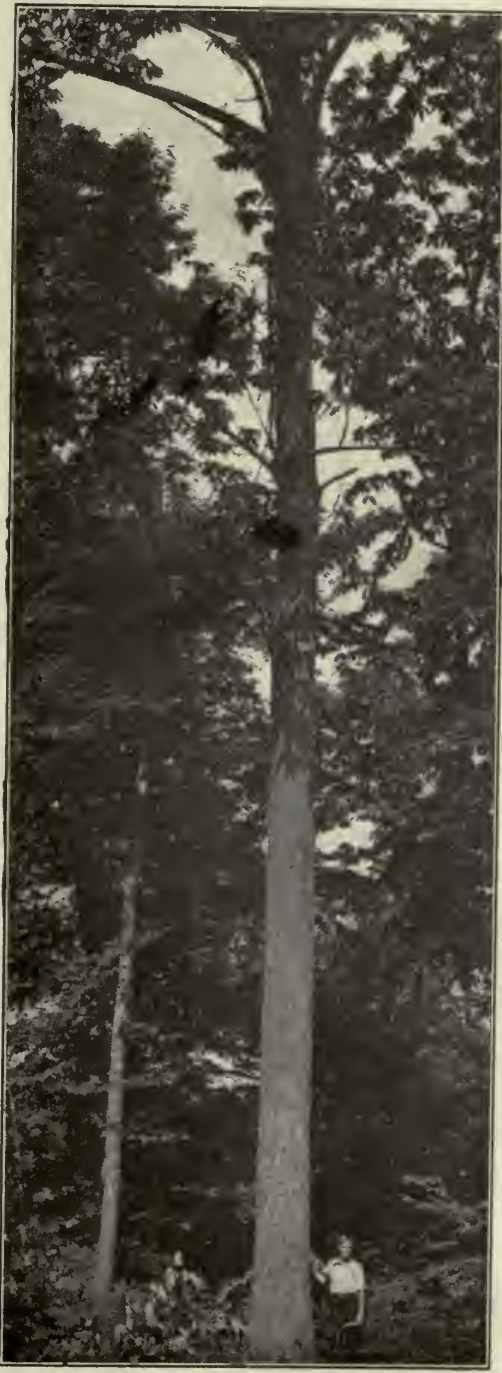

FIG. 27-SEEDLING CHESTNUT 103 YEARS OLD-Shade caused natural pruning of limbs for over 30 feet. 
for existence does not always result from competition among fellows, but may arise from the crowding of other plants (Figs. 18, 25).

The three strong branches are less than 4 feet from the ground, but other old cherry trees standing near it have no branches within 15 and 20 feet of the ground. They, no doubt, branched low down, as this one, but the branches eventually died in the struggle, and we, therefore, have reason to conclude that of all the branches on this little tree only the terminal one can long survive. One has only to look on the forest floor to see how freely trees shed their twigs. The trunk of a tree, then, is the remainder in a long problem of subtraction.

So every tree is a record of defeats and disasters in order that the stronger parts may live. It is safe to conclude that if nature is such a scarching and undogmatic pruner, man may prune, too. Those persons who declaim that pruning is unnatural should be taken into a neglected orchard and be made to see what has transpired in the tree tops.

41. Is artificial pruning excessive?-I may be met here with the criticism that artificial pruning is excessive; but $I$ answer that it is not different in kind from natural pruning, and that it is fully warranted by the different objects in view. The ultimate object of nature is the production of seeds, and the larger number of viable seeds. produced the better. Man covets the fleshy portion of the fruit, or some other cliaracter which is of minor importance to the plant. He must, therefore, thin the plant rigorously-reduce the struggle for existence-in order that size and quality may come before number. He simply deflects the energy into another channel!

42. The argument from plant physiology is equally important. It is a common assertion that cutting off a limb is an injury because it removes a given amount of tissue in the production of which the plant expended effort; that is, that pruning exhausts the plant. This statement as- 
sumes that a plant has a certain fixed vitality, from which a given amount is withdrawn whenever a portion of the plant is cut away. I might illustrate this by supposing that a plant has an initial vitality represented by the number 10 ; then, if one-tenth of the top is removed, there is left a vitality of 9 . But this assumption is wholly gratuitous. Vitality is very largely determined by the conditions under which a plant grows-the character of the soil and treatment. As plants have no nerves, they cannot die of shock, as we sometimes hear it said.

Every fruit grower knows that two trees, of the same initial vigor, if given different soil and care, may differ widely from each other in thrift and healthfulness at the expiration of five years. If the plant is very largely what its food supply and other environments make it to be, if it is constantly renewed and augmented, then the removal of a portion of it cannot destroy its vitality unless the removal is so great as to interfere with the nutrition of the remaining parts. It may be replied that the tissue, the wood, which is removed in large limbs, might have been saved to the tree by directing it into other parts of the top by means of earlier pruning. This may be true; but this saving would have resulted only in an economy of time by building up the other parts earlier in the lifetime of the tree, and not in an economy of vitality, for vitality. is constantly renewed.

43. Early pruning as a life saver.-It may be a question if we really save a proportionate amount of time by early pruning; that is, whether we can direct the same amount of growth into the remaining portions of the plant by pruning very early in its lifetime, as we can by pruning when the superfluous branches have attained some size and have, perhaps, begun to bear. There is an exact balance between the root-system and the superficial growth of the plant. The more active and efficient the root, the larger the top. If we remove a large portion of 
this top, there is an endeavor to supply the deficiency by an exceedingly rapid growth. So pruned plants are nearly always more vigorous than unpruned ones, because of the concentration of a somewhat constant food supply into a smaller number of branches. Therefore, pruning must have much the same effect as manuring.

The stimulating effect of this new growth, or new disposition of energy, must be felt upon the root system

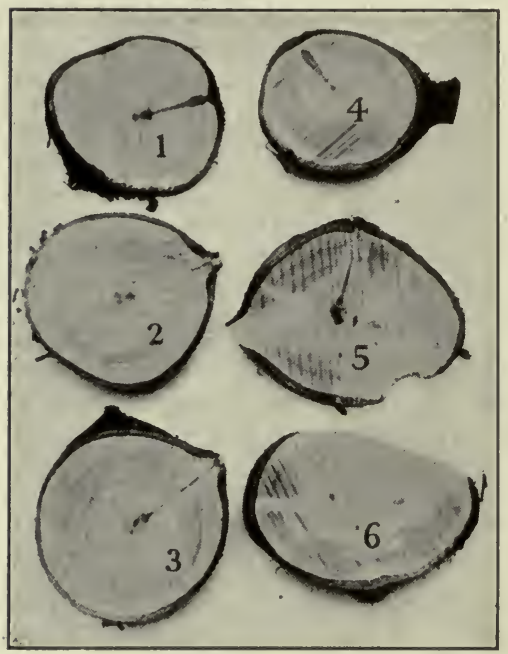

FIG. 28-HOW BRANCHES ARE BURIED

1, Dead twig healed In; 2, twig dead at tip being healed in: 3 , twig with decayed pith being healed in; 4 , dead twig completely healed in: 5, two branches healed in, one pointing left, vigorous when cut, one pointing up dead part way out; 6, "eyes" where oblique limbs started from main trunk. also; and it is a point for discussion as to whether this stimulus and response to new conditions may not be greater when the pruning is somewhat heroic than when it is so evenly distributed over the lifetime of the tree as to be imperceptible. Growth is certainly more emphatic following a heroic pruning, but its total may not be greater than that which follows several prunings of equal aggregate severity.

My own observation and experience lead me to believe that annual pruning of all fruit trees is desirable, but I am equally convinced that to cut out all the superfluous twigs at each pruning does not pay, either in cost of pruning or in good to the tree. These superfluous twigs may often be left with advantage until they are two or three or even four years old. Although stimulating 
effects may result from the considerable unbalance of the plant when many branches are removed, these superfluous and unpruned twigs often afford a very useful shelter or sun-screen to the inner parts of the top, and they lessen the danger of over-pruning, by which the nutrition of the tree may be injured.

I have said that pruning increases vigor. Two trees of Siberian Crab were set 25 feet apart near my house in the spring. These trees are as near alike as any two apple trees I have ever seen. I measured the growth on one of these trees and found it to have been 745 inches. The tree was then thoroughly pruned and 460 inches of wood removed. Of this, 432 inches was new wood. The total weight of this wood was $73 / 8$ ounces.

The other tree was not pruned. During the third season the unpruned tree produced 118 new twigs, with a total length of 1,758 inches, while the pruned tree produced 120 new twigs and made a total growth of 1,926 inches. The pruned tree, therefore, made 14 feet more growth than the other and stouter growth also, a large proportion for a tree only three years set. In other words, a tree from which about 40 feet of branches had been cut bore at the end of a single season 14 feet more wood than a similar tree which had not been pruned. Aside from the greater growth which this pruning induced, the experiment shows-in common with all similar ones-that it is impossible to injure trees by what is called a shock.

It is often said that the time of the year when pruning is performed influences the amount of growth [and] that pruning in winter makes wood and pruning in summer makes fruit $(83,95,97,107,108,109)$. Certainly winter pruning makes more wood than summer pruning does in the current year, because the season's growth is nearly or quite completed when the summer pruning is performed.

44. Why pruning is not injurious, - I have said that 
pruning, of itself, cannot be injurious so long as it does not interfere with the nutrition of the plant. It is important, therefore, that I explain how this interference occurs. A plant derives a certain portion of its food from the soil in the shape of soluble inorganic materials (Chapter II).

These materials ascend to the leaves through the young wood and become associated with organized compounds like starch and sugar. These organized compounds are used in the repair and growth of all parts of the plant and they are, therefore, distributed to the leaves, twigs, trunk and roots. The growth of the roots is, therefore, largely determined by the amount and vigor of the top or leaf-bearing portion. [Hence] the removal of the greater part of the top may interfere with the vigor of the plant by preventing the supply of a sufficient amount of elaborated food.

This difficulty is sometimes experienced in the girdling or ringing (100) of grapevines, which prevents the distribution of the elaborated plant foods to the roots. It should be said, however, that the grape is pruned the most severely of all fruits, and it is, therefore, easy to overstep the danger line; and yet it is strange that while certain writers disparage the pruning of trees, they do not object to the common pruning of the vine. In fruit trees the instances of injurious interference with nutrition by pruning are rare; they need not be further considered here. This is proved by the good results which so often follow the heroic treatment of top-grafted trees.

45. Removal of large branches bad practice.-But if pruning is not devitalizing, if the removal of strong branches induces more vigorous growth in the remaining ones, and if there is little danger of disturbing the nutrition of the tree, it must follow that there can be no objection to the removal of large branches. I cannot agree to this inference, although I am willing to say that the 


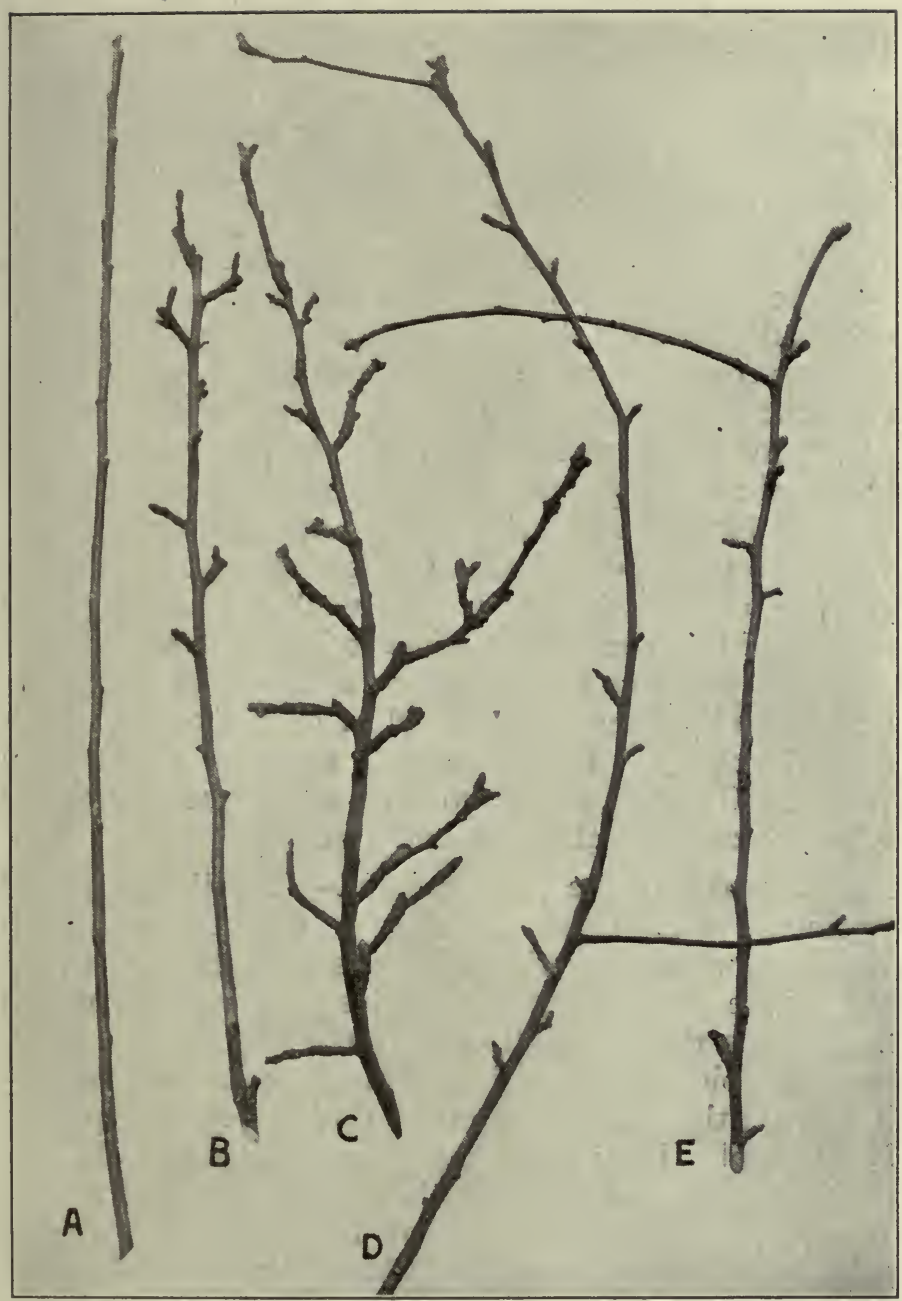

FIG. 29-APPLE TWIGS OF VARIOUS AGES

$A$, water sprout, one season old, numerous branch buds. B, shoot from a fruit spur bearing new fruit spurs toward its upper end. Each of these spurs has attempted to produce fruits, but the apples have almost all failed to mature. C, eight-year-old twig whose fruit spurs have made 31 attempts to bear, but have succeeded in maturing fruits only five times, most of the specimens falling before half grown. D, three-year.old shoot with vigorous fruit spurs. E, similar shoot with one fruit spur which "changed its mind" and became a branch. 
removal of such branches may not be objectionable so far as the direct injury or shock to the vitality of the tree is concerned. But there are important reasons why large branches should not be removed.

Such pruning exposes dangerous wounds; it is apt to open the tree so much that some of the remaining parts scald and borers obtain a foothold; it may spoil the symmetry or convenience of the tree, and such branches may represent a certain amount of energy which should have been earlier directed elsewhere. Aside from all this, the cutting away of very large branches often indicates a lack of enterprise and forethought on the part of the grower, and suggests the feeling that he may be remiss in all his operations. But while I discourage the removal of branches 3 and 4 inches in diameter, it is not because I consider such practice a devitalizing one. I should much prefer the removal of such large branches to total neglect. I have myself removed many such branches 10 and 15 years ago from apple trees which are today in most perfect health and vigor.

46. Experience the best teacher.-If philosophy and physiology show that pruning is not a devitalizing process, common experience affords still stronger proof. One of the commonest absurdities in our horticultural literature is the admonition to prune only with a knife, thereby avoiding the cutting of large limbs. Not an orchardist in the country practices this advice if he prunes thoroughly! If scientific teaching and permanently successful practice are opposed, then the teaching is wrong. [Certainly] some of our accepted teaching on pruning will not stand the test of time. I have frequently observed that well-pruned trees live as long as those unpruned, and I am inclined to believe that they may live longer. They [surely] produce more [and better fruit] during their lifetime.

But suppose that pruning is a devitalizing process- 
what then? Even then we could not afford to discontinue it. The gains in size and quality of fruit, in ease of cultivation and spraying of the plants, are advantages which progressive horticulture can never forego. Advise a grape-grower to discontinue pruning!

47. Summary. - It appears to be safe to conclude, from the foregoing considerations, that pruning is a legitimate practice, finding warrant in wild plants, in physiology and in the experience of centuries. It is not of itself, as ordinarily performed, a devitalizing practice, while its advantages are several and important. There is abundant opportunity for improvement in methods, and every plant needs a particular treatment, and perhaps some.species or varieties demand little, if any, thinning; but, as a whole, pruning is indispensable to successful horticulture. 


\section{CHAPTER IV \\ BUDS}

48. A bud is a rudimentary plant part which upon development produces (1) a leaf or a cluster of leaves, (2) a stem, (3) a flower or a cluster of flowers, or (4) a cluster of leaves and flowers together. The first of these are called leaf buds, the second wood or branch buds, the third flower buds and the fourth mixed or cluster buds.

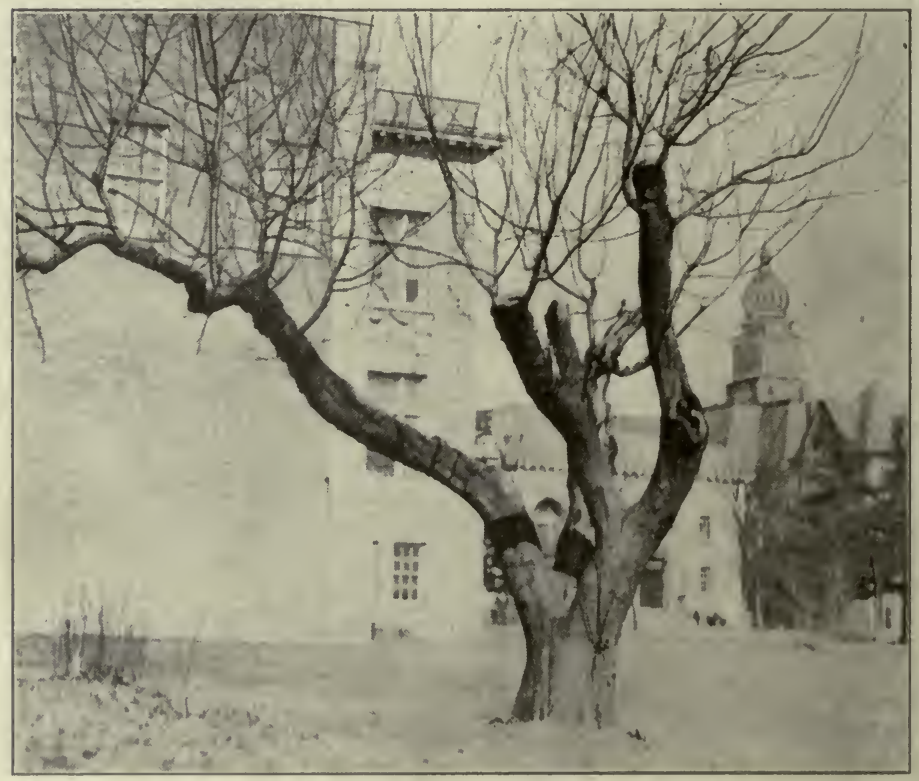

FIG. 30*-DEHORNING WITH A VENGEANCE

Instead of healing over, the stubs have decayed. Such a tree is a wreck.

* There's a joke in the tower seen in the background. The negative had been injured at this point, so the engraver built a new tower of a style with which he is presumably familiar because of his lodge affiliation! The actual architecture of this tower is seen in Fig. 94. 
49. Leaf buds may be produced anywhere on stems not too old to perform this function, but leaves are mostly developed at the nodes in spring and early summer upon shoots newly expanding from terminal and lateral buds.

50. A wood or branch bud is an undeveloped branch inclosed in modified leaves or bud scales which protect a rudimentary axis and leaves that under favorable conditions of growth expand into branches bearing leaves and perhaps flowers also.

51. A flower bud is an unexpanded flower protected or not by bud scales.

52. A mixed or cluster bud is often termed merely a flower bud, as in the case of apple and pear; but since, upon expansion, it develops both leaves and flowers, it is more definite to use the correct term.

53. Other names for buds.-For convenience, various terms are used to describe still more definitely all of the

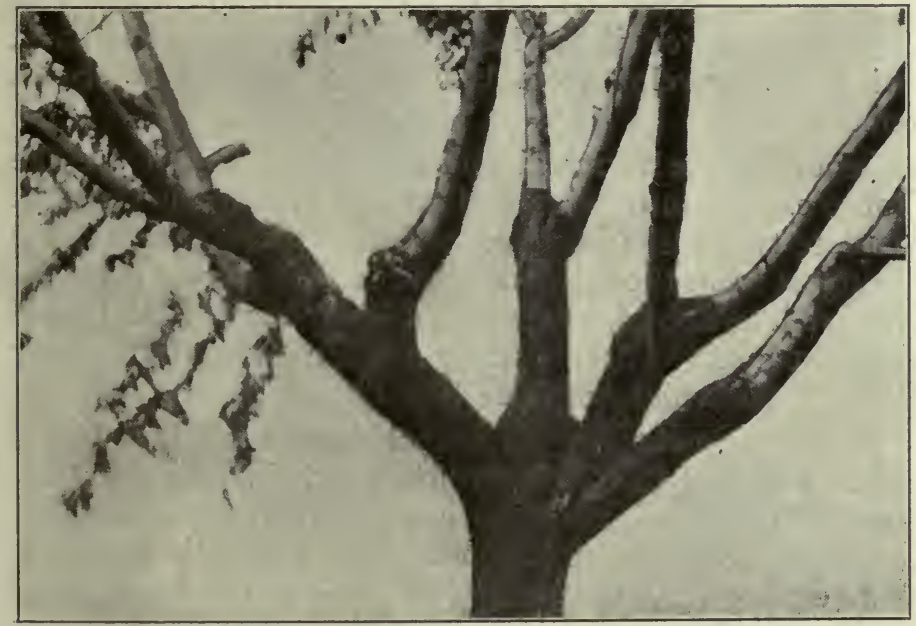

F1G. 31-NEW GROWTH ON "DEHORNED" PEACH TREE

Some of the cuts-for instance, the one in the center-should have been re-cut to favor healing over. Notice the sturdy new growths from the old branches. The tree was full of good fruit when the photo was taken. 
above classes. As to position, buds are (a) lateral or axillary; that is, produced in the leaf axils, or (b) terminal; that is, borne at the extremities of shoots. Buds may also be dormant or latent.

54. Dormant or resting buds are developed during the growing season, but remain quiescent during the winter or the dry season which follows. If they continue to rest longer than this, though still technically "resting buds," they are usually termed latent.

55. Latent buds require a more vigorous stimulus than do dormant buds to force them into growth. They are commonly located upon the lower portions of shoots and branches, and simply because of their unfavorable position do not as often expand under normal growth stimuli as do buds farther up on the stems. The peach, especially a young tree, furnishes an excellent illustration, because usually only the terminal and a few of the upper buds on "last year's" growth normally develop into twigs "this year." However, if the last year's growth be cut back, twigs will develop from buds which would otherwise remain latent.

Generally the terminal bud and those near it are the first to expand into twigs, and generally, also, the strength of these twigs is, according to their relative position, the strongest from the terminal bud the next strong from the nearest lateral bud, the weakest from the lowest lateral that expands. There usually remain several to many lateral buds which continue latent.

For experiment, let the branch be cut off just below the lowest bud that has developed a twig. In due time the highest latent bud will assume more or less satisfactorily the duties of a terminal bud and adjacent buds will develop lateral twigs (Fig. 66). If the original branch is long enough, this experiment may be repeated as long as any latent buds remain. Whether the experiment be performed on "last year's" wood or wood several years 
older is immaterial; the buds if still living may awake from their latency and produce twigs. Very important use is made of this principle in transplanting nursery trees and in dehorning (Fig. 31), though it must be said that in the latter practice the buds which expand are mostly

55a. Adventitious buds. - When buds are produced at unexpected points on roots, stems or leaves, they are said to be adventitious, because they are not in normal positions. From the standpoint of the pruner they are of great importance for two reasons ; namely, (1) they may develop suckers from the roots or water sprouts (Fig. 32) f rom the trunks and branches, and it may be necessary to destroy these adventitious, undesirable growths. The suckers in plants that have bee $n$ grafted or budded are almost inva-

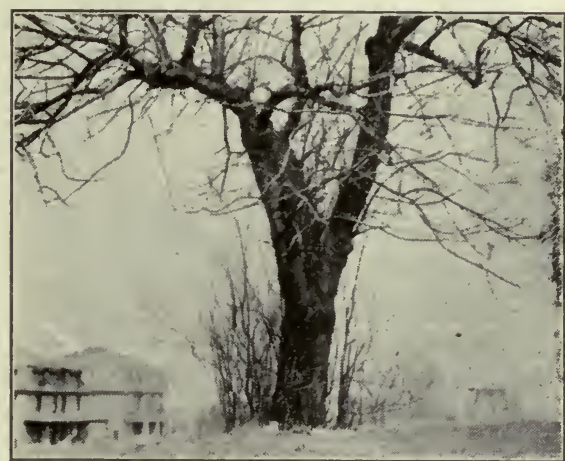

FIG. 32-NOTHING WRONG WITH THE ROOTS

Trees which show such vigorous growths of suckers and water sprouts always have sturdy, abundant and healthy roots. The trouble is in the top.

riably undesirable, because the stock is of a different character from that of the cion or top.

In some cases the stock, being often of more vigorous habit than the cion, would grow so rapidly that the cion might be starved to death, as often happens with grafted and budded roses that are neglected in this particular. (2) Conversely, adventitious buds are important because they may be relied upon to produce new growths. The most important applications of this development are (a) 
in plant propagation, where the adventitious buds produce roots on layers, cuttings, etc., and (b) in pruning and "dehorning," where they, as well as latent buds, are relied upon to produce new shoots, some of which may be favorably enough placed to develop new branches or even whole heads.

56. Where blossom buds are borne.-In order to prune intelligently for the production of flowers and fruit, it is essential that the pruner know where blossom buds are normally borne. While the positions of these buds naturally vary among the varieties of any species with the vigor and the age of the plant, with environment and other factors, yet each species has its own characteristic method of blossom or fruit bearing. In general, species and their varieties may be grouped in two general classes each with its subdivisions. These are characterized thus:

A. BLOSSOM OR CLUSTER BUDS EASILY SEEN DURING WINTER on "last season's" twigs: 1, A.rillary": Peach (Fig. 46), hazel, filbert (almost always), almond, currant (Fig. 49), gooseberry (mainly, Fig. 50), apricot and Japanese plum (partly, Fig. 48), apple and pear (sometimes). 2, Terminal, mainly on spurs. Apple, pear (almost always, Figs. 35, 36), cherry (Figs. 41, 42, 43, 44, 45), plum (Figs. 39, 40) and apricot (mainly), almond and currant (partly). B. BLOSSOM BUDS NOT VISIBLE DURING WINTER because borne on "this season's" twigs: 1, axillary on canes or strong shoots: Grape (Figs. 51, 57), mulberry, persimmon, olive, chestnut, fig (Fig. 33) ; 2 , $a$, terminal on terminal shoots: I.oquat; $b$, terminal, or nearly so, on lateral shoots developèd during summer: Orange and the bramble fruits (raspberry, Figs. 55, 56, blackberry, Fig. 54, dewberry); 3, co-terminal, that is on the ends of short shoots developed from buds formed "last season" and wintered over. Quince (Fig 58), medlar, hickory, and walnut.

From the above outline it is obvious that in pruning for flower and fruit production the operator, while not 
losing sight of the effects his work may have upon the general growth of the tree or shrub as to form and development, must consider the way in which blossom buds are produced so he can intelligently regulate the number and development of the buds, twigs and branches which are to bear these flowers and fruits. The following paragraphs will, therefore, help the uninstructed reader to determine how to make decisions so far as buds are concerned.

57. Age of shoot determined by bud scars.-In pruning practice it is often necessary to know the age of branches and twigs. Except where secondary growth has taken place this can easily be determined until the branches become too old to reveal the distinguishing marks, rings and a bulge. These may not, however, be as marked in this case as in normal cases. When the terminal is a fruit bud the branch usually kills back to the first sturdy lateral twig, which then assumes the duties of leadership. Very

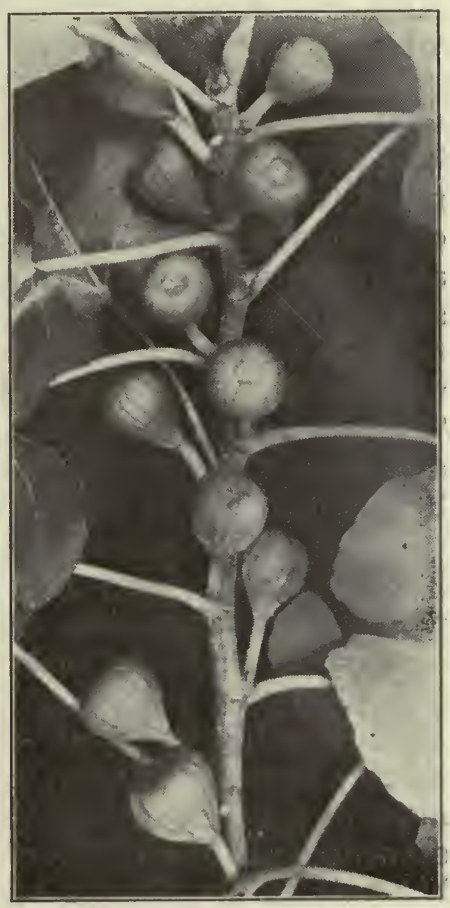

FIG. 33-FRUITING HABIT OF FIG Fruits axillary on "this season's"
growths. marked cases of thickening occur with some varieties of apple and pear fruit spurs which are often three times the diameter of the twigs below the swellings. The scars were left by the bud scales which fell off when the terminal bud pushed into growth. When the terminals 
are wood buds the direction of growth is practically straight, but when they are blossom buds or when the terminal wood bud or shoot is destroyed accidentally or purposely, an axillary bud will develop a shoot which will depart more or less from the straight line. (Fig. 67.) This is especially characteristic of apple and pear spurs, which in many varieties become greatly contorted.

58. Fruit spurs and buds.-An examination of twigs two seasons old of, say, apple and gooseberry, will show how axillary buds often develop, 1 , into twigs as already noted (50) and, 2, into tiny spurs terminated by blossom or cluster buds (Fig. 29). Often these latter are so short as to be mistaken for true buds instead of bud-terminated spurs. When these buds swell, they may develop several to many leaves or flowers or both. When they do not produce flowers, a terminal bud may be formed during "this season" for the extension of the twig "next season"; and when flowers develop into one or more fruits, a branch bud may be formed in the axil of a leaf to extend the twig more or less laterally "next season." In this last case the twig may grow for several seasons in the direction thus taken; that is, until it develops a terminal cluster bud and thus makes a change of direction necessary.

59. Meaning of scars on fruit spurs.-When fruit reaches maturity it leaves a scar at the point of its attachment to the fruit spur or twig. It is often said that such scars indicate the number of fruits borne by the spurs, but this is not always true, because frequently short twigs, which at some previous time bore flowers, may kill back to the main fruit spur, and when they fall off leave scars like those left by fruits that matured. The only way to be sure is to note whether or not the scars are solitary or in clusters. Where solitary they have probably been formed by twigs; where in clusters, by flowers or more or less mature fruits surrounding the scar of a fruit that reached maturity. 


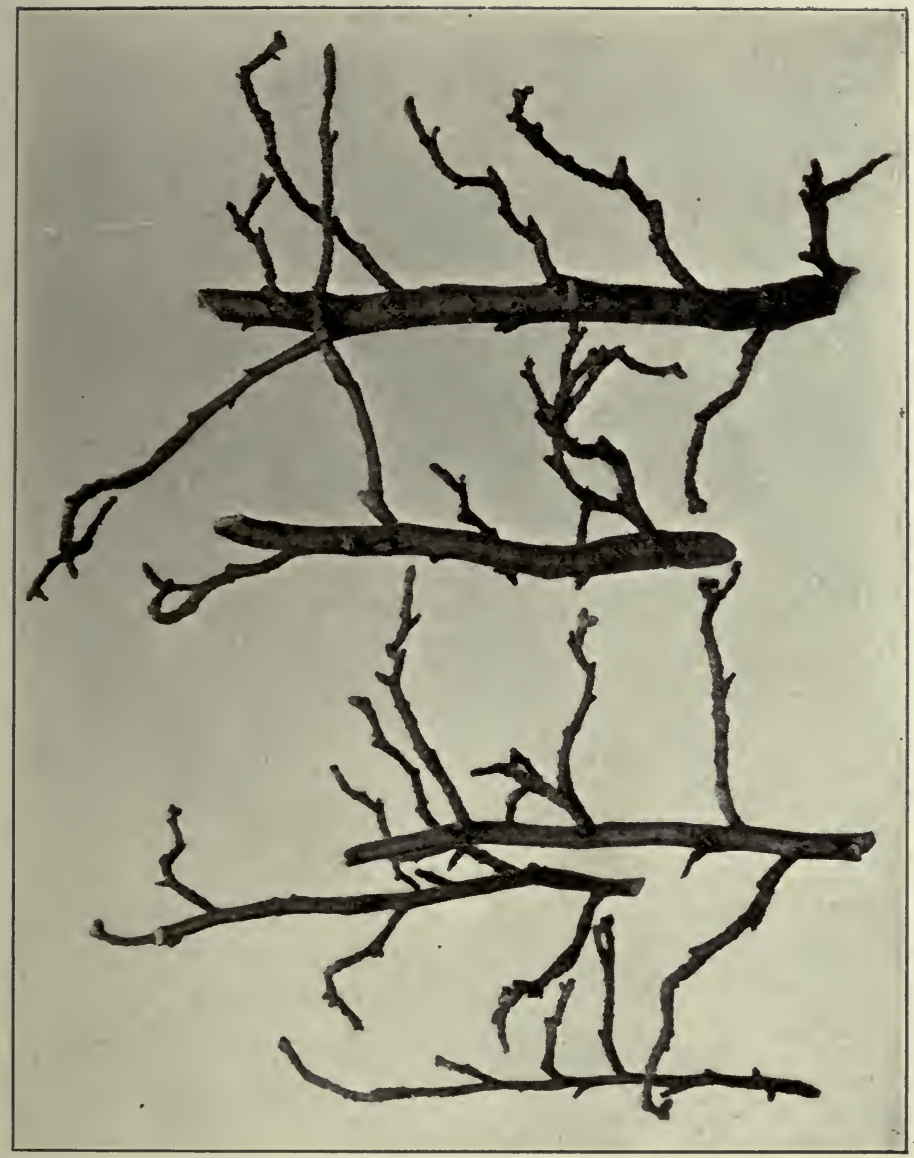

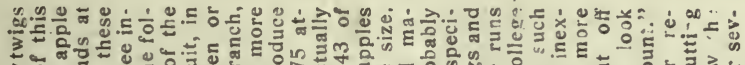
I 0 즌

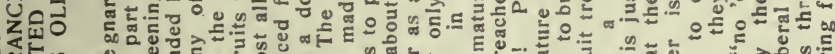
लेरी की m纯 क्य Q

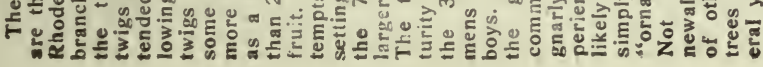


60. Slow growth favors fruitfulness.-Since lack of light due to disadvantageous position tends to reduce food supply and consequently size of twigs, many twigs so deprived develop into fruit spurs. Hence it may be concluded that slow growth favors fruitfulness. Generally when twigs have developed the fruit-bearing habit they continue in this habit. Thus at, say, 20 years of age, they may be only a few inches long though they may have produced a considerable number of fruits. It does not

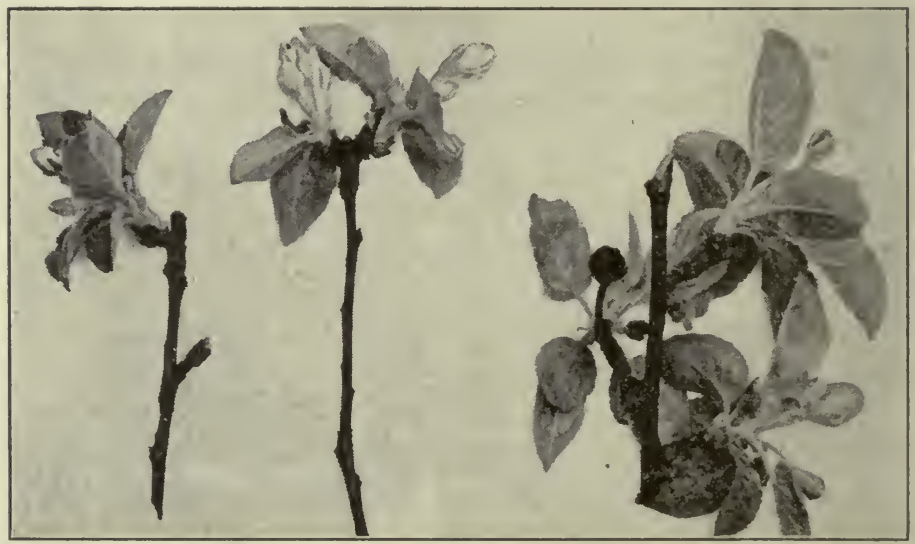

FIG. 35-FRUITING SPURS OF APPLE

The left-hand specimen has evidently borne a fruit. A cluster bud has developed on the stub and a branch or spur bud is swelling below. A similar case is in the middle, but two cluster buds have been formed. The right-hand specimen shows the mummy of an apple that failed to mature beside the branch bud of which a new branch bud has formed. The other spurs also on this twig show norma! growth, the spurs being two years old.

follow that the habit cannot be broken or that advantage cannot be taken of it, as in invigorating old fruit spurs. (Fig. 150.) Injudicious pruning is one of the surest ways of destroying the fruit-bearing habit; and this, too, without the removal of any of the spurs. (Fig. 171.) Heavy pruning, especially during the winter of a season when the crop is light, will force many strong growths from the fruit spurs as well as from other parts of the tree, so that, 
as many an orchardist will shamefacedly admit, there will be little or no fruit for one to several years.

61. Pome fruit bud positions vary.-Most commonly apples and pears bear their cluster buds terminally on gnarly little twigs called fruit spurs (Fig. 34). When these buds expand, they show perhaps half a dozen to a dozen leaves surrounding maybe as many flowers. Usually not more than one, or possibly two, of these blossoms develops into a mature fruit (Fig. 35). The others lrop off. The fruitripening process is apparently an exhaustive one, for the spur which matures a fruit "this season" will usually not develop o n e "next year." While the fruit is ripening, a branch bud is developing near the fruit-stem attachment to the spur. This branch bud

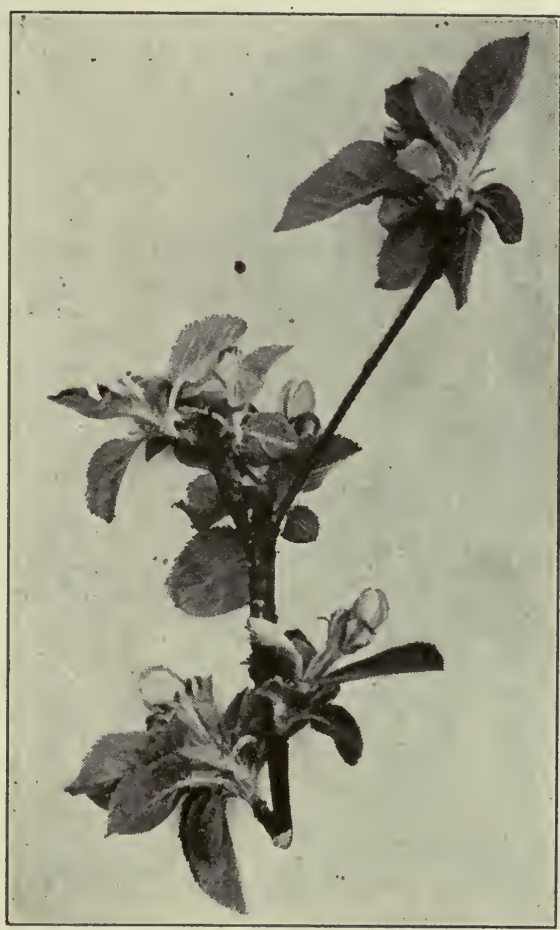

FIG. 36-BLOOMING TWIG OF APPLE

Variations such as these are not uncommon. Note that the cluster buds are mainly on short spurs (below); that in the center a fruit has evidently been borne and other fruit spurs have developed from the sides of this spur; also that one of the buds has developed a short branch with a terminal cluster bud.

swells the following season into a short growth terminated by a cluster bud. Thus fruit spurs theoretically 


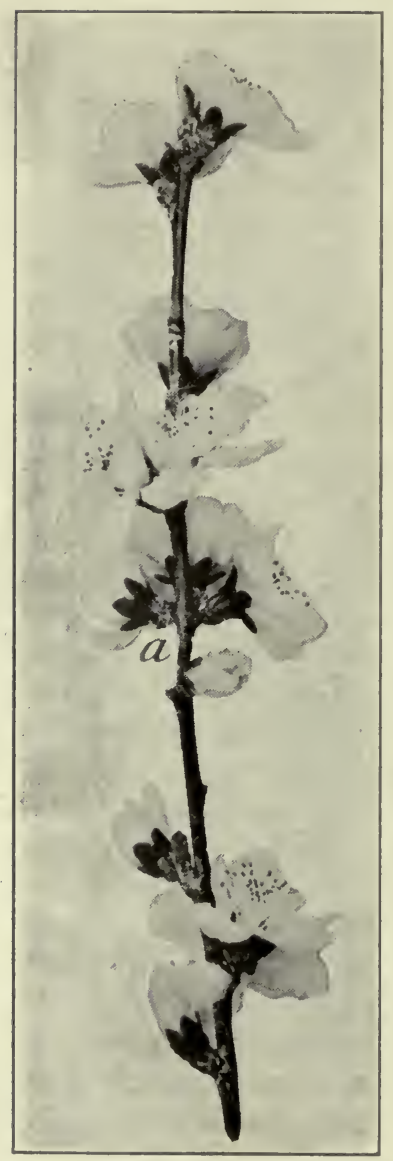

FIG. 37-PEACH SPUR

This twig grew on the interior of the tree. Notice 1, the large number of blossoms; 2, the small number of branch buds; and 3 , that in several cases (clearly seen at a) branch buds have been replaced by flowers. of this fact is that those varieties which produce blossom buds on growths only one season old tend to bear each alternate year anci continue for many years to make their gnarly growth. Such being the case, great care must usually be exercised to prevent injury to the fruit spurs: for if they are destroyed they cannot be replaced. The only ivay new ones can be secured is $t$, develop water sprouts. upon which, after much loss of time, new spurs will form.

Apple and pear cluster bud: though uswally terminal as shown in the outline (56). : $\mathrm{r}$ ? not always so. Though fruit spurs are usually two seasons old before mature fruit's can be gathered from them, this rul. has its exceptinns. Indeed. some varieties proriuse considerable fruit on the tins of "last season's" twigs or (i) spurs of the same ane (Fig. 36). Certain varieties of apples produce blossom huds in th. axils of leaves of "last season" and mature their. fruits "this season." Such cases as these a p pear to be very exceptional in the easteri United States, but comparatively common in the $T T^{\top}$ est, especially in sections where urrigation is practiced. The practical valuc 
be more regular annual bearers oi fruit than do those varieties which produce fruit buds only on older growth. Annual bearing, it must be stated, however, is a habit which is dependent not upon thic one factor alone, but upon other factors. For instance, certain spurs tidy Lear fruit one year, while others are fruitless. "16 fllowing season the fruitless spurs may bear the crop, while the previously fruitful ones may iake a rest. Fruit spurs MAY produce fruit each alternate year. but this is not nearly as regular a habit as it is popularly believed to be.

62. Pit fruit bud positions.While the outline (56) shows the general ways in which pit fruit buds are borne, yet the rariations due to variety, environment and other causes deserve a special paragraph.

Stone fruit blossom buds are unlike those of apple. and pear in being simple; that is, they are not clustered with leaves, though plum and cherry buds often contain a few little leave: that ustually drop off before the fruit ripens. Sometimes peach and apricot buds contain two flowers, though one is the normal number. Cherry buds

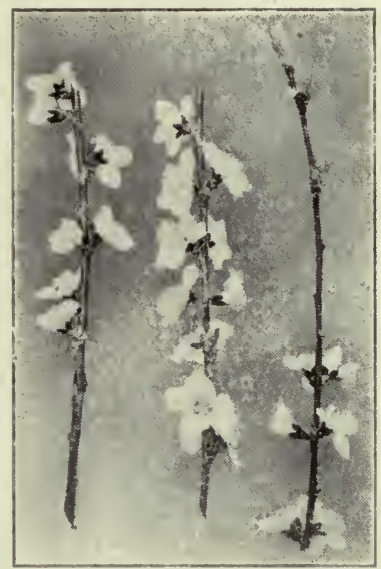

FIป. 3:-ANN'IA'. GROWTH OF - PEACH

The three picces constitute on branch of "lact" segson's growth. Note, 1, positions o" ti e bloom ncar the middle of tha Jranch; 2 . that normally a branch bud li $\equiv s$ between two blozm bu's ard els ? at the erminal: 3 that bloom $\in Y$ tends nearly to th? ti? with or $y$ short, bar? intrrv-ls above ard b-lo: the main blooming area, ard the in $^{2}$ ervis's bear br $r$ h or le $f$ but s; 4, that the lowest bran.h buds are not swelling while tha upper ones are.

usually reveal two flower buds, though the number may vary from one to five. The same is true of plums, excep: that two or three are the usual numbers.

The pearh bears its blossom buds singly beside ; branch bud or in pairs with a branch b 1d between, except 
as noted two paragraphs below. It is believed by many fruit growers that this simple bud habit is one of the reasons why peach buds are usually more largely winterkilled than are the buds of apples and pears, which are in well-protected cluster buds. In the bud which contains no leaves the flower parts usually have few protecting bud scales.

An examination will show that the branch buds of the stone fruits are closely similar in structure and position to those of the pome fruits. Still there are

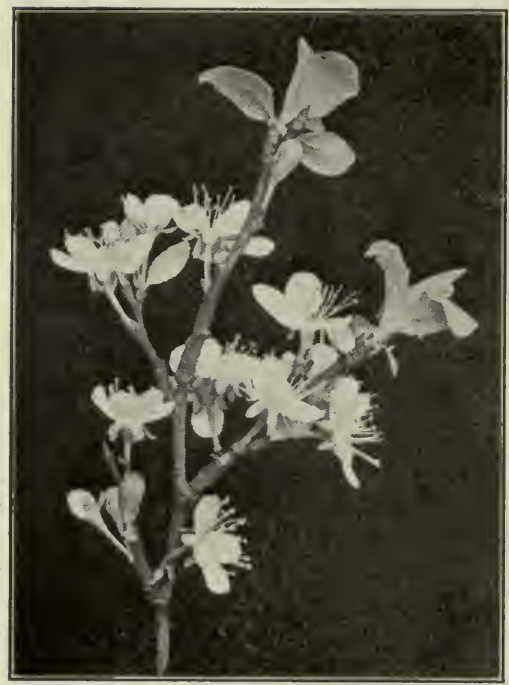

F1G. 39-EUROPEAN PLUM

Branch shows typical blooming habit, flowers being borne largely in pairs or singly on last season's wood. differences. For instance, apricots and many plums seldom develop terminal buds of any kind, and the axillary buds of these two f ruits and also of peaches may produce blossoms instead of leaves.

To illustrate $\mathrm{th}$ is point still further: Normally the peach produces two blossom buds with a wood bud between them, but often even this central wood bud gives place to a flower, so three flowers are produced in a group (Fig. 37). When the terminal bud fails to form, the nearest axillary bud, if a branch bud, assumes the duties of a terminal wood bud and the following season extends the branch in practically as straight a line as if it were a true terminal.

When peach trees are making normal growth the blossoms are more often in couples than they are solitary. 
When the growth is strong the blossom buds are nearer the tips than the bases of the twigs, because their positions are largely determined by the vigor of the trees upon which they are borne. When the growth is weak the buds are mainly solitary and scattered from end to end of the twigs. When the growth is moderate the buds are mostly near the middles of the twigs. Young and rankgrowing trees show them near the twig tips.

It is important to remember that the blossom-bearing habit of the peach tends to make the fruit-bearing area of the tree move each season farther from the center of the tree (Fig. $46)$, instead of continuing, as in the apple and the pear, in a practically set area. The pruner must, therefore, maintain a supply of bearing wood on the branches, which he must not allow to extend too far. The wiry interior growths re-

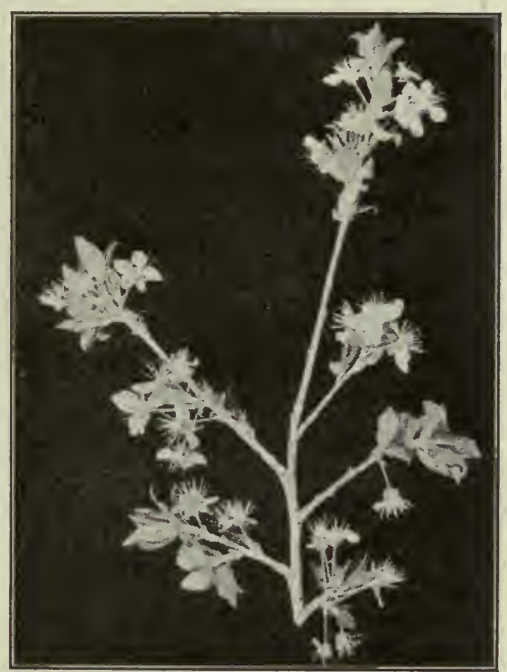

FIG. 40-JAPANESE PLUM

It is characteristic of this species to produce flowers largely in threes.

ferred to above rarely bear fruits more than two years, often only one. They soon die and must be cut out.

All this indicates far more severe pruning of the peach than of the apple or the pear. This is especially the case with young trees whose "leaders" are prone to make the trees too high. Pruners often remove or very severely cut back all the leaders for several years, even though they know new ones fully as vigorous will replace them.

62 a. The plums vary somewhat with their species as 
to the positions of their blossom buds. None of them bear on "this season's" growth so they naturally belong to the first group in the classification (56). The great majority of the fruit buds are borne on short spurs similar

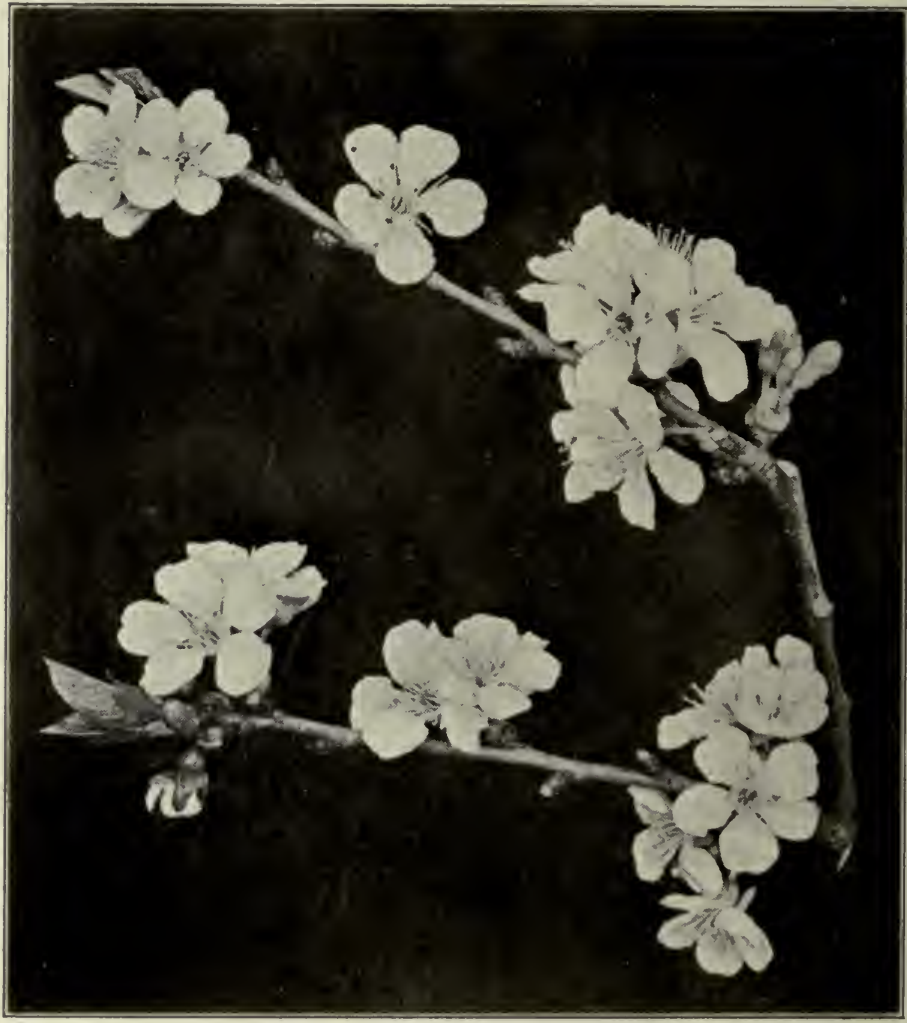

FIG. 41-BL.OSSOM BUDS OF SOUR CHERRY ARE BORNE AL.YOST TO THE TERMINALS, BUT ARE MOST NUMEROUS NEAR THE BASES OF THE ONE SEASON'S GROWTH

to those of the cherry, though in the varieties of some species and hybrids many are developed in the axils of leaves on the one-year wood. These bloom "next sea- 
son." The spurs bear their fruit buds mainly near the ands and lose the function in their lower parts as the spur elongates and branches. This may be readily determined hy examining an old spur: the scars indicate where buds formerly developed into fruit. The distinction between fruit and leaf buds is not as easy to make as in the peach, pear or apple. Position is the safest guide. Usually the tip bud will produce a twig. Often, however, a side bud

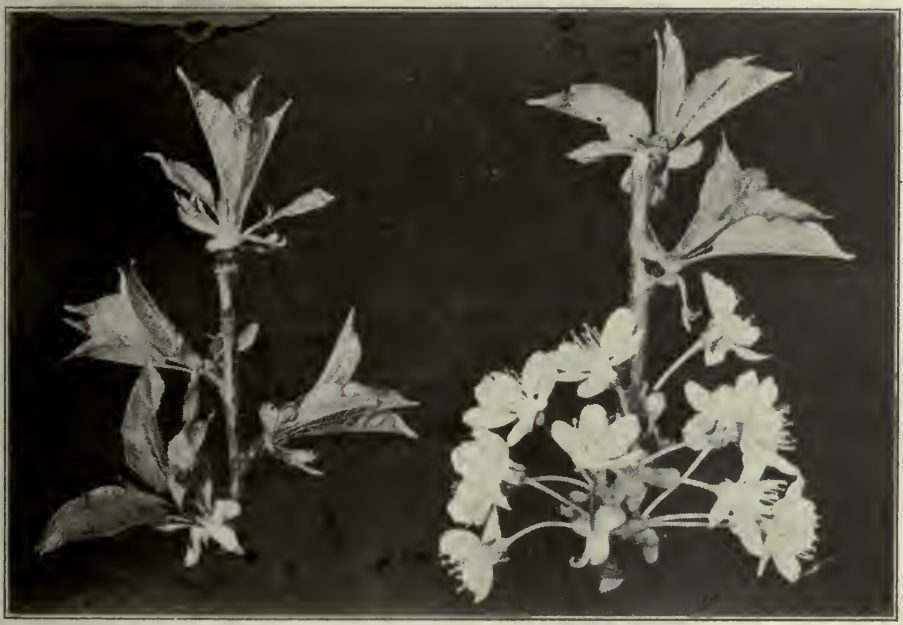

FIG. 42-SWEET CHERRY TWIG IN TWO SECTIONS

Blossoms opening on the right from cluster buds near the base of the annual growth. On the same twig higher up other buds have produced only leaves. The end of the two-year wood is seen at the base of the right-hand section.

will also do so, though it is generally a flower bud. The best time to study this point is when the buds are swelling in spring.

63. The apricot resembles the peach in fruiting habit, though it bears fewer fruit buds on the vigorous new woor. It bears considerable numbers on short growths which resemble the spurs of cherries and plums, though some are so short as to appear almost sessile and thus 
to be clusters of buds on the branch. A close examination will show that each of these groups of buds is borne in the axil of one leaf. This method of flower bud bearing is less general than the production of buds singly in the leaf axils.

64. Cherries bear their fruit buds mainly on short spurs (Figs. 44, 45), much less laterally on the vigorous young shoots, except as noted below. In all

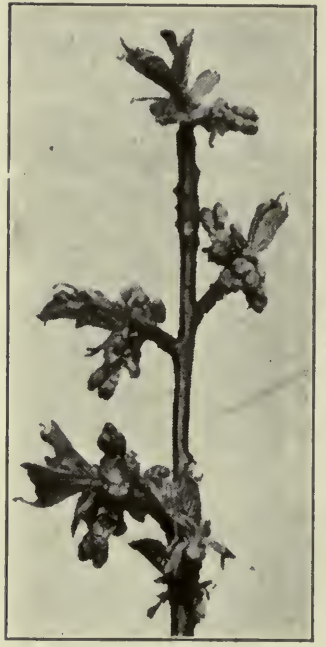

FIG. 43-SWEET CHERRY

Twig shows numerous spurs on two and three-year wood. Cluster buds (not seen) form near the base of one-year wood. Note that the tips of all spurs produce branches as indicated by the leaves. The same is true of terminal and axial buds. cases, however, the buds are axillary, the termnal being a branch butl. hence the usually straight fruit spur:. As in the peach the twigs produced "last year" often bear blassom buds mostly near their bases. The branch buds farther up these twigs will many of them develop "this year" into spurs for "next year's" fruiting (Fig. 45). Among the sour cherries certain varieties produce considerable numbers of bloom buds on the new growths. After these have fruited they drop off and thus leave the long naked branches so commonly seen among the sour cherry varieties. The only areas that bear fruit in such varieties are near the ends of these slender branches.

65. Recognition of fruit buds.The cluster buds of apples and pears are readily distinguished by their plumpness and their wellrounded shape. Those of apricot and peach, though smaller, are about as conspicuous as apple and pear buds because of their positions as well as their forms. Cherry buds, especially on "last season's" wood, are harder to recognize because they are not very much 


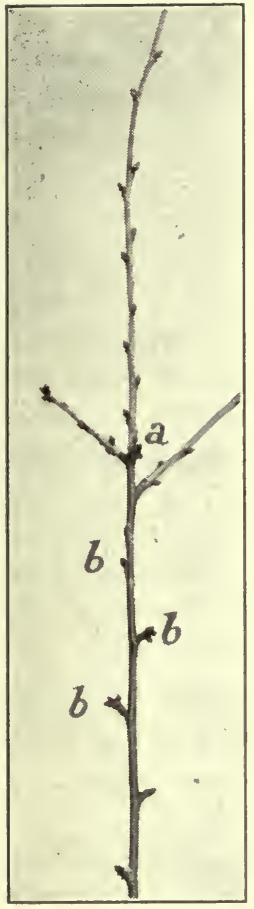

F1G. 44-SOUR CHERRY

At $a$ is the dividing point between oneyear and two-year wood. A fruit spur is also shown here. Similar spurs are seen at b. Each of these bears three or four blossom buds and one branch bud, the latter at the tip. The spurs lower down have only branch buds at their tips. Branch buds are also seen on the one-year wood.

themselves, all have axillary fruit buds-sometimes on vigorous "last season's" twigs, sometimes on older wood. 


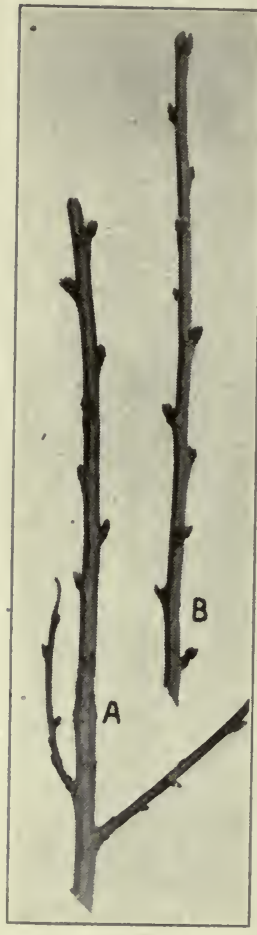

FIG. 46 .
FIG. 46-FRUIT AND LEAF BUDS OF PEACH

$A$, end of two-year and beginning of oneyear wood. Buda largely in threes. Tre outside ones are fruit buds the ones between leaf buds. B, is continuation of another part of the shoot-another third part. Such growths must be cui back severely both to reduce the numb $\equiv \mathrm{r}$ of fruits and to prevent the undue extens on of the branches from the terminal buds, more particularly. The whole one-year part of the branch in this case is 30 inches long. It is cut in $A$ at 8 inches and in $B$ at 10 .

\section{FIG. 47}

PEACH TWIGS THAT HAVE BORNE, FRUIT

$B$, note annual growih ring at $c$, above which the twig is one ycar old. $C$, four ye $r$, growth of a so-call d spur with annual growths starting at $c$, $d, e$. Fru't stems on both twigs at $b$. Th $s$ the fruits and th: growths from $e$ to the tips of branch $C$ w $r$ developed simultareously. Branch $C$ is 12 inches long from $c$ t the tip. Compare Fig. 46.

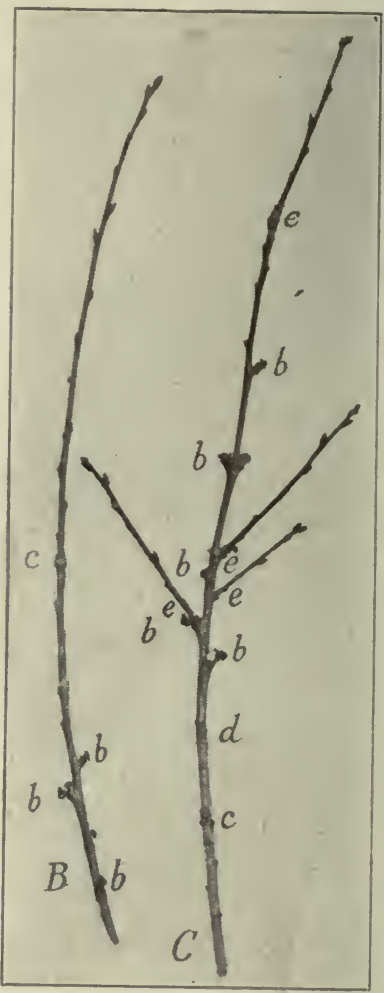

FIG. 47

Japanese plums suggest the apricot in bloom-bearing habit-axillary buds on spurs and also on vigorous young wood; in this latter case. like peach bloom buds, in couples, with a branch bud between. During the dormant season the recognition of plum blossom buds is often exceedingly difficult, though in some varieties it is easy.

66. Fruit bud formation and development.*-The fruit lepends upon the formation and proper development of

* Paragraphs 66 to 69 are svnossized from the extensive studies of A. W. 1)rinkard, Jr., of the Virginia Experiment Station, annual report, 1909-10. 


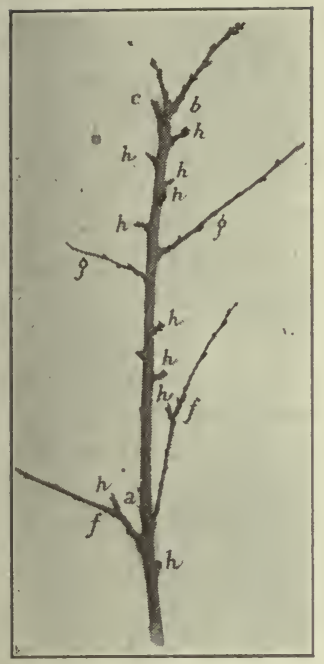

FIG. 48-JAPANESE PLUM

The branch shows one year's growth from $a$ to $b$ at which latter point the terminal bud died and a lateral branch $c$ developed 24 inches long the following season. At the same time two other laterals on the underside of the branch also developed 1 and 2 inches long respectively. The twigs $f$ are two years old, the annual rings being shown at $f$. Twigs $g$ are one year old. Fruit spurs are seen at $h$. The fruit buds are largely in threes. Hence the need of fruit thinning.

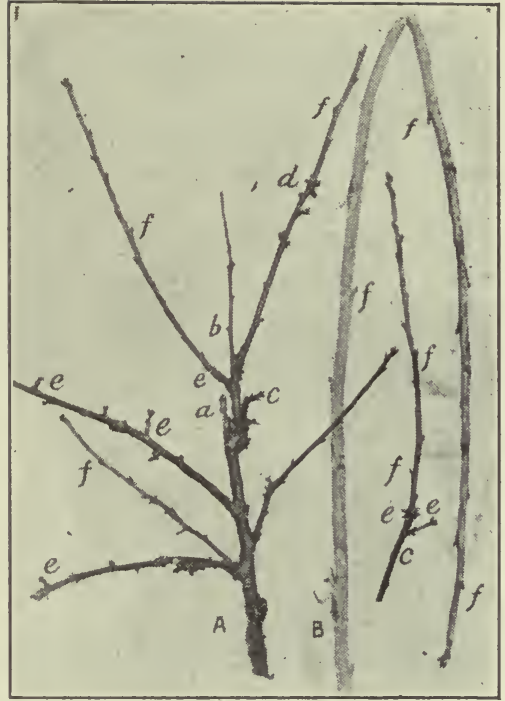

FIG. 49-CURRANT BRANCHES OF VARIOUS AGES

A, four-year cane which has twice had its leader injured- $a$, broken; $b$, girdled. Branch $c$ is two years old, the dividing point being at c. Branch $d$, also two years old, just above the upper cluster of blossom buds at $d$. Notice blossom buds on two-year spurs at $e$. The buds on the one-year growths at $f$ should produce spurs and bloom buds for the following year's fruit. B, one-year cane produced from the base of the bush. Two or three such canes should be allowed to grow each year to take the place of the four-yearold wood removed each year. C, two-yearold branch with bloom buds on older part, and branch (spur) buds on the younger.

fruit buds. Hence knowledge of the time such buds are formed and developed will lead to knowledge of the factors that influence fruit bud formation and are conducive or detrimental to bud development. With these assumptions an enormous amount of work was conducted by Mr. Drinkard to determine, (1) the period of fruit bud formation by field observations; (2) the gross development of floral parts by microtome sections covering the 
changes between the initial period of terminal bud formation (lateral for peach and plum) and the time of flowering; (3) the exact date of differentiation of pollen mothercells and of the similar stage in ovogenesis; (4) the period

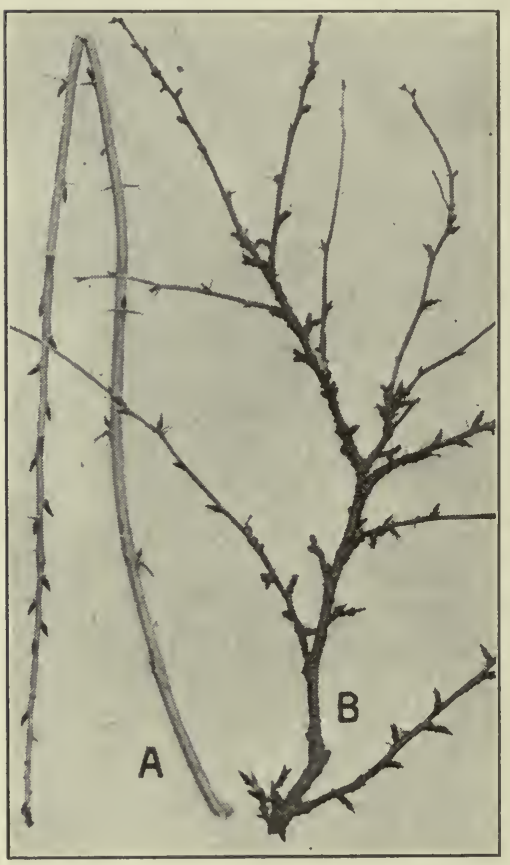

FIG. 50-GOOSEBERRY BRANCHES, YOUNG AND OLD

A, one-year growth from root. Two or three of the strongest of such shoots should be allowed to grow each year to replace old wood cut out after fruiting. Notice position of buds and length of spines-three in a cluster. The buds should form spurs for fruiting next season. $B$, five-year-old branch of a much less spiny variety. Canes should not be allowed to grow as old as this, but be pruned out when three or at most four years old. Bushes kept young by such pruning are usually healthier than ones in which the wood is older. Best and most fruit develops on two and three-year wood. of origin of pollen grains and of ovules.

During the growing season buds were selected every week or 10 days and during the clormant season at longer intervals. They were killed, fixed, embe d d ed, sectioned, stained and mounted according to approved laboratory methods and the various stages of growth and developme n t recorded by photomicrographs, of which the original report shows 106 . It is not necessary here to detail these methods, so we will pass to the

67. General observations. - The great amount of work involved in preparing microsopic sections made it impossible to study a large number of varieties. At first four varieties of apples, three of plum and one each of peach, pear and 
cherry were studied, but later only one variety of each fruit was studied. Even these involved the preparation of many hundreds of mounts, mostly only those sections taken transversely

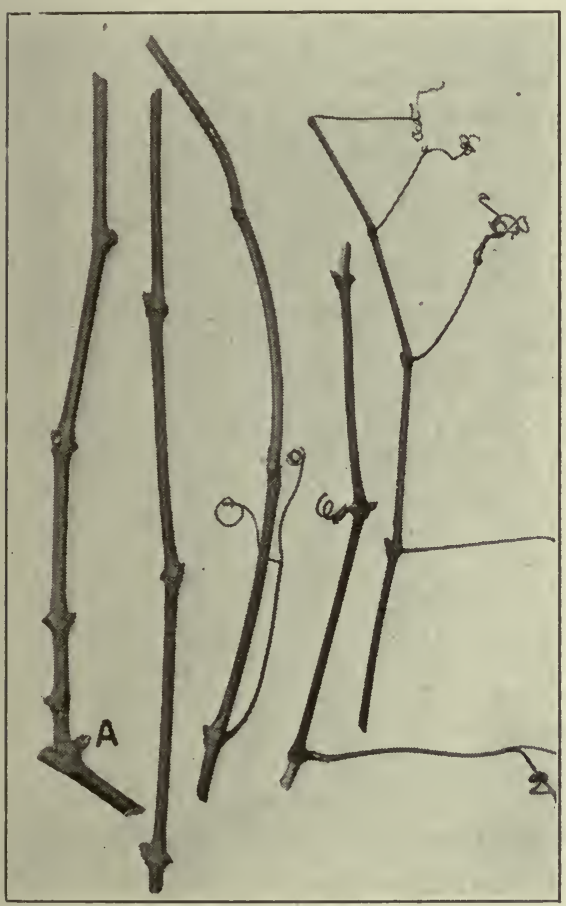

FIG. 51-GRAPE CANE ONE YEAR OLD

The small piece at the base of the left section is two-year-old wood. The little knob at $A$ is not a bud, but the remains of a lateral. Normally, buds develop opposite tendrils or fruit clusters (modified tendrils). Most of the tendrils in the specimen bud is capable of producing a new cane bearing leaves, fruit clusters and tendrils. were broken off during the growing season. Each through the pistil of the flower bud or through the center of the bud cluster.

In early November comparisons of sections of fruit buds from 25 varieties of $\mathrm{plums}$ showed a surprisingly wide range of development instead of expected uniformity. Hale, a Japanese variety, showed the most advanced development with flower parts apparently ready to unfold, pollen grains well formed, pistils well developed, ovules in the ovaries and buds decidedly swelled, as though preparing to open. On the other hand, some varieties, especially among natives, showed very slight development, even during the latter third of the month. Shortly after mid-December, examinations of 20 apple varieties showed a narrower 
range of development, the majority being approximately the same, with early blooming and fruiting varieties in the lead, but not so markedly as among the plums.

68. When fruit buds may be recognized.-Attempts to determine the approximate date when fruit buds may be distinguished by the naked eye show that observers should be guided partly by the positions in which such buds normally appear. Peach and plum fruit buds may be easily found in early fall, so may cherries, partly by position, partly by their larger size. With apple and pear the feat is less easy. Increased size is not pronounced enough until late November or early December; however, a pocket lens which magnifies 10 or 15 times will help locate such buds during October.

69. Summary and conclusions. -1. Oldenburg apple fruit buds began to form in late June. Several other varieties showed similar development; a large majority of the fruit bud's formed in July, though the initial stages in many cases appeared late into the summer. Development continued through summer and fall with completion of flower parts by about November 1. Development through the winter was mostly microscopic. In late February and early March important development occurred in the essential organs prior to blossoming.

2. Kieffer pear fruit buds did not begin to differentiate until after mid-July. Initial flower parts appeared in August. Development was rapid during the fall up to mid-November when the flower buds in the cluster were fairly well advanced. Unimportant changes occurred during the winter. In late February and early March, changes were similar to those in the apple.

3. Luster peach fruit buds began to form the first week in August. In about three months they were ready for wintering. After November 1 no noticeable change occurred until February, though cytological changes were 


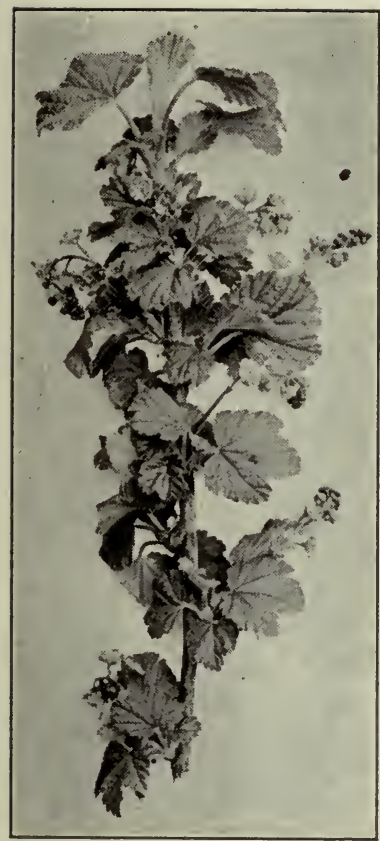

FIG. 52-RED CURRANT BLOOM CLUSTER

Buds borne on last season's wood; leaves and bloom together. Young wood like this bears more profusely and larger fruit than does older wood.

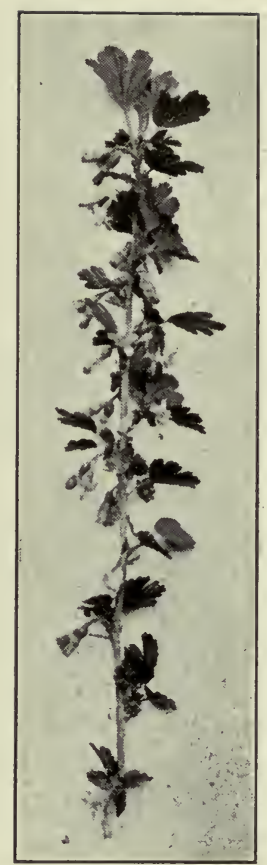

FIG. 53

GOOSEBERRY

Notice that the flowers are produced f rom over-wintering buds on wood of the previous season.

occurring in the essential organs.

Some buds showed division in the pollen mother-cells after mid-December; others had mature pollen grains in mid-January, a process complete at the end of that month when the buds were ready to unfold, which they did during February and early March.

4. Plum fruit buds showed wider variation of development than those of apples. Among Japanese varieties they began to appear the second week in July; among Americans, the first week; among hortulanas the first 
week in September. In this last case (the variety most studied) the buds differentiated into flower parts during October and continued development until late December. During January development was only cytological. In early February this variety resumed active growth and by the end of the month had developed important changes in the essential organs. The flowers were then ready to unfold.

5. Louis Phillippe cherry fruit buds began to form the first week in July, and by the close of the month the flower parts had begun to differentiate, but development proceeded slowly through summer and fall until late November. From then until February changes were cytological. In late February the essential changes had taken place. The buds began to swell rapidly and were ready to unfold in early March.

6 . The following general conclusions are deduced from the foregoing data:

(a) Buds which produce the crop of bloom for the current year are formed the preceding summer; initial fruit bud formation has its beginning in June or July, depending on seasonal conditions and the kind of fruit.

(b) The proper development of the fruit bud would, therefore, be influenced by factors brought to bear upon the tree prior to and during the period at which fruit bud formation takes place. In the practice of such orchard operations as are designed to influence or control fruit bud formation it appears that such operations should be more effective in spring and early summer than at other stages of development.

Among his conclusions J. H. Gourley reports the following (somewhat condensed) :*

70. Bud studies of Baldwin apple.-The formation of axillary buds on current season's growth is not uncommon with the Baldwin and many other varieties of apples. In alternate bearing trees we find a

\footnotetext{
- New Hampshire Technical Bulletin No. 9.
} 


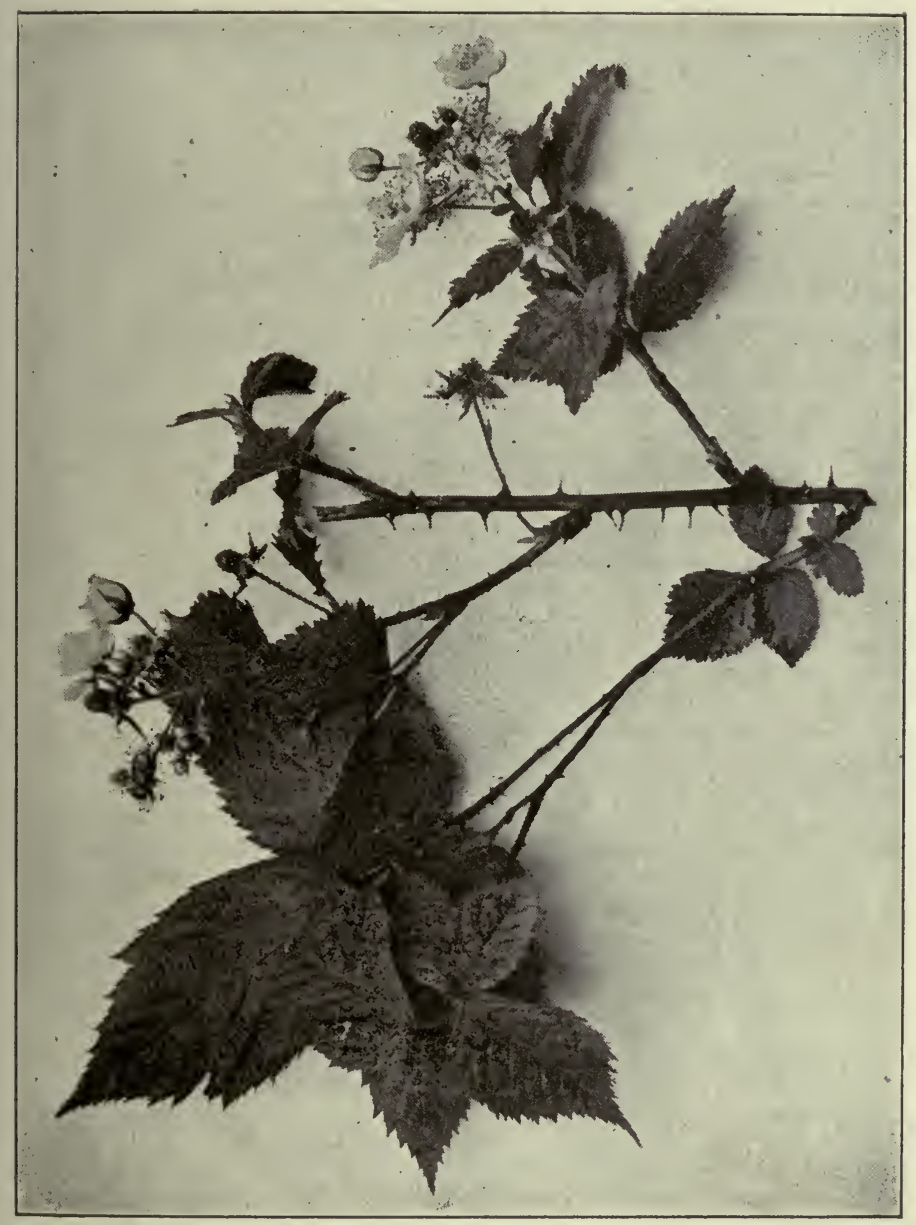

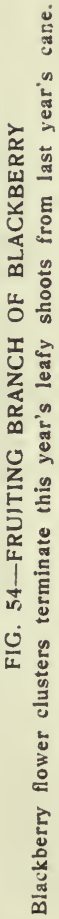


heavier deposition of food material in the storage tissues when the tree has formed fruit buds. On the average we found about 4 per cent greater specific gravity of the twigs and branches in winter condition where fruit buds were formed [than where they were absent]: A much larger leaf area is produced in the "off" year than in the bearing year, amounting to 2.08 square inches more to the leaf in the trees studied.

A second period of fruit bud formation the latter part of summer and early fall is evidenced by the fruit buds formed on the terminus of the second growth.

No relationship could be traced between the rainfall of the growing season and the fruit bud formation in this experiment through a period of seven years. . . The plots where the moisture ran the lowest during the period of fruit bud formation, coupled with good growing conditions earlier in the season, produced the largest number of fruit buds.

Trees receiving cultivation, and cultivation with cover, greatly increased their capacity for fruit bud formation over trees standing in sod.

The use of fertilizers in addition to cultivation has not as yet increased the fruit bud formation.

71. Currants and gooseberries bear their fruit buds largely upon shoots which grew "last season" (Figs. 49, 50). They also produce spurs which are often so short as to be mistaken for buds. Such spurs are, however, always on wood more than one season old; in other words a wood bud last season developed a twig perhaps only $1 / 8$ inch long and produced a terminal cluster bud on this tiny growth. This year the bud will not only develop leaves and fruits, but will extend more or less and produce one to several cluster buds or wood buds or both kinds. Currant and gooseberry spurs, rarely grow more than 1 inch long, perhaps because the tendency of the plants is to develop fruit on young wood-wood of last season, and two or three seasons ago. Bushes that have 
been allowed to shift for themselves show that spurs older than these ages lose the power to produce fruit and what fruit they do develop is of inferior size. Not only so, but the younger shoots borne on old canes are $\mathrm{shorter}$ and bear fewer and inferior fruits.

These phe$11 \mathrm{om} \mathrm{e} \mathrm{na} \mathrm{are}$ partly due to the shoot itself - its age, its injuries by insects and diseases, etc., and partly to the crowding of young growths sent up from the base of the plant. For these reasons, therefore, fruit growers rarely allow canes to grow more than five years old; in fact, many

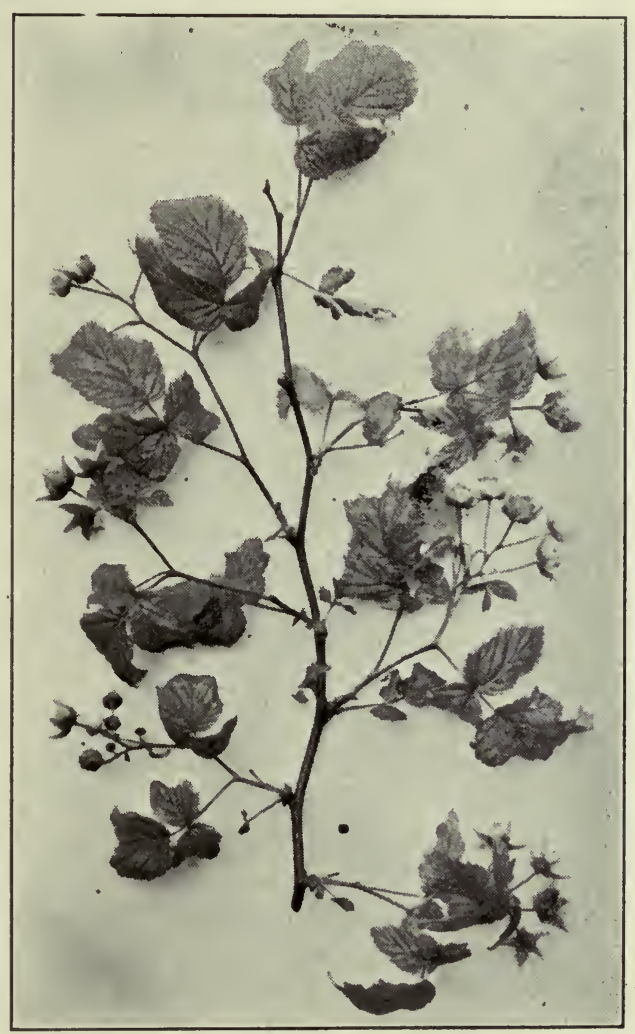

FIG. 55-RED RASPBERRY FRUITING BRANCH

The erect stem grew last year and this year developed its branches from over-wintering buds. After fruiting the whole stem will die, therefore it may as well be cut out as soon as the fruit has been harvested.

prefer to cut them out after they have fruited two or three times, or the three best new canes produced from the stool each season are allowed to develop so as to keep up a constant succession of young bearing wood. 
72. The bramble fruits (raspberries, blackberries, dewberries, etc.), like currants and gooseberries, develop new canes from their stools or crowns, as the starting points of their clumps are called, but these canes never live longer than two seasons. This year the cane grows and becomes more or less woody. It may develop few to several side branches. In some cases (St. Regis raspberry) flowers and fruits may be borne during the latter part of this summer, but normally not until next season. In other words, the resting buds normally push out in spring into shoots which terminate in flowers usually borne in clusters. (Figs. 55, 56). Thus the branches bear fruit on this season's leafy shoots produced from resting buds on last season's wood.

Because the fruits are borne terminally the shoots cannot extend to form long canes, as in the case of the grape 57). As soon as the fruit has ripened the canes begin to decline. They are of no further use to the plant because they will die next winter. Therefore, many raspberry growers cut them out as soon as they have fruited; others leave them until the following winter. The argument in favor of the former practice is that they are a menace to the well being of the plant, since they interfere with air circulation and light, and are sources of infestation both of insects and diseases. The argument in favor of cutting them out during winter is that there is then less danger of injuring the young canes by roughly pulling the old ones out, that the danger of infestation and the advantages of light and air are over-estimated, and that the pruning can be done at a season when work is not so pressing as during the summer.

73. Grapes resemble the bramble fruits in one respect, but differ in another. Like the brambles, their leafy shoots, developed from resting buds on last season's or older wood, produce fruits this season, but unlike the brambles their fruit clusters are not terminal. Therefore, 
grapes are not limited in either the age or the extent of their shoots. To state the case succinctly, grapes, except as noted below, bear their fruits on shoots developed from resting buds on last season's growth. As each shoot develops from a resting bud it unfolds leaves, opposite each of which is a cluster of grapes or a tendril. Whether the tendril is an aborted cluster, or the cluster a specialized tendril is a point concerning which botanists are not

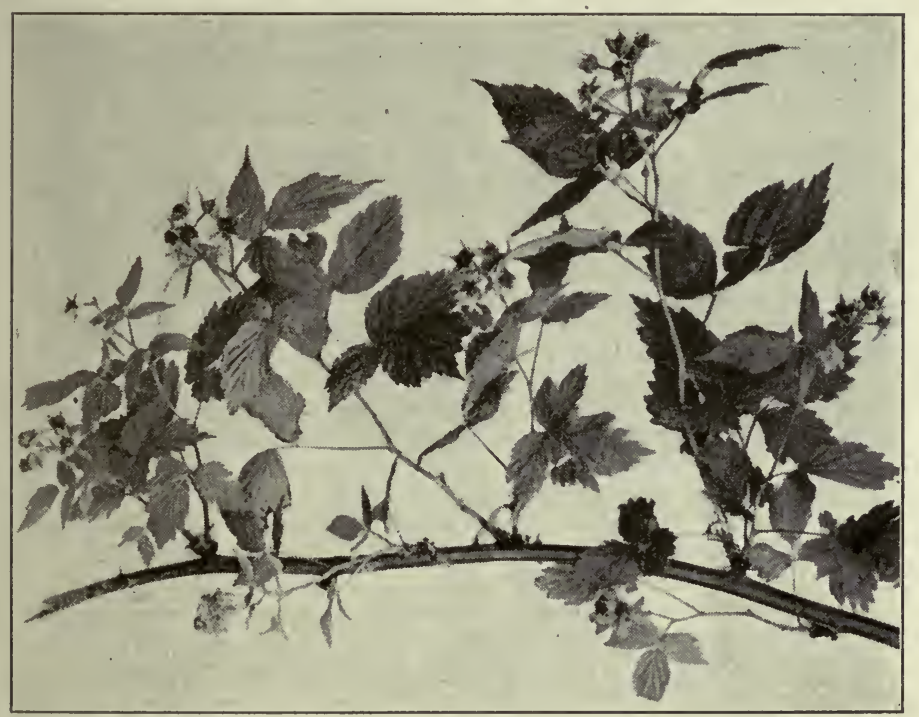

FIG. 56-BLACK RASPBERRY FRUITING LATERALS AND CANE

The large branch grew from the ground "last" year and developed buds from which the leafy, fruiting branches developed "this" season. After the fruit has ripened the whole branch will die. It may be therefore cut out of the stool or hill as soon as the fruit has been gathered.

agreed. The fact that one blends into the other is well shown in Figure 57 the lowest cluster being complete, the next one provided with a tendril, and the third being rather a tendril with a little cluster as a side issue. With knowledge that each resting bud on last year's canes is capable of producing two to five clusters of grapes, the 
pruner can decide in a general way beforehand how he shall cut each cane in order to produce a given number of bunches to the vine, a crop of a certain weight to the acre, or of a certain quality. Seasonal conditions may alter his calculations made at pruning time during winter, but skillful pruners' calculations are close to the actual yields.

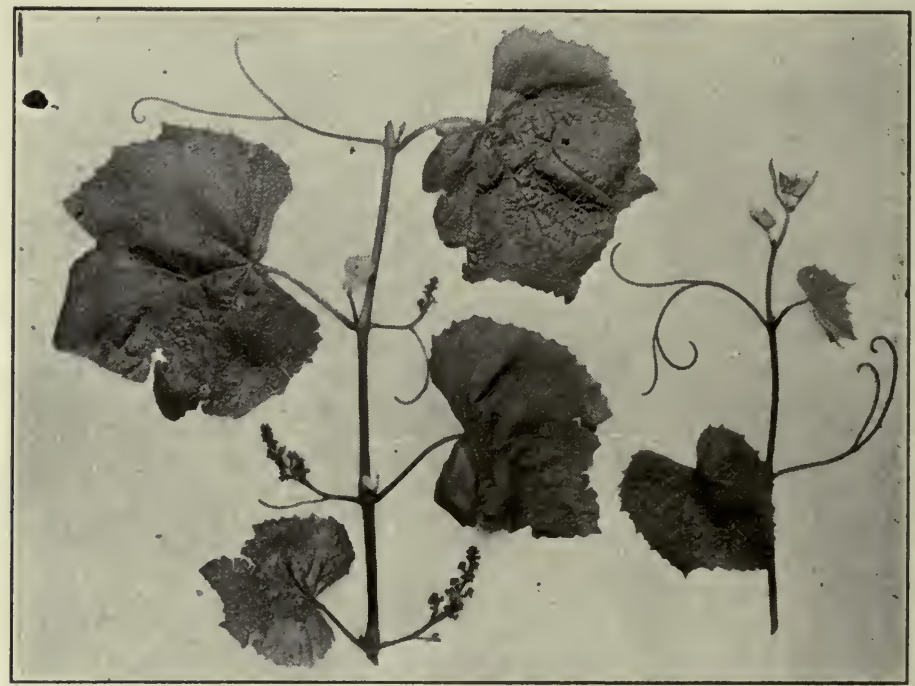

FIG. 57-CHARACTERISTIC GRAPE SHOOT OF A LABRUSCA VARIETY

This shoot developed from an over-wintering bud. Note that a tendril is opposite each leaf and that the lowest three of these tendrils have formed clusters of fruit. Observe also that two of these are part cluster and part tendril. In the axils of the leaves are buds which will form laterals. These rarely produce fruit in the northeastern United States because the season is too short.

Usually only two to five of the lower buds on the canes produce clusters, but under favorable conditions shonts produced in the axils of this year's leaves may develop lateral canes which may produce and mature clusters of fruits. In some cases this method may be again repeated by secondary laterals produced on the first laterals, so that in a sense a cane would bear three crops of grapes during the same season. 
74. Pruning vs. no pruning.-C. A. Keffer * draws the following conclusions from a series of experiments in pruning.

Unpruned grape canes give a heavier total yield of fruit the first season neglected than do pruned canes, but the average bunch weight is much less. As the result of over-bearing much of the new growth will die, thus greatly reducing the next crop.

The base bud in Concord, Niagara, Delaware and Brighton grapes gave the lightest weight of fruit. In Niagara and Delaware the average yield from the second bud was over twice as much as from the first bud, while in Concord and Brighton it was more than half again as much. In all four varieties the yield from the third bud was greater than from the second. Considering the first 12 buds (grape canes are seldom left longer than 12 nodes at pruning), the greatest yield is reached in Concord at the sixth bud, in Niagara and Delaware at the eighth bud, and in Brighton at the tenth bud.

Arranging the buds in groups of three, Concord gives the best yield from buds 4 to 6 ; Niagara, Delaware and Brighton from buds 7 to 9. The relative order of yield for the four

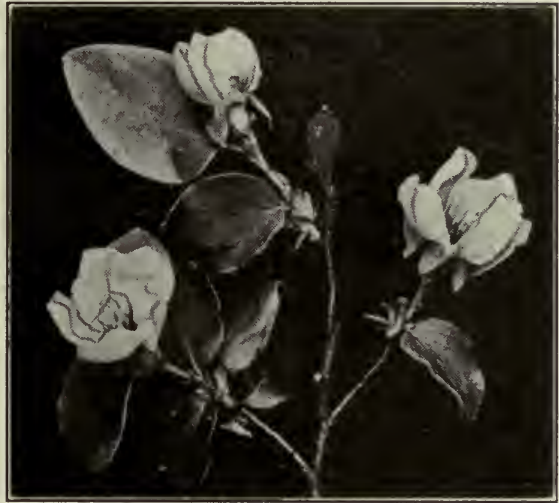

FIG. 58-HOW QUINCE BEARS BLOOM

Flowers terminal on shoots of the growing season. The main terminal of last year made an attempt to produce a fruit, as shown by the abortive mummy. Note that the buds below this mummy have produced new shoots with bloom buds. Thus the blooming wood is only about one month-old and the shoot bearing it a year old.

groups is as follows: Concord, group 2, 3, 1, 4; Niagara, grou', $3,4,2,1$; Delaware, group $3,2,4,1$; Brighton, group $3,4,2,1$.

Concord is better adapted than the other varieties named to shortspur systems of pruning and training. In this variety it would prol)ably be more profitable to reduce the number of spurs to the vine and increase the length of the spur to six buds. Niagara and Brighton would seem to be most profitably pruned at the tenth and the twelfth buds. While there is less difference between the yields of buds 1 to 6 and 7 to 12 in Delaware, the indications favor the longer cane.

* Tennessee Experiment Station Bulletin 77. 
In long-cane systems, horizontal training is preferable to upright or diagonal training, as the lower buds of the cane are better

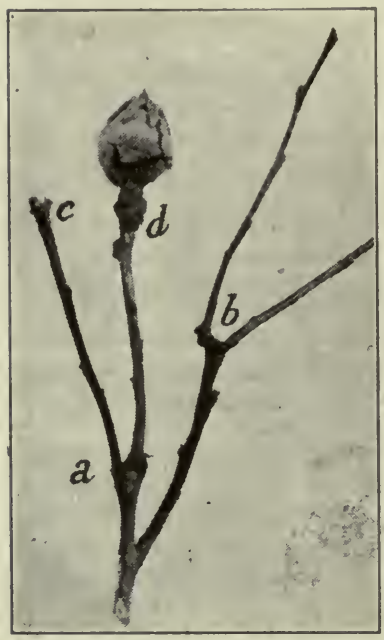

F1G. 59

QUINCE METHOD OF FRUITING

$a, b, c$, positions where fruits were borne in previous years. $d$, Last year's mummied fruit. Notice that the fruits are borne terminally and that new twigs $(a, b)$ appear from lateral buds close to the points where the fruits were produced the previous year. nourished in the horizontal systems.

The observations and conclusions herein indicated, being based on one crop, are not to be regarded as conclusive, but rather as a preliminary report.

75. The quince Fig. 58.Last season the quince developed resting buds which all looked alike. This spring the buds that grow will develop leafy shoots, mostly short. Some of these shoots in favored positions will produce terminal blossoms. Hence the shoots of the quince, at least in the fruitbearing parts of the plant, are irregular because the direction of growth is changed wherever a fruit is borne. This method of blossom bearing is called coterpinal, because the flowers are at the tips of axial shoots of this season.

Flowers are unquestionably formed the season previous to their expansion in quince, raspberry, blackberry and grape, notwithstanding the fact that no flower buds can be distinguished in autumn in these plants.-[E. S. Goff.*

* Wisconsin Annual Report 1901. 


\section{CHAPTER V}

\section{PRUNING PRINCIPLES}

Horticultural literature is full of rules for pruning, but since many of these apply to specific plants, aims and conditions, and therefore may not apply to other plants, aims and conditions, the reader is likely to encounter many apparent contradictions. From the standpoint of practice the student can become proficient only by working with a considerable number of plants, not merely specimens, but varieties and species, under widely varying environments. This is because no two specimens growing even side by side are alike. The differences in habit shown by varieties of the same species are still greater, and those between species greater yet; and all these differences are augmented or modified by the natural or artificial conditions under which the plants are growing. In order, therefore, to eliminate or at least somewhat reduce this confusion, the effort has been made to state the most important principles upon which rational pruning is based.

76. Pruning aims.-The aims of pruning may be grouped under three ideals. Namely, the forester's, the landscape gardener's or ornamental horticulturist's and the flower or fruit grower's. So far as pruning is concerned the forester is mainly interested in securing tree trunks which shall be free from large knots and decay. He considers beauty of form and yield of fruit little if at all. The landscape gardener and the ornamental horticulturist endeavor to have their plants attractive, either as individual specimens or as groups. If they consider the trunks of their specimens, it is not with a forester's eye to later profit, and if they think of the fruit at all it is for the sake of beauty. The florist and the fruit grower, 
like the landscape gardener, look to the health of their trees, shrubs and vines, but their main aim is the flower or the fruit.

77. Pruning principles classified.-While these three men differ in their ultimate aims, the methods they employ may be grouped under two main heads; namely, (1)

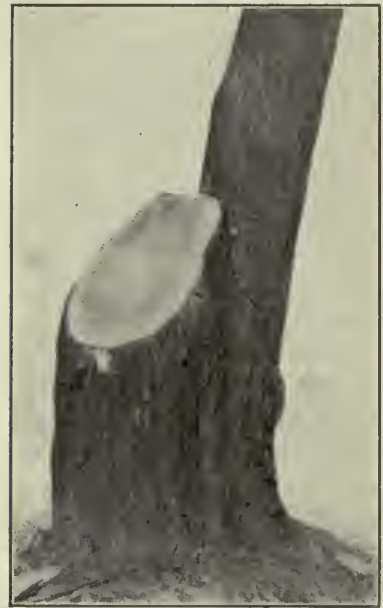

FIG. 60- "DER END OF DER LIMIT" IN PRUNING

This weeping willow wept several of its upper branches, so a tree butcher slashed oit a lot of the top. When his ghastly work was done it was decided to "go him one better," so the main trunk was cut as shown, leaving the secondary trunk to its fate-for already the stump shows decay. those which consider the health and the behavior of the plantpruning proper, and (2) those which consider the development of size and form of the plant-training. While these principles are more or less distinct, some of them nevertheless blend into each other. They may be summarized in the following table:

A. Pruning proper

1. Principles which deal with the removal of injured or unnecessary parts.

2. Principles which affect vegetative vigor.

3. Principles which affect flower and fruit production.

4. Principles which change, the wood-bearing habit into the fruit-bearing habit, or vice versa.

B. Training

1. Principles which limit the size or the form of plants.

2. Principles which affect plantation management, as in the facilitation of tillage, spraying, harvesting, etc.

3. Principles which underly training to special forms.

The most important principles which come under the former of these heads ( 78 to 112 ) are deduced from the laws of plant physiology (Chapter II). The others are mainly based upon convenience, economy or experience. Familiarity with these principles will enable the operator 
to approach a new variety or species with more confidence than if he have nothing but mere rule of thumb to guide him.

\section{PRINCIPLES STATED AND DISCUSSED}

78. I. In fruit production and in ornamcutal horticulture, pruning is of sccondary importance to constant good managcment of the plants; in forestry it is an incidental in tree sroting.

This rule is axiomatic, for no amount of pruning will make for the thrift of the plants where neglect and abuse run riot. Furthermore, the man who neglects or abuses his trees is not the one who will prune, except as some branch happens to inconvenience him. Even then his pruning is more likely to deserve the name of tree butchery (Fig. 61) than pruning.

79. 2. A definite idcal, familarity with the basic principles, and a carcful considcration of environment are esscutial to best pruning practice.

This principle is also axiomatic, for unless the pruner know what he is aiming at he cannot hit the mark; unless he apply the right principles he may work to the injury or the inferiority of the plant; and unless he study the environment he cannot apply what principles he may know as intelligently as he otherwise might.

80. 3. Climate and locality markedly influcuce both the necessity and the cffects of pruning. Methods that succed under one set of local conditions must be modificd or avoidid under others.

Plants show considerable differences of development in different parts of the country, even in the same state, as noted below. Then, too, local influence must be considered. In regions where the winters are mild. say from New Jersey to Ohio and southward, wounds may in no wise injure the trees pruned in winter; whereas where the winters are 
very cold and dry, as in the plains region of N.ebraska and adjacent states, wounds made at that season may allow so much water to evaporate from the cut surfaces that the trees may suffer more or less seriously from winterkilling. In such regions it is advisable to avoid breaking the bark between mid-autumn and early spring. Damage may be wrought in hot and dry regions, as in Arkansas, Oklahoma.

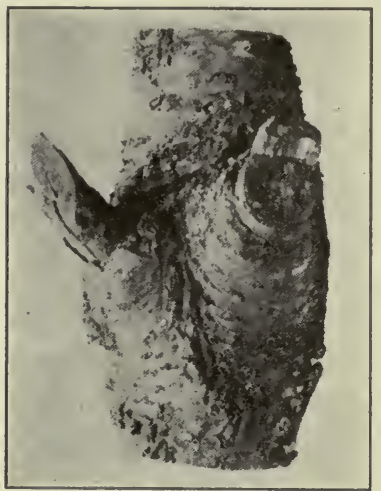

FIG. 61-THE TREE BUTCHER S METHOD

"Pruning" with an axe is a common tree crime in the neglected home orchard. Such wounds never heal over, but always shorten the life of the tree because decay will work its way into the heart wood of the trunk. Figs. 84 and 203 show advanced stages of this work.

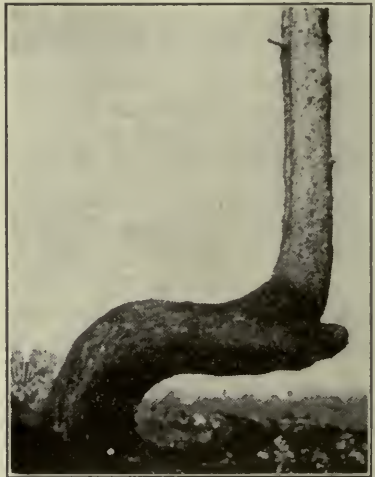

F1G. 62

- UPRIGHT LIMB REPLACES HORIZONTAL ONE

How this tree trunk became bent to horizontal is not known. The trunk after bending extended horizontally to the right, but as the vertical water sprout developed it robbed the prostrate trunk of food. The trunk shortly died, broke off and the stub slowly healed over.

Arizona and bordering states, by sun scalding, which often follows severe pruning, but such pruning generally indicates that the trees have been neglected perhaps cluring several to many years. Doubtless in such regions less pruning is necessary than in more humid regions.

While New York, Pennsylvania, Ohio and other eastern states with long extent north and south present considerable differences in pruning practice, a more striking instance is 
to be found in the state of Washington,* where the Cascade mountains divide the state into two climates, a cloudy humid area to the west and a clear dry one to the east. In the humid area the abundance of moisture in air and soil, and the mild climate favor excessive wood development, often an annual growth of 6 to 10 feet of cherry and prune branches. The trees continue to grow late in the autumn and fully ripened wood is of ten difficult to secure. Severe winter pruning aggravates the evil of this excessive wood growth by making more and longer wood growths. To check growth, therefore, growers resort to summer pruning, shootpinching and even root pruning. The eastern or dry area is characterized by "a long, dry summer, with a-fierce, scorching sun and strong, clrying winds ... followed by a severe winter with fluctuating temperature and sudden changes. In portions of the fruit belt there is barely enough moisture in the ground to sustain a tree." Under these conditions trees "come to maturity at an early age, and produce fruit at a time in their lives when they ought to be making wood growth and establishing a strong, healthy frame for future usefulness." In this region severe pruning is done in winter so as to overcome the tendency for the trees to bear too young. Cherries fruit at two years; pears an 1 apples bear full crops at five or six. The winter pruning is done to increase wood and leaf growth. Summer pruning and shoot-pinching are avoided in the clry area. In the dry plains region, the tops of trees must be kept more dense than in moister regions.

The fruit in these dry areas is less likely to suffer from shade than from exposure to sun and wind. In the east most orchardists keep the lower limbs up from the ground, to improve the flavor and the color of the fruit; in the central west this precaution is needless; therefore, very lowheaded trees are more popular than in the east, because the trunks and branches are believed thus to be better protected from sun scald.

* Bulletin 25, Washington Experiment Station. 
81. 4. Pruning does not alter the natural habit of plants, for pruned plants resume their normal habit when left to themselves.

Ordinary observation will show that each plant-specimen, variety and species-has an individuality which distinguishes it from every other plant. No matter what way or how much it may be pruned, therefore, it will seek to express that individuality in the new growth which follows

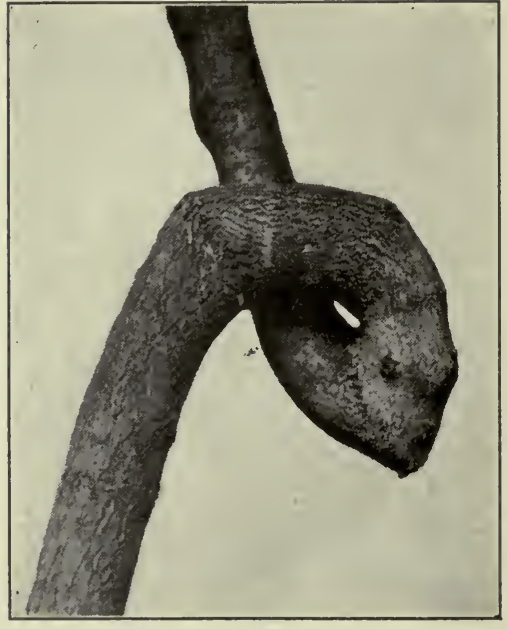

FIG. 63

LEADER RENEWED IN BROKEN TREE pruning, and its success will be largely proportional to its vigor. Trees which naturally sp r a w 1 , like Winter Nelis pear and Rhode Island Greening apple, cannot be made to grow erect by mere pruning, and those normally erect. like Northern Spy and Bartlett, cannot be made to droop. Rational pruning, therefore, seeks merely to correct faults and to maintain the natural form of the tree.

The proof of this rule is seen in the wilds and in orchards whicin formerly were trained in more or less artificial ways. but which have latterly been neglected. In nature trees which have been blown over or bent and held down by other trees falling upon them frequently develop new leaders (Fig. 62,63); in neglected orchards the formal outline of the artificially trained tree may often be traced through the surrounding younger growths which make a top more or less strikingly different in form. 
82. 5. Plants of the same species or variety vary in habit according to thcir age, hence must be pruned more or less differently at different ages.

The tendency for young plants is to make vigorous erect growths rapidly. As they more and more nearly approach the height at which the variety may be said to have reached maturity the more does the rate and extent of growth decrease. Nothing perhaps has so marked an influence in this respect as fruit bearing. The Kieffer pear, one of the most striking of instances, prior to fruit bearing, shoots upward rapidly and forms an erect tree; but when fruit bearing begins these long limbs bend over and spread the tree often widely. Hence it is necessary to bear Principle 5 in mind so as to avoid injuring young trees by injudicious pruning. Later when the trees begin to bear or are in full bearing the treatment may be considerably changed to suit the new type of growth.

83. 6. Severe pruning of the branches favors or increases regetatize growth (i. c., zeood production); hence it may be cmployed to help invigorate weak plants.

From plant physiology (Chapter II) it is evident that every plant which is growing normally has a perfect balance between its roots and its top. The root supplies the top with crude food materials and the top supplies the root with elaborated plant food. Thus each furnishes the other with nourishment. As the roots increase in number and extent, therefore, the larger the quantity of crude food taken in the larger must become the leaf development and consequently that of the whole plant.

Should a considerable amount of the top be removed, for instance, by breakage due to an overload of fruit, or ice, by storm (Fig. 94), by excessive pruning or by such tree butchery as telegraph, telephone and electric linemen and others too often practice (Figs. 64, 65), the amount of crude food taken up by the roots will be distributed in larger proportion to the remaining parts, unless. 
the root area be also reduced by root pruning. In other words, removal of the top upsets the balance between root and top. The result is that the remaining parts make greater vegetative growth than they normally would make and of ten water sprouts (Fig. 65), and suckers may be developed in greater or lesser number and size. Hence gardeners have formulated the rule that weak-growing shrubs should have their tops pruned severely, but strong ones only lightly. Should severe pruning become necessary to correct the form

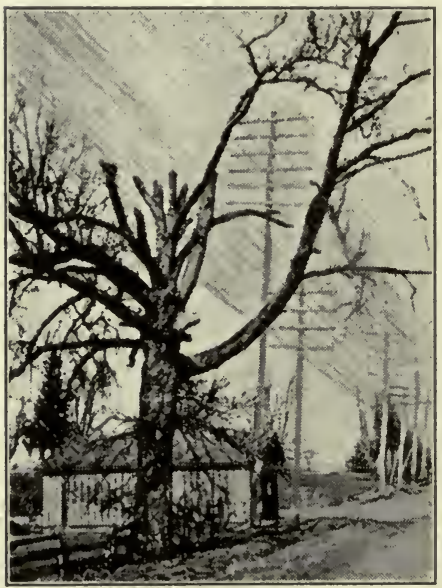

FIG. 64-ONE OF THE WORST FOES OF TREES IS THE "LINE MAN"

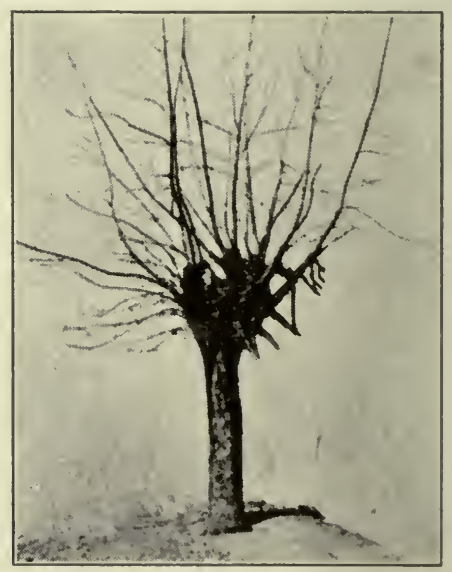

FIG. 65-TREE'S ATTEMPT TJ OFFSET BUTCHERING

or to train a plant, under-stimulation of the top may be avoided by doing the work piecemeal, say a quarter to a third at a time, with an interval of a week to perhaps several months between, depending upon the character of the plant being pruned-herbaceous ones, such as tomatoes grown t:nder glass, requiring very frequent, perhaps even semiweekly removal of small quantities of foliage, and trees demanding not more than one or at most two prunings a year.

84. Injurious effects of pruning on the growth of tree trunks are reported by German investigators who say the average thickness of 
the limbs of many trees pruned in pyramidal form was 8.4 centimeters; pruned by removing only dead and crossed branches 9.5 ; and the unpruned trees 11.7. Contrary to the general belief that regular pruning seems to make stockier trees, these experiments indicate that strong pruning prevents the rapid growth of the stem rather than furthers it.

85. Pruned Tomatoes.-In West Virginia,* L. C. Corbett found that tomatoes pruned after the fruit set produced a greater number of ripe fruits to the plant up to September 1 than did unpruned plants, but the total yield from each plant for the whole season was less. Of the various methods of pruning tomatoes, the single stem method gave somewhat earlier and larger fruits, but lessened the total yield considerably.

86. English experiments in apple pruning.-At Woburn, England, S. U. Pickering has conducted pruning experiments for 12 years. He reports that trees dug up and weighed show that the less a tree is pruned the larger and heavier it becomes. At the end of the 12 years those trees not pruned were 20 per cent heavier than the moderately pruned ones, whereas the heavily pruned trees were 16 per cent lighter. Since the difference in weight between the unpruned and the moderately pruned trees is greatly in excess of the wood removed by pruning, it is concluded that pruning does not increase the actual size of the tree, but even results in less new wood being formed. When similar branches on the same tree were pruner to different extents, it was found that the less the pruning the greater the number, length and weight of new shoots formed and the increase in girth of the original branch.

The reduction in pruning appears more marked as regards the crop. With dwarf apple trees, during the first five years, the crops from unpruned trees were more than twice as great as from those hard pruned. These differences were increased during the second period of five years, and at the end of the twelfth year the unpruned trees yielded nearly three times as much as the moderately pruned ones, while the hard-pruned ones had practically no crop at all. (Only one variety was in fruit for comparison during the twelfth year.)

Similar results were obtained with trees of 53 and 80 varieties of crab and paradise stocks, respectively. The trees were not allowed to overbear, and it is claimed that the size of fruit obtained from trees pruned to different extents was approximately the same, hence the values of the crops were proportional to the weights. Confirmative evidence of the antagonism of pruning to fruiting was obtained hy counting the fruit buds formed on similar branches of the same tree, which was cut back to different extents. All of the above results refer to healthy, vigorous-growing trees.

With dwarf apple trees 15 years old the author finds that hard pruning results in an increase of the new wood formed, but that

* Bulletin 49. 
the crops are even more reduced by the pruning than in former years. This result is said to apply also to trees which have become stunted, as from root injury in transplanting.

Since hard pruning has been shown to be the correction for fruiting, it is concluded that freshly planted trees should be cut back hard to prevent stunting by precocious fruiting.

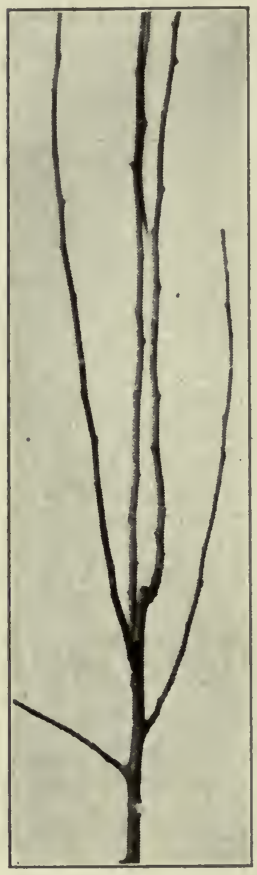

FIG. 66

YEARLING GROWTH CUT BACK

To cut back oneyear-old growth does not materially change the direction of the limb, yet it keeps the fruit-bearing area low. Note that the uppermost buds have made strongest growth. mean, besides the cutting back after planting,
a gradually reduced pruning for the first four or five years. Pruna gradually reduced pruning for the first four or five years. Prun-
ing after this time should consist merely in the removal of interfering branches and unripened wood. With precocious varieties or was 24 per cent less and the new wood formed 45 per cent less than with similar trees cut back when planted. The ultimate result was found to be that trees not cut back until the end of the first year continued to form wood in subsequent years, and the crop borne by them during the first 10 years was only onethird of that borne by those which were cut back when planted.

Experiments on apples, pears and plums show that the date of cutting back a freshly planted tree is immaterial, provided it is done before growth begins. If delayed until after the growth is well started the season's growth is much reduced. The rents were the same when the lopping was done luring the dormant period. Lopping toward the end of May or a few weeks after growth started, resulted in a less growth during the year. This was more than compensated, however, by an additional growth during the succeeding season.

While it appears to be established from these experiments that the crops are larger and the growth of the tree greater in proportion as the pruning is reduced, the experimenter believes that another series of experiments might demonstrate that a certain amount of pruning may bc good and even lead to better results, especially with certain varieties of apples which differ largely in their habits of growth and require different treatment.

The general conclusions reached are that prunings should be reduced to the lowest possible limits consistent with the formation of a tree of sufficient sturdiness to bear its crops with safety, which in most cases would mean, besides the cutting back after planting, 


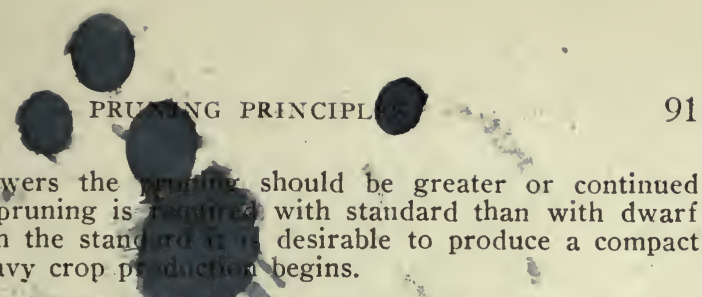

87. 7. Severe pruning the roots reduces vegetative growths (i.c., wood produclion); hence it may be employed to induce fruitfulness.

This is the converse of principle No. 6. In a sense it is equivalent to mor feeding; poorly supply in ith crudessat? they tend to beaper firmoul. It does tot matter why ther thi lack of to due to poor soil or to strary supply of crude sap taken up by tige roots, the results are the

She principle finds its most common pplication in the unavdiels dereduction of ront area in the ditging of nursery and other plants for - transplanting. No matter how carefully such work is performed, an enormous amount foften more than 90 per cent), an the feeding area (12) is cut off, thus reducinge the ssupply bo food which tain be sent up to the tops. To offset this unbalanced Indition and to distribute the aluced of of food effectively, the top must be reduced very considerably. Some plant-

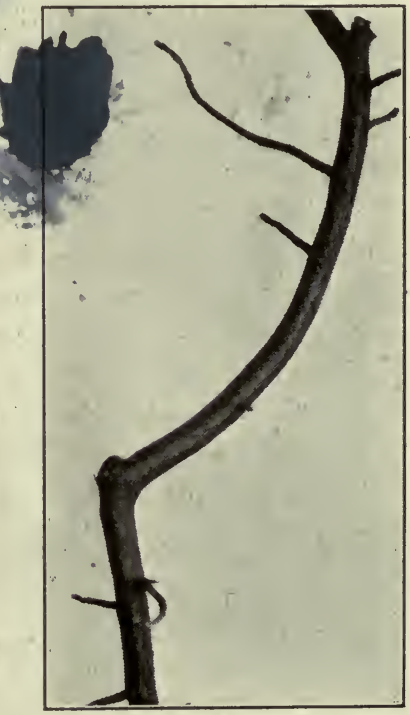

FIG. 67

HOW CROOKED BRANCHES ARE MADE

Cutting back second-year growth produces crooked branches, as the latter growth will not be erect. ers adyacate remoying not less than three-quarters of the previo ear's growth, and in many cases all but one strong ind on that growth. This tends to establish a new balance etween root and top.

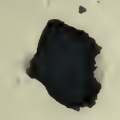


Root pruning is largely practiced by those nurseries which make a specialty of specimen plants several years old. It is performed by passing a large U-shaped knife from end to end of the nursery rows beneath the trees so as to cut the long roots at varying depths. In order to secure best results, the trees are set in check rows, so the second cutting may be clone at right angles to the first. This method compels the plants to produce many short fibrous roots in a clump close to the base of the stems. The chief advantages of the practice are (1) that the specimens may be traine 1 to any desired form in the nursery, where they may remain for several years, all the while becoming more valuable; and (2) the extensive root system, limited to a small area. is not seriously enough injured in digging to make the cutting of the top necessary to re-establish a balance.

Root pruning also finds employment in growing dwarf fruit trees and trees trained on walls and in special forms. such as espalier (283) and cordons (282). Unless the work is regularly done the trees are almost sure to develop unduly and to frustrate the objects sought. Its practice is mainly limited in America to amateur plantations.

At Harper-Adams Agricultural College* (England) root and branch pruning experiments during several years stimulated tree growth considerably, the effect being most marked on the weakest growing variety tested, Cox's Orange Pippin. The most fruit buds were formed on the unpruned trees.

In an effort to make six espalier pear trees levelop fruit burls, R. L. Castlet root-pruned two on both sides, two on one side only. the other two not at all, in January and February. Nothing special was noted that year, but the following year the trees pruned on one side produced a fair crop of good fruit; those severely pruted hat very few fruits, while those unpruned were still unfruitful. One of the latter trees pruned later gave results similar to the earlier root-pruned trees.

88. 8. Suckers and water sprouts are produced by local or general disturbance of plant equilibrium. The time of lear zehen the pruning is done has less influence upon their

- Report 1910, Page 52.

$\dagger$ Jour. Royal Hort. Soc. (London) 29. Nos. 1-3, Pages 146-160. 
formation than does the extcnt of the pruning and the rigor of the plant pruned.

As already noted under Principle No. 6, increased vegetative growth results from excessive pruning of the top, and water sprouts and suckers may be developed to a greater or lesser extent. When the plants are below normal vigor and when the root area is smaller than the top really needs, plant food will not be elaborated in sufficient quantity to

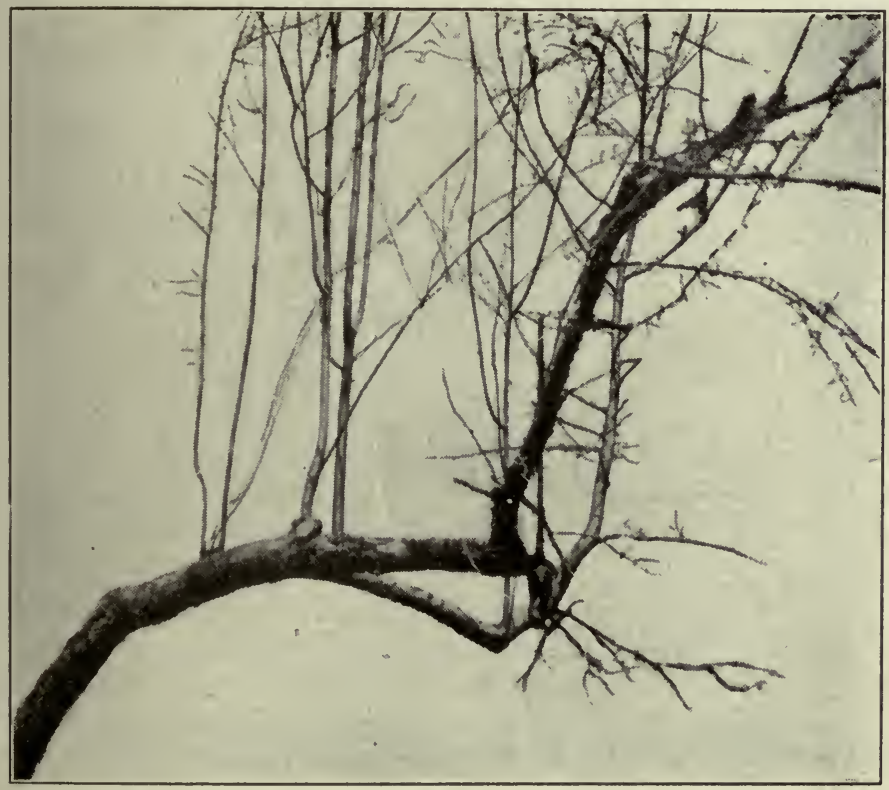

FIC. 68-ONE WAY HORIZONTAL BRANCHES ARE KILLED

When wat ? sprouts develop vertically from horizontal branches the parts beyond die soonir or laier. In this case the main branch beyond the erect ones has died. One water sprout was cut off (see scar at base of middle one) to perm.t taking a less confused photo.

produce water sprouts and suckers; for these growths are dependent upon ample if not excessive food for their development. Hence season of pruning cannot be a primary influence in their production. They may develop as the re- 
sult of ringing (98 to 103), girdling, notching, twisting or bending the stems, because in such cases the flow of elaborated sap has been checked and the food thus held back must find an outlet above the constriction.

Doubtless the time of year when the pruning is done has some influence upon the production of such growths. Common observation shows that they are produced mainly during spring. Rarely do they appear after midsummer, be-

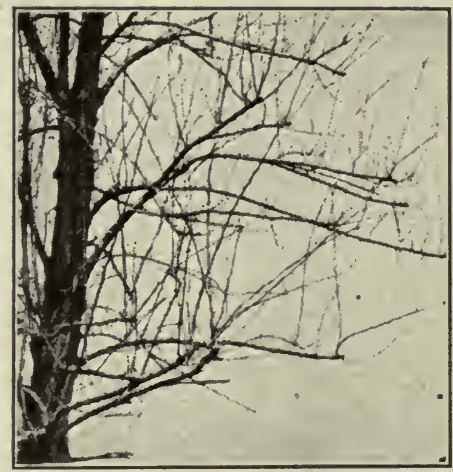

FIG. 69-POORLY “PRUNED" PEAR

The ends of the horizontal branches were cut off, with the result that a lot of "sap-pumping" growths developed. No care was given these new growths, or they would not have grown nearly so long and spindling. They have, however, begun to bear fruit, as indicated by the short, stubby spurs.

cause by that time the plants are ripening up the tissues rapidly formed early in the season, there is little or no food to spare and in general growth has ceased. Experience also teaches that plants pruned in midsummer rarely produce water sprouts or suckers the same season because of the cessation of growth just discussed. Even during the following spring the number and size of those which do appear will be smaller than when pruning is done during the dormant season. This is because the plants have ample time in which to make readjustment to the changed conditions in their tops.

The usual way in which any excess elaborated food is utilized in such cases is in the increased development of twigs already formed. Note the discussion as to summer pruning in eastern Washington (80). The suggestion to be drawn from this principle is that the fear of water sprout and sucker production should never influence the pruner. These growths are largely the result of previous neglect, 
but later attention should prevent their becoming a menace to the plant.

89. Renewal pruning of apple and pear.-E. S. Goff* points out that as apple trees increase in age the size of the fruit tends to become smaller. This he believes to be due to the increased difficulty of sap circulation in the fruit-bearing twigs. An instance is pointed out in which water sprouts on part of an apple tree were allowed to develop in place of a large limb that had been broken off. The fruit in this part of the tree was much larger than on the remaining older parts. The question is therefore raised whether the size of fruit on old apple and pear trees cannot be maintained by a careful system of renewal pruning.

90. 9. Since cach plant part is individual (39), competition among the parts may make one part thrive at the expense of another.

As elaborated plant food is formed it passes to growing and storage tissues (20). Toward the close of the season much of it is stored in or near the buds which are to start growth the following spring, when, with crude sap, it pushes out into shoots, leaves or flowers. There is thus competition among these various parts for a share of both kinds of food; but only those favorably placed or, through some unexpected circumstance, such as a constriction, similarly favored, secure an adequate supply of each. Then other things may give certain twigs the lead and the inferior ones a check. Hence each shoot draws upon its parent branch both for elaborated food and crude sap. Nay, more, each may steal from its fellows, as when very lush shoots, such as water sprouts and suckers, are produced. These shoots are seldom furnished with sufficient leaves to supply their own needs, so, being watery, they draw elaborated plant food from nearby tivigs and limbs. For this reason careful fruit growers remove these shoots while small between mid-spring and early summer, so as to direct the plant food where it will do the most good. The sprouts, being green, are easily broken off at the time mentioned. The slight wounds formed, being small, readily heal in a few weeks.

* Am. Gard. 23, No. 285, Page 302. 


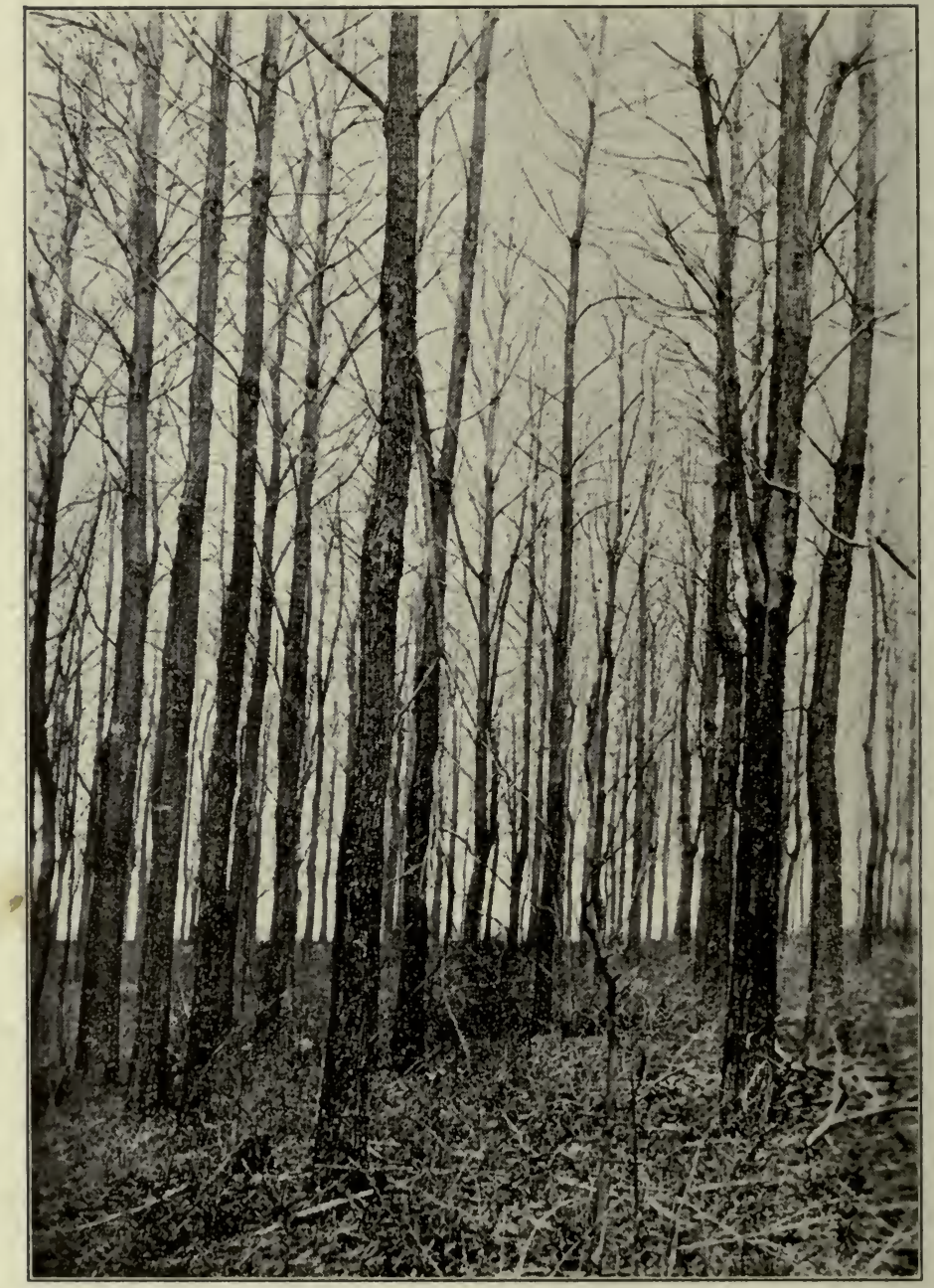

FIG. 70-TWENTY-YEAR-OLD CATALPA PLANTATION

Note that the trees are practically erect and almost branchless below. They have reached up to the light, and the lower branches have died because of lack of light. They have either broken off or been cut, 
91. I0. The uppermost buds, especially on young plants, tend to grow most vigorously.

Ordinary observation shows, and philosophy explains (Chapter III), that, due to the fight for air and light among the twigs, growth is from the uppermost buds. This natural method may be suppressed or emphasized according to the way the plants are managed. Shortening the annual growths (106). checks development and so does the formation of constrictions (98). These two methods each deserve separate discussion.

92. II. By shortening the twigs upon which they are borne, arillary buds may be more fully developed than would normally be the case if the twigs were not shortened.

It stands to reason that when part of a shoot is removed the food intended by the plant for the whole shoot will reach the remaining part in relatively larger supply. But this principle connotes still more. It deals largely with the practice of heading-in, a process which tends to broaden and thicken the top of the plant so treated. One or other of two objects may be secured by heading-in; namely, (1) the correction of an undesirable habit of growth and (2) the encouragement of fruit production (Principle 17, below). Each of these objects may involve the consideration of one or more of the following factors: (a) The grower's prefcrence as to the way the trees shall be trained, (b) the distance between the trees. (c) the nature of the trees, especially whether standard or dwarf, and (d) the rate of growth.

a. On the first point, the grower's preference, probably no one man can exactly meet the ideas of another man. It is usually a case of "what he likes, he likes." When a thick, round-headed tree is the aim, shortening-in must be practiced ; when an open centered one, it must be shunned, unless possibly before the tree comes into bearing.

b. When trees are set close together, just as when their tops are dense, the effort to secure air and light tends to 
induce long slender growth (Fig. 70). The same is true in very humid climates (80). Shortening to keep the tree heads within bounds may be done when the growths attain lengths of 3 or more feet in a season, but since mature and bearing trees rarely make such excessive growths, the practice is usually needed only with unfruitful or young trees. Excessive growth in mature trees generally indicates too rich, moist soil, or excessive pruning; hence the remedy is to check growth by making the proper

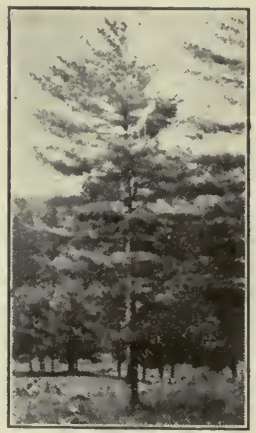

FIG. 71 - TYPICAL PASTURE - GROWN WHITE PINE

Note that. though 50 feet high, the trunk is branchy nearly to the ground. It will make inferior, knotty and tapering lumber. correction, or to have recourse to summer pruning, as practiced in Washington (80). The proper correction for excess moisture may be drainage or the use of a thirsty cover crop, such as clover or hairy vetch; that for too great fertility. a "nitrogen-consuming" cover crop, such as oats or rye; that for excessive pruning is to avoid winter pruning as much as possible. Heading-in during winter will only make matters worse.

c. Shortening-in the annual growths of dwarf trees is done to prevent the development of tops out of proportion to the roots. This feature deserves special treatment. (Chapter XVI.)

In all shortening-in it must be remembered that increased pruning in the interior of the top is necessary, especially when the work is done early in the growing season. For often lateral growths, especially on summer-pruned grapes, prove a great annoyance. The method is useful in helping to secure sturdier branches and to develop frame limbs. It need be employed less annually as the trees approach maturity, when it may cease altogether.

So far the discussion has considered the style of headingin usually practiced by gardeners and amateurs who see! specially fine specimens of fruit. A simpler method prac- 
ticed more largely by the commercial fruit grower is to cut out whole branches, one, two or more years old, when these extend beyond the general outline form and desired size of the tree. In all such cases the cuts are made at the points where the branches to be removed join older or larger branches. Clean, close cuts are macle. In a few years the vacant spaces fill up with bearing wood. This plan is especially popular in the management of stone fruits.

d. The rate of growth is a factor included in the discussion in paragraph $b$ above.

93. I2. Neither kind nor cxtent of pruning influcnces fruit bearing as much as does the condition and the cstablished habit of the plant. Quiescence rather than stimulation or spasmodic effort favors the fruit-bcaring habit, which is influcnced by pruning, as well as by other treatment, more in young than in old plants.

Doubtless this principle is the most important of the score discussed in this chapter, not because it emphasizes pruning so much, but because it teaches the importance of continuous good care of the plants. This matter of continuous good care cannot be over-emphasized. But it is not with these phases of plant management that this book is concerned: pruning is the subject in hand.

Even casual observation will show that plants, even of the same variety, differ more or less widely in habit, especially in the habit of fruit bearing. So noticeable is this fact that certain fruit growers and nurserymen favor so-called "pedigreed trees," these being propagated from trees of known performance. Doubtless part of the phenomenal prolificacy is due to individuality, but probably a large part is also due to some unrecognized factor which favors fruit bearing, so that the case may be more one of plant nurture than is supposed.

But let us set aside such cases and consider only average ones. When once plants begin to bear, the bearing habit should be maintained. Nothing will favor this more than 
judicious, continuous good management. Whatever seriously upsets the equilibrium so established will almost surely also upset the bearing habit. In cases where the bearing habit has never been developed, either due to neglect 1. improper management, experiment may enable the grower to discover a remedy such as giving a different type of till-

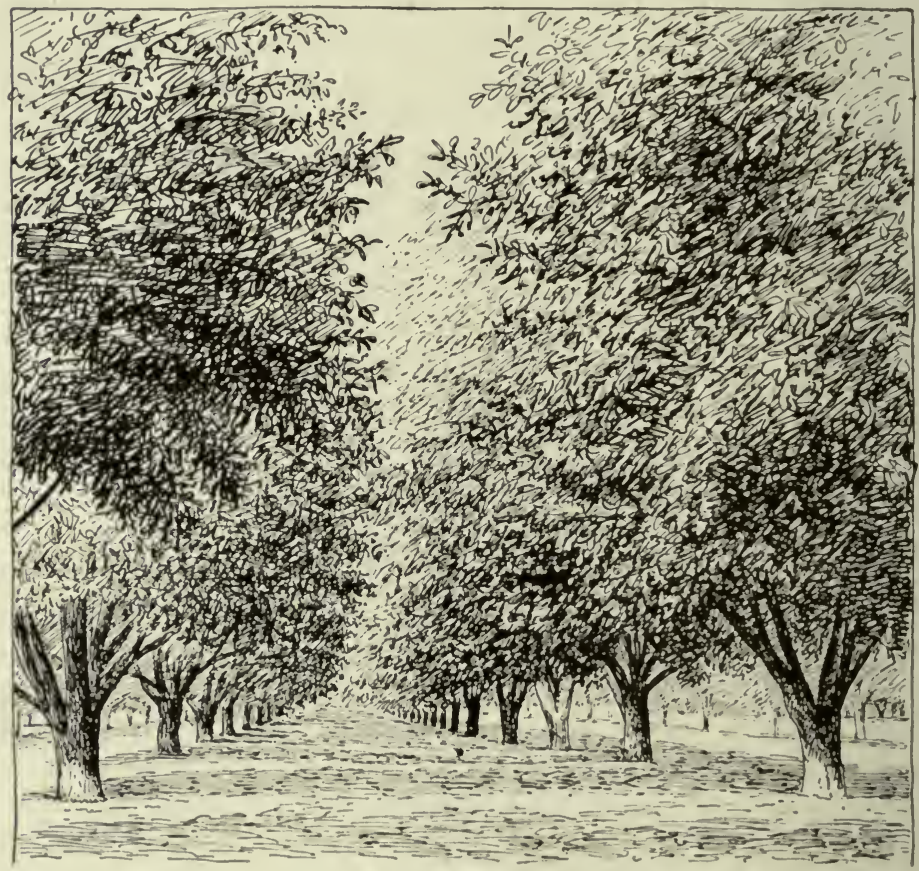

FIG. 72

BRANCHES OF 1.OW-HEADED TREES TEND TO ASCEND AT ACUTE ANGI ES This drawing from a photograph shows that trees started with low heads have branches that approach the vertical. Compare with high-headed trees (Figs. 3, 22,23.

age, a change of plant food, a better type of disease and insect control or a more or less radically different style of pruning.

A neglected orchard will furnish a typical case. Suppose the tillage, spraying and other factors just mentioned to be 
what they may; let us consider only the pruning. In this orchard it is evident that the first aim of pruning must be to overcome the neglect rather than directly to establich fruit bearing. Heavy pruning may be necessary and much new wood may be produced $(81,83,88)$, and the tree may take one or perhaps several years to adjust itself to the new order, but the rational treatment that should have been given while the trees were young will win in time. All will be lost, however, if the grower lets up, for the orchard will quickly return to its former unclesirable condition.

This last statement shows why orchards severely pruned only once in several years are so notoriously barren. They are literally prevented from establishing the bearing habit by being thrown out and kept out of balance. Annual goos care is necessary to secure good crops. Were the wholesale pruning spread out, then, over several years, a little and often an equal total amount of wood might have been removed and yet the trees might have been brought into bearing and kept actively fruitful.

One of the most common forms of disturbance of equilibrium is over-bearing. It is almost invariably succeeded a year later by the reverse condition. So common is this phenomenon that we have "full years" and "off years." Extremes tend to follow each other until the alternate year bearing habit becomes established. perhaps so firmly that it cannot be corrected, at least in old trees. Since the habit is most pronounced in long-lived plants, such as apple and pear, the conclusion seems safe that the habit started during the early years of the trees, and has been emphasized more and more as the trees grew older. Though pruning may have some effect in changing such a condition, more especially as affected by principle No. 18 , it is only one of the factors that may be influential.

It is well understood that a check to growth favors fruit bearing, but this bearing habit may easily be lost unless efforts are made to keep it up. While slow-growing and 
moderate-sized trees are often very fruitful, they are not necessarily so. Many instances might be mentioned of trees which have grown both very rapidly and very large, and yet have come into bearing young and been remarkably fruitful, perhaps each year, for a long series of years. Such cases, probably without exception, will be found to be due to rational management from the start or, at least, from the time when the fruit grower began such management.

94. Apple pruning investigations.*-Four years ago West Virginia Experiment Station began a test involving various amounts of dormant pruning in one orchard. The following spring this experiment was greatly extended to include six orchards in various parts of the state and 515 trees ranging from one to 25 years of age. In spite of unfavorable circumstances some features stand forth clearly and seem to warrant a preliminary report.

We will group the orchards and discuss two phases of the project; namely, the effect of amount of pruning and season of pruning upon vigor, growth and fruitfulness. In most cases the following series of plots were obtained: 1. Heavy dormant pruning. 2. Moderate dormant pruning. 3. Light, or corrective dormant pruning. 4. Heavy dormant and early summer pruning. 5. Moderate dormant and early summer pruning. 6. Early summer pruning. 7. Repeated summer pruning. 8. Midsummer pruning.

The early summer prunings were made at first during the last week of May, but for the last two years were made about June 15 . The midsummer pruning was made from July 1 to July 15 . The repeated summer pruning was simply a combination of the early and midsummer prunings.

95. Amount of dormant pruning.-Where varying amounts of dormant pruning alone were considered, we would expect that the heavier the pruning the longer and heavier would be the new growth (83). This was invariably the case. The question then arose as to whether the average length and diameter of the new growth is a true index of vigor. We are constrained to believe that this is not always the case, at least upon small trees.

The heavy pruning greatly reduced the number of buds and consequently reduced the number of shoots which started. It seems reasonable to believe that, though fewer in number, the shoots of the heavily pruned trees actually measure up as great as those of the lightly pruned back, perhaps even greater. To test this point, two blocks were selected in one orchard, and one was heavily pruned, while the other was lightly pruned. Annual measurements were made of the new growth and the prunings.

*W. H. Alderman in Proceedings of the Society for Horticultural Science, 1915, Page 54. 
The data obtained show that except at the very first, neither in total length of growth nor in increase of trunk diameter, have the heavily pruned trees made as satisfactory a gain as the lightly pruned ones. The only possible deduction from the figures is that continued heavy pruning acts as an inhibitor of growth rather than as a stimulant. In must be borne in mind, however, that no account was taken of the fact that the average diameter of the yearly growth of the heavily pruned block was greater than of the lightly pruned block, so that the real difference in amount or weight of actual tissue produced was not as much as indicated in the table. It is significant to note in this connection that in all the orchards the lightly pruned trees are noticeably larger than the heavily pruned ones. With few exceptions the increase of diameter of trunk has been in inverse ratio to the amount of wood cut off.

Thus far we find that heavy pruning forces a rank growth, although it retards, as a whole, the production of wood tissue. There is presented an interesting question of whether heavy pruning and particularly heavy heading back, tends to make more stocky that portion of a branch produced one or more years previous to the pruning. In other words, can a long slender branch be made more stocky by vigorous heading in at the extremity?

96. Effect of heading-back on stockiness.-On the young trees on which measurements were made to test this point the results were not as clear cut as could be wished, yet they indicate on the whole, that heavy heading-in tends to thicken the branch more rapidly than does light pruning [and this may be traced] even as far down as that segment of branch produced four years previously. This is not well correlated to our own results regarding the increase in trunk diameter as related to pruning. We frankly admit a high probable error in this part of our data and do not lay undue emphasis upon this phase. It must be substantiated by further work.

In the matter of fruitfulness, interesting correlations were secured. In the one middle-aged orchard in the test, heavy pruning proved to be a stimulant to fruit production, whereas in the younger orchards, it acted as an inhibitor.

In another six-year-old orchard the only fruits produced were upon the lightly pruned block, and in a five-year-old orchard the lightly pruned block averaged 85 per cent, and the heavily pruned block 50 per cent. In young trees heavy pruning delayed fruit bearing and light pruning encouraged it, but in older trees that had been bearing for some time and were in only fair vigor at the beginning of the experiment, the vigorous pruning stimulated fruit production. Heavy pruning also produced strong new shoots, but did not induce as great a total amount of new growth as light pruning, nor did it produce as great an increase in diameter of trunk or size of tree.

97. Season of pruning vs. vigor and fruitfulness.-We will now pass on the influence of pruning at various seasons on the vigor and fruitfulness of the trees. In every case either heavy or mod- 
erate dormant pruning stimulated a greater growth than any of the summer prunings, and the reduction in vigor was less in the case of early summer pruning than with either repcated summer or midsummer prunings.

The foliage is a very good index of the vigor of a tree. A careful study of leaf size, color and number was made in the Lupton and the Grimes Golden orchards. In all cases the blocks that

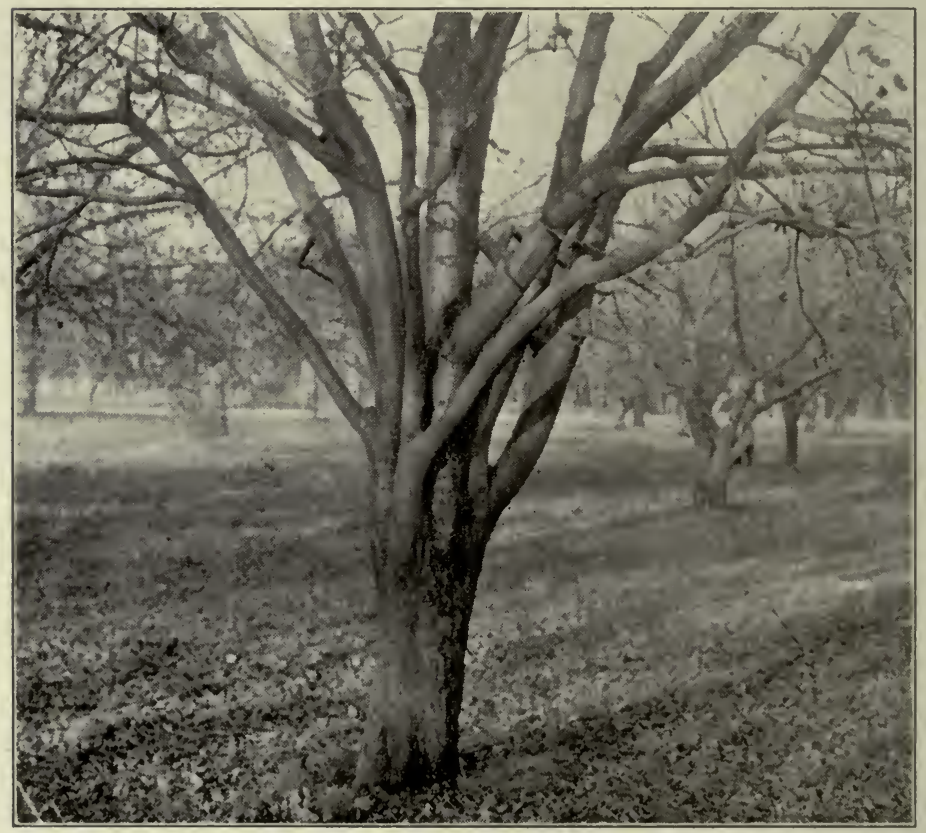

BADLY DEVEL.OPED TREE HEAD. TOO MANY LIMBS CLOSE TOGETHER Never allow a tree hezd to develop in this way. Such over-crowding can be prevented by correct, early pruning. It is difficult to remedy later.

had received summer pruning bore a paler or yellower foliage than those pruned in the dormant season. This difference in color was so distinct that there could be no mistaking the summer-pruncl blocks even at a distance.

It is clear [from the data secured] that summer pruning caused a great decrease in the size of leaf, number of leaves to the trce and in the total leaf area on the tree. If we further consider that these leaves are deficient in chlorophyll, as evidenced by their light 
color, we may readily see how greatly summer pruning has decreased the efficiency of the food factory of the plant (29).

Much of this loss of vigor we expected, but we also expected a compensating increase in fruitfulness. In the old orchard the data are conflicting. In the young orchards we have attempted to correlate summer pruning with early bearing, but the correlation is negative. Merely corrective dormant pruning far'exceeded all forms of summer pruning in bringing about early bearing, and in some cases the moderate and heavy dormant-pruned blocks produced more bountifully than did the summer-pruned trees. The writer has serious doubts as to the wisdom of deliberately impairing the vigor and the vitality of a tree to throw it into bearing.

98. I3. A check which does not impair the health or the strength of a plant tends to fruitfulness.

Too severe pruning, over-tillage, a too liberal supply of nitrogenous plant foorl in the soil, whether due to overtillage, over-manuring, or the too constant use of leguminous cover crops, all may produce the same effect; excessive wood growth at the expense of the fruiting habit. All but the first of these may be corrected by reverse practices, as already noted $(80,81,83)$. The bad effects of heavy pruning and how to correct them are also discussed in the same sections.

Other methods of checking growth, mainly of very local application, depend upon checking the flow of elaborated plant food; for, as already noted (Chapter II), this food, when in abundance, tends to fruit bud development, whereas abundance of crude sap tends to increase wood development. Among the ways adopted to secure this result are notching the stem below a bud to encourage the formation of a fruit spur, and above a bud to secure a long woody twig. Shallow girdling and ringing-i. e., no deeper than the cambiumfavor fruit bud formation above the cut; when through the cambium and the young wood the girdle favors the production of woody shoots below it, but generally results in the death of the upper parts of the stem so cut. When the girdle is placed lower on the branch than the leafy area, such twigs as may develop must do so upon the supply of elaborated food stored in the tissues below the wound. If 
this supply be small, no shoots at all may start. When heading-in is employed woody shoots generally start most strongly from the bud nearest to the wound. Those which start from lower buds are usually less and less strong as they are more and more remote from the cut.

99. Stripping trees.-A. W. Drinkard, Jr.,* reports an experiment in which trees were stripped by the removal of strips of the bark $1 / 4$ to $1 / 2$ inch wide from the trunks, beginning near the ground and extending up to, and frequently above, the main branches. Several of the main branches were stripped for 12 or 18 inches. Three to five strips were taken from each tree. The strip was first marked by a knife point. Then the bark could be readily peeled from the tree.

Trees stripped on April 23 made good growth and held their leaves until late in the fall. The stripping wounds heal over very well during the growing season. The operation does not completely cut off the movement of water in either direction, but must interfere with it in some measure, and the operation must administer a shock more or less severe to the growth processes. Trees stripped May 31 made excellent growth and the wounds healed well. When the trees were stripped on June 23 it appeared that the growth was noticeably interfered with, and the stripping wounds did not heal rapidly. This appears to be too late to secure the best results from the process. The removal of strips of bark from the tree trunks does less injury to the trees than does ringing, and gives promise of greater utility in practice.

100. Ringing experiments. - Drinkard also reports experiments $\dagger$ in spring pruning accompanied by ringing. The trees showed very little if any effect from ringing at various seasons after the spring pruning had been performed. The formation of fruit buds was not noticeably stimulated, being about the same as in case of check trees. The amount of fruit set and the quantity harvested was not essentially different from that of the check trees, and the wood growth was about the same as normal. The trees in this series carried a dense green foliage through the growing season, equal to that of the check trees. It seems clear that the influence of spring pruning in discouraging the formation of fruit buds is sufficient to overcome any stimulative effect which otherwise might have been derived from ringing.

Maryland§ performed an experiment by ringing crab apple trees to induce fruitfulness. He found that ringing or girdling increased fruitfulness, but he considered this operation as a measure that could be applied under only special conditions.

* Technical Bulletin 5, Virginia Experiment Station.

$\dagger$ Ibid.

8 Mass. Hatch Exp. Sta. Bul. 1. 
Leclerc du Sablon* ringed three or four-year pear trees before regetation started and a second lot after the first shoots had formed, At intervals of two months thereafter trees from each group were dug up and analyzed. The roots of the pears ringed in February contained more reserve material than did the check trees not ringed, while the stems contained less. After April, however, as a result of assimilation by the leaves, the roots of the ringed trees were much poorer in reserve material than those of the control trees. On the whole the experiment is believed to show that toward the end of winter and the beginning of spring the reserve material goes from the roots to the stems. From May to October the current of elaborated material is from the stems toward the roots.

Hedrick $\dagger$ and his assistants have reported unfavorably on ringing tomatoes and chrysanthemums. The tomatoes showed a loss in fruit production and in the leaf and root systems of the plants. The chrysanthemum plants also suffered.

Paddock§ carried out experiments in ringing grapevines. The process generally hastened maturity of the fruit, depending on season, variety and conditions of vine. On the whole the operation is devitalizing and care is required in its application.

101. Ringing fruit trees. $\$$-The object of ringing fruit trees is to induce unproductive trees to set fruit. Briefly stated, the theory of the operation is: That the removal of a band of bark through the cortex and bast of a plant, at the period of most vigorous growth, does not hinder the upward passage from the roots to the leaves of unassimilated sap through the outer layer of woody cells, but does prevent the distribution, through vessels in the cortex and inner bark below the wound, of assimilated food (20). The effect of this action is to cause an extra amount of reserve material to be stored in the upper parts of the plant for the production of fruit buds.

Ringing plants consists in the removal of a band of bark through the cortex and bast of the trunk. The term girdling is frequently used to designate this operation, but since this name is usually associated with wounds made more or less, deeply in the wood [and since the operation] results in ultimate death, as when a tree is girdled by mice or girdled for the purpose of killing. it is unfortunately chosen. French writers use the phrase. "decortication anmulaire" (annular decortication or bark removal), which is more exact than either ringing or girdling. The object of ringing is to induce and increase fruitfulness.

The object of the experiments was to determine, if possible, the extent to which fruit trees may be ringed without permanent injury

* Sur les effets de la decortication annulaire, Compt. Rend. Acad. Sci. (Paris), $140 ; 1553-1555 . \quad 1905$.

$\div$ N. Y. Agr. Exp. Sta. Bul. 288.

\$ N.Y. Agr. Exp. Sta. Bul. 151.

$\$$ Condensed excerpt from G. H. Howe's Bulletin 391. of the New York Agrlcultural Experiment Station. 
and in what degree, if at all, the operation induces and stimulates fruitfulness.

Ringing should be performed early in June or July, at which time the bark peels readily from the wood, leaving the cambium in a succulent condition. The success of the operation hinges upon the fact that at this season occurs the greatest cambial activity, which readily facilitates the rapid formation of new bark, and at the same time prevents exhaustive evaporation of plant juices. Any attempt to practice ringing when plant growth is sluggish or dormant always results in the death of the tree, since the cambium, being then firm, is torn from the woody cylinder during the operation. A common pruning knife (Fig. 112) or a sharp pocketknife is a suitable instrument for performing the operation.

From the data secured, it would appear that ringing tends to have injurious effects upon apple trees, and that the wider the

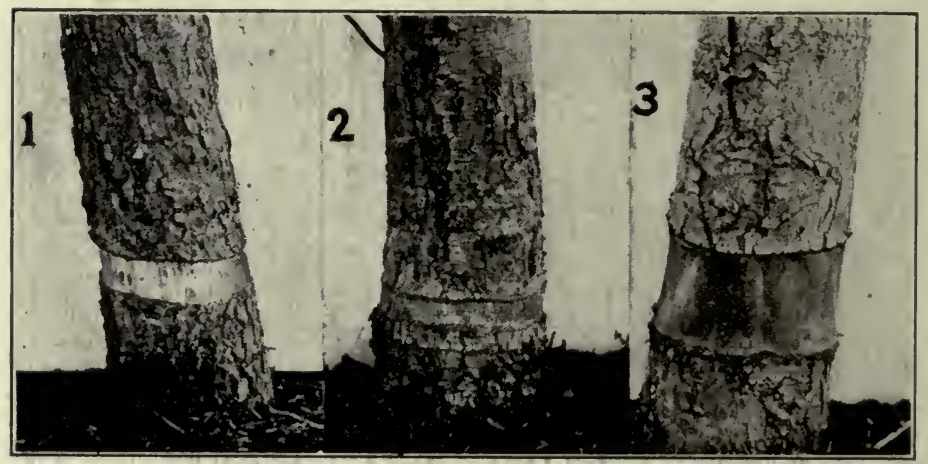

FIG. 74-EFFECTS OF RINGING YOUNG TREES

1. One-inch ring of bark freshly removed from apple tree. 2. New bark over 1 -inch ring. 3. New bark over 3 -inch ring.

bands the more serious will be the injury. It may be stated that the trees used were exceptionally strong and uniform in vigor and were therefore possibly in a better condition to withstand wounding than are average orchard trees. All of the trees making a weak growth showed smaller foliage and less wood production. The foliage, likewise, lost its color and fell from the branches four to six weeks earlier than that of normal trees. Two to six sprouts sprang up at the, lower edge of the wound on nearly every tree. This would indicate that nature was endeavoring to provide assimilated food for the roots since passage of such food from the upper portion of the trees had been cut off.

No gain in productiveness resulted from ringing. The few fruits which were produced showed no differences in size or color 
from the normal. Clearly, ringing these trees seriously injured their health without increasing fruitfulness. Examination of the root systems showed that, as a rule, the ringed trees had smaller, shorter roots (nearly approaching hairy roots) than the unringed trees. Trees low in vitality had extremely small root systems.

Early one June, 50 Baldwin trees three years from setting, were ringed, bands $2,4,6,8,10,12,14,16,18$ and 20 inches wide, respectively, being removed from groups of five trees each. At the same time i5 trees of the same variety and age in another block were ringed, groups of five trees each being ringed with 1 -inch wide rings at the surface of the ground and 4, 8, 12, 16, 20 and 24 inches, respectively, above the ground. In most cases new bark started to form, but at the end of the season not a single tree hacl made a perfect formation of new covering. Several trees in each lot were dead and all others lacked vigor. All foliage dropped about five weeks earlier than from adjoining unringed trees of the same age. The spring following the ringing but 10 per cent of the trees of both lots started growth, and this so weak that death resulted before midsummer. While these two lots of trees were less vigorous than the seedlings of the previous experiments, they were representative of average trees of the commercial orchard. (Fig. 74.)

From these experiments it is clear that the first ringing of the seedlings influenced fruitfulness and caused them to set a large crop of fruit. The experiments with the Baldwin trees, however, showed different results. These trees, lacking the vigor and hardiness of the seedlings, failed to survive a single operation.

In some of the western states orchardists frequently resort to the ringing of their young trees to induce them to bear fruit, with very good results. Under most favorable conditions, young, vigorous, thrifty trees ought to withstand and respond to one operation, but subsequent ringing is devitalizing and exerts practically no beneficial influence. From the experiments at this station, the practice of ringing apple trees to induce and increase productivenes; seems too drastic a practice for the good of the trees. Even if a slight increase in fruitfulness is brought about it seldom offsets the injury to the tree.

Ringing was also done on pears, cherries and plums with much the same, but more injurious results. It is, therefore, concluded that the results obtained from these experiments are not favorable to ringing fruit trees as a general practice. Under some conditions, for a limited time, a more favorable outcome may be expected. Hardy, vigorous, young apple trees may readily undergo a single ringing and be benefited thereby, but subsequent operations are injurious. Trees lacking vigor are often seriously injured by the practice. The deleterious effects of the treatment have generally been so marked upon various plant organs as to render the operation exceedingly hazardous. There seems to be no regular or systematic increase in fruit production. The gains do not offset the losses. 
102. Pruning, ringing and stripping vs. fruit bud formation.-In summarizing his findings in a series of experiments, A. W. Drinkard, Jr., says :*

The experiments, which extended over two years, were made to study the effects of pruning, root pruning, ringing and stripping at various seasons on the formation of fruit buds on dwarf apple trees. Spring pruning of the branches at the time of growth resumption had a tendency to discourage the formation of fruit buds, but there was apparent stimulation of wood growth in the trees. Summer pruning of the branches the latter part of June, when fruit buds normally begin to show differentiation, checked wood growth the year in which the work was done, and greatly stimulated the formation of fruit buds, as was shown by the bloom and the crop of fruit the following year. Fall pruning of the branches in November did not materially influence the crop of fruit buds, but caused vigorous wood growth the following year.

Severe root pruning at the time of growth resumption in the spring (April 23), at the time the leaves were well developed (May 31), and at the beginning of fruit bud differentiation (June 23 ), when accompanied or preceded by spring pruning of the branches, produced some stimulation in fruit bud formation. Another series of experiments showed that the spring pruning did much to offset the effects of root pruning, which treatment retarded wood growth in the current and the succeeding years; the leaf area of the trees was reduced and the trees showed injury from the treatment.

Root pruning on April 23, at the resumption of growth in the absence of spring pruning, did not give as much stimulation to fruit bud formation as the same treatment applied at later dates. Apparently this was too early for the full effects to be felt by the trees. Root pruning when the foliage was fully developed, and when the fruit buds began to become differentiated, in the absence of spring pruning of the tops, produced very marked stimulation in fruit bud formation. At these three times the treatment retarded wood growth and foliage development in the current and the succeeding year, and the trees suffered from the treatment.

Ringing at various seasons, when accompanied or succeeded by spring pruning of the branches, produced no noticeable stimulation of fruit bud formation. At the time when growth was resumed in the absence of spring pruning, it did not stimulate fruit bud formation. The treatment was given too early. At the time the foliage was fully developed, in the absence of spring pruning, it gave the best results; however, when the treatment was given at the time the fruit buds began to become differentiated, there was some stimulation of fruit bud development.

Stripping at various seasons when accompanied or preceded by spring pruning, had no stimulating effect on fruit bud formation.

* Ibid. 
The effects of stripping were offset by those of spring pruning. Stripping at the three seasons already mentioned, in the absence of spring pruning, stimulated fruit bud formation uniformly.

Not enough is yet known about the operations of root pruning, ringing and stripping for the formulation of rules by which practical fruit growers may utilize these operations advantageously in their orchards to increase the fruitfulness of their trees.

103. I4. A constriction or a girdle on a twig or a stem tends to increase and elongate growth from the buds nearest below and to thicken the twig immediately above (Fig. 96). The bud nearest above a constriction or a girdle usually becomes more or less quiescent and of ten fruitful (Fig. 95).

This principle is based upon the upward movement of crude sap and of elaborated plant food (20). The influence which a constriction exerts is largely proportional to the degree of the constriction. When only the tissues outside th e cam bium are affected, the buds and other parts above the constriction becom e filled with elaborated plant food because this material cannot go lower down the stem; when the alburnum or sapwood is affected the upward flow may be

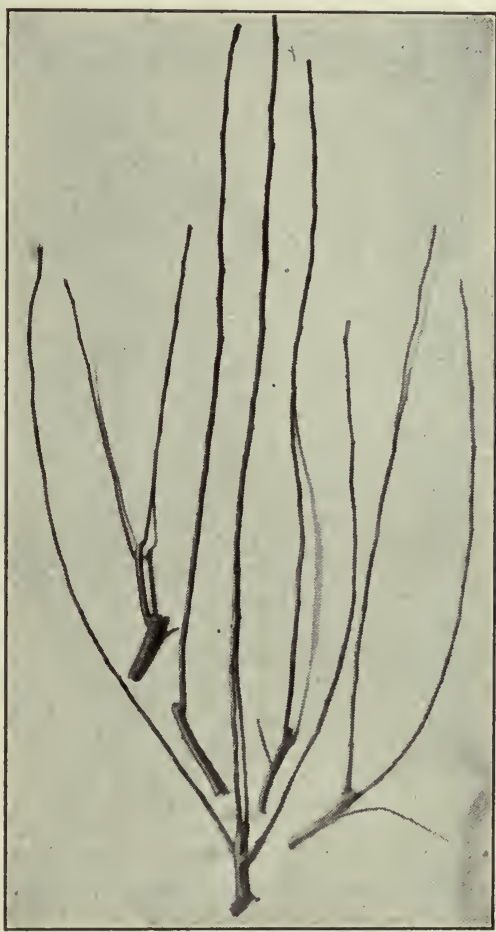

FIG. 75-SHOOT GROWTH FROM STUBS LEFT IN MAY

Almost as bad as winter pruning in the production of increased quantities of wood. checked completely, in which case the parts above will die 
sooner or later. This latter is equivalent, then, to headingin, a process which favors lateral bud development (106).

Among the methods employed for producing constrictions are girdling by wire, cord or a single knife cut through the bark to the cambium, and ringing. Bending the $s h$ ots, usually downward, from their normal direction of $\mathrm{g}$ owth

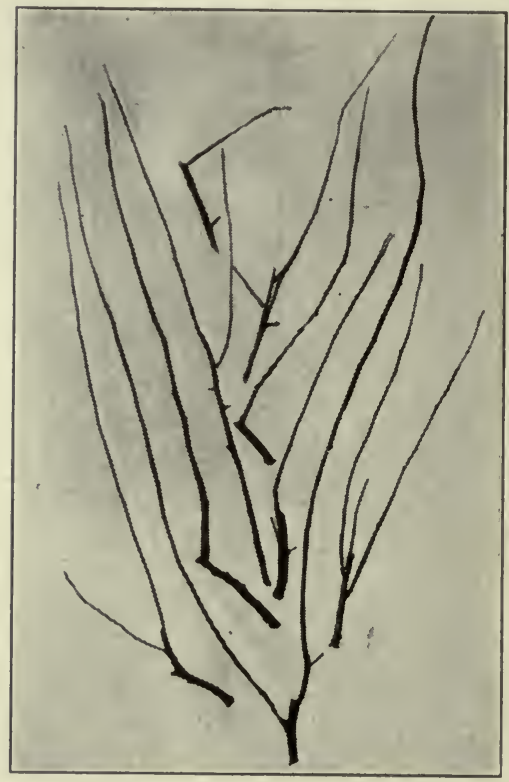

FIG. 76-SHOOT GROWTH FROM WINTERPRUNED STUBS

Unsatisfactory way to prune shoots in thick interior of tree. Growth becomes worse than before.

do with amateur gardening where individual specimen fruits rather than large commercial yields are the aim. Its cmployment is mainly confined to trees trained on walls or trellises or in special forms, such as cordons and espaliers. In such cases the grower must count bucls, develop fruit 
spurs and other twigs where required and observe many other finicky details.

With grapes some of these considerations may also be in orcler, but the pruning of the vine differs from that of trees mainly because of the natural habit of the plant. Two classes of ideas are employed in grape pruning; one which merely removes unnecessary wood, the other which seeks to train the vine to some desired form. Since the various forms differ widely, the number of buds left on individual canes also varies widely. Some of the principles of pruning, therefore, play a less prominent part in grape growing than in the management of other fruits.

105. I6. Fruit bearing is more or less influcnced by the time of lear aehcu pruning is done; summer pruning faz'ors fruit bud formation, whereas winter pruning tonds to branch bud and rood formation.

Plants pruned during the $d=r$ mant season promptly endeavor to make up their losses by developing increased growths during the following spring, but plants pruned between late spring and late summer usually

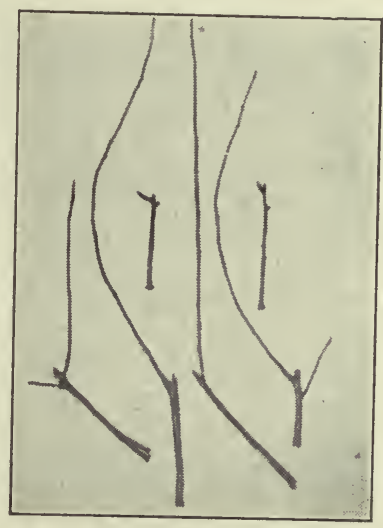

FIG. 77

EFFECTS OF AUGUST PRUNING

These poor results are the best secured from August pruning experiments to reduce wood and increase fruit spurs. have sufficient time to readjust themselves before the season closes, so there is little or no excessive development of woor the following spring. One reason for this effect is that summer pruning considerably reduces the leaf area, thus reducing the quantity of elaborated plant food. Hence the process tends to weaken rather than strengthen growth. In support of these statements it may be pointed out that suckers and water sprouts are far more numerous after 
pruning during the dormant season than after pruning in summer.

When pruning mèrely checks wood production without noticeably reducing the strength of the pruned plant, it usually favors fruit bearing; hence the value of summer pruning of whatever kind, but especially the shortening of excessive annual growths. The best time to do this is when the moisture in the soil becomes somewhat reduced in early summer, but after the twigs have attained their full length. If done then the probability is that the remaining buds will have enough time to fill with food and yet not have sufficient time to develop lateral shoots. In actual practice no set rule can yet be laid down, certainly not one based upon a mere date, nor can any set rule be given for the amount of summer pruning that may be done with safety. Even trees may be summer-pruned so severely that they will die!

The only safe guide is personal experience based upon such factors as climate, character of soil, species, variety, and even upon the behavior of the individual plant. Even then the newness of the practice so far as the individual plant is concerned will influence the judgment in one direction, whereas the accuistomedness of the plant, if I may coin a word, will influence in perhaps the opposite direction. Plants accustomed to a certain style of handling from the start will perhaps stand more, though they may not need more pruning than those new to the practice. In general, plants trained in special forms give best results when summer pinched or pruned.

Generally neither fruit buds nor fruit spurs are formed on the pinched parts the same seasons as the pinching is done. When the summer shortening-in is done early enough for this there is increased risk of getting undesirable lateral growths. If the operation is performed after the leaves have reduced their activity, these growths will rarely occur. During recent years considerable study of bud formation has been made, but so far the conclusions have brought forth 
iittle that has not been known for a long time from the standpoint of practice. Investigators, even if they have not greatly enlarged our knowledge, certainly deserve great credit for undertaking such tedious and painstaking work as that discussed above. To a large extent, their findings support pruning principles based upon plant physiology.

106. I7. Fruitfulness may be induced by shortening e.rcessive twig growth, thus favoring the development of fruit buds and spurs.

Since the vigor, the age and the method of handling the tree and other local factors must be considered, therefore no rule can be laid down as to how often or how much shortening-in may be done to secure productiveness. In proportion as the practice tencls to reduce production of woody parts it favors the formation of fruit buds; but when carried beyond this point it may be equivalent to a severe pruning and therefore may actually favor wood development.

Fruit trees that are producing 1 to $11 / 2$ feet of new growth annually may have these growths reduced 25 to 35 per cent. This statement is general enough to apply to cases other than the development of fruit buds. It includes such other aims as indirect fruit thinning, preventing dwarf trees from exceeding the development of their stocks, maintaining the desired form and size of trees to suit the ideal of the grower or the area available. So far as fruit bud development is concerned, shortening-in of this kind may have small effect if done only occasionally or spasmodically.

The shortening-in of terminal twigs favors the development of fruit spurs in the upper but interior part of the tree tops, spurs which sooner or later develop blossom buds (Fig. 173). The practice, fairly common in the commercial production of dwarf pears, is perhaps properly one rather of training for convenience than of pruning proper, and it is doubtful whether or not productiveness, or shall we say income, is enhanced by it. To be sure, the fruit may be horne in a much more limited area than in the case of trees not so treated. 
So far as the writer knows, no definite experiments have been tried to settle whether such trees are as productive as others not so treated, but grown under as nearly iclentical conditions as can be secured. One conceded advantage shortening-in frequently has: when judiciously perfomed it tends to early maturity of the trees and consequently precocity of bearing. This, however, finds its chief application in amateur practice; for commercial use it is of comparatively minor importance.

107. Pruning at various seasons.-Stimulation of wood growth does not necessarily mean increase in the total mass of the tree. From their studies of this question, the Duke of Bedford and Pickering* have concluded that hard pruning does not ultimately result in a larger tree than does light pruning. In later experiments $\dagger$ they found that the less a tree is pruned the greater is its wood growth, except in the case of old trees, on which the amount of wood is increased by hard pruning; the hard pruning is antagonistic to fruiting, this rule applying to both young and old trees.

108. Summer pruning experiments performed by Drinkard,ई at the time the fruit buds began to form, stimulated the development of fruit buds. These experiments give some evidence on the proposition, often expressed by horticulturists and practical fruit growers, that summer pruning increases the fruitfulness of apple trees. No doubt the degree of increase in fruitfulness resulting from summer pruning bears direct relation to the condition of the trees, the season and the time and severity of the operation. But the physiological principle involved is not clear. It is obvious that severe summer pruning reduces the foliage area, interfering with transpiration and photosynthesis. The balance between the root system and the branch system is suddenly disturbed. The nutrition of the various organs in the tree is changed in some degree by summer pruning.

Quinn, $\neq$ who has described the various methods employed in summer pruning-disbudding, pinching, thinning, heading-in, and fracturing or twisting of branches-found that these operations are effective in greater or lesser degree for conditions in Australia. Dickens** found from careful experiments that summer pruning gave better results than pruning during the dormant season. By means of summer pruning, he was able to induce fruitfulness on 10-year-old apple trees which had previously borne very little fruit.

\footnotetext{
* Woburn Experiment Fruit Farm, Second Report, 1900.

† Ibid. Seventh Report, 1907.

\$ Technical Bulletin 5, Virginia Experiment Station.

¥Jour. Agr. and Ind. South Australia, Fig. 3: 368 to 378. 1899.

* Kan. State Agr. College Exp. Sta. Bul. 136.
} 
Goumy* states the buds on very vigorous trees may be transformed into fruit buds by defoliation-that is, the removal of the supporting leaves from certain buds-but not all the buds on the branch; however, he considers this operation very limited in its application and not to be recommended for general practice.

Fruit growers in England have long practiced summer pruning. The consensus of opinion and experience of both practical fruit growers and scientists, given some years ago, is that summer pruning is uncertain in its effects, depending upon soil, climate, varieties of fruit and time of operation, that specific objects may be accomplished by the process, but that the operation is of doubtful practicability.

109. Summer pruning of apples.-In a recent bulletin $\dagger$ Batchelor and Goodspeed give the following condensed conclusions: Apple trees, pruned to induce a spreading habit by cutting back the terminal growth to lateral branches, produced a greater annual twig growth than trees similarly pruned, except that the terminal growth was untouched. Trees pruned during the dormant period and also during the summer, produced a greater annual twig growth than trees pruned during the dormant season onlý. Trees pruned during the clormant season produced a greater total twig growth than the unpruned trees.

Rubbing the water sprouts out of the center of the tree from time to time during the summer, had little or no influence on crop production. These shoots are removed much more readily and cheaply, however, during this season.

Trees pruned to a spreading form by cutting back terminal growth to lateral branches, in the case of both Jonathan and Gano [the two varieties experimented upon], averaged a smaller production to the tree than trees allowed to assume a more natural upright growth. The ratio of the total pounds of marketable fruit for the two varieties during four years is 86 for Jonathan and 91 for Gano from trees pruned to spread, as compared with 100 per cent each for trees allowed to take natural shape. The summer-pruned trees averaged less marketable fruit to the tree than either the winterpruned or the unpruned trees.

The winter-pruned Jonathan trees produced more fruit than the unpruned trees. The winter-pruned Gano trees produced less fruit than the unpruned trees. Summer pruning in this orchard has proved neither profitable nor successful in increasing crop yields.

Although the investigation is only in its first stages, there seems to be a correlation between regular bearing and summer pruning. In the case of the Gano trees the most regular bearing trees were the unpruned ones. Summer pruning throughout a period of two months between the third week in June and the third week in August produced much the same results.

* Recherches sur les bourgeons des arbres fruitlers. Ann. Sci. Nat Bot. (Par.s), de Serie 1: 135 to 246.1905.

$\dagger$ No. 140 Utah Agricultural College Experiment Station. 
The above results may apply only to young, vigorous bearing apple trees of Jonathan and Gano when planted on a rich, sandy loam, free from seepage, in a semi-arid climate, with an abundance of irrigation water available. These varieties under the above conditions show a tendency to overbear soon after reaching a productive age, and are usually thinned. Summer pruning reduces the area of fruit-bearing wood, the vitality of the tree and the productivity.

110. I8. Twig and small branch pruning may be used to thin the fruit and thus also favor regular annual bearing.

In order to apply this rule intelligently, it is essential that the pruner be familiar with the way in which the variety he is handling produces its blossom buds (Chapter IV). Otherwise, he may remove desirable parts and actually work against his own interests. Fruit thinning by the removal of twigs and buds during winter is generally a more expeditious and economical method than summer thinning of the actual fruit. It can be done by more intelligent labor when time is less at a premium and, therefore, when better care can be given to the trees. Its greatest drawback is the uncertainty as to the number of bloom buds that will expand, how many may be frozen after they have opened, how many fruits may fail to reach maturity. This uncertainty is obviously greater in March than in July! Still, many fruit growers practice it more or less systematically mainly because of its economy. Generally they wait until danger of frost injury has passed so as to reduce the uncertainty as much as possible.

The fact that thinning the fruit conserves energy is strikingly illustrated by the experience of J.Q. Wells of Shortsville, N. Y. An orchard, mainly of Baldwin apples, was 18 years of age, but had never borne a crop when $\mathrm{Mr}$. Wells took possession. Beginning a year or two after, however, it has borne 20 excellent crops during 22 years, the two failures being due to frost at blossoming time. This is the most striking argument for thinning the author knows. To be sure the achievement is partly due to the consecutive good care the orchard receives, but it is largely due also to the systematic thinning. If such is the record with the 
Baldwin apple, notorious for its "off years," what may not be accomplished with other varieties?

So far as the author knows, Mr. WVells practices only stmmer thinning; but winter thinning produces similar results, for it conserves energy. This conservation can be most easily noted in apples and pears because of the spur method of fruit bearing. In these fruits there is normally an alternation of cluster bud and branch (spur) bud development. This is due to the demand made upon the spur for food to (levclop the fruit, a demand that usually prevents the formation of a blossom bud on the spur during the same year as a fruit is developed on that spur. While the fruit is being leveloped the spur has only enough surplus energy to develop a branch (spur) bud near the union of the fruit stem with the spur. To induce annual fruiting, the trees must either be extra well fed or the fruit must be thinned. The former is generally not as certain as the latter.

One way in which annual bearing may be induced is to remove all the fruits while young from some of the spurs and only the inferior ones from others. Thus fruit buds should develop on the empty spurs and none on the bearing nnes, and an alternation of fruit bearing would tend to be leveloped on each set of spurs; but one set would bear in the even years and the other in the odd years. Thus the tree should never overbear in any one year, and the grower should always have at least a partial crop. This method, if applied while the trees are young, requires less work than may at first appear, because after once getting a start it will at least partly take care of itself. Whether mature trees with set alternate year bearing habits can be made to bear annually is a question yet to be decided. Much of the success of the plan will depend upon the character of care given the orchard.

What has been said under this heading as applying to thinning of the fruit applies with equal force to the thinning of the fruit-bearing areas of the trees. 
111. I9. Large zounds heal according to conditions, most important of which are the kind and the vigor of the plant, the length and position of the stubs, the smoothness or the roughness of the cut surfaces, the health of the wood and the time of year when made.

This principle needs elucidation in a chapter by itself (Chapter VI). Yet a few words may be here used to advantage in summarizing the discussion. From the standpoint of healing alone, large wounds heal most readily when made just before the growing season opens because the exposed tissues have but a brief time to dry out, and the cambium cells, very soon after the wounding, become active. However, the vigorous or feeble condition and the species and perhaps the variety of the tree, the character and position of the wound and the influence of many other local factors may affect the healing to a greater or lesser extent either favorably or unfavorably.

112. 20. Wound dressings, which do not injure the grow'ing tissues, which are antiseptic and durable, and which thus give physical protection, ma! prevent or check the cntrance of decay, but they do not hasten healinq.

This principle receives separate discussion. (Chapter VIII.) 


\section{CHAPTER VI}

\section{HOW WOUNDS HEAL}

113. Natural wounds in the bark, such as those caused by growth in girth, usually heal quickly and without danger to the life of the tree. From what has been said (Chapter II) it is apparent that the bark must necessarily become tighter and tighter over the woody cylinder as the cambium develops new cells. This internal pressure, which often reaches 50 pounds to the square inch, causes the rupture of the bark in countless exogenous trees and

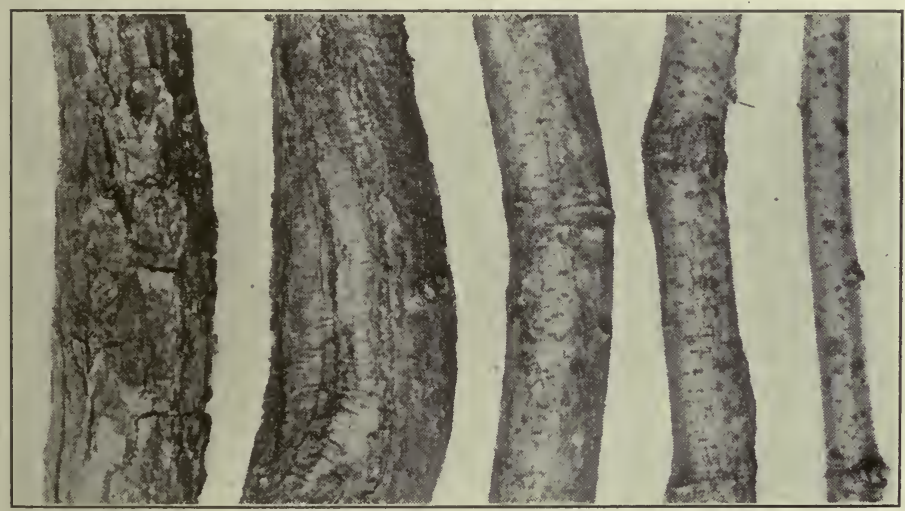

FIG. 78-HOW BARK BECOMES ROUGH BY SPLITTING AND HEALING

shrubs, and we thus see the wrinkled, contorted or scaly stems characteristic of old trees, such as oak (Fig. 78), hickory and sycamore. The splitting is due to the nonexpansion of the outmost or dead layers of bark: the wounds are healed by the development of new cells from below.

114. Bark-bound trees.-In some cases, for instance, neglected orchards, the bark may become so tough, hard 


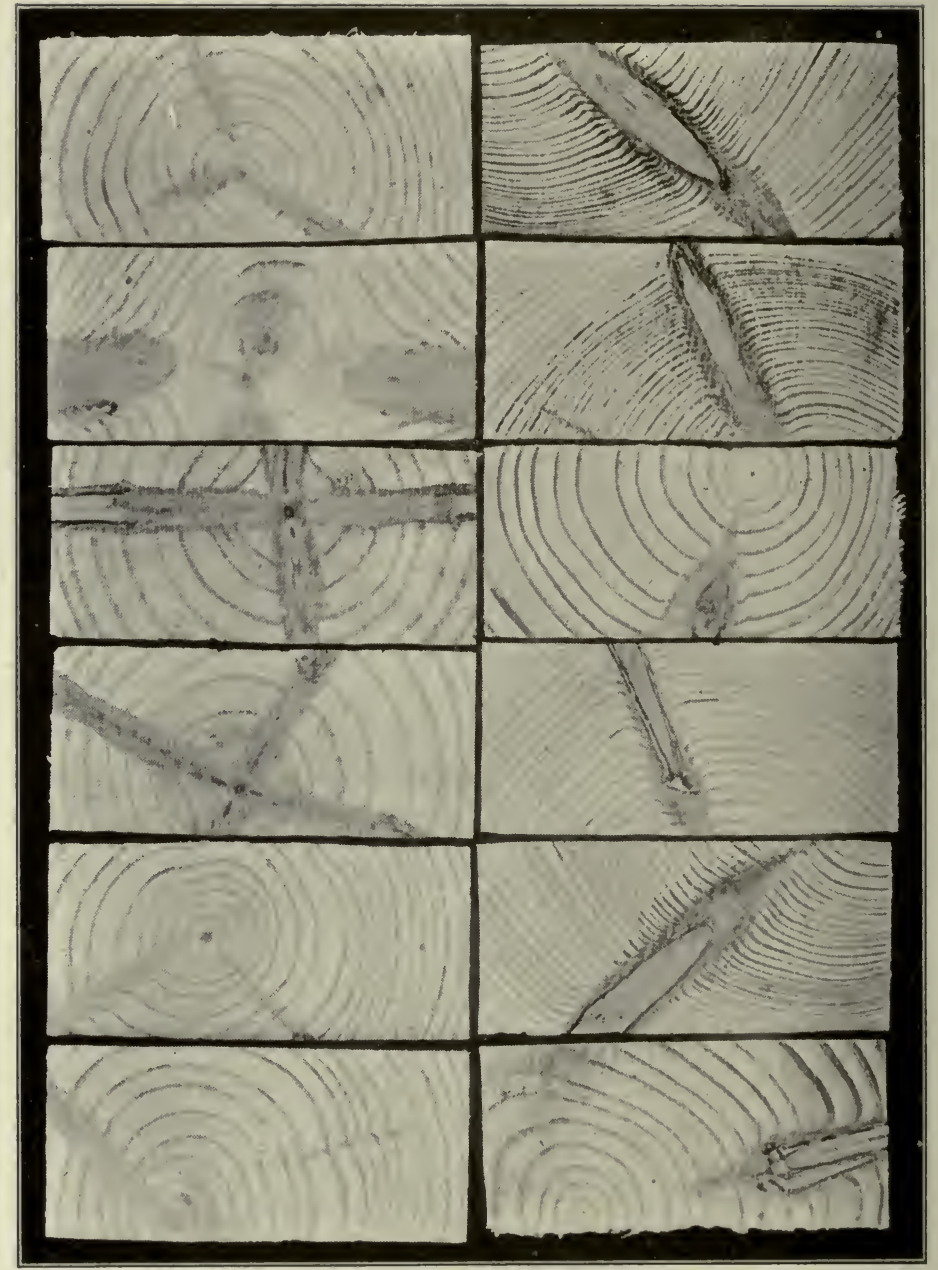

FIG. 79-CROSS SECTIONS OF WHITE PINE $(2 \times 4)$ SCANTIINGS SHOWINC, BRANCHES BURIED BY TISSUE

Left column, reading down: 1, living branches; 2, larger ones; 3 , where four limbs started together while the plant was very small, horizontal ones showing dead ends; 4, similar case; 5, living branch which started when the tree at this point was only two seasons old; 6 , similar to No. 5 . Right column, reading down: 1, oblique cut across dead stub; 2, ditto; 3 , oblique limb buried but cut across; 4, dead limb being buried; 5 , similar but at different angle; 6 , limb which started when the trunk at this point was probably six or seven years old, had a good chance to grow for a few years and then was killed. 


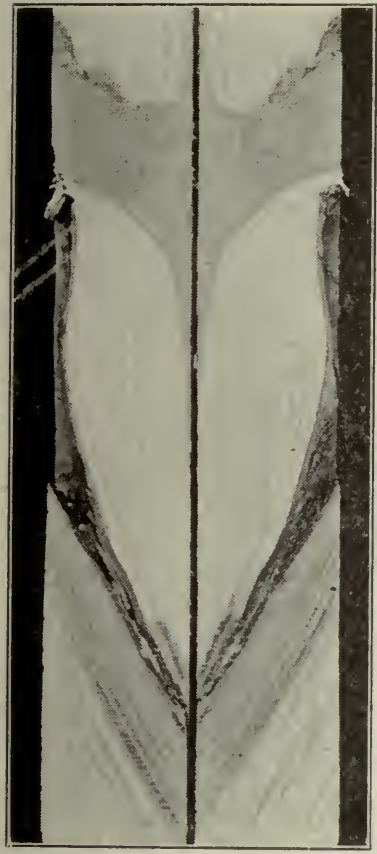

FIG. $80-$ CROSS SECTION O? PINE SCANTLING

Notice oblique grain of wood in lower knot and the bark which the trunk has tried to cover. Also notice the grain in the main stem bent out of shape by knots above and below. Compare Fig. 81 .

and dense that the trees are of ten saicl to be "bark bound." Good cultivation, fertilizing. pruning and cultural care may or may not promote expansion and rupture of the bark and consequent good health. Where these methods fail fruit growers may effect a change for the better by softening the bark with washes of lye or soap, or by slitting. This latter process consists in cutting

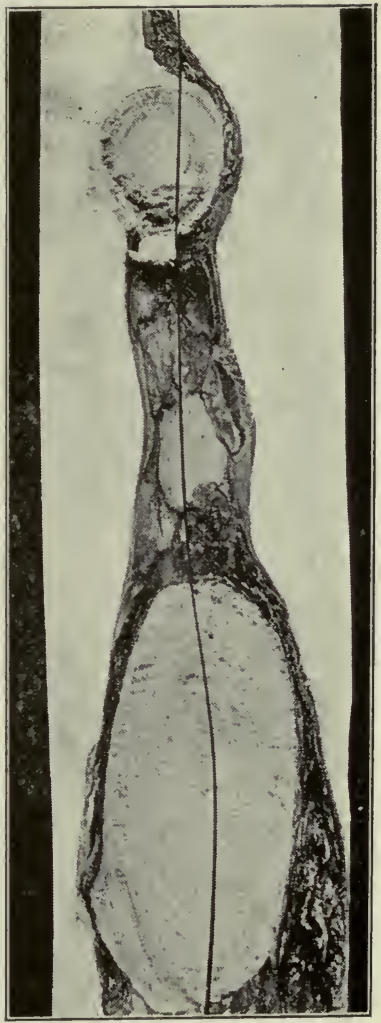

FIG. 81

DEAD LIMBS BEING BURIED

The lower limb has been cut The trunk. is making a desperate attempt to cover the stub, but the dead bark in Fig. 80 (a cross section) shows how poorly it is suc. ceeding. more obliquely than the upper. 

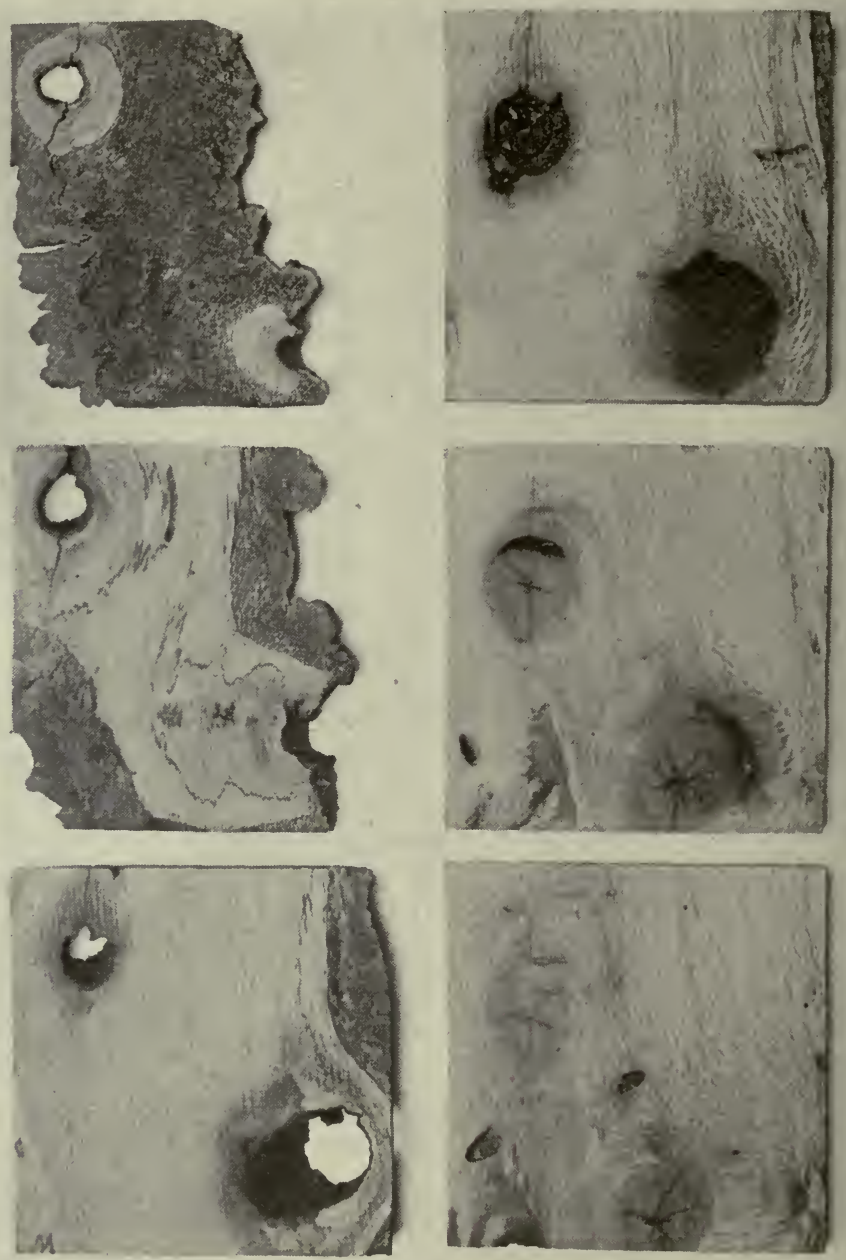

FIG. 82-HISTORY OF A STUB IN SIX CHAPTERS

Reading down (left) 1 , outside bark section showing extension of wood from trunk to try to heal in the stub rotted out where the hole is left; 2 , stub rotted out, leaving hole. Decay of wood occurred after the tree was cut; 3, wood nearer h art of tree. (Right) 4, decayed knot in place; 5, decayed spot beside almost hea thy knot; 6, knot in healthy condition except for checks-decay not progressed so far. In the lower right-hand corner of each section is shown a second knot left by a stub. In 4,5 and 6 note holes caused by borers. Decay often enters by such means. 
through the bark to the cambium layer, but no deeper, the cut extending parallel with the direction of growth on the trunk and the main limbs. Very large limbs and trunks may have two or three slits made at equal distances from each other. 'This op-

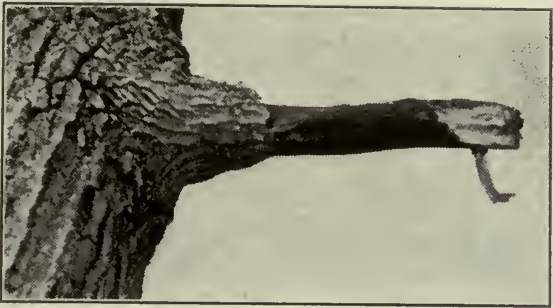

FIG. 83-HOPING STILL!

This oak tree keeps the bark alive around the decaying stub in the "hope" to protect itself from the decay creeping nearer the trunk every year. eration is always performed in spring just as growth begins. When made the cuts are scarcely visible, but in a. few days their elges will have spread, perhaps half an inch apart.

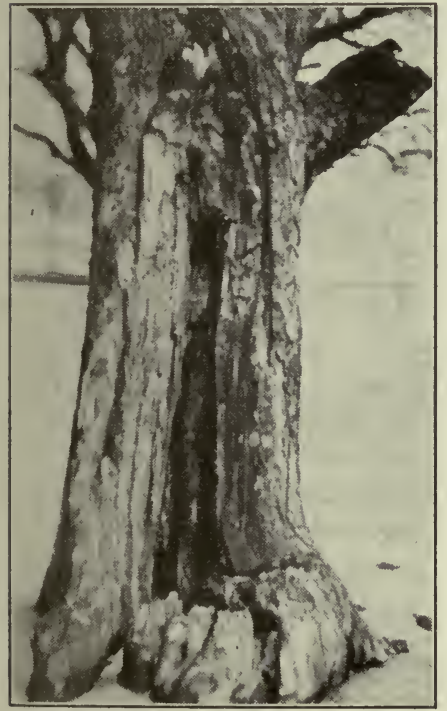

FIG. 84 - MORE THAN THREEFOURTHS OF THE TRUNK LOST BY DECAY AND BREAKAGE. YET THE TREE BEARS APPLES ANNUALLY.
Soon new cells will develop from the cambium and the wound be closed with new tissue. In no way does this healing process differ from that following the splitting of bark in forest and other trees. (Compare 99.)

115. Limb connections with the trunks of trees. Cross sections of tree trunks made at certain points will show how limbs are proluced and how they leave records of their development and decline in case of injury (Fig. 79). When a limb starts while the trunk is small its initial point will be found close to the center of the trunk, and as it grows it will enlarge, and its base 
be covered with the annual rings of the trunk. Generally such limbs are only one year younger than the trunk at the point where they are produced, but sometimes a latent bud may develop several years later than the limb produced in normal time. In such cases the initial point of the limb will not be from the central portion of the trunk, but from one of the annual rings more or less distant from the center of the tree trunk. Whenever logs are cut into boards the positions of the limbs on the trunks are shown by the knots (Figs: $80,81,82$ ).

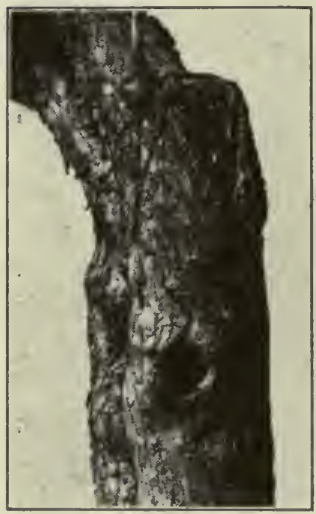

FIG. 85-FLICKER'S NEST

A cut was wrongly made at the elbow. Decay spread down the heart wood. Another stub just below the center also decayed and a flicker dug out a nest. This is a common thing in badly pruned orchards.
The history of the limbs is indicated by the condition of the knots. W'hen the knots form a close. union with the trunk the limb during the life of the tree was healthy -at least at the point where cut (Fig. 8:). When the knot is surrounded by a black ring, and especially where it is loose and can be knocked out, it shows that the limb was dead at the point where the board was cut from the trunk. Farther from the center of the trunk there may be only a hole where the limb has rotted back into the trunk (Fig. 82).

\section{Natural and artificial wounds} contrasted.-From what has been said in the previous paragraphs it may be rightly concluded that man may take advantage of and improve upon nature's methods, especially in the making of wounds, for if he will make wounds in such a way as to favor healing rather than decay, he will increase the longevity and the usefulness of the tree he so prunes. When 
the mere surface of the stem is injured, new cork cells will develop from the inner bark; when the cambium is reached and when the wound is deeper than the cambium, new tissue is produced by the cambium and the attempt made thus to heal and bridge over the wound. Outer bark cells and wood cells beneath the cambium are helpless to perform any healing function, because they are lifeless or nearly so (Chapter II). In other words, when a limb is broken or cut off, or when it is exposed by pecling off the bark, the heart wood cannot heal itself but must rely upon the cambium.

117. Callus.-The tissue which is formed by the cambium and the inner bark over a wound is called a callus. Always such growths begin around the edges of the wound and gradually or rapidly grow toward the center. In no case does the callus have any physiological connection with the heart wood of the original trunk or of the limb broken or cut off (Fig. 83). The callus cap has often been likened to the metal or glass cover placed over a fruit jar.

118. The purpose of the callus is to serve as a protection to the tissues beneath. Part of this protective function is to check loss of moisture from the surface of the wound, but its

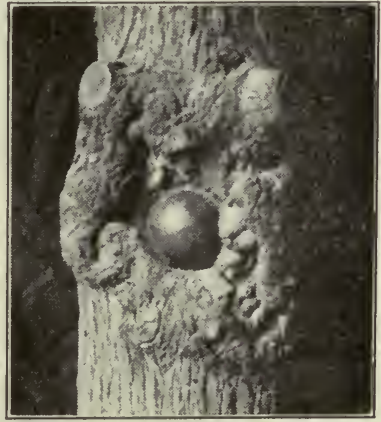

FIG. 86

CANNON BALL IN OAK TREE

Even the trees try to heal the wounds made by war. This specimen is in the Jenny Wade museum at Gettysburg, Md. Many trees still standing on the battlefield have completely buried the shots that wounded them. more important role is to prevent decay by protecting the wood from weathering and, most important of all, the entrance of rot-producing fungi and bacteria. Once such organisms gain an entrance into the heart wood, the limb and the tree so affected are doomed sooner or later to breakdown and death. When limbs 
die or break off trees they leave stubs on which dust collects and with moisture furnishes congenial conditions for the germs of decay. As the decay extends down the stub it enters the trunk despite the efforts of the cambium to cover over the end of the stub (Fig. 203). In time the whole of the heart wood may rot away, leaving a bee tree! When properly handled by man - that is, when no stubs are left-the heart wood will not decay but will continue to perform its function, namely, that of strengthening the tree so it will bear heavy loads of fruit, ice or snow.

119. Rational wounds may be defined as those which reduce to a minimum the danger of killing plant tissues

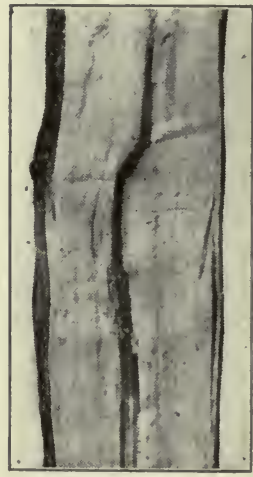

FIG. 87

HEART DECAYING

The dark streak shows how the original seedling grew-crooked -and how the irregularity disappeared as the tree increased in girth. A broken branch left a stub which admitted decay to the heart wood, as shown by the dark streak. in young and growing parts of trees and of decay in mature limbs and trunks. The making of wounds in pruning naturally resolves itself into a threefold question - when, where, how? It will simplify matters to consider these three phases all together rather than to take them up separately.

120. Pruning small twigs and branches may often be done with a knife or a pair of shears (Fig. 88), the former preferred wherever possible. (a) Always such implements should be sharp so as to leave a clean, smooth cut. (b) The surface exposed by cutting should be as small as practicable so as to favor most rapid healing. (c) The cut should be made neither too far above, nor too near the uppermost bud left to continue growth. because if made too high, the stub above the bud, being deprived of food, will die back to the bud and thus make a second later cut necessary; and if too near, the surface will dry out and thus enfeeble or 
kill the bud. The amount of wood to leave will depend somewhat upon the species and perhaps the variety of the plant being operated upon, those with open, porous wood, like the grape and the peach, being cut with longer stubs than those with dense wood, like apple and pear.

When pruning small branches or seedlings in which buds or grafts have been inserted it is often advisable to leave fairly long stubs and to make second cuts nearer to the unions some weeks later after the. tissues have $\mathrm{knit}$ firmly. In such cases the stubs should be pared down smoothly and close to the cion growths.

(d) In the formation of tops in young trees. the heads may be spread somewhat by pruning to buds on the outside of the twigs; they may be brought somewhat closer together by pruning to inside buds; raised somewhat by pruning to buds on the upper sides and lowered by pruning to buds on the lower

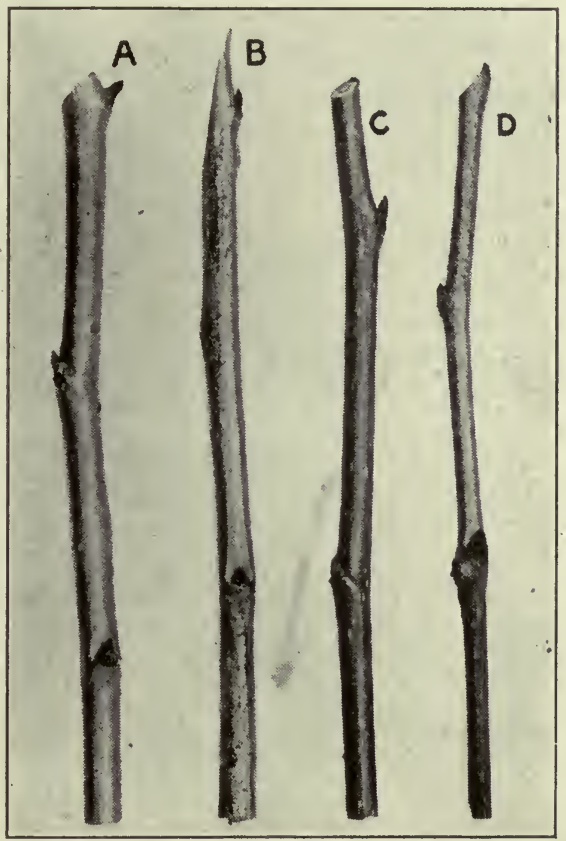

FIG. 88-CUTS MADE HEADING-IN TWIGS

$A$, cut correctly made not too close but with proper slant from the bud. B, cut far too long. Too large surface exposed. Likely to dry badl . C, too large an amount of wood left above bud. Will dry and de back to bud and must te cut a second time. D, cut too close to bud. Sure to dry out and kill bud. Will die back to next bud. sides. Thus erect growers, such as Northern Spy apple 
trees, may be somewhat spread out, and sprawling ones, like Rhorle Island Greening apples, raised, and so on.

121. Fall vs. spring pruning of twigs and small branches.-Common experience shows that even when small twigs and branches are cut properly, as just in-

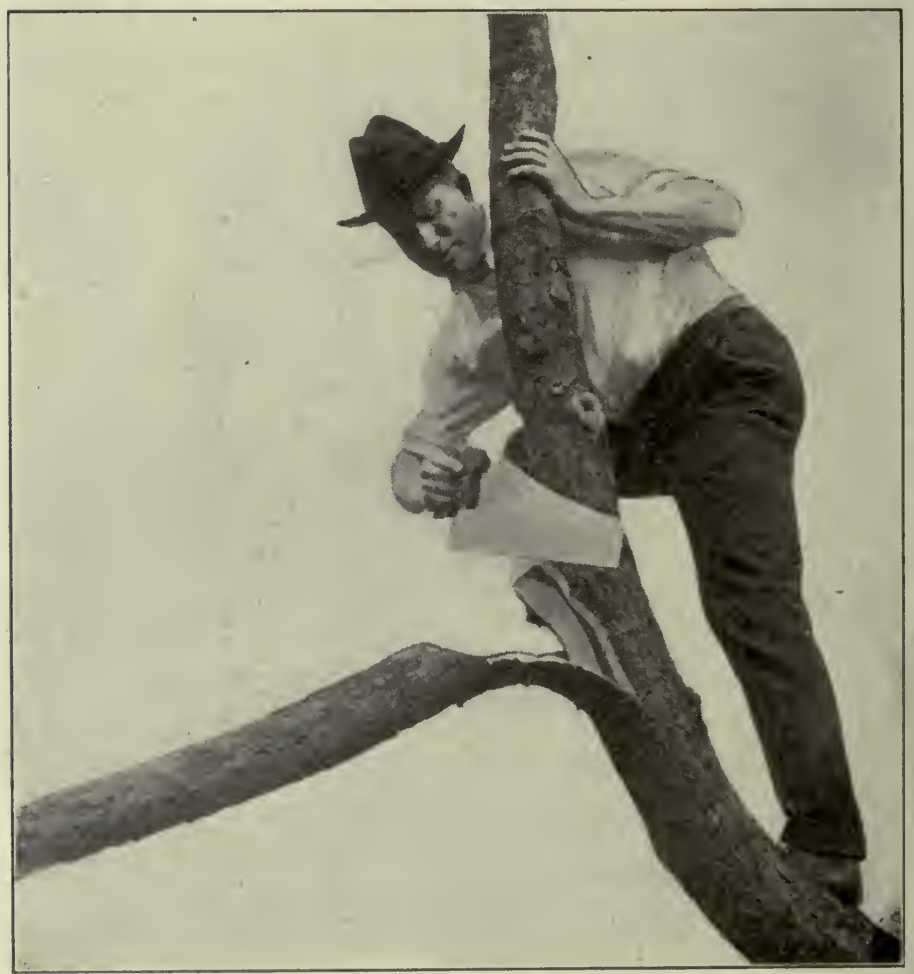

FIG. \{9-WRONG WAY TO CUT OFF BIG LIMB

Th ? leverage due to the weight of the $1 \mathrm{mb}$ will almost always preduce this kind of break. The tree was to be cut down anyway to clear the ground for a bui.ding !]

dicated (120), there may be dying back. This rarely occurs, however, when the pruning is done in the spring. Fall-pruned twigs very frequently kill back an inch to 
scveral inches, because the exposed ends of the twigs dry out and therefore die back as far as the drying extends, perhaps even farther. For this reason fall-planted trees should never be as severely pruned back as those set in the spring, the idea being to leave the stubs, say, 6 inches longer than they should be, so that second cuts may be made at the desired places just before growth starts in

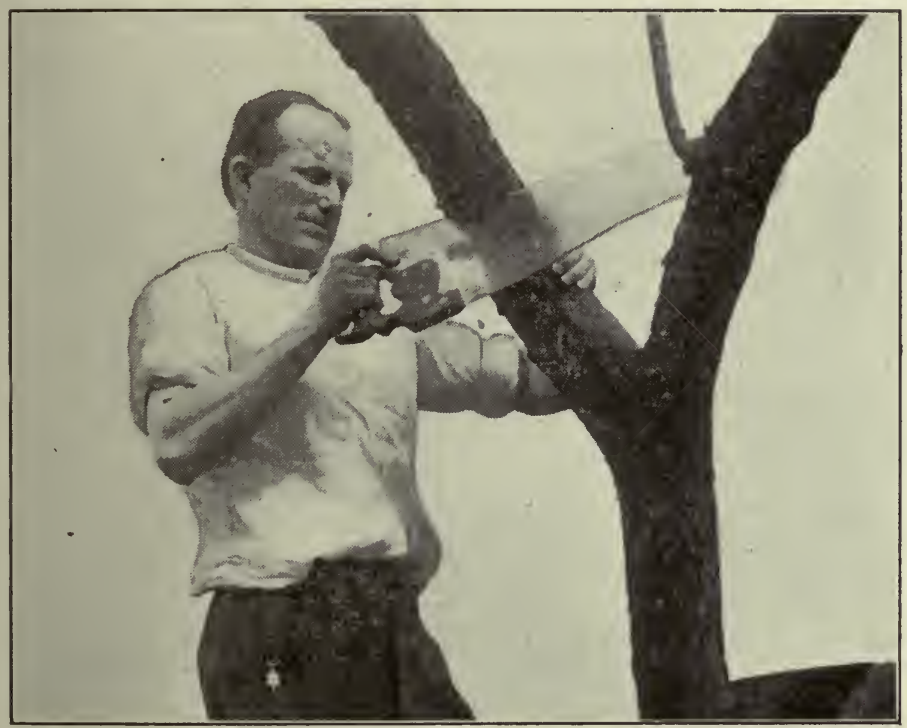

FIG. 90-PROPER WAY TO START CUTTING OFF LARGE LIMB

$A$ cut should first be made underneath the limb a foot or more from the union of this limb with the trunk. When the s? $w$ binds or sticks a second cut should be made from above and near to the first. See Fig. 91.

the spring. When the second cutting is not given, the uppermost bud on each twig will attempt to bury the dead stub. Whether or not it succeeds is immaterial, there will always be a weak spot in the branch at such points even though no actual decay may follow. Healing occurs most satisfactorily when the stub is very short and the bud develops a sturdy twig. 
When branches as thick as one's little finger or somewhat larger are to be cut close to the main trunk, leaving the 6 -inch stubs will be found a decided advantage for another reason; namely, the ease of cutting. For when branches of these sizes are to be cut with a knife, as they should be, far less effort will be needed if the branch is hent upward or toward the trunk or main limb. A branch that would require about all one's strength to cut while

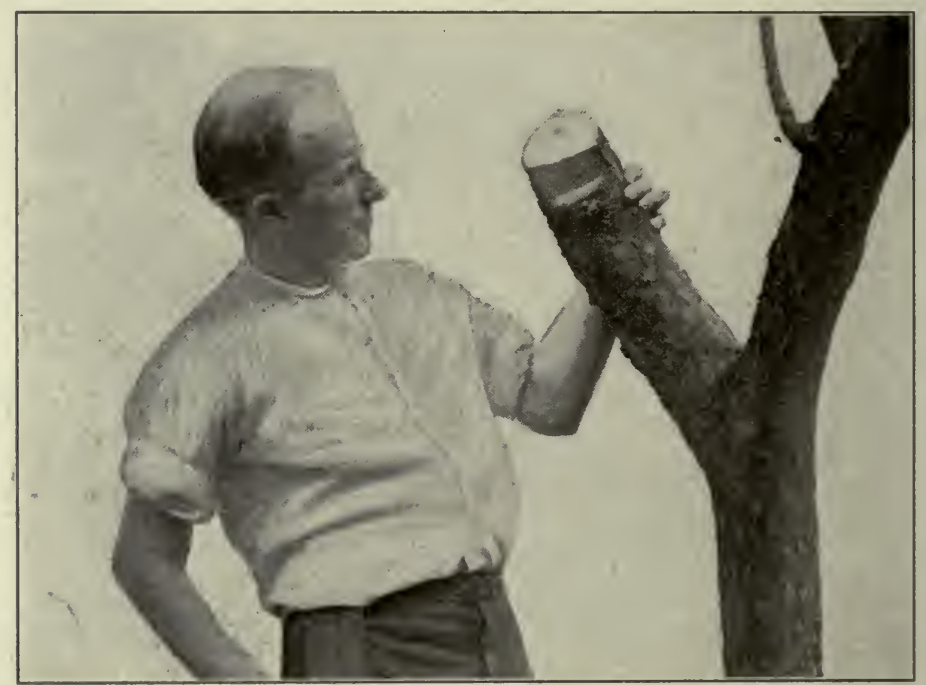

FIG. 91-SECOND CUT PROPERLY MADE IN SAWING OFF LARGE LIMBS

This is the same branch as shown in Fig. 90. Notice there is no splitting or tearing of the wood, as in Fig. 89. All that is necessary now is to saw off the short stub close to the remaining limb.

in normal position may, when so bent, be cut as easily as cheese, and a smoother, neater job done as well. This is one of the most valuable points to remember in pruning newly set trees.

This matter of twig pruning has special importance in the training of trees as dwarfs (270), espaliers, cordons, etc. (Chapter XVII), for much of the successful fruiting 
of such plants is due to it. In Europe, where the training of fruit trees on walls and trellises is far more common than in the United States, the expert gardener may cut off undesirable shoots at his leisure during the winter, but leave stubs several inches longer than necessary for an inexperienced assistant to remove just before growth starts in the spring.

122. Where to cut large limbs.-From what has been explained (116), it is evident that stubs should never be

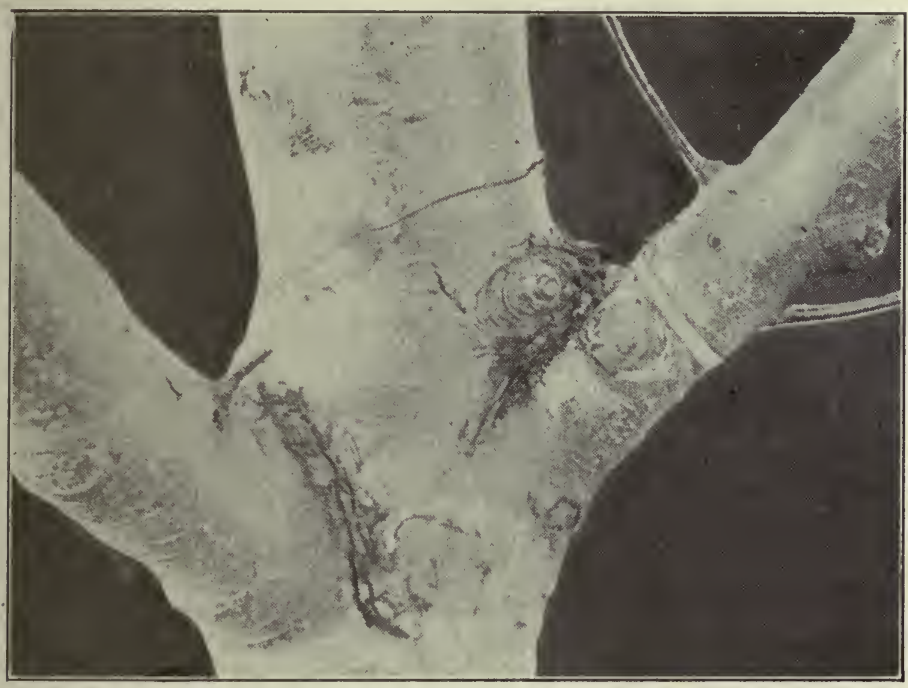

FIG. 92-WRONG WAY TO MAKE A CUT IN REMOVING A LARGE LIMB

left permanently when limbs are cut off. It is, however, not so evident how close to the main trunk cuts should be made to remove large limbs. Some pruners contend that a. slight shoulder should be left so as to expose a smaller area of cut surface to the air. They claim that the sawcut should be approximately at right angles to the limb being removed. Experiments in many parts of the coun- 
try, however, have proved beyond question that the more nearly parallel the cut is made to the direction of sap flow, the quicker will be the healing, because all parts of the wound are thus kept in close connection with the downward flow of elaborated sap. The objection that the wound thus made must almost always be larger than in the other case is discounted by the better results secured in healing. To make this matter emphatic, the principle mav be laid down that no part of an amputated

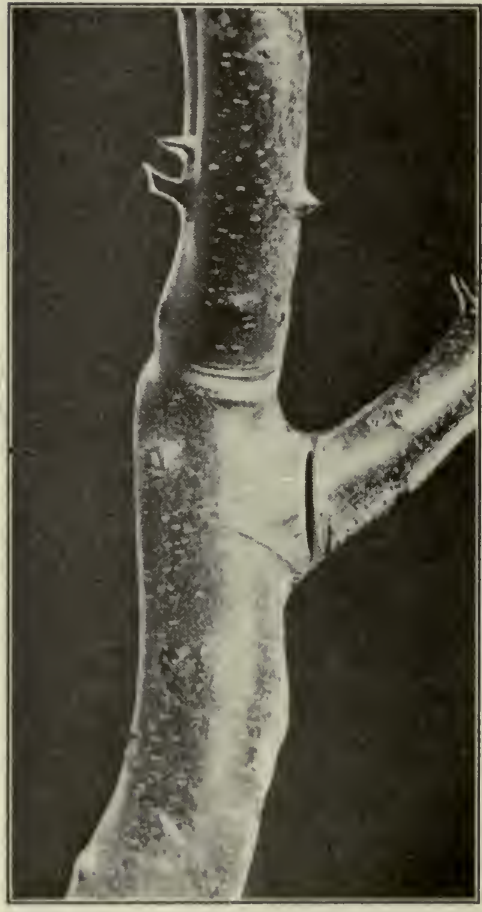

RIGHT WAY TO MAKE PRUN NG CUT branch should extend beyond the trunk from which the branch has been cut.

123. Time to cut off large limbs. - From numerous experiments it has been deduced that the time of year when a wound is made is a very minor factor to consider in pruning. No one season invariably gives best results. It must be noted, however, that no healing can occur while the cambium is inactive. as in late fall, winter and perhaps also during protracted dry weather. This statement has special force in very cold, dry climates, because the exposed tissues will probably dry out seriously. In all fall and w in t e $r$ pruning, particularly of large limbs, the cambium and the bark have 
a tendency to die around the margins of wounds even to the extent of loosening the bark. Unquestionably such drying is a hindrance to healing. Another point against pruning at that season is that the exposed wood is sure to check more severely than if it is exposed to the air for a shorter time and during a period of the year when the sap flow is more active.

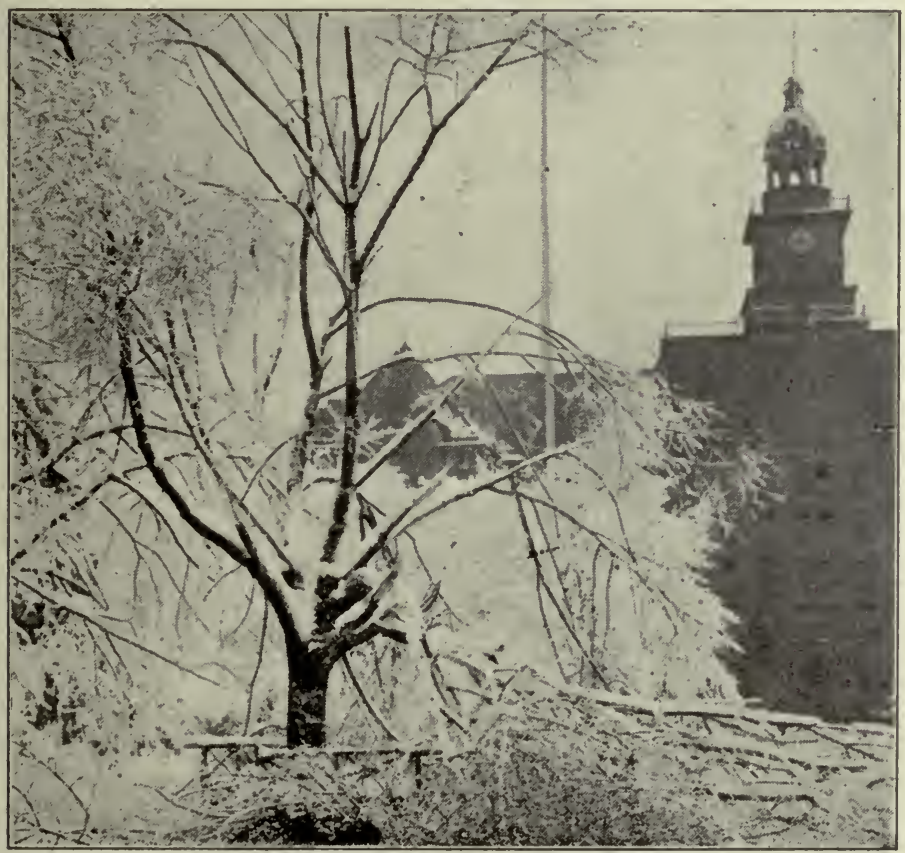

FIG. 94-SAD EFFECTS OF SLEET STORM

This Norway maple is one of several seriously injured by a recent storm at State College, $\mathrm{Pa}$. It is doubtful if any pruning or training could have prevented injury in this particular case, for the limbs are practically all broken where there were no bad crotches or decayed parts. The Norway maple seems to be specially weak.

But how about pruning during the growing season? Is there no objection to it? Yes-a theoretical one; at least. It is claimed that pruning in spring and early 
summer favors "bleeding" from the exposed surface. The author, though he has looked for instances and has searched horticultural literature, knows of only one case,

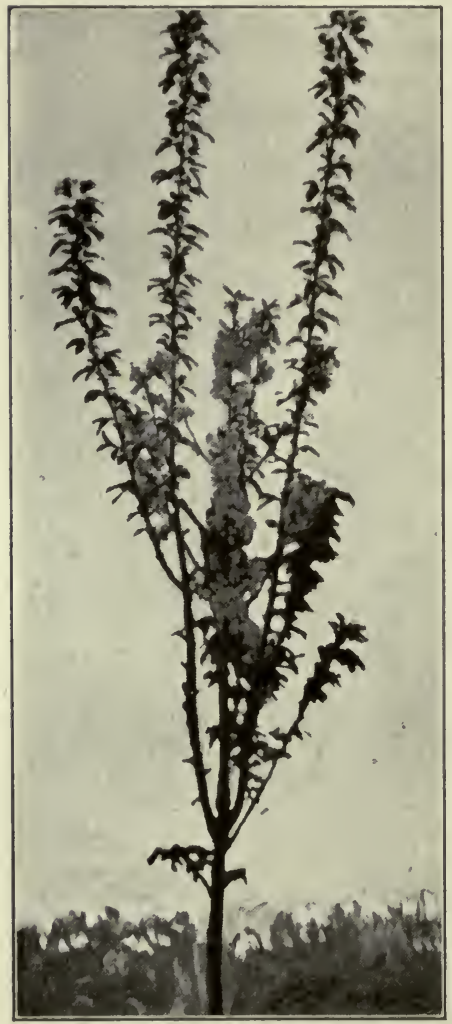

FIG. 95

LABEL WIRE MAKES GIRDLED LIMB BLOOM PREMATURELY that reported by Newman 15), to support this claim that plants which "bleed" when cut are injured thereby. Grapevines, maples, Japanese walnuts, box elders and many other woody plants bleed profusely when wounded, especially in early spring. But these trees appear to suffer no injury from the process. Yet one well authenticated case, such as that of Newman's. supports the contention that injury does result from such cutting. It is therefore well to err on the safe side and avoid cutting after or just before growth of such plants starts.

As the result of several series of experiments in pruning trees during every month in the year, it has been concluded that season is of far less consequence than the length of the stub and the position of the wound with respect to the trunk from which the limb was removed. Of these two, the latter is the more important. Wounds on actively growing limbs heal most quickly, and when the limbs are erect or nearly so, the healing is quicker than on horizontal 
or nearly horizontal limbs. Contrary to popular belief that it is not wise to prune limbs that are frozen solid, experiments have shown that the mere frozen condition has no influence except,perhaps, as noted by Lewis (159). As a summary of all the experiments as to season of pruning, it may be said that the best time to prune is during the six or eight weeks that precede the resumption of growth in spring.

124. How to remove large limbs.-Next to making a wound in the correct position is the importance of making the surface smooth; for a smooth surface will not favor the development of fungi and bacteria to the same extent as will a rough or splintered surface. It is folly to remove a large limb with one cut, even if that cut is made in the ideal position. The leverage of the limb will surely split, splinter or tear the trunk more or less seriously (Figs. 89,92). Safety lies in making three cuts, the first on the lower side of the limb and at a distance of a foot or more from the main trunk, the second on the upper or opposite side of the limb and close to the first cut (Fig. 90 ), the third close to the trunk where the final wound is to be (Figs. 91, 93). In making the first cut it will not be long ere the saw will bind or stick. When this occurs the second cut is started. Often before the second cut reaches the first the limb will fall, leaving a stub which can be easily removed at the proper point when the third cut is made close to the trunk. 


\section{CHAPTER VII}

\section{PREVENTION AND REPAIR OF MECHANICAL INJURIES}

125. Kinds of injuries.-Casual observation will show that trees suffer from many kinds of mechanical injuries. Storms, particularly of sleet (Fig. 94) and those which arrive while the trees are loaded with fruit, cause serious breakage of branches, but such injuries usually resolve themselves into cases of a simple pruning. The injuries here to be considered are those mainly due to the ignorance or the carelessness of the planter or to animals, such

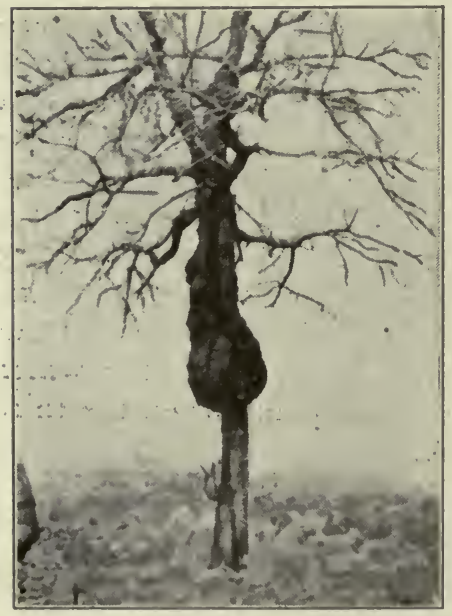

FIG. 96-A WIRE GIRDLED THIS CHERRY TREE as hogs, rabbits, mice and hired men. Many of these injuries may be easily prevented and cured. Several typical cases will be considered here. The reader may also refer to the chapter on tree surgery for the treatment of a different class of injuries.

126. Label wire injuries are very common (Figs. 95, $96)$, so are those caused by tying trees too tightly to stakes and by fastening guy wires and ropes around trunks and branches (Fig. 313). The effect is the same in all cases. Wire fences often injure tree trunks more or less when fastened to them (Fig. 309 C), but usually such injuries extend only part way around the trunks. Instances are recorded where the growth of such 
trees as poplar has extended over even board fences fastened to them. Figure 97 shows an oak tree which has grown around the end of a bench at Hunter's Park, Pennsylvania.* Label wire injuries are always due to carelessness or ignorance. At planting time the wire is left encircling the trunk of the newly set tree. Because it is loose it looks harmless, but when the $\mathrm{tree}$ grows it soon begins to cut the trunk and to check the flow of elaborated sap from the leaves downward. Copper wire, the kind usually employed by nurserymen, is especially pernicious because it lasts much longer than does iron or string. When the wire is on the main trunk its injury may be so severe as to kill the tree; when on a branch, it may cause an abnormal development (Fig. 95). Generally the trunk

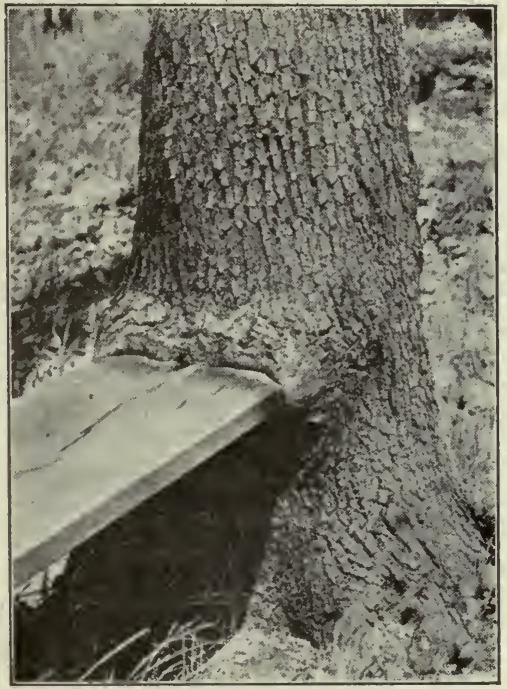

FIG. 97

BENCH SUPPORTED BY LIVING TREE

Originally there were upright supports beneath the bench, but these have rotted. aw ay. The board, not being in contact with. the soil and being quickly dried after rains, continued sound and rigid. The bark therefore grew around the end as seen. The tree at the other end of this bench shows similar. growth, and on its opposite side shows where. another board was similarly buried but has been destroyed by fire, leaving a slot 4 inches deep where the bench originally met the trunk. becomes larger above than below the girdle (Fig. 96):

Label wire and other girdles are not necessarily fatal to the trees so injured (Fig. 96). As long as the sap,

* A similar case is pictured in Popular Mechanics, March, 1916. In this case the trees grew around the boards of a fence. 
continues to flow upward there is a chance that the parts of the stem above and below the girdle will unite and form new conduits for elaborated food to reach the parts below the girdle, especially the roots. The season when the injury occurs has much to do with the healing.

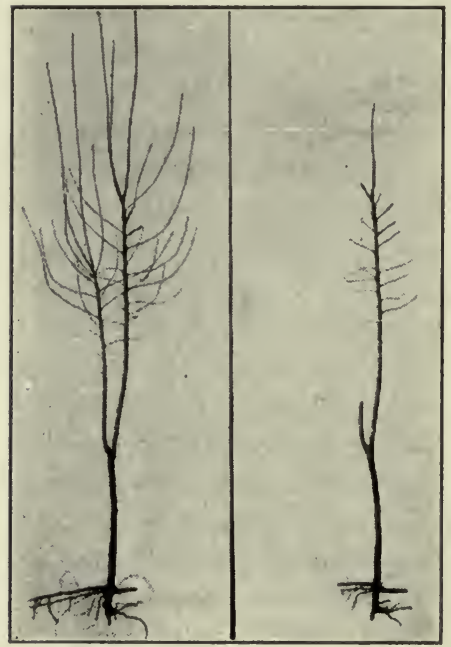

FIG. 98-HOW TO HANDLE YOUNG FORKED TREE

When limbs occur below the natural head they should be cut of as close to the trunk as possible, unless they are so large that the cut will make dan. gerous wound. Then they should be shortened to few inches to prevent their making much growth and the stubs removed the following season. In this case the branch cut to a stub would have formed $\mathbf{Y}$-crotch. Had there been no good head above, the cutting back would have allowed new limb to form. (See text.)

union (Fig. 98). As the leverage increases and the decay descends farther into the trunk the union becomes so weak that one or both the branches will break and thus ruin the tree. Nursery and other young trees with Y- 
crotches may be treated in three ways to prevent splitting. (a) One of the branches may be completely cut off at planting time or while still small. Doubtless this is generally the safest and most satisfactory method because it disposes at once of all possibility of breakage. (b) One of the branches, the smaller usually preferred, may be cut back severely so as to make it develop into a side branch rather than into a leader. Often this is an effective plan, especially if the pruning be such as to spread the tree and make the side branch less erect than it would be as a leader. (c) The third method applies or should apply only when the $\mathrm{Y}$-crotch has not been treated as above suggested, but has been allowed to grow for a year to, say, perhaps, ten years. A brace of living wood may be developed between the two arms of the $\mathrm{Y}$ so as to form, when finished, an inverted capital letter A.

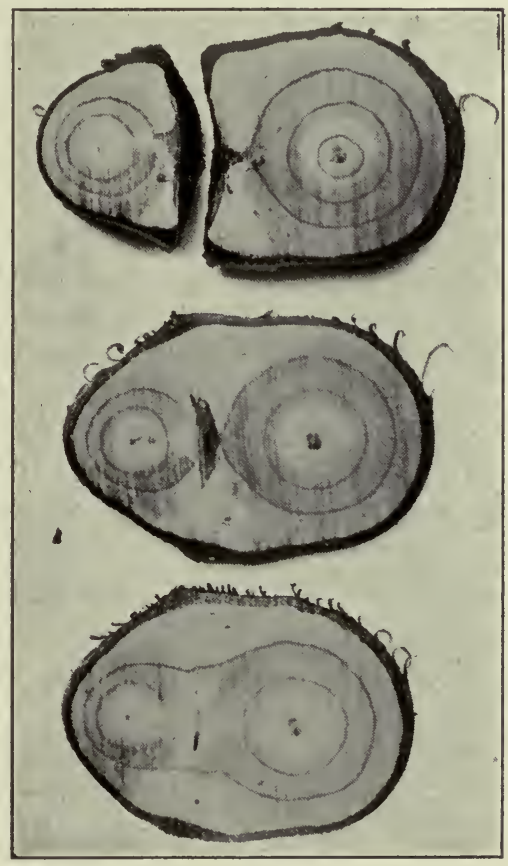

FIG. 99-HISTORY OF A CROTCH SPLIT

These sections of a black cherry limb show the progress of decay downward between the branch and the main trunk. In the top section the decay has progressed to the extent of separating the two parts-not so much as shown, but with a distinct cleavage. The middle and lower sections show the decay working downward at the discolored spot on each.

Usually the best way to secure such a brace is by twining together two living branches produced by opposite arms of the Y. Preferably each branch should be 


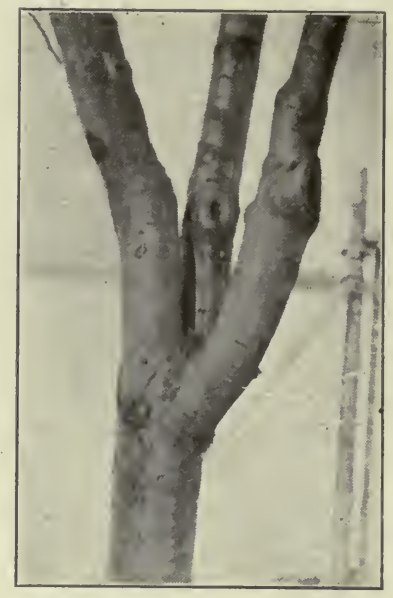

FIG. 100-TRIPLE Y-CROTCH

This badly neglected tree is triply weak because of the three $Y$-crotches. It is doomed. Several large branches have been cut off. Two scars show.

by natural graftage. As soon as the graft union is complete the tips of the branches may be shortened little by little annually and finally cut off close to the arms of the $Y$. It is advisable to leave as many leafy twigs as possible on the intertwined branches, but to remove these little by little in spring. beginning with the largest, as the union of the two branches becomes stronger. The finished brace will more or less resemble the one shown in Figure 104.

When only one branch can be secured to form the brace, it may be grafted to the opposite arm. The branch selecteci should be well ripened when used. This grafting

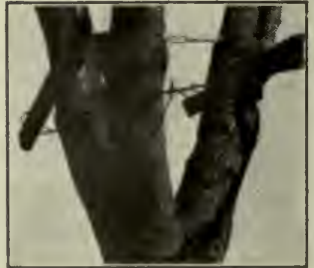

FIG. 101

SAVING A Y-CROTCH

Pine $2 \times 4$-inch scantling with telegraph wire is here used. This is better than wire alone, but is not very effective because there is too much "give." The limbs should be bolted together higher up. 
is of the simplest nature. In spring the cambium on both branch and arm may be exposed by a small cut on each. The two cut surfaces may then be brought in close contact, fastened so firmly that there will be no motion, and then covered with grafting wax.

Each year the binding rope should be loosened to prevent girdling of the arm. Probably in three to five years the union will be complete and the tip of the branch may be cut off close to the arm. A modification of this method, applicable to $\mathrm{Y}$ arms of rather large diameter, is to bore

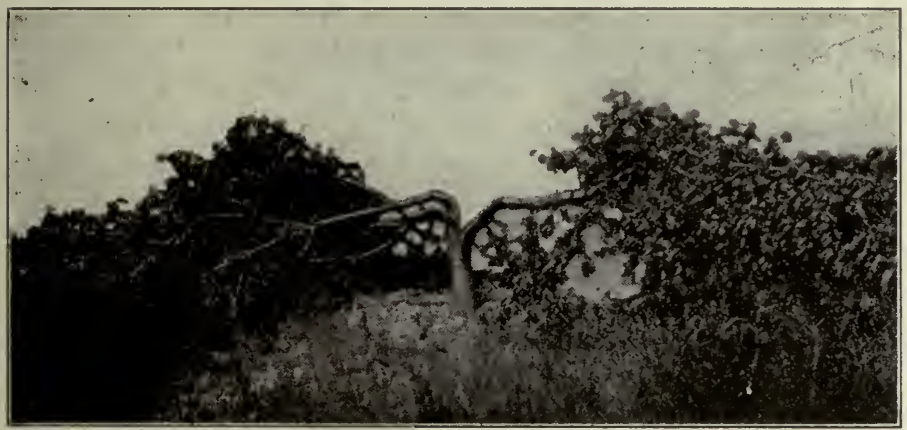

FIG. 102-SPLITTING OF PEACH TREE WHERE THE TOP WAS IMPROPERLY FORMED WITH A Y-CROTCH

a hole through one arm for the branch from the other arm to pass through and beyond. Tying and waxing as above recommended are advisable in this case also.

127a. Grafting wax.*_"The resin and beeswax waxes are all started alike; the materials previously made into small lumps may all be placed in the pot together, but preferably the resin is melted over a very gentle fire first and the other ingredients added. Boiling must be avoided. After stirring to make uniform, the melted mixture is poured into a tub of cold water and flattened out so it will cool evenly. When cool enough to handle, it is

- Kains, Plant Propagation, Greenhouse and Nursery Practice, Page 222, 
kneaded and pulled till the color resembles molasses taffy. To prevent its sticking to the skin, the hands are kept greasy. Should lumps occur (because of improper handling), it may be re-melted and re-cooked. Usually the wax is made into balls or sticks for convenient use. It will keep indefinitely. Linseed oil for making grafting waxes must be free from adulterations such as cottonseed

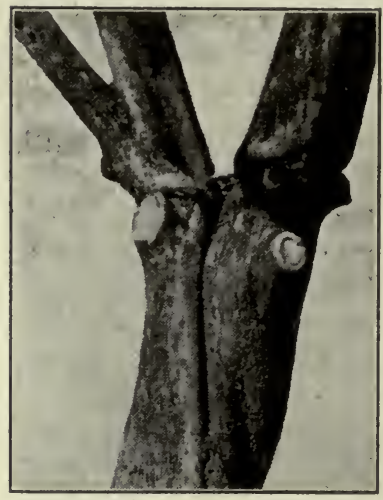

FIG. 103-ONE WRONG WAY TO MEND Y-CROTCH

The $Y$ split because of overload of fruit, but the owner brought it back to place with tackles and put a chain around the arms. Growth is burying the chain. Notice the attempts of the tree to heal the wounds made by the cutting of limbs. The interior of the trunk is decayed badly because of wrong methods of cutting branches. oil." Favorite formulæ are as follows: Resin 3 pounds, beeswax 3 pounds, tallow 2 pounds; a cheaper wax: Resin 4 pounds, beeswax 2, tallow 1 ; resin 4 , beeswax 2 , linseed oil 1 pintincrease oil for softness; resin 6 , beeswax 2 , linseed oil 1 pint.

128. Bridge or repair grafting,* sometimes erroneously called inarching, may be the means of saving valuable trees which have been injured by mice, rabbits, hogs, human carelessness or accident.

Unless the girdle has cut through the sap-wood it is an error to say that bridge grafting is necessary to establish connection between root and top, for the upward current of sap passes through the sapwood and not through the bark. It is correct, however, to say that the bridge establishes a connection between top and root. for the downward flow of elaborated sap is through the bark layers. As soon as the wound is discovered the operation should be performed. If the injury occurs in winter the wound should be protected to prevent drying.

\footnotetext{
"Quoted from the author's book, Plant Propagation, Greenhouse and Nursery Practice.
} 
In spring when the buds begin to swell the grafting should be done. The operation is performed as follows:

The injured, and perhaps dry bark, on both upper and lower edges of the wound is pared back to living tissue. Several cions are cut long enough to extend a little be-

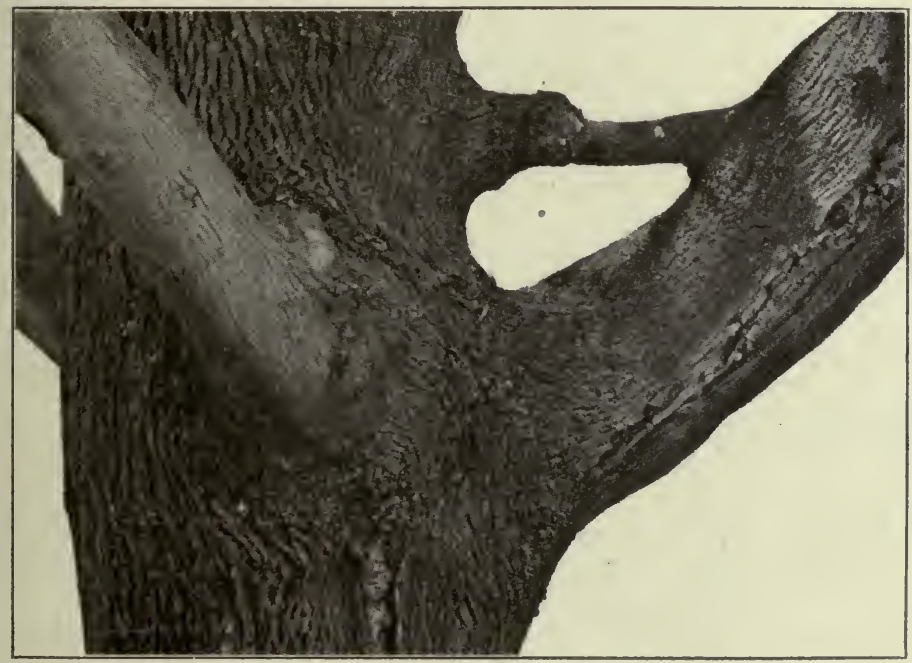

FIG. 104-LIVING WOOD BRACE BETWEEN TRUNK AND LIMB OF NORWAY MAPLE. SHOULD HAVE BEEN MADE HIGHER UP TO BE STRONGER

yond these trimmed edges, and inserted beneath the bark both above and below, thus making little "bridges" across the gap. The ends of the cion are cut obliquely, to insure fitting of the cambium layers of cions and trunk. It is often a help to bow the cions outward slightly, because the spring thus formed aids in holding them in place. But these and other minor details may be left to individual preference. If placed an inch or so apart around the trunk, enough cions should succeed to save the tree. Both wound and cions should be completely covered with grafting wax, preferably made warm so as 
to fit into every chink and thus exclude air and water. In a few years the cions will grow together and in time lose their identity in a smooth trunk.

Bridge grafting is a makeshift method not to be compared with proper protection of trunks by keeping animals out of the orchard, by avoiding accumulation of grass, straw, etc., in which mice might form nests, and by using trunk protectors-splints, tarred or building

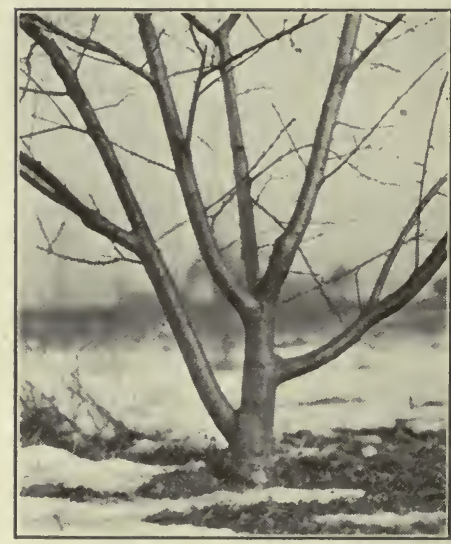

FIG. 105-WELL-BRANCHED LUWHEADED PEACH

No danger of splitting from even paper, but preferably halfinch galvanized hardware cloth - around the trunks until the trees have developed rough bark. Sucl methods will prevent the necessity of bridge grafting except in cases of unusual accident.

When the girdles are narrow-say only one to three inches - no bridging may be necessary. In such cases, however, it is well to err on the safe side by covering the wound with grafting clay (half clay and fresh cow manure) and bandaging this in with cotton cloth, or by using grafting wax. Often such wounds will heal over in a single season.

129. Pruning tools of many styles are upon the market, but many of them are of small utility and some worse than useless, positively harmful. Of course the tool equipment will vary with the man and with the type of work to be done. In general, however, the kit will consist of a knife, a pair of hand shears and two or three different types and sizes of saws. If there is to be much heading back of side branches out of hand reach a pole pruner (Figs. 106 to 108) may be added, and for removing dead 


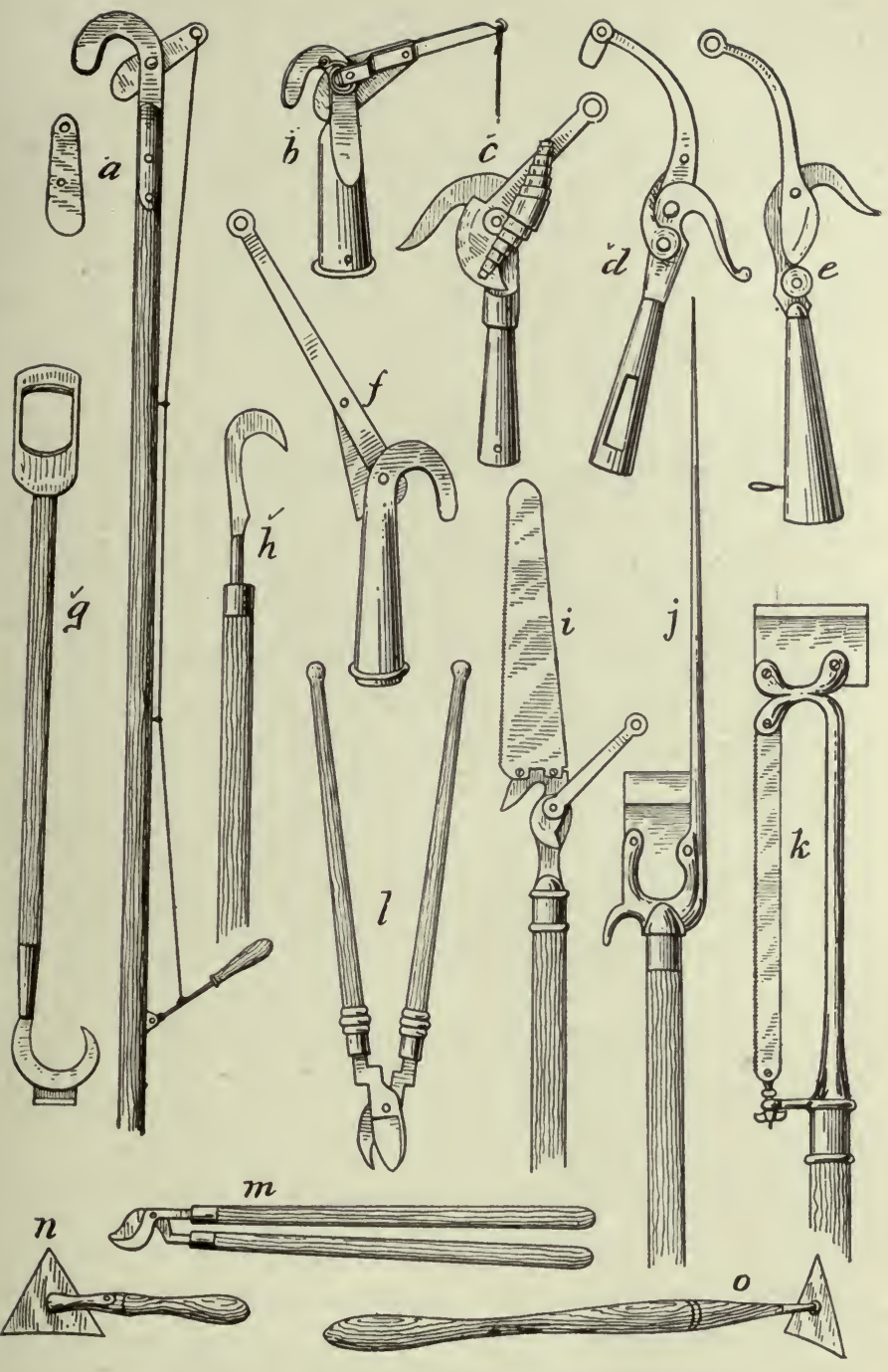

FIG. 106-MISCELLANEOUS PRUNING TOOLS

$a$, Waters' tree pruner; $b$, stronger pattern; $c, d, e$ and $f$ four styles of branch loppers-all clumsy; $g$, pruning spud and hook for brambles; $h$, raspberry hook; $i$, combined saw and lopper; $i$, pole chisel; $k$, combined saw and chisel; $l, m$, lopping shears; $n$ and $o$, trunk scrapers. 
blackberry canes from the stools a hook pruner also (Fig. $106 h$ ). Even the best pole pruner does poor work except, perhaps, in heading-in, and then the work itself is inferior to that done by the shears, the knife and the saw, but these cannot be used without taking too much time to reach the parts to be removed. The pole pruner simply cannot be constructed or used so as to make a cut properly.

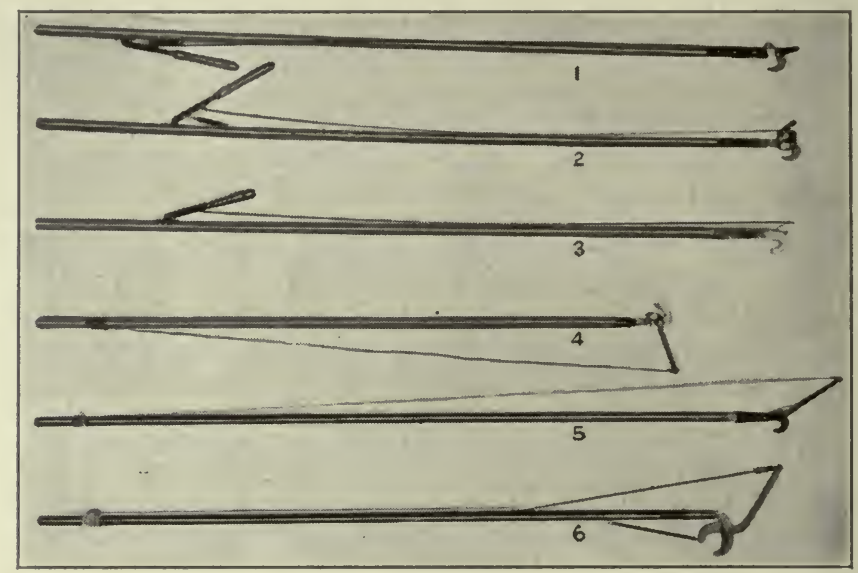

FIG. 107-POLE SHEARS FOR OUTSIDE BRANCH PRUNING

No. 1. Good shear, simple, strong. The most satisfactory pole shear. Inex. pensive. No. 2. Double lever in shear. No better than No. 1. Has more parts to get out of order. No. 3. Old type of "Waters"" shear. Double guard prevents close cutting, leaves a bruise and often becomes choked with wood and bark. No. 4. Good shear, but the long arm is clumsy. A very good shear to transport because the pole is detachable. No. 5. Objectionable double guard and clumsy arm. No. 6. Very awkward and clumsy. Inefficient and much too expensive.

Next to the pole pruner the knife will be used least of the general equipment because the shears are quicker, yet it cannot be dispensed with, because, for certain work, such as pruning side shoots off young tree trunks, nothing will take its place. The pruning knife should be stout, the blade made of the best steel and kept always very sharp. For this reason the style which permits the re- 
moval and replacement of blades in the one handle offers special advantage where a large amount of pruning must be done. It saves time going to and from the tool house and investment in knives. Fig. 112 shows popular styles of pruning knives.

Pruning shears will be used a hundred times where the tree pruner is used once, and at least a score of times

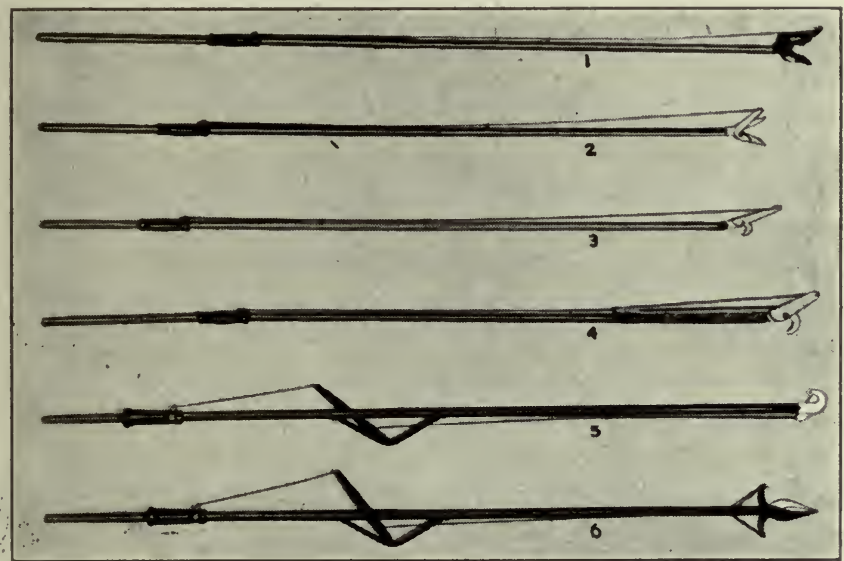

FIG. 108-POLE SHEAR PRUNERS, SLIDING HANDLE TYPE

Nos. 1 and 2. Reverse or U-type. Not as handy in use as common hook type. No. 3. Satisfactory light type. No. 4. Powerfully made and cuts fairly well, but the head is extremely heavy. Undesirable. No. 5. Objectionable double guard style. Pole seriously weakened by the peculiar lever device. No. 6. Double shear type devised for light work. Pole weakened by peculiar lever device.

to the knife. It is of especial use in pruning trees up to the age of five or six years for the removal of branches up to say half an inch in diameter. Many makes are for sale, some of them excellent. Points to bear in mind when choosing a pair are to have first-class steel in the blade, because a keen edge is necessary to do good work and prevent injury to the parts to be left on the plant. Next, the shears should be free working, with a good spring to open them promptly after making a cut. The 
style of spring is a matter of preference. The author likes the style shown in Fig. $109 a$, because it is less likely to become caught: in branches than are the styles shown in $b$ and $c$. For general orchard work the shears should be rather heavy, with a handle long enough in proportion to the length of the blade to give plenty of power when cutting fairly large branches. A 10-inch size is

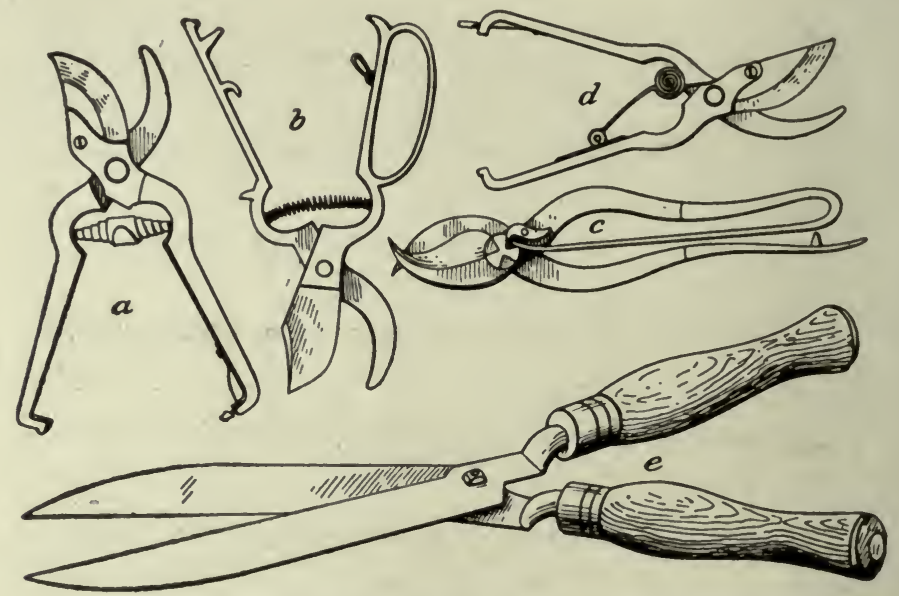

FIG, 109-PRUNING SHEARS OF VARIOUS STYLES

$a$, Author's preference because spring is strong, small and not likely to be fouled with twigs; $b$, undesirable form of spring because, unless very stiff likely to be pulled loose by, twigs caught in it; handle also poorly adapted to hand; $c$, parrot's beak (see Fig. 110), spring not very good form; $d$, French style, author's second choice, but preferred by many fruit growers; $e$, hedge trimmers, ordinary style. An improvement is the hollowing of the blade near the hinge so as to hold large limbs and prevent slipping. More costly, but decidedly better.

about right for general orchard work; a smaller one for cutting twigs and berry bushes. Double-handed shears have their special uses in removing larger branches than could be cut easily with the single-hand shears. Unless kept very sharp they are likely to do injury to the parts left. Therefore, the saw should be preferred to them wherever it can be used.

130. Pruning saws (Figs. 111,115 to 117 ) are by no means 


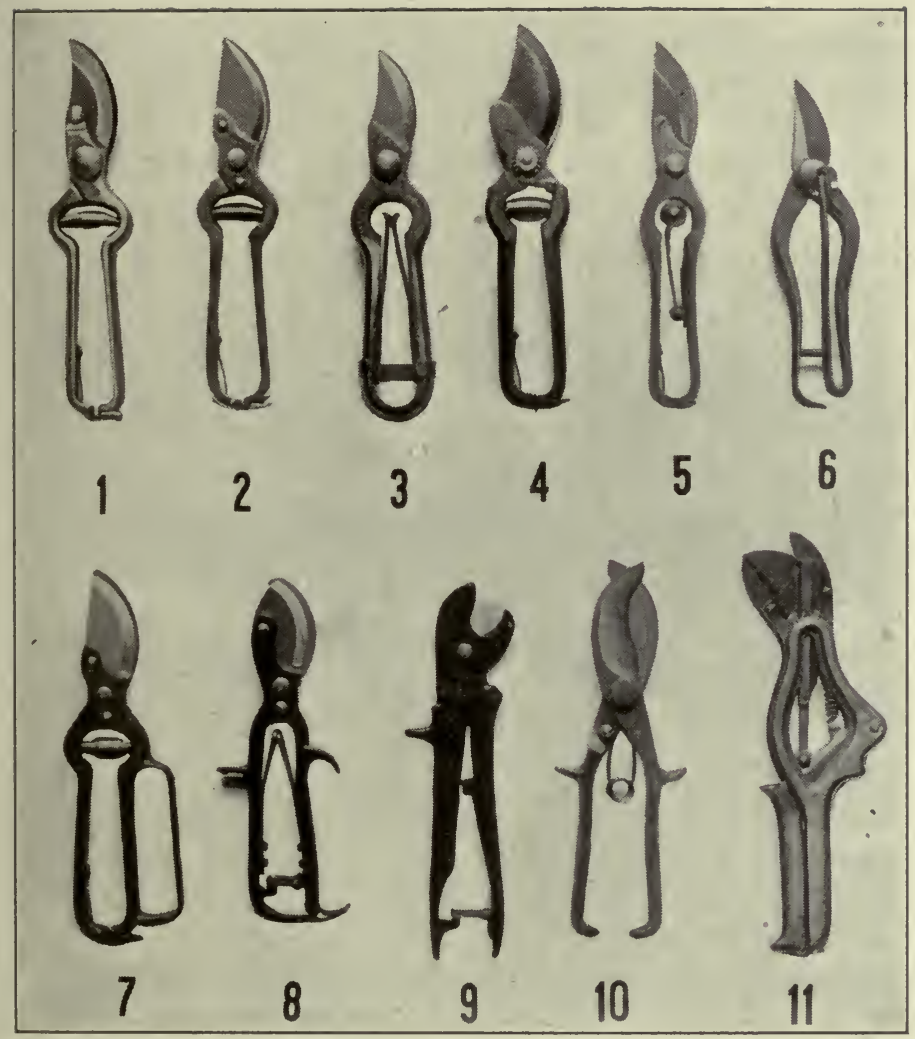

FIG. 110-GOOD, BAD AND INDIFFERENT HAND SHEARS.

The shears in the upper row are simply and durably constructed and are efficient in operation. Note the sharp-pointed blades. The good grip secured by smooth handles makes it possible to turn these in the hand very easily. Turning secures the best cuts by keeping the blade always close in with the guard on the outside of the cut. Numbers 5 and 6 are light shears for use with small fruits or grapes. The shears in the lower row present several kinds of objectionable features, and most of them are poorly made. No. 7 has a loop handle which prevents turning. Nos, 8,9 and 10 have knobs on the handles. They invariably produce blisters and may prevent turning for proper use. No. 8 has too blunt a point. No. 9 has an objectionable double guard and a poor point. No. 10 opens too wide and has a very poor point. No. 11 is a freak device of no value except as a curiosity. 
perfect; indeed the majority on the market do too inferior work to deserve the name. Most conspicuous among these is the double-cdge abomination (Fig. 111) pictured in seedsmen's and nurserymen's catalogs. It not only cuts the trees where it should not, but cuts the man who uses it the least bit carelessly. Experienced pruners shun it.

Several styles and sizes of saws are needed because of the varicty of work to be done. For heaiy work, such
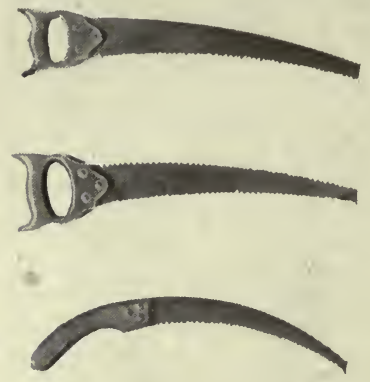

FIG. 111

COMMON PRUNING SAWS

The uppermost saw differs from an ordinary pruning saw only in having a slightly curved blade. The handle is too small for the gloved hand. So is the $r$ andle in No. 2, which is a very objectionable type of saw because of its double-edged blade. The lowest tool is popular in California for cutting grapevines that are to be grafted near the surface of the ground. On it the teeth are set for a draw cut. as orchard renovation, the blade should be 24 to 27 inches long. 5 to 6 inches wide at the base. about 1 inch wide at the small end and have five or six teeth of ordinary form to the inch. The ordinary tooth will give better satisfaction than the "lumberman's tooth" often on the double-edged saw (Fig. 111). For lighter work, such as that on trees well handled from the start, a lighter, smaller saw is needed. One with a blade 21 to 24 inches long, 4 inches wide at the handle, 1 inch at the tip and with $5,5 \frac{1}{2}$ or 6 ordinary teeth to the inch will be found very satisfactory. For smaller branches a still smaller, thinner saw will do excellent work. One 15 inches long, 3 wide at the base, tapering to a point and carrying $6,61 / 2$ or 7 ordinary teeth to the inch is about right. A curved saw with teeth pointing toward the handle is often of special use in making draw cuts. Its length may be about 1i) inches, its width at the point 1 inch and at the handle 2 or $2 \frac{1}{2} 2$ inches. In California it is largely used in sawing old grapevines for grafting. 
A modification of the butcher's saw, with swivels that permit the very thin, narrow, fine-toothed blade being set on the bias, is particularly good for small branches and twigs, because the heavy bow gives weight to the light blade, which makes clean cuts at any angle desired. This is the type of saw the author specially likes for the work it is capable of doing.

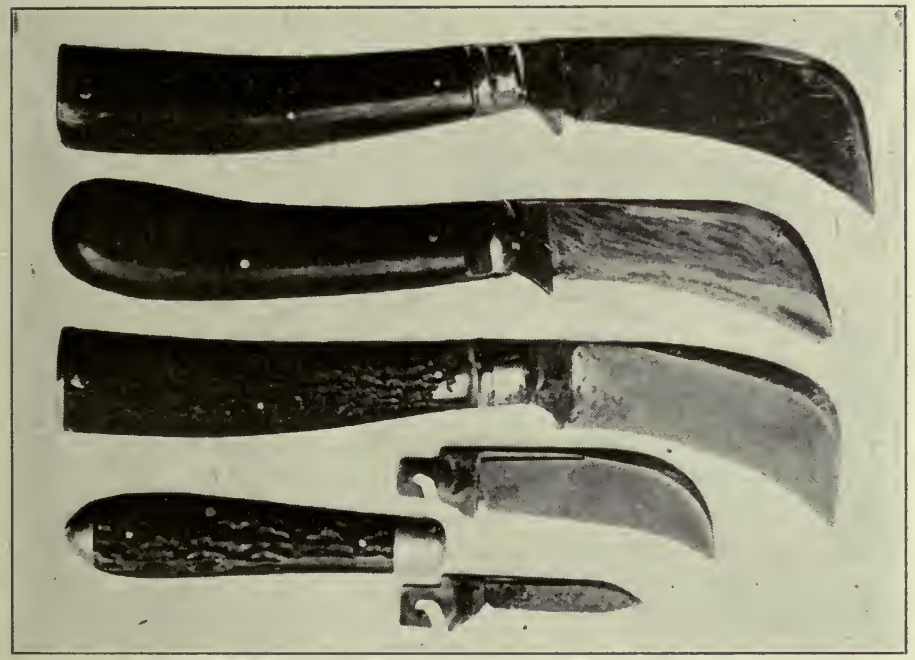

FIG. 112-PRUNING KNIVES OF VARIOUS STYLES

The three upper ones differ little except in the shape of the handle. The bottom one is a Nagle Re-blade knife in which the blades are replaceable. This is a convenient style because an assortment of blades may be kept for changing from dull to sharp ones, or to different forms. The blades readily slip into the handle when in the nearly closed position.

In Fig. 117 is shown a set of saws designed for student use. The interchangeable blades permit a variety of demonstration work. In practice, however, the author and his experienced students did not like this particular design. The blades are too light, and the grip part of the handle too small for any but small-sized hands. 


\section{CHAPTER VIII}

\section{DRESSINGS FOR WOUNDS}

Many things have been recommended for protecting wounds. Poultices of fresh cow manure mixed with clay were lauded by fruit growers 50 years or more ago ; grafting wax and paint during the past 50 years; creosote and tar by some fruit growers and foresters of the present day. While the manure method is nowadays rarely used, the paints and the grafting wax are doubtless most popular, but objections are raised to them because of their expense and their faulty protection.
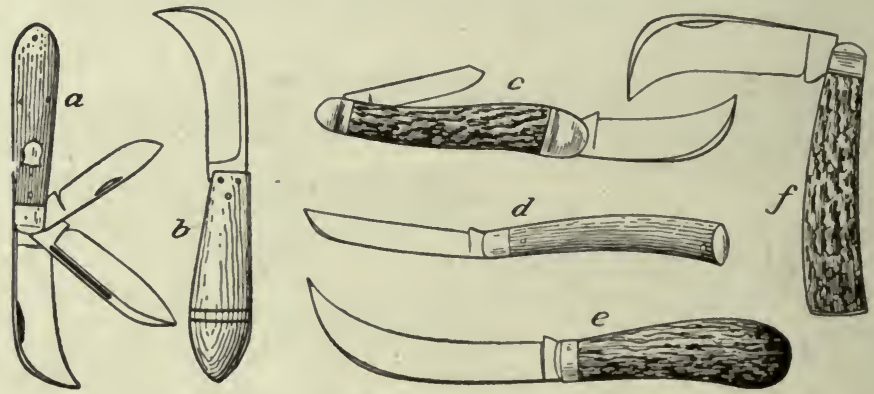

FIG. 113 - COLLECTION OF PRUNING KNIVES

$a$, Combination of pruning, general and budding blades; $b$, stationary pruning blade; $c$, pocket pruning and penknife; $d$, pruner for herbaceous and other small growths; $e$, hawk-bill knife; $f$, popular style of pruning knife.

In an old orchard the author found a slab of paint (!) made by the coats of several years' painting. It was a quarter of an inch thick, had a little rotten wood clinging to its under side. Beneath this "protection" the heart wood of the 6 or 8 -inch branch wound it had covered was so decayed that quantities of it could be pulled out by hand with almost no effort. Such cases should condemn painting. 


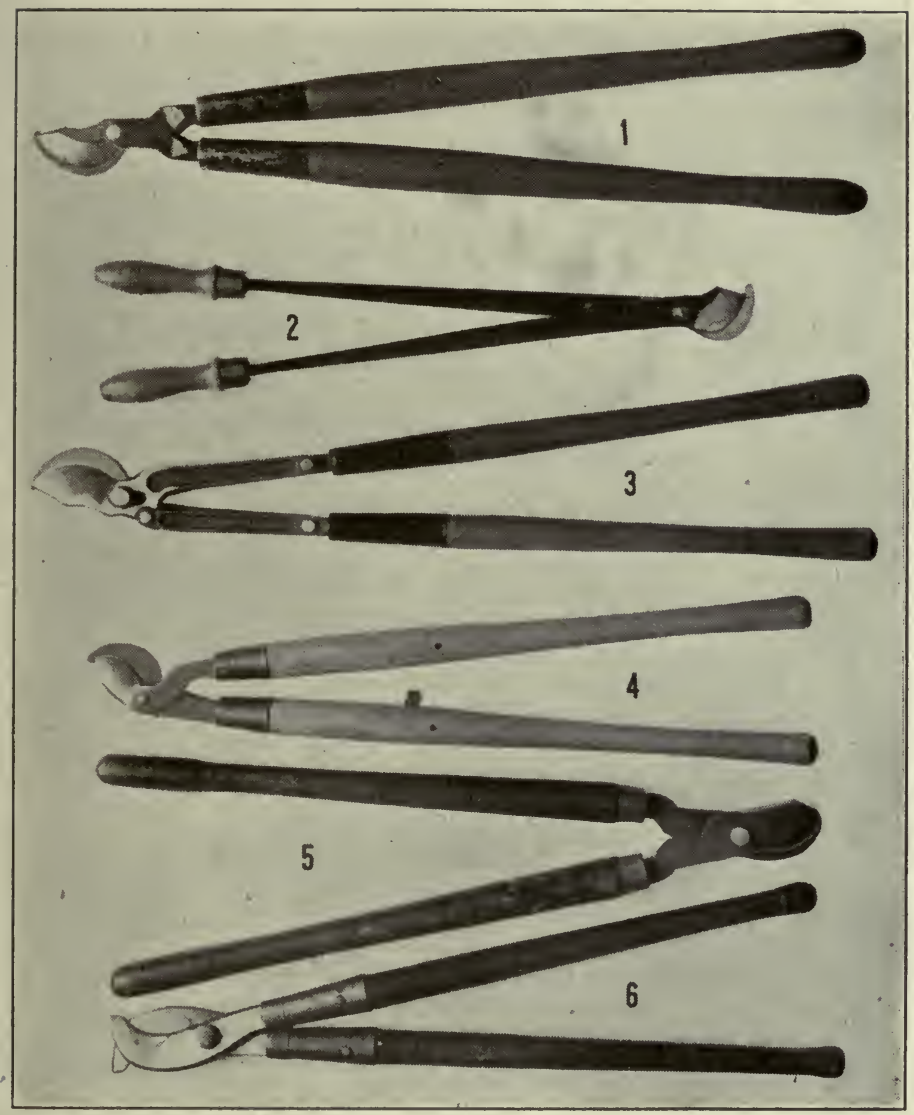

FIG. 114-PRINCIPAL STYLES OF DOUBLE-HANDLED LOPPING SHEARS

No. 1. A strong, well-made shear of simple construction and moderate cost. The bolt has a lock nut to allow for adjustment. Desirable type. No. 2. Strong, well made, light weight shear of moderate cost. If provided with a. bolt and a lock nut instead of a rivet it would be as good as No. 1. No. 3. A very powerful wellmade shear, but does not show desirable simplicity of construction. Cos's more than the average. No. 4. Fairly good and inexpensive. The blade has a blunt, rounded bevel which is not as good as on those above. A stop must also be provided to save the pruner's knuckles. No. 5. Powerful shear of English make. Has a rivet instead of a bolt and a lock nut and costs more than the average. No. 6 . The "double cut" type of shear. Cannot be used in close quarters where pointed blades work easily. Has no locking device for the nut and the handles are weak. Not desirable. 
During the past decade much experimenting has been done by botanists, foresters, pomological investigators and others to determine the desirable and the undesirable dressings. Many experiments are as yet incomplete;

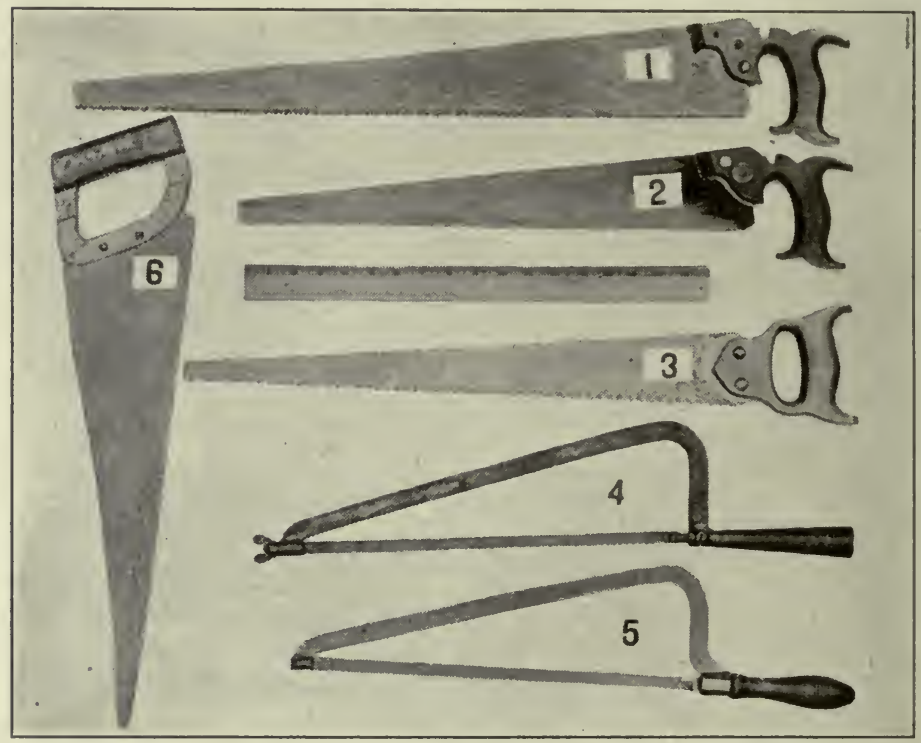

F1G. 115-GOOD, BAD AND INDIFFERENT PRUNING SAWS

No. 1. Long. heavy saw for large limbs. No. 2. General purpose saw. Both these styles are good. Compare lengths with the 18 -inch ruler. No. 3 is the "made to sell" saw with the "Iumberman's" tooth on one side and the ordinary tooth on the other. It is a dangerous weapon both to trees and operators. The best place for it is in a museum of torture implements. No. 4 is a pole saw with swivel blade. Where branches can't be reached easily it serves fairly well because the thin, small-toothed blade makes clean cuts. No. 5 differs from No. 4 only in the handle. It would be better with a handle similar to No. 1. No. 6 is a heavy affair with an iron handle. It is a mean thing to use on a cold day, because th: handle chills the hand in spite of the exercise of sawing.

some have been reported upon. In order to present all sides of such an important question the author has quoted freely from several of the already published writings. Hitherto the author has favored pure white lead in pure raw linseed oil, but this is too expensive as well as too risky. At present, the case appears to him in favor of 
.asphaltum, creosote, tar and carbolineum, as recommended by Selby $(132,135)$ and Cook (134).

Wherever a dressing is used it may be made less conspicuous by adding some pigment to change the color. For instance, white lead paint may be turned to a barkcolored gray with a little raw sienna, and cement may be similarly treated with asphaltum.

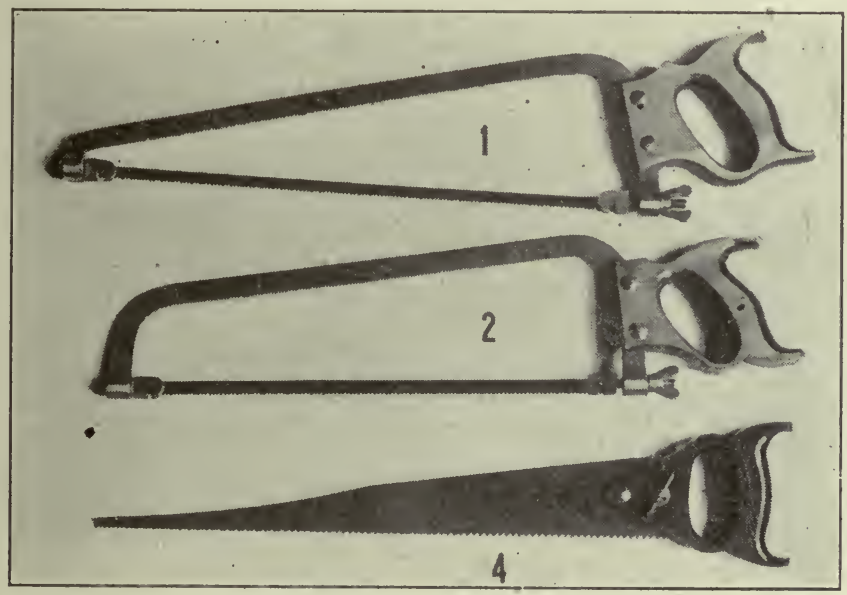

FIG. 116-TYPES OF HAND SAWS FOR TREE PRUNING

Nos. 1 and 2. Good examples of the swivel blade type. Good grips. Make good cuts in any position and are not expensive. This type once used is always used. No. 2 has loose pins in the blade. These are often lost when the tension is slackened. No. 4. Common type, with fine teeth toward the tapered point for fise in narrow quarters. The handle is small for the gloved hand. Does fairly good work and is inexpensive.

131. Experiments in wound healing.*-Experiments in wound healing were made in Nebraska with six treatments-liquicl grafting wax, shellac varnish, white lead paint, pine tar and coal tar and no treatment. "Wax is the only application which appears to possess any advantage in aiding the wound to heal, though most of them did not hinder the process. . . Those treated with shellac did not [in June] seem to have healed quite as well as those left untreated [but in September there seemed to be] a slight difference in favor of shellac over those untreated. Paint does not hinder the process

* Epitomized from Nebraska Bulletin 50, Page 8. 
of healing, and there is little evidence that it favors it, the slight variation being no more than would naturally occur between two sets of wounds treated in the same way. Those treated with pine tar seem not to have healed quite so well as those untreated, although the difference was not great. Coal tar, however, seems to have been a positive hindrance to the healing process, not one wound having been reported as healing extremely well, while the majority [healed] only fairly well."

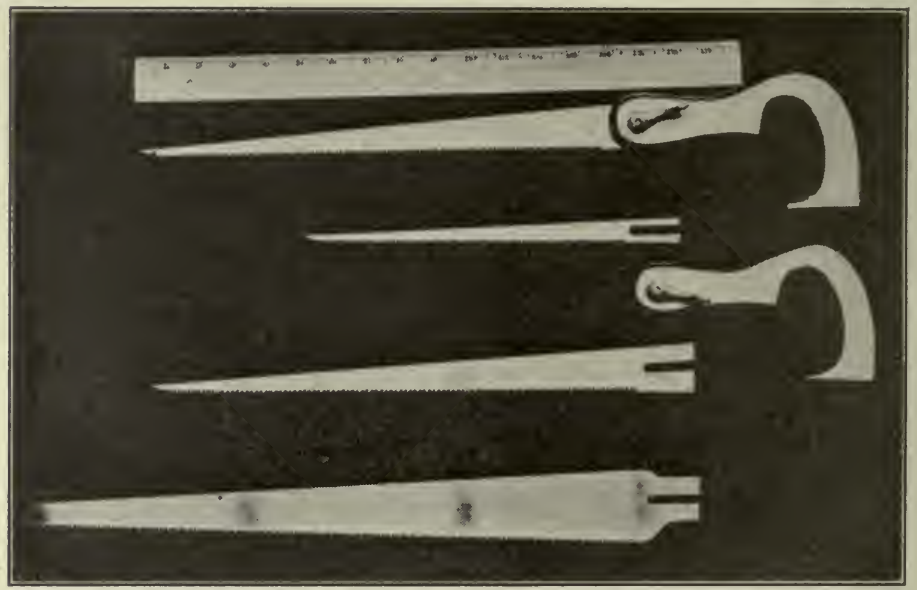

FIG. 117-STUDENTS' COMBINATION SAWS

The upper tool shows the saw complete. The lower blades with the handle make up the set.

132. Wound dressings.*-Experience has recently shown the practical value of gas tar and forms of liquid asphaltum as wound dressings. The relatively low cost of the gas tar, 15 to 20 cents a gallon, and certain of its qualities, render it adapted to use for wound dressings. This material is not without limitations. One of these is a certain difficulty in securing a continuous covering of sensible thickness with the gas tar. Apparently very good results are secured by using it in the semi-fluid or rather thick state, and this applies as well to forms of liquid asphaltum made with linsced oil, etc.

While at times, especially in cooler weather, it is desirable to heat the gas tar, imperfect covering is secured with the very fluid, hot tar. After cooling in part, a more favorable condition is reached. In general, it would seem that two applications give more desirable results. The second of these may be made after an interval of a

- A. D. Selby, Circular No. 150, Ot.io Agricultural Experiment Station. 
few weeks or even a year. This material is often referred to as coal tar. Certain forms of thin or very fluid character used for roof coverings and as metal paints are not well adapted for use as wound dressings.

In general, pruning wounds less than one and a half inches in diameter scarcely require a covering. There may be cases, however, where heavy pruning is practiced, in which more general treatment of the wounds is advisable. Solid asphaltum has not proved successful as a wound covering. It may be rendered fluid as detailed below (142).

133. Effect of various wound dressings.*-Fruit growers have long used paints, tars, waxes and other substances as coverings for wounds of trees. The following paragraphs report the efiects of

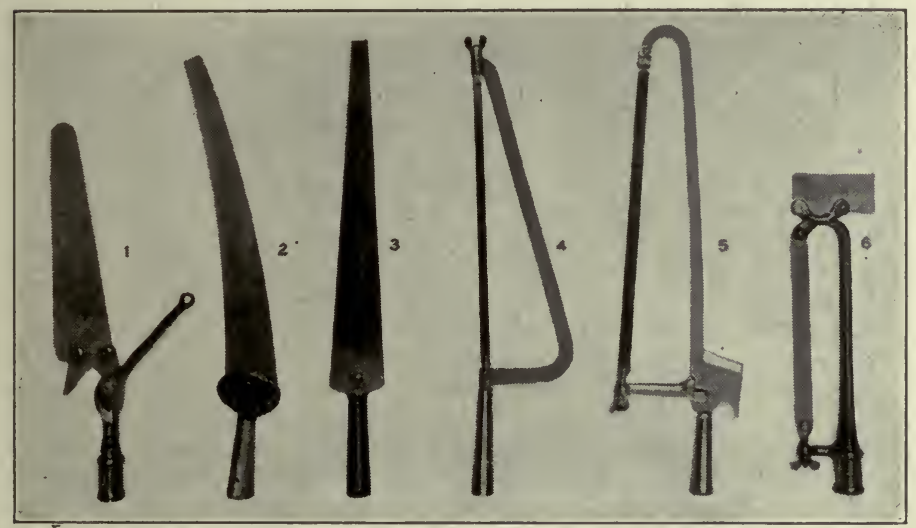

FIG. 118-POLE SAWS ARE ALL AWKWARD IN USE, MAKE RAGGED CUTS AND ARE UNDESIRABLE

Nos. 1,5 and 6 are freak devices. No. 2. Objectionable because double edged. No. 3. Single edge straight blade. No. 4. Swivel type, the best pole saw if one must be used.

white lead, white zinc, yellow ocher, coal tar, shellac and avenarius carbolineum on wounds made on apple and peach. The dressings of these materials were applied when the pruning was done at various seasons of the year and upon wounds of various ages.

In all cases undressed pruning wounds healed more rapidly than those whose surfaces were protected. Shellac seemed, the lirst season, to exert a stimulating influence upon the wounds, but the second season this effect disappeared. Of all the materials used shellac was least injurious. On the other hand it adheres to the wounded

* G. H. Howe's summary and conclusions, somewhat condensed from New York Agricultural Experiment Station Bulletin 396. 
surfaces least well of all. Avenarius carbolineum and yellow ocher caused so much injury that neither substance should ever be used (compare 134). Coal tar not only caused injury, but quickly disappeared, either through absorption or evaporation.

White lead and white zinc caused some injury at the time of application, but the wounded tissues recovered rather quickly, and at the close of the first season the injury was not very marked; at the close of the second season it had nearly disappeared. These two paints are the best of the protective substances used, and of the two, white lead is the better.

Nothing is to be gained in the treatment of wounds by waiting seieral weeks before applying any of the various dressings used in these experiments.

The treatment of peach tree wounds with any of the substances under experiment caused so much injury that it may be said that the wounds of the peach should never be treated with any of them, and it may be inferred that this is true of wounds on trees of all stone fruits. There is nothing to show in this experiment that it is worth while to treat large or small wounds of tree fruits with any of the substances in common use. Had there been a longer periocl of observation, it might have developed that the wood exposed in the larger wounds would have been somewhat saved from the decay which often sets in on exposed wood of fruit trees. It may prove to be worth while, therefore, to cover large wounds; in which casc white lead is undoubtedly the best dressing to use.

From the results of this experiment several deductions seem warranted. First, the dressings commonly applied to pruning wounds retard rather than accelerate the healing of the wounds. Second, the effects are the same whether the dressings are applied when the wounds are made or some weeks later when the cut surface has dried out. Third, the effects of the dressings used are so injurious to peach wood that wounds on peach trees should never be covered. Probably this statement holds true for other stone fruits as well. Fourth, these experiments suggest that the popular notion that wounds need to be covered with some dressing to preverit the entrance of fungi, in sprayed orchards at least, is usually exaggerated. It is doubtful if it is necessary to attempt to prevent decay by applications of dressings of the kinds under discussion in wonnds under 4 or 5 inches in diameter. It remains to be proved whether they have any real value in covering large wounds. It may be suspected that the injury caused by the dressing when applied to the wounds largely, if not wholly, offsets or even over-balances the protection offered, if there be such, against decay.

134. Painting tree wounds. -The statements quoted from the New York Experiment Station bulletin above, prompted Howard B. Cook to publish in the Country Gentleman* an article from which the following passages are condensed. Mr. Cook agrees that peach

* May 6, 1916, Page 988. 
wounds should not be painted because the trees are short-lived, quick-growing, quick to heal, and because large cuts are uncommon on them. He also agrees that wounds less than 2 inches in diameter on trees younger than thirty years need not be painted.

But, he writes, the experimenters state that when trees are sprayed yearly with a fungicide, it is doubtful whether any decay will derelop. If this proves true, it will be fine indeed. In the experiment. however, young, low trees were used, except for a couple of years' observation on older trees with a few 5 -inch wounds. With older trees having wounds open from seven to ten years or longer it is not at all certain that decay will be kept out by spraying alone, especially since larger trees are not so minutely covered in spraying. A thirty-year experiment to discover the effect of spraying on the decay of apple trees would eventually be of considerable value. The data in the bulletin are of great value, even though the conclusions drawn are too broad and unnecessary in view of the "way out" which will soon follow.

Armed with a hammer, a saw, and perhaps a chisel, go into an orchard of some fifty years' standing. Notice a wound not fully healed, but evidently daubed with paint some years ago. Rap this wound sharply with the hammer. A cave-in occurs; or instead the wound seems sound at the surface, but gives evidence of being a sort of bung to a decaying mass half an inch farther in. Pry out the bung and you will see. So much for paint as a preservative!

Now select a fair-sized perfectly healed wound and saw off the healed part or cap. You are very apt to discover a decayed wound or even a hollow limb. Therefore it is seen that we can have perfect healing over a decaying wound. Let us see how such a condition of affairs can affect the owner of an orchard. From an upward and outward swinging section of a tree are suspended four or five barrelfuls of apples. The limb looks sound - all wounds being nicely healed-and the owner ventures out upon it. Crack, snap, crash! So much for perfect healing!

These examples show there is just one reason why we must apply something to pruning wounds-that is, for the preservation of the wood. The most effective of preservatives must be used-either a carbolineum or a grade one creosote oil. The bulletin says we should never use these oils because they are the most injurious of paints in killing back the bark. But usually wl:ere there is a must, there is a may, if the problem is sufficiently studied. The solution of the problem I will presently come to. First, however, we must see what happens when our painting kills the bark: Under dead and dying bark borers start, and following them comes a whitish rot of the sap wood which also affects the heart wood or middle of the limb. This destroys the tensile strength of the wood to such an extent that in two or three years the limb is likely to break down under its fruit load (Fig. 82).

Now we come to a method of applying the liquid to preserve thoroughly both wood and bark in a healthy state. Since ordinary 
heartwood-destroying fungi, start in the center or pith and seldom if ever affect the true sap wood, always paint from the center of the wound outward. Instead of painting across the sap wood clear to the bark, the ordinary way, leave a circle absolutely bare arouncl the outside from $5 / 8$ of an inch to an inch in width. Remember that these oils will penetrate a little farther than you paint, especially at the base. So you must have a care about using a too heavilv charged brush. It is good practice to have a rag handy to swab away any surplus.

In using these oils, the addition of just enough coal tar to give them a dull black color after drying will overcome any tendency they may have to drying in or out, so that they at least appear to have partly faded away. The main reason for this appearance is that the oils have sunk deeply into soft, decaying spots, the result of the decay traveling from some hole through the pith of the parent limb to the wound affected. For best results in preserving wood, two coats are usually recommended. The second may be applied at any time a month after the first, but ordinarily some time after next year's pruning will be most feasible.

It is sometimes desired to stimulate quick healing. While the cut or a barked place anywhere is fresh, paint the edge of the bark and the sap wood only with liquid wax. This is made as follows: Best white-yellow will do-resin, one pound; beef tallow, one ounce. Melt together, remove from the fire and stir in eight ounces of alcohol. Keep and use from a wide-mouthed bottle tightly corked. Through a hole in the stopper, thrust a small brush for applying the solution. Perfect results have been secured by the use of this material.

135. Available antiseptic materials.*-According to A. D. Selby two steps in wound treatment may be found necessary in many cases, although in the average case of pruning to remove a branch with a healthy base only one may be essential. These steps are: (1) Sterilization of the wound surface per se. (2) The application of a dressing to protect from infection through the entrance of spores or bacteria.

(1). The sterilization consists in killing any possible spores or bacteria, etc., that may be upon the surface, by the use of a torch to cauterize the surface, or more easily by the application of an antiseptic or spore-destroying substance. Among these germicides are corrosive sublimate, gasoline, kerosene, carbolic acid, petroleum, copper sulphate solution, carbolineum, formaldehyde, etc. The availability of any of these processes will depend especially upon the effect on the living layer of the wounded surface. If the cambium is killed appreciably it will raise the question of possible injury.

Because of such possible injury only corrosive sublimate, copper sulphate and formaldehyde are apparently safe. Petroleum com-

* Paragraphs 135 to 142 have been excerpted and condensed from Circular 126 of the Ohio Agricultural Experiment Station. 
pounds, like gasoline, kerosene, etc., penetrate and destroy the living tissues. As to avenarius carbolineum, a proprietary substance, some doubt has been expressed. Because of its complete absorption by the wounded surface it offers many advantages. Upon dead surfaces, such as those from which decay has been removed, it is available, as are also carbolic acid and solutions of copper sulphate, corrosive sublimate, etc. Upon wounds made by the removal of malignant growths, such as crown gall, hairy-root or malignant blister cankers, an active antiseptic agent is required, and for such use it promises to be superior to copper sulphate or corrosive sublimate solutions.

(2). When effective dressings are applied to newly cut surfaces, especially if these dressings are of possible antiseptic value, the one operation of applying the dressing may be considered as relatively adequate to the demands.

136. Essential requirements of a wound dressing.-Wound dressings should be sufficiently fluid to be applied readily under spring pruning conditions-[fairly low temperatures]. They should form an impervious, non-cracking layer over the surface, even though large, since such a dressing will prevent the later drying out and checking of the wound. These two requirements are essentially antagonistic, since practically no covering within reasonable cost will form an impervious covering from a single application at ordinary temperatures. Whenever the covering is not secured by a single application serious danger through subsequent checks may occur and thus admit disease spores. This tendency to dry out limits the usefulness of paints and pastes, which look satisfactory when applied, but dry out hy nidsummer. Dressings should not be unreasonably costly, an ohjection to grafting wax, which, like paraffin is also objectionable because of separating freely from the wounded surface. Adhesiveness is a valuable property in a dressing because it prevents abrasion. Lastly, a dressing should not injure the growing tissues, though slight killing may not be as objectionable as imperfect covering.

137. Available materials for wound dressings.-Of the really available materials we have chiefly preparations of asphaltum and the residual tars from the distillation of wood (pitch), and from the manufacture of artificial gas, gas tar. The materials used in Europe under the name of "bitumen" are essentially forms of liquid asphaltum. The varnishes or proprietary preparations offered for: dressing wounds are essentially liquid asphaltum in some form. The fossil "gilsonite" of California is a hardened form of asphaltum. The western petroleums, which contain an asphaltum base, contrast with the Pennsylvania crude 'oil, which has a paraffin base. Another advantage of asphaltum and gas tar materials is low cost as compared with the very high cost of paints containing linseed oil. The low cost of naphtha or gasoline as a solvent is much in its favor, were the preparations without risk. 
138. Gas tar and pitch.-Gas tar is the residual tar obtained from coal used in gas making. This is produced in considerable quantities, and there being only a slight demand, it is sold at low prices, ranging from 6 to 12 cents a gallon, exclusive of package. Pitch is the pine tar derived from the distillation of nitch pine. Gas tar handled in warm weather is fluid and very tenacious, with a strong tendency to be completely absorbed by the wood. Upon this absorption it is not clear that it gives a sufficiently continuous covering over the wound to guard against subsequent openings.

139. Forms of solid asphaltum.-Besides the more or less impure Trinidad asphaltum, used largely in street paving, there are available various types of asphaltum, which are essentially pure and differ only in their melting points. All of these grades require heating in order to apply them.

For heating, we use a charcoal heating pot with tall bail of sufficient spread to swing freely above a 10 to 12 -quart galvanized bucket. This heater is provided with openings below and vent opening toward the top of the metal cylincler; also legs to keep free from the ground. In such a case it is better to melt the asphaltum upon some hotter fire, and merely to use the heating pot to maintain its temperature in the orchard. The gasoline torch type of heater may also be used and freely transported in the orchard. It will usually require special modifications to enable one to use a sufficiently large vessel for the asphaltum.

The asphaltum is carefully melted until thoroughly liquid, in which condition it is applied with a brush, preferably an old hearth broom, a thin coating being run over the surface beyond the edge of the living tissue. A second coating may be given after the first one becomes partly cooled. The thickness of the cuat should be determined by the surface, as thin upon smooth surfaces as will give complete covering. New hair brushes are usually destroyed in the highly heated asphaltum.

140. Advantages and disadvantages of solid asphaltum.-The advantages of solid asphaltum are most appreciated when one nust cover a rough splintered wound, for the cavities may be filled with the liquid. The disadvantages of heating are usually great. Under ordinary conditions it is not feasible to build a fire in the orchard, except in moist weather, since there is danger of igniting the dead grass. The troubles in maintaining liquid conditions are also considerable, since to apply it effectively in a thin coating this asphaltum must be kept hot and very fluid. Probably the most serious disadvantage is the tendency to crack off during winter. There is danger also, where the surface is not entirely dry, that the moisture will produce bubbles when the asphaltum is applied. This is dangerous. especially if bubbles crack and expose the surface below. Y'et, despite these disadvantages, for large wounds melted asphaltum offers a rather higher efficiency than anything else we have tried.

141. Liquid forms of asphaltum.- To make liquid asphaltum, use, say, 10 pcunds of solid asphaltum to 20 pounds of Varnolenc, a 
compound petroleum oil, containing more or less naphtha and costing about 20 cents a gallon. Melt the asphaltum in a kettle of several gallons capacity. When thoroughly melted withdraw the fire, then add the Varnolene and stir thoroughly until of uniform character. If desired, the vessel may be again heated and uniformity better assured. This gives suitable consistency for warm weather and is in the proportion of one part asphaltum to two parts Varnolene by weight. In the winter a preparation of one part asphaltum to $2 \frac{1}{2}$ parts Varnolene by weight may be desired. IVARNING-WHEN THE VARNOLENE IS ADDED TO THE HOT ASPHALTUM AN INFLAMMABLE GAS IGNITES, AFTER THE MANNER OF GASOLINE VAPOR.

This formula is for asphaltum having a melting point of $285^{\circ}$. With asphaltum with a melting point of $200^{\circ}$, the proportion of Varnolene may be reduced.

142. Linseed oil fluid asphaltum.-To make a fluid asphaltum from linseed oil, use one part of asphaltum to $13 / 4$ to 2 parts of linseed oil by weight. Heat the asphaltum until liquid, then add the linseed oil as per directions given above. The danger from the formation of inflammable gases is much less with the linseed oil than with the Varnolene, but cannot be entirely overlooked. [Linseed oil costs several times as much as Varnolene.]

These forms of liquid asphaltum may be prepared and packed in suitable cans for use at any time required. They should be put up in tins and soldered, since exposure to the air will make a slight difference in the consistency.

143. Asphaltum and sawdust filling for cavities.-The difficulties arising from using cement in filling cavities in orchard or shade trees are largely traceable to the rigid character of cement filling. The light color is at times likewise an objection to cement as a material for such filling; it also lacks adaptability for use in swaying branches. For these reasons and others, asphaltum and sawdust fillings, originated and tested by John Boddy, City Forester of Cleveland, Ohio, are recommended by A. D. Selby.* Dry sawdust of any variety and solid asphaltum, such as "Byerlyte" and that used for filling in brick pavements, are used according to the formulæ below. The details, briefly stated, are as follows; all material being designated by volume.

144. For cavities in swaying branches: -1 part asphaltum to 3 to 4 parts sawdust. Moisten tools in crucle oil.

145. For cavities in trunks:- 1 part asphaltum to 5 to 6 parts of sawdust. Moisten tools with crude oil. Stir sawdust into hot melted asphaltum until desired consistency is reached. Distribute sawdust, as added, evenly over surface of vessel to avoid boiling over. Apply in cavities while still hot. No joints or sheet paper separations are required as in cement fillings. If surfaces of fillings are irregular or lack uniformity of color, coat them with gas tar or liquid asphaltum.

* Circular 150, Ohio Agricultural Experiment Station. 
In the preparation of cavities to be filled with sawdust and asphaltum, as with cement, or to be rendered antiseptic without filling, it is recommended that the decayed parts be removed to sound wood. This involves removal of all soft and rotten material; somewhat deeper cutting away seems advisable in shade trees than in fruit trees. It is further recommended that the interior surfaces be rendered sterile by applications of corrosive sublimate, carbolineum or kerosene. It is not advisable to use creosote, because it is too penetrating for use next to living parts. The thoroughness with which the work of removal and disinfection is done will very largely determine the success of the fillings made.

In case of very large cavities filled with asphaltum-sawdust mixture, it may be desirable to use an outer screen of close wire netting or of poultry netting. In any case the outer line of the filling will be kept more uniform by some surface, as of oil-coated wood or metal, against which pressure is exerted as the filling is made. Finally, the irregular and general surface of the filling may be coated properly and successfully with gas tar or liquid asphaltum; either of these is a proper dressing for any border surfaces that may have been cut to secure contact with the filling.

It is to be noted that the solid asphaltum referred to in materials is that derived from the refining of petroleum with an asphaltum base. It can be stored and shipped in iron drums. In recent years it has been used for filling the interstices of street pavements, and for many other purposes. 


\section{PRUNING NURSERY STOCK*}

Digging stock destroys roots. Were it possible to dig such plants with all the root area intact and to place it where desired without loss of any of this area, there would be no check to growth. Hence every effort should be made in digging to approach this ideal as nearly as possible, for thus will success be greater. As already shown, roots extend far in each direction from the base of the stems, often farther than the spread of the branches on one side plus the length of the trunk. That is, a tree with a trunk 4 feet high and a spread of 3 feet on each side of the trunk would extend its roots usually at least 7 feet on each side, and thus cover a circular area fully $\mathbf{1 4}$ feet in diameter. Examples that prove this are locust and poplar, which often send up suckers farther away from the main trunk than thè height of the trunk plus the spread of the branches on one side.

This fact shows one reason why losses of newly set trees improperly transplanted are so great; so great a quantity of the most important roots-the feeding areais lost in ordinary digging that the trees can't recover. Such losses may, however, be prevented to a very large extent. In experimental practice they have been reduced to almost nothing. From what has been said (Chapter II) the reasons for reducing the top are evident. A word, however, must be said concerning the roots. As ordinarily dug and delivered by the nurseryman, they are more or less mangled, split, bruised or otherwise injured, for the most part unavoidably. If planted just as received they will grow, to be sure, but better results will be se-

* The trimming of young trees in the nursery rows is discussed in the author's book, Plant Propagation, Greenhoure and Nursery Practice, Page 279. 
cured if they are pruned. For this work nothing equals sharp pruning shears or a heavy sharp knife. Special emphasis is laid upon the "sharp," because the cleaner the cut the better. The work consists in cutting off all injured roots just above the wounds so as to have clean surfaces to develop good calluses and new roots (Fig. 119).

About two decades ago the horticultural world was much stirred by the Stringfellow or stub-root method, a

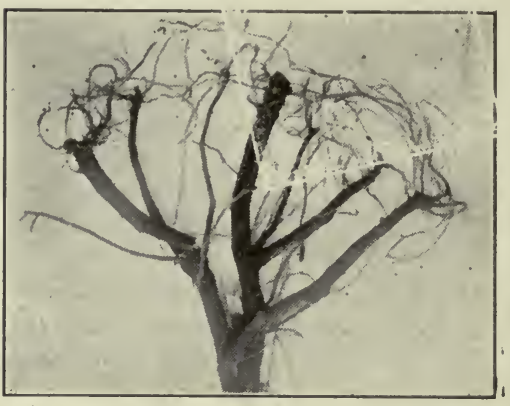

FIG. 119-WHERE NEW ROOTS START

The roots of this Kieffer pear tree were cut back at planting time. The following spring (a year later) the tree had developed new roots as shown. Note that most of them appear near the cut ends of the old roots. The injuries were caused by careless digging. Roots so injured should be cut back just above the wounds so as to leave clean, smooth surfaces which will heal over better and quicker than will ragged and badly dried tissues. "horticultural heresy," as to the trimming of nursery trees for transplanting.

The great apostle of this system, the late H. M. Stringfellow, a prominent horticulturist of Texas, advised that the roots of nursery trees be cut to mere stubs a few inches long and the tops to sticks or whips. In some c a s e s absolutely no stumps of roots were left below ground and none of limbs above, the "tree" when thus pruned sometimes being jammed into a hole made in the soil with a crowbar! One distinct advantage is thus gainedplanting requires a minimum of time! A modification of the method is to leave stubs of roots an inch to perhaps 4 inches long on the main root axis, and perhaps a few stubs of branches if specially well placed. Tests at a large number of experiment stations show that the method was sometimes an all-around advantage, sometimes the reverse. Doubtless the plan cannot be generally" recommended. At any rate it has fallen into "in- 
nocuous desuetude," and except as an interesting theory it is rarely discussed today.

146. Advantages of Stringfellow system.-The main points claimed by Mr. Stringfellow for the stub-root system of pruning are as follows: 1. The saving in hole dig-

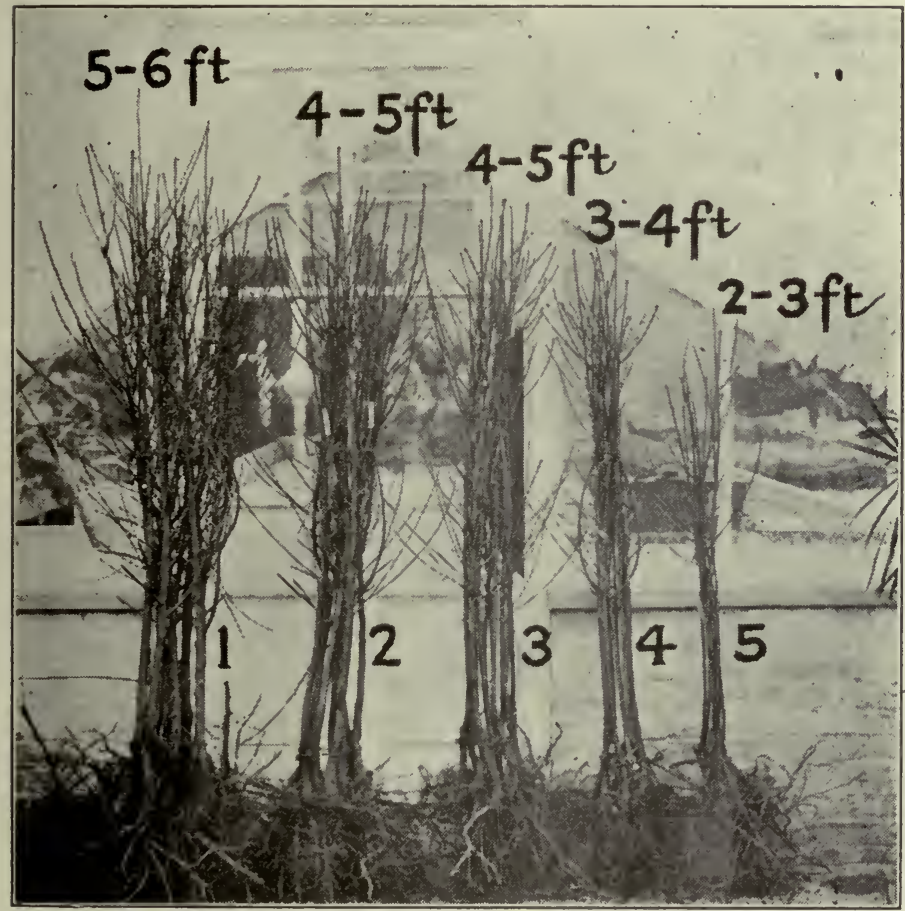

FIG. 120-VARIOUS GRADES OF PEACH TREES

Caliper (left to right) No. 1, 7/8 inch; No. 2, 3/4 inch; No. 3, 5/8 inch; No. $4,1 / 2$ inch; No. $5,3 / 8$ inch.

ging; 2, saving in freight to purchaser if trees are root and top pruned at the nursery; 3 , corresponding saving in charge for packing; 4 , saving to nurserymen in taking up trees for shipments; 5 , reducing to a minimum, through the removal of most of the roots, the danger of 


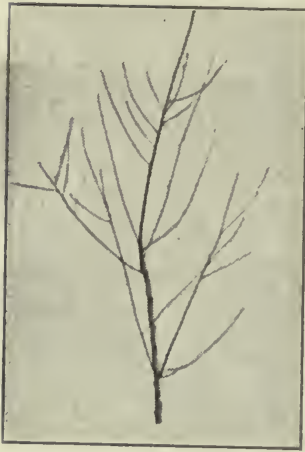

FIG. 121

YEARLING PEACH WITH CENTRAL LEADER spreading all kinds of fungous diseases and insects; 6 , enabling two and even three-year-old trees to be used for planting as advantageously as one-year-old trees, thus saving losses to nurserymen, who ordinarily burn such trees.

Stringfellow* holds that the usual ill success in transplanting the pecan is due entirely to leaving too long a top root. He advises cutting this root to 4 or 5 inches and setting the tree at least 6 inches deeper than before it was taken up.

The main peach plat used in the experiments conjucted by $H$. N. Starnst to test the Stringfellow plan presented on the whole as fine an appearance as any two-year-old peach orchard the writer [Mr. Starns] has ever seen. The trees at the time averaged 12 to 15 feet in height and bore 'considerably over 300 crates upon one acre. It may be stated that the writer [Mr. Starns] is fairly satisfied that peach trees, pruned by the Stringfellow method, will live and flourish in Georgia, even in stiff clay soil and under adverse meteorological conditions. This statement may also be extended to cover apples and cherries.

Dr. J. C. Whitten concludes from experiments and from reports of growers that the method of stub-root pruning and cutting back to 12 to 18 inches, according to the Stringfellow plan, has been of great service in showing that it is not necessary to retain anything like the large quantity of fibrous roots formerly supposed to be necessary.

In the year book of the Netherland Pomological Society§ for 1902, A. C. Ide reports experiments on severe pruning of young apple and pear trees at time of transplanting. He used one, two and

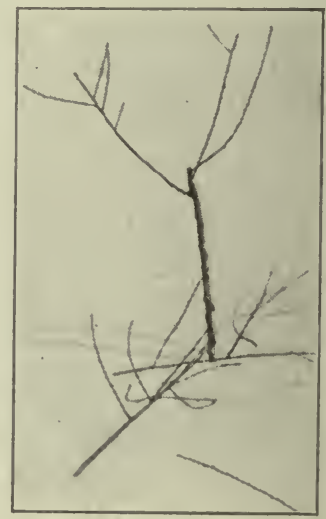

FIG. 122 - AFTER PRUNING TREE IN FIG. 121.

* Texas Farm and Ranch, 24, Page 10.

+ Georgia Experiment Station, Bulletin 40. The reader will here find a series of half-tones illustrating the discussion on the experiments and also numerous articles quoted from the agricultural press, giving both favorable and unfavorable comment on the theory.

8 Cultura, 14, Page 424. 
three-year-old trees. One-half of each lot were transplanted in the usual way; others had their roots pruned to mere stocks. Trees in the first lot started off more vigorously in the spring, but before the end of June the closely pruned trees were larger than the others, and this lead was maintained throughout the season. When the trees were dug the closely pruned ones had developed much better root systems than the others.

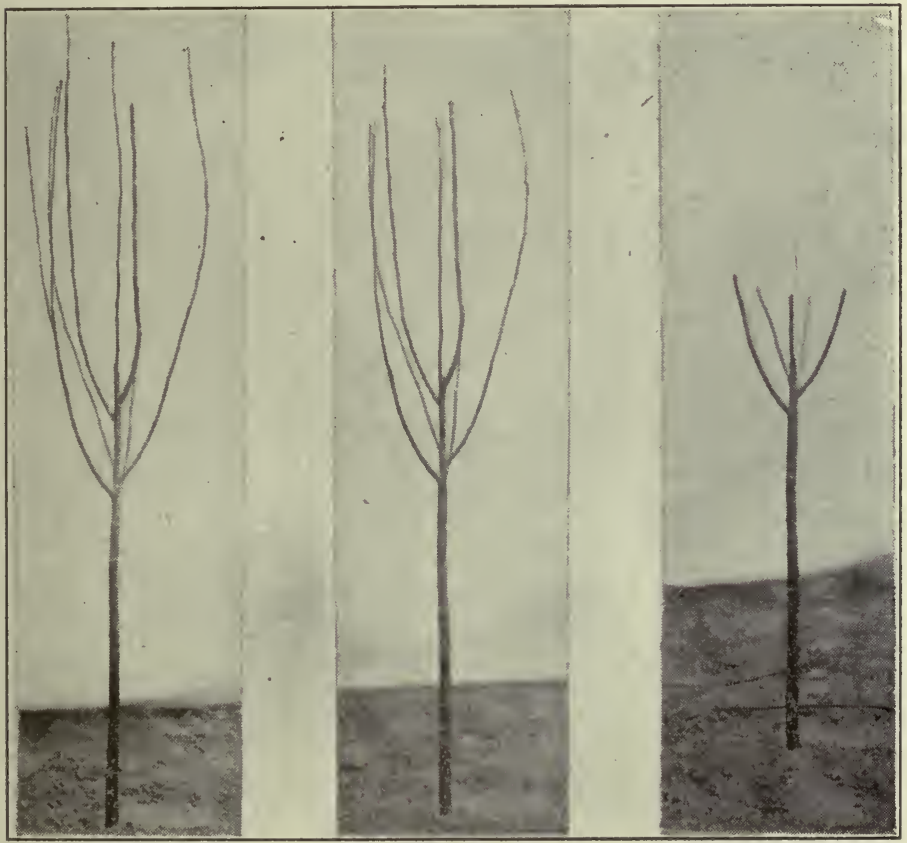

F1G. 123-HOW TOP OF NEWLY SE TREE MAY BE PRUNED

The top of a tree should be pruned immediately after planting. Most orchardists do not prune enough. On the left the tree is shown as received from nursery; in the center as ordinarily but insufficiently pruned; on the right pruned much better. The branches should be farther apart to make for strength. Better leave the lowest and the highest in this case, cut out the others and develop new ones upon the leader as seen in the left-hand picture.

147. When to prune nursery tree tops.-While the roots may be pruned prior to carrying the trees to the field, it is conceded to be best practice to prune the tops after the trees have been planted. When pruned prior to 
taking to the field injuries may occur in the handling, and the very parts most prized may be lost. When pruned after planting the head may not only be started to best advantage at the desired height, but there is a better chance of having the branches in good condition as well as having a larger number among which to choose. Always in doing such pruning the feet should be placed one on each side of the trunk and the cuts made from below upward with a keen-edged knife. IVhen trees are transplanted in autumn, the pruning should be say 6 inches beyond the point where the frame limbs are de-

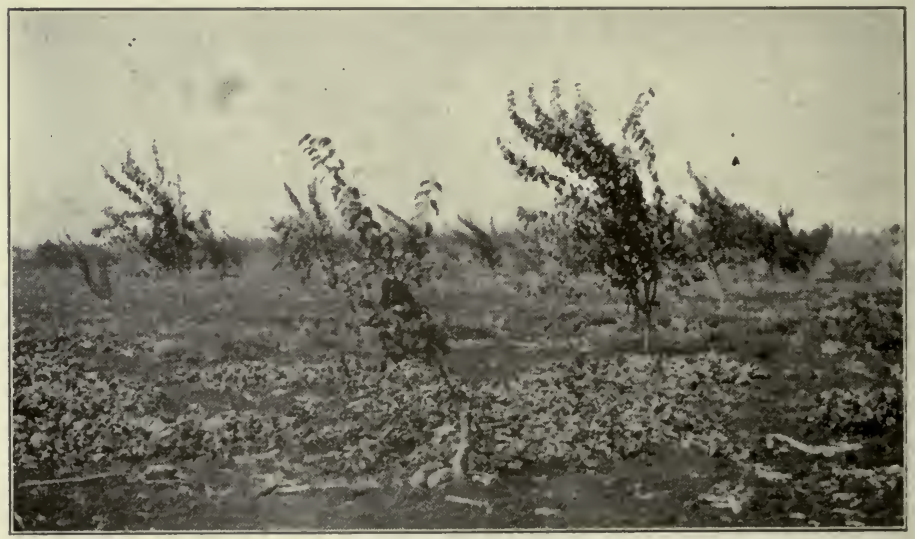

FIG. 124-EFFECT OF WIND ON UNSTAKED TREES. WINDBREAK NEEDED Only by the most careful pruning can these trees be balanced and then only with the greatest difficulty. Staking would have helped many of them.

sired, because there may be more or less winterkilling. The final pruning should be given just before growth starts in the spring. (Compare 121.)

148. Lengths of nursery tree trunks.-Because tree planters in the past have generally called for trees with trunks of certain lengths the nurserymen have pruned off the lower limbs, especially when the trees were to be sold when two years old. Formerly the height of the 


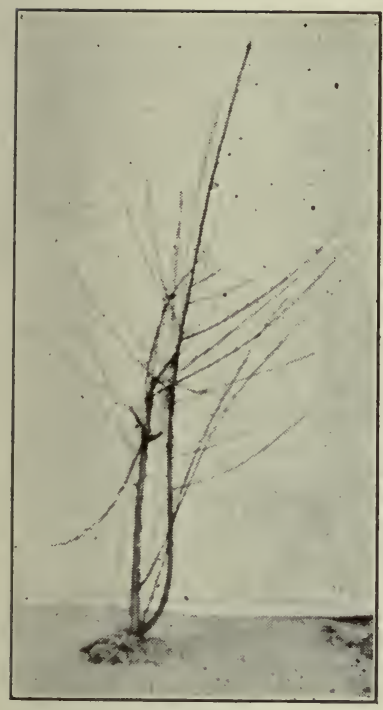

FIG. 125

PEACH OF POOR FORM

This one-year tree failed to develop well-placed branches on the main trunk. Compare Fig. 126.

trunk was 4 to 5 feet; during the first decade of this century 3 to 4 , because low-headed trees are steadily gaining in popularity. Still more recently certain nurserymen have been heading their trees still lower or in some cases allowing practically all of the lower limbs to grow (Figs. 195, 200). The distinct advantage of this practice is that the purchaser may start the head just where he happens to want it.

149. Trimming trees at transplanting time. - Because such a large proportion of the root system is left in the soil when nursery trees and shrubs are dug, even when the trees are most carefully lifted, it is necessary to establish a new balance between top and root. First, however, all torn, dead and injured roots should be pruned back by clean cuts through living parts of these roots. A knife makes a clean job, but shears do quicker work. Both implements should be-keen-edged. On the roots slanting wounds which face downward are supposed to heal more quickly than those facing upward or to one side. Second, the top must be considerably reduced, otherwise the trees may suffer, be slow to establish themselves. Often they die. Peaches are usually trimmed to a mere whip, but apples, pears and

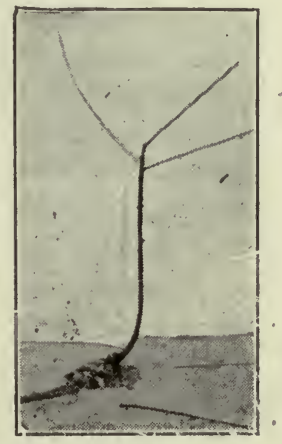

FIG. 126 AFTER PRUNING The same tree as in Fig. 125. The dead trunk has been cut out. 
other trees do not seem to be able to stand quite such severe handling. Always a goodly number of robust buds should be left to develop the frame branches. Some of these may be upon the main stem, others upon the stubs of the branches developed in the nursery.

"Whip" pruning and "stub" pruning have each their advocates. The former is the more popular with and applicable to yearling trees, and since one-year trees are steadily gaining in popularity, this method is the more important. It consists in leaving nothing but the original

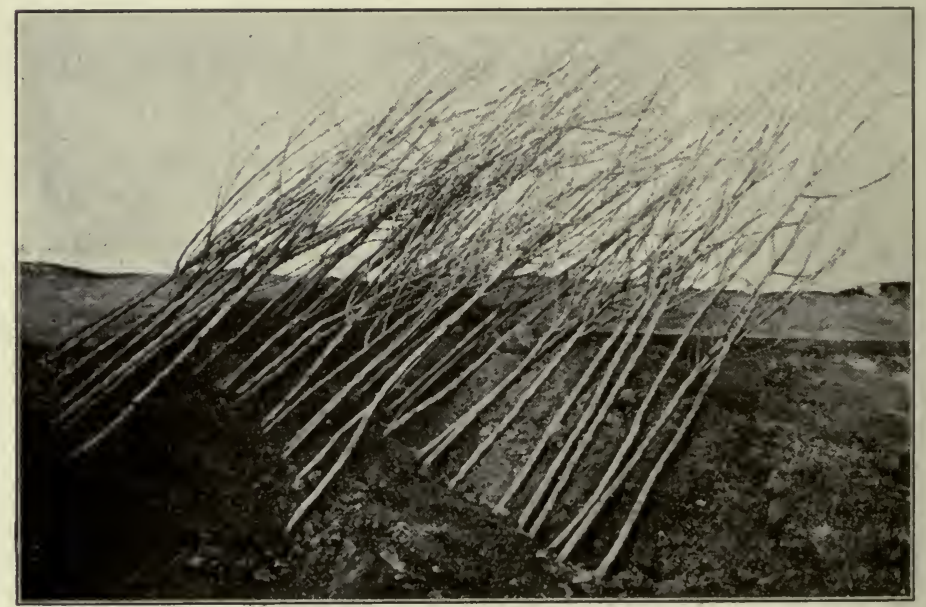

FIG. 127-YOUNG TREES PROPERLY HEELED IN FOR TEMPORARY STORAGE When received too early for planting, nursery stock should be properly cared for. "Heeling in" keeps the roots moist and insures growth when the trees are planted in the field.

stem-no branches at all-and shortening this to the desired height. During the first season the tree "feathers out" or develops many twigs, among which may be sereral properly placed to form the head.

When the nursery trees are sturdy and have several branches, the stub method may be used, the head being started at the height desired. This method leaves one to 


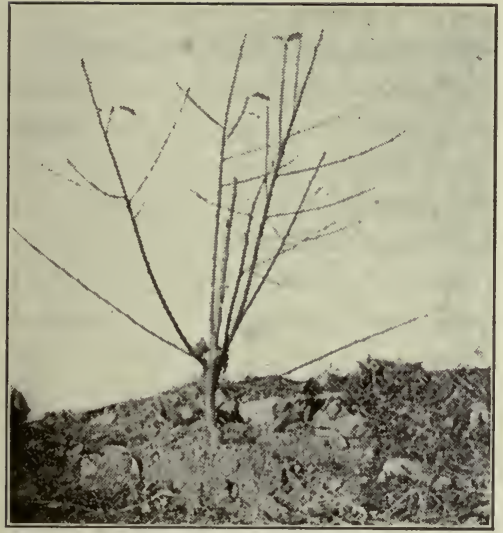

FIG. 128

YEARLING PEACH BEFORE FRUNING

This tree was cut back to 18 inches when set, but did not develop any branches near the top.

three buds on such branches as may be well enough placed to form the head, the balance of the wood being cut off. While five branches are generally advised, yet it is often better to start with six or eight, spaced as far a part as possible, Should an accident occur, the injured branch may be cut out and yet not spoil the top. Should no injury occur, the inferior limbs may be removed when such danger has passed and the trees are beginning to settle dow $\mathrm{n}$ to business. This plan is generally more successful than that of trying to develop a new frame limb where too few have been started or one has been lost. Practical orchardists are by no means unanimous in their methods of starting the head. It may be said that success may follow each m e thod-and no. method - as has been shown (151) by the Rhode Island Experi-

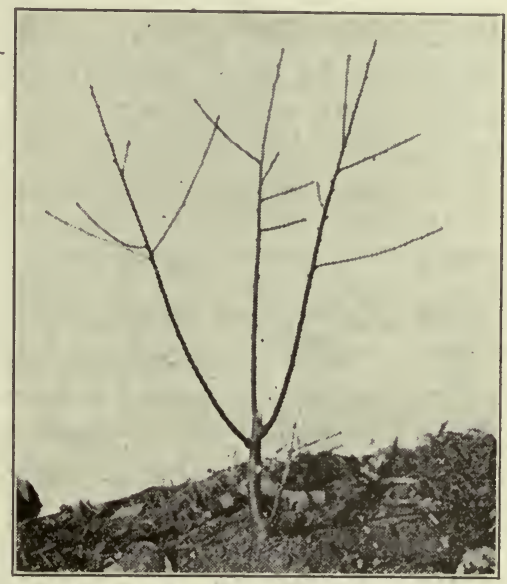

FIG. 129-SAME TREE AS IN FIG. 128 AFTER BEING PRUNED 


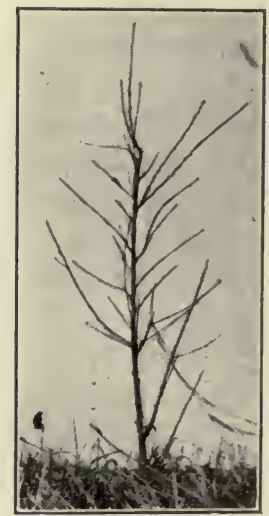

FIG. 130

UNDESIRABLE FORM

Iree was headed 3 feet high when set.

ment Station* (Figs. 137 to 144). Even second-grade treẹs may, with some extra work, be made to produce fairly well-formed heads, as has been shown by the Colorado Experiment Station in the following condensed account.

150. Actual experience pruning young trees.-Paddock presents an interesting discussion of some photographs (from which drawings are herewith reproduced $\dagger$ ), to fix the points of the various stages of pruning in the reader's mind. His article is condensed as follows:

The trees were second grade and evidently three years old when planted. The lower laterals had all been pruned away in the nursery, so the tops were much too high for Colorado. There was also difficulty in getting branches to form at suitable places to make the selections for the head. However, the results are much better than if the tops had been left as received from the nursery, as is so often done.

The trees 1, 2 and 3 in Figure 132 were headed back to about 24 inches in April. Had there been any laterals below this point they would have been prunerl hack to single buds, so clusters of leaves might have formed and thus provided some shade for the trunks.

* Annual Report, 19:1.

† Colorado Bulletin 106. 


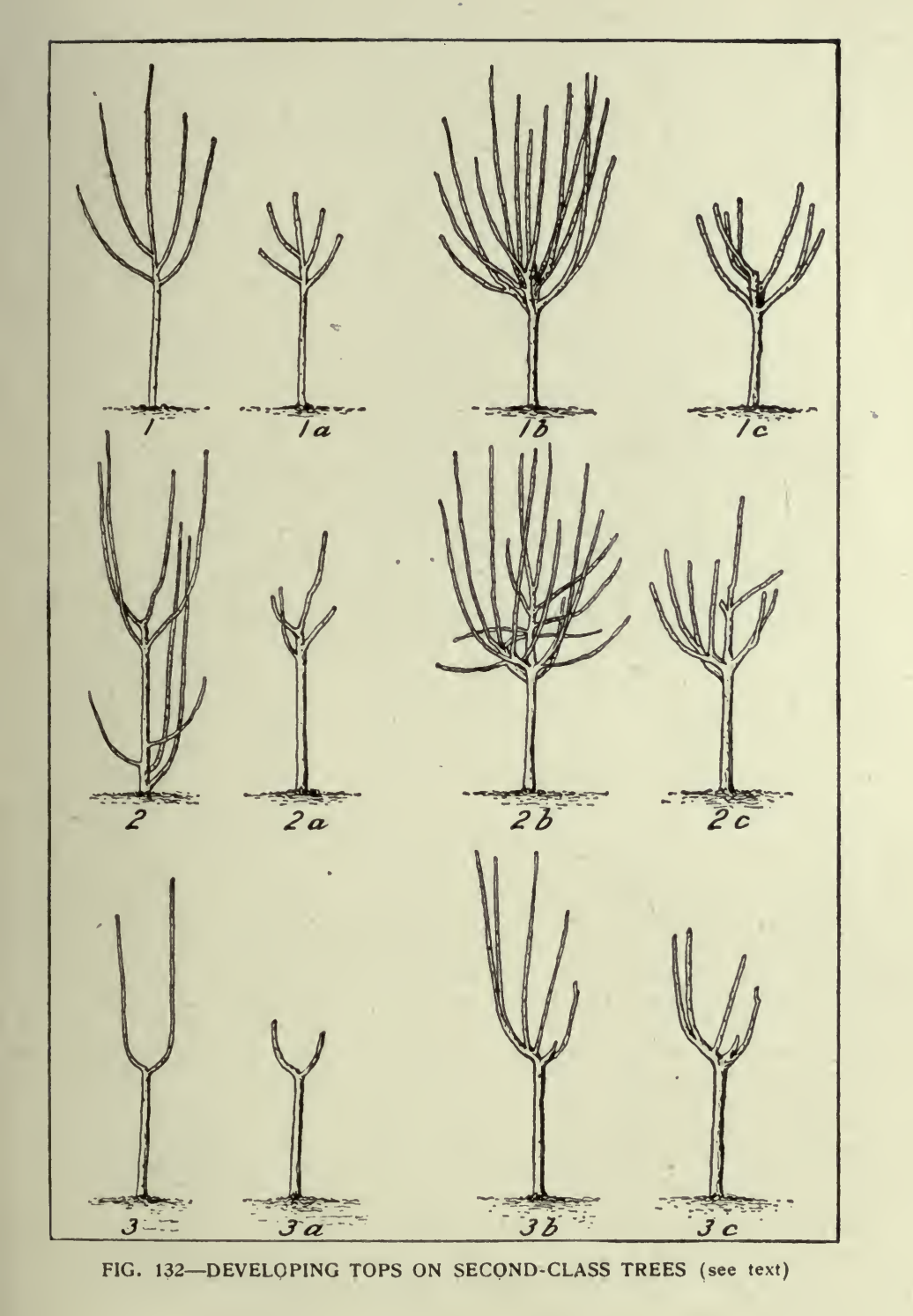


The pictures show how the trees looked in the following April at the time of the first pruning. No. 1 had formed five vigorous branches, No. 2 produced four and No. 3 but two.

The five branches on No. 1 were saved to form a framework for the tree and were cut back to about one foot. These are well distributed about the trunk, but are too close together. The lowest limb might well be double the distance from the top. No. 1a shows No. 1 after it was pruned, with the idea of making an open-centered tree.

In No. 2 the limbs are too close. All of these were saved to form the framework of a tree, with a leader, as is shown in No. 2a. The only difference between this and No. 1a is that the tcpmost branch was left longer than the others. The pruner of this tree carelessly allowed three vigorous limbs to grow from near the surface of the ground, for they could serve no useful purpose, but only rob the other limbs of plant food. Such growths are best prevented by pinching off the buds early in the season.

No. 3 failed to throw out enough branches to form a suitable top. The two produced are nearly opposite, so a bad crotch would soon result. Both branches were cut back to the second bucl, as shown in $a$, in hope of inducing dormant buds to push out lower down. At the close of the second season the pruned trees hal made a growth respectively as shown in $1 \mathrm{~b}, 2 \mathrm{~b}$ and $3 \mathrm{~b}$.

Pruning results are shown in 1c, 2c and 3c. Tree No. 1 is shown in $1:$ One of the frame limbs seemed su-erfluous, so it was removel and the ne $v$ growth, shown in $1 \mathrm{~b}$, was c1't back about one-half. The few side shoots were ea.h cut back to a single loud, with the icle a uf developing fruit spurs during the se ond year, when numerous branches should clevelop on all of the limbs. As a rule two of the best placed of these secondary limbs will be selected on each of the main limbs to form additional framework. The rest may be removed or cut back to clevelop fruit spurs as may seem desirable.

The form of the tree, then, should be developed at the beginning of the third season, and subsequent pruning should be direcied toward retaining this shape, cut-

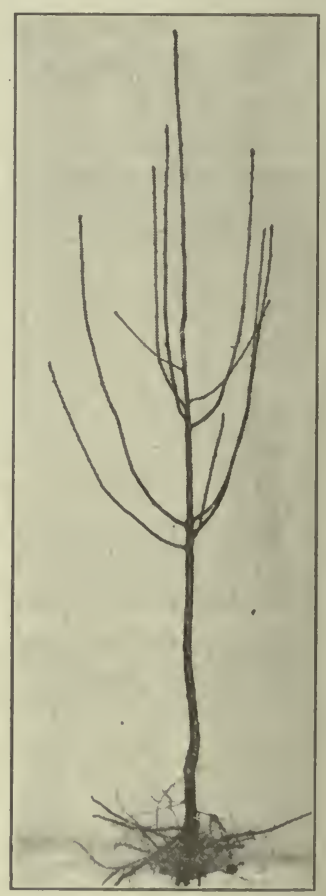

F!r. 133

WELL-BRANCHED NURS ERY TREE. NOTICE HOW ERAME LIMBS ARE PLACED. 


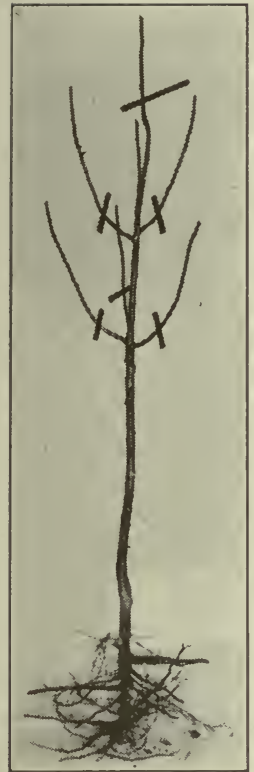

FIG. 134.

WHERE TO CUT

Same tree. as shown in Fig. 133. The cross marks indicate where the limbs should be cut off when the tree is set.

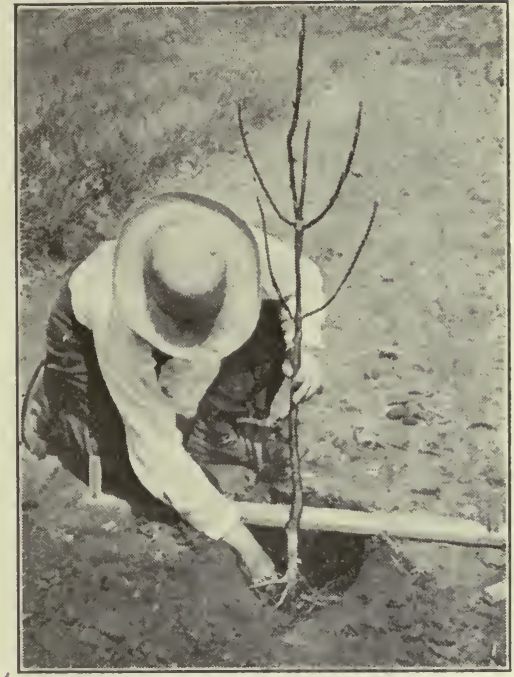

FIG. 135-HOW TO PIANT. A TREE

It is important to work the soil among the pruned roots and then to pack it down hard by trampling so as to bring every part of the root in contact with the moist earth and prevent the formation of air spaces.

ting back excessive growths and thinning and renewing the bearing wood.

The pruning of tree No. 2 is much the same, except that a leader is being developed. Although the top of $2 \mathrm{c}$ was cut back the same as tree No. 1, the topmost branch is developing into a vigorous central shaft. The first set of frame limbs has formed and a second set is to be developed at a suitable distance above. The new growth is to be cut back.

The tree shown in the series 3 to $3 c$ is, so far, pretty much of a failure. The severe heading given it in the spring following setting failed to make branches develop lower down. It would have been a better plan to insert two or three buds at suitable points around the main stem in June of that year. This can probably be done next June, but the chance for success is not so great. Limbs can be developed by this means just where wanted, but the average person will succeed better with trees which do not require such manipulation.

151. Methods of tree planting.-An experiment to test 


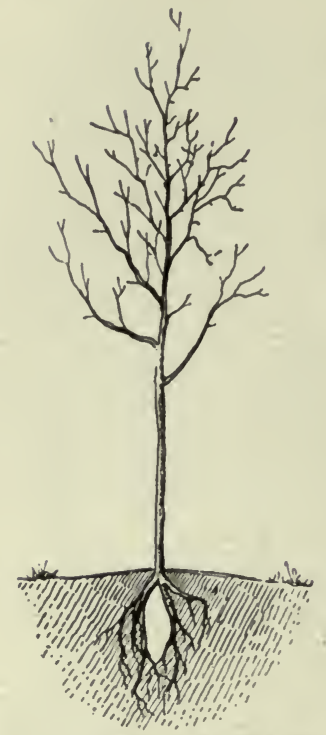

FIG. 136-AIR SPACE A M ONG ROOTS OF BADLY PLANTED TREE various methods of tree planting was conducted by F. W. Card* and the results of one season's growth shown and described. Ten twoyear Northern Spy trees were planted by each of the methods as follows: 1, Trimmed to whips and cut back to about 3 feet; 2 , trimmed to whips and the leader left untouched; 3 , branches cut back half, leader left; 4 , untrimmed. In all of these cases the roots were left untrimmed unless injured or decayed at the end, in which case they were cut back to sound wood. 5, Roots untrimmed; 6 , roots cut back half; 7 , roots cut back to mere stub. The tops of trees 5,6 and 7 were treated as in No. 3.8 , St ring fellow method, the roots being cut back to a mere stump 1 or 2 inches long, and the tree to about a foot high. In the spring of the fourth year following, representative trees in each lot were photographed (Figs. 138 to 144) and the following notes taken:

1. Whips with leader cut back (Fig. 144). Good trees and for the most part well branched. Their greatest defect is in the long, spindling growth which has resulted from lack of pruning. Heads have formed at 2 to 3 feet from the ground. 2. Whips with leader un-

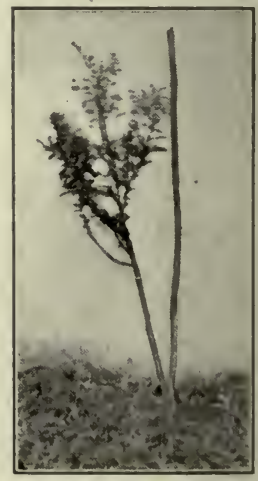

FIG. 137-TREE SET OBLIQUELY AGAINST WIND

In regions of high winds plant the trees with the tops leaning toward the wind as shown here. On hillsides lean them uphill.

- Rhode Island Experiment Station Report 1901, Page 238. 
touched (Fig. 143). These trees do not average so well as those in the previous lot. Most of them do not have good branches low down, the real heads having formed 5 or 6 feet from the ground, though in some cases the lower branches will make good heads. These trees seem to be the most undesirable ones in the experiment. 3. Branches cut back half, roots unpruned (Fig. 142). Good trees, with uniform heads about 3 feet from the ground. The heads well balanced and trees well formed.

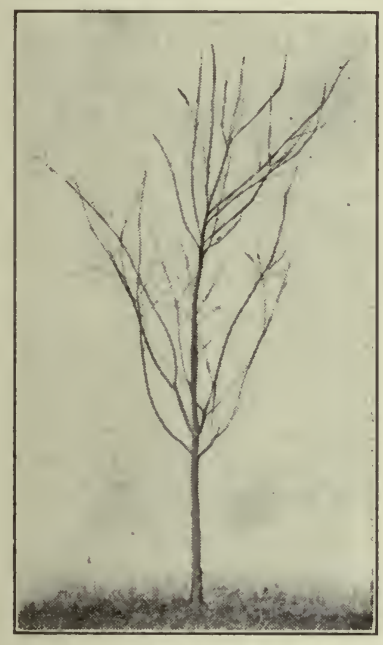

FIG. 139-TREE GROWN FROM UNTRIMMED NURSERY STOCK

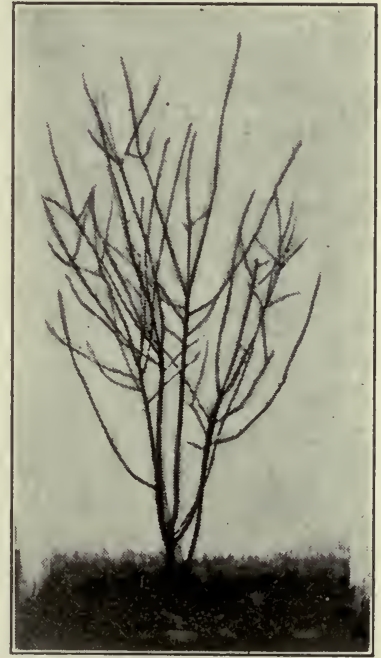

FIG. 138a-TREE FROM "STRINGFELLOWED" ROOTS

4. Branches untrimmed, roots untrimmed (Fig. 140). Good trees. A few seem rather slender, but most are excellent. Heads formed about as in Fig. 138. Growth not quite so good on the average. 5. Branches cut back, roots untrimmed (Fig. 138), a counterpart of Fig. 140. Very similar in appearance to Fig. 140. Growth a trifle better, heads well formed (Fig. 141). 6. Branches cut back and roots cut back (Fig. 141). More uneven in 
growth than the other lots, but much the same in general habit. 7. Branches cut back, roots cut by the Stringfellow method (Fig. 139). Trees somewhat uneven. The lot contains one or two very fine trees, but no poor ones. 8. Stringfellow method (Fig.138a). These trees have made an excellent start. They will make well-formed trees, with heads just at the ground. Generally a large number

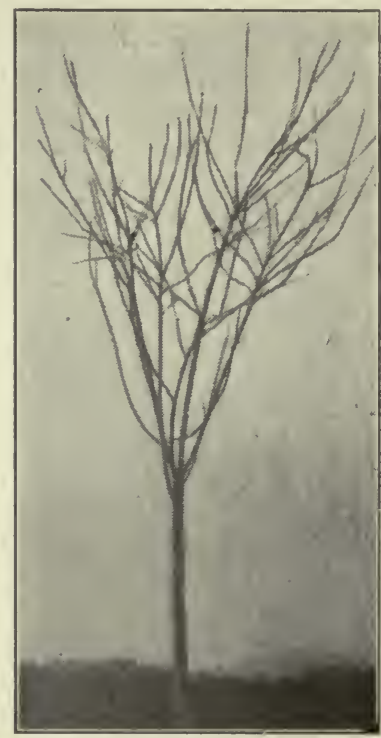

FIG. 139-TREE GROWN FROM STUB-PRUNED ROOTS

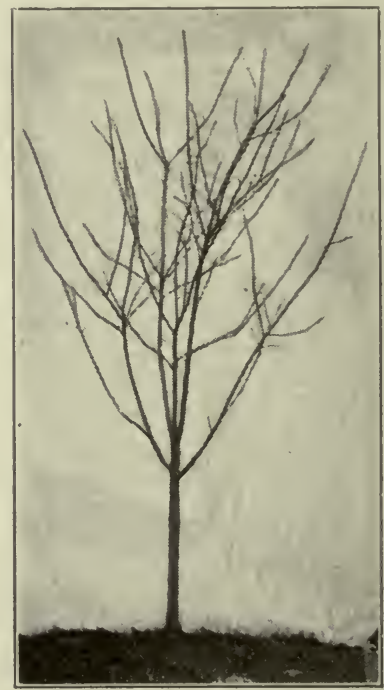

FIG. 140-TREE GROWN FROM UNTRIMMED NURSERY PLANT

of branches start, and these in turn branch at about 30 inches from the starting point.

In these observations it should be remembered that the eye takes account of the tree as it stands, regardless of whether much or little wood was cut away at time of planting. The experiments show that under favorable conditions a tree will adjust itself to almost any kind of treatment and still make a good tree. For practical pur- 
poses the most rational method seems to be to leave ail sound roots and shorten back the tops, which not only helps to bring about a proper balance between root and leaf, but also improves the subsequent character of growth of the tree.

152. Low-headed trees have so much to commend them that they are annually becoming more popular. 'To se-

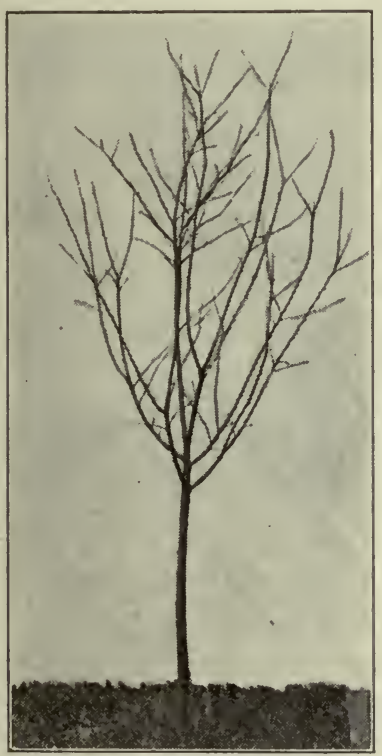

FIG. 141

HEAD ON TREE WHERE ROOTS WERE CUT BACK

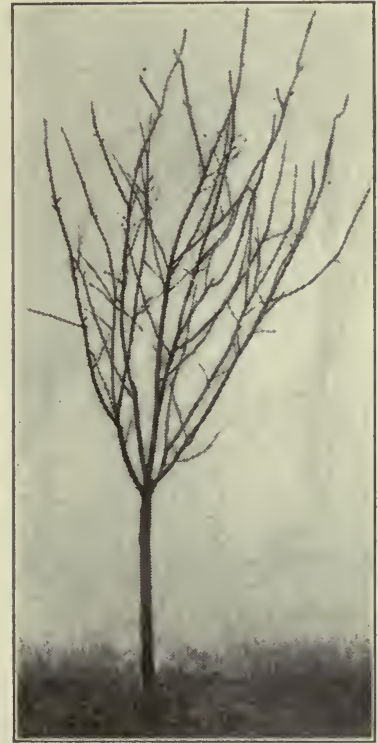

FIG. 142-AT PLANTING TIME THE BRANCHES WERE CUT BACK

cure them it is adrisable to buy from nurserymen who make a specialty of such trees or to purchase only yearling stock, because the heads on such stock may be started as low as desired. In the former case all that is necessary is to thin out and cut back the top as may be desired. In the latter the "switches" for the "trces" are little more than that, have their bud systems intact, therefore the 


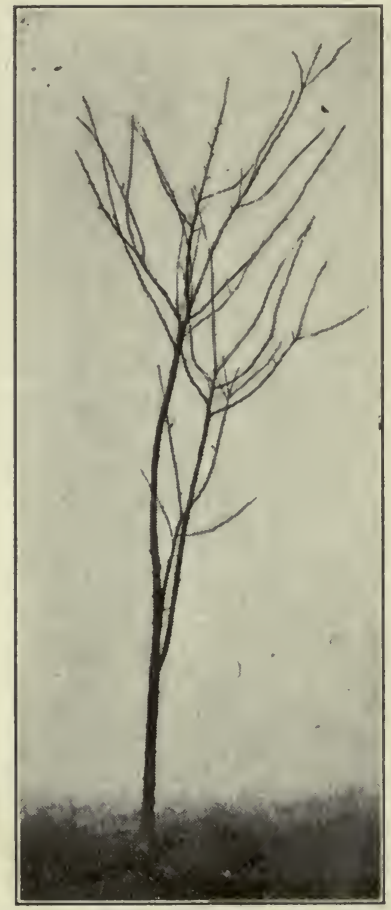

FIG. 143-TREE GROWN FROM A "WHIP" WITH THE -
LEADER LEFT

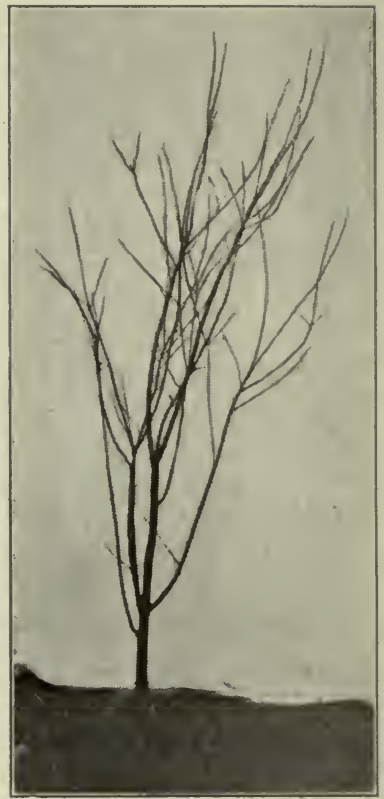

FIG. 144 - HEAD FORMED BY "WHIP" WITH LEADER CUT BACK

head may be started anywhere. Trees which naturally grow erect, at least on the start-apple, sweet cherry and pear-may be headed at 18 to 24 inches from the ground; and those smaller growing, more spreading trees, such as the stone fruits, other than sweet cherries, may be headed 6 or even more inches lower. This pruning must be done immediately after the trees have been set. If delayed for a year the chance to get a good, low head will have been lost ; for no attention will make up for the neglect to do the work at the proper time.

During the first summer practically all the buds will start and the "whips" will "feather out" abundantly" 
Every leaf and twig should be allowed to develop to its fullest extent without let or hindrance (except as outlined in 165,166 and 169) because this green stuff will help to establish a sturdy trunk and a strong root area. Root action depends on leaf action (Chapter II). The following spring will be soon enough to do any cutting. Then, among the often broom-like tops, the desired number of twigs may be selected to form the frame limbs. From this time forward the pruning and training may be done as recommended by Lewis (Chapter $\mathrm{X}$ ). 


\section{CHAPTER X}

\section{PRUNING YOUNG TREES*}

153. Disappointments attributed to pruning. $\dagger-M a n y$ orchardists growing young trees have been disappointed with the results obtained from pruning. While these disappointments may be due, on the one hand, to a lack of knowledge of fundamental principles which underly pruning, on the other hand, we believe much of the dissatisfaction is because the grower has expected too much from

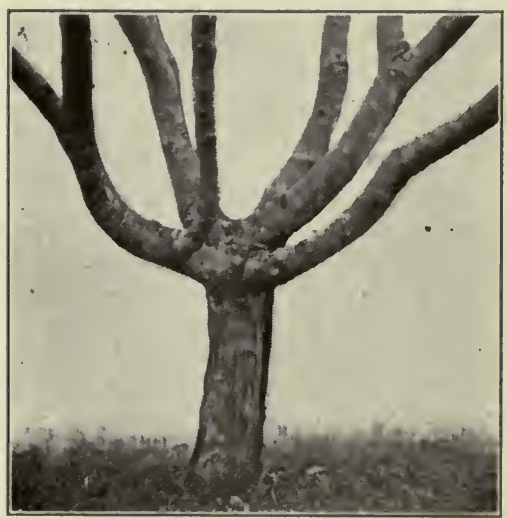

FIG. 145-BADLY FORMED TREE HEAD

Never start the main limbs in this manner. They should issue in a spiral whorl with 4 to 12 or 15 inches between one limb and the next one above. Such an arrangement will prevent bad crotches and will greatly strengthen the tree. pruning alone, and has failed to realize the importance of other orchard practices-irrigation, tillage, maintenance of soil fertility, etc.

No matter how skillfully we prune for fruitfulness, unless we have such soil conditions as to furnish sufficient food and moisture at the right time to develop good, strong buds, we cannot expect to secure satisfactory results. Again, we must realize that soil.

* Paragraphs 153 to 177 have been somewhat condensed from the article by Professor C. I. Lewis in Bulletin No. 130, of the Oregon Experiment Station. With slight modifications, indicated in brackets or cross referenced to other parts of this volume by the present author, the methods apply to a very considerable area of the United States and Canada.

t As noted in paragraph 172 the directions given in paragraphs 153 to 172 apply chiefly to apple pruning, but also to all deciduous fruits and nuts. Specific directions for these other fruits are in paragraphs 173 to 177. 
elevation, and climate are factors which have a very close relation to pruning. Likewise, the variety question is always to be taken into consideration. For example, the pruning of the Jonathan in southern Iclaho, at an altitude of 2,000 feet, on a silt loam, is a different problem from that of pruning Yellow Newtown in western Oregon on

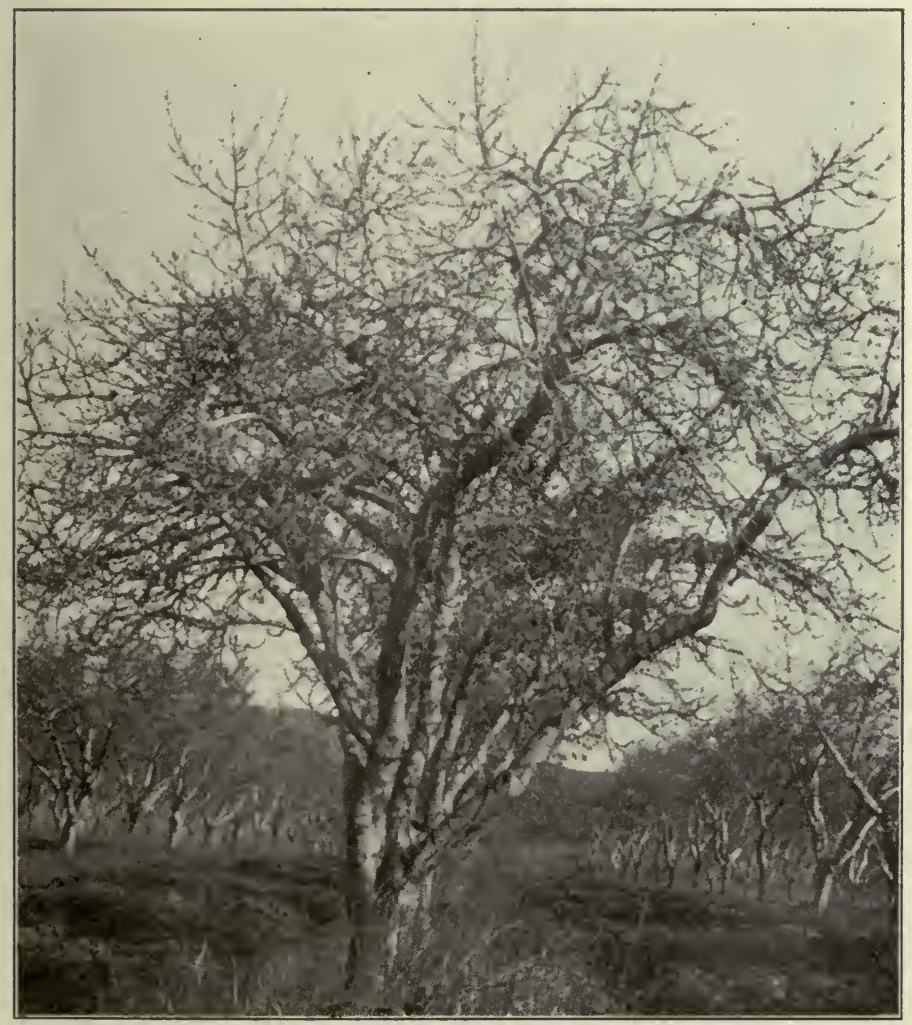

FIG. 146-MAIN BRANCHES BARREN BECAUSE OF NEGLECT

This old Italian Prune tree has not been pruned for years. The frame and lower branches have become barren through the dying of the fruit spurs which were too much shaded by the thick, bushy top. This top consists largely of long, slender, weak fruit spurs and fruiting branches like those in Fig. 168. 
a heavy soil at an elevation of 100 feet (80). While the principles underlying the pruning of these two trees may be the same, the application may be radically different.

We need, first, to form a clear understanding of what these principles are, and, second, to study more closely than we ever have in the past their application to our individual orchards.

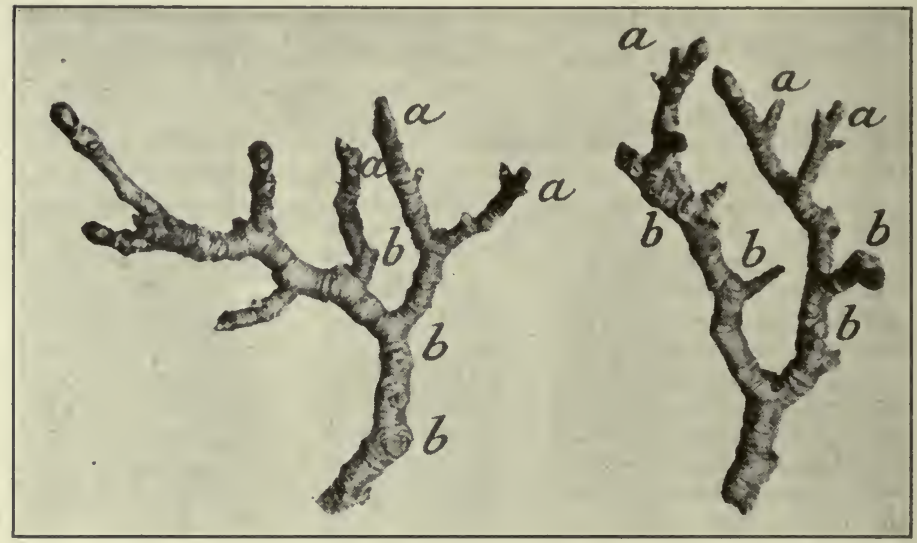

FIG. 147-OLD BARTI.ETT FRUIT SPURS WHICH BLOOM YEARLY BUT SELDOM BEAR FRUIT

At $a$ are spurs which bloomed but set no fruit. Some of them have produced blossom buds for next year. At $b$ are scars where fruits probably set and in the cases of the larger scars possibly ripened. Perhaps, however, some of these are scars left by twigs which died.

154. Three types of trees are grown in the Northwest: the so-called open, globe or vase-shaped tree, the center leader type, and the modified leader type.

154a. In the vase or open tree three to five branches are chosen to form the framework of the tree; any tendency of a branch to assume the lead is suppressed; no leader being allowed to grow. Each of the three to five branches is given equal prominence in the tree. This tree was borrowed from the French and has been modified in this country to suit our special needs. For example, in parts 
of the Middle West and in California the tree is allowed to carry a large number of laterals, summer pruning or shearing being employed to force out more laterals so as to shade the branches from sun scald. A dense con1pact tree is the result. In the Pacific Northwest the term "globe" or "vase" is seldom used, but almost always the term employed is the "open" tree. Instead of shearing to produce shade, growers prune out and keep the tree

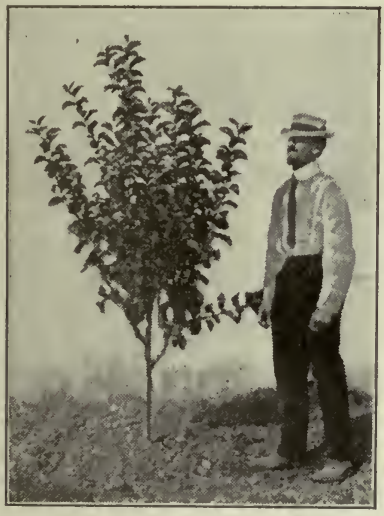

FIG. 148

YOUNG YELLOW NEWTOWN

TREE BEFORE AUGUST

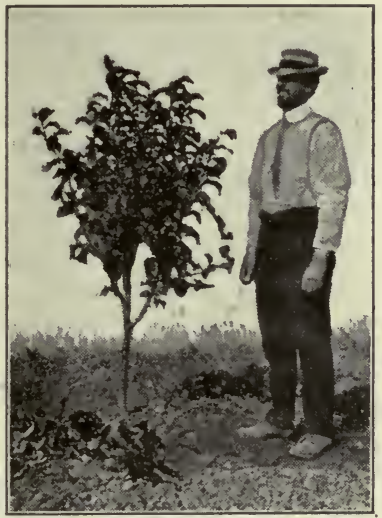

FIG. 149

AFTER AUGUST PRUNING YOUNG YELLOW NEWTOWN

open to admit more light. The general framework, however, of California and Oregon types is the same.

Our orchardists claim that the advantage of the open tree is that it allows more light to enter the tree, thus causing a better coloring of the fruit ; and second, it procluces a tree, broad, spreading and easy to keep low headed. The objections to this tree are: First, it is generally structurally weak, since the scaffold branches issue at one point, thus making weak crotches. If one branch breaks out the tree may be ruined. Second, it is used too generally; it is not adapted to all varieties 
under all conditions found in the Pacific Northwest [or elsewhere].

155. The so-called leader tree has been used largely in the East on the Atlantic Seaboard, and is used somewhat on the Pacific Coast, especially in British Columbia. There are a few orchards in the Pacific Northwest where the growers believe the leader to be the best type. With the leader tree, since the center branch is always allowed to have the ascendency, the tree grows more or less to the true pyramid. The growers obtain very large trees, which are, however, very difficult to keep low headed and open. The trees are probably stronger, there being less breakage from this type of tree than from the socalled open tree.

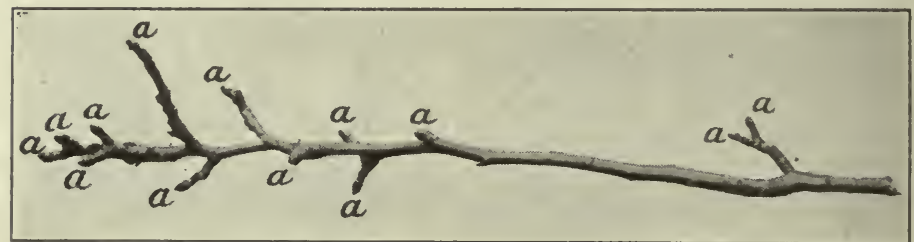

FIG. 150-VIGOROUS SHOOT PRODUCED FROM OLD BARTLETT PEAR SPUR The shoot was pruned and is now in healthy condition. Note the number of fruit buds at $a$.

156. The modified leader.-In this type we start the trees exactly as though we were going to grow the center leader, but, beginning with the second to the fifth year, the leader is suppressed. The advantages are that this type of tree allows us to space the branches well, to build strong crotches and main frame limbs, and at the same time keeps the tree relatively close to the ground. This type is growing in favor where it has been tried throughout the Northwest.

With any of these types, weak trees or strong trees may be built, and also bushy or open trees may be secured with any one of the three systems. [It depends upon the handling.] 
157. Form of tree often due to local whim.-The type of growth of trees in one's locality may determine to a certain degree what system shall be used. For example, Oregon growers wouldn't grow Wagener ordinarily as an open type of tree. It is rather an upright grower for a few years, but later becomes a feeble grower. On the other hand, they should not think of growing varieties like Tompkins King or Northern Spy as center trees, since these trees shoot up too straight, are too big and too hard to control. Y e $110 \mathrm{w}$ Newtown is too often pruned as a typical open tree. On light soils it becomes very weak when 12 or 15 years old. A modified leader, or in some cases even the oldfashioned leader, would be better with Yellow Newtown. On the other hand, on some very strong loams, Yel-

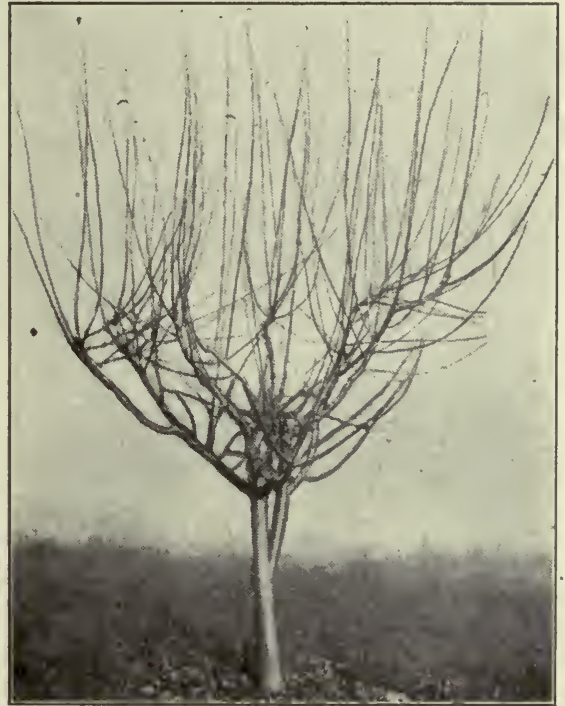

FIG. 151

HEAVY HEADING BACK DEVELOPS WOOD Young vase-formed apple tree which shows the effects of very heavy heading back. In this case the pruner cut back to two-year and three-year wood. Fruit spurs that had started to form were forced into shoots. The entire energies of the tree have been temporarily turned into shoot formation. The age of bearing has probably been delayed two years by this treatment.

low Newtown can be handled very satisfactorily when grown as an open or globe-shaped tree, provided a little care is taken in spacing the branches carefully the first two or three years.

158. The height of head is only a relative term. One 


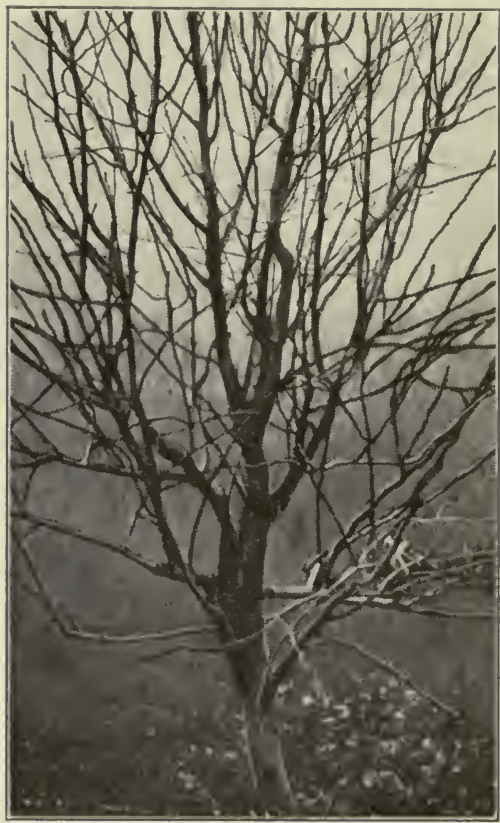

FIG. 152-TYPICAL LEADER TREE

Five-year-old Winter Nelis pear beoun as an open center, but typical of the leader type of training. The lower branches are not keeping pace with the upper and are becoming weak in comparison. To save or restore balance the upper branches must be suppressed.

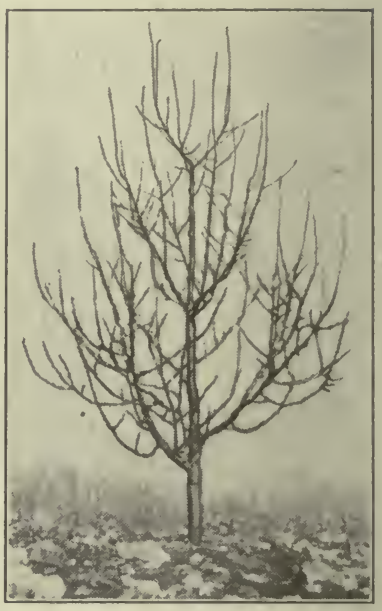

FIG. 153 - THREE DECKS OF FRAME LIMBS

Note distances between decks and the general stociky appearance of the tree.

man would say that 30 inches will make a lowheaded tree; another that this is extremely high. The Pacific Coast grows low-headed trees. Experience has shown that these are the easiest to care for, that they are the most economical for thinning, harvesting, spraying and pruning, and that. we can shade the trunks and main scaffold limbs better with this type of tree, than with a high-headed tree. In parts of the Inland Empire growers often head their trees at 8 or 9 inches. Many Jonathan trees in the Rocky Mountain district, and in certain portions of Idaho, eastern Oregon and Washington, are headed in this way and are giving satisfactory results. Under such conditions they must protect the trees as 


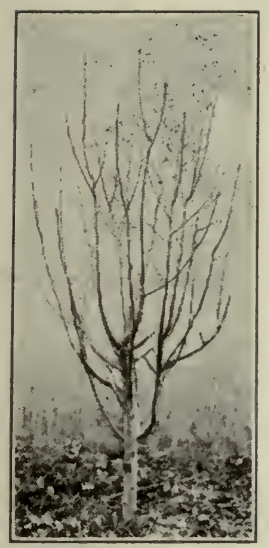

FIG. 154

MODIFIED LEADER

Five-year Bartlett pear after pruning.

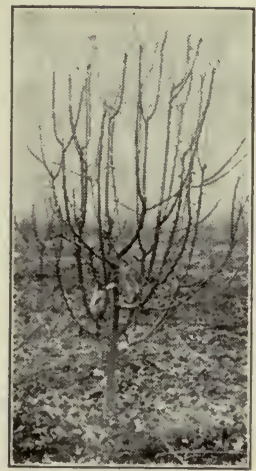

FIG. 155 MODIFIED LEADER

Same tree as Fig. 154 pruned. Note how little wood has been removed in thinning out; almost no heading back.

much as possible against sun scald. In Western Oregon 20 to 25 inches is considered a better height of head. Many growers have felt that 20 to 25 inches is the proper height for apples and pears. Peaches should be headed as low as they can be grown ; cherries at about 25 inches; prunes 30 to 35 inches. It was formerly believed that walnuts should be headed very high, 7 or 8 feet, and no laterals allowed to grow the first few years; but this is now considered a mistake. About 35 inches will make a splendid head for walnuts.

159. Season for pruning.-In the Northwest, only two scasons for pruning are considered; namely, winter and summer. There is no question that in the Northwest, where mild winter conditions prevail, winter pruning may be done safely in most years at any time when the trees are dormant. In sections of severe winter conditions, delaying the pruning as late as possible before the growth starts in the spring seems to be wisest. Very rarely good 
fruit growers would advise fall pruning in the Northwest, unless one has such a large acreage that it is impossible to complete the work unless the pruning is commenced early in the season. If it becomes necessary to prune

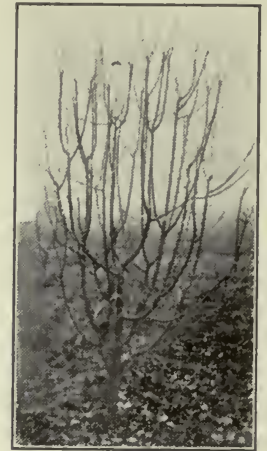

FIG. 157

MODIFIED LEADER

This splendid type of modified leader tree, a five-year-old Wagener apple, was summer pruned in July and photographed in January. Note the amount of after-growth. Th's indicates that the tree was pruned at about the right period.

trees in fall or very early winter, growers prune the older trees first, leaving the younger ones for the last. We should caution against pruning trees when they are frozen. Much heart rot and die-back have resulted from pruning frozen trees. It is possible to prune trees somewhat even after they come out fully in the spring.

160. Three lessons in pruning young trees.-Pruning 
young trees depends upon three great fundamental principles. If these are mastered the problem of pruning young trees will become rather simple, but unless they are mastered it is difficult to develop strong, wellbalanced young trees.

161. Choosing and spacing the frame branches.-For an open or a modified leader type of tree, four or five branches are recommended. [In eastern practice many growers start with six to eight, but prune out some of these after the head has been fairly well developed; say when the trees are 5 to 10 years old.] For the typical leader tree it does not make much difference, as from year to year new branches are added. In Oregon

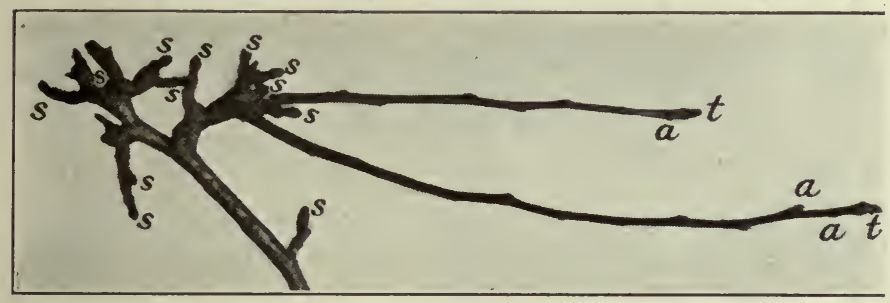

FIG. 159

GOOD VEGETATIVE RESPONSE FROM THINNING BARTLETT PEAR SPURS Note the numerous fruit buds at $s$ on spurs which did not push into long branches; - terminal buds at $t$ and axillary fruit buds at $a$ on one-year shoots.

the four or five-branched tree is preferred. While it may be true that the three-branched tree will produce three branches that average larger in diameter than if four or five are allowed to grow, nevertheless, the threebranched tree is considered a dangerous one; that it is structurally weak; that if one of the three branches is lost the tree is practically ruined; whereas, with four or five frame limbs, one may lose a branch and still balance the tree in such a way as to save it. [This is the main idea with the eastern growers who start with more than the required number of frame limbs.] 
The first lesson, then, is to choose four or five wellspaced branches, having them issue in a spiral around the tree, if possible, and having them as far apart as they can be conveniently spaced [not less than a handbreadth, preferably two handbreadths or more]. The farther

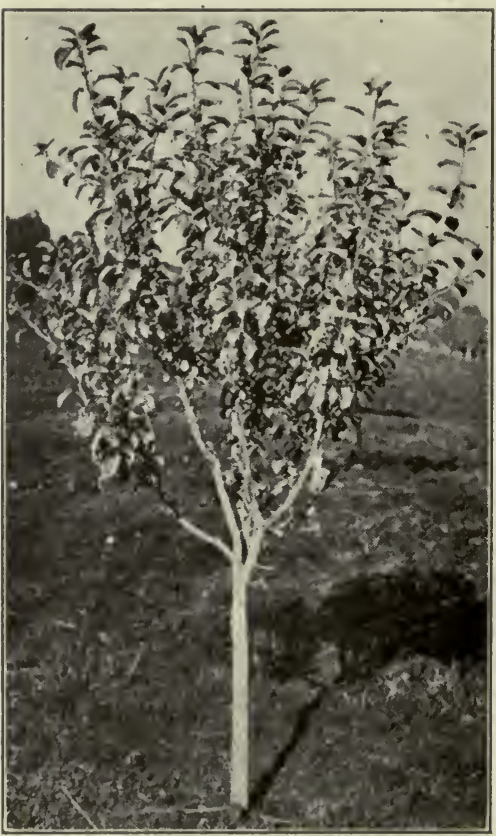

FIG. 160

FIVE-YEAR-OLD WAGENER APPIE TREE

This tree of less than average vigor was pruned in July. The photo was taken in October. Note that there has been practically no growth response as the result of pruning. apart they are spaced, the stronger and better will be the trunk and the better the tree obtained. To do this, one must not neglect the tree as soon as it is headed, but must watch it very carefully the first month or two after it is set out. It will be necessary to rub certain undesirable buds: off, to remove certain undesirable branches, or possibly to suppress from time to time certain branches which tend to run away with. the tree. By observing these simple rules one can build a stronger tree. It is for this reason that growers often advocate cutting the tree at 25 or 28 inches instead of at 20 inches at setting time, and then spacing the branches from as near the ground as they can get them up to the top of the trunk. However, if the tree is left to itself. the branches will all develop near the top of the trunk, and the tree will be weak. Only by careful watching can 
the extra increase in height of head be made of any material advantage.

162. Keep main branches properly dominant.-When one branch tends to grow at the expense of the rest of the tree the weaker branches gradually become side branches to the two or three remaining stronger ones. Proper pruning will obviate this. The average pruner does one of two things: cuts the tree level across the top, or cuts the weakest wood most and the strongest wood least. The former will never build a strong, well-halanced tree, because in doing this no attention is paid to the relation of one branch to another. [The other practice is erroneously based on the principle] that the more wood is cut, the more it grows (83). In other words, it is concluded that if wood is weak and is cut back it will grow stronger!

It is true that the more a tree is pruned back as a whole while dormant the more will be the resulting growth; that heavy heading-in of a tree during winter means a heavy aftergrowth. This, however, has to

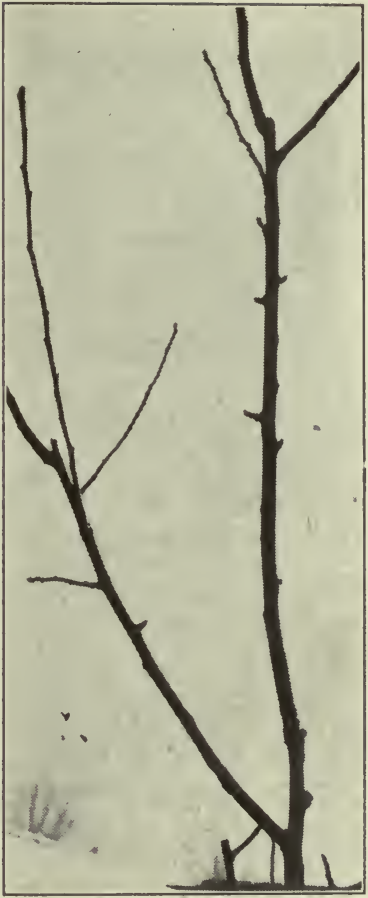

FIG. 161-HEADING BACK MAKES GROWTHS

The lower left fork of this Yellow Newtown apple tree was headed back rather severely, the upper right-hand one only moderately. From the former four shoots and three fruit spurs have developed; from the latter three shoots and nine spurs. This photo shows that heading back, whether heavy or light, tends to increase the amount of shoot growth in the tree. However, heavy heading back affords a greater stimulus to shoot formation and less to spur making than does moderate heading back. do with the tree as a whole and has little to do with the relation of one branch to another. If a strong branch is 


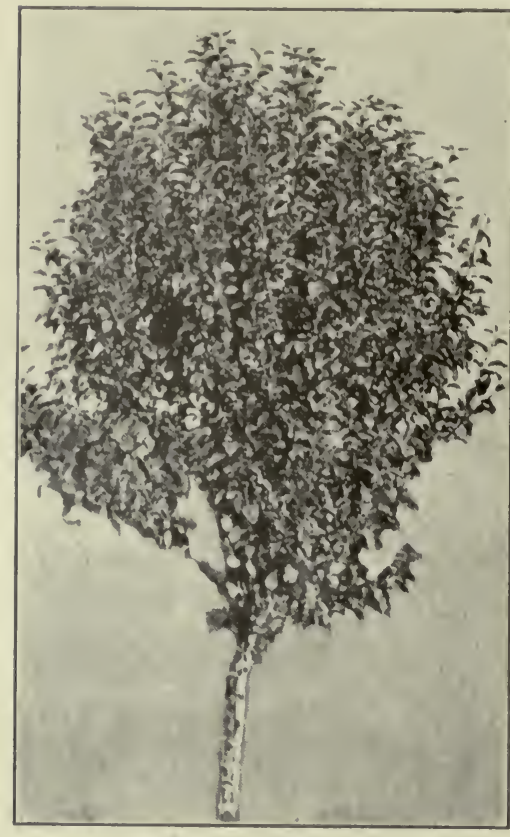

FIG. 162

GOOD EFFECT OF JULY PRUNING

This vigorous five-year Wagener anple tree was pruned in July and photographed in October. A vigorous response of new shoots averaging a foot followed the trimming. in close proximity to a weak one, the best way to strengthen the weak branch is by cutting back the strong onc. The development of the weak branch will be in proportion to its leaf and branch area; if there is a large amount, there will be a heavy demand on the sap, and the weak branch will develop. By limiting the branches and leaves on the strong branch, growth is restricted. As a result, the following year there will be less discrepancy between the development of the two branches. A continuation of the practice should lead to a balance between the two. The heading back should be dlone, then, not so much from the point of view of the tree as a whole, as from the point of view of the relation of one branch to another.

Cut the strongest branch the hardest; cut the second hranch in vigor not quite so much; the third in vigor still less, until the weakest branch is reached. Then cut that onc least. It is only by suppressing the strong branches, limiting the number of leaves and buds, that one can possibly hope to encourage the weaker branches. If it is desired to grow a modified tree, or a leader-type tree, the only difference that need be made in this pruning 
would be to choose one branch for a leader and not cut it back quite so heavily, to maintain that position.

A great deal of so-called corrective pruning may be done. That is, a tree four or five years old may develop two branches weaker than the rest of the tree. These may be encouraged to grow-stronger and larger: To do this, prune them very lightly, and prune the other parts of the tree more heavily so as to encourage the two weaker branches.

163. Avoid sharp-angled, equally balanced crotches.(Compare Figs. 163, 164.) Examine the average frame branch of a tree carefully, from the point where it leaves the main trunk up to its last year's growth. Its development will probably have been about as follows: The first year the branch was cut back it forced out laterals, all except two of which were removed. These two were cut equally and in most cases were not spaced very far apart. The next year on each of these the same treatment was repeated. Two branches were chosen and these were cut equally. The result is that the branches all over the tree are in pairs of equal length, and form very sharp forks. This $\mathrm{makes}$ weak branches which

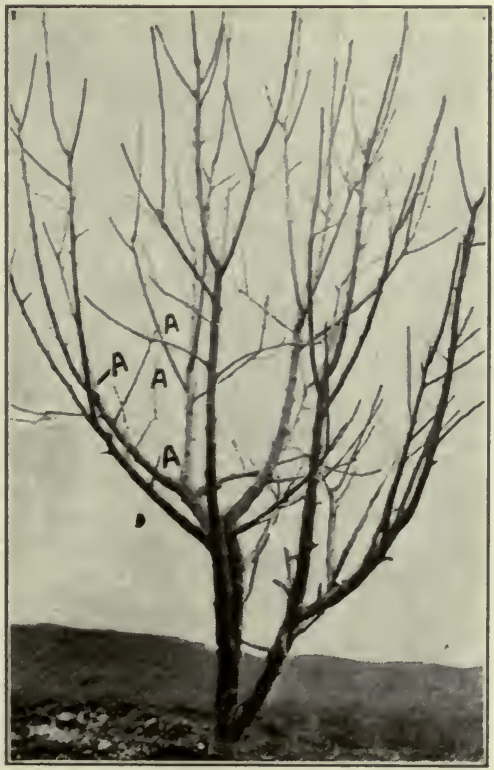

FIG. 163-GOOD EXAMPLE OF PROPER BALANCE BETWEEN BRANCHES

Note that whenever there is a crotch in most cases one branch is stronger than the other. At A A are bad forks due to even cutting. 
will break easily, as the stress and strain all come at critical points; namely, at the numerous balanced crotches

To avoid this condition, treat each of the main branches as a leader. This means that when two branches are chosen, they shall be as far apart as possible. Second. in pruning cut one harder than the other. Thus one will become a leader and the other a side branch. If this

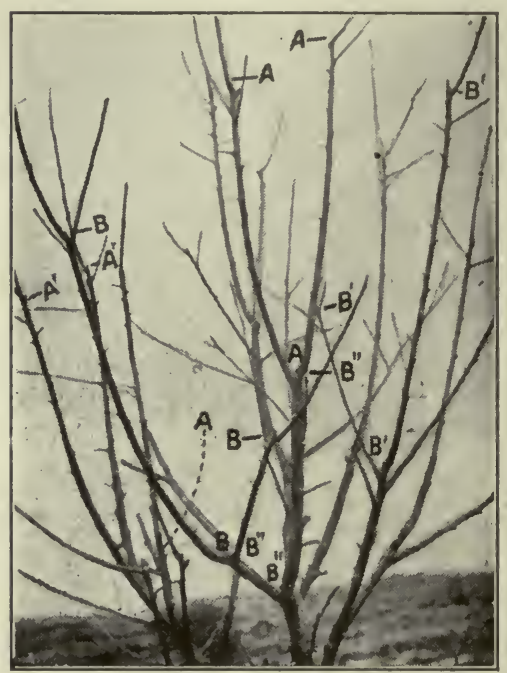

FIG. 164

BALANCED AND UNBALANCED PRUNING

Note that at $A A$, equal cutting has resulted in nearly equal strength of branches; at $B$ B, unequal cutting (the desirab'e me'hod) h's resulted in completely destroying such balance by making stronger crotches.

process is continuer. the whole branch will become a strong learler with a great many side - branches which (listribute the strain in such a way as to reduce breakage to a minimum.

164. Classes of nonbearing trees. - F o r convenience of discussion, young and nonbearing trees may be divided into three classes. First, those from one to four years of age. This is the formative, the bodybuilding period of the young tree. Second, the period from four $t o$ seven years of age, the critical age, a transition period from the body building on the one hand to the heavy fruiting on the other. With Yellow Newtown, Baldwin, Winter Nelis. Comice and many other-trees, pruning at this time wi:1. to a very large degree, determine the fruitfulness of the trees for a number of years. Third, those trees from seven to twelve years, which have reached the bearing age, 


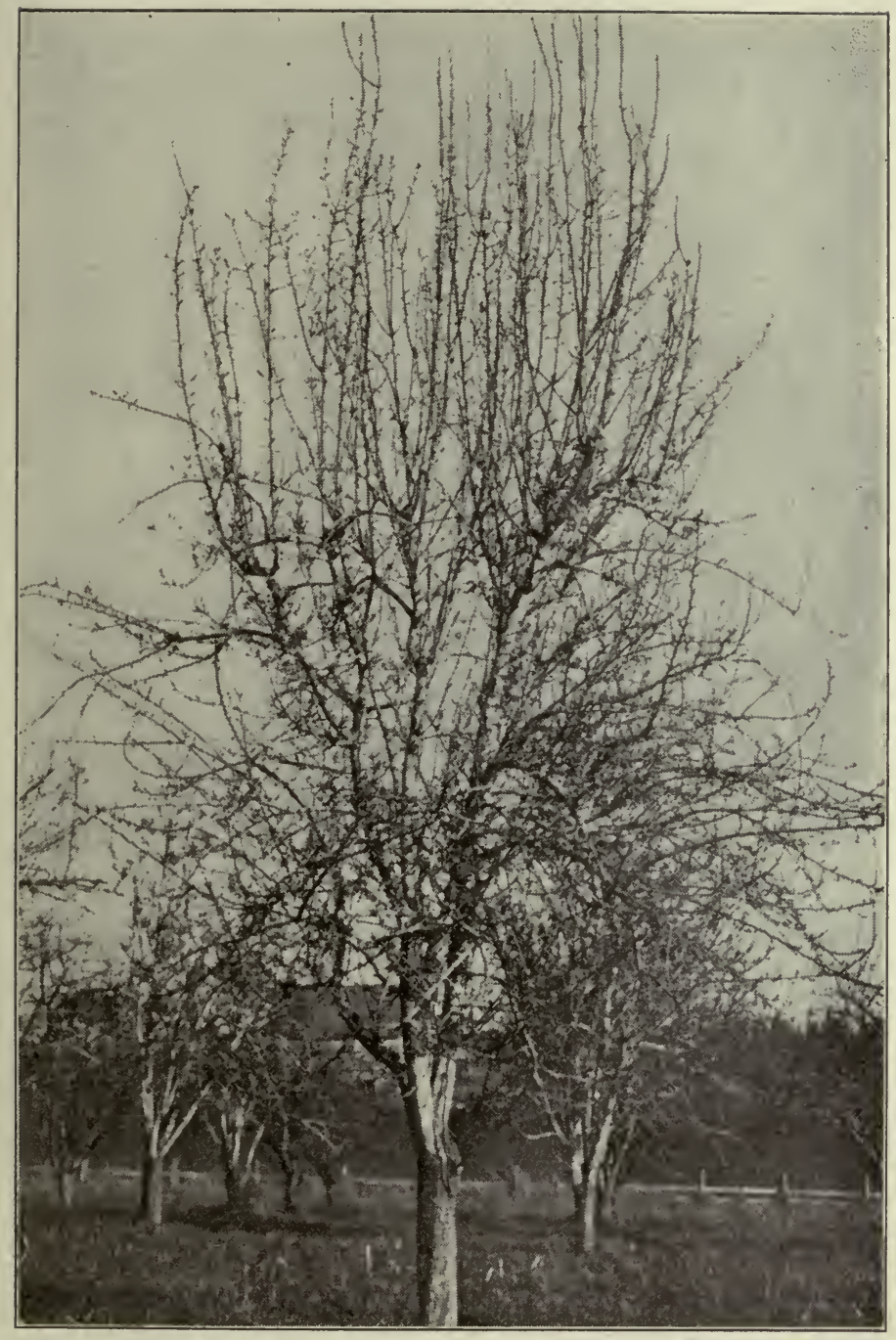

FIG. 165-REINVIGORATED TOP OF OLD PEAR TREE

Dehorned Bartlett pear formed many new, strong shoots and fruit spurs above, but showed littie change in spurs below. Thinning of top probably better. 
but as yet have not borne a commercial crop. Before taking up the details of pruning these three classes, summer pruning and its relation to such trees should be considered.

165. Summer pruning young non-bearing trees.-Of recent years we have heard much about summer pruning. which, with many fruit growers, has become a fad. Many people are expecting too much from it.

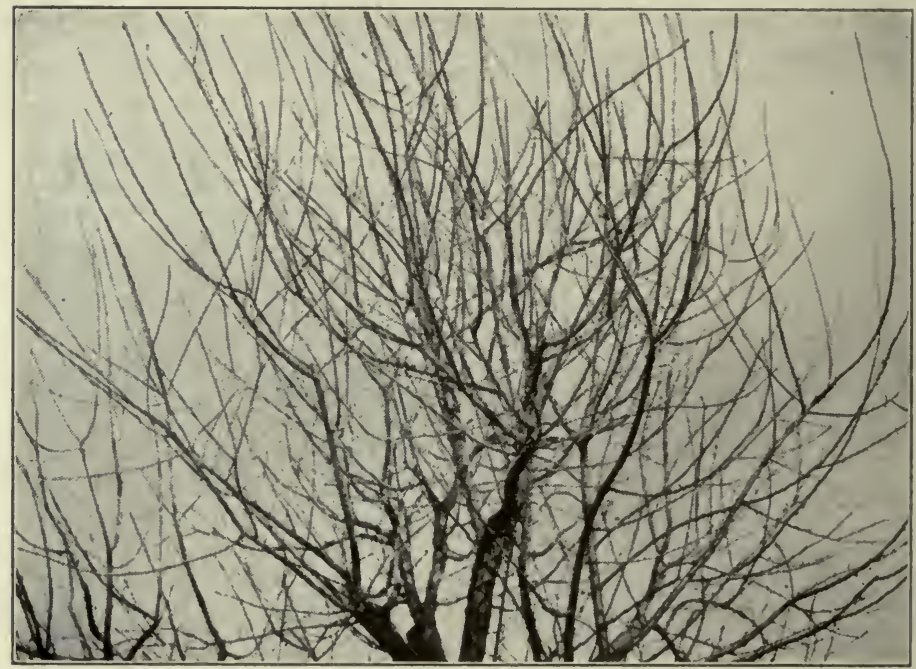

FIG. 166-MODERATE PRUNING STIMULATED SHOOT FORMATION

In this old Tompkins King apple tree two and three years ago moderate pruning stimulated the formation of a rather large number of medium long shoots. These have not been headed back and have consequently developed large numbers of fruit spurs. Many of the small spur-bearing branches should now be removed to afford the remaining ones ample light throughout their length. Thinning out is more needed than heading back here, though a limited amount of heading back will tend to keep the tree from growing too high.

In many cases not much pruning will be done during the first summer of the tree's life, as the trees oiten do not make very much growth the first season, but where they do make a vigorous growth by the middle of June, or early July, it will often be found an advantage to head 
the trees at that time, cutting them back about the same way as they might be cut back the following spring. That is, terminal growths 12 to 30 inches long should be cut back to the point where new laterals are desired for the future body-building of the tree. With a tree running to one or two branches at the expense of all the others. it may be well to pinch these strong branches, to hold them back for the time being, and thus encourage the weaker branches to grow.

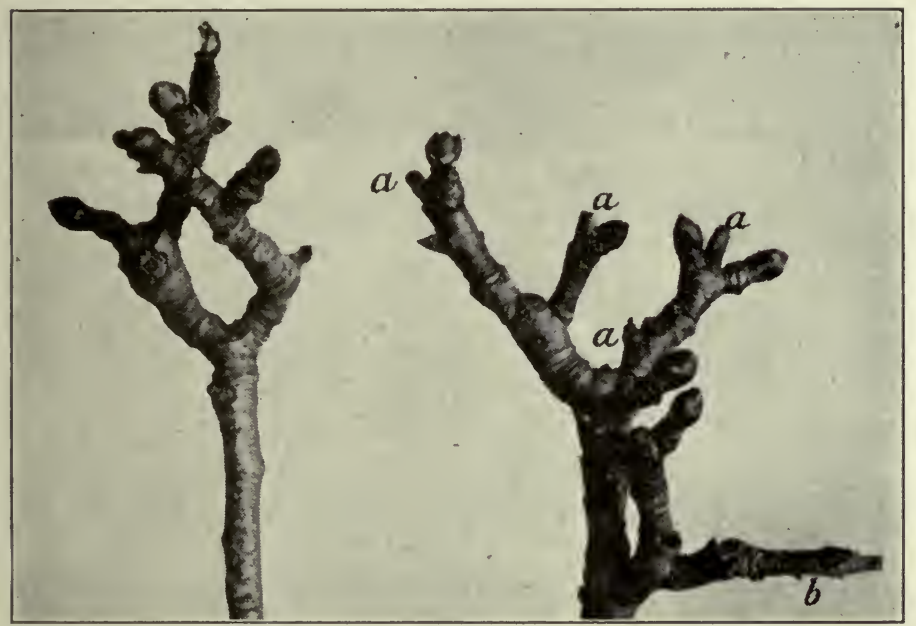

FIG. 167-PEAR SPURS WHICH HAVE BORNE WELL IN PREVIOUS YEARS At $a$ are spurs which bloomed but set no fruit, again producing buds for the following season's crop. At $b$ the same except that no fruit buds formed.

By the second year, nearly all these trees can be greatly benefited by summer pruning any time from the latter part of May up to the middle of July, generally about the middle of June. This pruning consists of cutting back the rank terminal growth so as to force out and allow the laterals to make a good growth and become hardened before fall. In this way a whole year may be gained in forming the framework of the trees. A good practice to 
follow with such trees is to do most of the heading-back in June and most of the thinning out in March or April, or whenever the winter pruning is done. However, should the trees, after they are pruned in June, make such a rank growth that they need some topping-back again the following spring, by all means do it.

In nearly all cases, it will be advisable to do some topping-back of the terminals, or else the terminal bud will

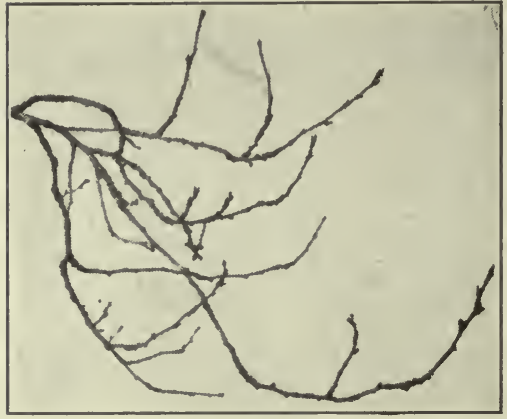

FIG. 169-TOO MUCH SHADING BY UPPER BRANCHES KILLED THIS TWIG

This old, much branched Italian Prune fruit sour is being starved by lack of light. Some of its branches are already dead; the living ones lack in vigor. Only a few fruit buds and these near the tips. Soon the whole spur will die as the result of too much shade from branches above.

growing at the expense of some branch which should be developed. Caution, however, must be exercised against the too strenuous thinning-out of young trees, especially the thinning-out of lateral branches.

This pruning young trees, while it does not, as a rule, directly induce fruitfulness, will tend to bring the trees up to the critical period in much better condition than otherwise, since it tends to balance the tree; and since it distributes the pruning over two periods of the year, it climinates the necessity for very vigorous pruning which many fruit growers give trees. The heavy winter prun- 
ing given young trees serves as a stimulus and often causes too much vegetative growth (83).

166. Objections to summer pruning.-Some growers are opposed to summer pruning on the ground that it weakens the trees, that it is devitalizing, that it is unwise to remove any of the leaves as they are the "lungs" and

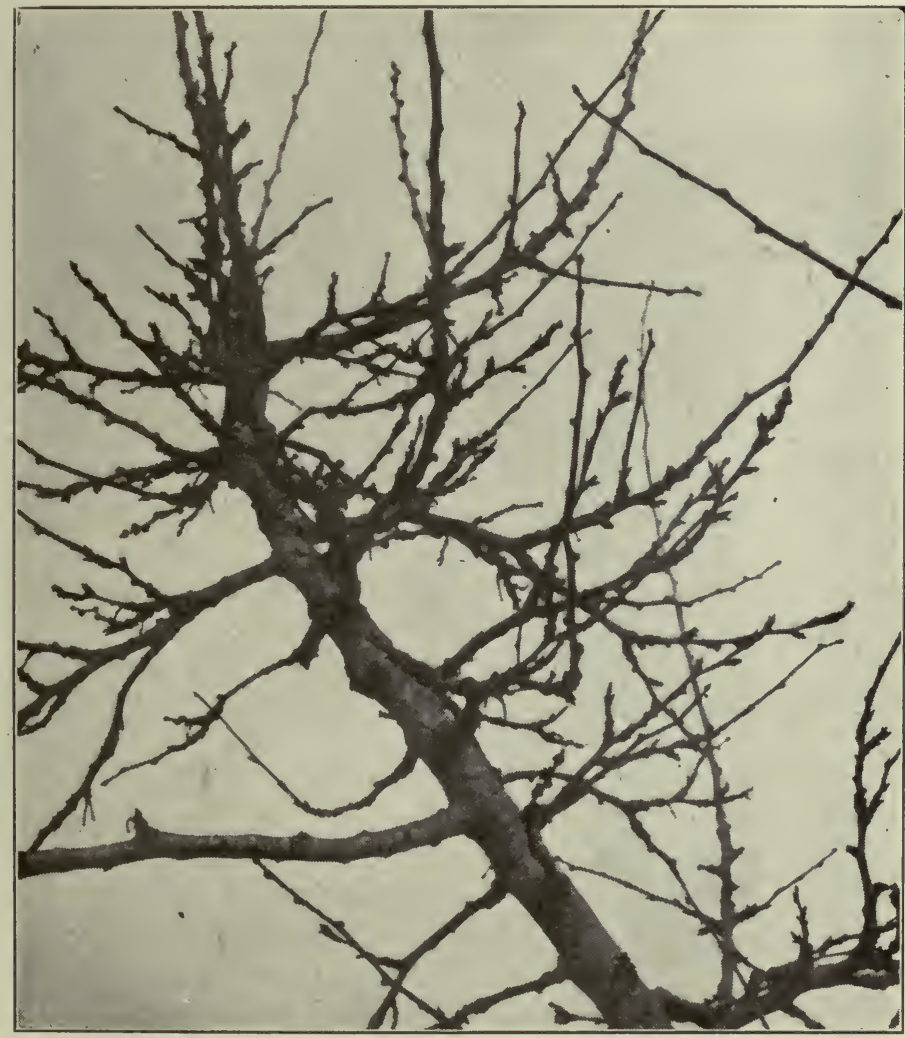

FIG. 169-ABUNDANCE OF FRUIT SPURS IN THE LIGHT

This limb in the upper part of an Italian Prune tree shows that the spurs have had abundant light. Note the individual spurs, and the small fruiting limbs are short, stocky and vigorous. However, it would be desirable to remove a few of the smaller branches to prevent too heavy shading of those below. 
manufacturing organs of the tree (29). It would be, however, only in very extreme cases that summer pruning would ever be devitalizing, certainly where one makes the single summer pruning. Such pruning, in some cases, might give increased vigor. In others very little difference will be noted. In still others, the growth may be modified to the extent that there is less vegetative growth, but even in the last case there is modification rather than devitalization.

The result of a single summer pruning, as recom. mended for these young trees, is not so much a question of vigor as it is a question of change in direction of

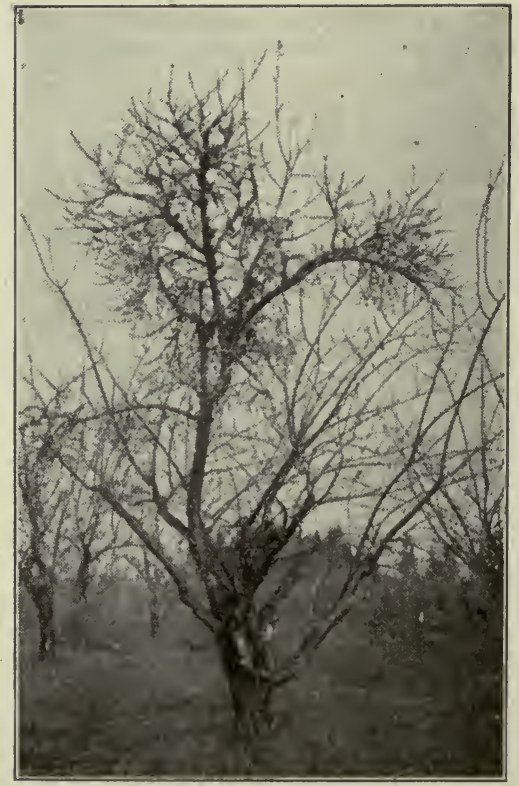

FIG. 170-PARTIAI. DEHORNING FAILED

Old Italian Prune tree partially dehorned four years ago. Note that the treatment ap. narently had little influence upon the vigor of the small fruiting branches and indivifual fruit spurs of the limb not cut back. growth or energy. The clipping-back of a terminal forces the growth into desirable, new lateral framework rather than into a useless, additional terminnal growth. There are cases where frequent summer pruning at short intervals during the summer has a tendency to check or dwarf a tree; for example, in growing dwarf trees, we must not only have a dwarfing stock. but we must practice frequent pinching back of shoots (Chapter XVI). Again walnut trees may be dwarfed by removal of all lateral growth for a period of years. These last two cases, however, are ex- 
treme and represent excessively frequent pruning. The greatest danger of devitalizing young trees does not come rom a single summer pruning, but rather from allowing too heavy bearing of young trees.

167. Trees four to seven years of age have now gone through their formative period. They should have good trunks and frame limbs, and should be approaching that period when they can begin to bear heavy crops. Summer pruning for these trees, as compared with the younger trees, must be modified with the idea of trying to induce fruitfulness directly if pospossible. The pruning will generally come considerably later with these older trees.

There is no definite time to set. It is recommended, however, that the pruning be done at the time the terminal buds are forming on the ends of the shoots. Note that the leaves are beginning to get larger on the ends of the twigs, and the terminal buds a re forming. At that time the termi-

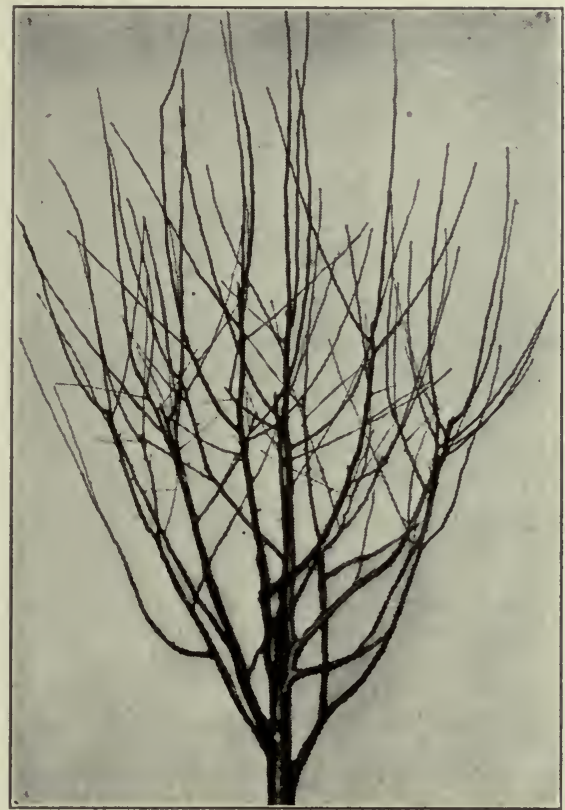

FiG. 171-HEAVY PRUNING MAKES FOR WOOD

This five-year Yellow Newtown has been heavily pruned each year. Last year it received a light thinning out and a comparatively heavy heading back. When compared with Fig. 173, a tree of the same age and variety, it shows how heavy pruning tends to stimulate wood growth as opposed to fruit production. Note the comparatively few fruit spurs on the two-year wood. The tree has been com. pelied to devote its energies mainly to shoot formation. 
nal growth may be cut back to the point where it is desired to force out new laterals for another year's growth. The cutting at this time seems to cause a thickening of the branches, probably an accumulation of tissues around the buds.

With some varieties, probably, it will lead to direct fruiting the following season; with others, however, it will simply tend to keep the trees in balance, and probably encourage earlier fruiting than would otherwise be

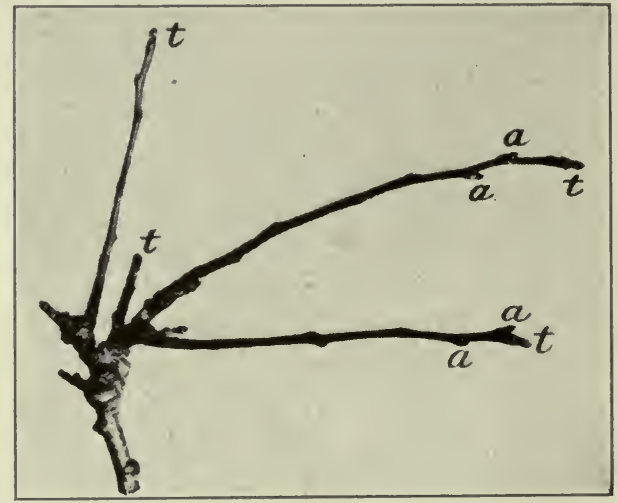

FIG. 172

VIGOROUS GROWTHS FOLLOW THINNING

Bartlett pear spurs were thinned out of old tree. Vigorous shoots resulted. At $t$ are terminal fruit buds; at a axillary fruit buds on last season's (one year) shoots.

true. That is, results may come in two or three years rather than in one year. If this pruning is done at about the right time, very little secondary growth will take place, and what does will naturally be very small. Of course in many cases these trees, four to seven years of age, do not harden-up until late in September or even in October, and then it would be too late to do any pruning to advantage. Even though summer pruning with these trees might not lead to an increase in fruiting the following summer, it would be a distinct help in keeping the trees in balance, and in eliminating the excessive cutting which might otherwise be necessary the following spring.

168. Trees eight to twelve years old, which should be in fruiting but have never horne, have almost always been over-stimulated--over-pruned, over-tilled, over-irri- 
gated, or a combination of stimuli-which results in forcing rank wood growth, producing heavy, large leaves, but little or no fruit. The remedy is to remove the stimulus, whatever it may be, and prune several times a year.

Summer pruning for such trees will come probably more about the time very young trees are pruned: that is, along in June. At each time when the termin a 1 growth threatens to become excessively $10 \mathrm{ng}$, it should be cut back and the trees thinned out somewhat. The following spring a little more thinning and pruning-out $\mathrm{may}$ be done to advantage. The application of summer pruning to these trees should be largely a distribution of the pruning over two periods, thus avoiding an excessive pruning. Only in very rare cases can one expect direct results

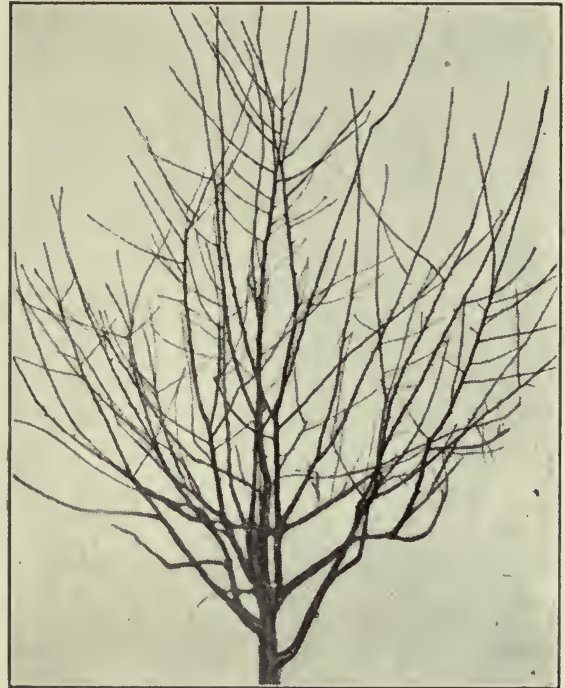

FIG. 173

FRUIT SPURS DUE TO GOOD PRUNING

Five-year Yellow Newtown apple tree rather heavily pruned each year until last, when no winter pruning was done. When compared with Fig. 171, a tree of the same age and variety, it shows how light, as opposed to heavy, pruning tends to throw a tree into bearing. Note the many fruit spurs on the two-year-old wood (enlarged in frontispiece). During the preceding season a large part of the energies of the tree was devoted to fruit spur formation. from such pruning. Results will come indirectly in bringing the trees back to their normal balance. It often becomes necessary to reduce the amount of tillage or irrigation given such trees, and in cases where the growth is ab- 
normally excessive it is sometimes found advisable even to check this by growing crops, such as hay or grain, between the trees.

169. Applications of pruning principles to young trees. At the time the tree is given its first pruning we should definitely settle the question of head (158). Most growers

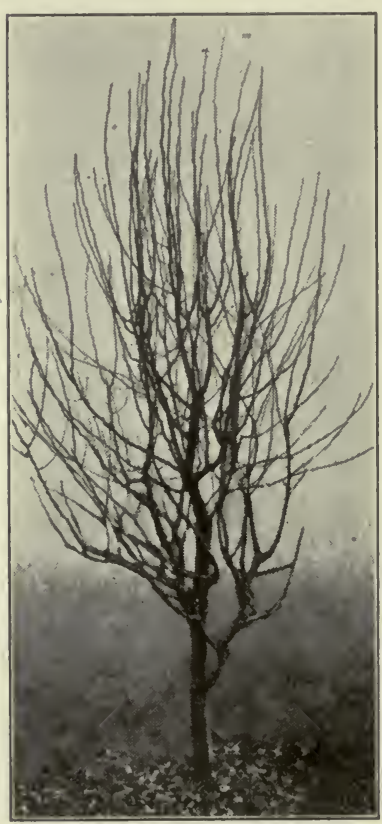

FIG. 174-TYPICAL FIVE-YEAR WINTER NELIS PEAR after they have headed the tree, pay no more attention to it until the following spring, when they are ready for the second pruning. In many cases this is a mistake. It will be found very advisable in May and June to go through the orchard and look over the newly set trees carefully. At this time, certain very small shoots or buds should be rubbed off. If one branch is growing at the expense of all the others, it may be suppressed. The orchardist may do very much the first year to start the tree in the proper way, and to put it in better condition for the second year's 'growth.

Only in rare cases will it be advisable to give the trees a systematic pruning the first year, because it will be only occasionally that the trees will make a sufficiently rank growth to warrant such a pruning. Many young trees do not make much top the first year; they are building roots and getting firmly established. In cases, however, where they have made a strong growth, it is suggested that the trees be summer-pruned as soon as they have made sufficient growth, so that new laterals may be 
formed to advantage. Those shoots that are making such growth should be pinched back, provided this pruning can be done not later than the middle of July and preferably in June. Such laterals should be cut back to stubs from 8 to 15 inches long, depending, of course, upon the vigor of the branch. One may make the mistake, however, of pinching them back so hard as to force the new laterals too near the main crotch, and thus make a very close, heavy crotch which wlll pile up in years to come.

170. The second spring, unless the start was made the first year, one should choose definitely the shape of the tree to be grown; either the open, the leader, or the modified $1 \mathrm{eader}$ tree. If the tree was summer-pruned the previous season, that question should have been settled at the time of pruning. If the leader or the modified

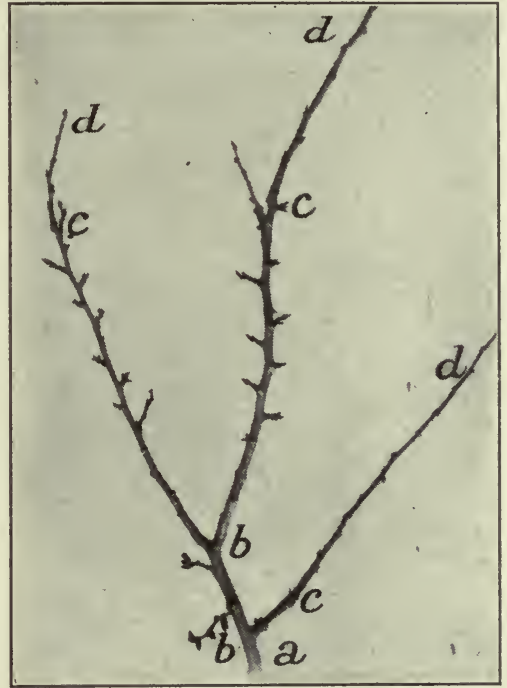

FIG. 175-FRUIT SPURS FORM ON LAST YEAR'S SHOOTS

On this Italian Prune branch the main stem from $a$ to $b$ is three years old. Two years ago three shoots, $b$ to $c$ and two fruit spurs, $b, b$, were formed. Last year three shoots, $c, d$, developed from the terminal buds of the preceding year's growth and many fruit spurs sprang from the lateral buds. The lateral buds on these fruit spurs are fruit buds; the terminal ones leaf buds.

leader is the type, choose one branch to maintain the lead and prune this in such a way that it may maintain such a lead. If the open tree has been decided upon, choose the four or five branches, spaced as far apart as possible, and cut these back according to their strength, cutting the strongest branches the most and the weakest ones 
the least. One will then have five main branches with a few laterals on each. It is customary to remove all these laterals. [But "custom" should be based on principle. Each case should, therefore, be decided by the pruner's best judgment. Cut or leave the laterals as judgment may dictate.] By the middle of June, the young tree should have made sufficient growth to allow for summer pruning. Each branch should be pinched back so as to leave it from 8 to 15 inches long, cutting according to vigor, always suppressing the stronger.

171. In the third spring each of the original five main frame limbs will have from one to a dozen lateral or addi-

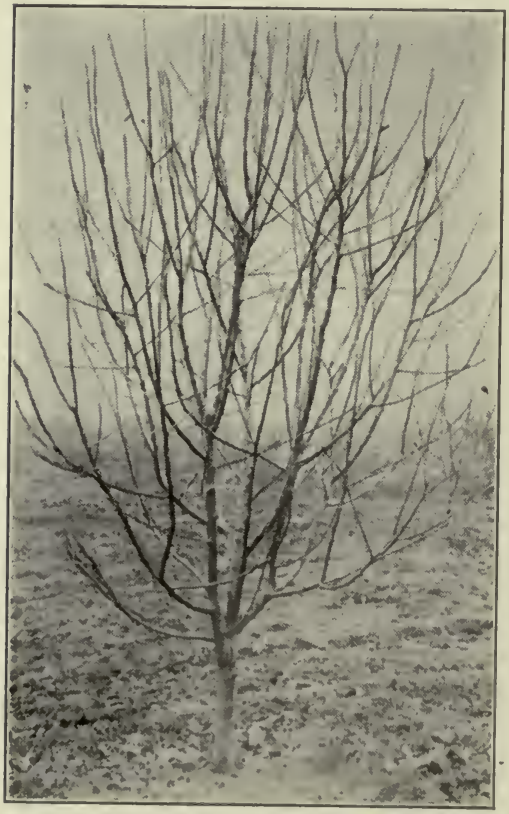

FIG. 176-FIVE-YEAR NEWTOWN PRUNED

The winter pruning has been light because the tree is reaching the critical stage when it should begin to bear. Heavy pruning might keep it from bearing. tional branches. It is customary to remove all but one from each main branch, so that when the tree is pruned there will be ten branches on the tree where there were five before. A great deal of care should be used in selecting these new branches. The two branches on each frame linul) should be spaced as far apart as possible. Of course avoid the choosing of laterals which will tend to grow in toward the center of the tree. Then avoid cutting these two laterals equally. Choose one branch which will grow as a leader and do not cut this back quite 
as heavily as the second branch, which wi11 make a side branch.

By the second [third?] summer, these trees should be so well established that by June they may be given a second pruning. Each branch left on the tree will have grown 15 to 18 , or in some cases, as much as 30 inches long. Instead of letting them go the entire summer, whenever they have made sufficient growth, they may be cut back in order to force out a new set of laterals. The following spring in all probability about the only pruning that will

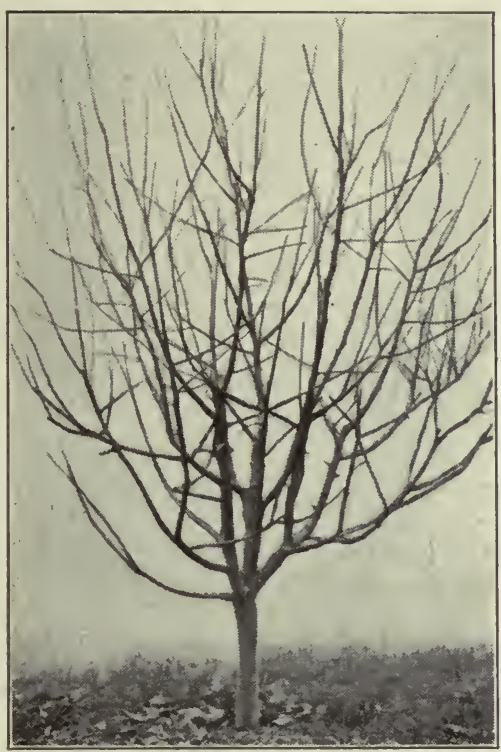

FIG. 177-FIVE-YEAR APPLE PRUNED PREVIOUS SUMMER

Note the length of the shoots which resulted from summer pruning.

have to be done will be a little thinning out here and there. In case the laterals which come out as a result of the pruning in June have made a very vigorous growth, and are getting too rangy, they may be cut back somewhat, although it will be in only extreme cases that much cutting will have to be done on these branches. Moderate clipping back is often advisable to prevent the terminal bud from continuing growth, and producing long, willowy growth. So this pruning may be continued for two or three years, never leaving, as a rule, more than about two branches where one was before.

172. The fourth year.-At the beginning of the fourth year, a modification of the pruning may be made. It is coming time now to let down on the heavy pruning. If 
one practices as severe pruning as during the previous years, the tendency will be to force the tree into wood. Many growers thin out the laterals excessively, force an enormous terminal growth, and cut back this terminal growth vigorously, thus forcing out new laterals. We

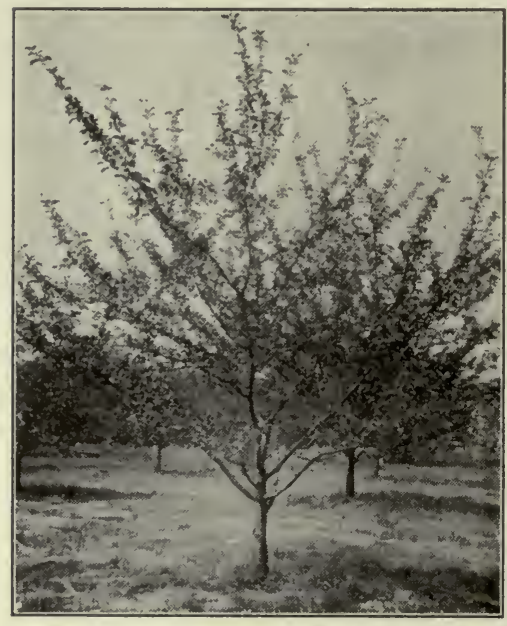

FIG. 178

WELL-FORMED APPLE TREE HEAD

Note how well the frame limbs are distributed and how strong the crotches are. Compare with Fig. 73. believe that too many growers make a mistake by pruning too vigorously at this time. It would be an advantage to leave more lateral wood than most growers leave. Just how much is advisable to leave in all cases is very hard to say, because the relation of shade to the formation of fruit spurs or fruit buds has not be e $n$ worked out very definitely (66 to 69). Until that can be done, it won't be possible to give very explicit directions, but we would rather let the tree grow a little brushy, because after it comes into bearing this excess wood may very easily be thinned out.

The summer pruning now changes from the former early summer pruning in early June to the time the terminal buds form (66). The rule, then, with trees from four to seven years old is simply to cut back the terminals sufficiently so they will not run away with the tree, and thin out so that the tree will not become too dense. If this is followed, the tendency will be for young trees to come to bearing earlier than they otherwise would. 
The amount of pruning that trees, which have just come into bearing will stand, will, of course, vary greatly with their vigor. The soil, the climate, and the variety should all be taken into consideration. There is a great difference in the bearing habits of trees. The amount of pruning which regular bearers, like Jonathan, WVagener, Winesap, Grimes, etc., will stand will vary considerably as compared with the pruning that Yellow Newtown, Northern Spy, Baldwin, Tompkins King or varieties of their habit of growth will stand. As a general rule, the growers of Yellow Newtown on the heavier soils of Oregon are making a mistake with their young trees. In almost all cases they are over-pruning, cutting their trees so hard that whatever tendency the trees may have to bear is directed into other channels.

The directions given so far apply chiefly to apple pruning. Never-

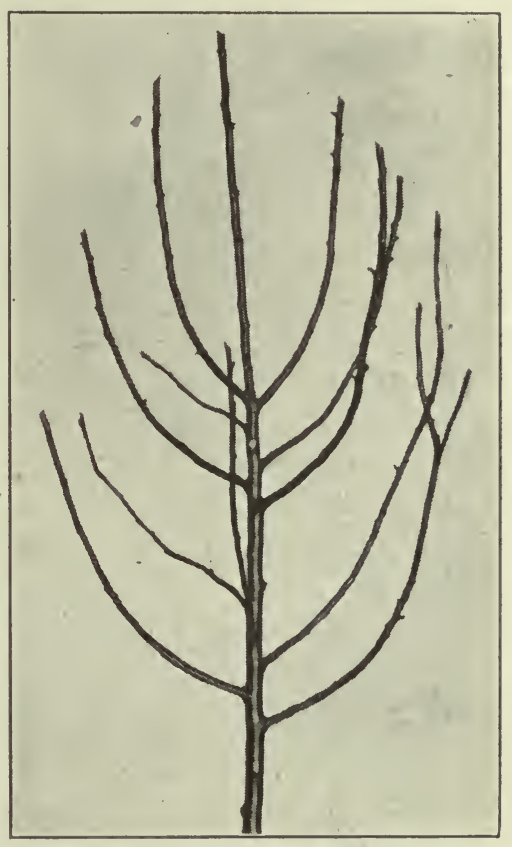

FIG. 179-SPLENDID DISTR FBUTION OF FRAME BRANCHES ON FOUR-YEAR APPLE TREE theless, the recommendations apply equally well to all deciduous fruits and nuts, such as prunes, pears, cherries and walnuts. A few special recommendations, however, may be given for fruits other than apples.

173. Recommendations for pears.-Growers generally feel that it is harder to fight the blight with the leader 


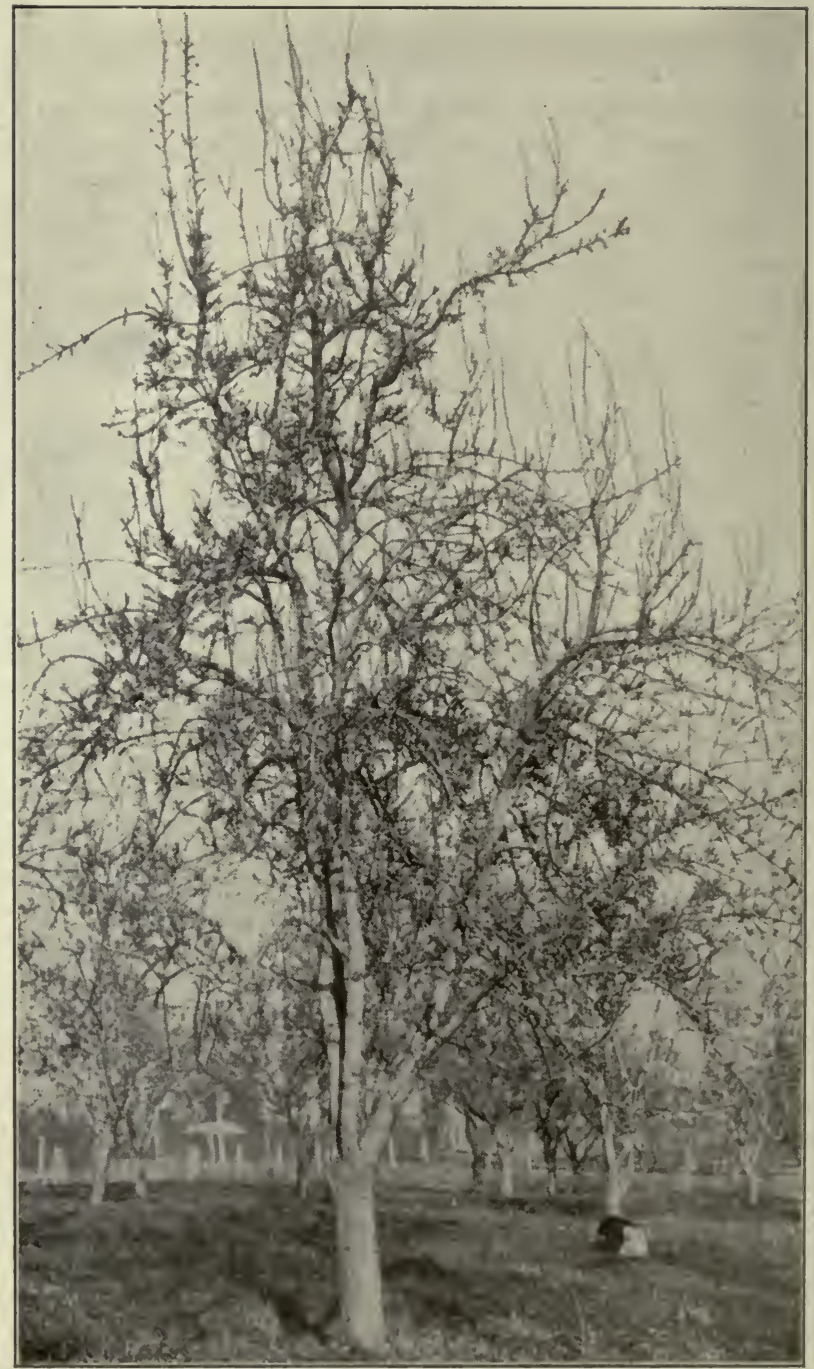

\section{FIG. 180-FAR TOO MANY FRUIT SPURS}

This old Bartlett pear tree has become too full of many-branched fruit spurs. Most of these are weak. Hence they produce flowers and fruit very irregularly -only once in five or ten years. 
than with the open type of tree. So it is generally recommended that either the open type or the modified leader be chosen. They must remember, however, that many of the open trees are very easily damaged by blight and are often ruined because the crotches are poorly formed (Fig. 164). An effort should be made to have the branches spaced as far apart as possible, so if a branch is lost from blight, the remainder of the tree may be easily saved. It should always be borne in mind that fire blight works in succulent growth, and that in handling pear trees one should avoid excessive wood growth.

Pears begin their growth earlier in the spring and cease it earlier in the summer than do apples. This should be specially borne in mind with young trees, if summer pruning is to be practiced. Some varieties of pears, especially Bartlett, have a tendency to form fruit buds and

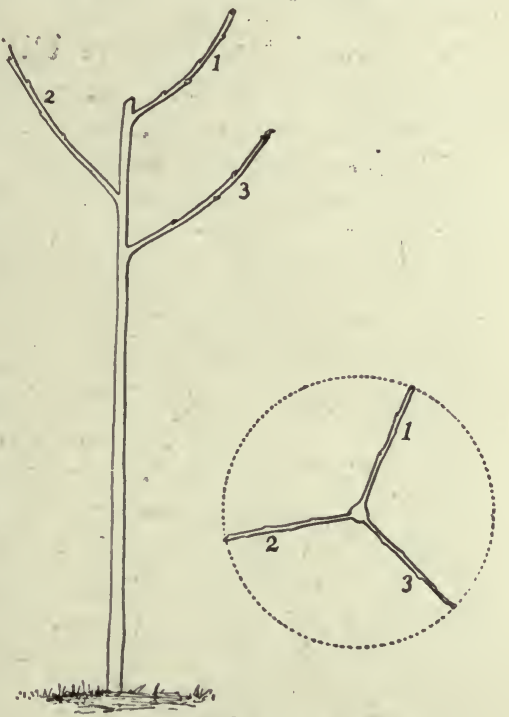

FIG. 181

PLAN OF TREE AT PLANTING TIME Numbers indicate branches

to bear fruit on the ends of the terminals. They will do this often while the trees are still very young, but should be discouraged from bearing in this way. The tendency to bear on such terminals should be overcome by summer pruning. The crooked growth of Winter Nelis and Bosc is very troublesome to the beginner in pear growing. Growers should not, however, worry too much about the crooked growth, for as the trees become older, they will take care of themselves very largely and this crooked 
growth will cease to be troublesome. Prune the trees in practically the same way as those that grow straight.

Pears may carry more lateral wood than apples. They spread relatively farther when they produce a heavy crop, so one should avoid thinning the young trees excessively. Keep all spurs, or fruits (196) from the main trunks and low down on the frame branches, as these are a source of infection from the blight. It is also wise, in pruning in any district where fire blight is troublesome, to see that the pruning tools are carefully sterilized (Fig. 183) before the cuts are made.

174. Recommendations for cherries.-Formerly the cherry was headed at about 35 inches. Many growers head at 20 to 25 . They are building very nice trees. There seems to be a prejudice against pruning a cherry tree. The first six years it may be pruned about the same as has been directed for apples. Summer pruning is recommended, as splendid results may thus be obtained. The cherry has a tendency to shoot up

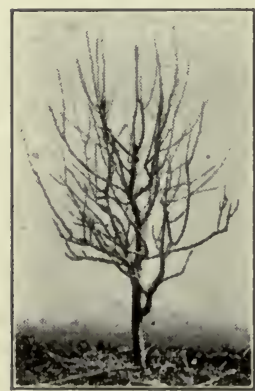

FIG. 182

PRUNED PEAR

Typical five-year Winter Nelis pear tree. Note that the center is being suppressed. This tree gives indication of bearing a crop. If it should bear, it will stand heavier cutting b a ck next season. Compare with Fig. 174. in the air very rapidly, making an enormous growth the first two years. The result is that the average grower has not the nerve in the winter to cut this back severely, so he leaves his trees too leggy (Fig. 184). One way to overcome this leggy, high type of growth is to cut back the terminals in the summer. A very good type of tree to get would be the Mazzard hody, making the trunk and main frame branches of the Mazzard, later budding these over. This will give strong crotches and there will be little gumming and loss from trees of this type. Should cherry trees need heavy cutting, do not hesitate to take large branches. However, take care to protect the wounds carefully 
as cherry wood is softer than that of most pomaceous fruits.

175. Recommendations for prunes and plums.-The recommendations for apple trees apply very closely. The trees are generally headed higher than any of our other fruits, 30 to 35 inches. Some growers, however, are heading at 20 to 25 . The tree never becomes extremely highheaded, and since most of the fruit, which is to be evaporated, is allowed to drop on the ground before harvesting, the height of the he ad from the harvesting point of view does not need any con$\mathrm{sid}$ e ration. $\mathrm{H}$ o w e ver, growers will probably get better results by constantly suppressing terminal growth a nd thinning out the centers where these be-

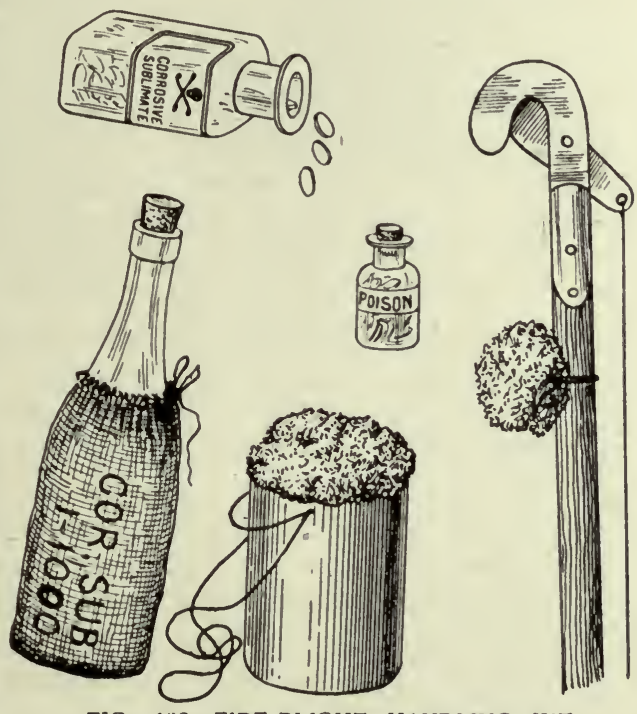

FIG. 183-FIRE-BLIGHT HANDLING KIT

Corrosive sublimate in bottle. One tablet to a pint of water makes a 1 to 1000 part solution. The can containing the sponge is fastened to the belt. The largest bottle is similarly fastened. It is uncorked and tilted to wet the sponge in the can when necessary. The pole pruner has a sponge to swab cuts as made. A wooden bucket with a large sponge to clean out cankers completes the outfit.

come too dense, so as to allow the development of strong wood. Do not overdo this, however, by removing all small laterals, spurs and secondary branches. Also, do not remove too much wood from the outside of the tree, and yet keep the tree fairly open. Many growers 
of young trees practice cutting off considerable wood on the outside of the tree and leave the centers a little dense. The reverse is the better policy. Try to keep the trees low headed, broad and low spreading, so as to build a large framework for fruiting wood in succeeding years.

176. Recommendations for English walnuts.-Trees should be headed at about 35 inches, and at the time they are headed a heavy stake 7 or 8 feet long should be driven in the ground close to the body of the tree. The first summer choose four or five laterals that will give a good framework and tie these to the stake. If this is not done they will tend to droop to the ground too much, but by careful tying one can keep them well in shape. The following spring cut back the trees exactly as though they were apples. In many walnut trees one branch may grow up 6 or 8 feet -3 or 4 feet higher than any of the other branches.

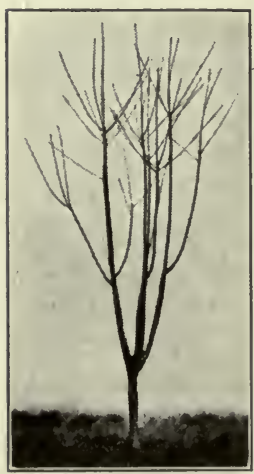

FIG. 184

POOR TYPE CHERRY

All the main branches issue at one point. Note how "leggy" the tree is. This is due to insufficient heading back the first two years. Heading this tree back twice a year might have been help. fui.
Cut this back hard so as to bring on the other branches. Generally the pruning should be done just before the starting of the sap flow. Formerly the trees were allowed to grow three or four years, all laterals were taken off and the trees grown to poles. We find that when they are handled as though they were apples, we get more spreading trees with larger fruiting areastrees which will be much easier to handle from the orchard management point of view.

177. Recommendations for peaches. The peach has a different fruiting habit from any other trees we have mentioned (56). However, the aim in pruning such trees the first few years is much the same as that for other types of fruit: namely, the building up of a strong framework for future years of 


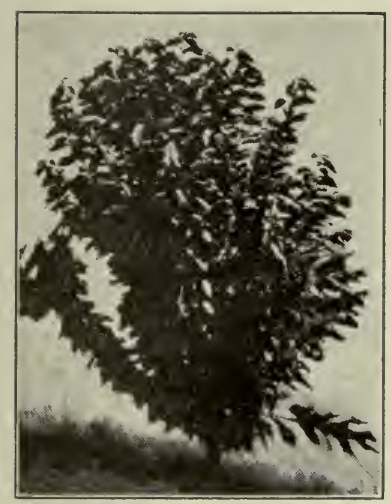

FIG. 185 - THREE-YEAR LAMBERT CHERRY BEFORE EARLY JULY PRUNING

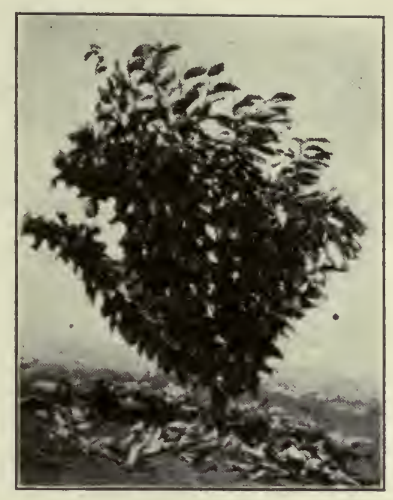

FIG. 186 - THREE - YEAR - OLD LAMBERT CHERRY TREE AFTER PRUNING IN EARLY JULY

fruiting. The peach, when secured from the nursery, is generally too large and has a large number of branches. An ideal tree is a straight whip, but it is almost impossible to buy such trees. Under our soil and climatic conditions the trees tend to grow very vigorously in the nursery. A general heading to about 18 to 20 inches is recommended.

If whips can be secured, they should be pruned as is customary with the other trees. If there are a few weak laterals, they should be removed, but if the trees have strong laterals, instead of removing all lateral growth, which is practiced by some growers, half a dozen wellspaced branches should be chosen and cut back to one or two buds. This will give a large leaf surface the first year, will remove the danger of having a tree stand with only one or two branches, and also will remove the danger of the tree's dying. Under our climatic conditions a great many peach trees, when they are pruned back to whips, after they have once formed strong laterals, never start to grow. Some trees will force out new buds and shoots, but others will not. If, after the buds start on the 
short laterals, there are found to be too many, it will be a simple matter to thin out undesirable growth.

It is customary to try to head peaches as low as possible; to have the first branch to come out very close to the ground and to get the crotches as well spaced as is consistent with the amount of area one can work with.

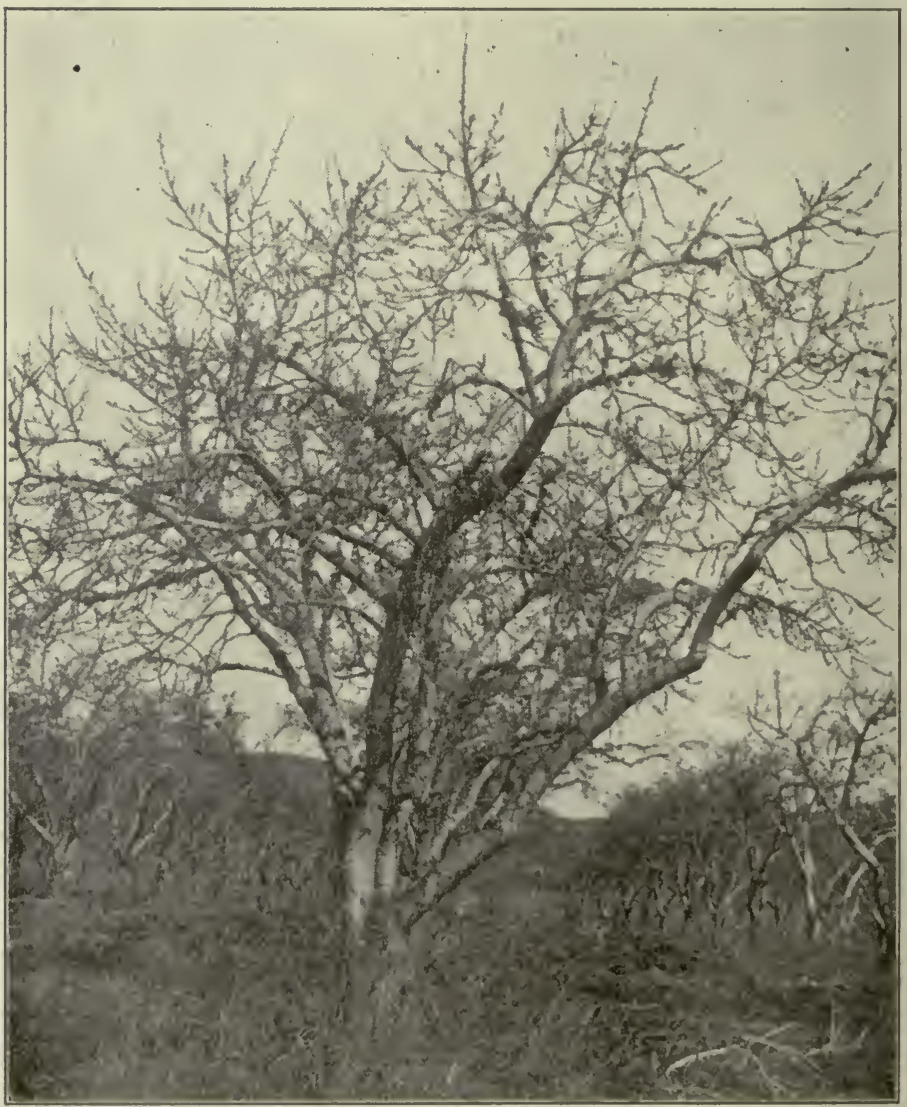

FIG. 187-OLD PRUNE TREE AFTER RFMOVAI OF DEAD WOOD AND SEVERE THINNING OF THE LIVING SPURS 
At the end of the first year choose four or five of the best spaced branches and cut them back on an average of 8 to 12 inches. Not much summer pruning is practiced for peaches. By the end of the second year the tree should be cut back again so it will be $3 \frac{1}{2}$ to $4 \frac{1}{2} / 2$ feet high. Constantly train the tree to spread by cutting to outside. buds, constantly forcing the tree to make a broad, spreading top, rather than to allow it to shoot up in the air. It takes more nerve than the average grower has to cut the tree as hard as indicated, but it is neccssary if one is to keep it near the ground and have profitable fruiting.

It will be necessary to cut off about two-thirds of the last year's wood from the inside of the tree. Practice this constantly with the peach. The aim should be to keep the center open so as to give light and develop strong wood. Cut out all weak wood and limit the amount of annual wood so what is left may grow strong. It

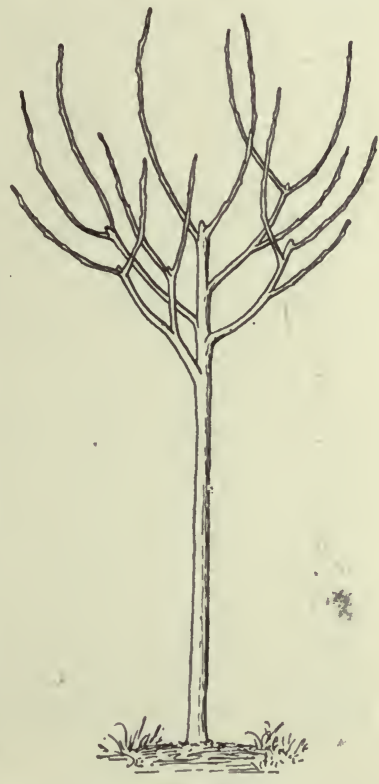

FIG. 188

FIVE-BRANCHED TREE AT END OF FIRST SEASON will be only on the strong wood that large peaches will grow. Growers, however, may go to extremes in growing vigorous wood. If the wood becomes too vigorous the first two crops will be borne on the ends of the shoots and it will be almost impossible to prune the trees and still have any fruit. Medium-sized wood is more desirable. If the wood is getting too vigorous be sparing in the pruning and it will tend to check the trees. A little summer pruning may be used to advantage where the 
wood tends to become excessive. Not much fruit should be looked for until about the fourth year.

178. Best height for peach tree head.*-There is considerable variation in the recommendations and suggestions of various authorities as to the proper

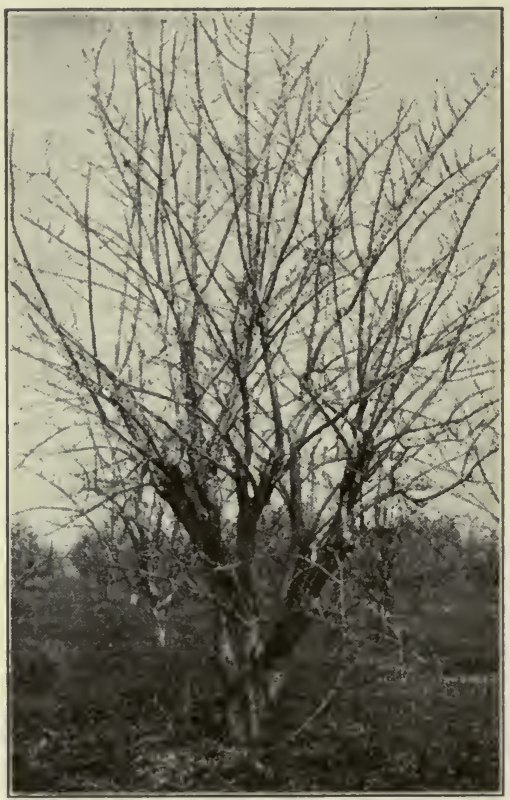

FIG. 189

NEGLECT FOLLOWING DEHORNING

Four years ago this old Italian Prune tree was "dehorned" for renovation. Little or no pruning has been done since. Last year the tree bore a small crop of prunes on spurs that had developed on the water sprouts stimulated by the dehorning. There is promise of a medium crop this year; but the newly formed spurs in the lower part of the tree are already declining because of too much shade. To keep them from getting long and willowy, and finally dying, considerable thinning out is necessary. Heading back which would stimulate the formation of more water sprouts would increase the trouble. Compare with Figs. $30,31,150,159,161,165,166$ and the explanations accompanying them. method or degree of pruning peach trees at the time of planting. A common recommendation is to cut the trees back to a height of from 18 to 24 inches regardless of grade. Some recommend cutting back the trunks to 6 inches and others even 30 inches. These suggestions are apparently based on some ideal with respect to the height at which the individual prefers to have the branches form.

In order to secure a relatively low-headed tree, one must cut back the trunk of the nursery tree rather severely at planting time to make it branch low. This has led some to believe that the more severely the tree is cut back the lower the head will be; and that hence spraying and picking the fruit may be performed more easily. But the mere cutting back of the trunk to a low point does not necessarily mean that the fruit may be picked more easily or the tree sprayed more economically than from one whose head is formed several inches higher (Fig. 72). For example, some fruit growers cut the trees back to a six-inch stub at the time of planting and then proceed to remove all side branches that form on

* Paragraphs 178 to 186 condensed from M. A. Blake's Bulletin (293) of the New Jersey Experiment Station. 


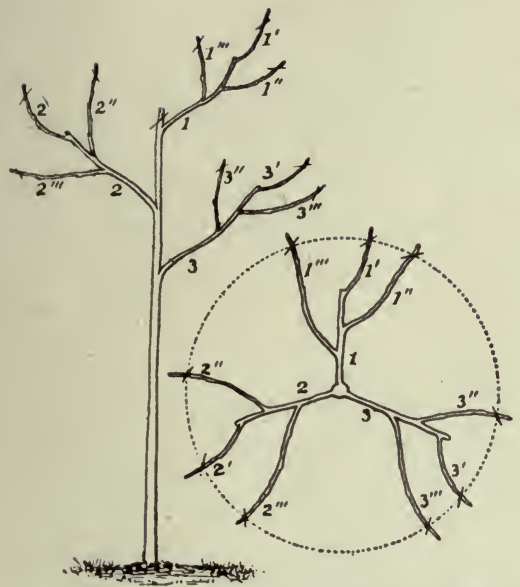

FIG. 190-PLAN OF TREE TOP AFTER ONE SEASON'S GROWTH IN ORCHARD

Numbers indicate primary and secondary branches and the little cross lines the positions to make pruning cuts.

whether the trees are freshly dug from the nursery at time of planting, or whether they have become severely dried out for some rea son before planting. The variety may also be a factor, as would certainly the grade or size of the trees.

Although "June buds" are used to some ex. tent in New Jersey for planting, most growers purchase one-year-old trees, hence these studies are confined to trees of that age. Such trees are commonly graded by height and caliper. Trees of the same height may vary considerably in stockiness or caliper as grown in different nurseries, so the caliper method is the better basis for a study of differences in vigor. As representing common sizes offered for sale the following sizes of trees were used in the experiment: caliper $7 / 8,3 / 4,5 / 8,1 / 2$ and $3 / 8$-inch. The pruning treatments studied were as follows: 1 , not pruned; 2 , back to 36 -inch trunks; to 30 -inch; to 24 -inch; to 18 -inch; to 12 -inch; to 6 -inch.

One of the principal objects of cutting back the tops of trees at the time of planting is to reduce the twig surface to balance the loss

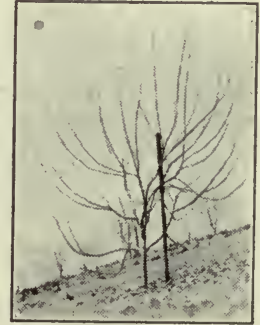

FIG. 191

ENGLISH WALNUT

This three-year tree is properly staked. In pruning, the two lowest laterals should be cut and last year's growth cut back. The tree was It would be better if 5 or 6 inches higher. headed at 30 inches. 
due to digging, and therefore to decrease the danger of loss of trees and to secure a better growth.

The experiment was started in the spring with two lots of Elberta trees. One lot consisted of trees which had been dug the previous fall and kept in a large nursery storehouse. Such trees are nearly always drier than freshly dug trees. It was planned to compare these with a lot of freshly dug trees, but the latter lot became badly dried out because of improper handling by the nurseryman before they were delivered, the bark upon many of the trees being badly shriveled at the time of delivery. This, however, furnished an equally good comparison, although from another standpoint.

Thirty-five trees of each grade were selected making five trees to each pruning treatment. The roots were left in the form in which

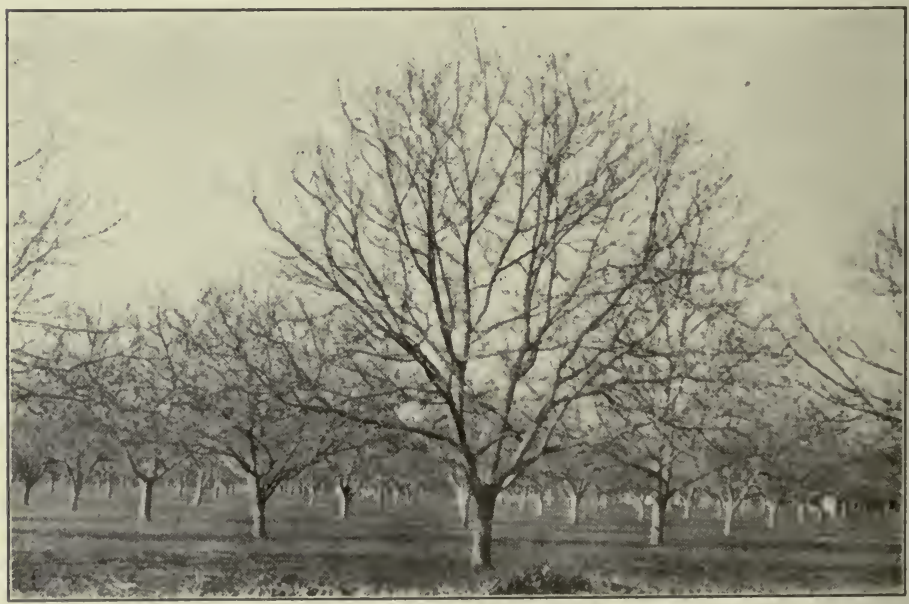

FIG. 192-SPLENDID TYPE OF LOW-HEADED, SPREADING ENGLISH WALNUT

they came from the nursery except that any broken tips were cut off cleanly. They were all planted the same day in good soil and were given good culture throughout the season.

At the close of the growing season and after the foliage had fallen, notes were taken as to the number of living trees, and measurements were made of the linear twig growth upon each tree. There were $\mathbf{1 7 5}$ of the stored trees at the time of planting, 35 each of five grades. All lived except one in the $3 / 8$-inch grade which had been pruned to 30 inches. One tree of the 78 -inch grade was slightly injured in cultivation and was not averaged with the thers of the 12 -inch treatment. This experiment shows practically 
no loss of trees through lack of cutting back of the top at the time of planting, as all the unpruned trees were alive at the end of the growing season.

180. Effect of pruning upon total twig growth.-On the basis of a comparison of grades regardless of any pruning treatment the $5 / 8$-inch trees made the best average total $\mathrm{grow}$ th, closely followed by the $1 / 2$-inch trees. The smallest average total growth was made by the $3 / 8$-inch trees. A comparison of the various pruning treatments regardless of $\mathrm{grade}$ shows that the best a ver a g e total growth was made by the trees pruned to 36 inches and the next best by

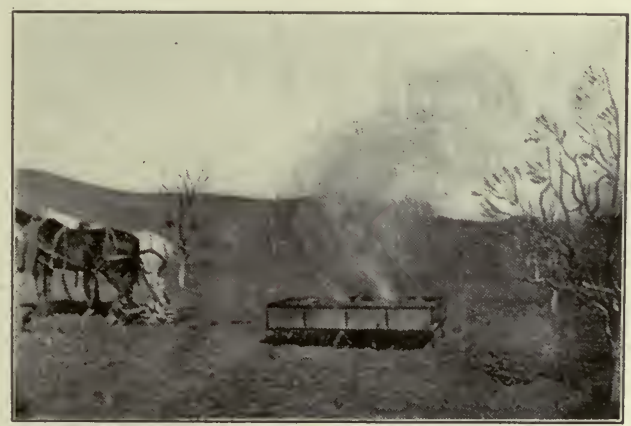

FIG. 193-PORTABLE BRUSH INCINERATOR

Built of sheet iron on runners. Holes in the bottom admit air and allow ashes to fall out. those cut back to

12 inches. The lowest average growth was made by the trees cut to 18 inches. The unpruned trees made a very creditable and uniform growth in comparison with the other treatments based on total growth regardless of form.

181. Effect of pruning growth of dried-out trees.-When the driedout trees were received the bark was much shriveled and the roots in a dried condition, but they were soaked in water for several hours, heeled into moist soil for a few days and then pruned and planted. The same number of trees were used as in the experiment previously noted, except that it was not possible to secure trees of a $7 / 8$-inch grade.

A record of the number of living trees at the close of the season's growth clearly indicates, as would be expected, that the small trees suffered the most from the drying out in transit. The roots of $3 / 8$-inch trees are all small and easily dried out. The bark of twigs and trunk of the smaller trees probably also permits more rapid evaporation of moisture than does that of the larger trees.

One would expect to find the greatest loss among the unpruned trees and the least among the 6 -inch trees. This is practically true, but it is worthy of note that the 12 -inch treatment and the 36 -inch treatment have as high a percentage of living trees as the 6 -inch, and that the 18 and 24-inch treatments suffered nearly as much loss as the unpruned trees. This is significant in connection with the comparisons on the basis of total growth in the various treatments. 
The loss of so many trees in the $3 / 8$-inch grade seriously affects the number to be averaged as to total growth. The dried-out trees made hardly more than a third of the growth that the stored trees did.

The best average total growth among the dried-out trees was made by the $5 / 8$-inch grade. A comparison on the basis of pruning treatment regardless of grade shows the following: The unpruned trees made the poorest average growth; the 36 -inch treatment resulted in the next poorest growth; the 30 -inch treatment resulted in the best growth; the 24-inch treatment resulted in the next best growth. It was to be expected that the unpruned trees of this lot would make the poorest growth, and one might expect that the more severe the pruning the better the growth. This is true to a certain degree, but it does not follow in regular proportion to the severity of the pruning. Another factor appears to enter into the case.

182. Studies with freshly dug nursery trees.-The following spring trees of the Belle of Georgia variety were secured freshly dug from

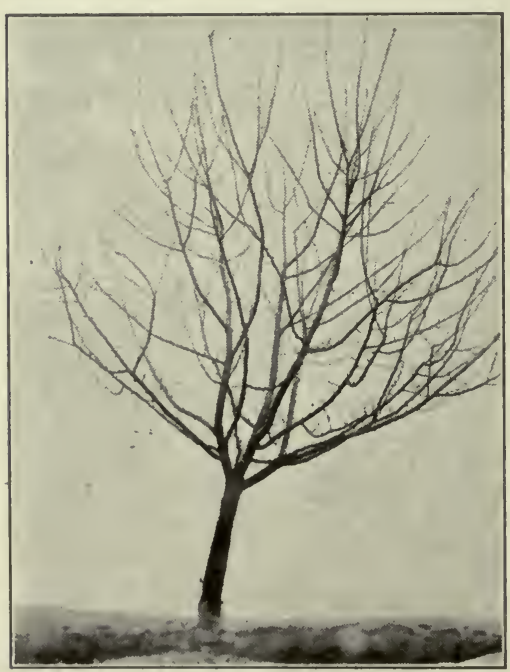

FIG. 194

WELL PRUNED AND OPEN HEADED

Such a tree facilitates spraying, thinning and harvesting and produces large crops of better fruit than does a neglected tree. Compare with Fig. 314. and character of growth as
related to successful support of a heavy crop of fruit later and to related to successful support of a heavy crop of fruit later and to sequence. In order to determine and show the effect of pruning mediately planted. The same grades and pruning treatments were used as in the former tests. Two trees out of 140 in the 36 -inch treatment died. One was of $3 / 8$ inch caliper ard the other $1 / 2$-inch caliper. The results of this test in terms of twig growth show that the larger the grade the poorer the growth of unpruned, freshly dug trees. The smaller the grade the better is the growth of 6-inch pruned trees. Or expressed in other words, the larger the trees the more they are depressed in growth by a 6inch stub pruning treatment.

183. Distribution and size of branches.-A free, vigorous growth is clesired the first season the trees are set, but mere volume of growth is not the only consideration in a commercial fruit planting. The form and character of growth as
$y$ crop of fruit later and to

a local nursery and im- 
upon branch formation upon the trunk, the number of branches tc each 6 inches of trunk was noted in all grades and treatments of the experiment with Belle of Georgia trees. The numbers of branches at various heights upon the unpruned trees are of direct interest because they should indicate fairly accurately the distribution of buds and branches at the time the trees were set. As dead branches were not recorded, however, the actual distribution of branches at time of planting may not be accurately indicated by these figures.

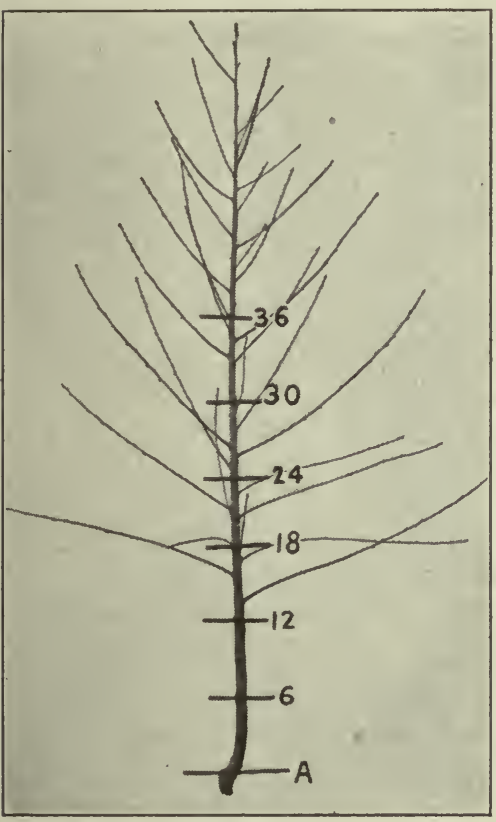

FIG. 195-GOOD YEARLING PEACH

This 1 -inch caliper tree is exceptional as to size and branch development. The numbers indicate the height in inches from the bud at $\mathbf{A}$.

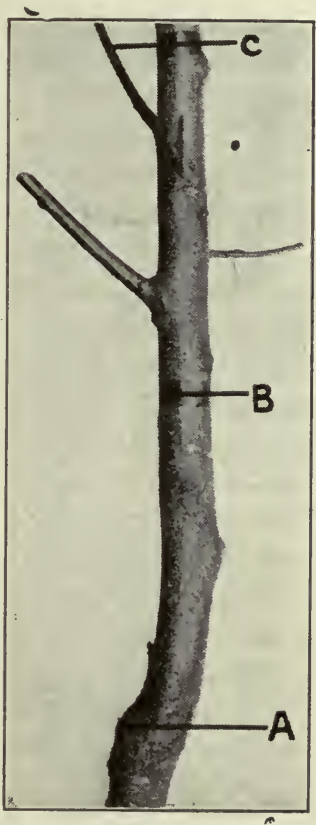

PEACH TRUNK, 1

Close view of lower part of one-year trunk. Note buds and branches.

The observations upon the unpruned trees as a group show that the number of branches increases for each succeeding 6 inches of trunk from the ground to a height of 24 inches. From this height to 36 -inch the number remains quite uniform and then decreases for each succeeding 6 inches of height. The unpruned trees of the $3 / 8$. grade vary to a slight degree from this rule. The decrease in 
the number of branches to each 6 inches of height of trunk begins at the 24-inch height instead of at the 36-inch height in the case of the larger trees.

In a further study, the results show that the largest number of branches to develop upon the first or lowest 6 inches of trunk-occur

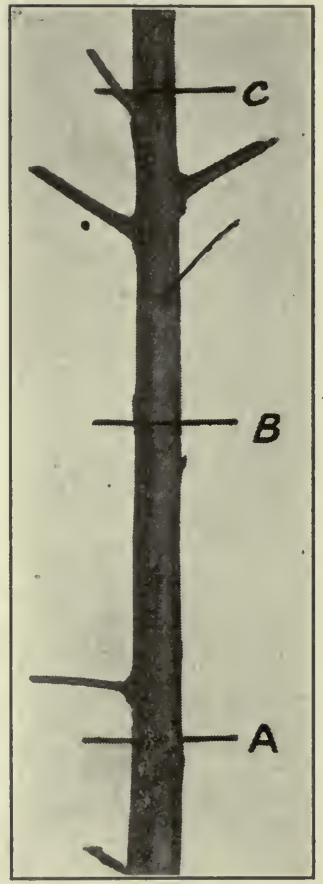

FIG. 197

PEACH TRUNK, 2

This is a close view of the upper section of a trunk one year old. Letters show 6 inch lengths. Note bud and branch formation. in the 6 -inch treatment. The largest number of branches upon the second 6 inches of trunk, or from 6 to 12 inches above the point of budding, occurs in the 12-inch treatment. The largest number of branches upon the third 6 inches of trunk is also found to occur in the 8-inch treatment. Thus far, then, branches have developed more freely upon the 6 inches of trunk immediately below the point where the tree was cut back. The trees in these treatments, then, follow the plant law that growth is strongest at the tips of the branches (91).

Beginning with the 24-inch treatment, however, the largest number of branches is not found upon the 6 inches of trunk immediately below the point where the tree was cut back. Before this exception is discussed further, it may be well to note what the results were in the case of the other lots of trees. At that time the location of the branches upon the unpruned trees was not considered to be of any practical importance.

One lot of trees behaved somewhat differently from that just referred to. There appears to be a great tendency for trees at all dried out to develop the greater number of branches on the first 6 inches of trunk near the ground regardless of the pruning treatment. This is to be expected perhaps since that portion of the tree would dry out more slowly than any other. Tre trees pruned to 12 and 13 inch trunks did not develop the greatest number of branches along the 6 inches of trunk immediately below the point of cutting back, as was the case with the freshly dug trees.

Several other facts may also be noted. The number of branches developing on the first 6 inches of trunk tends to increase with the severity of the pruning. The 18 -inch treatment falls below its proper place in the scale, but the figures undoubtedly correctly indicate the 
condition of this lot of trees.

The number of branches developing on the second 6 inches of trunk is also limited in the 18 -inch treatment. The unpruned trees and the 36 -inch treatment of the freshly dug Belle of Georgia trees developed the largest number of branches on the 18 to 24 -inch section of the trunk. The 36 -inch treatment of the stored Elberta trees, however, developed but few branches on the 18 to 24-inch section of trunk, and developed by far the largest number on the first 6 inches.

It is evident that the branch formation upon the pruned trees is largely controlled by the distribution of the buds upon the trunks of the nursery trees. Upon the larger grades of stored Elberta trees there were

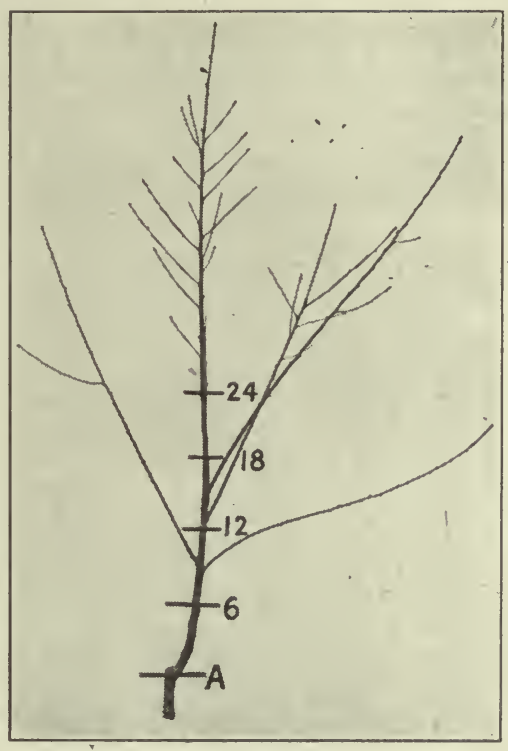

FIG. 199

ONE-YEAR PEACH FROM NURSERY

Numbers are inches from the bud union at $A$

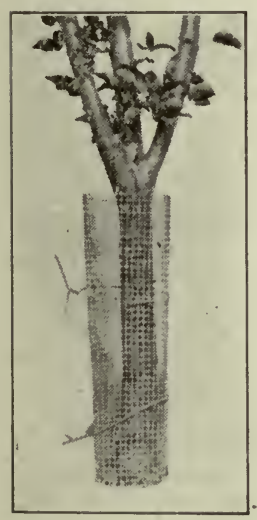

FIG. $\quad 199-\mathrm{G} O \mathrm{O}$ D TREE PROTECTOR very few vigorous buds on the trunks from 6 to 18 inches above the point of budding, with the result that very few branches could develop. Stored trees are commonly somewhat dried out and any poorly developed or adventitious buds are not likely to start as freely as in the case of freshly dug trees. The light grade of stored trees, the $3 / 8$-inch, had more buds upon the 6 to 18 -inch sections of trunk.

It is plain from the above facts why the stored trees failed to give the same results as the freshly dug trees in the matter of free development of hranches upon the 6 inches of trunk immediately below the point of cutting back in the 12 and 18-inch treatments. It should be noted further, however, that the section of trunk 12 to 18 inches above the point of budding is a weak spot from the 
standpoint of branch growth, even in the case of the freslily dug trees, as is indicated by the total growth of all trees pruned to a height of 18 inches. Such evidence indicates that some of our arbitrary and "rule of thumb" methods of pruning peach trees at time of planting may need revising.

A question which also arises is whether the trees of the 12 and the 18 -inch treatments which died back to 6 inches because branches failed to start near the tips

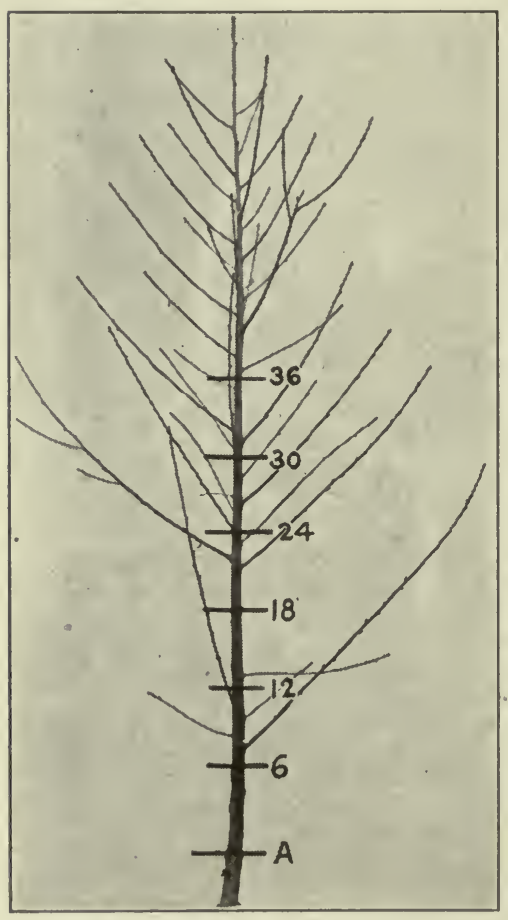

FIG. 200 - ONE-YEAR PEACH FROM NURSERY - $7 / 8-1 N C H$ CALIPER

Figures indicate inches above the bud at $\mathrm{A}$ made as much growth as trees originally pruned to 6 inches. The records of total linear twig growth do not indicate that the dying trunk stubs had a depressing effect upon growth. In fact, the growth upon these trees is fully equal to that of the 6inch stubs. These dying stubs, however, cause the branches to spread out at the base, and it would be well to remove such stubs as soon as it is certain that they will not develop any branches.

184. Length of the branches. The total twig growth of the tree is important as indicating general vigor. The points at which the trees develop branches concern the formation of the head of the tree. The number and length of the branches may also be factors in the development of the form of the tree.

The largest total number of branches occurred in the lengths from 7 to 12 inches. The largest average total number of branches of all lengths occurred in the 36 inch treatment, and the next largest average number in the 12 -inch treatment. This is the same ranking as occurred on the basis of total growth. The 18-inch treatment resulted in the smallest average total number of branches and it also produced the lowest average total growth. The number of branches regardless of their length, therefore, appears to be correlated with amount of growth. We may conclude, then, 
that the more severe the pruning the greater the tendency toward the production of long branches.

The total number of branches from 24 to 50 inches in length serves as a good basis for comparing treatments. The results were as follows: Not pruned, 27 branches; 36 -inch, 71 ; 30 -inch, 69 ; 24inch, $68 ; 18$-inch, $65 ; 12$-inch, $69 ; 6$-inch, 54 . This shows an average of at least three branches to the tree from 24 to 50 inches in length for all treatments except the "not pruned" and the "6-inch" trees. This indicates that about the same number of vigorous branches developed under all but the most extreme treatments, yet the actual position of the branches may vary greatly. If each grade is examined separately, differences are noted.

Increased size and vigor of the trees and their root systems may be expected to offset a slight advantage in the number of buds beyond certain limits. The proportion of top to root also bears on the case. Yet, with due consideration to the importance of these factors, there is abundant evidence to show that bud and branch development at different points upon the trunks of one-year-old peach trees as received from the nursery has an important hearing upon the growth of these trees as they are pruned and planted.

If a tree is cut back above a point where well-developed buds are numerous, good branch development may be expected. On the other hand, if a tree is cut back just above a point where there are but few buds, the tree may fail to start well, or perhaps not start at all, leaving a dead stub. Some variation is to be looked for between different lots of nursery trees even of the same variety, and especially where insects or diseases have affected the dcvelopment of the trees; yet the data demonstrate that many facts are remarkably constant.

185. Commercial results.-A treatment of a plant that results in the most vigorous growth is not necessarily the most profitable or desirable treatment from a commercial standpoint. It is possible for a tree to make a large amount of growth, bus it may be in such a form as to be poorly adapted to the production and support of a crop of fruit. In general, however, any treatment which depresses growth interferes with the tree's commercial possibilities.

The tendency for trees of $3 / 8$-inch grade, cut back to 6 inches when set, is to develop one or two large leading branches from near the point of budding and sometimes below. Where several branches develop close to the surface of the ground the control of borers is made difficult. Trees of the same grade cut to 12 inches are quite similar to the 6 -inch trees. Trees of the $3 / 8$-inch grade cut to 30 inches are well-formed trees which permit of a short trunk and a good distribution of the main branches.

The 18 and 24-inch treatments of $7 / 8$-inch stored Elberta trees failed to produce branches much above 6 inches from the ground and the "stub" finally died. Trees of large caliper commonly have few or no well-formed buds upon this portion of the trunk and fail 
to start well, especially if they have become somewhat dried out before being set. The $1 / 2$-inch grade cut to 24 inches easily forms trees with short trunks and well-placed branches. The growth upon unpruned trees is not desirable commercially even if the trees should make a fair to good growth.

From the results of these studies it is evident that should a fruit grower prefer to cut his trees back to 6 -inch stubs at planting time, he should purchase trees of a $3 / 3$-inch caliper. Small trees suffer most if they are allowed to become dry at any time previous to planting. Trees cut to a height of 36 inches when set make a better average top growth than trees cut more severely, if the question is considered broadly and regardless of grade.

186. Summary.-One-year-old peach trees of a $5 / 8$ or $3 / 4$-inch grade made the largest average total growth. The larger the trees the poorer the growth when unpruned at planting time. The smaller the trees, the greater the damage if the trees are allowed to become dry before planting.

The largest average total growth regardless of grade was made by trees cut to a 36 -inch trunk when set, except in the case of driedout trees. Trees cut to 12 -inch trunks when set made the next largest average total growth. The smallest average total growth occurred when trees were cut to 18 -inch trunks when set. Trees of $3 / 8$-inch grade made the largest amount of growth when cut back to 6 -inch trunks when set. Trees as large as $3 / 4$ inch or larger were depressed in growth when cut back to 6 -inch trunks.

Trees in general failed to develop branches well upon the 12 to 24-inch section of the trunk. Very few well-developed buds occur upon this section of the tree under average conditions. The largest total number of branches occurs in the lengths from 7 to 12 inches. The largest average total number of branches of all lengths occurred in the 36 -inch treatment, with the 12 -inch treatment second. The number of branches of all lengths is, therefore, apparently correlated with the amount of growth. The unpruned trees developed the smallest number of branches more than 24 inches long. The 36 -inch trees developed the largest number of branches that were more than 24 inches long. The 6 -inch treatment resulted in the formation of the largest number of branches, 40 to 50 inches long. The 12-inch treatment gave the largest number of branches. 37 to 40 inches long. The 18 -inch treatment gave the largest number of branches, 25 to 30 inches long. The 24 -inch treatment gave the largest number of branches, 25 to 30 inches long.

We may then conclude that the more severe the pruning the greater the tendency to produce long branches (83). It should be noted further, however, that so-called main branches are reduced in number when the trees are cut to 6 inches. One-year peach trees from the nursery start into growth best when planted in the orchard if there are well-formed buds just below the point where the tree is cut back. The number of such buds varies at different points along the trunk of a nursery tree. Buds are found to be most 
numerous at the 6 to 12 -inch space, followed in order by the 12 to 18 and the 24 to 30 -inch spaces.

Peach trees at the time of planting should be pruned somewhat according to grade and the character of the stock, and not according to some definite height regardless of all other factors.

187. Citrus trees.-Few fruits demand as little pruning as do the citrus trees-oranges, lemons, grapefruits, etc. -after once having been "educated" by training through their youthful days. Much of the pruning is done when the trees are set and during the first season or two. The lemon (190), however, is more pruned than any other member of the citrus group, its handling by many growers thus approaching that of the peach. High heads are rapidly giving place in popularity to low ones, so low that often the branches rest on the ground. So satisfactory have low heads proved that many high-headed trees are being lowered by the encouragement and development of water sprouts on the lower parts of the trunks and the gradual cutting of branches high in the upper parts of the tops. In due time the suckers properly handled will bear fruit.

In Florida "die-back" of the tops commonly follows a freeze or severe pruning. The roots are usually unhurt. Root pruning therefore aids in re-establishing a balance between top and root. A sharp spade thrust deep in the soil in a circle at nearly the limit of the branch spread will usually produce good results. The cause of the malady should, however, be discovered and the proper remedy applied.

Frozen trees may be left alone, cut back somewhat or actually at the ground surface. The first is objectionable because the dead top must be removed some time; why not at once? If left, a large part of the new growth must be injured in taking it out. In cases of slight injury the pruning may be postponed until the dead twigs become dry enough to break out. Cutting is, however, better than breaking. In cases of severe injury the whole of the injured part should go at once, preferably at the 
ground. Sprouts or grafts may be used to form a new top. The sprouts may be budded when large enough. When the trunk seems unhurt it may be left to develop a new top, only the injured parts being removed. Most pruners leave too much of the old wood. In such cases the heart wood decays leaving only a thin cylinder of living wood. This becomes so weak that the loaded branches break unless propped or wired, processes which are both costly and unsatisfactory.

188. Pruning and shaping orange trees.-According to J. W. Mills,* the tendency of young trees of Washington Navel and some other varieties to assume a drooping habit when making a vigorous $\mathrm{g}$ owth is because the soft shoots are unable to support the weight of the large, heavy leaves. Even trees that have been long in bearing will be benefited by pinching back every branch that takes too vigorous an upward growth. This pinching process is especially necessary with trees one to five years old.

188a. Pruning bearing trees. - An upright tree has a deciced advantage over a drooping one when loaded with fruit. The crop is borne with less breakage of limbs, and not so much fruit is injured by the wind. After the trees are in full bearing, there seems to be no pruning that will promote the health of the trees or improve the crop other than cutting out limbs that project abruptly from the side, or those that make a sudden skyward growth, and the constant trimming out of dead or stunted wood found on the inside of the trees.

If too close, the branches should be thinned out from the inside until the sunlight has had free access. This does not make any noticeable difference in the appearance of the tree, but makes it bear fruit on the inside. Such fruit is safe from sunburn and frost and packs as "fancy" grade. By early attention to pruning, the trees need never be allowed to grow too close in the center.

189. Renewal of tops. - Some groves of old orange trees do not respond to even "the best treatment the owners can give them. Under such circumstances, the most effective way to stimulate new life and vigor is sometimes to remove the entire top, leaving enough of each of the main limbs to distribute equally the suckers that will afterward make the new top of the tree. If the tops are only thinned out and but partially cut back, there will be a proportionate amount of feeble growth and a corresponding lack of productiveness.

An old orange tree will rapidly produce a new top, even when cut back to a mere stump. It is soon in a condition to bear again at - its full capacity. When the roots are healthy and the soil is properly cultivated and fertilized, the orange tree appears able to produce

- California Experiment Station Bulletin 138. 
several generations of tops on one stock. But it will generally be found that the trouble with old, non-productive trees lies in the root-system, or in the management of soil, or in both. Thorough investigation of roots and soil should be made before any severe cutting or pruning of the top is resorted to.

Except as noted in preceding paragraphs, all trees should be trained low for protection against frost, heat and wind, and to aid the gathering of fruit. Heavily laden branches are generally propped to prevent breaking down, as the loss from dropping and splitting is so great that the trees cannot be safely lightened by thinning the fruit when small.

19i. Pruning and training young lemon trees.*-The lemon tree must be watched closely and built up year by year, and deck by deck. The first and most important thing to consider is the building of the framework, which must carry a heavy load of fruit and which should be strong enough at bearing age to support this weight without breaking. Three kinds of materials are needed: building wood to construct the frame, fruit, limbs and spurs to bear fruit. Building wood is that part of the growth that is inclined to grow straight up, and when a tree is young sometimes outwarl at an angle. Fruit limbs grow from 1. to $2 \frac{1}{2}$ feet long and are distinguished by their position on the frame of the tree and by the ends of the limbs, which show matured leaves and indications of buds forming at the tips. Sometimes a blossom occurs and often a little cluster of lemons. Fruit spurs are the growths that come on these fruit limbs, as also on the framework of the tree, if the tree is of a fruiting nature.

Another growth about which there is a good deal of discussion is the sucker wood. A growth, or sprout, is a sucker only when it grows where it cannot be used on that part of a tree already developed. The question has been raised, When is a sucker not a sucker? When something unexpectedly happens to a part of the tree so the sucker may be used, not for a fruit limb, but as a part of the tree. For instance, when a large limb has split off one side of a tree, just above it being a sucker 12 to 16 inches long. The split limb may be taken off entirely and the abrasion smoothed off and painted. The sucker may then be tied to the main part of the tree to prevent its breaking off, when it is large enough to cut back at the proper point to make it branch and spread it may be used to fill in the gap. In this case the sprout was a sucker when it could not be used, but when circumstances permitted its use it was no longer one.

Building a lemon tree is accomplished by a systematic cutting out and back. This does not necessarily mean that the tree should not be expected or allowed to bear fruit during the building of the frame. More and better fruit will be produced at an earlier date than if the

* Excerpt from an address by W. H. Fleet before the Special Citrus Convention, San Bernardino, Cal., February, 1916. 
tree is allowed to follow its natural propensities, as the fruit limbs and fruit spurs will develop each year in the part of the frame built in previous years. It must be remembered while building the framework of the tree that fruit limbs and fruit spurs are being developed also, and care must be exercised luring the building process not to trim out these fruit limbs or fruit spurs except where they are too thick. Never crop off the ends of the fruit limbs or fruit spurs.

The question when to begin to build or train a lemon tree is an important one. When the bud sprout grown from the seedling stock has reached a height in the nursery so it may be cut cff at a point where there is matured wood, 32 to 34 inches from the ground, is the time to begin training and developing the tree. $U_{p}$ to this time it has had to be held up by stakes and given every care, not having been trusted to its own propensities. Now, it is to be cut back. On the little stick or stem will be built a crown as a foundation of the tree. The height of cutting back to begin the framework is a matter of choice with the orchardist. I prefer a crown started within 32 to 34 inches of the ground. Four branches or crown limbs are allowed to grow out from the stem, no one being opposite another. It is not always possible to carry out this particular plan in the crowning of the tree, but in most cases the limbs can be spaced so as not to allow one to come exactly opposite another (12i). I prefer to have only two limbs with the center stem, if it be not possible to grow four without having one opposite another. Three crown limbs are enough and four are plenty.

It is dangerous to make cuts too long the first two or three years, as long cuts mean small limbs and weak frames. If the tree is planted early and makes a good growth, the first pruning may be necessary in August or September. This will be the thinning out of the top branches and cutting back rather short those limbs which are needed to make part of the framework. By first pruning I do not mean suckering or rubbing off the water sprouts, etc. It is very important to keep the tree, especially the trunk, free from suckers.

A young tree should be watched very closely the first two or three years. If it forms the habit of suckering, especially on its truak, there will be trouble in starting the sap in full flow through the limbs and foliage of the tree. Also allowing the suckers to grow stunts the growth of the tree. Therefore, the suckers should be taken off when they are so tender that they can be rubbed off with the hand. Rubbing them when they are very tender prevents knots from forming on the trunk or limbs. These I believe retard the frec flow of the sap.

In pruning a lemon tree planted nine months in the orchard the tall branches are cut back very short for the next deck or framework. This close cutting is done to develop strength in the crown of the tree before a heavy top growth is developed. Although this tree is only nine months old, some short, healthy wood developed 
in the nursery has been allowed to remain in the crown. These little fruit limbs will, during the second year of growth, blossom and set some fruit.

From now on the fruit spurs and fruit limbs may be left in the crown of the tree, so they may grow and produce lemons in limited quantities while the tree is young. Do not be alarmed if trees one or two years old begin to bear. Let them get the habit while they are young. A lemon tree properly trained and pruned, should bear a fair crop when three years old. The little limbs will first blossom on the ends, bearing from one to three lemons. Then on the limb, back toward the trunk of the tree, fruit spurs will develop and set fruit.

Tall limbs should be cut back from 6 to 12 inches, depending upon the fruit line, or deck, a vertical growth of fruit limbs that will blossom and set fruit on the ends, then bend downward, causing fruit spurs to develop on them. Each year a new deck of fruit wood or limbs is developed. This growth should be cut only when it becomes too thick.

It is important to go over the two-year trees at least twice a year to take all suckers and cut back the limbs that have grown out of proportion to the other part of the tree; such growth is round and not smaller than a lead pencil; larger would be better. Never cut angular wood. In some cases it will be necessary to take out entire limbs if they have grown too thick, and also to cut those hack that have grown in the right place to add to the framework of the tree.

Some of the tender growth will commence to develop rapidly early in the spring of the fourth year, and so will have to lie gone over at least three times to thin out and cut back at proper points. A lemon tree at this age, properly pruned and trained, should show a well-defined fruit line.

When a lemon tree reaches 10 or $1: 2$ years, very little cutting back is necessary. Yet almost all of the vertical growth should be taken out. A tree properly pruned from its infancy is brought to this age without large stubby limbs near the top of the tree. This method of pruning and training of a young lemon orchard will hring the trees to full bearing age without any long bare limbs devoid of fruit limbs and fruit spurs on the frame of the tree. Great care should be taken not to allow the growth to become too thick. Sometimes it may be necessary to take out a whole limb and open the tree to let in the air and light, so the fruit-bearing wood in the interior of the tree will bear fruit. The tendency is to allow much of the growth to become woody and, therefore, to be wasted because it will have to be taken out. Therefore, time will be lost in the proper building of the frame of the tree and in the development of fruitbearing wood.

191. Good rules in training and pruning young lemon trees.1. Use sharp shears so as to make a smooth cut. 2. Never cut off a limb over $3 / 4$-inch thick with the shears. Use a sharp saw, smooth 
with a knife and then wax. Every limb $7 / 8$-inch and over when cut should be waxed, especially in training and pruning trees up to five or six years old. 3. In cutting out limbs entirely, cut close and smooth, then wax. Do not leave stubs. 4. Never cut angular wood. Where a cut is made the wood should be round, no smaller than a lead pencil, and a little larger would be better. 5. Never crop or shear off ends of fruit limbs. Never shear the tree under any circumstances. 6. Keep the trees free of water sprouts, especially the trunks of the young trees. 7. When in doubt leave it! That is, when in loubt whether a limb ought to be cut out or cut off, leave it until next time. It may be taken out in the future if necessary, but if cut off it can never be put back. It is necessary to go over the orchard at least three times a year with the pruning shears. 8. Never cut out the little fruit limbs which grow in the framework of the tree unless they become too thick.

A very important point which should not be overlooked is the soil. Unless the soil is kept in good physical condition, manufacturing food for the tree; one cannot expect good results. The framework of the tree has been built. On it are hundreds of fruit limbs, fruit spurs have set, thousands of buds are ready to produce more fruit limbs and spurs, and more fruit limbs are continually coming into bearing, so unless the tree is properly and regularly fed one cannot expect prolific and continuous fruiting. Every bud on the lemon tree is capable of growing fruit limbs and fruit spurs-even ciown on its trunk to the ground. Keep the food reservoir in good running order, furnishing the proper diet for the tree. With the proper handling of the soil and proper training and pruning one can develop a tree which will always and indefinitely be a prolific bearer and a profit to its owner. 


\section{CHAPTER XI}

\section{PRUNING MATURE TREES}

When the principles of pruning (Chapter $\mathrm{V}$ ) have been properly applied in the education of young trees as described in Chapter $\mathrm{X}$, the mature trees will, barring accidents, need very little annual attention-a mere reminder now and then of their training and purpose in life. From the time they come into bearing the pruner should expend his energy for sawing, hacking and whittling upon some friendly wood pile where he will do no harm to his fruit crop prospects and the well-being of his trees. For the trees can be thrown out of bearing very easily by injudicious pruning. The y may even be made to produce brush without fruit when erroneous pruning is extensive enough and continues from year to year.

192. Bearing habit dictates style of pruning.-As already noted (56), fruit trees bear their fruit buds in two general ways-laterally, as in the peach; and terminally, as in the apple. There are many exceptions where various varieties bear both ways, but the rule is as stated. Naturally the trees which produce fruit from lateral (axillary) buds, set more buds and will stand more pruning of the smaller branches than will the other kind, be-

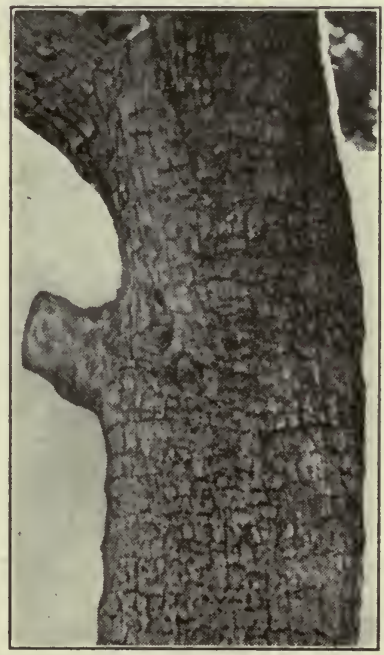

FIG. 201.-INVITING DISASTER.

This shows how not to cut a limb. A stub is always a menace. because decay is sure to enter. 
cause this pruning helps to thin the fruit (106). Such a methodapplied totrees which produce terminal fruit buds, wholly or largely, would probably not only destroy to, many fruit buds, but also upset the normal habit of growth and cause the development of wood, even to the extent of destroying the bearing habit altogether. Even with trees that produce axillary buds, good judgment is needed, for the bearing habit may differ among varieties as well as species. For instance, the peach bears its fruit buds on strong annual growths of last year; whereas the

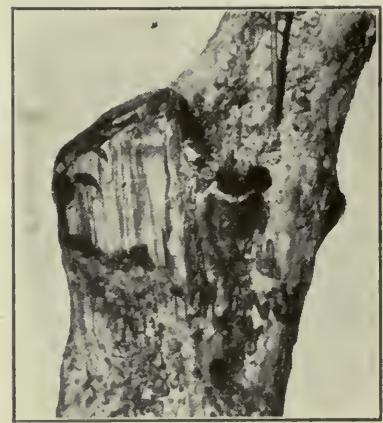

FIG. 202

UNPARDONABLE "PRUNING"

This style of cutting courts disaster because it favors the entrance of decay. The wound should be close to the trunk as shown in Fig. 93. cherry blooms on less vigorous twigs. Therefore the severe pruning considered ideal for the peach would in the cherry derelop many and large twigs which would bear little fruit. Apples and pears, which form axillary fruit buds and also terminal ones on young fruit spurs, must be pruned more severely than those which bear in the more normal way, because they are prone to overbear. To sum this matter up, then, the pruner may decide how much he shall prune each tree by noting the way in which it forms the majority of its fruit buds.

193. Pruning the apple.-In a general way the following rules, based on the principles already discussed (Chapter V), will aid the pruner in developing his judgment of how to prune bearing trees, not only of apples but of other fruits:

1. Study the habit of growth as well as the method of fruit bud formation. Trees which normally grow erect may be spread somewhat by cutting to outside buds; 
those which tend to sprawl may be raised slightly by pruning to upper buds (120).

2. Save the small shoots, because many of them are fruit spurs and the others may later become such. If they are stripped off, the tree will not be as prolific. It may even be made barren (Figs. 171, 189).

3. Remove dead, diseased and broken limbs, making the cuts cleanly and close to the larger tree parts which bear them (Fig. 93).

4. Cut out water sprouts and suckers except where needed to fill in gaps. Where needed, shorten them so as

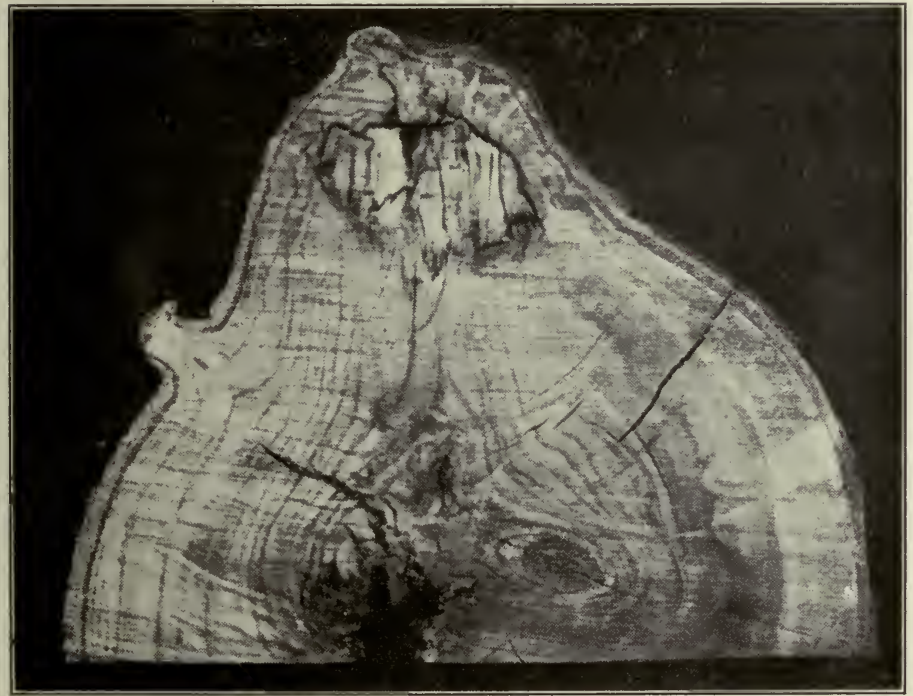

FIG. 203-CROSS SECTION OF TRUNK SHOWN IN FIG. 204.

At the top a stub healed over but decayed beneath. At the left a little healthy stub healed over. Below, the hole left by decay of limb shown diagonally in Fig. 204.

to compel branching and later the fruit-bearing habit. In properly handled bearing trees such growths are not excessive either in number or size. so there is usually little need of saving them. They are of most interest to old trees 
which need renovation. In such cases they should be shortened to two or three good buds so they will form

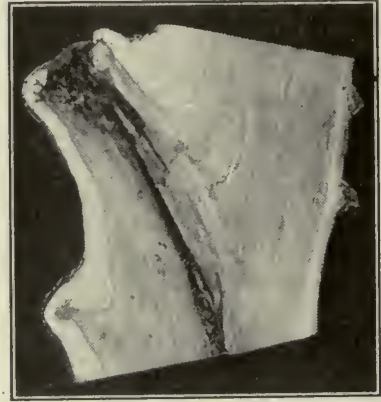

FIG. 204

HOW TREES BURY STUBS

The lightest colored wood is the youngest. It is being used to try to bury the stub. Decay has rotted out much of the stub wood down into the heart of the tree. In the lower left corner, note that the wood has healed in a small decaying stub. No hope for trees handled in this way. fruit spurs. If they do not so develop they should be removed. The easiest way to remove water sprouts is while they are still succulent in midspring, when they may be easily pulled off by boys.

5. Avoid cutting la rge hranches as much as possible. Rather remove an equal amount of wood by cutting several small branches, say the thickness of one's thumb. mainly because small wounds will heal quicker than large ones, but also because the removal of large branches leaves hig gaps in some places, whereas others will be as dense as ever. Sun scald of the branches often follows the removal of too large branches.

6. Cut back leaders which are over-developing and threatening to injure the form of the tree, but always cut back to some shoot which will take up the work and also aid in healing the wound. In other words, never leave a stub (Fig. 92). Following this rule will aid in keeping the trees low-headed and, hence, also help the work of spraying, thinning and harvesting.

7. At least one of such limbs as cross or seriously interfere with others, especially in the interior of the tree, should be removed. When trees have been properly trained, however, these limbs will be neither large nor numerous before discovered.

8. If necessary thin out the top. Usually, however, it 
will not be necessary to do much of this because the rules given above will have done enough thinning.

9. Branches that threaten to form Y crotches should be handled as already indicated (127).

10. Should a neglected orchard need very severe pruning to bring it back to shape, it will usually be an advantage to do the work in the winter preceding a full crop year.

194. Pruning to remedy winter injury.-Pruning experiments were undertaken by William Stuart* with a view of bettering the condition of some winter-injured trees. These were inaugurated in early June in an orchard where a number of eight-year-old Rhode Island Greening trees were severely injured. Some of the trees were severely pruned back after the secondary buds had pushed out new growths, others were somewhat less vigorously handled, while yet others were left untouched. It was thought that the severe pruning of trees on which new growths were being pushed out at the base of the limbs would tend to throw all the strength of the tree into a few branches, thereby securing during the first season a much more vigorous development as well as a much more shapely head.

Photographs were made of the injured trees both before and after pruning June 9, again on August 15 of the same season, and a final set September 27 of the following season. A careful study of these affords little evidence that pruning was beneficial. A comparison of one set would show a decided advantage in favor of pruning, while that of another set would be equally favorable to the unpruned. While no very sweeping conclusions can be formed from a single experiment, conducted on a rather small scale and under unfavorable conditions, this much at least may be said:

* Vermont Experiment Station Annual Report, 1901 .

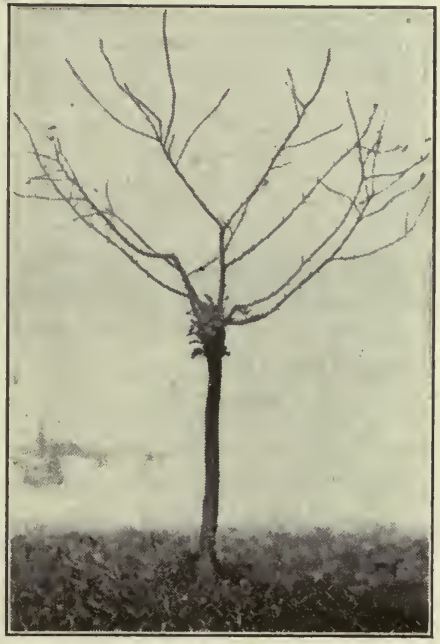

FIG. 205.-WINTER INJURED RHODE ISLAND GREENING APPLE TREE BEFORE PRUNING IN EARLY JUNE. NOTICE EXTENT OF DAMAGE. 
(1). That in cases of winter injury like that mentioned above practically nothing is to be gained by the hasty removal of the greater portion of the head of the tree. In other words, severe pruning is inadvisable and is probably more often injurious thati beneficial. (2). That in the light of the observations made it wou'd seem advisable to defer pruning operations to the latter part of the growing season or possibly until the following spring. (3). That whenever pruning is to be done no more branches should be removed than is necessary to preserve the balance of the tree top. (4). That winter injury could be avoided by keeping the tree in a thrifty, vigorous condition. Weak, unhealthy trees are less able to stand extremes of temperature than thrifty ones. Compare statements by Whitten (203).

195. Mature pear trees, if properly trained while young and if healthy, réquire little pruning. Even when un-

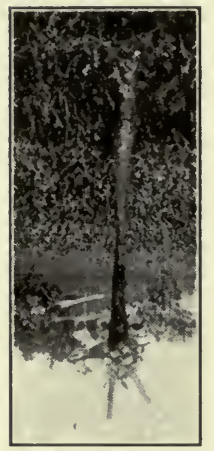

FIG. 206

PRUNED APPLE

This is the same tree as shown in Fig. 205.

pruned they bear tolerably well. But for high-grade fruit judicious

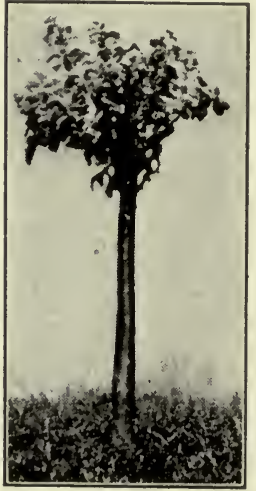

FIG. 207-AUGUST

Tree shown in Fig. 206 as seen in August; 67 days after pruning.

pruning is necessary. In general the fruiting habit resembles the apple. The habit of growth is more erect, but pear trees may be readily trained in almost any form desired, as, for instance, espaliers, cordons, etc. (Chapter XVII). Generally the trees in commercial orchards develop as nature dictates, but broad, low heads are not hard to secure. 
One disadvantage of tall trees is that the fruits borne high up are knocked off or rendered unsightly by wind; another that spraying, thinning and harvesting are needlessly expensive. The form which the mature tree shall maintain is mainly decided by the pruning of the young trees. Heading back to outward pointing buds and twigs will tend toward broadness of top, and if the erect leaders are cut, the trees should be kept low-headed without much trouble. To attain this form, the work should be done while the trees are young, otherwise heading back a tree which has grown at random will produce great quantities of wood which will not bear. If the tree is in good bearing when this heading-in is done, the fruit spurs will probably develop long shoots instead of fruits, and this will be all the more pronounced when the pruning is done in the "off year," for it will force the development of the branch buds.

It is an erroneous notion that the pear must not be pruned. Some varieties, notably Anjou, must be pruned severely while dormant in order to get profitable crops of fruit. If not so pruned, a large proportion of the blossoms or the young fruit will fall. Men successful with such varieties cut out a good deal of wood annually until the trees begin to bear good crops.

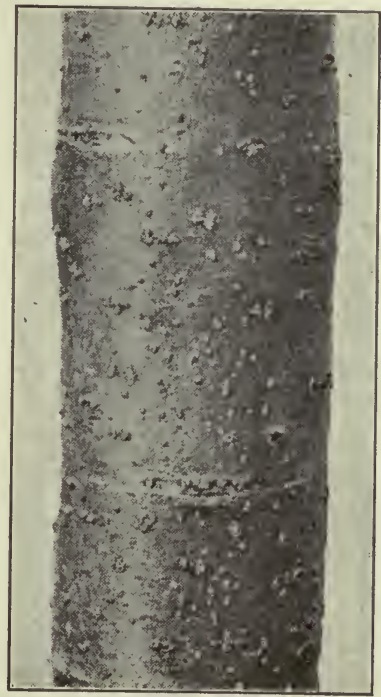

FIG. 209-HEALTHY PEAR BARK SHOWING LENTICELS

Tardy blooming varieties must not be pruned heavily while dormant because they would thus develop wood (83). Pruning in early summer is sometimes helpful. 


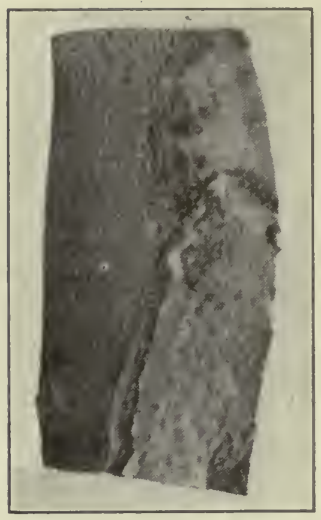

FIG. 210-FUNGI ATTACK INJURED BARK

Stripping (99) may also help. It is probably safer than girdling.

Just how much pruning may be done in mature pear trees must be left to the pruner's judgment and experience, the idea being more to thin and thus improve the quality of the fruit than to remove wood for its own sake. Such a policy will tend toward regular annual bearing. Pruning of this kind, however, cannot wholly obviate thinning the fruit itself in summer. Both practices are necessary as a general rule.

196. Pear blight, if it attacks the trees, will upset even the best pruning methods. Yet the damage this disease may do may be very largely prevented by a proper system of training (173). Heavy pruning should be avoided as much as possible; also all soil management that makes for heavy growth-notably over-cultivation, over-fertilizing with nitrogenous manures and the excessive use of leguminous cover crops-because trees in rank growth are more susceptible to blight than those less amply nourished. Since the chief points of infection are the blossoms, thence through the fruit spurs to the branches, the development of fruit spurs on main limbs should be prevented as much as possible. Instead, the growth of strong new wood should be encouraged so that new fruit spurs ma

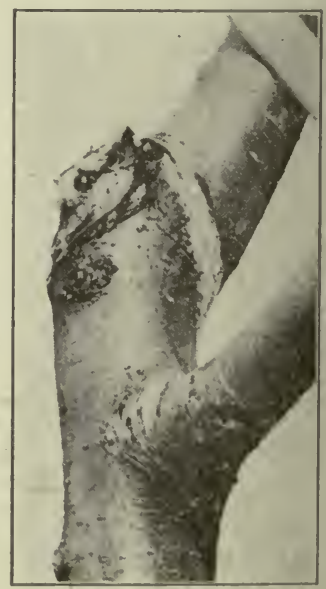

FIG. 211-PEAR STUB ADMITS BLIGHT

$\mathrm{T}^{\mathrm{r}}$ is stub was blighted because the pruning saw was not sterilized. 
be developed to take the place of those that must be removed because of becoming infected. The two imperative rules for preventing the spreading of blight are (1) cut out and burn all infected parts, making the cuts in healthy wood below the lowest point of discoloration of the wood (as viewed in cross section of the twig or branch) and (2) the thorough sterilization of all wounds and tools after making each and every cut. (Figs. 183, 209 to 213.)

197. The quince is trained either as a bush with sever 1 stems or as a tree with only one stem. Each form has its advocates. The points claimed for the bush form are that damage from borers is likely to be less serious than where only one stem is maintained and that there may be a constant succession of new wood to replace the old. The claims for the tree form are that the plantation is easier to manage than where there are several stems and that the likelihood of clamage from iorers is less serious than it is believed to be, provided proper attention is given the trees.

To secure the bush form one sprout is allowed to grow each year from the base of the plant in the same kind of way that currant and gooseberry canes are allowed to grow. The old stems are removed after having fruited three to six times, depending mainly upon the health of the plant. Sometimes there may be as many as six or seven stems of various ages in a bush, but four is probably the commonest number. The tree form is produced in the same way as in

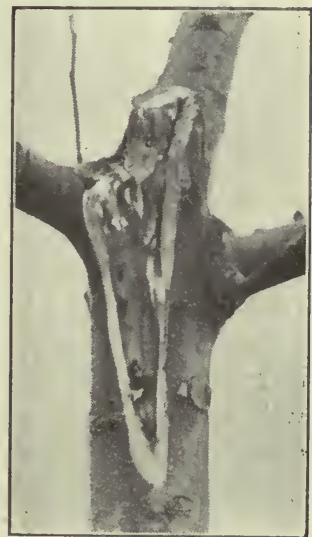

FIG. 212

BLIGHT SPREAD FROM PRUNING WOUND

This stub became infected from an unsterilized saw. The blight spread downward rapidly. As seen now the diseased tissue has been pruned away and the wound is ready for disinfection. 
the growing of other fruit trees. Some varieties are more amenable than others to this form.

Annual pruning after the quince reaches the bearing age consists in thinning the young growth and shorten-

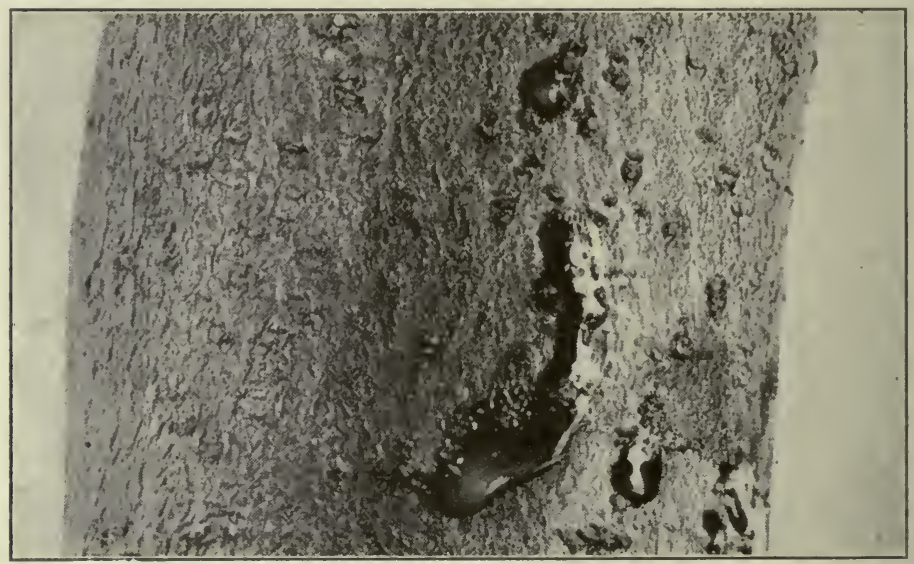

FIG. 213-CANKERED LIMB SHOWING BLIGHT EXUDATIONS

These sticky, milky drops are made up almost wholly of blight bacteria

ing the balance 50 to 70 per cent. When properly managed, the annual growths should be from 1 to 2 feet, with an excellent range of 15 to 18 inches. When the growth is rank the buds which are to produce blooming shoots will be near the tips and so will largely be lost in the pruning. The best buds, by the way, are not usually the terminals but the laterals on the upper half of the annual growths. The main ideas in annual pruning should be to keep the plant well within bounds and to secure an ample supply of new shoots each year. Since the quince is susceptible to fire blight, care should be exercised to cut out and burn affected parts whenever discovered, just as in the case of the pear (196).

198. The mature cherry tree requires little pruning if it has been properly started and trained for three or four 
years. The aim should be to keep it low-headed. There is no difficulty in doing this with the sour varieties and even the tall-growing sweet varieties may be made to form spreading heads like apple trees by judicious heading back. Unless so pruned sweet varieties will often reach heights of 35 or 40 feet when 25 years old. Since the bearing wood is always near the ends of the branches too much time will be required to harvest the crop. Then, too, spraying is more difficult and costly on such tall trees.

The aims with both sweet and sour varieties should be to keep the fruiting parts of the trees as near the ground as possible, to develop fruiting wood throughout the whole top and to keep the trunks and frame limbs well shaded so danger of sun scald will be reduced to a minimum. In all pruning to develop fruiting wood, the fruiting habit of the cherry $(56,64)$ must be borne in mind, because trees with this habit will not submit to excessive cutting. Over-pruning will force excessive growths of strong wood which bears fruit buds sparsely. On the other hand the fruit spurs on trees neglected from the pruning standpoint, become puny and spindling after bearing constantly for several years, and what fruit is borne appears singly instead of in clusters of two or more. Also the fruits so produced are usually of inferior size.

Varieties which produce abundance of bloom, but which set fruit sparsely, thus indicate that they are either not being pruned correctly or severely enough, or that they are self-sterile. In the former case it is recommended that they be severely pruned while dormant; in the latter. that fertilizing varieties be either grafted or budded in or planted near by. In cases where few or no blossoms are produced the trouble may be that the trees have been pruned too severely or fed too liberally, or, in irrigated orchards, that too much water has been applied during 
the previous season. In each of these cases the reverse method is indicated.

199. The mature plum tree-While there arè many species of plums which differ more or less widely in

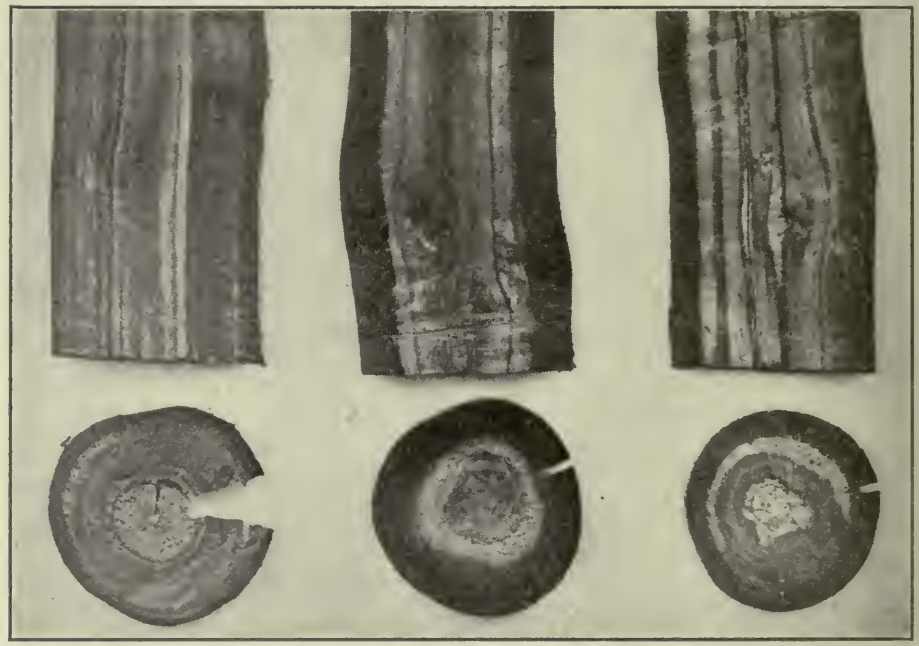

FIG. 214-FROST-KILLED PEACH WOOD VARIOUSLY HANDLED

Left, tree not cut back in spring before or spring after the winter injury. Middle, tree cut back both spring before and after that winter. Right, tree cut back spring after, but not before said winter. The dark portion represents new wood formed since the injury.

their habits of growth, yet growers of varieties now used for commercial purposes agree that the trees must be pruned far less severely than peach trees because the fruit is borne largely on spurs which may continue prolific for four or more years, but more severely than the apple, partly because some of the fruit is produced by lateral buds and partly because it is necessary (1) renew the bearing wood oftener than in the case of the apple.

Since the trunks and the frame limbs of plum trees 
are easily injured by sun, pruning should aim to keep plenty of leafage in the top to shade these susceptible parts. Yet it is necessary to cut back and thin out the tops of most varieties, especially of the Americana class, so as to maintain a good form, a low head and enough light and air to favor the production of first quality fruit. The Domestica varieties, as a rule, including the prunes, are pruned probably less than any of the varieties of the other groups. Those varieties, however, that tend to overbear require more or less thinning out of the fruiting wood so as to augment. both size and quality of the fruit, to favor regular annual bearing

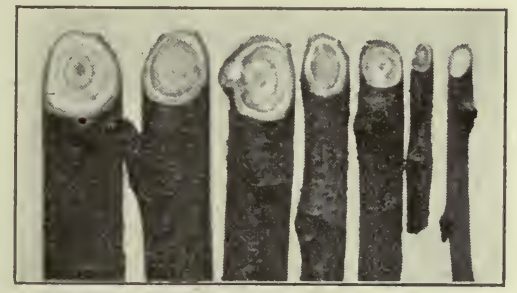

FIG. 215-WINTER INJURY OF PEACH

Left one and extreme right healthy; others injured. Dark parts are injured wood. Light ones new wood forming. and to facilitate work, especially thinning and harvesting.

The Japanese varieties as a group will stand fairly severe pruning. Special care should be taken to avoid weak crotches (Figs. 99, 100, 102) because the Japanese varieties have unusually brittle wood. In general, the method of pruning employed with the apricot will bc found to work well with the Japanese varieties because the habit of fruit bearing is closely similar. When neglected the trees tend to develop "full" and "off" years. Annual heading back and thinning out of the smaller branches will develop strong new growths of wood that later serve well in fruit bearing. Pruning to thin the fruit, while of some service, is not as productive of good results as in the case of the peach. First quality plums demand also summer thinning of the fruits. This rule 
applies to Domestica and other varieties as well as to the Japanese kinds.

200. The mature apricot tree resembles in habit of growth the peach in some respects and the cherry in others. Hence the method of pruning is a modification of the methods employed on these fruit trees. Since the apricot while young grows vigorously, it may then be pruned and trained like the peach so as to produce a sturdy framework and secure a broad low head. When

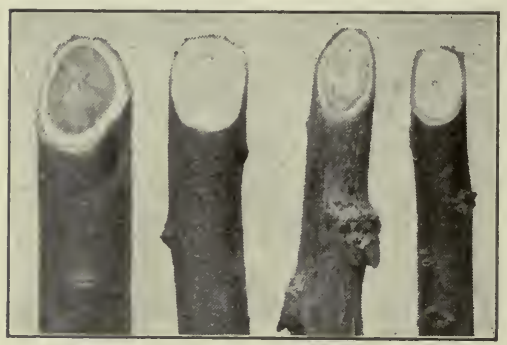

FIG. 216-WINTER INJURIES

Left to right, injured apple, healthy apple, injured plum, healthy plum. Dark part, injured; light ring, new wood forming. the growth calms down at three or four years to a normal gait, it produces less wood than the peach, so that from that time forward the pruning may consist merely of heading back and thinning out the stronger growths-just enough to keep the fruiting wood in thrifty condition and the tree well in hand. Such pruning will reduce but not obviate the necessity of summer thinning.

After the trees get old severe pruning may be necessary to develop new fruiting wood in the interior of the tops. This necessity is perhaps of even more frequent occurrence than with the peach. Hence it is advisable to keep close watch of the trees from year to year so as to avoid neglect; for even though the apricot will stand much neglect, it will respond nobly to proper care.

As in the case of the peach the pruning season in commercial orchards is through February and March, it is well to delay the work until just before growth starts so as to avoid unnecessary cutting of the fruit buds that have survived the winter. In the Pacific Coast states summer pruning is popular, the work being done as soon 
as the fruit has been gathered. The result is a strengthened growth of the laterals that have already started. These laterals produce fruit buds for the following year's crop. Just how far this method may be applicable to other parts of the country remains to be seen. So far as the author is aware, it has not come into prominence in orchard practice east of the Rockies-but there are few

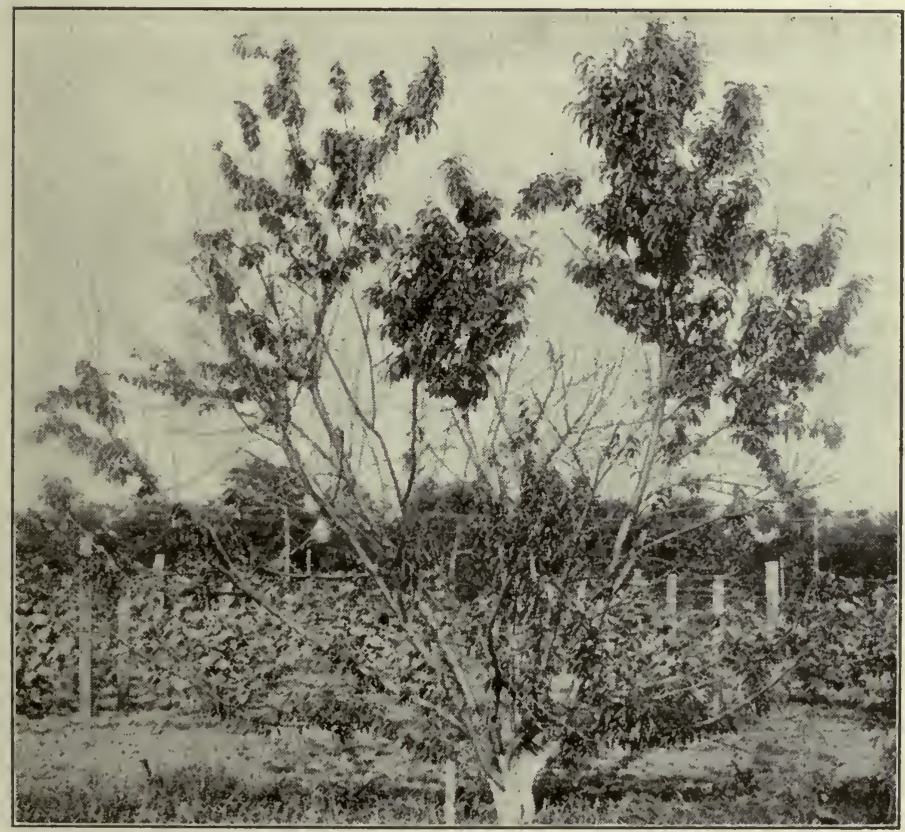

FIG. 217-POOR GROWTH OF PEACH TREE NOT PRUNED AFTER SEVERE WINTER INJURY

commercial apricot orchards in this great area! In some of the mountain states the practice has been followed by a good deal of winterkilling, but this has been more or less balanced by tardy bloom, the flowers appearing several days later than on trees not summer pruned and 
upon which the wood is generally more fully ripened. Where late spring frosts are to be expected summer pruning may thus be an advantage, since the blossoms may appear after the danger has passed.

201. The peach more quickly responds to pruning than any other woody fruit-bearing plant, with the exception of the grape. The pleasure that peach growers take in pruning it accounts largely for the fact that peach or-

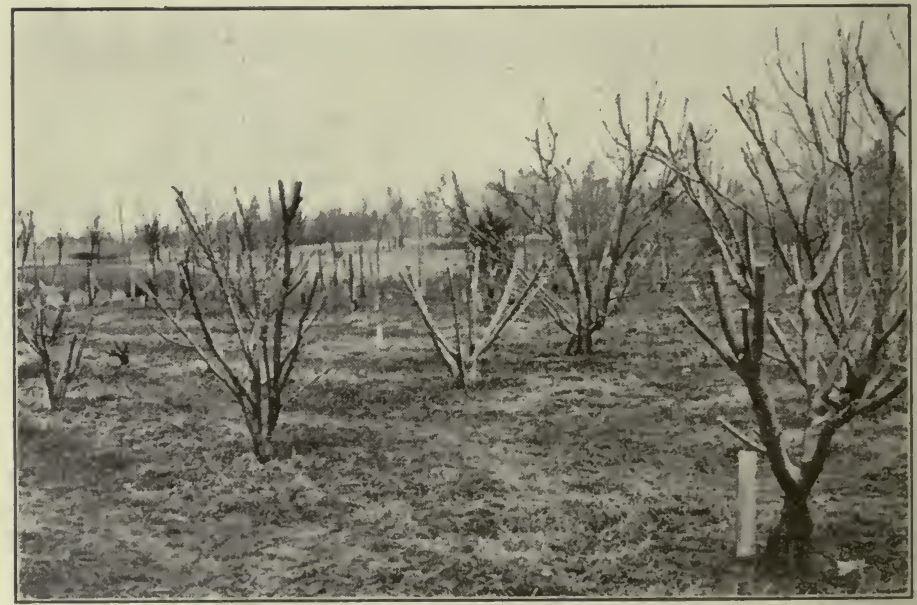

FIG. 218-PEACH TREES CUT BACK WITH VARYING DEGREES OF SEVERITY AFTER BEING INJURED BY A SEVERE WINTER

chards generally look better and are better than orchards of other tree fruits. Failures to have well-pruned peach trees are most often due to want of nerve to cut. There is less danger of over-doing the pruning than with any other fruit except the grape. This is because of its axillary method of producing its fruit buds.

Mature peach trees should make annual growths of 18 to 24 inches. It should, therefore, be the aim of the orchardist to secure abundance of such growths by consistent annual pruning as well as effective soil manage- 
ment. The removal of unnecessary wood and the effort to maintain a well-shaded tree are incidental to the thinning out and shortening-in of the annual growths. It is customary to cut out 40 to 60 per cent of the new growths - the poorer ones, of course, first-and to shorten the balance fully as much. Thus a total of 70 to 80 per cent of the young wood is cut out annually. The arguments against allowing all the annual wood to grow are that the

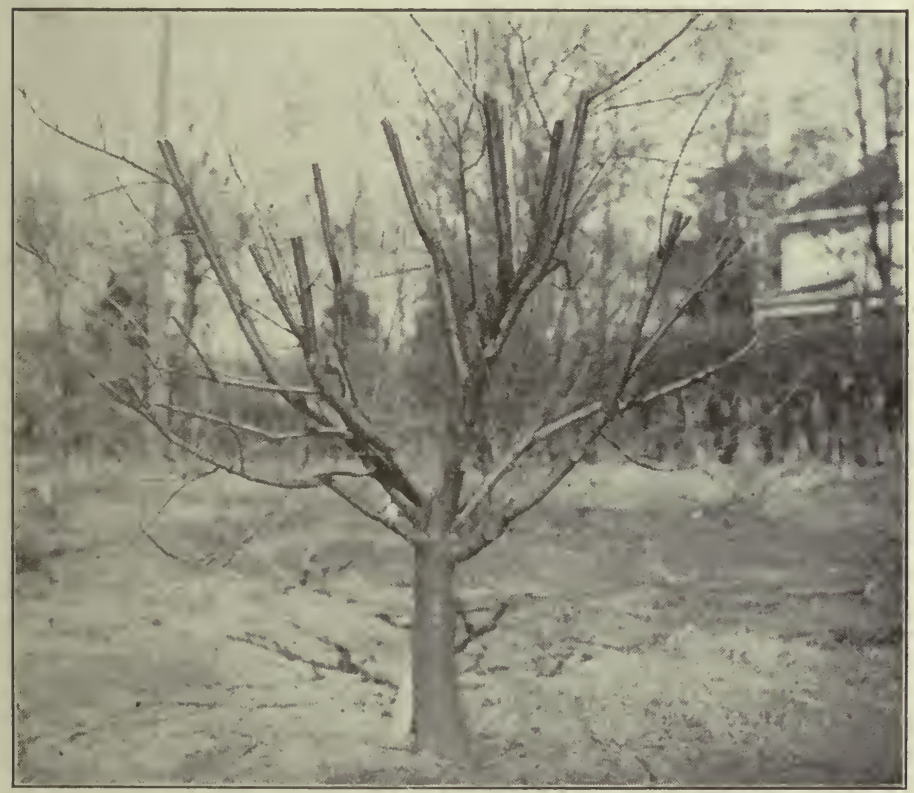

FIG. 219-TREE HEADED BACK MORE SEVERELY THAN IT SHOULD BE AND TOO MANY BRANCHES LEFT. IT WILL GIVE A VERY LARGE UPRIGHT DENSE GROWTH, LIKE THAT SHOWN IN FIG. 225.

trees become too thick, too wide spreading, too easily broken down and the fruit too inferior.

The pruning just referred to is done preferably just before growth starts in spring, when it is comparatively easy to distinguish living buds from those killed by frost 
during winter. Such pruning aids in thinning the fruit (106), but does not wholly obviate summer thinning. Always the aim should be to keep the trees low-headed, so as much fruit as possible may be gathered without the aid of ladders, and when ladders are used at all they should be not more than 6 feet high.

202. Pruning vs. peach bud vigor.-W. H. Chandler* experimented with peach trees to determine the effect of pruning and trimming upon bud vigor. His main conclusions follow:

In Missouri nearly every winter warm weather starts the buds into growth more or less. Fruit buds on trees that have made a vigorous growth, caused by reasonably

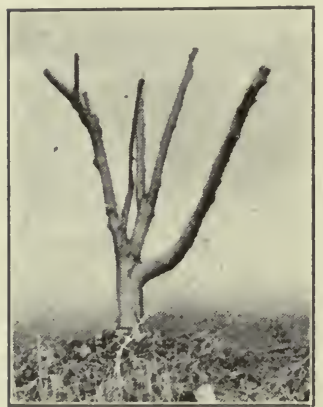

FIG. 220-PROPERLY CUT BACK PEACH

This five-year tree had been severely winter injured. It was saved by radical cutting.

cept with early varieties, where smaller growth. This is true except with early varieties, where a tree making a rather small wood growth bears the better fruit.

Thinning the fruit enables the tree to set more hardy fruit buds for the next crop [than where it is not practiced]. In the station orchard a temperature of 6 degrees below zero one winter killed from 5 to 40 per cent more buds on the unthinned side of a tree than on the thinned side.

In experiments conducted by F. A. Waugh in Massachusetts, peach trees left unpruned for nine years became open headed and of vase form, but the lower parts of the branches were bare and the fruiting wood sparse, weak and high up in the trees. The trees were also much less vigorous than pruned trees of the same variety:

* Missouri Experiment Station Bulletin 74. 
several died from winter injury. Trees in an adjacent row headed back moderately two or three times were thick topped with much weak sappy growth on the insides, but the annual growth was more vigorous and the trees healthier than in those not pruned. More and stronger fruit branches were shorter, stronger and more capable of bearing a large crop of fruit. It is concluded from these experiments that the best form of peach tree cannot be secured and maintained without pruning.

As a result of three years' special experiments, IVaugh concludes that the heading back of peach trees in early

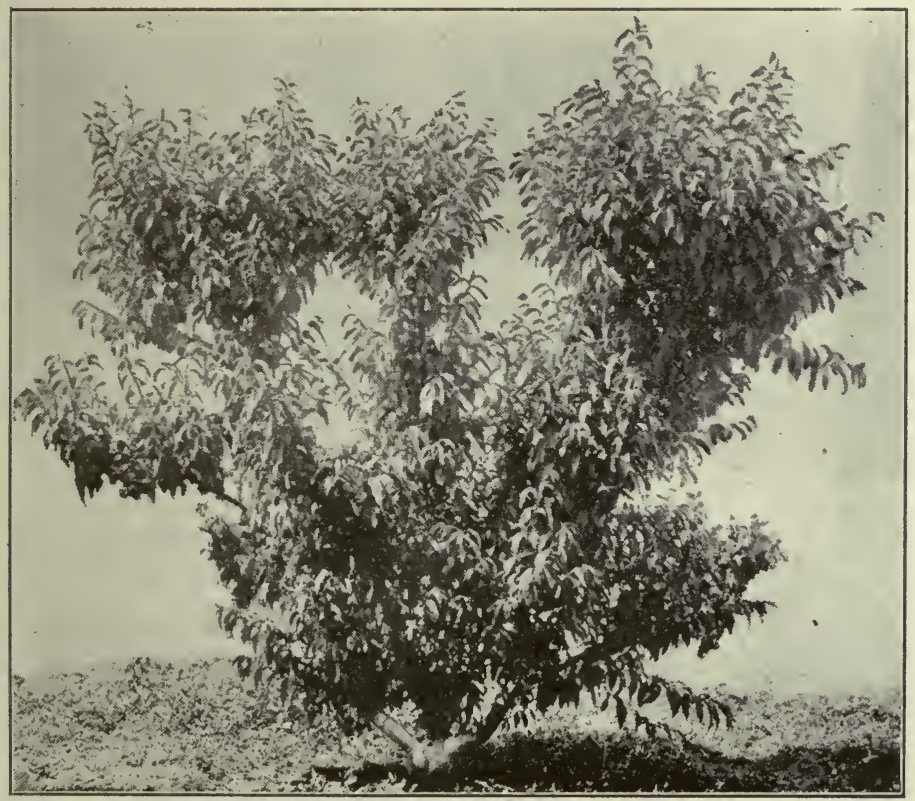

FIG. 221 - UNSATISFACTORY GROWTH OF PEACH NOT PRUNED BACK SEVERELY ENOUGH AFTER WINTER INJURY

spring is good practice and in all cases advisable. In this pruning from one-third to two-thirds of the wood of the previous year should be removed, depending on the number of living buds on the one-year-old wood. When from any cause there are no fruit buds, advantage should 
be taken to cut back with comparative severity. Only in extraordinary cases, however, should the cutting extend back to two or three-year-old branches.

In treating winter-injured peach trees, Waugh left one block unpruned, another pruned in midsummer, a third cut back one-third to three-fourths of the previous year's growth, and a fourth headed back near the trunk so only the stubs of main branches were left. While a large number (93 per cent) of the unpruned trees lived, the growth made by the headed-in trees was much better. Ninety per cent lived. The experiment also seems to indicate that trees seriously injured by freezing should not be cut back close to the main trunks. Only 52 per cent of the trees so treated lived after

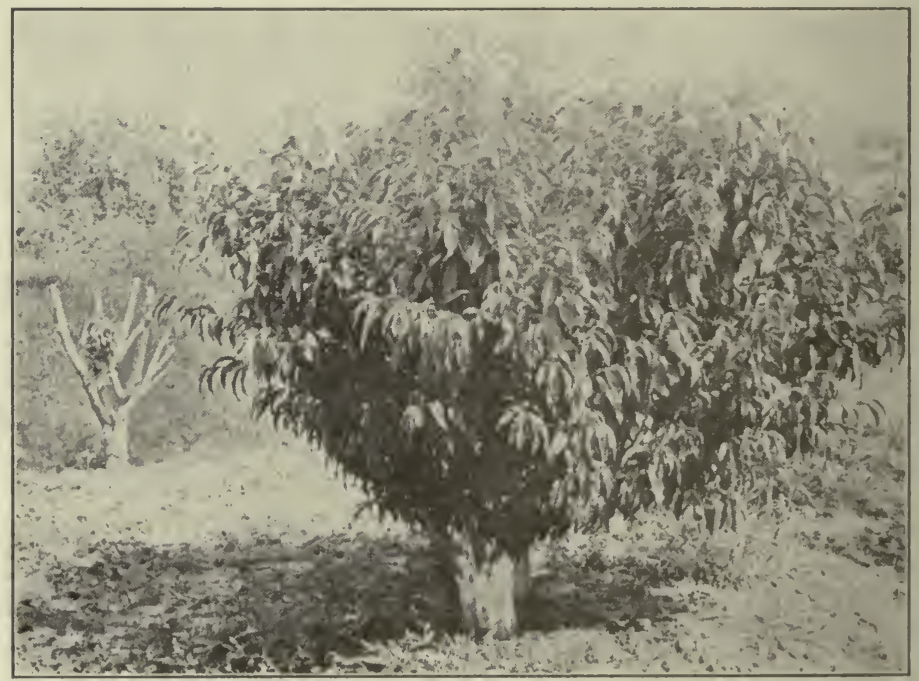

FIG. 222-PEACH IN FOREGROUND SHOWS GOOD GROWTH

This picture taken in June shows how trees differ. The tree at the left is slow starting into growth. Both trees were cut back severely after winter injury.

treatment. (Compare statements with those of Chandler 202 and IVhitten:203.)

Experiments conducted at the Michigan sub-station indicate that pruning (heading-in) of peach trees late in the fall and in early winter if continued may result in serious injury.

Experiments conducted* for years to determine the best seasons

* Hawaii Station Report, 1913, Pages 22-26. 
and methods for peach pruning in the tropical climate of the lowlands in Hawaii, have shown best results when practically the whole top is renewed annually. The pruning is done in June very soon after the gathering of the fruit. Although the foliage is almost entirely removed, the trees soon send out many new branches, which grow vigorously until winter, when they begin maturing fruit buds. All suckers not needed to improve the shape of the tree are removed.

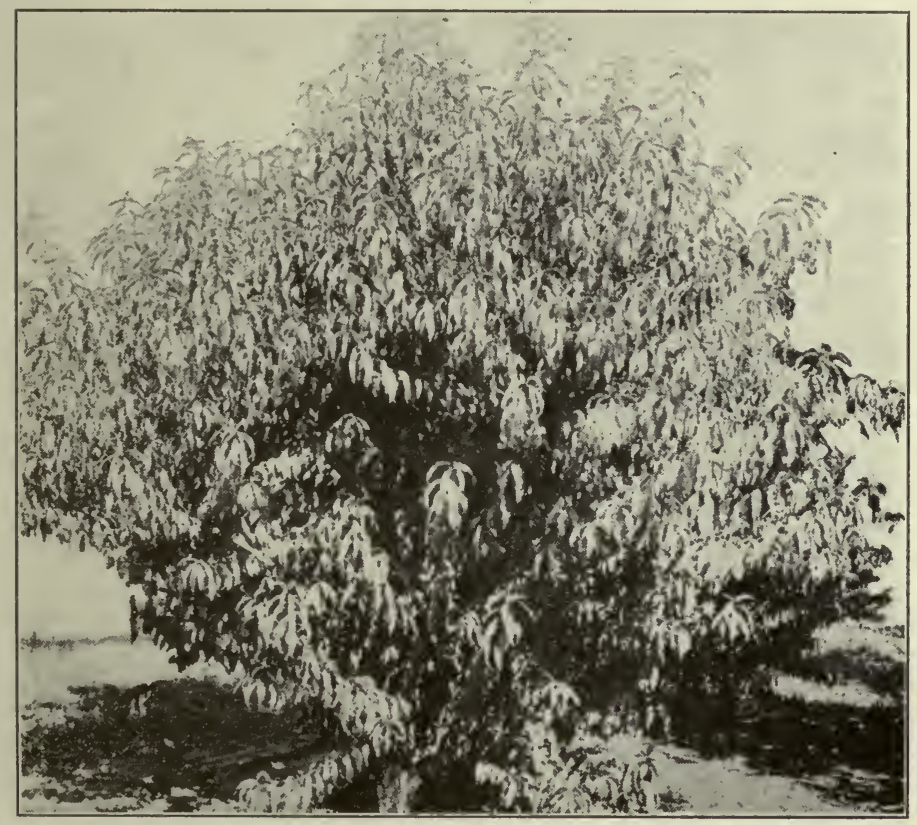

FIG. 223-ONE SEASON'S GROWTH OF EIGHT-YEAR PEACH AFTER CUTTING BACK TO MERE BRANCH STUBS FOLLOWING SEVERE WINTER INJURY

203. Peach pruning experiments.*-Experiments conducted by J. C. Whitten to determine the best method of pruning peach trees, especially those injured by winter, have yielded the following summarized results.

1. Under normal conditions, when peach trees have passed the winter safely and promise to produce a crop of fruit, they should be pruned [late] each winter by cutting back the main limbs, so as

* Missouri Station Bulletin 5.5 . 
to leave onc-lialf to two-thirds of the new growth which contains the fruit buds. 2. When the fruit buds have been winterkilled, the main limbs may be cut back more severely, thus securing more compact trees and avoiding the formation of long, straggling limbs which the trees have a tendency to form if they are not cut back. 3. The amount of cutting back must depend upon the extene to which the trees have been injured.

4. If only the fruit buds have been killed and the wool of the tree is uninjured, trees of compact form, if they have been annually pruned, should have their main limbs shortened so as to leave only a few inches of the new wood. If, however, the limbs are getting long and straggling they may be cut back into two or even three-

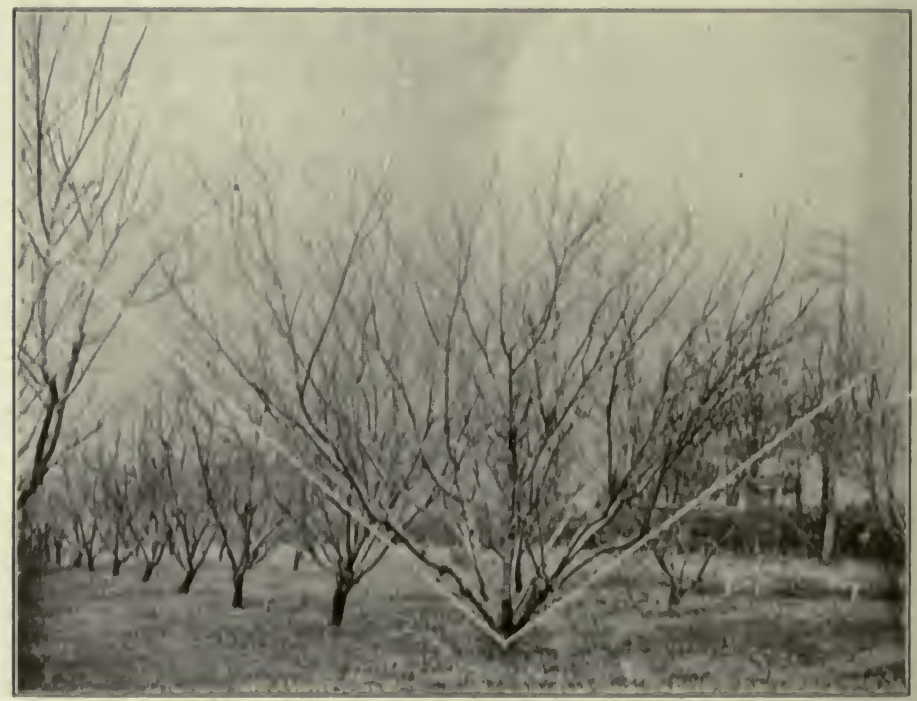

FIG. 224-OL.D MIXON PREB PEACH WITH SPREADING HEAD

Note how well thin form admitn light well down into the tree. Thin Inmures budy formed at the base of the new wood where they are hardiest. One winter when this free had only $60 \%$ of lis buda kllled, others of the name variety with denuer heads had $861090 \%$ killed.

year-old wood. Before severe cutting is done the grower should he certain that there are not enough live buds left to produce fruit. The peach sets such an abundance of fruit buds that if a small percentage of them have escaped injury there may still be enough (o) produce a paying crop of fruit.

5. When the winter is so severe that not only the fruit bur. are killed, but the wood is badly discolored, the trees may be invigorated 


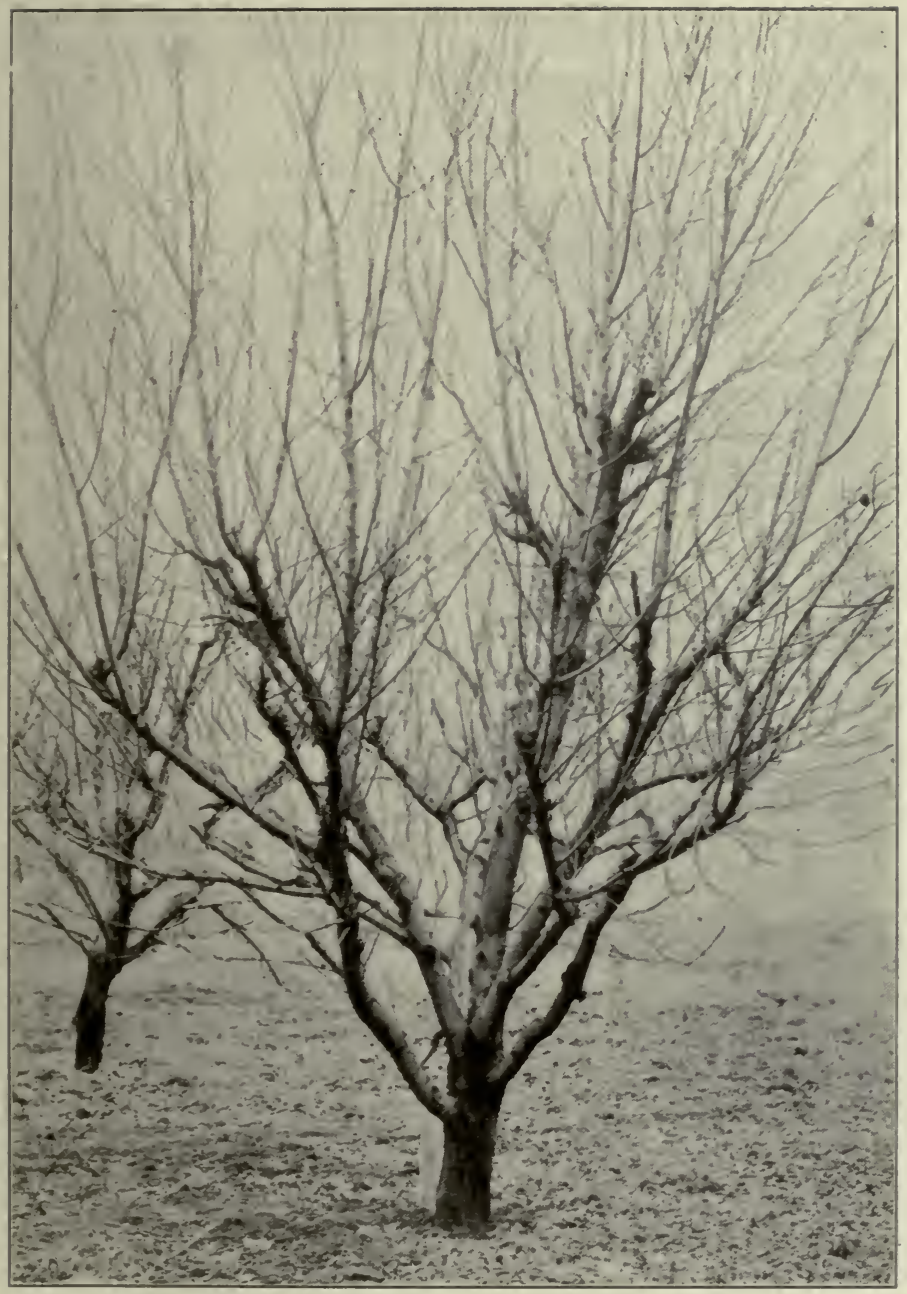

FIG. 225-PEACH TREE WITH VERY DENSE NEW GROWTH AFTER HEADING BACK TOO SEVERELY AS IN FIG. 219.

The only buds formed are at the ends of the branches where they are easily killed. A much smaller number of buds on this tree survived the winter following the besding back than lived on more open trees of the same variety. 
by cutting them back severely. The following is a summary of results of pruning peach trees subsequent to a severe freeze:

6. Peach trees which were not pruned, or in which oriy a part of the new wood was removed after the freeze, started into growth first in spring and for two weeks appeared to be in more rigorous condition than did pruned trees. 7. This apparent vigor was only

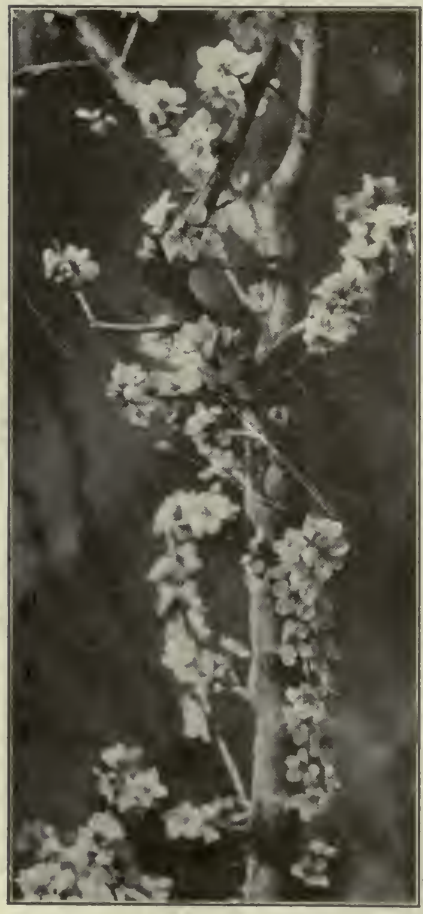

FIG. 226

\section{GREENSBORO FIVE YEARS OLD}

One of the main limbs. pruned immediately after harvesting last year's crop. See lower right-hand part of frame limb. in Fig. 227. temporary, however. Some of the trees died a little later and none of then made satisfactory growth throughout the season. They seemed to have used up all their energy in making a start. At the close of the season they had made but little new growth, and this was confined mainly to the tops of the branches, the old limbs and trunks containing only dead twigs. Their annual layer of new wood was very thin and some of their roots died.

8. Trees of bearing age cut back so as to leave only the trunk and the bases of the main limbs died in some cases, and where they did live their growth was unsatisfactory, many of the sprouts starting from the unreliable seedling stock below ground.

9. Trees of bearing age cut back into two-year-old wood in the case of young trees, and to three or four-year-old wood in older trees, thus leaving stubs of the main limbs 3 to 4 feet long. made the best growth. They marle 6 to 9 feet of new growti and entirely renewed their heads during the following season. They also develóped a good layer of new wood on their trunks and formed a good crop of fruit buds.

10. In the case of two-year-old trees, those cut back so as to leave the trunk and spurs of the main branches 2 or 3 inches long dicl best and made fine heads.

11. One-year-old trees cut back nearly to the original bud and with a single sprout trained up during the growing season made fine trees. 
12. The principal growth took place near the extremities of the parts left after pruning. Trees cut back into more than four-yearold wood failed to grow at all in some cases, showing that in very old wood the buds are too dormant to be easily started into growth. The amount to cut away in renewing winter-injured trees requires good judgment in choosing between leaving too much wood (which results in weak growth and too high heads) and cutting back too far into old, dormant wood that will not start new limbs.

13. Experiments to determine the best time to prune showed that trees pruned any time after the severe cold spell up to the time the buds began to start in spring grew equally well.

14. Good cultivation is of more than usual benefit to peach trees during the spring and summer following severe winter injury.

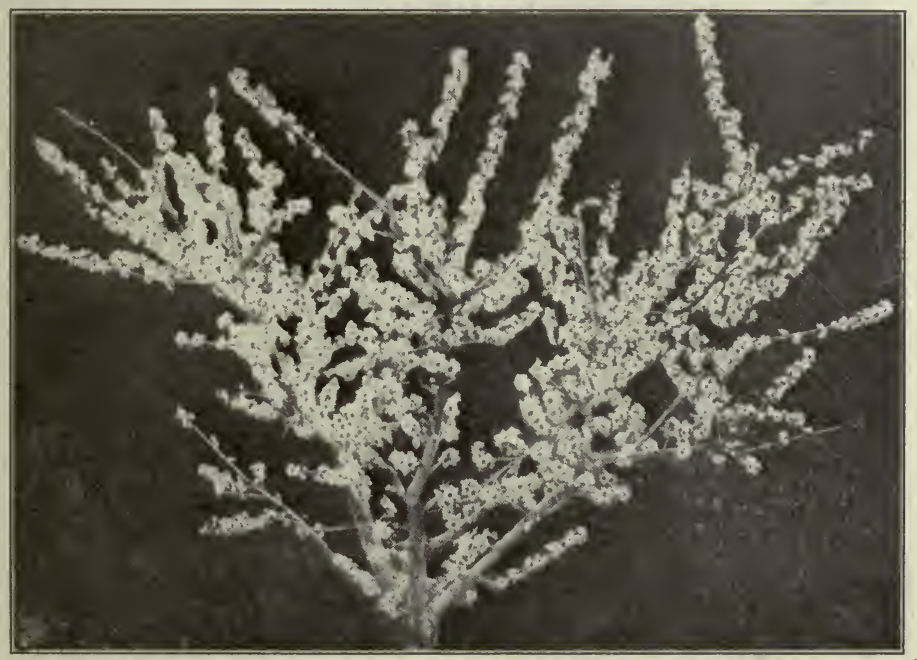

FIG. 227-GREENSBORO PEACH. FIVE YEARS OLD, PRUNED IMMEDIATELY AFTER HARVESTING FRUIT IN EARLY JUNE

20.1. Summer pruning the paach.*-It is the usual custom to prune peach trees while dormant, in late winter or early spring. When pruning is done before growth begins in the spring, the new growth has the entire season for its development. When summer pruning is not practiced, the more rapidly growing upper shoots shade the lower, slower growing ones, which in most cases die. The result is that year by year the fruiting wood gets farther and farther from

* Paragraph 204 has been condensed from C. A. Keffer's Bulletin (108) of the Tennessee Agricultural Experiment Station 
the ground; so in the course of five or six years, even when the trees are regularly pruned, it is necessary to use high step-ladders to harvest the crop. Every few years dehorning becomes advisable to keep the trees within reasonable limits.

Moreover, when the fruiting wood is permitted to form principally toward the outer parts of the main limbs the bark of those near the base of the tree is open to sun scald during winter, thus shortening the life of the tree. The difficulty of spraying and harvesting is greatly increased when the trees are high. For all which reasons it is desirable to keep the crowns of peach trees as close to the ground as possible.

In order to get a full crop from a low-crowned tree, however, approximately as much fruit-bearing wood is necessary as in trees

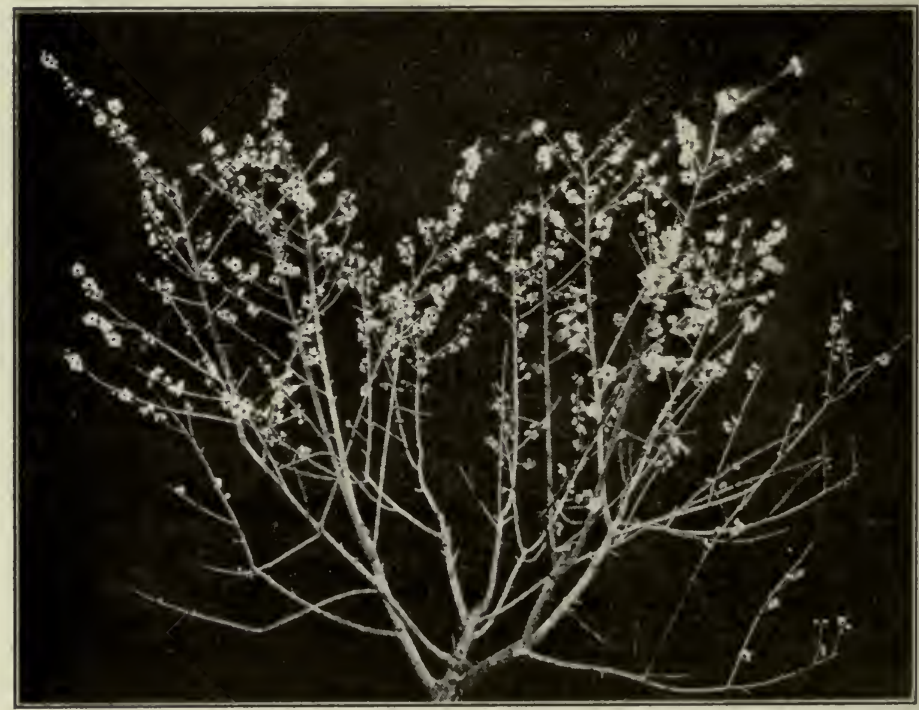

FIG. 228-GREENSBORO, FIVE YEARS OLD, NOT SUMMER PRUNED

of the usual shape. The purpose of summer pruning is to enable the tree to develop fruiting wood on the lower part of the main or skeleton branches, which are usually bare.

Seventy trees, including early and late varieties, were set $18 \times 20$ feet. In the following spring one-year-old trees were interplanted for a peach borer investigation, so since then the trees have stood $9 \times 10$ feet. As the trees came into bearing it was deemed desirable to ascertain how long they could be kept profitable at this close dis- 
tance. Heavy pruning was resorted to, and last year the usual winter pruning was supplemented by summer pruning.

. Previous work of a similar nature had proved that in seasons of average moisture the Greensboro and all earlier varieties set a crop of fruit buds after harvest. Greensboro ripens the first week in June; Red Bird ten days or two weeks earlier. These two varieties were pruned the second week in June. The trees were divided into four groups, with an unpruned check row, and in each group the wood of the previous year's growth, whether it had produced peaches or not, was pruned back to varying lengths, from 1 to 8 inches.

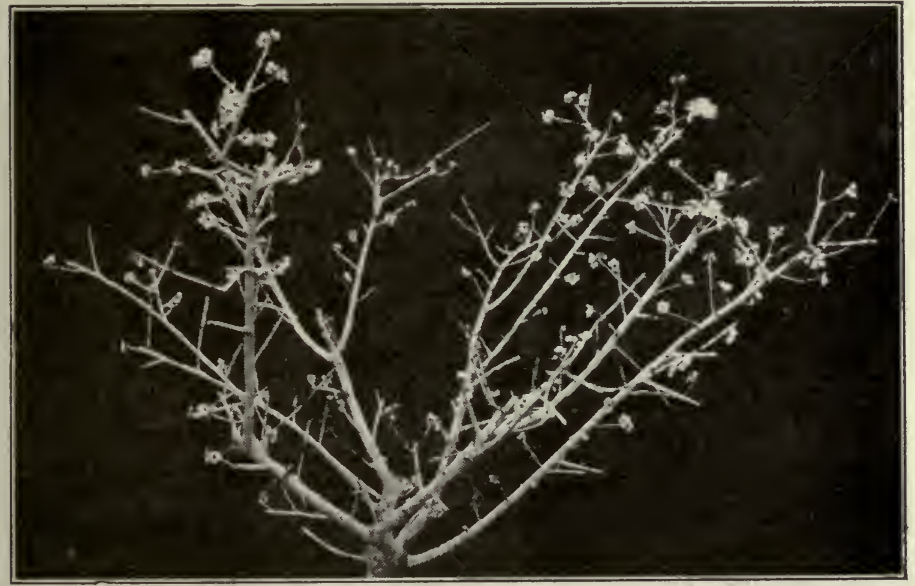

FIG. 229-GREENSBORO, FIVE YEARS OLD, PRUNED IN AUGUST

By far the best results attended the close pruning. Where the spur was very short the new growth in many cases sprang from its base and, at most, it was close to the main limb that supported it. But in the long spurs in most instances the new growth was near the extremity of the spur, thus defeating measurably the purpose of the pruning. Many spurs did not send out new shoots.

In all cases of early pruning the new wood was well set with fruit buds during the season, as is shown in Fig. 227, a picture of a Greensboro tree photographed when in full bloom in April. It is difficult by photography to show the fruit on the tree because leave.s and fruits are so nearly the same color and the picture is necessarily greatly reduced. As the peach blooms in advance of leafage, the blossoms show exactly the location of the fruiting wood and trees in full bloom are therefore used in illustrating this article. 
Comparing Fig. 227 with Fig. 228, a tree that was not summer pruned, it is seen that the result of summer pruning is to bring the fruit of the next season nearer to the main limbs, and also that in the unpruned tree the lower part of the crown has very many less blossoms than the tree pruned by the middle of June. Figure 226 is a letailed view of the lower part of one of the main limbs of the tree shown in Fig. 227. In the lower left-hand corner the trunk of the tree and its separation into three main limbs is shown. It will be observed that this limb (and the others equally) is clothed with blossom-covered shoots from its base outward. Fruit set on

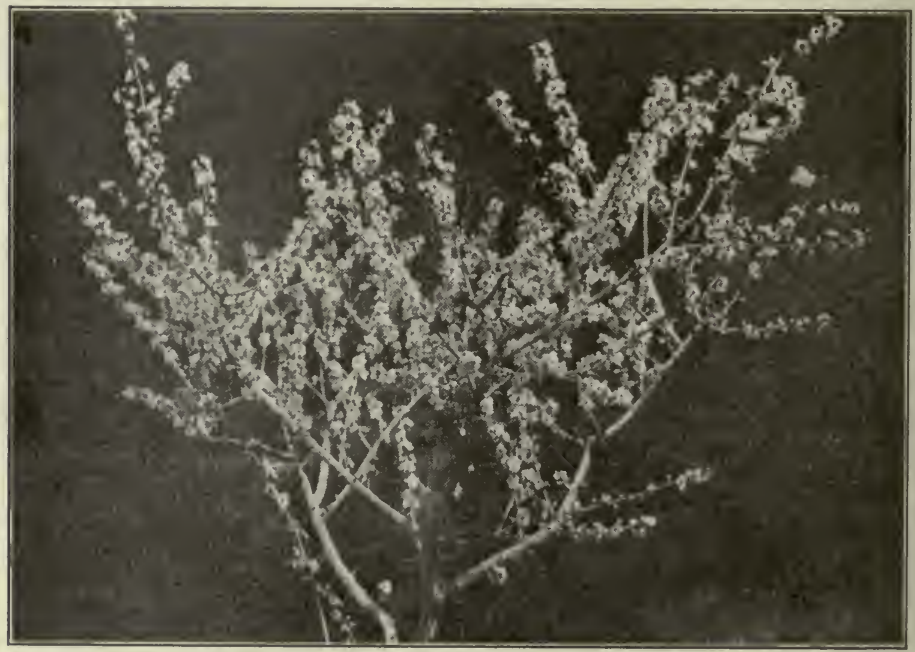

FIG. 230-GREENSBORO, FIVE YEARS OLD, PRUNED IN JULY

cvery one of these shoots, so fully a fourth of the entire crop of the tree is produced within 4 feet of the ground. All the fruit on the tree can be picked from the ground by a man of averagc height.

Early summer pruning permits the formation of fruit buds during the remainder of the growing season for the next year's crop. But late pruning is harmful to the succeeding crop. The tree shown in Fig. 229 is a Greensboro tree pruned in August. Very few fruit buds formed on the new growth, which was very short. A Greensboro tree, pruned in July (Fig. 230) set a good stand of fruit buds in the upper part of the crown, but the lower part is relatively hare. Red Bird trees pruned in early June were quite as full of bloom in the lower branches as was the Greensboro tree shown in Fig. 227.

The later varieties respond in practically the same manner to early and late summer pruning. Figure 231 is a Belle (of Georgia) 
tree, pruned in early June, and Fig. 232 is a Belle not summerpruned. The late-pruned Belle trees were no better than the latepruned trees of the earlier varieties. Champion gave results so similar that it was not thought necessary to multiply photographs. Elberta is not included in this orchard, but in all probability its action would be the same.

To prune any variety of later ripening season than Greensboro after its crop is harvested would seem to be unprofitable. Is it feasible to prune Carman and all later varieties before their crop is gathered? What sacrifice of crop is involved?

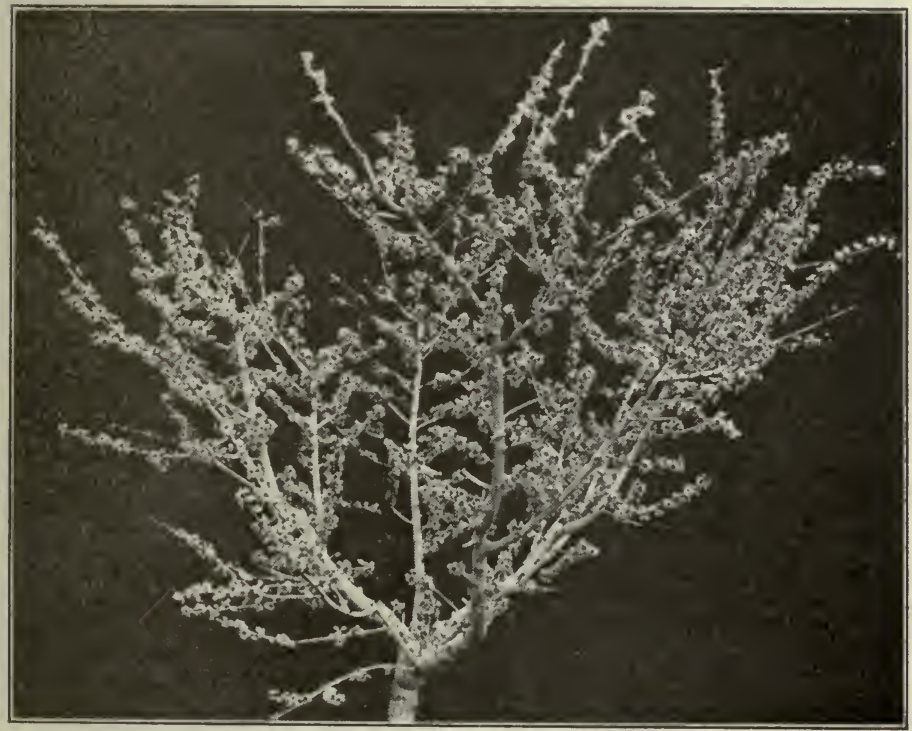

FIG. 231-FIVE-YEAR BELLE OF GEORGIA PRUNED IN EARLY JUNE

Carman, Belle and Champion trees were pruned as lescribed ahove in early June, July and August. In every tree there are shonts that do not bear, and others that grow so closely together on the main limbs as to shade one another too much for good fruit development. In the case of these varieties the barren shoots, and a part of those placed close together, were pruned, leaving fruiting wood the whole length of the main limbs. In this way all the trees produced as full a crop as they should. In all cases the early-prunerl trees developed fruiting wood in the lower part of the crowns, as indicated in Fig. 231. The late-pruned trees and the unpruned trees 
gave much less fruiting wood, particularly in the lower part of the crown (Fig. 232).

All peach trees tend to develop a stronger growth toward their outermost parts, whatever the pruning. This is seen in all the trees illustrated herein. But if the center of the crown is kept open, enough light will reach the lower parts to insure the development of a profitable crop, where in unpruned trees little or no fruit is produced.

It is recognized that summer pruning involves additional expense to the grower. But the method is quickly learned and cheaply

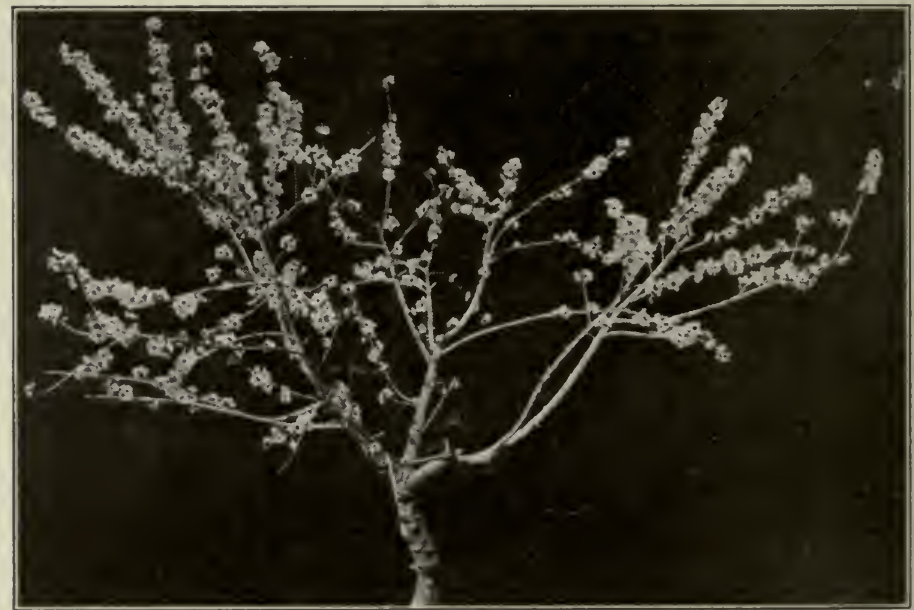

FIG. 232-FIVE-YEAR BELLE OF GEORGIA NOT SUMMER-PRUNED

employed. All that is necessary is to cut back the wood of the previous year's growth before the middle of June, and only in the inner part of the crown; the outer branches get enough light laterally. Figure 233 is a fourteen-year-old Greensboro tree that was summer-pruned after its crop-a full one-was harvested in June. It has been dehorned twice, the last time three years previous. Its center has not been kept as open as in the trees previously illustrated, but there is a fine setting of bloom throughout the crown. Fully one-third of its crop is set within 5 feet of the ground, the total height of the tree being 9 feet. Compare this tree with Fig. 234, in which the new wood was permitted to grow unpruned throughout the summer. The practice of summer pruning for early varieties at least, would seem to be established.

Summer pruning will enable the grower to develop a full crop of fruit in the lower part of his late varieties if he trains the trees 
properly. Let us suppose a tree, open at the center, with fruiting wood well distributed along its main or skeleton limbs from the crotch to their ends. Young trees in which three skeleton limbs radiate from the trunk in spreading fashion will produce new shoots at close intervals. If these new shoots are pruned alternately, before the middle of June, one set being allowed to grow throughout the season and the other pruned to a spur, the following year the unpruned shoots will bear a crop. The second year they will be reduced to spurs and the alternate set will bear. Thus both late and early varieties may be kept in full bearing the entire length of their frame limbs. Even with this heavy pruning the greatest convenience of harvesting and spraying the low-crowned trees will warrant whatever increased labor the plan involves.

When winter pruning alone is practiced heavy growth follows. Such new shoots as form on the lower parts of the crown reach

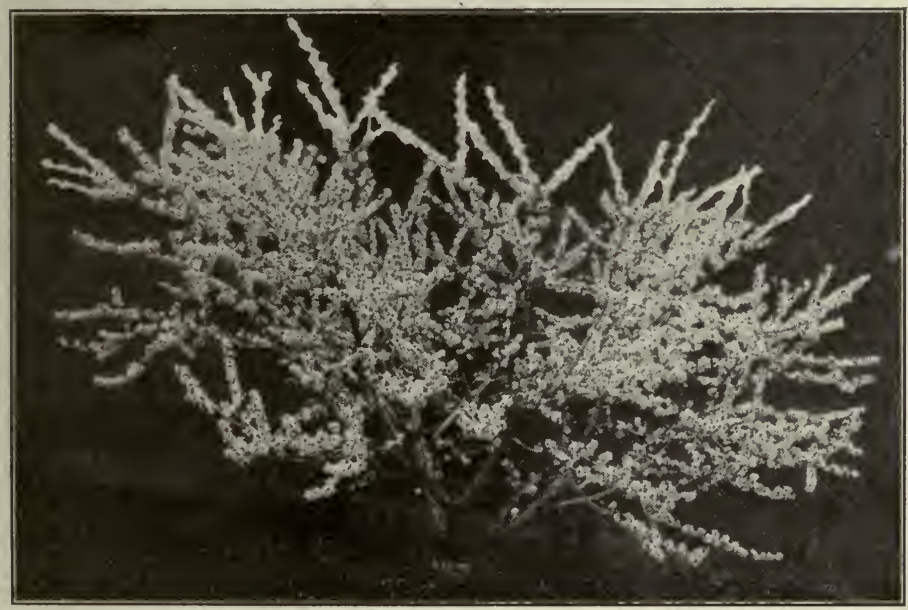

FIG. 233-GREENSBORO TREE, SEVEN YEARS OLD, NOT SUMMER-PRUNED

up for light, and before midsummer are crowding one another so much as to overtop completely the weaker growths. By fall these smaller shoots are dead, and because of lack of lighıc very few fruit buds have formed on the lower parts of the surviving shoots. Thus the fruit forms toward the ends of the new wood, where it is poorly supported. As the crop approaches maturity these long branches bend and break beneath a weight of fruit that could have been safely carried had it been placed near their bases. Summer pruning evades this difficulty by thinning the new growth and giving the parts remaining full sunshine. 
Summer pruning is an insurance against sun scald on the frame limbs; for the shoots that spring from the upper sides of the main branches not only shade them but draw into their supporting tissues a constant flow of sap, thus keeping them in vigorous health.

Because the peach tends to form a densely leafy head, care in pruning should be exercised to keep the head fairly open so sun and air may have free access to the center. This end may be attained perhaps most easily by extending the diameter of the head rather than increasing the

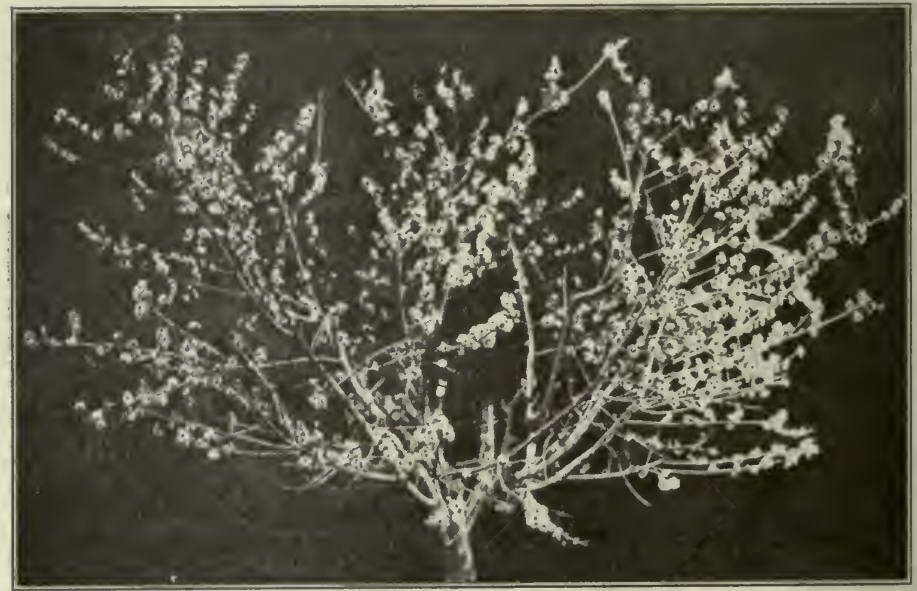

FIG. 234-FOURTEEN-YEAR GREENSBORO SUMMER-PRUNED IMMEDIATELY AFTER HARVEST LAST YEAR

height. Most growers strive to have the frame limbs form as nearly an angle of 90 degrees with each other as possible and to spread the top so that the height will be about half the width (Fig. 224). By proper attention to pruning, cultivation, feeding, spraying and especially borer control, peach trees may be made to continue profitable far beyond the usually allotted half score of years. The author has visited orchards 30 years old and older that still bear profitable crops simply because of adequate attention. 
One of the commonest errors in peach pruning is to get rid of too much interior growth. This may be either because of over-shading by growths higher up or by poor judgment in cutting. Nothing but careful and vigorous pruning in the top will maintain bearing wood in the lower parts of the trees; and yet care must be exercised to prevent having too open a top. Plenty of fruiting wood must be there also. While central bearing twigs usually are not as sturdy as exterior ones, yet the fruit borne there is less likely to be blown off. It may also be of fully as good quality on properly handled trees.

Often an old peach orchard may be rejuvenated. Perhaps the best time to undertake the work is during a season when frost has ruined the crop. The earlier the work can be done in the spring the better so that plenty of fruit buds may be formed for the following season's crop. When there are young growths low down on the limbs and the trunk, the top may be cut back severely, the cuts being preferably close to points where good but smaller limbs are already growing well. "Dehorning" is an exaggeration of this cutting back. In it practically all the top is removed except a few feet of the frame and secondary limbs. Figure 31 shows a tree that was so treated four years before the picture was taken. It bore a partial. crop the second year after being dehorned and a good crop the following and the fourth years. 


\section{CARE OF TOP-WORKED TREES}

205. Availability of top-working.*-"In orchard (less in nursery) practice unsatisfactory trees are top-worked. also trees of strong growth are used as bodies for poor straggling growers and those that have trunk weakness. Thus any desired variety may be worked on trees by the individual orchardist. The method is of practically universal utility, because nearly every fruit grower is sure to have at least some trees that do not please him, but which are too good to destroy-seedlings, trees untrue to name, shy bearers, others in which graft or bud has failed but a sucker developed, and so on. Any desired number of varieties may be worked upon the same tree, the number being restricted only by the available branches or stocks."

206. Top-working finds its widest application in new fruit districts where the promiscuous variety growing of the home orchard or the speculative style of planting is giving place to the commercial planting of a few varieties specially adapted to the district. In other words, experimental planting is being replaced by business planting. When this period arrives there may be thousands of undesirable or, from a business standpoint, less desirable varieties in this district-trees too good to destroy, yet not profitable enough because their fruit is not in demand, is too sparsely borne or for some other reason. Moreover, if properly top-worked and handled they may be made to yield profitable crops several years before nursery trees would come into bearing. Sometimes topworked trees produce a fairly good crop four years from the operation.

- Kains Plant Propagation, Page 238. 
As top-working is based on processes of graftage, and as such is fully discussed in the author's book, Plant Propagation, Greenhouse and Nursery Practice, it need" only be mentioned here that "Cleft grafting . . . finds its chief use in amateur practice to work over seedling and unsatisfactory trees to desired varieties. Everyone should know how to perform it, because there is no telling when it may become useful."* Usually the whole top is changed over to the desired variety by grafting or budding all of the principal limbs-preferably in $\mathrm{their} s \mathrm{maller}$ branches if the frame limbs are large-so as to maintain or perhaps improve upon the original form of the tree. Better results are generally secured in this way than by cutting of the trunk or frame limbs. When this latter is done, there is danger of ugly and dangerous $\mathrm{Y}$ crotches. Another advantage in us-

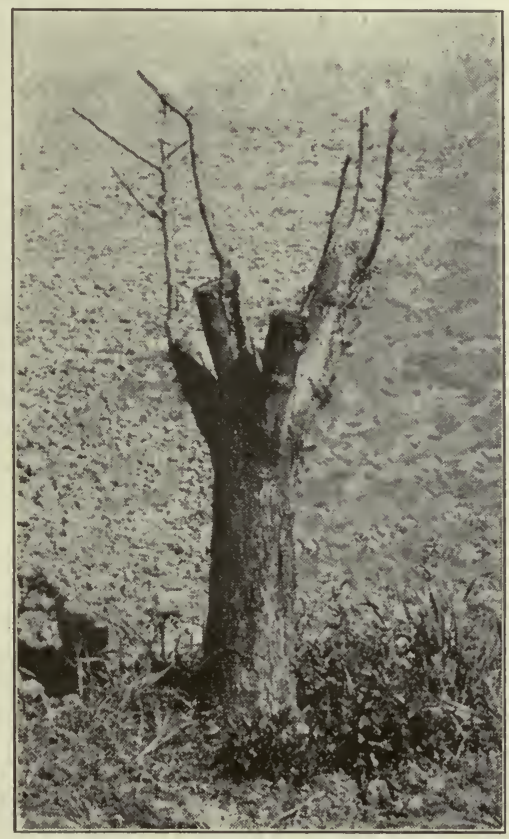

FIG. 235-NEW GROWTH ON TOP-WORKED APPLE, HEADED BACK AND THINNED AFTER ONE SEASON'S DEVELOPMENT, ing the smaller branches (say $3 / 4$ inch up to 2 inches for cleft grafting, and smaller than $3 / 4$ inch for most other methods) is that the new growths from the cions are not so likely to be broken by wind, ice or snow as when the

* Ibid. Page 239. 
work is done in large stubs, which tend to produce far longer and usually weaker growths. Apple and pear trees under five years may be changed to the new variety in perhaps two years, half the top each year; but mature trees should not be worked over so fast-not faster than

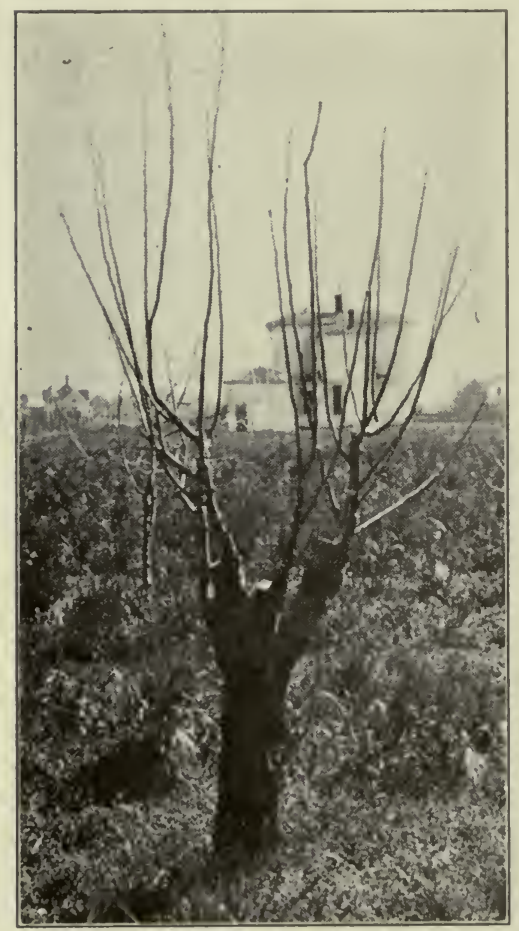

FIG. 236-ONE SEASON'S GROWTH ON TOP-WORKED APPLE

New growth headed back after second season. Compare Fig. 235.

four to six years, depending on size, agc and character of growth. Mature stonc fruit trees may be topworked, but though young trees may develop good tops, little if any time is gained because nursery trees of these species come so quickly into bearing.

While proper setting of the cions is important, the after care of the trees is at least as necessary. Unless this care is given even the hest "take" of cions may prove a more or less dismal failure in developing a new top. Us ually the cions which "take" develop rather rank shoots which, while looking strong, yet if left to themselves may be topheavy and therefore weak and easily blown out by wind or knocked out by snow, ice, birds or accidents. They should be headed in when, say, 18 inches long. so as to make them branch rather low down. Sometimes the 
branches may also need to be headed back somewhat. The idea should be to secure stocky rather than spindling growth and also a strong union of stock and cion.

Another highly important point is to remove the water sprouts and suckers that almost always derelop on the stubs and trunks of the stock trees. Some of these growths, however, may be left to shade the trunks if there is danger of sun scald. To make them serve this purpose most effectively, they should be pinched back to make them branch and thus develop $\mathrm{morc}$ leaves. Except for such purposes they should be rubbed off as soon as they form.

In the spring of the year following the grafting the grafts should be pruned in much the same way as young trees are handled at that time. Preferably no growths should be left longer than 18 inches, and when they are not of satisfactory length they should be cut back

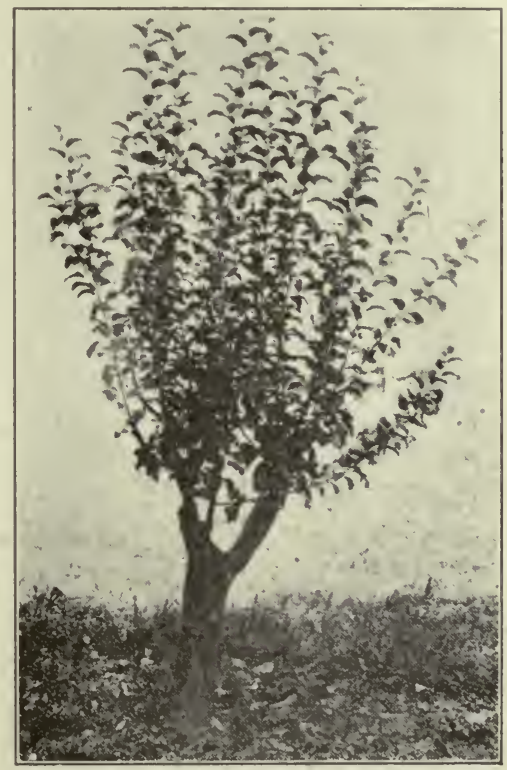

FIG. 237 - NEW GROWTH AT END OF SECOND SEASON ON TOP.WORKED APPLE TREE. (Shown in Fig. 236.) severely (Fig. 236) so as to make them develop better growths the second season. Should two or more of the buds on the original cion grow, all but the best-placed twig should be cut off, to prevent crcwding. Usually the lowest bud will make the best growth and should therefore be saved. Perhaps some training may be necessary 
to spread, contract, raise or lower the top (120d). Since top-worked trees frequently tend to contract, it will oftener be necessary to prune so as to spread the top. In such cases the graft should be cut back to branches pointing in the desired direction.

Should two cions grow on the same stub, both may be left the first season so as to heal over the stub quickly, but in the spring of the second year the poorer or the one less favorably placed should be cut off close to the stub so as to hasten healing of this wound. When the stubs are larger than 2 inches in diameter, both cions may be allowed to grow during the second year, the removal of the inferior one thus being in the second instead of the first year following the grafting. The case will usually be improved if the cion to be removed is cut back rather severely so as to check but not entirely stop its development (compare Fig. 98). When removed the wound should be made as small as possible so as to facilitate healing. Never should both cions be allowed to grow longer than this because they will almost certainly form a bad Y crotch.

Attention each year after the first should be the same as that given young trees, the effort being to make wellformed and stocky tops. The small wood may be allowed to take care of itself, for some of it may develop into fruit spurs. A few may need to be clipped or removed, but it is better to leave them for a few years to see what they will do. Even if they reach diameters of half an inch to an inch, the wounds left when they are removed will quickly heal if properly made $(116,119$. $122,124)$. 


\section{CHAPTER XIII}

\section{BUSH FRUIT PRUNING}

207. The bramble fruits.-As already noted $(56,72)$ raspberries, blackberries and dewberries usually produce their fruit upon shoots of this year's development from buds which have lived over winter upon canes of last year's growth. The exceptions are those varieties, such as St. Regis raspberry, in which the buds instead of resting over winter push out into growth the same season as the cane grows. In all cases the canes die after they have finished fruiting.

Four pruning practices are based on this method of growth. 1. Unnecessary shoots are removed from the crown of each plant and from between the rows. Thus half a dozen, or often less, canes are left in each crown, stool or hill. 2. The tops of the canes are pinched when they reach the height favored by the grower. This tends to develop branches low down on the canes, which are also made sturdy enough to stand without supports. 3. The laterals produced on the canes are shortened, generally in spring before growth begins, so as to develop finer fruits from the reduced number and more compactly borne blossoms. 4 . The canes that have fruited are cut out of the hills, preferably as soon as the fruit has been harvested, but usually during the winter when time is less at a premium.

208. Pruning and training red raspberries.-In the pruning of all brambles method No. 1 is in general use: With the red raspberry the second is only occasionally used in commercial plantations, the canes being allowed to develop to their full size without any summer attention. Lateral shortening (No. 3, above) is the same as for the other brambles, but removal of the old canes 
(No. 4) is generally done in the winter (Figs. 238, 239). When summer pruning is done, the tips of the young canes are pinched when they reach a height of 18 to 24 inches. An important objection to shortening the red raspberry is that while it develops desirable lateral growth it also encourages the development of undesirable suckers and often unnecessary canes in the stools. The number actually produced will vary more or less with the variety, the character of the soil, the amount of available plant food and other factors. The advantages gained by summer pruning are to increase the bearing wood, and to secure low canes which need no supports.

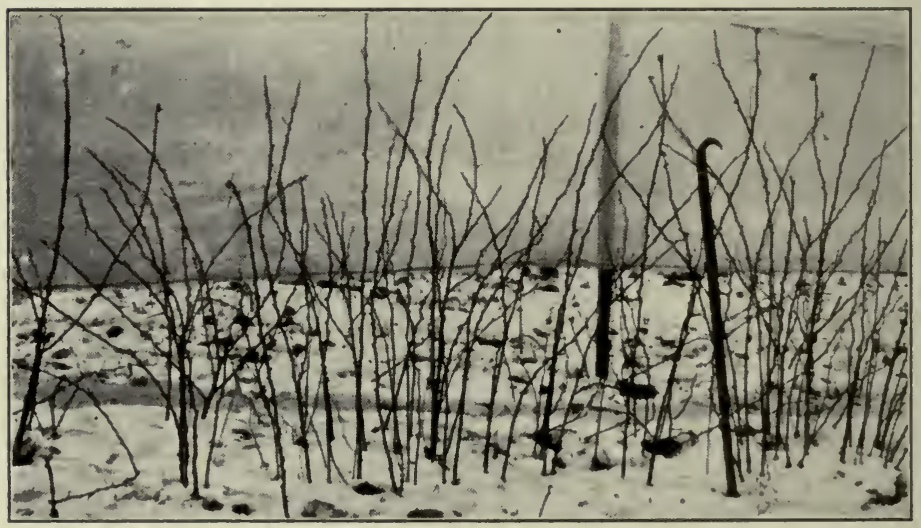

FIG. 238-RED RASPBERRY CANES BEFORE PRUNING

Note the continuous row as compared with hills in Figs. 240, 242.

Craig* found that with 16 varieties of raspberries the plants whose tips were pinched back twice yielded only abcut two-thirds as much as vines left unpruned.

As the result of a five-year test at the Wisconsin Experiment Station $\dagger$ F. Cranefield writes: The facts lead to the conclusion that pinching the growing shoots of black raspberries, to cause branching, gives rise to a slightly increased production of fruit, while the Cuthbert was decidedly injured by this practice. The

* Garden and Forest 10, Pages 3-4.

† Annual Reports 1899 to 1903 inclusive. 
gain in the case of Gregg is so slight, however, as to be more than offset by the cost of pinching and the increased labor involved in the winter protection of the plants. As a general conclusion drawn from this very thorough trial covering five years, it may be stated that pinching is not a profitable practice.

209. Pruning and training black raspberries.-Summer pinching (No. 2, above) is a very popular practice among black raspberry growers, mainly because this plant does not produce suckers. The work is done at frequent intervals during the growing season-whenever the young

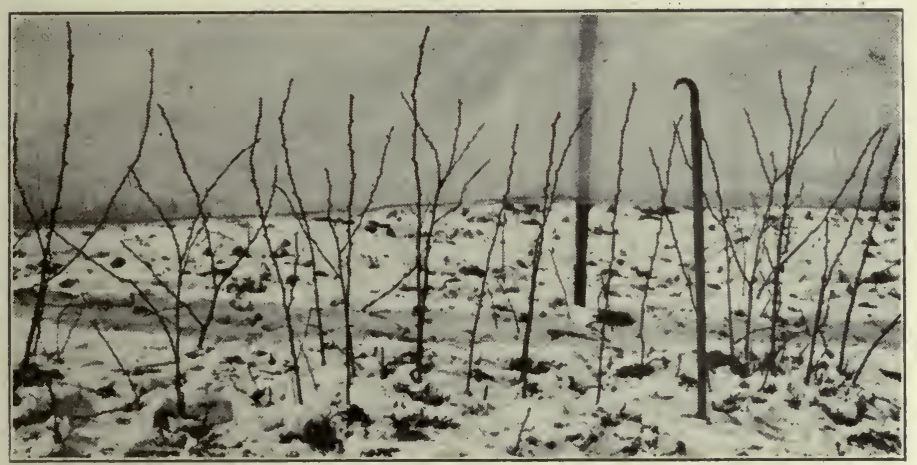

FIG. 239-RED RASPBERRY CANES AFTER PRUNING

Same as Fig. 238 after thinning out and cutting back.

canes reach a height of 18 to 24 inches. If done then, the thumb and forefinger, in a small way, will do the work effectively because the tops will be succulent. If the canes are allowed to grow taller so that several inches of wood must be cut with a knife or a pair of shears, the result will be far less satisfactory because the canes will not branch so low down and will not be nearly so selfsupporting. Moreover, there will be a smaller number of laterals, a smaller quantity of fruit, and that usually of poorer quality, than on canes pinched at the proper height and time. (Note Cranefield's conclusions, 208.)

Proper summer pinching, therefore, predetermines both the quality and the quantity of fruit to be borne the fol- 
lowing season. In fact, it is the most important single factor in the growing of first-grade black cap raspberries. Wires, stakes and other supports are rarely used in commercial raspberry plantations because the canes may be made to support themselves. When pinched low (18 to 24 inches), they will do this far better than if pinched high (30 to 36 inches), for the stems are not only more stocky, but the laterals are also. High canes frequently bend over to the ground and often break from the weight of fruit. Frequently also the fruit becomes soiled.

Generally, in commercial plantations, the fruited canes are removed in the winter, at which time also the laterals are shortened to 8 to 12 inches, depending somewhat on

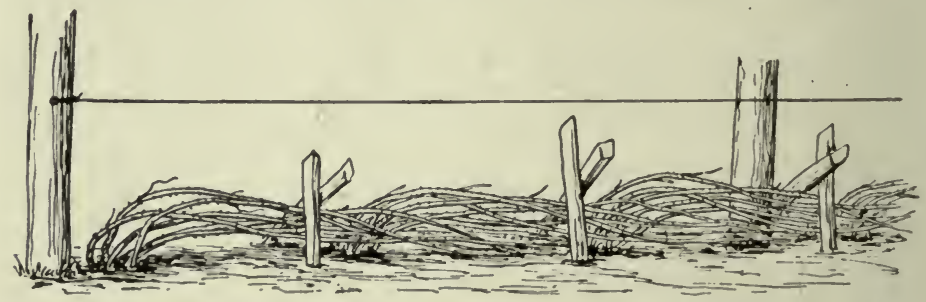

FIG. 240-BRAMBLE CANES IN POSITION FOR COVERING WITH EARTH
FOR THE WINTER

the grower's ideal, but more by the positions of the fruit buds upon them. In some varieties those buds are borne rather far from the main canes; in others closer. Nothing will take the place of personal observation of the behavior of the variety in hand.

210. Pruning and training blackberries.-What has been said above concerning the suckering of red raspberries and the pinching of black cap raspberries applies more or less strikingly to the blackberry. But since this fruit is often trained in other ways it may be well to condense and quote what G. M. Darrow* has to say and to show the various forms of training he illustrates. What he writes will apply with more or less force to the man-

- Farmers' Bulletin 643, Pages 5 to 7. 
agement of other bramble fruits, especially red raspberries, which have the similar habit of throwing up suckers.

If all of the suckers are allowed to grow, by the end of the second year the field will be a dense thicket of canes, from which the berries can be picked only with great difficulty. The suckers will compete with the parent plants for food, moisture and light, and the whole plantation will be inferior. The plants must therefore be kept in rows or hills, and all suckers which appear between the rows must be destroyed by frequent cultivation. Suckers do not reappear as rapidly if pulled as if cut, but this method requires much hand labor. If all are destroyed, the plants will have much stronger roots and canes, and the berries will be larger and better.

As soon as the last berries have been picked, the canes which have just borne fruit should be cut out and burned. This allows the young canes more room in which to develop, and destroys any insects or diseases on the old canes. It will rarely be necessary to leave them to support the new canes during the winter snows. Wire trellises are usually to be preferred where support is needed. Not more than four new canes to each plant should be al-

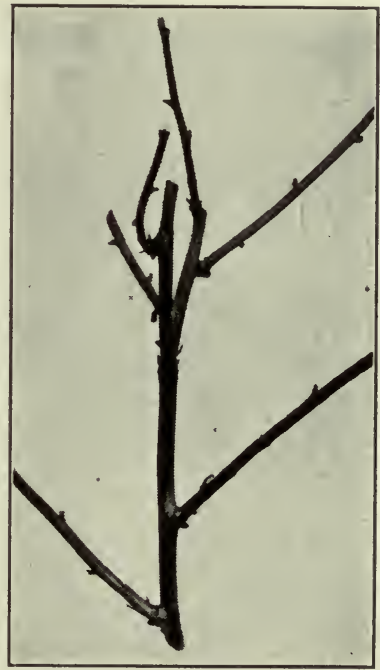

FIG. 241

RED RASPBERRY CANE IMPROPERLY PRUNED

This cane was clipped not pinched during midsummer when nearly full grown. Lateral branches developed later as shown near the top. The cane is 30 inches long up to the point cut. It should have been pinched at 13 to 24 inches. Such canes as this are often borne to the ground by the weight of fruit because of their weakness and top-heaviness, whereas short, pinched canes stand up. The laterals, which winterkilled badly because produced late in the season, have been cut back to permit clear photographing. 
lowed to grow in one season, all in excess of this number should be cut out not later than the time of the removal of the old bearing canes. The remaining canes will be larger and stronger because of the thinning.

The systems of training vary in accordance with conditions in various sections of the country. In some sections where the plants do not grow large and where the soil does not wash, the new canes may be pinched off with the fingers-when they reach a height of not more than $21 / 2$ feet. When the bushes are very vigorous, the height may be increased to 3 feet. As the canes do not all reach the height of $2 \frac{1}{2}$ feet at the same time, the

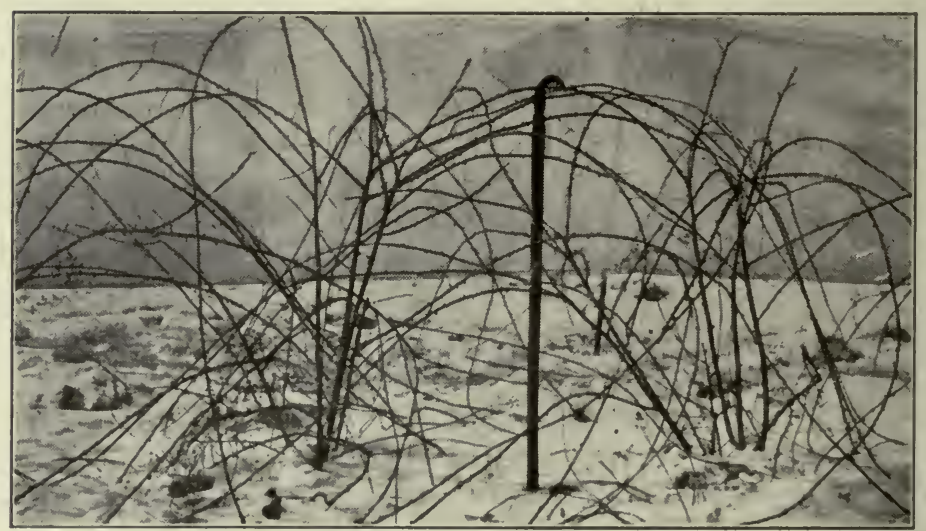

FIG. 242-BLACK RASPBERRY BEFORE PRUNING

The pruning hook shows the relative height before and (Fig. 243) after.

plantation must be gone over several times at frequent intervals. The pinching causes the canes to branch [comparatively low] and to be better able to stand erect with a heavy crop of berries.

Even when this method of training is used, the canes may be bent over and broken either by tillage implements or by the pickers, the number of canes and the quantity of fruit being thus materially reduced. Under 
such conditions a wire trellis will save sufficient fruit to make it a profitable investment. Such a trellis consists of posts set in each row at intervals of 15 to 30 feet; the canes are tied to a wire stretched along this line about $21 / 2$ feet above ground. This keeps the canes upright and facilitates cultivation and picking. (Figure 248 shows this and other popular forms of trellises. See also Fig.247.)

Another satisfactory form of trellis is made as follows: Crosspieces about 18 inches long are nailed to the top of each post and two wires instead of one are stretched from the ends of the crosspieces. The blackberry canes

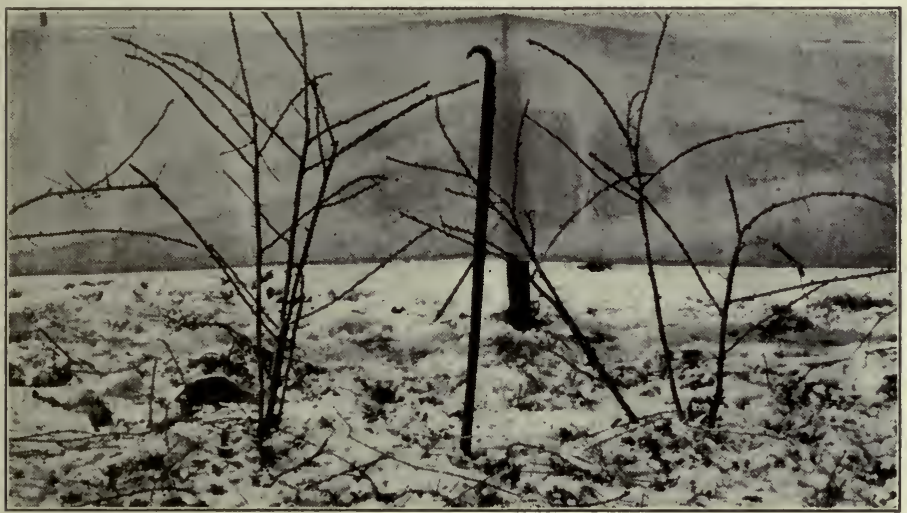

FIG. 243-BLACK RASPBERRY AFTER PRUNING. COMPARE WITH FIG. 242.

are kept inside these wires, which support them on either side.

These systems of training are adapted to certain varieties and to those sections of the country where the bushes do not grow very high. When the canes grow very long or are inclined to run somewhat like a grapevine, a much higher trellis is used, with two wires (Figs. $247 b, 248-1$ ), one about 3 feet, the other about 5 feet from the ground the height depending upon the vigor of the plants (Fig. 244). The canes of the erect varieties are fastened to 
the wires, while those of the trailing varieties are tied either horizontally along the wires or in fan-shape (Fig. $247 c$ ).

A variation of this trellis (Figs. $247 d, 248-2$ ) is used in some sections where the trailing varieties are grown. Two cross-pieces 18 or 20 inches long are nailed to each post, one near the top and the second about 2 feet below. IVires are strung along the ends of the crosspieces. Sometimes both bearing and nonbearing canes are trained to the same wires, frequently the nonbearing canes on the lower

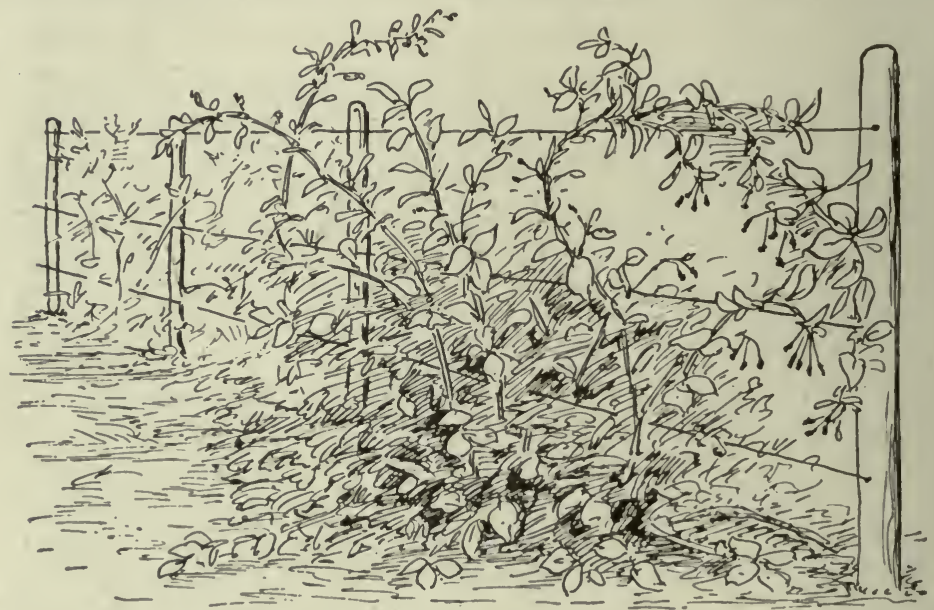

FIG. 244-LOGANBERRY PLANTS WITH FRUITING CANES SUPPORTED ON WIRE TRELI.IS

wires and the bearing canes on the upper wires and sometimes vice versa.

These systems are the most popular ones; they are often varied to suit particular conditions or the convenience of the grower. When the plants are set in hills 5 or more feet apart each way, the canes may be pinched back at about 3 feet to make a stocky growth. Frequently, when the plants are set in hills, a post is set by each plant and the canes tied to it (Fig. 248-5). The trail- 
ing varieties, with the exception of the Mammoth, are rarely trained to the hill system.

211. Currants are sometimes pruned and trained in tree and pillar forms, but these are too fussy for business purposes. The method adopted for them is much the same as that employed to make the heads of trees such as peach and cherry. All buds on the lower part of the

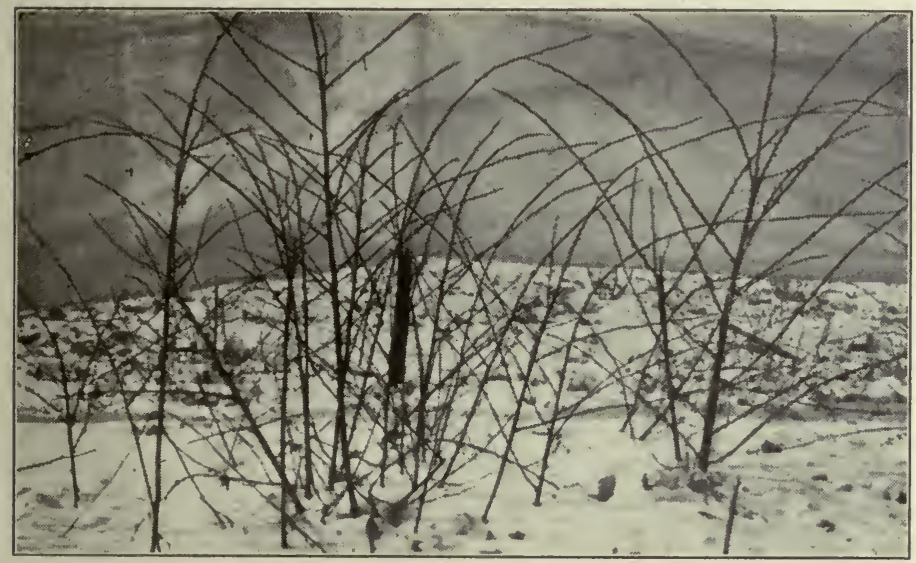

FIG. 245-BLACKBERRY CANES BEFORE PRUNING

cutting are removed and four to eight frame limbs allowed to develop. These are shortened to 4 to 6 , or at most, 8 inches and two to four main laterals allowed to each frame limb. After the framework and the first laterals have thus formed the head, two to four shoots are allowed to grow for the making of fruiting spurs, being cut back to one to three buds early in the spring after their formation. From time to time wood that has fruited twice or thrice or perhaps oftener is cut out and new growths encouraged.

Apart from the labor involved in this method of training, there are the serious objections that the "trees" are 
less productive than the bushes and much more likely to be killed by borers; for when the tree is so attacked its one stem is destroyed, whereas when a stem in a bush becomes infested it may be cut out and burned and the other stems allowed to continue to live and bear fruit.

The bush form is the popular one, both with people who neglect their plants and those who grow currants for profit (Figs. 250, 251). No matter how badly neglected, some fruit may be expected. Pruning, combined with other rational treatment, will make the plants bear fine fruit abundantly. The flower buds are borne mainly on twigs

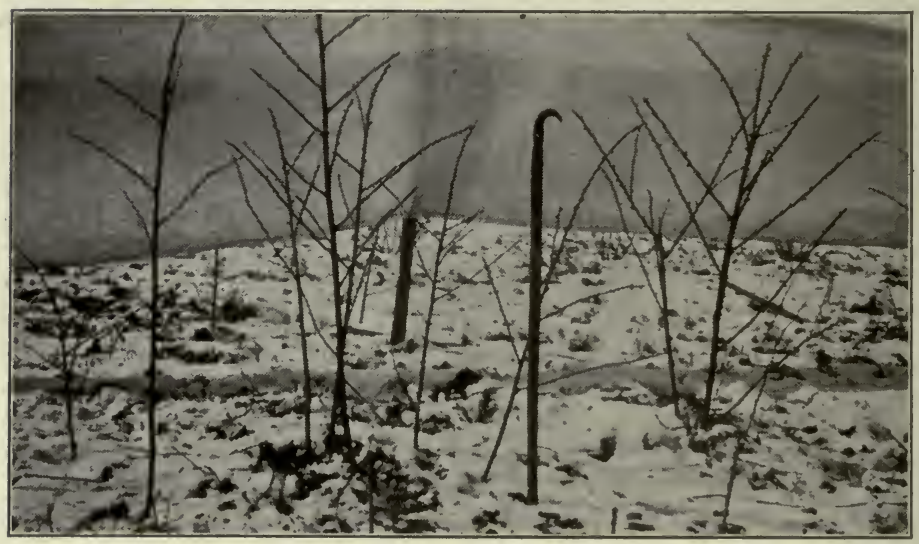

FIG. 246-BLACKBERRY CANES AFTER PRUNING

Same as Fig. 245 after thinning out and cutting back.

of last year's growth and on short annual spurs on wood two or more seasons old. Usually the finest fruit is borne on the young wood, but it is unwise to dispense entirely with older wood. The best practice keeps a constant succession of new canes coming up to replace the old ones. Commercial growers favor six to 12 canes to the bush, two or three new ones being allowed to develop each year, the oldest ones being cut out after having produced two or usually not more than three crops. 
Many more canes are likely to spring from the base of the bush, but all but the two or three best should be cut out, preferably after fruiting, at which time also the old canes may be cut out and immediately burned to get rid of any insects and diseases that may be present. Unnecessary and lusty shoots on the main canes may be cut back to one or two buds in the early summer in which they develop. Thus they will form fruiting spurs which may fruit the following season. Upon these will be borne
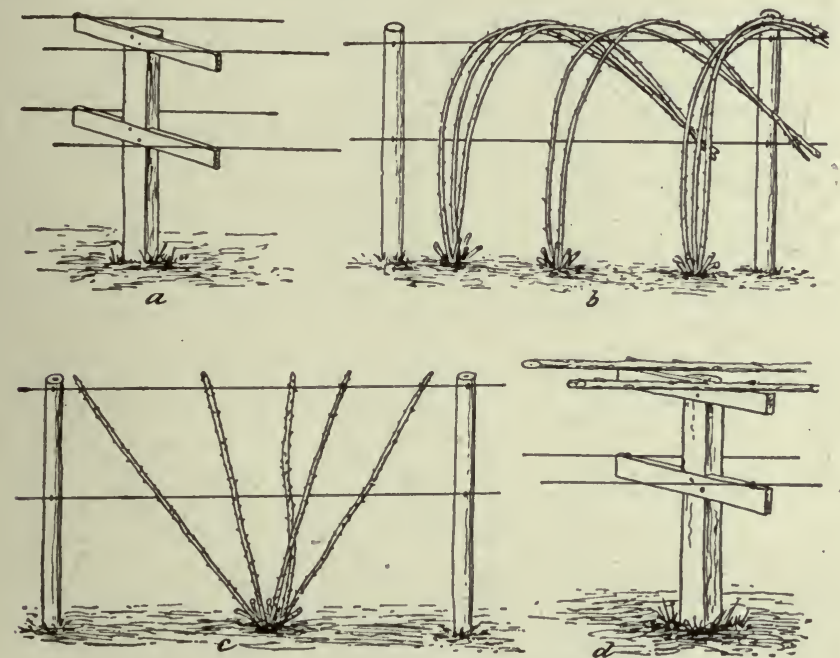

FIG. 247-STYLES OF BRAMBLE CANE SUPPORTS

$a$, Considered best for vine-producing kinds. $b$, Used for extra long canes, in this case 12 -foot canes. $c$, Good for windy places. $d$, Good framework for supporting red raspberries.

much of the best fruit. Beyond such pruning as just outlined little else need be done, though thinning out the old wood and the young growths in spring may be necessary when the bushes become too thick.

212. The gooseberry, if neglected, as it often is, becomes one of the most unsatisfactory of fruit plants to deal with. Under such treatment it produces far too 
much wood and far too little and too small fruit. The fruit deteriorates in size and quality and harvesting becomes a difficult and painful operation. To handle the plants properly the amount of wood must be vigorously con-

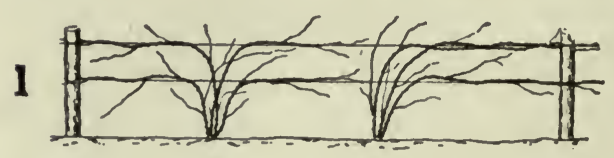
trolled or the fruit will be inferior. Just how this is done is of minor

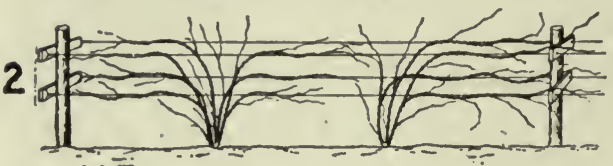
consequence to the actual doing of it.

Since fruit is

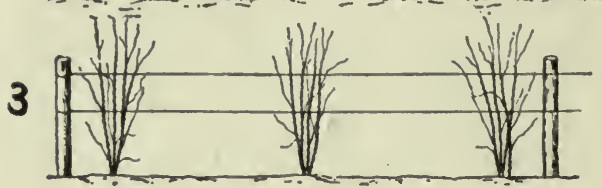
borne on wood of all ages except the present season's a nd the oldest, wide latitude may

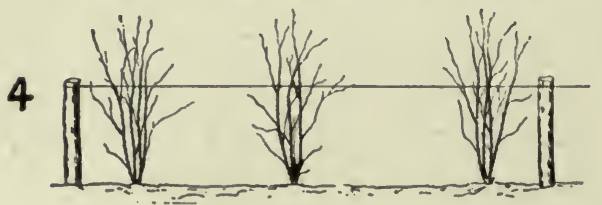

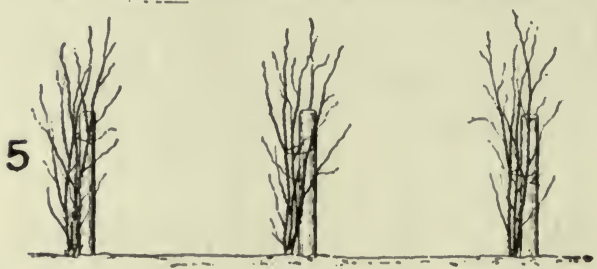

FIG. 249

POPULAR S YYLES OF BI.ACKBERRY TRAINING

1, Canes of trailing type on two-wire trellis. 2, Fourwire trellis for trailing vines. 3. Upright canes on two wires. 4, Canes of upright type on single wire. 5, Postmethod used for upright çanes.

erally cut out and burned immediately after harvest. Two or three shoots are allowed to develop annually from the base of the bush to replace the wood cut out, all weak 
or otherwise inferior shoots from that point being cut out, and lush shoots on other parts of the plants shortened to two or three buds, so the bush may be kept well within bounds and fruit spurs be developed from them.

The principle involved is to have an annual renewal of bearing wood in sufficient amount to give good crops. In cool climates and situations, such as partially shaded gardens and beneath grapevines trained on Munson and Caywood trellises (Figs.271,278) the bushes may be given open heads, but in warm situations the heads should be more dense.

Sometimes $\mathrm{th}$ e gooseberry is trained in tree form with six or eight to ten or a dozen frame limbs, the lowest of which may be a foot or 18 inches from the ground. These are headed back to 6 or 8 inches and allowed to develop

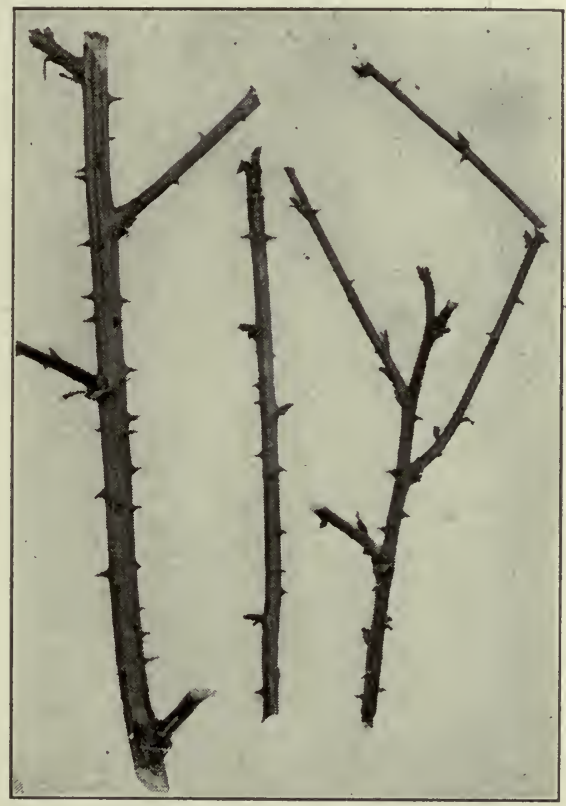

FIG. 249

BLACKBERRY CANE AND MAIN BRANCH

This cane was cut in July or August at about 30 inches from the ground. It sent out laterals which winterkilled somewhat. Canes'so treated rarely do as well as normal or as pinched ones. Note the prominent buds. one to three or four side shoots, which in turn are also shortened. The method is too fussy for commercial practice in America. In England, where the fruit is to be exhibited in the gooseberry contests, the tree form and 


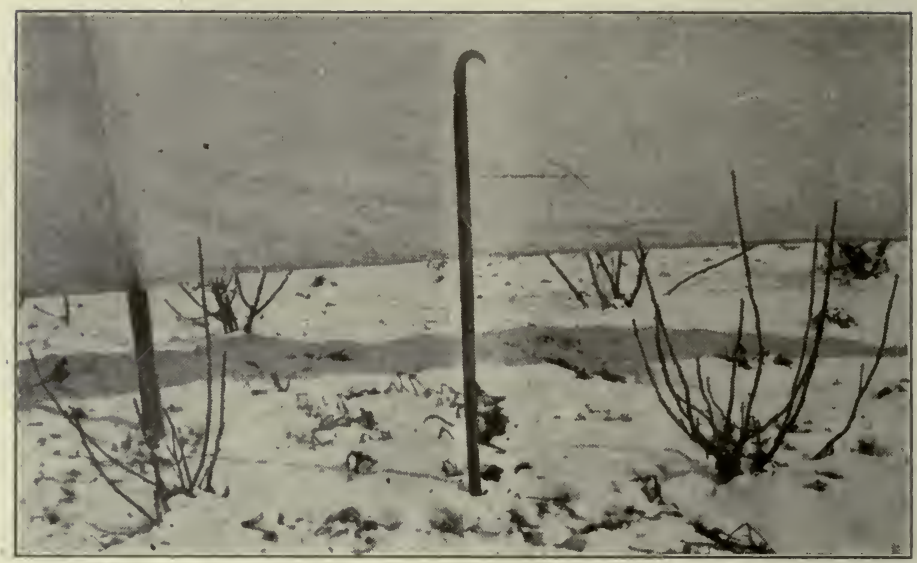

FIG. 250-UNPRUNED CURRANT PLANTED ONE YEAR

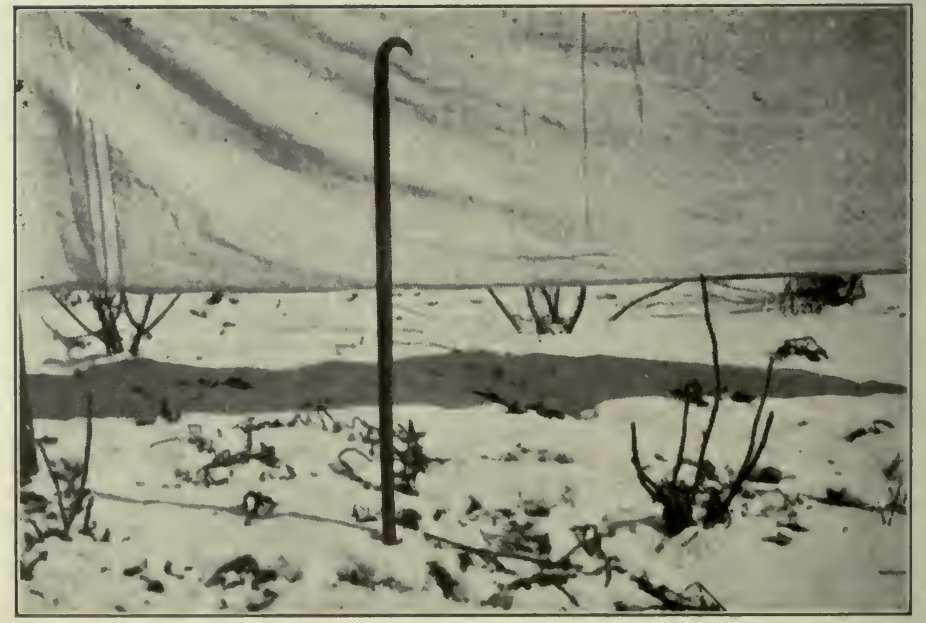

FIG. 251-ONE-YEAR PLANTED CURRANT, PRUNED. SAME AS FIG. 250 Gooseberries and currants are pruned very much alike. 
the thinning of the fruits are two of the ways which aid in developing the plum-like gooseberries of which the American markets know nothing. So far as thinning in American plantations is concerned, it is all done by removing more or less wood at pruning time. It is important and it pays, but it is not productive of such spectacular fruits as the British methods yield.

Some of the gooseberry "trees" of England are remarkable for their size, age and productivity. One reported

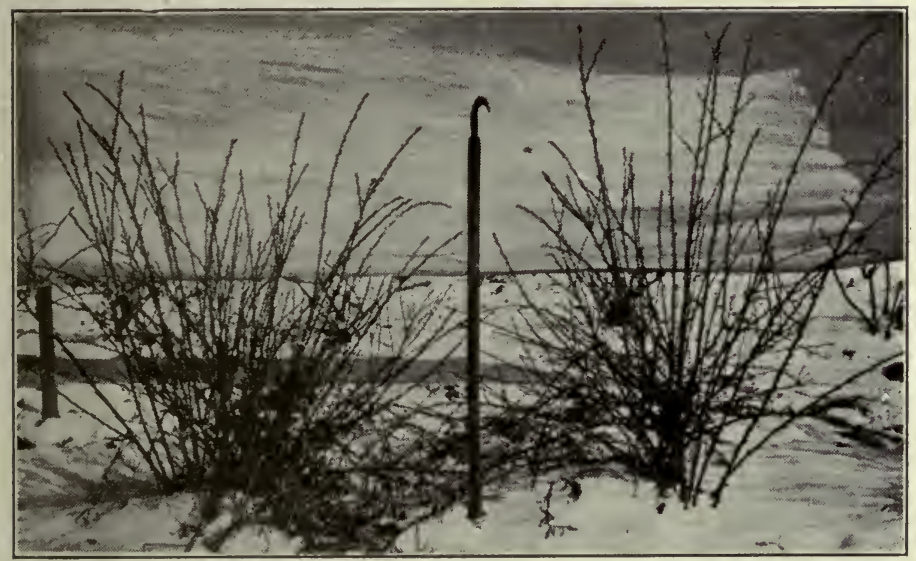

FIG. 252-GOOSEBERRY BEFORE PRUNING. PLANTED THREE YEARS

to the London Horticultural Society* measured 36 feet in circumference and when 46 years old had a 30 -year record of several pecks of fruit each year. It is doubtful if such results could be even approached in many parts of America, because the climate is not humid enough and our people are too busy to take the trouble to do the necessary pruning and training.

* Transactions Vol. 5, Page 490. 


\section{CHAPTER XIV}

\section{GRAPE PRUNING AND TRAINING}

213. Principles of grape pruning.-In addition to the general principles that-apply to all plants discussed in Chapter V are several that apply especially, or even perhaps exclusively, to the grape.

a. Since the youngest growing parts, including the leaves, derive all their food from other parts, they act as parasites (Chapter III, 90). When mature they deliver food to the balance of the plant. Hence whatever de-

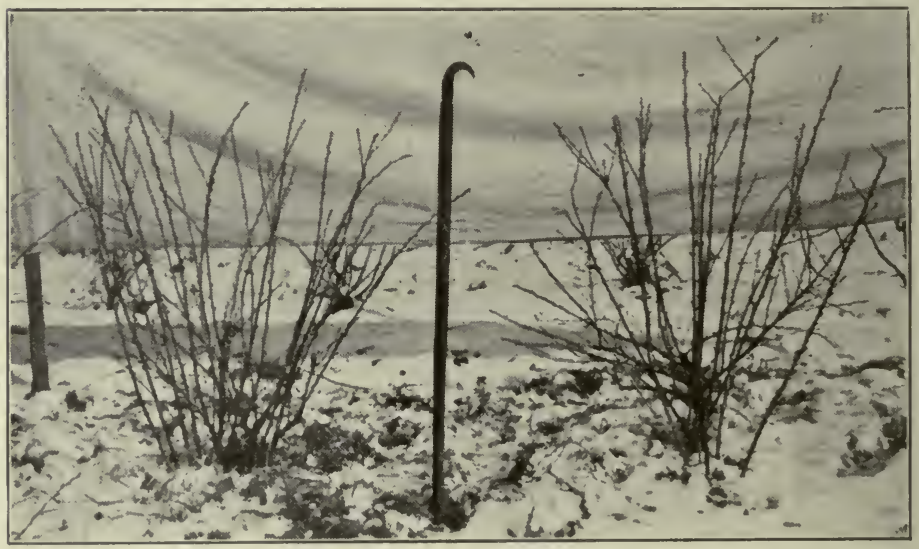

FIG. 253-GOOSEBERRY AFTER PRUNING. SAME AS FIG. 252, BUT PRUNED velops superfluous growth or impairs mature active leaf functions, as in the case of insect or disease attack or injudicious pruning, proportionately inhibits fruit production possibilities, and if excessive may starve the vine.

b. The tendency for a vine or a vine part to be fruitful is in inverse proportion to vegetative activity. Hence, practices which augment such activity tend to reduce 
$\mathrm{f}_{s}$ uitfulness, and vice versa. Disregard of this principle may result either in over-bearing and premature exhaustion or in inferior yields, even practical sterility. Correct management invigorates the vine to the highest possible degree without reducing the crop.

c. Excessive foliage and small yield usually go hand in hand; and, conversely, excessive fruit and reduced foliage are partners.

d. Injuring the tissues-bending, twisting, etc--tends

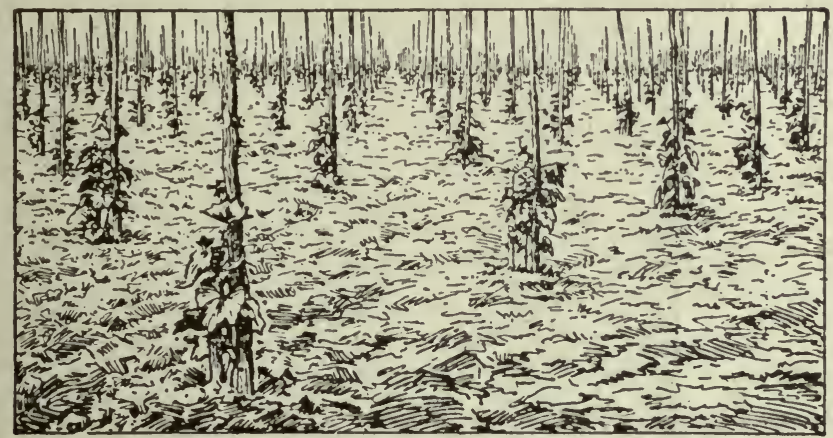

FIG. 254-VINES GROWING IN VINEYARD THE FIRST YEAR

Shoots are tied to stakes to keep them off the ground and thus protect them from whipping by the wind and from cultivating tools.

to reduce vegetative vigor and, except when excessive, to increase productivity (103).

e. Terminal buds and shoots farthest from the main head usually develop most actively. Hence, to prevent this and to keep the vines within bounds, such buds and growths must be removed or methods adopted to check the sap flow so buds and shoots nearer the head will develop well. Various methods of pruning and training are faulty because they disregard this principle. They cannot be followed indefinitely. The vertical tying of fruiting canes to stakes is one of the most common of these faulty methods.

f. The more nearly vertical a shoot the more will be 
its vigor. The Hudson system typifies this principle (239).

g. Other conditions being equal, the sizes of vines or vine parts are inversely as their number. Hence the larger the number of shoots, or clusters, or of berries in a cluster, the smaller they will average; and the larger the number of vines to the acre the smaller the individual vines.

214. Pruning units.-In California the term "pruning unit" is applied to the treatment of single arms, whether

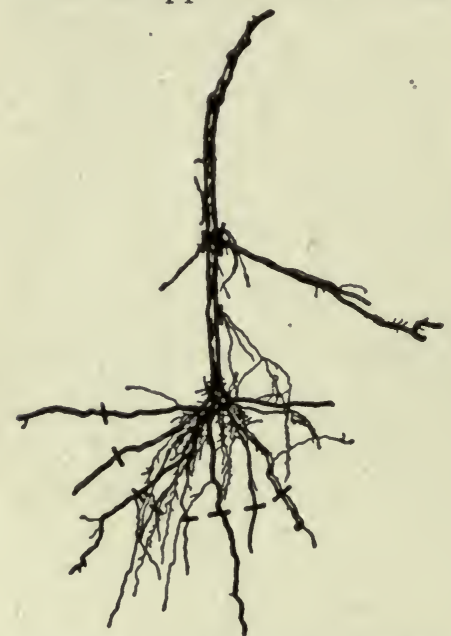

FIG. 255 - GRAPEVINE SHOWING METHOD OF PRUNING ROOTS READY FOR PLANTING. the method of training be spur or cane pruning. The term, though less used in other parts of the country, is just as applicable under similar circumstances. Vines which have reached maturity are pruned so that certain parts are left for fruit production, others for renewal and others for replacing, extension or shortening the arms. All other wood is cut off. No matter what the system of training or pruning the fundamental principles and the rules which govern the system are applied to each arm of every vine so trained, except that vigor of vine. arm or cane may modify the application somewhat. Biolitti presents two diagrams (Figs. 257, 258), * which illustrate units of short and long pruning. His description is slightly condensed as follows:

The unit in spur pruning illustrated in Fig. 257, represents a long arm about seven years old. At the end of the arm is the two-eye

* California Bulletin 241. 
spur ( $a$ ) of the previous year bearing two canes ( $b$ and $c$ ). Near the base of the arm is a single water sprout (d) growing out of old wood. Such an arm would normally bear other canes, but as they would all be removed entirely at pruning they are omitted to simplify the figure.

In pruning one of the canes growing out of the spur of the previous year $(a)$ is cut back to form a new spur and the other removed entirely. In deciding on which cane to use for the new spur, we must choose the one suitable for fruiting; viz, well ripened, of moderate thickness and with well-formed buds. Of those which fulfill this condition, we must choose that which is in the best position to preserve the form of the vine. This, in most cases. will be the lowest ( $b$ in the figure), because it increases the length of the arm the least. If the lowest, however, is weak, broken or otherwise unsuitable, we are obliged to take one higher up.

When a cane arising from the base bud of the spur of the previous year is chosen for the new spur, the length of the arm is lengthened imperceptibly. A spur from the first bud $(b)$ will lengthen it usually a little over an inch, one from the second bud (b) 3 or 4 inches. In any case, the arm finally becomes too long, like the one in the figure, so must be shortened or replaced. This may be done by using a conveniently placed water sprout for a replacing spur as at $e$ in the figure, and cutting back the arm in the
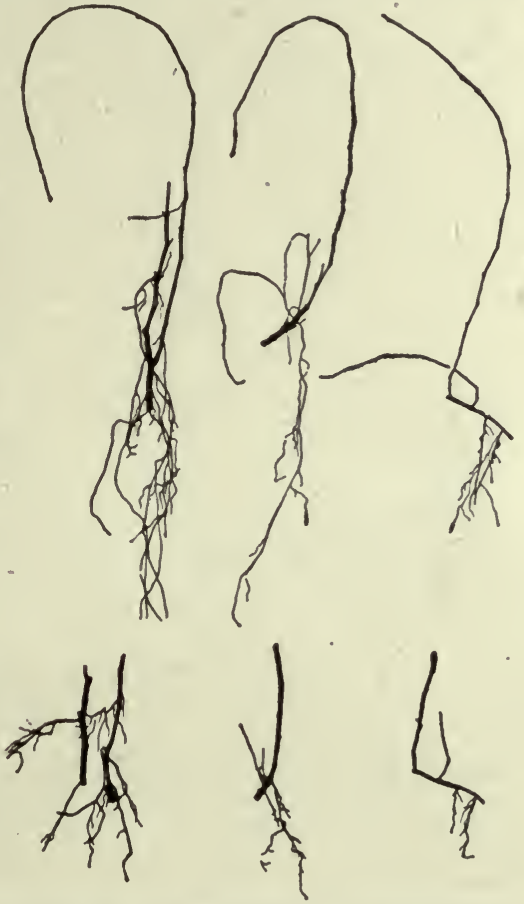

FIG. 256 - ROTUNDIFOLIA (MUSCADINE) Above, as dug; below, pruned for planting. place indicated by the line $f$. Cutting back of an arm should be deferred until the following year as the replacing spur will produce litcle or no fruit. In the meanwhile the fruit spur from cane $b$ will bear a crop and the replacing spur $e$ will produce fruit wood for the following year. 
The cane chosen $(b)$ is cut at 1,2 , or 3 , leaving a fruit spur of one, two or three fruit buds and the cane. $C$ is remored entirely by a cut at $g$. The more vigorous the variety and the particular cane, the more buds should be left. The water sprout $e$ is cut back at 1 , leaving a replacing spur of one eye. Of course a replacing spur is left only in case the arm is too long and will require shortening the next year. The unit in short pruning consists then of a single fruit spur of one, two or three fruit bucls.

The unit of pruning in long and half long systems shownin Fig.2.58 consists of a fruit cane, $a$, with its renewal spur, $d$. In the illustration, $a$ represents the renewal spur of two years previous. On it was left a fruit cane, $a$, which has produced the crop of the previous season and a renewal spur, $d$, which has produced fruit wood for the present season.

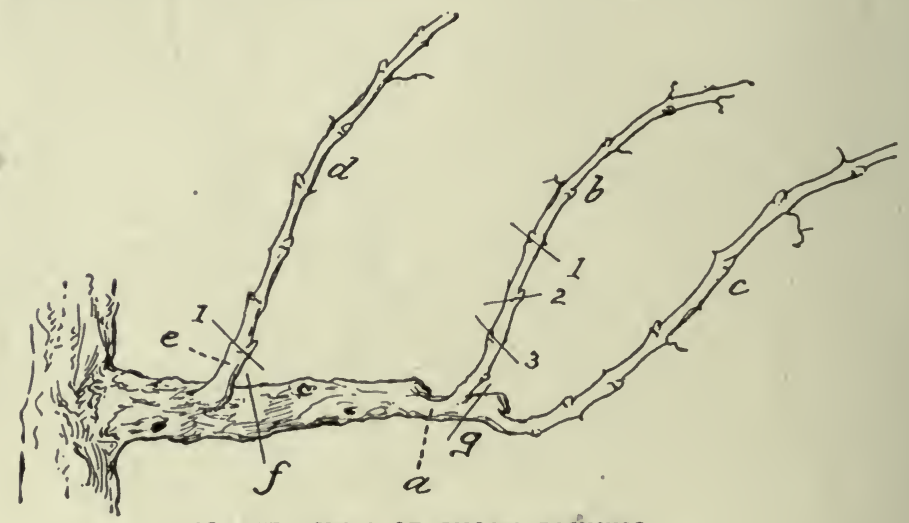

FIG. 257 -UNIT OF SHORT PRUNNING

In pruning, the fruit cane, $a$, is removed entirely at $j$. The upper cane, $g$, of the renewal spur, $d$, is used for a new fruit cane and shortened to about 1 for half long and to about 2 for long pruning. The lower cane, $f$, is cut back at 1 to form a renewal spur, which will produce the new wood for the next winter pruning.

This is the normal method of procedure, but various modifications are often necessary. If the cane $g$ is unsuitable on account of lack of vigor, other canes such as $f$, or even $h, i$, near the base of the old fruit cane, may be used for a new fruit cane. The essential point is that the cane used for this purpose shall originate from two-year-old wood. In the same way, any suitably placed cane may be used for a renewal spur. Water sprouts from three-year, fouryear or older wood being available $(c)$. The essential point in 
this case is that the renewal spur shall be below the fruit cane, that is, nearer the trunk.

Replacing spurs for shortening the arms are occasionally needed as in spur pruning, but usually the same spur may be used both for renewal and replacing. The water sprouts, $c$, may be used for this purpose, cutting it at 1 or :, according to its vigor.

215. Time to prune vines.-The most extensive and important pruning is done during the dormant season. Vigor and fruitfulness are often profoundly influenced by the time the work is done, so are the quantity and the location of the reserve plant food in the vines. J. I. Vidal, a French investigator, has studied minutely the nutrition of the European grapevine.* Among his findings the following are of special interest at this point. In summer the leaves feed the various other parts (29)

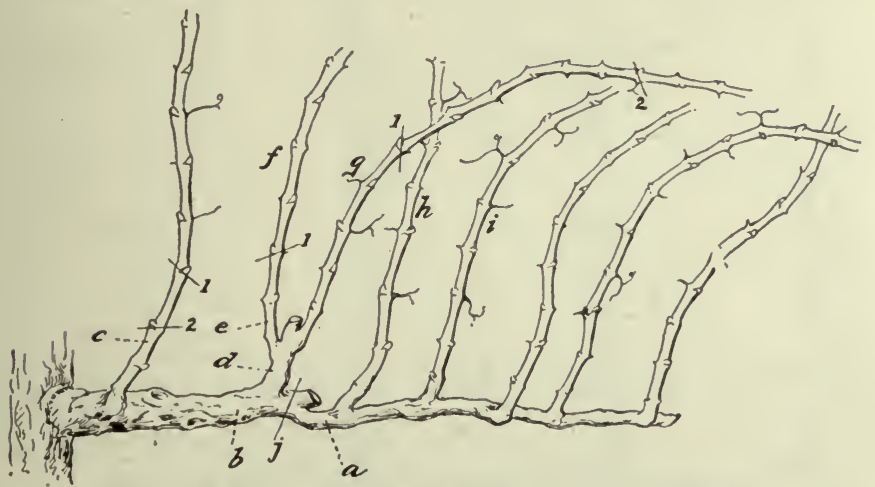

FIG. 258-UNIT OF LONG PRUNING OF GRAPEVINE

Just before the leaves normally drop the canes are richest in plant food. Immediately after the leaves drop and during the following two to five weeks, this food is carried to the roots, where it is held in storage. Part of this ascends again gradually during the dormant period to supply the needs of the parts above ground; for even though dormant these parts must be nurtured. When spring opens the ascent of this food is often extremely

" "Les Reserves de la Vigue." Revue de Viticulture 1, Pages 895 to 903. 
rapid. It continues until the new growth can elaborate more food than is needed for its maintenance.

Hence if vines are pruned immediately after the leaves drop the cuttings are in best possible condition for propagation. A month later they will not be so good for such purposes, but the largest proportion of food will have been saved in the roots to develop the new spring growth. If pruning is delayed until spring, large quantities of the reserve food will be lost in the prunings. Therefore, vines pruned then will develop poorer shoots, but a better set of fruit.

Vidal also concludes* from three years' experiments that, other conditions being equal, the time of pruning modifies only slightly

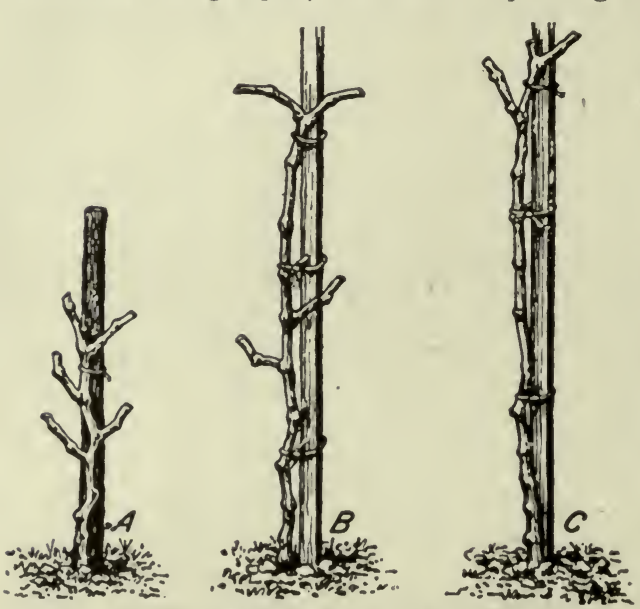

FIG. 259-VINES HEADED BACK FOR VARIOUS SYSTEMS OF PRUNING

$A$, The spur and the fan systems; $B$, the four-arm renewal system; $C$, the two-arm Kniffin, Munson, um. brella and overhead systems. the number of bunches borne. With extremely late pruning the bunches are more vigorous and the proportion of imperfect bunches and aborted flowers is less. The individual berries are larger, heavier and more numerous. $\mathrm{Th}$ e growth is more rapid for late pruned vines and continues for a longer time. The vegetation is at times diminished and at times increased by spring pruning just as in winter pruning. These positive or negative variations in vegetation progress or retrogress in more or less regular order with the progression of the time of pruning. The prunings were made at intervals between January 1 to about April 1.). With vines pruned after mid-February, the later the pruning

- Compt. Rend. Acad. Sci. No. 17, Page 1,192. 
the greater the retarding effect on bud swelling and the flowering season.

In a progress report on experiments in pruning grapes at various times of year, L. Ravaz* concludes that pruning after the terminal shoots have started serves as a partial protection against spring frosts and increases production without materially affecting the vigor of the vine. The chief value of this late pruning appears to be due to the removal of the outlying buds which are the first to open in the spring.
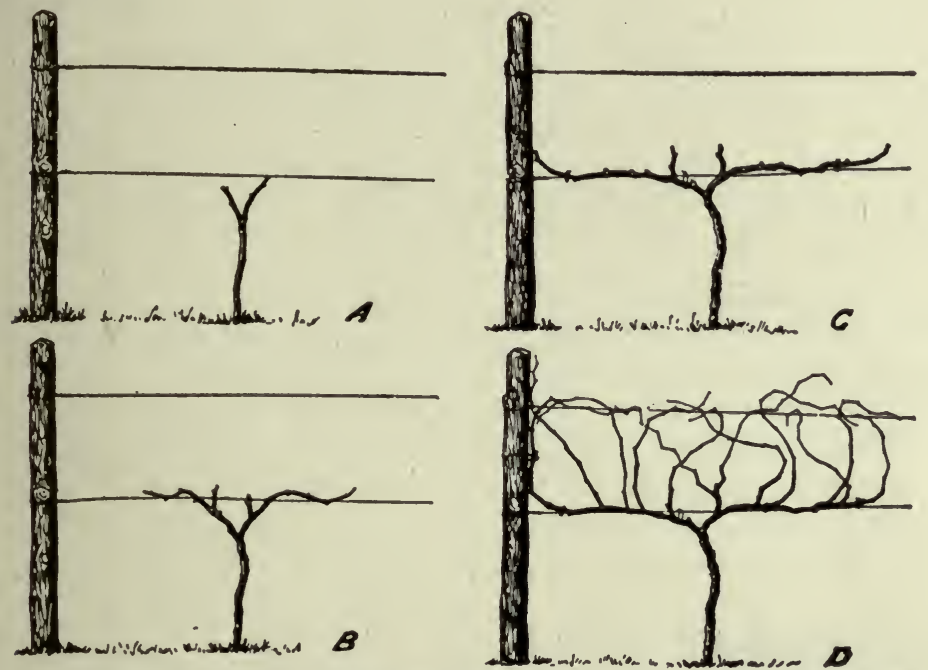

FIG. 260-PRUNED AND UNPRUNED VINE AT VARIOUS STAGES OF THE RENEWAL SYSTEM

$A$, Second year; $B$, third; $C$, fourth; $D$, unpruned vine in its fourth year.

He questions whether the bleeding caused by pruning after the shoots have started is harmful. (Compare 15.) To avoid this, however, and still prevent the vines from starting too early in the spring, all unnecessary growth may be removed during the dormant period, the fruiting shoots shortened somewhat, and all cyes removed except the two nearest the base. Since the basal eyes are affected by the length of the shoot rather than by the number of eyes beyond them, they will not start any earlier in the spring for having the remaining eyes removed. He found also that sulphate of iron, which has been suggested as a dressing to prevent bleeding, has a tendency to increase the sensibility of the tissues to cold.

* Taille Hative au Taille Tardive, Montpelier, 1912, Page 15. 
The experiments have been conducted in a vineyard planted in 1905. Prunings were as follows: one row, immediately after vintage; another at the time of full leaf; during the dormant period; at the time the eyes first appeared; during the budding period; and when the terminal shoots were about 2 inches long. The shoots in all cases were cut back to two eyes.

His conclusions drawn from his seven years of experiment* are that vines pruned promptly after leaf fall were the first to start growth the following spring; vines pruned when most dormant (late December and early January) started four days later; those pruned when bleeding may be expected (in southern France about February 20) resumed growth six days later; those pruned when the terminal buds began to swell in March were eleven days later, and those cut when the terminal growths were 2 or 3 inches long were 20 days late. Hence growth started according to the lateness of the pruning. The only exception was with vines fall pruned soon after harvest while the leaves were still green. These pushed into growth 10 days later than the vines pruned immediately after the fall leaves dropped.

One practical application of this knowledge may be the retardation of shoots and blossoms in early spring long enough to escape late frosts. Experiments in California have proved the utility of this; several vines pruned about the middle of March were saved, while those pruned in late fall and early winter were killed by a late April frost. March pruning in California may delay blooming ten days. Season of ripening is slightly de-

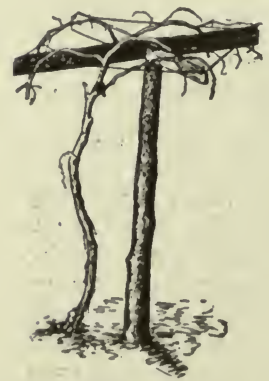

FIG. 261

UMBRELLA TRELLIS

Post 4 feet above ground. layed, but when frosts occur the earlypruned vines may bloom early but mature their fruit late, because the earliest shoots may be destroyed and only such flowers and fruit as are on tardy buds escape the injury.

216. How much to prune. - A vigorous vine may carry 20 to 30 canes each bearing a dozen to a score of buds, a total of perhaps 250 to 300 or more. Probably not more than 50 or 75 of these buds will produce shoots, the

- Taille Hative au Taille Tardive, 1912. 
others remaining latent (55). If the vine is pruned so as to leave only 50 to 75 buds therefore, the result will probably be the same number of shoots, though doubtless from a somewhat different set of buds, because the buds near the bases of the shoots rather than those nearer the terminals will grow (55). Neither the quantity nor the quality of the crop nor the vigor of the vine or its shoots will show any conspicuous difference.

Should the vine be pruned more severely, leaving only 25 or 30 buds, the number of shoots will, of course, be smaller. Hence the supply of stored food in root, trunk and branches and the supply of crude sap from the unpruned roots will be distributed in larger quantities to the shoots, which will thus grow more vigorously than they would were there more of them. This smaller number of large shoots will produce fully as great an area of leaf surface as would the greater number of smaller shoots on the unpruned vine, so the vigor of the vine will in no way be impaired by the reduction in number. Similarly, a smaller number, but larger-sized bunches and berries, will be produced by the smaller number of large shoots; so the total weight of the crop will be at least as great as when the greater number of clusters and berries are borne on the smaller but more numerous shoots. Indeed, experience proves that size of both berry and cluster is larger and weight of crop greater on pruned than on un-

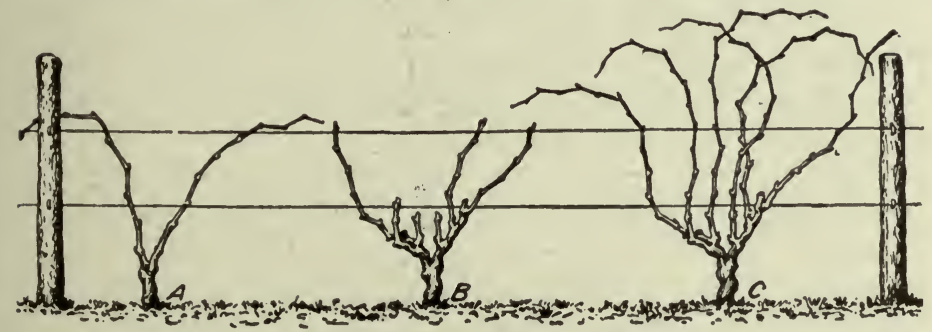

FIG. 262-FAN SYSTEM, VINE AT VARIOUS AGES

$A$, Unpruned vine in third year; $B$, pruned vine in fourth year; $C$, unpruned vine in fourth year. 
pruned vines. This is because it is easier for the pruned vine to supply the sugar and water, the principal constituents of the large berries, than to produce the stems, skins and seeds which make up the principal part of the small fruit clusters on the unpruned vines.

There is, of course, a limit beyond which such results begin to diminish. This is due to one or both of two causes; namely, the maximum sizes for berries and clusters and the undue development of vegetative functions which often cause the blossoms to drop without setting fruit. The aim should be therefore to leave the optimum number of buds for the production of fruit. The

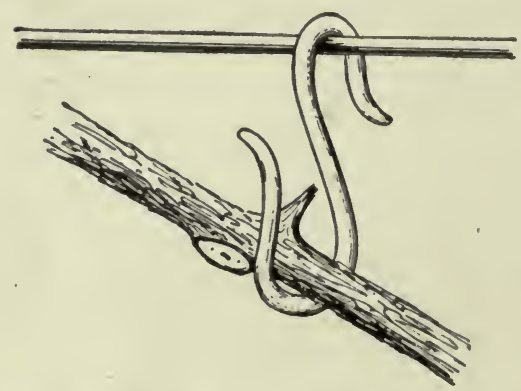

FIG. 263 - WIRE $\underset{\text { VINE TO TRELLIS }}{\text { HOOK FOR HOLDING }}$ number will vary with the age and individuality of the vine, the variety, the method of training and $\mathrm{many}$ other factors. Nothing will take the place of experience in this matter. However, it may be said that with vines four to, say, ten years old in commercial vineyards, the number may range in a general way between 20 and 40 buds.

In general, light winter pruning increases the yield, whereas heavy winter pruning makes for vigor of vine and reduction of yield. Hence, it is a safe rule to leave as many fruit spurs and fruit buds on mature vines of normal vigor for the variety as were left the previous year; to leave fewer on weak vines, which should be pruned more severely; and larger numbers on vines of unusually great vigor. Attempts to make weak vines produce normal crops tend to augment weakness and to produce inferior fruit; but by pruning to secure small yield, the quality will be maintained while the vine is 
being strengthened for subsequent production. Individual parts of vines act in the same way as the whole vines; i. e., pruning of canes and arms should be governed by the same principles as govern the pruning of one vine as compared with another. One way to judge the vigor of a cane is by weight; heavy and firm ones are better than soft, pithy and light ones.

217. Herbaceous or summer pruning consists in the cutting of green parts. It differs in its effects from winter pruning (83) in being in general a weakening process. The maximum of weakening seems to result when the cutting is done during midsummer while the vine most needs its elaborated food and when it is most active. Insects and diseases may produce the same results. In the spring the effects of herbaceous pruning are not so serious because the vines have a chance to develop enough leaf surface
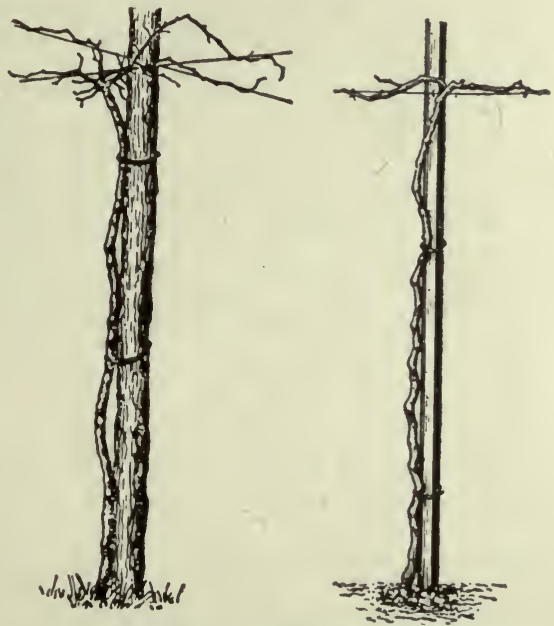

FIG. 261-POST AND STAKE METHODS OF GRAPE TRAINING

Left, rotundifolia (muscadine) grapevine trained to a post with crossed wires at the top. Right, vine trained to a stake. Often no wire is used in stake-training methods. to equalize the loss. This is well shown by vines injured in the spring by late frosts; the following year such vines are often more vigorous than before because lack of crop gives them a chance to recuperate.

Herbaceous pruning often resembles winter pruning in that it concentrates growth in the remaining parts. This effect and that mentioned above are more or less 
balanced against each other in inverse ratio, depending upon the method employed and the time when applied. In spring the concentrating effect is greatest, the weakening least; in early summer the two may balance; later the concentrating may be inferior to the weakening.

217 . Summer pruning practices.-The principal uses of summer pruning are, 1 , to develop useful vine parts by removing water sprouts, suckers, unnecessary buds, shoots and tips of vines; 2 , to reduce vine vigor and increase fruitfulness by pinching and removing vine tops; 3 , to enlarge the berries by topping - this reduces the

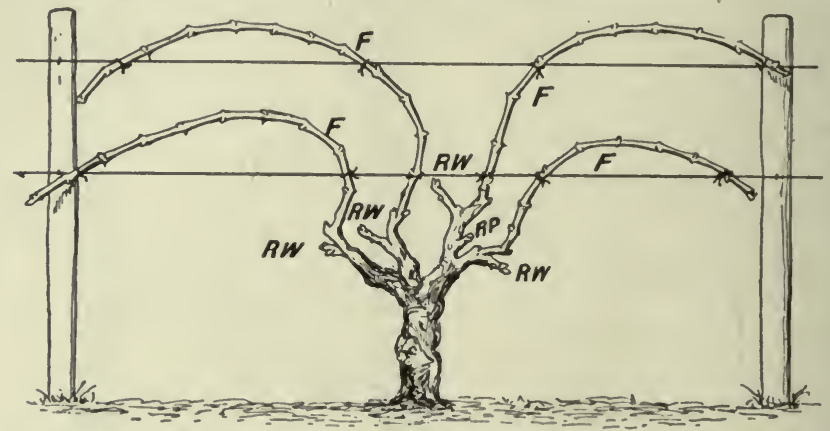

FIG. 265-HEAD PRUNING: FAN-SHAPED HEAD, FRUIT CANES TIED TO HORIZONTAL TRELLIS

sweetness; 4 , to increase shade on the fruit by pinching or topping to develop laterals and to make shoots grow upright; 5 , to decrease shade by defoliating. Fruit thinning, ringing and pruning away of surface and cion roots are also done during the growing season.

Disbudding, which is practiced on vines during the second and third years, consists in removing the buds on the lower part of the stem when they have developed shoots an inch long so the upper roots may become strong. Thinning shoots is for the same purpose, but is done when the buds have developed shoots several inches long. Disbudding is superior to it because of less weakening to the vine. Topping is the removal of the end of a shoot 
when about a foot longer than desired. It is most practiced when the disbudded or shoot-thinned canes have grown excessively long because of the concentration of food in them. Development of laterals is its chief effect. These may be used to form fruit spurs the following season. It is usually done about midsummer; sometimes twice or thrice. Suckcring is the removal of shoots that appear from or near the ground surface. It is most necessary with grafted vines. Water sprouting is the removal of sterile shoots where not needed. Pinching is the removal of the growing tip with finger and thumb. It tends to increase the size of the leaves below. Usually it is done when the shoots are 15 to 18 inches long. Thus the shoots have ample time in which to mature. Defoliating is the re-

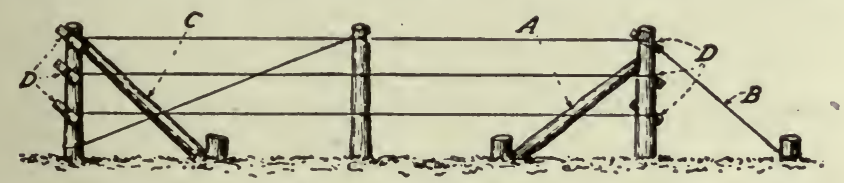

FIG. 266-DIAGRAM OF ORDINARY TRELLIS

Note braces $A, B, C$ and devices $D$ used for tightening the wires.

moval of leaves to expose the fruit better to the sun so as to increase color. It may be largely superseded by an improved form of the vine.

L. Ravaz* summarizes the results of investigations in heading in grapes by declaring that if employed shortly after the flowering season production is increased, but at the expense of quality.

218. Pinching grapevines.t-Experiments by G. Riviere to determine the effect of pinching the flowering shoots of grapevines just before flowering to "no leaves and to $1,2,3$ and 4 leaves respectively beyond the second bunch of grapes, showed upon analysis more or less chemical difference in the composition of the must according to the number of leaves left. The sugar content decreased approximately in proportion to whether $4,3,2,1$ or no leaves were left on the shoot beyond the bunches-145.8 gm. where 4 and 70 where none. On the other hand, the acid content increased from $36.3 \mathrm{gm}$. where 4 leaves were left to 60.5 where none. With the variety studied (Chasselas Doré) it seems advisable where

* Ann Ecole Nat. Agr. Niontpelier N. Ser. 11, (1912), No. 4, Page 285-323 t pl.

$\dagger$ Soc. Nat. Hort. France, 1907. 
pinching is employed to leave at least 4 leaves beyond the last bunch of grapes."

Later experiments in grape-shoot pinching by Riviere show that the sugar content increased from $159 \mathrm{gm}$. per litre of must where no leaves were left beyond the bunches to $205 \mathrm{gm}$. where 5 leaves were left. No further increase was obtained where 6 or 7 leaves were left. Similar results were found for the acid content, which decreased from an amount corresponding to $3.95 \mathrm{gm}$. sulphuric acid per litre where no leaves were left to $3.65 \mathrm{gm}$. where 5 leaves were left. As a result of the work it is recommended that in pinching back the bearing shoots 5 leaves should be left beyond the second bunch.

219. Wounds, their effects and treatment.-Barring frosts, drouths, diseases, insects and accidents, properly managed vineyards may continue productive perhaps indefinitely. The most frequent proxi-

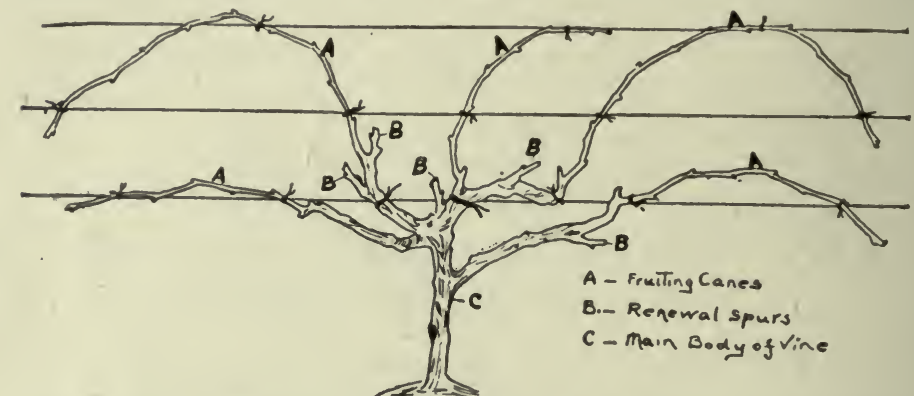

F1G. 267-RECURVING THE CANES AS IN THE FAN SYSTEM USUALLY TENDS TO PROMOTE FRUITFULNESS

In this system the trunk may be trained as a permanent single stem which reaches to the first wire; or in regions where laying down is necessary the renewal canes may be started from a short stalk near the ground. Some fruit will be produced on the short arms during the third season. However, with the average young vine the wood should be headed back pretty severely so as not to permit over-bearing.

mate cause of decline is the cumulative effect of little injuries, such as pruning wounds, which permit the entrance of disease, decay and insects as well as interfere with the physiological functions of the plant. Hence the smaller the wounds the better, especially on the main trunk and the arms. By proper planning, large wounds may be avoided more or less completely. Antiseptics and wound dressings may be used as in the treatment of tree fruit wounds (Chapter VIII).

L. Petri*, an Italian investigator, found that two fungi were always present in the brown streaks which follow pruning of grapevines; mainly, Cephalosporium and acremonium. He believes the

- Staz. Sper. Agr. Ital. 45, No. 7, Page 501. 
gummy-resinous formation to be the direct result of wounding (though there are degenerative changes). The fungi are apparently a secondary feature which, however, may spread the injury to portions of the wood distant from the original points of the injury.

Cuts should always be made with sharp shears in such a way as to prevent cracking and splitting. This may be avoided by holding the shears so as not to bend the part at or below the point of cutting. Canes to be cut for spurs should never be cut at right angles to the grain, but at a slight angle. To do this best the blade of the shears should be placed against the vine part that is to remain and the cut made upward. On this subject Bioletti presents lïg. 285 and the following discussion:*

In spur pruning it is considered best to cut through the bud above the last one that it is desired to have grow, as at $C$ in Fig. 285. This leaves the woody diaphragm intact and protects the spur from injury. If the spur is cut at $C_{1}$ a long piece of internode is left, exposing the pith. As this pith dries and shrinks it allows water to enter and forms an excellent place for molds to grow which may destroy the bud below. It requires some skill and practice to cut exactly in the right place, and if by mistake the cut is made just below the diaphragm the breeding place for molds has its maximum size. For this reason most pruners make the cut at $C_{2}$ about half an inch above the last bud. If the shears are sharp and the cut made at an angle of about $45^{\circ}$. behind the bud, no injury results.

In removing a piece of old wood at the base of a spur or fruit cane it is best to leave a little projecting stub. Too close cutting in this case is apt to injure the spur or cane. The projecting stub can be removed the following year, when the spur has grown larger, without danger of injury.

220. Vine pruning tools.-When vines are properly pruned annually the pruner will rarely need a tool stronger than the single hand shears (Fig. 110), of which there are many styles. Some pruners prefer French, others Swiss patterns, but any shears that will hold a keen edge well, are of moderate weight and fit the hand well will do good work. Only when arms must be replaced will the double hand shears (Fig. 114) or the saw be needed. Most pruners prefer the saw to the double hand shears for heavy work. The double hand shears are open to the objection that they split or otherwise injure the part to be left. Many pruners prefer that the saw shall have a curved rather than a straight blade.

221. Trellis construction.-The most popular support

* California Bulletin 241. 
for grapevines, certainly of American varieties, is the trellis. Though there are several forms, depending upon the system of training, they all agree in the main points of construction. Posts of cedar, locust, chestnut or other wood durable when set in the ground are spaced at distances depending upon the system, the character of vine growth, etc. End posts must be very firmly braced to withstand the weight of vines and fruit, especially during the strain caused by heavy winds. Figure 266 shows two ways of bracing, the most popular at $A$ and $B$. Number 10 or 12 wire is generally used. Because of expansion and contraction due to temperature the wires should pass through the staples loosely and at each end the slack be wound on a reel of some kind. Unless this is done and the wires partly unwound in the fall, the end posts and perhaps some others may be pulled loose during winter.

222. Other supports than trellises and stakes.-In amateur practice grapes of all classes are largely grown upon arbors, porches, fences, buildings, trees, etc. The first is often excellent as a landscape gardening feature when it covers a walk. Where the principles of pruning and training are adapted to the kind of support. grapes of good enough quality for anyone may be so produced. But for business purposes trellises and stakes are deservedly most popular because better results can be so produced. The advantages of the trellis over the arbor are: The trellis is cheaper and more easily built; it will last longer and can be more easily repaired; it will double the fruit-bearing surface of the vines, the size of arbor and trellis being the same; the vines will be more productive and they may be pruned, sprayed and cultivated and the fruit more easily harvested.

223. The American grape (mainly Labrusca varicties and hybrids) must be pruned both to prevent overbearing and to secure high quality fruit without jeopardizing the vigor of the vines. If common sense does not 
acknowledge these points the experiments of Keffer in Tennessee* will prove enlightening (74). Unpruned rines, according to this investigator, during the first season of neglect yielded more fruit than did pruned ones, but the clusters on the pruned vines averaged heavier, and the load of grapes on the neglected vines was so heavy that a large proportion of the new growth died so that the subsequent crop was lighter on the neglected than on the pruned vines. Hence vines must be held within bounds in order to secure size and flavor and, in a series of years, quantity also. Proper pruning does this and also economizes land and facilitates various vineyard operations-spraying, cultivating, harvesting, etc.

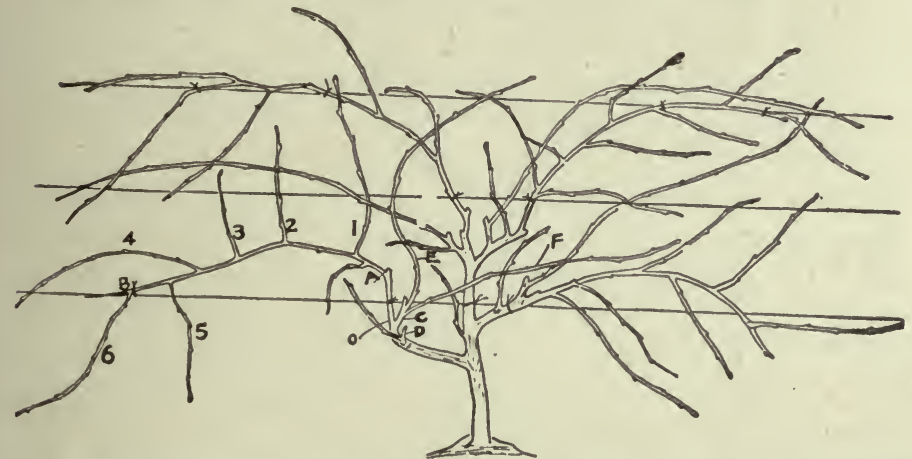

FIG. 268-UNPRUNED VINE TRAINED ACCORDING TO THE FAN SYSTEM

$A O$ is an arm of old wood attached to the main body of the vine. When pruning was done in the spring the cane A B was left as the fruiting cane. It produced the fruiting shoots $1,2,3,4,5$ and 6 that season. In addition to leaving A B, two other canes were cut back, forming the spurs C and D. The spur D did not develop a renewal cane, but $C$ produced two strong shoots, $E$ and $F$.

In order to prune intelligently, the operator must understand the fruit-bearing habit and its relation to wood growth. As already noted $(56,73)$, the fruit is borne near the bases of this season's shoots, which spring from resting buds formed last season. Hence it is easy to calculate the amount of fruit a vine should bear. In order

* Bulletin No. 77. 
to produce the average yield of 15 pounds-about 50 good-sized clusters-20 or 30 buds, or an equivalent of spurs, must be left at pruning time in winter or early spring, this calculation being based on an average of two clusters to each bud left. Sometimes these buds may be on only one cane, but generally better results are secured when two or three canes are chosen upon the main stem or stems, according to the system of training employed. Hence proper pruning of the grape aims to remove all canes and spurs except those needed to supply the desired number of buds and bunches.

Pruning may be done at any time between the fall of the leaves and a time two or more weeks before the buds are expected to swell in spring. It is not considered good practice to prune very near the time of bud swelling because the vines are very prone to "bleed" (15). Where the winters are severe and the vines must be covered it is a good practice to give a rough pruning in the fall so they may be covered easily. More wood should be left in such cases than is actually needed because there may be more or less loss due to covering and uncovering as well as to possible frost injury. The superfluous wood and buds may be removed when the vines are uncovered shortly hefore growth starts. While there is some basis for the advice not to prune when the wood is frozen, it is less because of any physiological reason than because the wood is then very brittle and hence subject to unusual breakage.

That the system of training is far less important than judicious pruning is proved by the fact that excellent results are secured with a considerable number of systems. Nevertheless there is, between pruning and training, an inter-relationship that fits a certain system better than any other to a given variety or environment. Hence the many systems and modifications of systems seen in the various grape-growing sections. Pruning and training depend largely upon the fashion of the locality and the 
judgment of the operator. Vigorous vines, such as Concord and Niagara, may be trained in a greater variety of ways than can the weaker ones like Delaware. The former seem to be best adapted to the drooping systems of training and the latter to the upright styles. The terms "drooping" and "upright" refer to the positions taken by the bearing shoots, not to those of the arms or canes. These two general classes are widely popular, whereas the horizontal styles have practically gone out of use. Before discussing systems of training, however, let us develop the vines through the preliminary stages to the time when systematic training really begins.

The young grapevine. received from the nursery is sometimes the growth of one season, but usually that of two seasons. Often, perhaps generally, it may have two or more canes, each bearing numerous buds. All of this growth, except two or three nodes and internodes on the strongest cane, should be cut off, thus leaving a single stem perhaps a foot long and bearing two or three sturdy buds. The plants so pruned should be set at desired distances apart ( 8 to 10 feet) between both vines and rows and given good cultural care the first season. The shoots may sprawl on the ground or better be fastened to bean poles to prevent injury. A couple of weeks before growth starts the following spring the vine must be cut back again to two or three buds. From these only one, or at most, two shoots, depending on the system of training later to be adopted, should be allowed to grow during the second season in the vineyard. These two shoots will form permanent trunks. Up to the beginning of the third season no trellis is usually needed. Sometimes, however, extra strong vines are trained to the lowest wire during the second season. The style of trellis will depend upon the system of training to be followed.

As the illustrations of grape-training systems (Figs. 269 to 273) have been borrowed from the Kentucky Experiment Station, clearness of description will be 
ganed by using the condensed text used in Bulletin 92 of that station (224 to 226). This follows:

224. The double Kniffin system.-The permanent trellis may now be erected. At each end of a row a stout post is set and firmly braced. At intervals of 20 feet, or twice the distance of the vines in the row, the intermediate posts are set, thus allowing two vines in the space between any two successive posts. For this method of training the posts should be long enough to stand $5 \mathrm{~T} / 2$ to 6 feet above ground. Two No. 10 wires are stretched along the row, the lower 36 to 40 inches and the upper

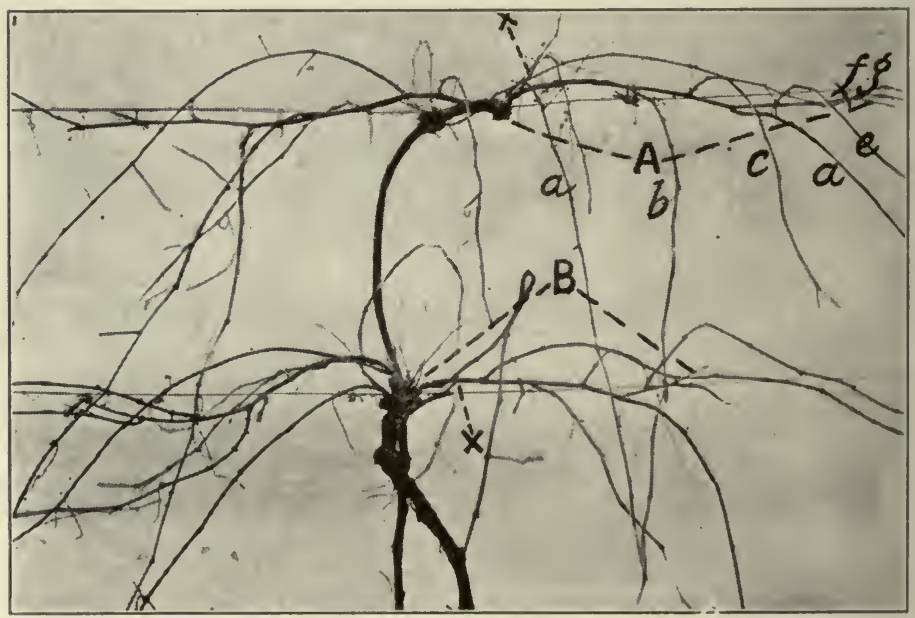

FIG. 269-THE KNIFFIN SYSTEM. BEFORE PRUNING GRAPEVINE

(66 to 70 inches above ground. These wires are stapled to the posts, but not so tightly as to prevent the slack from being taken up from time to time, preferably at the ends.

If the growth of the second year is strong and vigorous, one of the two shoots referred to above may be permitted to grow until it reaches the lower wire and the other to the top wire. Each must have its tip pinched off when it reaches its respective wire. This will usually cause the 
development of two or more lateral branches, one of which may be trained in each direction upon its own wire and tied loosely, all others being pinched out. If this pinching of the tip should not be done at the proper time, each cane at the annual pruning time should be sharply bent and tied to its respective wire. When spring growth begins this will commonly cause the pushing out of a strong shoot at the point where the bend occurs. This shoot may be trained out upon and loosely tied to the wire in the opposite direction.

The object in either case is to produce two main upright stems, one stopping at each wire, each with a T-

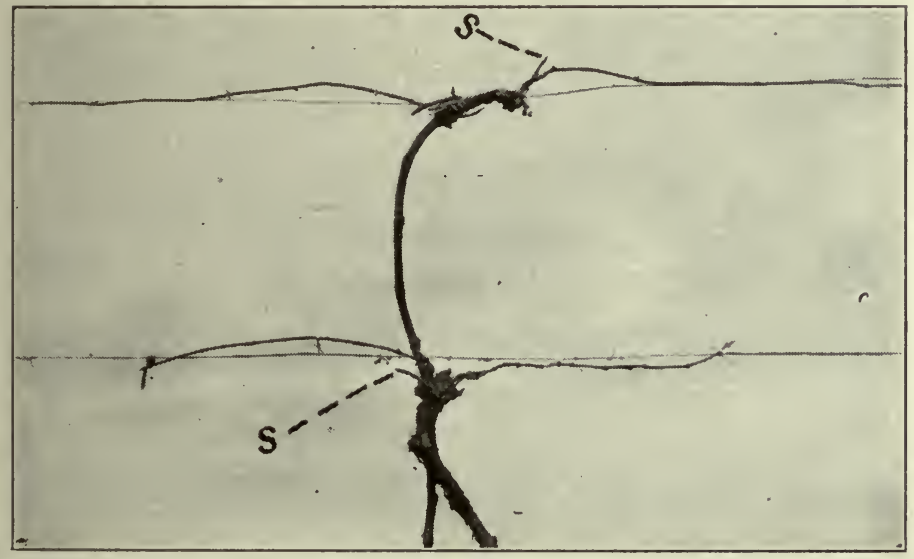

FIG. 270-THE KNIFFIN SYSTEM OF TRAINING THE VINE SHOWN IN FIG 271

shaped head whose branches run out horizontally upon the wires. If the $T$ head is complete at each wire at the end of the second season, the horizontal canes, after the wood is well matured, should be cut back in most cases to not more than three or four buds each. In later years, as the vine grows larger and stronger, the horizontal canes may be left longer at each annual pruning.

Upon the opening of spring a strong shoot will com- 
monly grow out from each bud of these horizontal canes. Upon the first three or four joints of these spring shoots flowers and fruit are produced. In this system these shoots should not be permitted to grow out horizontally along the wires. If they become attached by their tendrils they should be pulled loose again and allowed to hang directly downward. This will tend to equalize the growth of the several shoots, which, under natural conditions, tend to develop most vigorously from the terminal bud.

The subsequent pruning and training of the vine can best be explained by reference to the figures. Figure 269 represents an average six-year-old vine as it appeared in January just before pruning. The cane or arm, A, grew two years before and was considerably longer than now when the vine was pruned in January one year ago. This cane was then shortened to the length now shown, all its neighboring canes were removed and it was tied to the wire. During the following summer the seven strong shoots, $a, b, c, d, c, f, g$, grew from it, together with one or two weaker shoots, and bore fruit in that season. When pruned in late winter, the entire arm, down to $1 / 2$ inch from the base of $a$, together with the canes $b, c, d$. ' $c, f$ and $g$, was removed by one cut at $\mathrm{X}$, and the cane, $a$. was shortened to about ten buds and tied to the wire in the same position formerly occupied by $\mathrm{A}$, as will be seen in Fig. 270.

The arm B also grew two years ago and was shortencd to about seven buds in January last year. From these seven buds there grew, as will be seen in the figure, six strong shoots, each of which, like the shoots from arm A, bore two to four clusters of fruit. This arm B was also, like $\mathrm{A}$, cut off at $\mathrm{X}$ with all its canes except the onc nearest the base. This only is reserved to take the place of $B$ upon the wire, after being shortened to eight or nine buds. The same process was repeated upon the lefthand side of the vine, leaving it, after the pruning was 
completed, as seen in Fig. 270. It will thus be seen that the entire pruning for a vine trained upon this method can be done with from eight to twelve cuts. As the vine grows older the canes in the annual pruning may be left a little longer, the number of buds to be left varying with the age, vigor and variety of each individual vine to be treated.

It will be noticed that two other canes growing out upon the old wood at the head have been shortened to two buds, thus making the so-called spurs as seen at ss in Fig. 270. This is done more or less frequently when $\mathrm{s} u$ i t a b 1 e strong-growing canes are developed close to the top of the main trunk. It provides a new cane tc place upon the wire the following year from a point as close to the original $\mathrm{T}$ head as possible; otherwise the horizontal arms will become longer each year. It is desirable to keep the old wood as short as practicable.

To one unaccustomed to this work, it would appear that the vine as seen in Fig. 270 is ruined from such close pruning, but experience has demonstrated beyond ques-

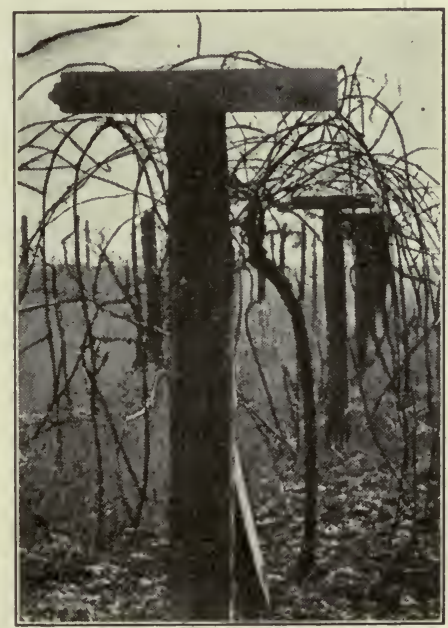

FIG. 271-END OF MUNSON ROW Note vines are fastened to the wires, not to the posts tion that it is only by such apparently severe treatment that the best and most profitable crops of fruit can be grown.

During the coming season a strong shoot may be expected from most of the 30 to 35 buds left upon the horizontal canes, and each shoot may reasonably be expected to bear two to four good clusters of grapes. It will be 
seen, therefore, that it is not necessary to leave a large number of buds upon a vine after pruning to meet the requirements of a good crop of fruit. The fruit will, moreover, be of much better quality than that produced by an unpruned and neglected vine (74).

225. The Munson system.-A second method of management, which possesses much merit, is the Munson system of training, so called from its originator, the late

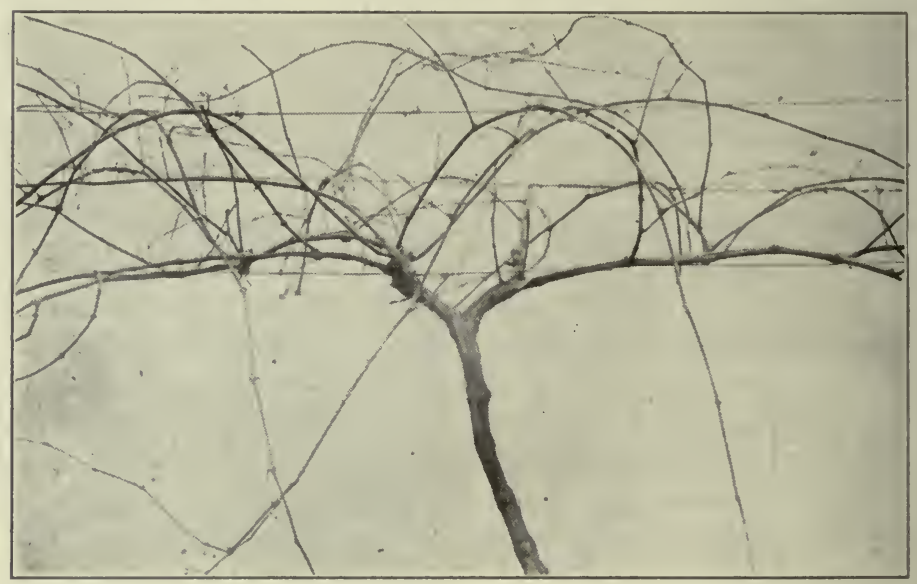

FIG. 272- MUNSON SYSTEM OF TRAINING VINE UNPRUNED

T. V. Munson, the grape specialist of Texas. In this system, as practiced by the originator, the trellis is made by placing two light posts or stakes in each hole along the row, their tops separated 18 to 24 inches, like the two sides of the letter $\mathrm{V}$, and standing 6 feet high. A wire is stretched lengthwise along the tops of these posts and a third wire about a foot lower upon cross wires midway between them.

In our own practice essentially the same arrangement of wires is secured by the use of a single post in each hole with a 2 -foot piece of $2 \times 4$-inch joist spiked firmly 
against the top like the letter $\mathrm{T}$, as shown in Fig. 271 The wires in this way are stretched along the ends of this horizontal piece, with the third midway between them and 10 or 12 inches lower. In this system a single main trunk is grown to the middle or lower wire, and one or two canes (depending upon age and vigor) are left after pruning to run each way upon this middle wire and securely tied. The remaining or outer wires are used only to support the growing shoots, which, with but little attention, grow out over them as seen in the illustration.

As their length and weight increase they gradually droop toward the ground, having in the meantime secured

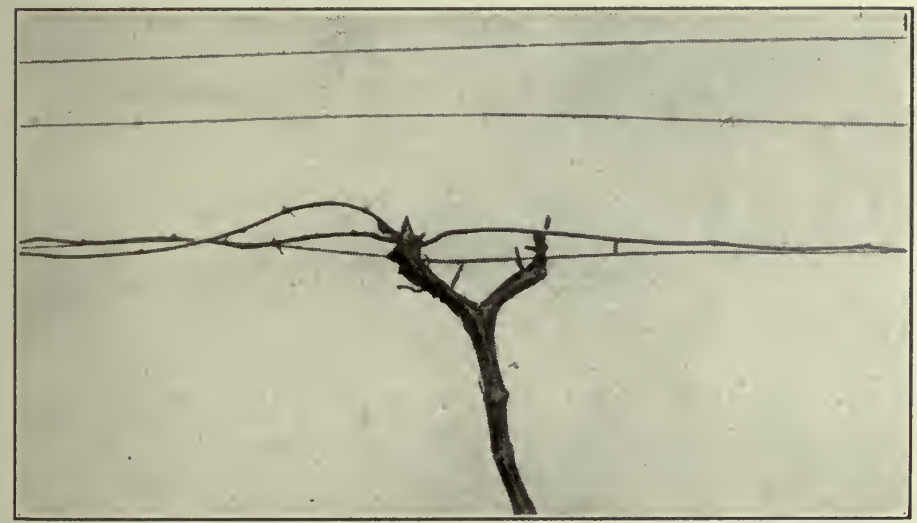

FIG. 273-MUNSON SYSTEM OF GRAPE TRAINING. VINE PRUNED

by their tendrils a firm hold upon the wire. The appearance of the vine at the end of the season's growth will be easily understood from Fig. 272.

Pruning vines in this system is similar to that in the Kniffin system, except that only one main trunk is used and the canes are attached to only the middle or lowest wire. Thus a strong and vigorous mature vine should have two or more canes left in each direction after pruning, in order to furnish a sufficient number of buds for 
fruiting. The vine is renewed back to the head as completely as possible each year. Fig. 273.

This system requires slightly more material and trouble in erecting the trellis, but the results secured have been unexcelled by those of any other system, especially in the case of strong-growing vines, while even with weak growers, like Delaware, the results have been highly satisfactory.

Among the advantages of this method is the favorable position of the fruit, which cannot be soiled by spattering of mud in heavy rains. The grapes are overhung by a leafy canopy which protects them from the hot sun, while a free circulation of air is secured, and they are conveniently placed for spraying and gathering. A minor advantage, appreciated in a private garden, is the facility it affords for passing from one row to another by slightly stooping and walking under the wires. The elevated position of the wires and vines also greatly adds to the ease of cultivating the entire ground beneath.

226. Kniffin modifications and other systems.-F. F. Gladwin* discusses several modifications of the Kniffin system and other systems more or less prominent in the east and in growing varieties in which Labrusca "blood" plays an important part. "His descriptions, slightly condensed, follow (227-237).

227. The two-stem four-cane Kniffin system is very similar to the one described above, the only difference being that two permanent trunks are brought up from the ground, one to the height of the lower wire, where two canes are developed from spurs on one stem, and tied to the wire as before; the other stem is carried to the top wire and two canes are developed from it. Some vineyards tie the two stems together to make them stiffer. In using this method, the canes from each stem may have the same number of buds, each stem being considered as a distinct vine.

* New York Agricultural Experiment Station, Circular 16. 
228. The Y-stem Kniffin system differs from the above in that instead of the two stems being brought up from the ground, one is taken from the other at a distance a little below the lower wire, carried to the top wire and there tied. The number of canes and the subsequent treatment are the same as in the others so far described.

229. The umbrella Kniffin system (Fig. 274).-The chief differences between this and the true Kniffin system are the use of two instead of four canes, and the somewhat changed position. Two canes of eight to twenty buds are developed from spurs on the trunk at the top wire. These a r e tied to right and left along this wire, the n bent down to the lower wire and secured. The canes are r e n e w e d yearly from

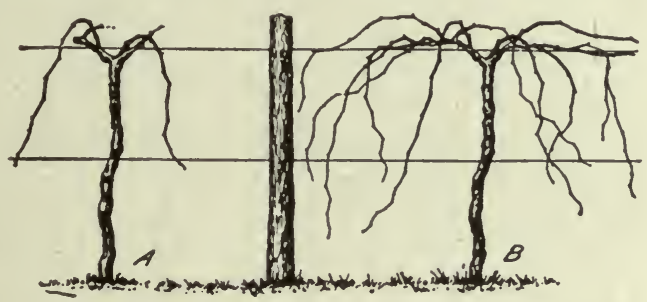

FIG. 274-PRUNED AND UNPRUNED VINE, "UMBRELLA" KNIFFIN SYSTEM spurs.

230. The one-wire Kniffin system or low Kniffin system is a modification of the umbrella, but differs in that the trellis has only one wire three to four feet above the ground. The single stem extends up to the wire, where two canes of ten to twelve buds extend to right and left. The renewal each year, like all the others so far discussed, is from spurs. High quality of fruit and cheapness of trellis commend this system.

Other modifications of the drooping type of training for one reason or another have been dropped in commercial vineyards. The more common are the six or eight-cane Kniffin in which three and four wires are required respectively, making an expensive trellis necessary. 


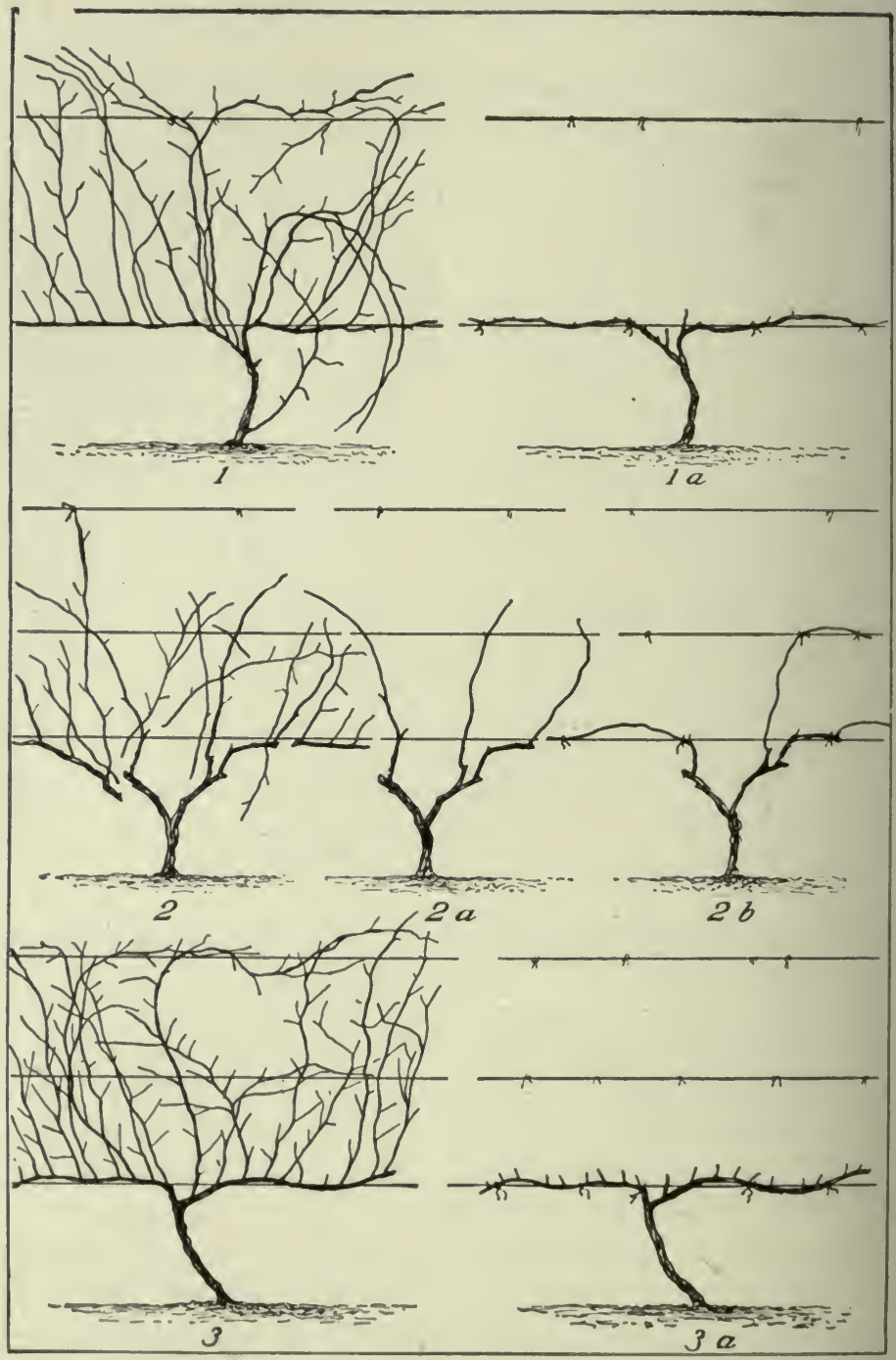

FIG. 275-VARIOUS METHODS OF VINE PRUNING POPULAR IN NEW YORK 1 , High renewal system at end of season's growth; $1 a$, vine trimmed and tied following spring; 2 , Keuka Lake system, ten-year vine, pruned, not tied; $2 a$, stripped for tying; $2 b$, tied; 3, horizontal arm spur system, end of season's growth; $3 a$, after trimming. 
231. The upright type of training carries two or more canes or arms along a horizontal wire or obliquely across the wires. The two methods of renewing in this type naturally divide into two groups, namely "high renewal," or "cane renewal," and "spur renewal."

232. The high renewal system is popular in many grapegrowing sections, there being much to commend it. The trellis is made with two, three or more wires, usually three. The lower wire is placed 18 to 30 inches above ground, while the second and third are from 18 to 20 inches apart, respectively. The main trunk or stem of the vine is carried up to or just below the first wire, and two canes, each bearing from 6 to 10 buds, are taken off, preferably a little below the level of the wire. One is tied to the right and the other to the left. The bearing shoots that grow from the buds on these canes are tied to the second wire when they have reached a sufficient length and to the third as soon as growth will permit. When they reach above the upper wire, they may be pinched back or cut off.

The beginning of the next year should see the vine again cut back to two canes that have grown from spurs or canes of the previous year, this cutting being as close to the head of the vine as possible. Near the base of each of these canes, but upon older wood at the head of the stem, short spurs carrying two or three buds are maintained. From these spurs shoots develop and in turn are used to furnish the fruiting canes of the following year. Thus, the spurs are the means of renewing the fruiting wood. From the above, it will be seen that the amount of old wood retained is reduced to a minimum, while the labor of tying is greatly increased.

233. The Keuka system (Fig. 275-2) practiced in the Keuka Lake, New York, district, appears as a modification of the high renewal, but as there are some differences a description is warranted. The first year after setting, the vines are allowed to grow at random on the ground. At the 
beginning of the second year they are pruned back to two buds. If the vine is a strong grower, it is tied this season to the lower wire of the trellis, which is from 18 to 20 inches above ground. The beginning of the third year finds the vines cut back to a stem or trunk 10 to 20 inches high, tied to the lower wire. The fourth year the vine consists of the short stem and two or three canes, each of 5 to 8 buds, laid along the lower wire and tied. 'The shoots from these are carried perpendicularly to the second and third wires, which are about 20 inches apart, as fast as growth will permit.

The following year all the wood is cut away except two or three canes that have grown from the buds nearest the head of the trunk. These canes have five to eight buds. The number retained after each pruning depends upon the variety and the vigor of the vine. If two canes are left they are tied to right and left along the lower wire; if three, the third is carried to the second wire and tied.

As there is a tendency for long spurs to result from the repeated renewals secured in this manner, frequently buds from the head of the stem are allowed to develop and fruiting wood secured from them. Thus the fruiting wood arises from near the head of the trunk, and as this is usually short almost the entire vine is renewed annually. When the trunk approaches the end of its usefulness a shoot is allowed to grow from the ground to develop into a new trunk, the old one being cut away. The advantages claimed for this method of training are the low head, the reduction of the old wood to a minimum and the ease of getting a complete renewal.

234. The spur renewal or horizontal arm spur system. (Fig. 276.) The trellis for this system is practically the same as for the high renewal. Two canes are placed right and left of the trunk, which has been brought to the height of the lower wire or just below. The number of buds left on each cane will depend upon the vigor of the vine and the availability of the space between the adjoining vines. 
These canes are to become permanent arms, doing service for several years. The shoots that develop from buds on these canes the present year are cut back to two buds in fall or winter. Two shoots are allowed to grow from each of these spurs and tied to the upper wires.

In the fall the cane developed from the upper bud of the spur is cut entirely away, and the other cane cut to two buds as before. Then at the beginning of the next season there are, as in the previous year, two shoots

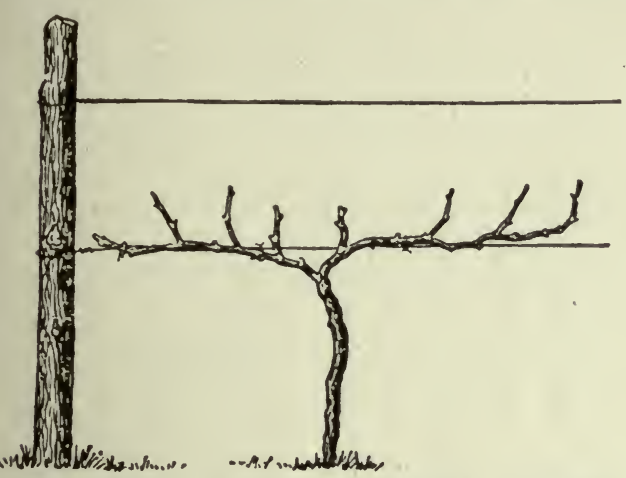

FIG. 276-VINE IN ITS FOURTH YEAR. PRUNED ACCORDING TO HORIZONTAL-ARM SPUR RENEWAL SYSTEM. springing from a spur on a permanent a r m . The spurs will lengthen fast and becom e crooked, hence it is the best practice to cut them away entirely every $\cdot$ few years and grow others from shoots $\mathrm{th}$ at arise from the arms. The spurs may be distributed from 5 to 20 inches apart on the arms.

235. The spur renewal or Chautauqua system is a modification of the horizontal arm spur system just described. Permanent arms are used to support the canes, which are tied yearly to a two or three-wire trellis. These canes may be tied obliquely or perpendicularly. If two wires are used, they are usually 34 inches apart, if three, about 20 inches apart. The canes for tying up the following year either develop directly from the old wood of the arms, from spurs on the arms, or from the base buds of the past season's canes. This system has a strong hold upon the vineyardists of Chautauqua County, New 
York, as the principal grape, the Concord, adapts itself fairly well to it. The old arms should be renewed at frequent intervals in order to use it to the best advantage, as in time they become crooked, gnarled and the extremities often a great distance from the head of the vine.

236. The fan system, while still used in certain localities, is not nearly so popular as formerly. Here the re.ıewals are made yearly from spurs near the grounci, retaining very little old wood. One serious objection to the system is the tendency of the spurs to be lengthened, becoming crooked and reaching in some instances to midway between the first and second wires. The shoots are tied to the wires in the direction they naturally assume, vertically, horizontally or obliquely across the wire. In regions where grapes are grown for home use

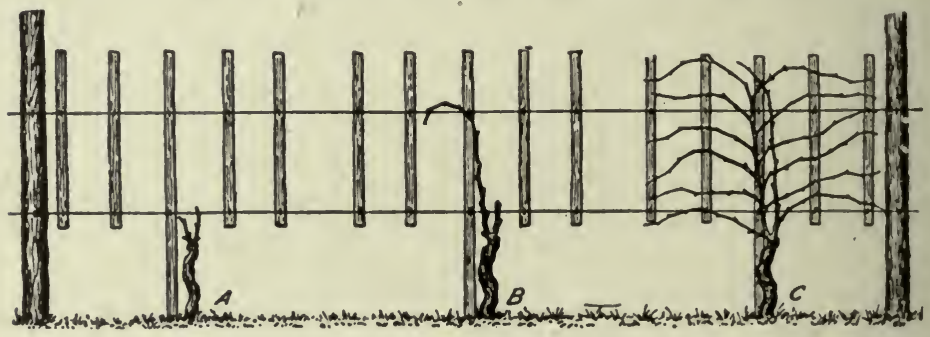

FIG. 277-HUDSON HORIZONTAL SYSTEM. VINE OF VARIOUS AGES $A$, pruned vine in third year; $B$, pruned vine in fourth year; $C$, unpruned vine in fourth year.

and the climate necessitates winter protection, this system is used to advantage.

237. The horizontal type is little used at present, as the cost of the trellis and the labor of tying render it prohibitive. One cane arising from a trunk 1 to 2 feet high is left after each pruning. This is carried perpendicularly to the top wire and the shoots arising therefrom are tied to slats or wires extending vertically from the lower to the upper wire of the trellis. The one advantage of the system is the ease of control for varieties that are 
likely to overbear or are already weakened and require careful nursing to bring them back.

238. The horizontal-arm spur system (Fig. 275) has a permanent arm on each side of the vine head at the lower wire to which each is tied. Annually each cane produced from these arms is cut back to a spur with two wellformed buds, the number of spurs depending upon the variety, the age of the vine, etc. The bearing shoots are tied to the upper wire. When spurs become weak or gnarly, they are replaced by new shoots made to start from a node on the horizontal arm. When an arm be-

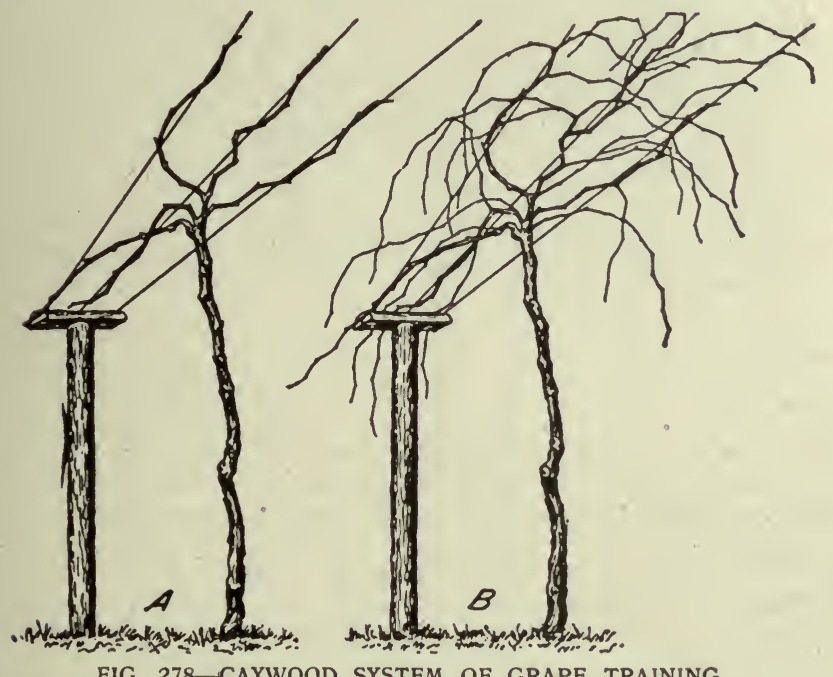

FIG. 278-CAYWOOD SYSTEM OF GRAPE TRAINING

$A$, pruned vine; $B$, one unpruned. Compare with Munson system Figs. 271 to 273. gins to fail a new one is developed from the head. Pruning and training are otherwise the same as in the upright or high renewal system. While this system produces more fruit with certain varieties, it is open to the objections that pruning is more costly and tedious, and more old wood is left than is usually considered desirable.

239. The Hudson horizontal system (Fig.277), popular 
in the Hudson Valley, employs two wires, a stout stake which reaches above the top wire, and is driven in the ground behind each vine, and four vertical slats to each vile fastened a foot or so apart to the wires, but not reaching the ground. Some growers use narrow woven wire fencing of large mesh. The vine trunk is about a foot high. O.ne cane and a spur are left at pruning time, the former to renew the bearing part. The new shoot from the spur is tied to the stake. It is cut long enough at pruning time

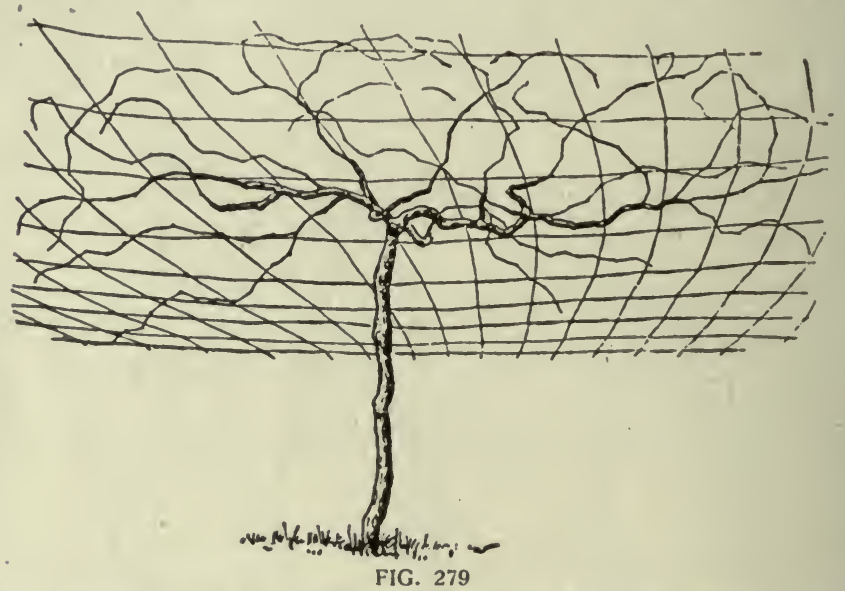

PARRALES SYSTEM OF TRAINING VINES. NOTE ARRANGEMENT OF WIRES to reach the top of the stake, to which, or to the wires, or both, it may be tied. Each cane is counted upon to bear a dozen shoots, six on each side. These are trained horizontally and fastened to the slats. Summer pruning is done when the shoots threaten to become too long. Growers claim that this system favors uniform distribution of the bearing wood and that the fruit is both well supported and shaded.

240. The overhead Caywood system (Fig. 278) has no dvantages over the Munson system, of which it is ápparently a modification. In it the three horizontal wire's, 
stretched at equal height, are 6 feet above ground. The center wires are stapled to the posts, the other two to 3 -foot wooden crosspieces. In pruning, the vines are cut back to five spurs and five canes, the latter fastened to the wires three to right of the head and two to the left one year, the division being reversed the next year. Except when currants, gooseberries or plants of similar growth and habit are grown beneath the trellises (a popular method in the Hudson Valley), this system seems to have little to commend it above the Munson system in its modern form (Figs. 271 to 273).

241. The Parrales or overhead trellis used in training certain Almerian $\mathrm{variet}$ ies is virtually identical with the style used in growing muscadines in America (243). From the head 10 or 15 canes each 1 to 6 feet long, depending on the vigor of the vine, are extended in various direc-

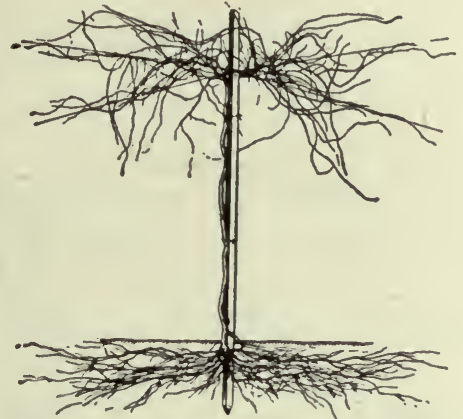

FIG. 280-MUSCADINE (ROTUNDIFOLIA) GRAPEVINE, SHOWING ITS SHALLOW SPREADING ROOT SYSTEM AND A POPULAR METHOD OF TRAINING THE TOP.

tions. Annually these canes are renewed as near as possible to the main trunk. Spurs are left each year to provide for this renewal.

242. The overhead arbor or multiple cross wire system (Fig. 280) is popularly employed in growing the muscadine varieties (243), which are usually set $20 \times 20,10 \times 20$ or $15 \times 15$ feet apart. The posts, one to each vine, are very stout and long enough to extend 7 feet above ground. At the ends of the vine rows on each side of the plantation, wellbraced posts are set. From them No. 10 galvanized wires are passed over the tops of the vine posts to which they are stapled. Other wires of smaller size (No. 14) and 2 feet apart run parallel with each set of main wires, thus 
forming squares. Cienerally only one trunk is grown beside and to the top of each post, to which it may be fastened at various points. At the top it is pinched to develop side shoots for covering the arbor. The shoots are trained out in various directions so as to distribute them evenly over the wires.

243. The muscadine grapes, popular in southern gardens, but only recently becoming known commercially.

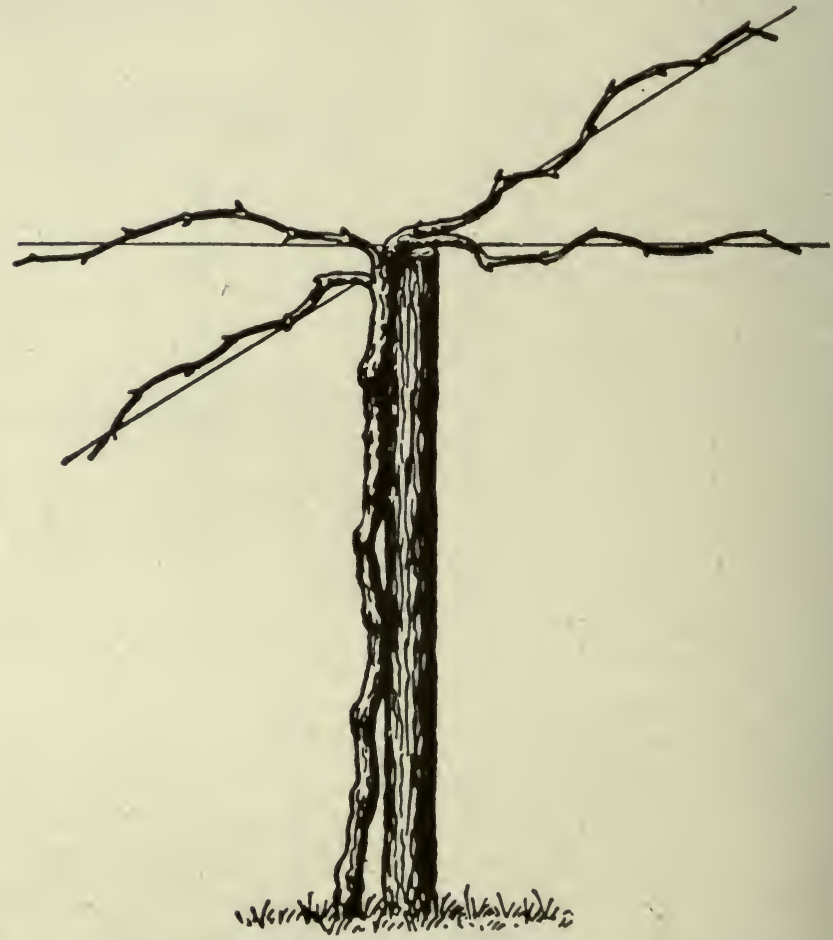

FIG. 281-CROSS-WIRE SYSTEM SHOWING PRUNED VINE

are rarely pruned because pruning is supposed to injure the vines. This is an error; for if pruned at the proper season-October or November-they will not be hurt. 
but benefited. If pruned later-December to Februarythey bleed more or lesscopiously as spring opensand make poorer growth the season following (15). After young vines have made growths of, say, 6 inches in spring, they may be pruned without serious damage, but large vines pruned then will bleed badly. Vines pruned later may be a week or two later in producing their shoots than unpruned vines or vines pruned at the proper time (215). Methods of pruning used upon Labrusca varieties may be employed with this group of varicties. but the muscadines are generally grown upon arbors (Fig. 280).

244. The cross-wire system, used near Marlboro, N. Y., has posts 8 feet apart each way $61 / 2$ feet above ground and surmounted by two wires crossing at right angles. The vines are trained to the posts as single trunks and made to develop four arms, each of which extends along a wire (Fig. 281). Annually these canes are renewed.

245. The umbrella system, sometimes used on hillsides and uneven ground where a trellis would be difficult to construct, consists of a post with two cross arms at right angles at the top (Fig. 261). The vines reach the cross during the second year. From the vine head arms and canes are developed as in the cross wire system (244). Pruning consists in cutting back the vines to the requisite number of buds indicated by the strength of the rine. The posts are usually 4 to 5 feet above ground.

246. Californian systems* of vine pruning may be divided in'o two classes according to the arrangement of the arms on the trunk of the vine. In the commonest systems, there is a definite head to the trunk, from which all the arms arise symmetrically at nearly the same level. The vines of these systems may be called "hearles vines." In the other systems, the trunk is elongated 4 to 8 feet : in: 1 the arms are distributed regularly along the whole or the greater portion of its length. The vines of these systems, owing to the ropelike form of the trunks, are called "cordons."

The headed vines are divided according to the length of the vertical trunk into high, $2-3$ feet, medium, $1 \frac{1}{2}$ feet, and low, $0-6$ inches. The cordons may be vertical or horizontal, according to the direction

* Paragraphs 246 to 263 have been condensed from F. T. Bioletti's Bulletin 246 of the California Experiment Station. 
of the trunk, which is from 4 to 8 feet long. The horizontal cordons may lie single or composed of two branches extending in opposite directions. Double and even multiple vertical cordons occur, but they are very inadvisable and have no advantages.

The arrangement of the arms of a headed vine may be symretrical in all directions at an angle of about 45 degrees. Such a vine is said to be "vase-formed," though the hollow center which this term implies is not essential. This is the form used in the great majority of California vineyards. It is suitable for the "square" system of planting and cross cultivation. Where vines are planted in "avenues," particularly when trellised and where cross cultivation is inpossible, the arms are given a "fan-shaped" arrangement in a vertical plane, to facilitate working of trellised vines.

On the vertical or upright cordon, the arms are arranged at as regular intervals as possible on all sides of the trunk from the top to within 12 or 15 inches of the bottom. On the horizontal cordon they are arranged similarly, but as nearly as possible on the upper side of the trunk only.

Each of these systems may again be divided into two sub-systems, according to the management of the annual growth or canes. In one, called short or spur pruning, spurs of one to three eyes are left for fruit production. In the other, called long or cane pruning, long canes are left. In rare cases an intermediate form is adopted in which long spurs or short canes of five or six eyes are left. In cane pruning and half-long pruning each fruit cane is accompanied by one or two short renewal spurs. Systems of pruning, where only long canes are left without renewal spurs, are not in use in California. In all systems, replacing spurs are left wherever and. whenever needed.

Other modifications are introduced by the manner of disposal of the fruit canes which may be tied up vertically or bowed in a circle and tied to a stake driven at the foot of each vine, or they may be tied laterally to wires stretching along the rows in a horizontal, ascending or descending direction.

Figure $290 b$, representing a headed, vase-formed vine, with a medium trunk and short fruit spurs, is the most common system used in California. It is suited for all small growing vines which bear on the lower buds, for most wine grapes and for muscats. The unit of pruning in this case is a fruit spur of 1 to 3 internodes, according to the vigor of the variety and of the individual cane.

Figure $290 a$ differs from $b$ only in the higher trunk and the longer arms. It is commonly used for Tokay and other large growing varieties, especially in rich soil and when planted far apart.

Figure $290 \mathrm{c}$ has the same form of borly as $a$ and $b$, except that the arms are somewhat less numerous. The unit of pruning is a short fruit cane of four to five internodes, accompanied by a renewal spur of one internode. It is suited for vigorous table grapes, especially for Cornichon and Malaga in rich soil, which do not bear well on short spurs. This is a difficult system to keep in good shape owing 
to the tendency for all the vigor to go to the ends of the fruit canes. It is difficult to obtain vigorous canes on the renewal spurs. Occasional short pruning is usually necessary to keep the vines in proper shape.

Figure $290 a$ is similar to $c$ in form, but the number of arms is still further reduced to 2,3 , or at most 4 . The unit of pruning is a fruit cane of $21 / 2$ to $3 \frac{1}{2}$ feet with its renewal spur: Owing to their length. the fruit canes require support and are tied to a high stake.

This method is used in a large number of Sultanina and Sultana vineyards and for certain wine grapes, especially Semillon and Cabernet. It is not to be recommended in any case, as it has several very serious defects.

The difficulty of obtaining new wood from the renewal spurs is even greater than in the system shown in Figure $290 c$. The length and vertical position of the fruit canes cause the main growth and vigor of the vine to be expended on the highest shoots (73). The renewal spurs are thus so shaded that, even though their buds start, the shoots make but a weak growth. The result is that at the following pruning all the good new wood is at the top of the fruit canes of the previous year, where it cannot be utilized. The pruner has to choose then between reverting to spur pruning, thus getting no crop, or using the weak growth from the renewal spurs for fruit canes, In this case he may get blossoms but little or no fruit of any value.

Other defects of this method are that the fruiting shoots are excessively vigorous and therefore often tend to drop their blossoms without setting and the fruit when produced is massed together so it ripens unevenly and is difficult to gather. It also requires a tall and expensive stake.

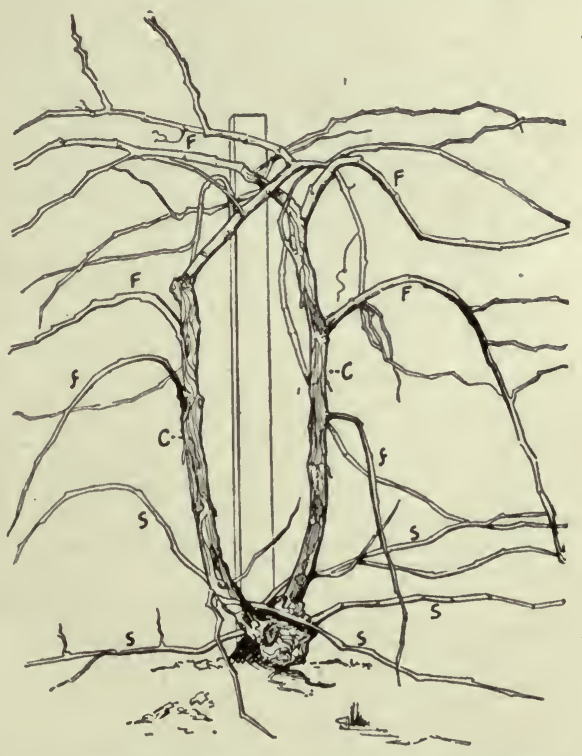

:IG. 282-SULTANINA VINE SHOWING EFFECT OF TYING FRUIT CANES IN VERTICAL POSITION

$S$, suckers and water sprouts; $F$, strong fruit wood; $f$, weak fruit wood; $C$, previous year's fruit canes which have borne a crop. 
Figure $290 b$, an improvement on the last system, differs only in the method of treating the fruit canes. These are bent over in the form of a circle and tied by their middle part to a stake which may be smaller and lower than that needed for the vertical canes. This - bowing of the canes has several useful effects. The change of direction moderates the tendency of the vigor of the vine to expend itself only on the terminal shoots. More shoots therefore are formed on the fruit canes and as their vigor is somewhat decreased they tend to be more fruitful. The slight mechanical injury caused by the bending operates in the same direction (104).

The excess of vigor thus being diverted from the fruit canes causes the renewal spurs to form vigorous shoots, which soon grow above the fruit shoots and obtain the light and air they need for their proper development. This method is used successfully for certain wine grapes such as Riesling, Cabernet and Semillon. It is unsuited to large, vigorous varieties or for vines on rich soil planted wide apart. In these cases two fruit canes are usually insufficient and, if more are used, the grapes and leaves are so massed together that they are subject to mildew and do not ripen evenly or well. The bowing and tying of the canes require much skill and care.

The body, arms and annual pruning of the system shown in Fig. 265 are similar to those of Fig. 288, with the exception that the arms are given a fan-shaped arrangement in one plane. It differs in the disposal of the fruit canes, which are supported by a trellis stretching along the row from vine to vine. This method, largely used for the Sultanina (Thompson's Seedless), is the best system for vigorous vines which require long pruning, wherever it is possible to dispense with cross cultivation. It is also suitable for any long-pruned varieties when growing in very fertile soil.

The vertical cordon system consists of an upright trunk $4 \mathrm{~T} / 2$ feet high with short arms and fruit spurs scattered evenly and symmetrically from the top to within 15 inches of the bottom. This system is used in many Emperor vineyards in the San Joaquin valley. Its advantages are that it allows the large development of the vine and the large number of spurs which the vigor of the Emperor demands, without either crowding the fruit by the proximity of the spurs or spreading the vine so much that cultivation is interfered with. It also permits cross cultivation.

One of its defects is that the fruit is subjected to various degrees of temperature and shading in different parts of the vine and the ripening and coloring are often uneven. A more vital defect is that it cannot be maintained permanently. The arms and spurs at the top of the trunk tend to absorb the energies of the vine and the lower arms and spurs become weaker each year until finally no growth at all is obtained helow. After several years, most of the vines therefore lose their character of cordons and become simply headed vines with abnormally long trunks.

'The cordon can be re-established in this case by allowing a vigor- 
ous sucker from which to develop one year to form a new trunk the next. The following year the old trunk must be removed entirely. An objection to this method is that it makes very large wounds in the most vital part of the vine-the base of the trunk.

The unilateral, horizontal cordon system consists of a trunk about 7 feet long, supported horizontally by a wire 2 feet from the ground. Arms and spurs are arranged along the whole horizontal part of the trunk. This system accomplishes the same objects as the vertical cordon. It allows a large development of the vine and numerous fruit spurs without crowding. It is superior to the vertical cordon in the distribution of the fruit, which is all exposed to approximately the same conditions owing to the uniform distance of the fruit spurs from the ground. All parts of the trunk producing an annual growth of wood and fruit are equally exposed to light, and the tendency of the growth to occur principally at the part of the trunk farthest removed from the root is counteracted by the horizontal position. There is not the same difficulty therefore in maintaining this form of vine permanently there is with vertical cordons.

The system should not be used for small weak vines, whether the weakness is a characteristic of the variety or due to the nature of the soil. It is suited to only very vigorous varieties such as Emperor, Almeria and the Persian grapes when growing far apart in rich, moist soil.

246a. Periods of development.-The first period of development, which lasts one or two years, is devoted to developing a vigorous root system; the next two or three years to building up a shapely trunk and head, and a like period to forming the full complement of arms. At the end of five to nine years the framework of the vine is complete and should undergo no particular change of shape except a gradual thickening of trunk and arms.

There are, therefore, several periods in the life of the vine with varying objects, and the methods of pruning must vary accordingly. These periods do not correspond exactly to periocis of time, so it may be misleading to speak of pruning a two-year-old or a threeyear-old vine. One vine under certain conditions will reach the same stage of development in two years that another will reach only in three or four under other conditions. Under exceptionally favorable conditions the first and second periods may be included in the first year and a completely formed vine may be obtained in five years.

247. At planting time.-Whether cuttings, one-year-old rooted vines, or bench grafts are used, the vines need attention. The usual way to prune a good, rooted vine of average size with a single cane at the top and several good roots at the bottom is to shorten the cane to one or two buds and the roots to 2 or 4 inches, according to their size. Shortening the cane nuakes the vine less liable to dry out before rooting and forces the growth from the lower buds, which produce more vigorous shoots. The roots are shortened 
(Fig. 283) so there will be no danger of the ends being turned up wards when planted. If they are to be planted in a large hole they

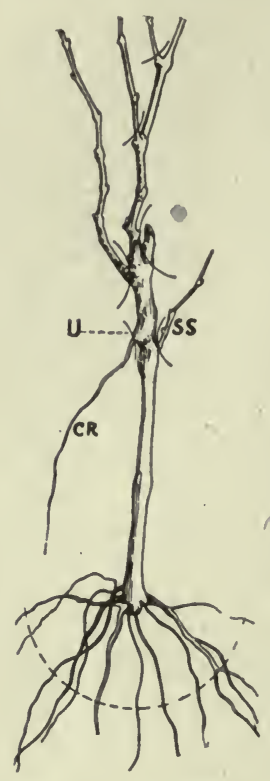

FIG. 283 - ROOTED VINE PRUNED

This is a benchgrafted vine in which SS shows a sucker from the stock; $U$, the point of union of stock and cion, and $C R$ the cion root. The dotted line at the bottom indicates where the roots should be pruned. may be left as long as 5 or 6 inches; if to be planted with a crowbar or a dibble, they must be cut back to $1 / 2$ inch.

There is little if any advantage in leaving long pieces of roots. They are not feeding roots and are of no use to the vine until they develop feeding rootlets. This they will do as well if shortened as if left of full length, often better. The main advantage of a rooted vine over a cutting is that it forms rootlets more easily and rapidly. There may be a slight advantage in leaving 3 or 4 inches of the sound well-grown roots, as the reserve matters they contain probably promote a better growth of rootlets, but little or no difference has been noted between the growth of vines of which the roots have been shortened to $1 / 2$ inch and those which have been left longer. Where the roots are left long, moreover, more care and time are needed in planting.

If the rooted vine has several canes, all wut one should be removed entirely, and this one shortened to one or two eyes. The one left should be that which is strongest, has the best buds, and is the best placed. Where a horizontal cane is left, it should be cut back to the base bucl. Otherwise the main growth may occur at a higher bud and the vine will have a crook which will result in a badly formed trunk.

If equally vigorous canes are growing from different joints it is usually best to leave the lower cane. This brings the buds from which growth will come nearer to the roots, and leaves less of the original cutting. The upper joint between the canes is, moreover, oftell more or less decayed or imperfect.

248. Planting.-Cuttings differ only in length; the shortest, 8 to 10 inches, are best suited to the nursery, those 12 to 14 inches to the field, the longest 16 to 18 inches in only the driest soils. Always they are cut just below a bud to facilitate healing and root formation. The top may be cut just above a bud so as to leave the pro tecting diaphragm or about 1 inch of internode. Cuttings are planted with the second bud at the level of the ground, leaving only one bud above. Rooted vines are planted with the two buds just 
above the surface. Bench grafts are planted with the union 1 inch above the surface. In the last case the soil must be hilled up so as to cover the union.

249. First growing season.-The treatment during the first spring and summer will depend on what growth the vines are expected to make and on whether or not the vines are staked the first year.

With cuttings and with both rooted vines and grafts where the growth will be moderate, staking the first year is unnecessary, though it has some slight advantages. In these cases, no pruning of any kind is necessary until the winter following the planting, except in the case of bench grafts, in which case the removal of the suckers from the stock and roots from the cion is essential. If the stocks have been well disbudded by the nurseryman, few suckers will develop. In moist soil, the cion roots may develop vigorously and must be removed before they grow too large, or they may prevent the proper development of the resistant roots.

The removal of roots should usually be done some time in July. For this purpose the hill of soil is scraped away from the union and after the cion roots and suckers are removed it is replaced. In this second hilling up, the union should be barely covered so the soil around the union will be dry and unfavorable to a second growth of roots. Later in the season, about September, the soil should be removed entirely from around the union and any new roots that may have formed removed. The union is then left exposed to harden and mature, so it will pass the winter without injury.

If the main shoot is kept upright it will be easy to produce a wellformed vine. In many cases no disbudding, thinning of shoots, or topping need be done. The object is to have as abundant a growth of foliage as possible in order to stimulate a vigorous and abundant root development (213, a). In other cases, where very good, rooted vines of vigorous varieties are planted in rich soil abundantly supplied with water, it is desirable to disbud the vine early in order to throw all its energies into the single main cane. In such cases staking before or just after planting is necessary, and methods similar to those described for the second season are used.

250. First winter pruning.-At the end of the first growing season, an average good vine will have produced from three to five canes, the longest of which will be 2 to 3 feet long. Soon after the leaves have fallen in December or early in January the vines should be pruned. The method is precisely similar to that used for rooted vines before planting except that the main roots are not touched. All the canes except one are removed. This one should be well matured, at least at the base, and should have well-formed eyes only, two eyes of which are saved. It is well also to cut off all shallow roots within 3 or 4 inches of the surface. This is necessary in the case of grafted vines if any have escaped the summer root-cutting. Some vines which may have made an exceptionally large growth may sometimes possess a cane large enough from 
which to start the trunk in the way described later for the seconrl winter pruning.

251. Staking.-If the vines have not been staked before, the stakes should be driven soon after pruning and before the starting of the buds. In order to preserve the alignment of the vineyard, they should be driven on the same side of every vine at a uniform distance of about 2 inches. If driven closer they may injure large roots or even the main underground stem if the vines have not been carefully planted vertically or slanting toward the side on which the stake is to be placed.

The position of the stake should always be the leeward of prevailing winds during the growing season. That is, the stake should be so placed that the wind will press the vine toward it instead of
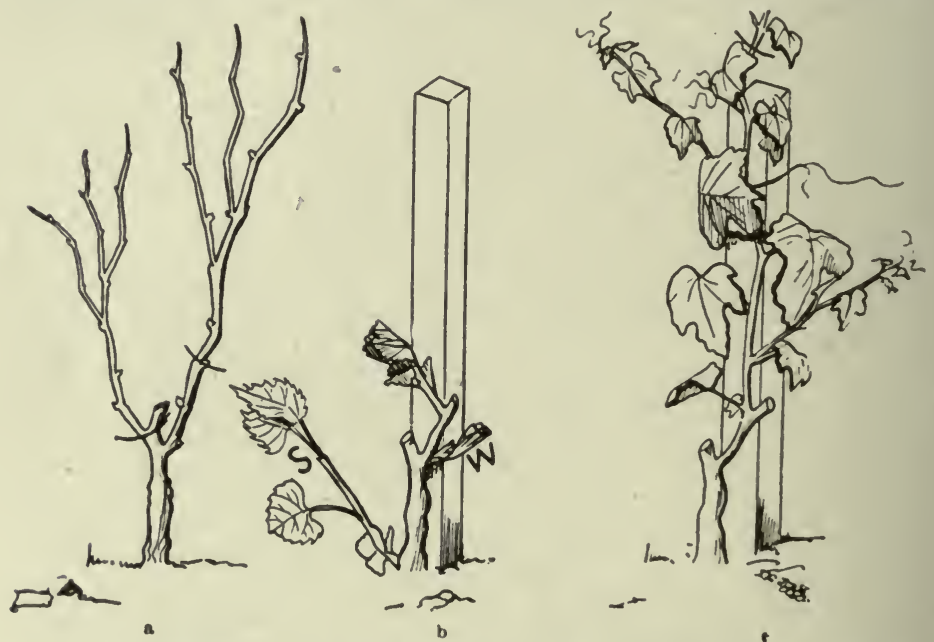

FIG. 284-TREATMENT OF AN AVERAGE VINE DURING SECOND SEASON a, Winter pruning; b, spring pruning-removal of suckers (S) and thinning of shoots (W); c, summer treatment-tying to stake and topping.

azvay from it. This will facilitate the work of keeping the vine upright and attached to the stake. If the vine is on the other sicle the pressure of the wind will stretch the string tight and the swaying of the vine will gradually wear it until it breaks, necessitating retying. By carefully observing this rule, very few vines will require retying even if weak material like binding twine is used.

252. Second summer pruning.-Before the starting of the buds, in the spring following the planting, most of the vines appear about the same as when they were planted. There is, however, a very notable difference; they have well-developed root systems in the 
soil where they were formed. The result is they make a much more prompt and early start and will produce a much larger growth than the first season. Hence they require very careful attention from the pruner during the spring and summer of the second season. Vines neglected at this time, in this respect, may make as large a growth, but a large part of it will be wasted, the vines will be misformed and it will require one to two years longer to develop a suitable framework and to bring them into bearing, even though they are properly handled during subsequent years. The more vigorous the vines, the more necessary it is to handle them properly during this period.

The main object during this second growing season is to develop a single, strong, vigorous and well-ripened cane from which to form the permanent trunk of the vine. This is done by concentrating all the energies of the vine into the growth of a single shoot. As soon as the buds start, or when the most precocious has developed a shoot of a few inches, the vines should be disbudded. This consists in rubbing off with the hand all buds and shoots except the two largest and best placed. The lowest upright shoots are usually the best. Leave only those which will make a straight vine. It is better to leave less-developed buds than a shoot which, when it grows, wili make an awkward crook with the underground stem.

After this disbudding, the two shoots left will grow rapidly, as they receive all the energies of the root system. When the longest have grown 10 to 15 inches, they should be tied to the stake. Unless this is done, they are likely to be broken off by any heavy wind, owing to their soft, succulent texture. Only the best placed and most vigorous of the two shoots should be tied up. If this shoot is growing upright and near the stake, this can be done without any danger of injuring it. In this case the second shoot should be removed. If the shoot has to be bent over in tying it to the stake it may be injured. In such a case the second shoot should be allowed to grow until it is known whether the first has been injured. In case of injury the second shoot may be tied up the next time the vines are visited and the injured shoot removed.

At the tying up of the reserved shoots, all new shoots which have developed since the first disbudding should be removed. As they are soft and easily injured the shoots should be tied up loosely after being brought around carefully to the windward side of the stake.

They will require tying once more when they have grown another foot or 18 inches. There will then be two ties, one at 2 or 3 inches from the top of the stake and the other at about the middle. If the vines have a tall stake and are to be headed very high, another tying higher up may be needed later.

With vines making only a moderate growth, no other pruning will be needed until the winter. Exceptionally vigorous vines, however, may make a cane 8,10 or more feet long. Such a cane is heavy and is very likely to break the cords by which it is attached 
to the stake. In this case it may break off at the bottom, or at least will form an awkward crook near the ground when it matures. In either case it is difficult to form a good trunk the following year. Even when the ties do not break, the cane will not be well suited for the commencement of a trunk, as the joints will be so long that it will be impossible to leave enough well-placed buds at the winter pruning.

Both these difficulties are avoided by timely topping. When such vigorously growing canes have grown 12 or 18 inches abnve the top of the stake they are cut back about level with the stake. This is most conveniently done with a long-bladed knife or a piece of split bamboo. After topping, the cane ceases to grow in length and

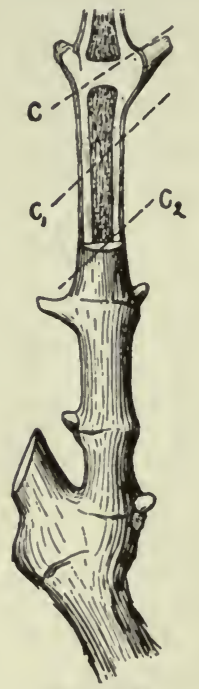

FIG. 285

GRAPE SPUR

Letters and lines indicate positions of good and bad cuts (253). laterals start at most of the joints. It is less exposed to the action of the wind and the laterals supply the buds needed for forming the vine at the winter pruning.

The result of the second season's growth, then, is to produce a single vigorous cane with or without latcrals. This is the cane which is to develop into the permanent trunk of the vine. It must not only be large and vigorous, but must be properly matured. If the vine is allowed to grow too late in the season, an early frost may destroy the unmatured cane and much of the results of the year's growth will be wasted. Such a frost may incleed kill the entire vine. Grafted vines are particularly liable to injury from this cause, as if they are killed down to the union they are completely ruined. Ungrafted vines when killed to the ground may be renewed from a sucker next year. This sucker, however, is likely to grow with such vigor that it is even more liable to injury from an autumn frost than the original shoot.

This late growth is much more likely to occir with young vines than with old. The old vines stop growing earlier because their energies are directed into the crop, and as they produce a larger amount of foliage they draw more upnn the moisture of the soil, which therefore dries out earlier.

If possible, late growth of the young vines must be prevented and the wood matured before frost. This is accomplished hy means which promote the drying of the soil in autumn. Iate irrigations should be avoided. Cultivation should usually stop by midsummer. In very moist, rich soils it is often an advantage to grow corn. sunflowers or similar crops between the rows of vines to take off the surplus moisture. In some cases it is good practice to let the summer weeds grow for the same purpose. 
253. Second winter pruning.-With vines which have been treated as described and to which no accident has happened, the second winter pruning is very simple. It consists simply in cutting back the single cane which has been allowed to grow to the height at which it is desired to head the vine.

In all cases a full internode must be left above the top burl. This is done by cutting through the first bud above the higlest which it is desired to have grow. This cut is made in such a way as to (lestroy the bud (Fig. 285), but to leave the diaphragm intact and part of the swelling of the node. This upper internode is left partly to protect the upper bud, but principally to facilitate tying. By making a half-hitch around this internode, the vine is held very limmly. If the swelling at the node of the destroyed bud is not left, many vines will be pulled out of the hitch when they become heavy with leaves and supple with the flow of sap in the spring.

In tying the vines, no turns or hitches must be made around any part except this upper internode. A hitch below the top bud will result in a crook-necked vine, as the top will bend over in the summer under the weight of the foliage. A hitch lower down is even more harmful, as it will girdle and strangle the vine. A second tie about half way from the upper to the ground is always necessary to straighten the cane. Even if the cane is straight when pruned, a second tie is needed to keep it from curving under the pressure of leaves and wind in the spring. For high-headed vines three ties are usually necessary.

For the top tie, wire is particularly suitable. It holds better than twine and does not wear. Even though it is not removed, it does no harm, as the part around which it is wound does not grow. The lower ties should be of softer material as wire has a tendency to cut into the wood. They should be placed so the cane is able to expand as it grows. With thin and especially with round stakes this means that the tie must be loose. With large, square stakes there is usually sufficient room for expansion, even when the twine is tied tight.

However careful the pruner, many of the vines cannot be pruned quite so simply as those described. These methods therefore must often be modified. Some of the vines may not make a sufficient growth of cane to be tied up in the way indicated. They should be pruned back again to two buds, as at the previous winter pruning, and special care taken during the following summer to develop a good cane on each. Vines in which the development of the tying-up cane is thus delayed a year will usually make a very vigorous growth the following summer. They must be topped. The result at the following winter pruning will be a vigorous cane with laterals, which should be pruned. All vines which have not made a growth of well-developed, mature cane of the length desired should be cut back to two buds. This length will usually be at least twice that of the desired height of trunk because the upper part of the cane is usually badly matured and with imperfect buds. It is bad practice to cut canes to intermediate lengths, as this results usually in crooked 
trunks and inevitably to variations in the height of the heads of different vines.

If the suckering, disbudding and thinning of shoots have been neglected, there will be more than one cane on the vine. In this case all but the strongest and best placed must be removed and this treated like a single cane. Unfortunately the strongest is often not the best placed. In fact, if tying up during the summer has been neglected it is often the worst placed. The more vigorous the vine the more likely is the position of the canes to be defective. This is especially true of grafts on old vines, which should be trealed like exceptionally vigorous vines during the second growing season. In
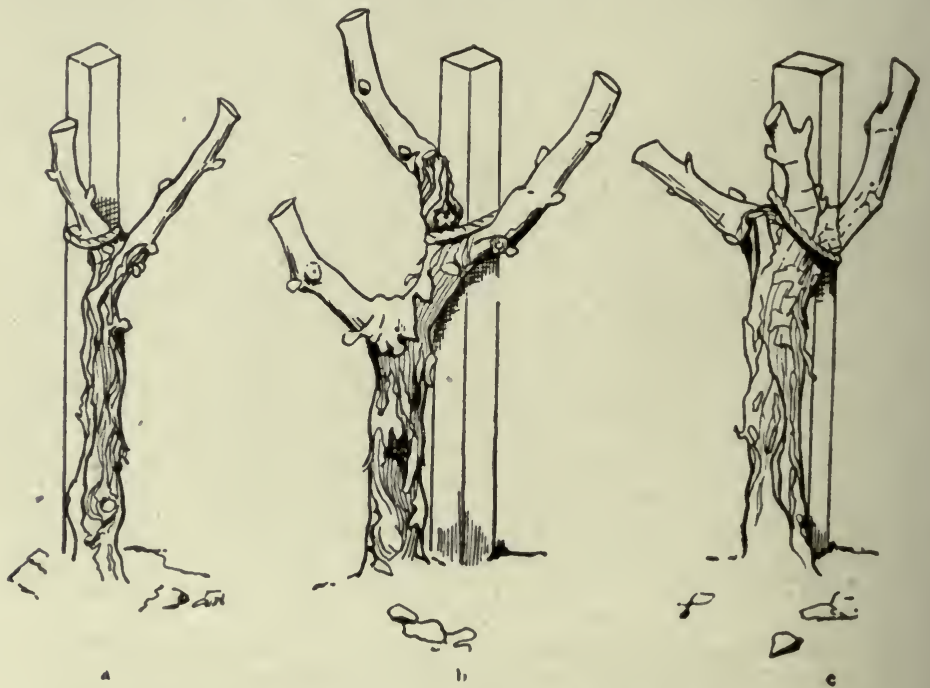

FIG. 286-THREE-YEAR-OLD VINES AFTER PRUNING

a, Average vine with two spurs; $b$, vigorous vine with three spurs, the lowest to be removed next season; c, vigorous vine with three spurs.

these cases of neglected vines, the best canes are often lying flat on the ground. It will require all the ingenuity and skill of the pruner to get them into a more or less erect position. At best they will result in crooked, misshapen vines.

By removing the soil from around the base of the vine the cane can often be raised more easily and the bend will then be at least partially in the underground stem, where it is less harmful. In the worst cases it may be impossible to raise a cane. It is then necessary to cut all the canes back to the old wood and to develop a 
new cane the next year. Even if the main cane has been tied up, the removal at the collar of the vine of the other canes, if they are numerous and large, makes many serious wounds, which in some cases weaken the vine considerably.

254. Third summer pruning.-During the third season, average wèll-grown vines will produce their first considerable crop and develop the canes from which will be formed the first arms. During this spring it will be necessary to sucker and remove low shoots at least once more. This may be done when the vines are hoed. If
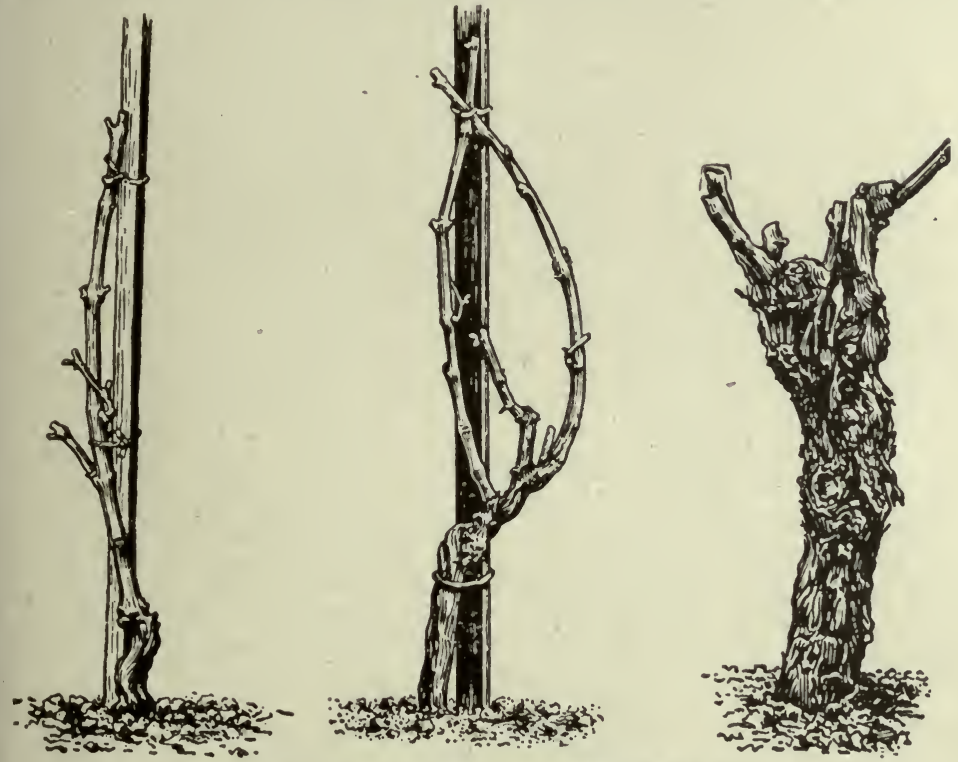

FIG. 287-GRAPEVINES OF VARIOUS AGES

Left, vine in third year pruned by cane system. Middle, vine in fifth year (cane system). Right, spur, stool or short system; vine in its fifth year.

the vines grow vigorously the shoots should be pinched when they are 18 to 24 inches long to protect them from the wind.

255. Third winter pruning.-At the end of the third season's growth the vine should have a straight, well-developed trunk with near the top several vigorous canes from which to form the arms. The pruner should leave enough spurs to supply all the fruit buds the vine can utilize. The number, size and thickness of the canes show the vigor of the vine. It will depend somewhat on the variety how many buds should be left. For a variety whose bunches average one pound, and which produces two bunches to the shoot, 12 
fruit buds should give about 24 pounds, or about seven tons to the acre, if the vines are planted 12 by 6 feet. The number of spurs will depend on the length. Six of two buds each will give the required number, but where the canes are exceptionally vigorous they should be left a little longer, in which case a smaller number of spurs will suffice.

When the number and length of the spurs are decided on, the canes should be chosen which will leave these spurs in the most suitable position for forming arms. This position will depend on whether we want a vase-form or a fan-shaped vine. In the first case, we choose those which will distribute the spurs most evenly and symmetrically on all sides, avoiding any which cross or point downwards; in the second, only those canes which run in the direction of the trellis, avoiding canes which stick out between the rows. Downward pointing canes may be used in this case.

It is comparatively easy properly to shape vines which make only a moderate growth during the first three seasons. On the other hand, very vigorous vines may finally be brought into practically perfect shape. The somewhat larger and more numerous wounds necessary are more easily healed by a vigorous vine.

256. Pruning after the third winter.-For the pruner who understands the pruning of young vines and has brought them to approximately the desired form, the subsequent winter pruning is very simple. It involves, however, one new idea-the distinction between fruit and sterile wood.

$\mathrm{Up}_{\mathrm{p}}$ to the third winter pruning, this distinction is not necessary; first, because practically all the wood is fruit wood, and second, because the necessity of forming the vine controls the choice of wood. From this time on, however, this distinction must be carefully made. At each winter pruning spurs of fruit wood must be left to produce the crop to be expected from the size and vigor of the vine. Besides these fruit spurs, it may be necessary to leave spurs of sterile wood to permit of increasing the number of fruit spurs the following year.

Each winter after the third the same process must be followecl. First, enough fruit spurs, as well placed as possible, must be left to produce the crop. Second, on most vines, supplementary spurs of sterile wood must be left to supply more arms where they are needed, and finally, when the full complement of arms has developed, to supply new arms to replace those which have become too long or are otherwise defective.

Sometimes it is difficult to find water sprouts in suitable positions for replacing spurs. This may be due to weakness of the vines, which are able to develop shoots on only the fruit spurs and have no surplus vigor to force out dormant buds on the older wood. This difficulty may be met by shorter pruning. If an arm is too long, and at the same time weak, it should be pruned to extra short spurs. This will tend to force water sprouts to start from the older wood near the base of the arm. Their absence at the winter prun- 
ing may also be due to the water sprouts having been removed during the summer. When water sprouts are removed the need of replacing wood should always be kept in mind, and one vigorous, well-placed water sprout left near the base of every long arm.

257. Fan-shaped vines. -With headed vines, the treatment up to the second winter pruning is the same except for the variations in the height of the head. At the third winter pruning, however, the formation of the head commences, and the pruner determines whether it shall be vase-formed or fan-shaped. At the third winter pruning, the vine should be pruned to two spurs. More vigorous vines should not be given more spurs, but the spurs should be made longer, with four, five, or even six eyes in some cases. This is in order to obtain some fruit, which might not be obtained from long pruning varieties by leaving many spurs. With extremely vigorous vines one fruit cane may be left at this pruning. The wires of the trellis should be put up this year, if this has not already been done.

258. Double-he a ded vines. - Some growers attempt to arrange the arms of their vines in two stages, one above the other, forming double-headed or twocrowned vines. The method is applied to both vase-formed and trellised vines. It is open to the same criticisms as is the vertical cordon. The chief of these is that it cannot be maintained permanently. The lower head or ring of arms finally becomes weak

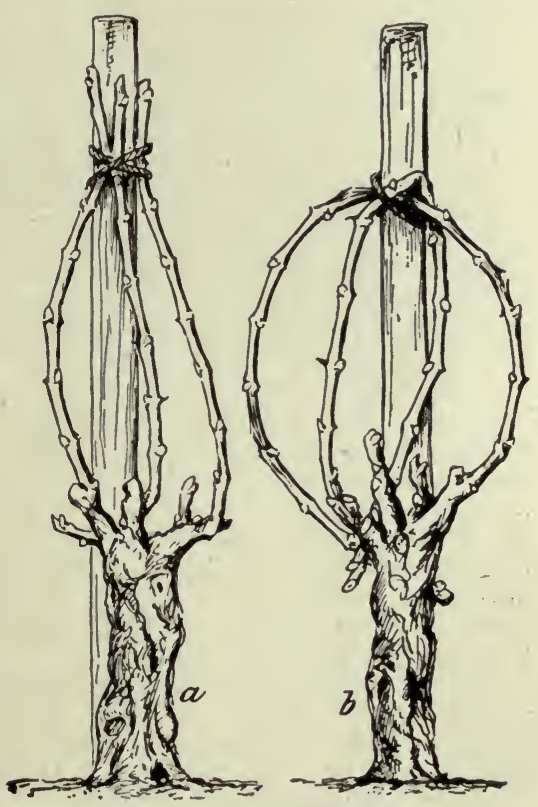

FIG. 288

FORMS OF GRAPEVINE HEAD TRAINING

$a$, vertical fruit canes and renewal spurs; $b$, bowed canes and renewal spurs and fails to produce wood. It is easier to maintain in trellised vineyards and has some advantages, the chief of which is that it is easier to keep the vine in the single plane and to prevent arms get: ting into the inter-rows. 
259. Vertical and bowed canes.-This is a method used commonly in many vineyards. The unit of pruning is the same as in the method just described, consisting of a fruit cane and a renewal spur. The framework of the vine consists of a trunk of medium height, with a vase-formed head consisting of three or four arms. The defects of this system have been pointed out (246): In the hands of skillful pruners it is used with fair success with seedles: Sultanas and with some wine grapes such as Colombar, Semillon, Cabernet and Reisling. The results with Sultanina are very unsatisfactory. By this method, on most of the vines, the fruit canes start from high up near the middle of the stake, and are therefore too short for the best results. The canes which start from low down are in most cases suckers, and therefore of little value for fruit bearing.

Figure $288 b$ shows a vine with bowed canes. The method of pruning is exactly the same as in the method just described. The bowing of the canes, however, overcomes some of the defects of that method. It is used regularly in many wine grape vineyards of the cooler regions. It is unsuited for very vigorous vines in rich soil.

260. Vertical cordons. - In head pruning, the treatment of young vines up to the second or third winter pruning is identical for all systems. In cordon pruning the treatment for the first and second is also the same. That is, the vine is cut back to two buds near the level of the ground until a cane sufficiently long to serve for the formation of the trunk is obtained.

In the vertical cordon the trunk is 3 to 4 feet long instead of 1 to 2 , as in head pruning. This makes it necessary to have a longer and more vigorous cane to start with. It may require a year longer to obtain this. That is to say, at the end of the second season's growth many vines will not have a single cane sufficiently developed to give the necessary $3^{\mathrm{T}} / 2$ feet of well-ripened wood and properly developed buds. At the second winter pruning, therefore, it will often be necessary to cut the vine back to two buds, as at the first winter pruning.

Finally, a cane of the required length will be obtained. The vine may then be formed as already described for the second winter pruning of headed vines, except that the cane is left longer. This cane is then tied to the stake. When such a vine is pruned spurs are left at intervals along the trunk. Each of these spurs is a fruit spur and is also the commencement of an arm. The future treatment of these arms is the same as that of the arms in head pruning.

261. Horizontal cordons.-During the first two or three years, vines to be given the form of horizontal cordons are treated exactly as for vertical cordons, that is, they are pruned back to two buds each winter and the growth forced by disbudding into a single cane during the summer. As soon as a well-ripened cane of the required length is obtained, it is tied to a wire stretched horizontally along the row at from 15 to 24 inches from the ground. 
For this system of pruning, the rows should be 12 to 14 feet apart and the vines 6,7 or 8 feet apart in the rows. As the cordon or trunk of each vine should reach the next vine, it will have to be 6 to 8 feet long. The best shape is obtained when the trunk is all formed one year from a single cane. It is necessary, however, sometimes to take two years for the formation of the trunk. In any case, the cane first tied down should reach at least half way to the next vine. The following year a new cane from the end of this should be used to complete the full length of the trunk. In attaching the cane to the wire, it must be bent over in a gentle curve and care taken not to break or injure it. Sharp ends should be avoided.

The cane should be placed on top of the wire, not twisted around it. The end should be tied firmly and the rest of the cane supported by strings tied loosely in order to avoid girdling when the cane grows.

In the following spring, most of the buds on a good cane will start. If the cane is short jointed, some of the shoots should be

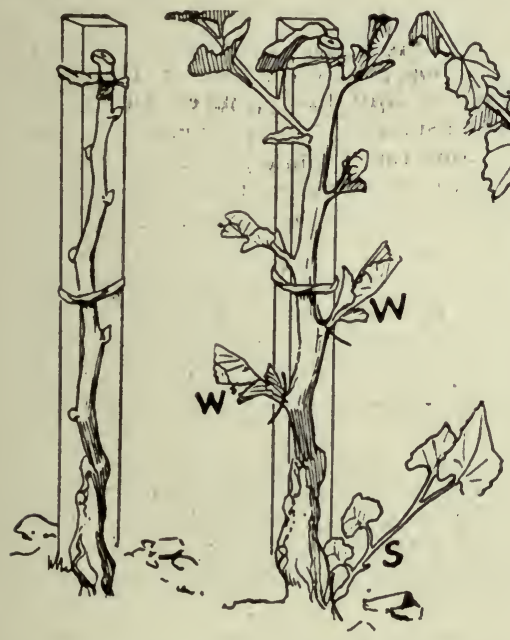

b

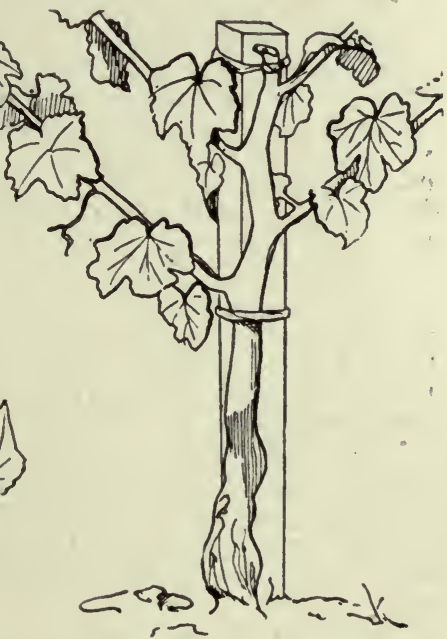

c

FIG. 289-TREATMENT OF AVERAGE VINE IN THIRD SEASON OR VIGOROUS ONE IN SECOND

a, Vine pruned to one cane and tied to stake; b, removal of suckers (S) and lower shoots (W) in spring; c, vine in summer at time of pinching.

removed and only those shoots allowed to develop which are conveniently situated for permanent arms. If the vines are to be short pruned, the arms should be developed every 8 to 12 inches from a few inches beyond the bend to the extreme end. For long pruning, the arms should be farther apart, 12 to 20 inches. Shoots starting 
from the top of the cane and growing vertically upwards are to be preferred.

As the shoots develop, the strongest should be pinched repeatedly. if necessary. This will tend to force the growth of the weaker shoots and to equalize the vigor of all. At the end of the season, there should be from 5 to 10 canes growing on each cordon of full lengtli. These canes are then pruned back to two or three buds, or a little longer for long-pruned varieties.

During the following spring and summer, the vines should be carefully suckered and unnecessary water sprouts removed. Any shoots coming from the lower side of the cordor should be removed early to strengthen the growth in the shoots on the upper side. Such vines are apt to become dry or decayed on the upper side. At the end of the fourth or fifth year from planting at the latest, the cordon will be fully formed and the final style of pruning may be applied.

262. Renovation of imperfect or misshapen vines.-The-pruner who with definite ideas properly handles his vines from the begiuning can, in most cases, bring them into the required shape with comparative ease. Often, perhaps usually, he has to deal with vines which have some more or less serious fatlt. They may be misshapen owing to defective pruning, or otherwise imperfect owing to mechanical injuries, or as the result of frost, fungi, or insect pests. If the vines are young, the defects can often be overcome and the vine given a proper form very easily.

As the vines become older, it hecomes increasingly difficult to overcome defects of formation. The disadvantage of a low head may be in part avoided by gradually lengthening the arms and giving them a more vertical direction. An ill-formed head may be improved by removing badly placed arms and developing new arms where needed.

The trunks of many old vines are so defective that little improvement can be obtained by these means. It is possible and occasionally profitable completely to renew the trunks of such vines. This may be done by developing a new trunk from a strong cane originating at or below the surface of tise ground and then cutting away the old trunk.

But this method has the same defect as the grafting of old vines: leaves a large wound where the old stump was removed, a wound which may never heal and which finally allows the entrance of wood-rot fungi. Such renewed vines, however, may last as long as if the old decayed trunk had been left, perhaps longer. They will also be more fruitful and easier to handle properly. The change may be made without the loss of a crop, as occurs in grafting. If the stumps are large, the expense of sawing them off is consicierable.

263. Choice of a system.-In choosing a system, we must consider carefully the characteristics of the particular variety we are growing. A variety which bears only on the upper buds must be pruned "long," 
that is, must be given fruit canes. It should be noted that many varieties, such as Petite Sirah, which will bear with short pruning when grafted on resistant roots require fruit canes when growing on their own roots. In general, grafted vines require shorter pruning than ungrafted. If pruned the same, the grafted vines may overbear and quickly exhaust themselves. This seems to be the principal reason for the frequent failure of Muscat vines grafted on resistant stock. The cultural conditions also affect the vine in this respect. Vines made vigorous by rich soil, abundant moisture, and thorough cultivation require longer pruning than weaker vines of the same variety.

The normal size of the bunch is also of importance. This size will vary from one-quarter of a pound to two or three pounds. It is difficult to obtain a full crop from a variety whose bunches are very small without the use of fruit canes. Spurs will not furnish enough fruit buds without crowding them inconveniently. On the other hand, some shipping grapes may bear larger crops when pruned long, but the bunches and berries may be too small for the best quality.

The possibilities of development vary much with various varieties. A Mission or Flame Tokay may be made to cover a quarter of an
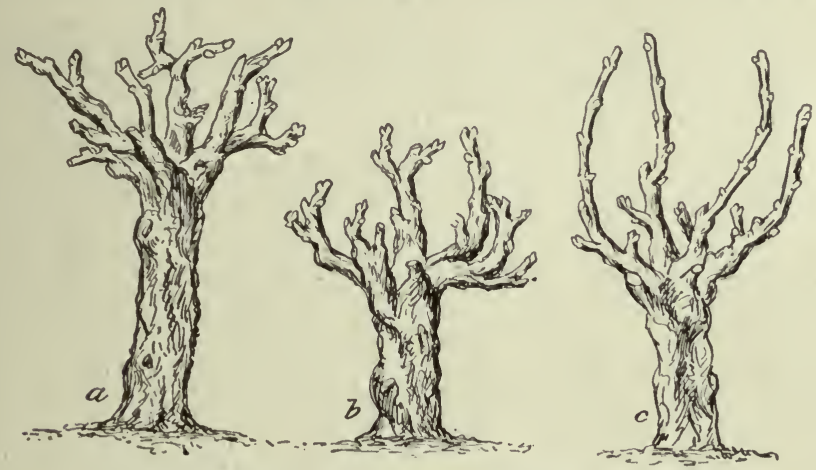

FIG. 290-FORMS OF HEAD PRUNING OF GRAPES

$a$, Spur pruning with high trunk; $b$, spur pruning with medium trunk; $c$, half-long pruning with medium trunk.

acre and develop a trunk 4 or 5 feet in circumference. A Zinfandel vine under the same conditions would not reach a tenth of this size in the same time. Vines in a rich valley soil will grow much larger than on a poor hillside. The size and shape of the trunk must be modified accordingly and adapted to the arailable room or number of vines to the acre. 
The shape must be such as to protect the vine as much as possible from various unfavorable conditions. A variety like the Carignane, susceptible to oidium, must be pruned so fruit and foliage are not unduly massed together. Free exposure to light and air is a great protection in this respect. The same is true for varieties like the Muscat, which have a tendency to "coulure" if the blossoms are too moist or shaded. In frosty locations, a high trunk will be a protection, as the air is always colder close to the ground.

The qualities required in the crop also influence our cloice of a pruning system. Even with wine grapes, perfect ripening and full flavor are desirable. These are obtained best by having the grapes at a uniform height from the ground and as near to it as possible. The same qualities are desirable in raisin grapes, with the addition of large size of the berries. With shipping grapes, the size and perfection of the berries and bunches are the most essential characteristics. The vine, therefore, should be so formed that each bunch hangs clear, free from injurious contact with canes or soil and equally exposed to light and air.

The maximum returns in crop depend on the early bearing of young vines, the regularity of bearing of mature vines and the longevity of the vineyard. These are insured by careful attention to all the details of pruning, but are possible only when the vines are given a suitable form.

The running expenses of a vineyard depend in a great measure on the style of pruning adopted. Vines of suitable form are cuitivated, pruned and the crop gathered easily and cheaply. This depends also both on the form of vine adopted and on care in details.

It is impossible, therefore, to state for any particular variety or any particular location the best style of pruning to be adopted. All that can be done is to give the general characteristics of the variety and to indicate how these may be modified by grafting, soil or climatic or other conditions. The most important characteristics of the variety in making a choice of a pruning system is whether it normally or usually requires short, half-long, or long pruning. With this idea, the principal grapes grown in California, together with all those grown at the experiment station on which data exist, have been divided into five groups in the following list:

I. Varieties which require long pruning under all conditions.Clairette Blanche, Corinth White and Black, Seedless Sultana, Sultanina White (Thompson's Seedless) and Rose.

2. Varieties which usually require long pruning.-Bastardo, Boal de Madeira, Chardonay, Chauché Gris and Noir, Colombar, Crabbe's Black Burgundy, Durif, Gamais, Kleinberger, Luglienga, Marsanne, Marzemino, Merlot, Meunier, Muscadelle de Bordelais, Nebbioln, Pagadebito, Peverella, Pinots, Rieslings, Robin Noir, Ruländer, Sauvignon Blanc, Semillon, Serine, Petite Sirah, Slancarnenca, Steinschiller, Tinta Cao, Tinta Madeira, Trousseau, Verdelho, Petit Verdot, Wälchriesling. 
3. Varieties which usually require short pruning.-Aleatico, Aligoté, Aspiran, Bakator, Bouschets, Blaue Elbe, Beba, Bonarda, Barbarossa, Catarattu, Charbono, Chasselas, Freisa, Frontignan, Furmint, Grand Noir, Grosseblate, Green Hungarian Malmsey, Mantuo, Monica, Mission, Moscatello Fino, Mourisco Branco, Mourisco Preto, Negro Amaro, Palomino, Pedro Zumbon, Perruno, Pizzutello di Roma, Black Prince, West's White Prolific, Quagliano, Rodites, Rozaki, Tinta Amarella, Vernaccia Bianca, Vernaccia Sarda.

4. Varieties which require short pruning under all conditions.Aramon, Burger Chardonay, Chauché Gris and Noir, Colombar, Crabbe's Black Burgundy, Durif, Black Morocco, Mourastel, Muscat of Alexander, Napoleon, Picpoule Blanc and Noir, Flame Tokay, Ugni Blanc, Verdal, Zinfandel.

5. Varieties of table grapes which usually require half-long or cordon pruning.-Almeria (Ohanez), Bellino, Bermestia Bianca and Violacea, Cipro Nero, Dattier de Beirut, Cornichon, Emperor, Black Ferrara, Malaga, Olivette de Cadenet, Pis-de-Chevre Blanc, Schiradzouli, Zabalkanski.

These lists must not be taken as indicating absolutely for all cases how these varieties are to be pruned. They simply indicate natural tendencies. Certain methods and conditions tend to make vines more fruitful. Where these occur, shorter pruning than is indicated may be advisable. On the other hand, other methods and conditions tend to make the vines vigorous at the expense of fruitfulness. Where these occur, longer pruning may be advisable.

The more usual factors which tend toward fruitfulness are: Grafting on resistant vines, especially on certain varieties such as those of Riparia and Berlandieri; old age of the vines; mechanical or other injuries to any part of the vine; large development of the trunk, as in the cordon systems. The more usual factors which tend toward vigor at the expense of fruitfulness are: Rich soil, especially large amounts of humus and nitrogen; youth of the vines; excessive irrigation or rainfall (within limits).

In deciding what system of pruning to adopt, all these factors, together with the nature of the vine and the uses to which the fruit is to be put, must be considered. It is best when the vineyard is started to err on the side of short pruning. While this may diminish slightly the first one or two crops, the vines will gain in vigor and the loss will be made up in subsequent crops. If the style of pruning adopted results in excessive vigor of the vines, it should be gradually changed in the direction of longer pruning with the object of utilizing this vigor in the production of crop. This change should be gradual, or the risk will be run of injuring the vitality of the vines by one or two excessively heavy crops.

Finally, each year the condition of the individual vine should determine the kind of pruning to be adopted. If the vine appears weak, from whatever cause, it should be pruned shorter or given less spurs or fruit canes than the year before. On the contrary, if 
it appears unnecessarily vigorous, more or longer spurs or fruit canes should be left. Every vine should be judged by itself. It is not possible to give more than general directions for the pruning of the whole vineyard. It cannot be well pruned unless the men who do the actual pruning are capable of using sufficient judgment to modify their methods properly for each individual vine.

264. Grapes under glass.-Only the European grape is grown under glass. Two-year-old vines are planted inside the houses a foot or two from the outer walls, cut back to two or three buds and tied to iron brackets attached to the rafters so the trunks will be not less than a foot from the glass. Only the strongest shoot is allowed to grow. Two systems of pruning are in vogue, the spur and the long cane or long rod system. The former is perhaps the more popular.

In the spur system, when the tip reaches the top of the house it is pinched. The cane then fills out and stores food in lateral buds till the winter sets in, when it is cut back two-thirds and covered on the ground until spring. Since mice eat the buds they should be kept out of the house. In the second spring the canes are ticd up and the leader shoot trained to the top of the house and there pinched. No fruit is allowed to develop on this shoot. On the older cane each second lateral on each side is removed so the remaining ones may be a foot or 15 inches apart. This favors even distribution of the crop from bottom to top.

As a partial crop may be gathered the second season from the older part of the vine the laterals should carry not more than one cluster and should bepinched $(217,218)$ at two nodes beyond the cluster. The sub-laterals should be pinched when they have developed one or two leaves. Just before winter the terminal shoot should be cut about half way, the side ones, all but one bud, close to the main stem (often within the first quarter inch) and the vines covered as before.

In the third season the pruning and pinching are repeated, the laterals being allowed to bear about a pound 
of grapes to the foot of main cane. After this year the only pruning is that of the laterals, the main trunk having reached the top of the house. Mature vines may bear two pounds of grapes to the foot, but there is risk of overdoing this and having the grapes turn sour before getting ripe. Frequent pinching the laterals and sublaterals is essential to success. This work should be done while the tips are so small that all the pinchings from a vine could be placed in a lady's watch glass and yet not fill it!

In the long cane system a new cane is annually developed from the base of the plant to replace an older one. Well-established vines may bear fruit from end to end of this cane its first year, but there is more danger of breakage than in the spur system. Laterals are pinched as in the spur system. In late autumn the older cane may be cut close to the ground if it is thought to be failing and the new one laid down as already described. 


\section{PRUNING ORNAMENTAL SHRUBS AND TREES}

265. Shade trees - those whose flowers are inconspicuous-rarely receive the attention they deserve. They are planted and left to themselves with the result that they develop Y-crotches, limbs too near the ground (Fig. 292 ) or too high up, or too irregular or other faults. The same principles used to form the heads of fruit trees will apply with more or less modification to the development of shade tree heads. The results of neglect apparent on every hand are especially noticeable when winter storms load the branches with heavy coatings of ice. One of these storms recently more or less seriously broke several score of shade trees, principally Norway maples, on the campus of the Pennsylvania State College. Several trees with Y-crotches were thus broken down; and many others were cracked so severely that another such storm will break them because of the activity of decay that has gained entrance through the cracks then formed or extended from previous splitting. Figure 94 shows a characteristic view on the campus just after the storm. The beauty of this tree has been ruined.

Beyond the removal of dead, dying and broken parts and the occasional shortening of too rampant or too lowhanging branches, shade trees properly started demand very little pruning. The time required to give the trees an annual inspection will be well spent, for it should lead to the adoption of measures that will prevent injuries which if incurred might be ineffective and expensive.

266. A good hedge depends for its success upon the kind of plant, the thickness of the planting. the choice of form, the regular periodic attention and, to a less extent. 
the environmental factors, such as soil, climate, etc. Unless the plant be adapted to the style of training, unless a sufficient number of plants be properly set, and unless the necessary periodic attention be given, the hedge will be a more or less gruesome eyesore.

There is no use trying to make erect-growing species of plants develop flat-topped hedges nor in trying to force plants that normally spread to adopt an erect style of growth. The rule in all hedge growing should be to approach as nearly as possible the natural form of the plant. To the author's way of thinking the hedge that demands the least pruning attention is the one that will give most pleasure.

The Japanese barberry is most nearly ideal for a hedge up to 6 or 8 feet high; arbor vitæ for those 10 to 20 feet; and Norway spruce and hemlock for taller ones. When these are allowed to grow naturally they, none of them. require more attention than the shortening of occasional, rampant branches; but when forced to assume unnatural forms they give no end of trouble, besides being unsightly.

Unless a hedge is kept uniform and even in height, thickness and development its beauty will be impaired. To attain this development the plants must be set very closely and be pruned intelligently several times a yearonce in winter and two or three times during the growing season. When a definite form is decided upon at the start, very little pruning must be done at any one time. The form best adapted to plants of more or less erect habit is that of an inverted $\mathrm{V}$ with perhaps a slight flattenıng of the apex and a bulging of the sides. The reason is that such a form permits all of the branches, even the lowest, an opportunity to secure light, whereas in the inverted $U$ and the erect-sided, flat-topped styles the lower branches become more shaded as the plants grow older. The result is that the lower limbs of such hedges die and thus seriously injure the appearance of the whole place. 
No hedge will continue to look well or tr, thrive on only one pruning a year, and that in the winter. Shoots will develop a heavy growth which will give the hedge a frightened, ragged appearance, and the longer this practice is followed the worse will be the results and the harder to make proper correction. In addition to the winter pruning the new growths should be sheared in

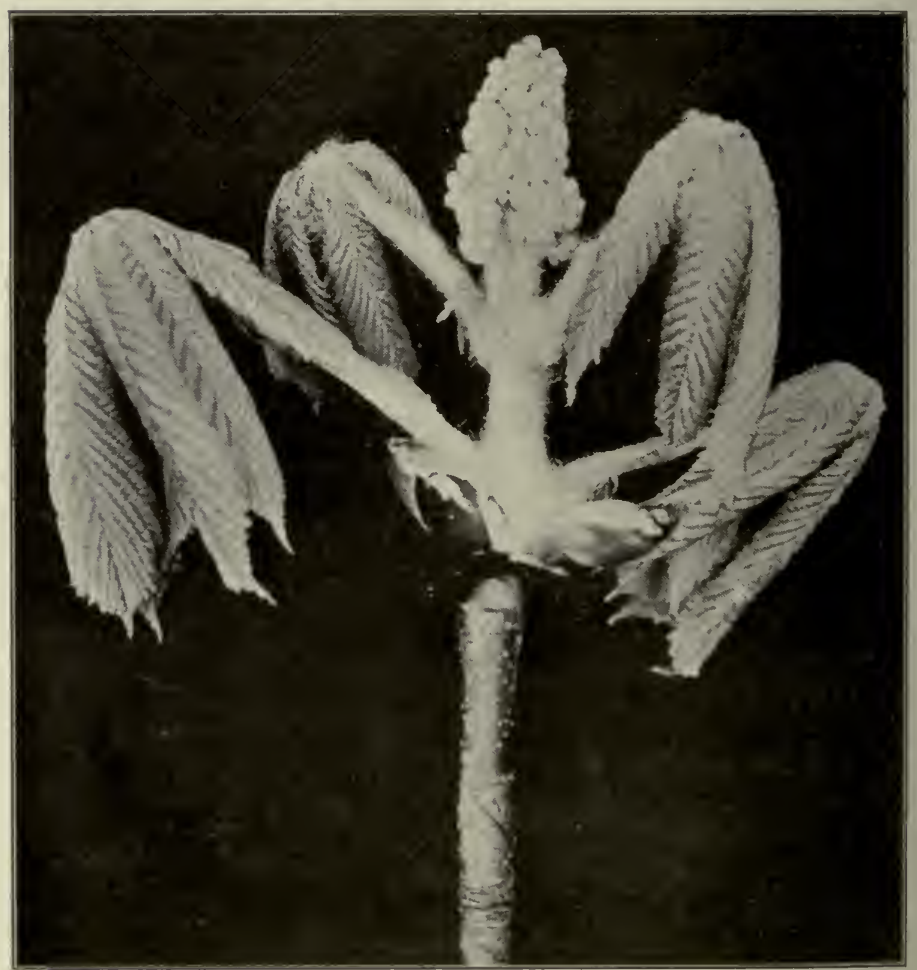

FIG. 291-HORSE CHESTNUT CO-TERMINAL BLOOM BUD EXPANDING

Notice, 1, that the direction of growth has been slightly changed near the base of the new growth where a scar indicates that a fruit was borne in a previous season; 2 , the annual growth rings at the bottom of the picture; 3 , the opposite leaves and the terminal cluster of bloom buds. 
summer two or three times whenever their development seems to demand such attention.

In America hedges are going out of fashion as stock fences, mainly because they make unnecessary demands upon the soil and because many of them (osage orange especially) are breeders of insects injurious to fruit trees. Where they are still planted for such purposes, the plants are sometimes pleached while still pliable so as to make them more difficult to get through. To get best results from this method the plants are set obliquely in the soil and the primary stems compelled to grow at this angle-usually about 45 degrees. The new shoots that develop may then be trained either at right angles to the stems which bear them or be allowed to grow erect-that is, at right angles to level ground. In either case the secondary branches cross the original stems and form a mesh, more especially near the bottom, through which even pigs cannot force their way. Perhaps the honey locust is the most popular plant for this kind

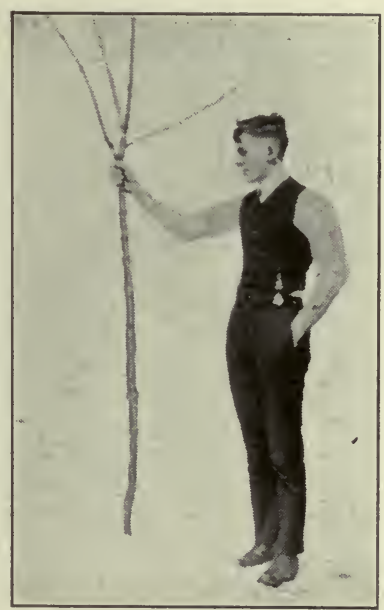

FIG. 292-SHADE TREE HEADED TOO LOW

Each of the three lowest limbs should be cut, because they will interfere with traffic later. of hedge.

267. Ornamental shrubs and trees.-Pruning ornamental shrubs and trees for other purposes than to promote the formation of flower beds may be done at any time, preferably in early spring or early summer, since wounds heal better during the growing season than if made in fall or winter. All that is necessary in pruning for form is to restrain the too rampant growth of some parts so as to make the bush symmetrical. Such pruning 
does not imply that the specimen shall be clipped or sheared into some artificial shape. It means merely keeping the plant within bounds, but allowing it perfect freedom within those limits. In all such pruning it must be remembered that each shrub has its own peculiar beauty -an individuality which should be retained. No pruning which destroys this beauty should be practiced, at least

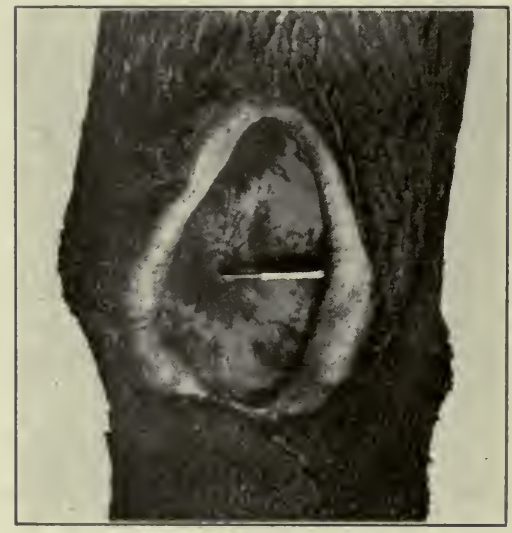

FIG. 293-HUGE WOUND WELL MADE

There is no excuse for such enormous wounds as this. Had the limb been cut off when the tree was small such a cut could have been avoided! The limb was so low it interfered with traffic. Hence its removal. The knife shown is $61 / 4$ inches long. Notice that the wound is healing most rapidly from the sides. where there is no definite reason for so doing -and such cases are rare.

When it is necessary to compel the plants to take fantastic forms, the young growths must be sheared several times during the $\mathrm{grow}$ ing season, as well as once during late winter or early spring, as in the case of hedges. When exceptionally good foliage is desired it is necessary to cut back the annual growths rather freely toward spring so as to encourage the formation of wood (83).

When flowers are sought, special note must be made of the blossom-bearing habit of the plant. A few fundamental rules will aid the pruner to make a success of this kind of work. When sturdy branches are pinched or clipped back during summer the remaining wood will ripen much more fully than might be the case if they were allowed to grow naturally. So the parts should stand the winter better than if unpruned. This applies more especially to semi-hardy and tender trees and 
shrubs. Summer pinching or clipping is of special use during wet seasons and when the plants are over-supplied with nitrogenous plant food, both of which tend to produce lush growths, which continue to develop late in the season, but do not ripen fully before winter sets in. Such wood being succulent is sure to be killed during winter. It also tends to keep the trees and shrubs low-headed and to develop fruit buds, as already noted.

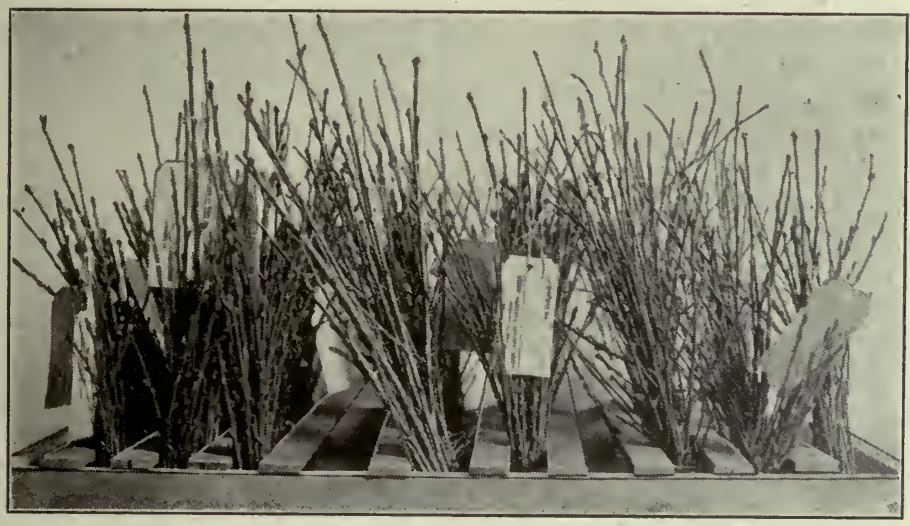

FIG. 294-HOW TO FORCE PEACH BUDS TO DETERMINE THEIR CONDITION

The twigs are placed in water in a warm room during late winter. Twigs from trees that had made a large growth one summer because of having been headed back severely in the spring of the previous year gave only 28.3 per cent of bloom when forced thus in December, while trees which made a smaller growth (not headed back) gave 44.3 per cent. This shows that the resting period ends earlier on trees making smaller growth.

268. When ornamentals form blossom buds.-Shrubs and trees which bloom in the spring develop their flowers from resting buds formed during the previous summer. As in the case of fruit trees the buds are protected by various devices, such as thickened, woolly and waxy bud scales. The fact that the flowers are in rudimentary form and are ready to open under favorable conditions may be proved by placing twigs of "pussy" willow, peach (Fig. 294), forsythia (Fig. 295) and other very, early 
bloomers in water in a warm room during winter. In a few days to a few weeks the buds will burst into bloom.

The first rule of pruning flowering shrubs and trees is based on this habit of bloom production. If the branches are cut back severely in autumn, winter or early spring, a large proportion of the blossom buds will thus be destroyed. In cases of severest cutting few or no flowers

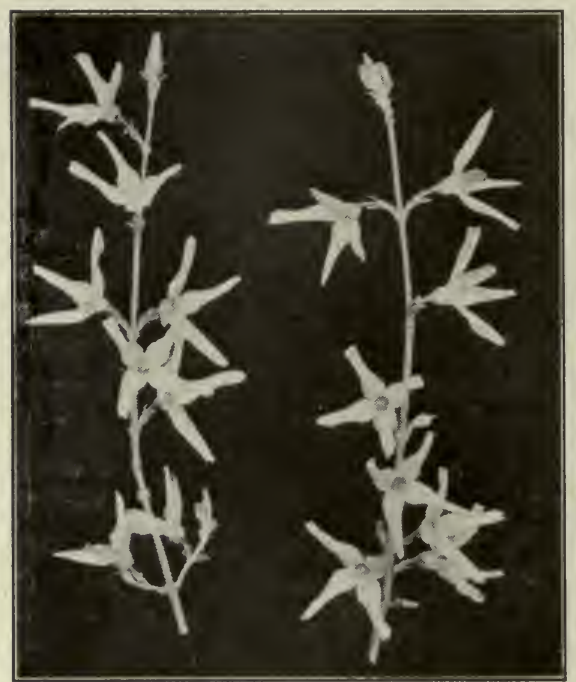

FIG. 295-GOLDEN BELL--FORSYTHIA

One of the earliest spring blooming shrubs. Note that the branch buds are only just starting. In some cases they are opposite the flowers, in others terminal, and in still others opposite each other near the terminal buds. Several flowers were cut from each of these twigs so the details would show in the picture. may be produced, partly because of their removal and partly because the bush or tree will make an effort to develop new wool (81, 83).

The converse of this practice is the cor rect method; namely, pruning inmediately after the blossoming "s e a son haspassed. Thus the new shoots produced will have thebalance of the season inwhich to develop new shoots largely from buds near the bases of the branches, and upon these shoots abunclance, of blossom buds will form and make a splendid display the following spring.

Shrubs and trees of the second group-althra, hydrangea, clematis, elder and certain roses-which bloom in summer and autumn, form their blossom buds on growths of the present season. Since some of these are 


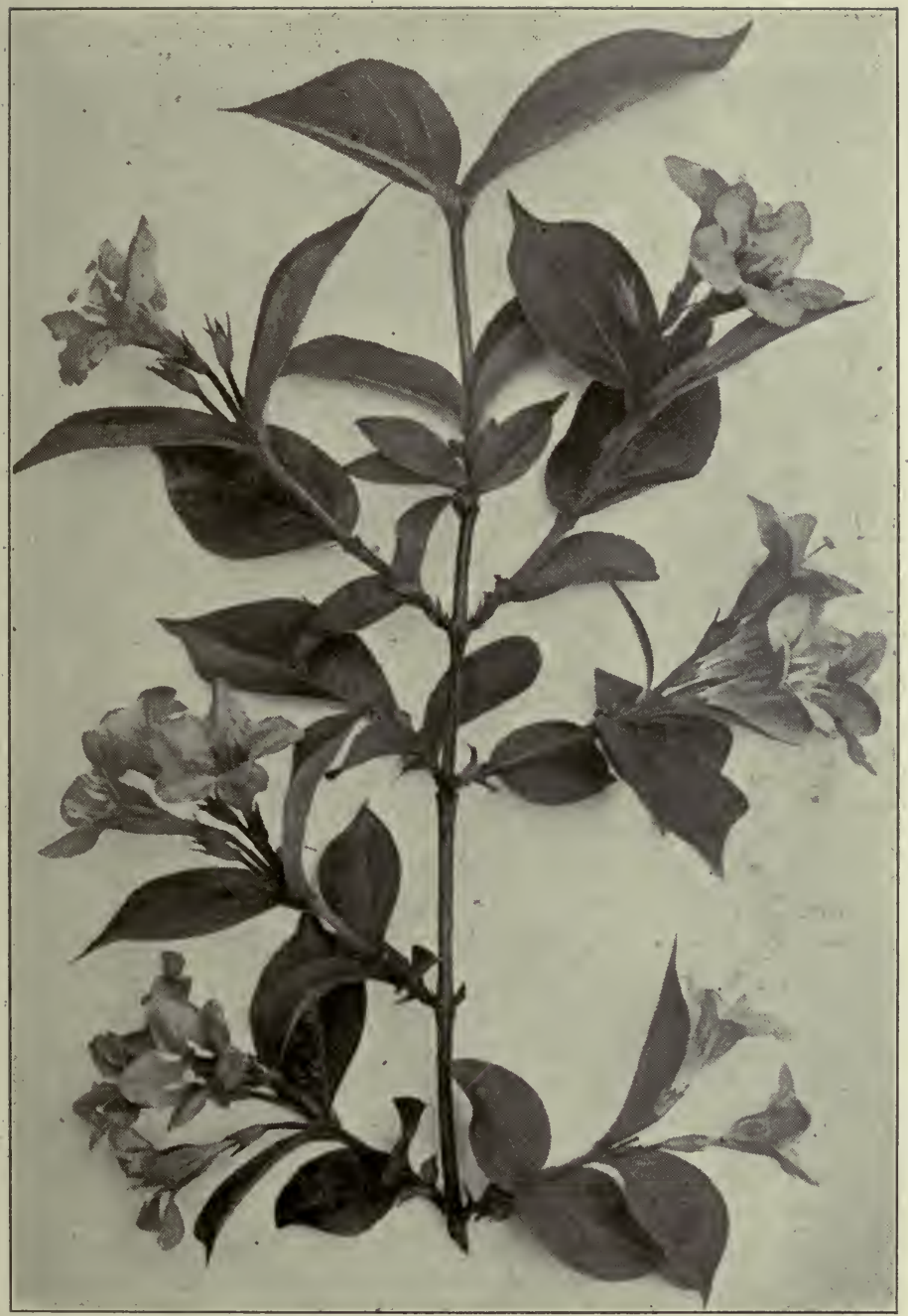

FIG. 296-CO-TERMINAL METHOD OF BLOOM BEARING-WEIGELIA

The over-wintering buds develop short shoots in spring and these bear the blossoms. Contrast with Judas tree (Fig. 297). 
tender to frost, some pruners leave them untouched until spring, others give a preliminary. pruning in the fall, protect the plants with mulches and give the final pruning in spring when the winterkilled stubs may be cut off. This encourages the development of

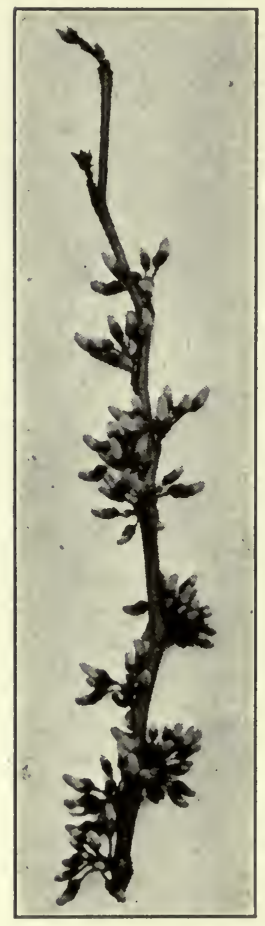

FIG. 297 - RED BUD

Blossom b u d a of the Judas tree or red bud ( $\mathrm{Cer}$ is) are borne almost sessile on the branches in spring before the leaf buds have expanded to any extent. What folly to prune any but desd wood out of such a tree after midsummopl strong and numerous shoots which bear abundance of flowers in due season.

To sum up the thought in the preceding paragraphs, the general rule for both cases may be expressed in three words: PRUNE AFTER FLOWERING. This means that, for flowers, the spring-blooming subjects should be pruned within a week of the fall of the blossoms; in the case of the summer bloomers, that the work may be done either in the autumn or at latest just before growth starts in the spring.

Plants properly pruned when transplanted, given good soil and sufficient food to make them grow well, and ample space in which to develop into good forms often need some pruning other than that already described; namely, they may need to have their interiors opened up to admit light and air. This may usually be done by cutting out old center stems. "Of course. any dead or dying wood should also be removed as soon as noticed. Except for such work, little more may be necessary than the occasional repression of a rampant growth.

269. Evergreens. - With respect to evergreens, the one rule to bear in mind is: Postpone pruning until the spring, since the danger from drying- 
1. 11t is greater than in the case of deciduous subjects. March is perhaps the best month in which such pruning should be done in the southern half of the northern hemisphere, and April in the northern half, because growth is usually strong during the next six to eight weeks and the healing of wounds will progress rapidly. 


\section{CHAPTER XVI}

\section{DWARF TREE PRUNING AND TRAINING}

270. Dwarf trees, those small growing varieties of a species, are considered desirable mainly because they require less space than do the normal-sized ones. There is no difficulty in maintaining dwarfness in the dwarf varieties-those that are dwarf by nature. They simply do not grow larger than their normal size and, therefore, do not require special treatment to keep then small. But there is another group - the plants that must be specially handled to make them dwarf in the first place and then specially handled to keep them small. The most extreme cases of this kind are produced by special cultural methods practiced by the Japanese, who compel trees which in nature attain considerable size to grow for many years in flower pots far smaller than would be required to hold the roots of a plant of the same species if transplanted from the open ground at the close of even its first growing season. The methods by which this is done, however, do not concern us here, as they are cultural rather than dependent upon pruning.

The plants that do concern us are those individuals which normally grow large but which, by means of graftage, top and root pruning are compelled to be small to suit our convenience or caprice. In order to understand how these should be handled to keep them small, it may be well to quote the following paragraphs from the author's book, "Plant Propagation."*

Dwarfing trees to be grown in the open requires that cions or buds be worked on slow-growing stocks and later headed-in. Plants may also be dwarfed by growing them in confined quarters, such as boxes, tubs and pots too small for their normal development. Nurserymen can go no further than supplying the specimens: after-

* Page 195. 
care depends upon the grower, who by neglect or ignorance may develop standards from those intended to be dwarfs.

When grafted or budded "dwarfs" are planted so deeply that roots are developed by the cion above the union with the stock, the tree will become "half dwarf" or even "standard." Such roots must be cut off from time to time as they develop. Dwarf cherries are grown on mahaleb stocks, but so is probably the majority of standard cherry trees. Annual removal of roots from the cion and heading-in will keep the trees dwarf in habit. So, too, of plums upon myrobalan, and apples upon Paradise and Doucin stocks.

Grafting or budding on a slow-growing variety or species, then, is only the first step toward the making of dwarf trees. The trees must have the expanse of their tops restricted by pruning and training. The expanse of their roots must also be restricted by pruning or by keeping them confined in limited space.

Root pruning (87) to restrict growth is little practiced in America. Our tillage methods largely replace it because they compel deep rooting. In the growing of dwarf trees and grafted grapevines it finds its most important application in the removal of roots which develop from the cion above the union with the stock.

Top pruning of dwarf trees is done to train the tree in some special way and to restrict growth. The latter is a winter practice for the most part-heading back (106). Various factors influence the amount of such work-age, vigor, variety, individuality of tree, etc. A terminal growth of 20 to 30 inches is common in the upper parts of dwarf pear and apple trees, especially in those under, say, ten years old. Some good pruners cut off 50 to 80 per cent of the annual growth all over the tree; and also remove inferior twigs entirely; others cut out a total of fully as much wood, but include a good deal of older wood, their idea being thus to keep the tree within bounds rather than to run the risk of getting too many small stubby twigs as might be the case were the former method followed too closely. In the former case the tree is more likely to grow too large than in the latter. In either case the lateral growth that develops on the in- 
terior of the tree during the following season must be thinned at the next pruning.

Pruning for form 'will depend upon the pruner's ideal (2). Dwarf trees, however, are generally grown as flattopped inverted cones or as pyramids. In America the former is the more popular; in Europe, the latter. To secure the pyramidal form a central stem is developed to the desired height. The branches are produced, as in the training of standard pyramids (154b), except that they are closer together. The author does not happen to know of vase-formed or open-centered dwarf trees, but he sees no reason why this form should not be as desirable for dwarf pears as for standards.

While the trees are young the pyramidal form is easy to get, especially with pears which normally grow in this way. As the trees grow older, however, particularly if the grower neglects to prune off the cion roots, they are prone to grow very tall, their form in long-neglected trees much resembling that of the Lombardy poplar, though, of course, much smaller than the full-grown trees of this species. This heightening may be easily prevented, first by cion root pruning and second, by extending the frame limbs and broadening the top, thus developing the inverted cone shape. In the most famous commercial dwarf pear orchard the author has visited the trees were only about 12 feet high, though they were then half a century old. If they ever got any taller it was after the death of Mr. T. G. Yeomans, the owner, who took special pride in keeping them in ideal form and stature. Since the Yeomans's orchard* was trained in the ideal form for American commercial dwarf pear growing, and since it is the one with which the author is most familiar the following description and comment are given:

* This orchard at Walworth, New York, was cut down in 1906 by the then owner of the Yeomans's farm, and Kieffer pears planted on the site, because he thought the trees had passed their proftable age limit and he believed the Kieffer would pay better. The original orchard began to yield paying crops before the war of the States, and continued to do so as long as Mr. Yeomans lived. 
First of all, decision in the choice of trees was against one-year stock because two-year-old dwarf pear trees give better results. One-year trees have only a single erect shoot 3 to perhaps 5 feet tall. If transplanted at this age and the top cut back severely as it should be to balance the loss of roots, the tree will be so weakened that fewer buds (perhaps only two or three) will develop branches, and these in the most undesirable position, the top of the stem, both on one side, or practically opposite each other in Y-crotch form. The other buds will remain latent and useless. By properly handling one-year trees in the nursery without digging and then allowing them to grow a second season a full complement of branches may be developed. This Mr. Yeomans was able to do to perfection because he was in the nursery business and grew his own trees from grafts he made himself. As good trees, however, may be bought from leading nurserymen.

In the nursery the one-year trees had the tops of their shoots cut at 21 to 24 inches so as to have a short, straight, smooth trunk, and of about 12 inches from the ground up to the first branch. The buds on this lower part of the stem were not permitted to develop shoots. Growths which started from them were rubbed off as early as possible. Above the disbudded part six or eight plump buds usually developed branches, because all the root surface was intact and there was plenty of sap to make good growth. In the fall the tree resulting from such treatment would be sturdy, have plenty of branches to choose from, be of good shape and in every respect desirable.

Y-crotches, which usually form in the two uppermost branches, were avoided by pinching the twig next to the top when it attained a length of 8 to 10 inches (127). Thus the uppermost branch became the leader and the second a side branch. 
When transplanted the trees were two years old from the bud, had been cut back in the nursery row at one ycar, had formed half a dozen or more good branches without any $\mathrm{Y}$-crotches and had excellent root systems. In pruning at planting time the uppermost twigs were cut back most severely, the lowest ones least because growth is greatest in the upper part of the trees (91). Only two buds were left on the leader and the next branch or two, while four or five were left on the lowest. This treatment brought the leader down to within 4 or 5 inches of its base (the two-year wood).

The cut on the leader was made so that the upper bud was immediately above the cut end of the previous year's stem. Because of the slight crooks formed by a side bud when so forced into growth (Fig. 66) the new branch from this upper bud was developed vertically above the original trunk of which it thus became an extension, but with two slight crooks. These crooks disappeared in a few years and the trunk looked perfectly straight. In a similar way branches too horizontal were slightly raised by pruning back to upper buds, or lowered by pruning to buds beneath. Others were moved to the side by pruning to side buds (120d).

When finished, the branches formed pyramids with bases a foot to 15 inches across and 18 to 20 high for the larger specimens. By cutting in this way not only was the pyramidal form secured, but the lower branches were favored and the upper ones checked in developmnt. Unless this is done at the time of setting out, the trees can never be made to take the desired form.

Pruning after the first year resembles that of the first. The leader is cut back severely so its upper bud will be above and in continuation of the main stem, and the lower and side shoots cut back less and less as the base of the pyramid is approached. As the trees approached maturity, care was taken to admit light and air by judicious thinning and removal of the interior shoots. Except the 
first pruning at planting time, the annual cutting was done during the dormant season at any time before growth started in the spring.

As the trees became aged-15 to 25 years-the method of pruning gradually flattened and broadened the tops, and the nature of growth gradually lessened wood production below, so that, when the author saw them, each tree was like an equilateral triangle set on its apex with its trunk as a pedestal. The tops were 10 or 12 feet across, and the height, including the trunk, about 12 feet. The result was that the top of the orchard looked as if cut with a huge lawn mower, it was so even in height and the trees so wide-spreading as almost to present a continuous carpet of green, except for narrow blank spaces between the trees and in the centers between the squares formed by each four trees. In the handling of dwarf apples, cherries and other fruits the same general rules apply.

Because of considerable agitation on the part of certain fruit growers and nurserymen, the fruit growers' associations of New York requested the experiment station at Geneva to conduct experiments in the growing of such trees in orchards of commercial size. An experiment was therefore carried out during ten years in three different parts of the state and the findings reported in Bulletin 406 of the station. In the main the report is unfavorable to dwarf apple trees as a business proposition.

271. Pruning dwarf apples.-We may as well confess, writes U. P. Hedrick concerning these experiments, that the pruning of these trees has been most unsatisfactory. A bad start was made, as the trees, for the most part, were cut to whips at transplanting time. No doubt, in the light of later experience, it would have been better to grow them in nursery rows a year longer and then make the start toward forming the heads (270). The trouble in cutting a whip at transplanting time is that branches fail to break forth as abundantly as they do in the nursery row unchecked by transplanting.

Summer pruning, supplementing winter pruning, is part of the recognized yearly treatment of dwarf trees. The more it is desired 
to restrict the growth, the greater the need of summer pruning and the greater the amount necessary. There is, however, much divergence of opinion as to methods in summer pruning. Scarcely any two authorities on growing dwarf trees agree as to the amount of wood to be taken out or the proper time to do the work.

Some growers use the knife and shears, while others say that pinching back with finger and thumb suffices. All agree that the practice must be largely regulated by season, soil, health of tree. age of tree and the variety. The difficulties in the way of laying down rules that would be fair in this comparative test of 26 varieties of apples on three stocks, three distinct soils and in three somewhat different climates, are patent to anyone who has tried to prune in the summer.

The winter pruning of the trees, though more difficult than in training standard trees, gave comparatively little trouble. It consisted of cutting out crossed branches, surplus branches and, of course, such few as were injured or diseased. It was necessary to head back the wood on Paradise and Doucin trees more scverely, depending upon the variety rather than on the standards, otherwisc the pruning was much the same on all.

For the first two seasons but little summer pruning was attempterl, the trees being small and none too vigorous. Then began a series of experiments, no one of which proved satisfactory. Suffice to say, in the light of ten seasons' work with dwarf apples, the training of the plants is the most difficult and the least satisfactory operation in growing these trees. Indeed, it is hardly too much to say that if dwarf apples must be headed back or pinched in during the growing season, it is impossible to grow them in the trying climate of New York.

In no one of the attempts at summer pruning have we been able wholly to avoid weak, spindling second growths which would not mature and succumb to the cold of the next winter. IVhen it was thought that reasonable success in time and manner of summer pruning had been attained one season, sooner or later identical treatment proved a failure because of some decided difference in weather when the work was repeated. We have been forced to conclude that the great variations in temperature and moisture in the summer and the cold winters in New York almost or quite debar the summer pruning practiced in the Old World. 


\section{CHAPTER XVII}

\section{ODD METHODS OF PRUNING AND TRAINING}

The principles and some of the practices discussed in previous chapters find bizarre application in special modes of training, which in America have practically no commercial use. Hence almost the only attention they attract is that of amateurs, in which class of gardeners is included those wealthy people who take pleasure growing extra choice specimens of fruit, especially if these are produced under glass, upon walls, or by specimen plants trained in some unusual form.

While these forms are immensely popular in Europe where land is costly and hand labor cheap, they are not suited to other continents where land is cheap and labor high priced; as in America. This is the sufficient answer for their comparative rarity in the United States and Canada. Let it be said, however, that we have in the longer-settled parts of our country examples of these methods which compare favorably with those of the Old World. Probably a majority of these have been developed under the skillful fingers of some French, English or Scotch gardener who has served his apprenticeship in the gardens of an estate in the Old World. The three illustrations (Figs. 298, 299, 300) are excellent examples of special tree training in gardens in Rochester, N. Y. In the vicinity of Boston, New York and Philadelphia could be found many others.

In order to make a success of any of these special forms of growing trees and shrubs, it is essential to make a proper start. European nurserymen do this. They grow the trees two, three or more years under the constant watchfulness of men skilled each in his own line. All that a customer need to do, then, is to order the style, 


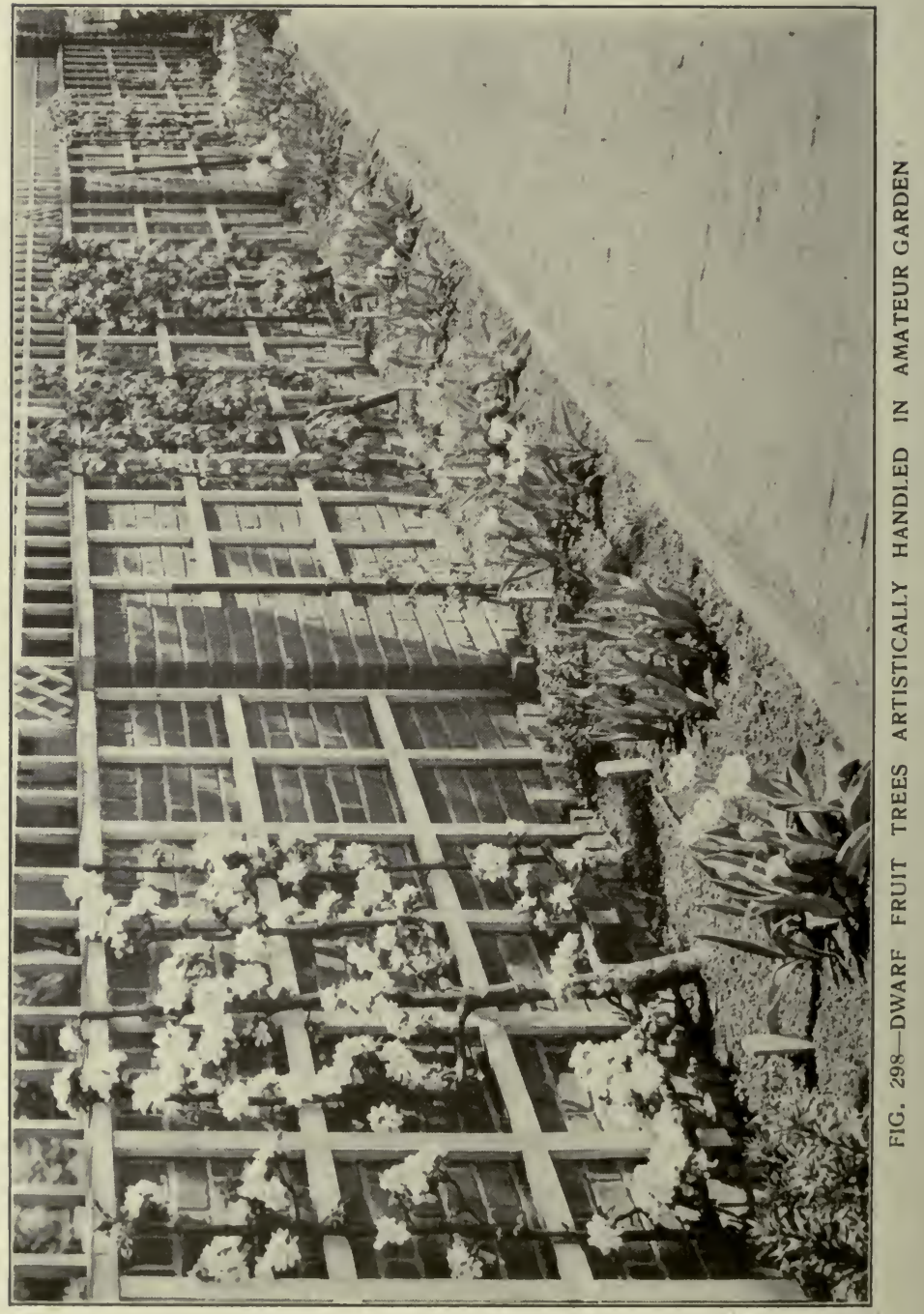


age and variety of plant he wants. In America the demand for such plants is so nearly nil that the nurserymen, with rare exceptions, do not carry any such trees in stock. Many of them, however, will develop such plants to order. But why should the amateur not develop them himself? He can probably command at least as good skill and in many cases far better at home because of personal interest in the plants. How shall he start?

It will be well whenever possible to do the propagation at home, so as to have the plants under ideal condition from the start. In perhaps no case should trees older than one year be chosen for any of these special forms of training. If the trees have been propagated at home, they need not suffer in the least from digging because they may be left during the second year where they grew the first. Note the reasons for this under the heading Dwarf Trees (270). Where it is not convenient to follow this suggestion, the next best thing is to buy yearling trees. Choice should be made among the medium-sized, well-grown specimens, the large and the small-sized grades being avoided for obvious reasons. The main reason for choosing yearling trees is that the buds on the trunk will be far sturdier than on trunks two years old or older and the branches may be developed exactly where wanted.

The height to have the trunk and the number of branches to develop will depend upon the style of training to be followed. In all such training it must be remembered that the tree is being forced to develop in a more or less unnatural way and, therefore, must receive special attention. To use an illustration, these methods are like steaching school children to write: a beautiful script specimen is set before them and they attempt to imitate the pretty writing, often with ludicrous though unintentional caricatures! If it is difficult to teach intelligent children so simple a feat as writing, how much more to train a tree in the way it should go! Success 
as in the above case is measured by the approach to the original design. While the style of training must be optional with the individual gardener the fundamental principles of pruning must be followed.

As American literature on these speciai modes of training is very meager, and as European writings are both voluminous and excellent, the following passages have been culled, mainly from French and English works, to

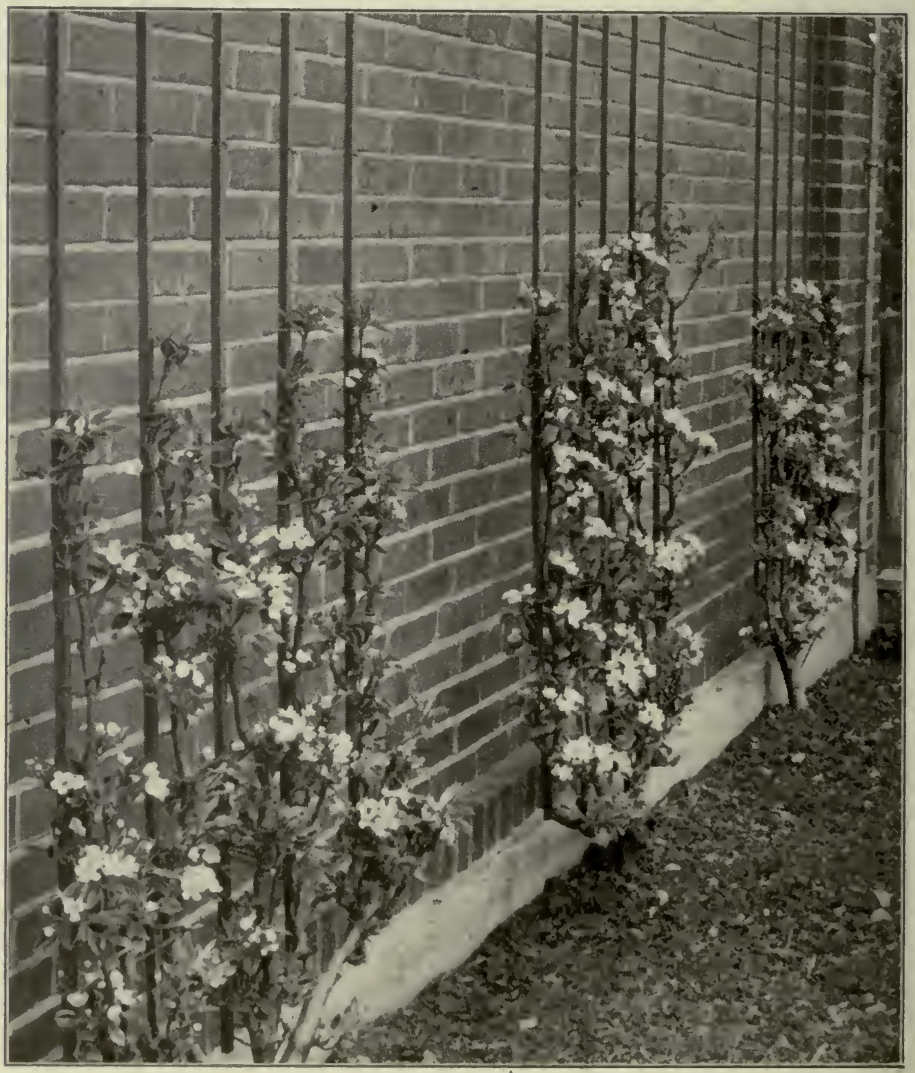

FIG. 299-DWARF PEAR TREES TRAINED IN SIMPLE WAY 
serve as suggestions of forms and methods that may be followed. In these excerpts the following words need definition: Cordon, a plant consisting of one shoot, or two trained opposite to each other, and bearing fruit spurs. A palmette is a single vertical stem with several side branches. Standard, in European usage, is a solitary trunk not attached to a support. It is not a synonym of dwarf, as in America. Espalier, a trellis or any plant grown upon a trellis, not a form of training. The modes of training described below enable the gardener to adapt trees to restricted quarters, to have each main branch supplied with bearing wood from end to end, to equalize fruit-bearing each year and each successive year, and to enhance both size and quality of fruit.

272. General principles of training.-Alphonse Du Breuil* gives the following general principles for training fruit trees on walls and trellises. The numbers indicate individual corollaries under the main principles printed in italics.

A. The permanency of form of trained trees is dependent upon the equal diffusion of sap being maintained throughout the whole extent of the branches.

1. Prune strong branches short; but allow weaker ones to grow long. 2. Depress strong parts, and elevate weak ones. 3. Suppress useless buds on strong parts as early as possible: Practice suppression as late as possible on leaf parts. 4. Suppress herl,aceous extremities on strong parts very early, but practice suppression as late as possible on weak parts, taking off only the most vigorous shoets and those that must be removed because of the position they occupy. 5. Nail up strong parts very early and very close to the wall or the trellis, but delay doing so to weak parts. 6. Suppress several leaves on strong sides [of the plant]. 7. Allow as large a quantity of fruit as possible to remain on the strong side and suppress all on the weak side.

8. Soften green parts on the weak side with sulphate of iron solution-24 grains in a pint of water, applied after sunset. [This is believed to stimulate leaf activity "in drawing sap from the roots." M. G. K.] 9. Bring weak side forward from the wall; keep strong side close to it. 10. Place a covering on a strong part to deprive it of light.

B. Sap develops branches much more vigorously on a branch cut short than on one left long (Chapter X, IO6). C. Sap has always a tendency to flow toward the extremities of branches and to make terminal buds develop more vigorously than lateral ones (9I).

- The Scientific and Profitable Culture of Fruit Trees, English edition. 


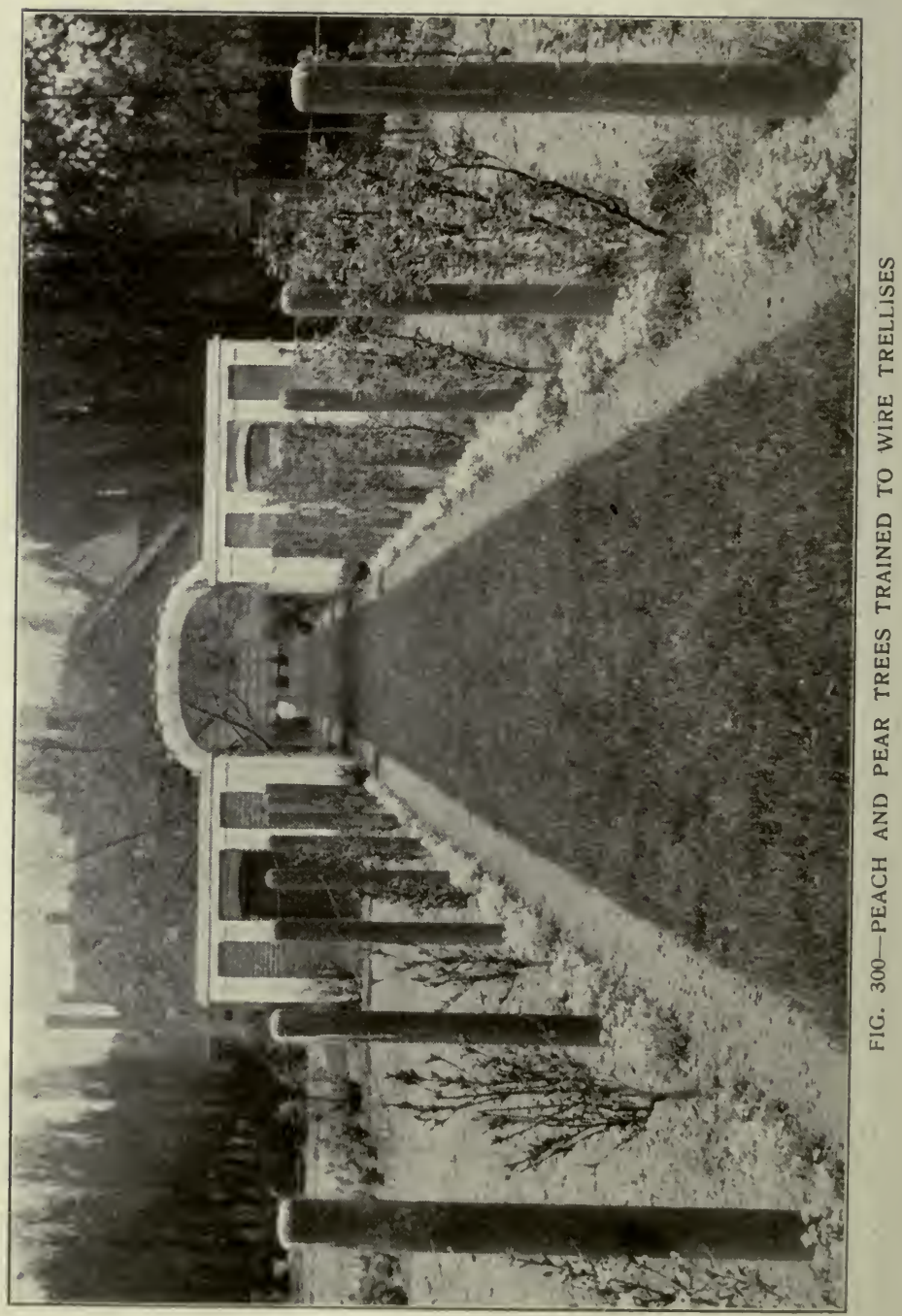


D. The more sap circulation is retarded the less wood and the more fruit buds will develop (98).

1. Apply to branches which grow from successive extensions of wood and also to those which spring from them, operations calculated to diminish vigor. 2. Apply to larger branches several Girardin's side grafts-cions of fruit spurs or fruit buds set into twigsto absorb part of the superabundant sap. 3. Arch all branches so part of their extent will be toward the sun. 4. In February make an annular incision 1-5 inch wide with a hand saw near the stem hase, and deep enough to penetrate the exterior wood layer (98). 5. In spring uncover the tree collar so as to expose the principal roots for several feet and allow them to remain thus during summer. 6. In spring cut away parts of roots and replace the earth. [These two practices are antagonistic--M. G. K.] \%. Transplant trees in late autumn, but with great care to preserve all roots.

E. Ev'ery method which conduces to diminish vigor of wood and to make sap flow to the fruit tends to augment size of fruit.

1. Graft upon stocks of a less vigorous species than the cions. 2. Apply suitable winter pruning; that is, do not leave on the trees more branches or parts of branches than is requisite for symmetrical development and formation for fruit-bearing branches. 3. Make fruit spurs grow close on branches by pruning them as short as possible. 4. Cut branches very close when flower buds are formed. 5. Mutilate summer shoots by repeatedly pinching off those not required to develop size of tree. 6 . When fruits are a fifth developed suppress a further number of them. 7. Make an annular incision about 1-5 inch wide upon the fruit-hearing branches when these expand their blossoms. 8. Insert Girardin's side grafts in some fruit branches of vigorous trees. 9. Place supports under fruits during growth to prevent stretching or twisting of their stalks. If unsupported, the fruit may grow unequally and the stretching or twisting stalk may injure the sap vessels. When fruits are supported they grow larger. 10. Keep fruits in their normal position during the entire period of their development; that is, with the fruit stem lowermost. Sap acts with more force when it flows upward; a vertical stalk therefore causes it to ascend more easily and the fruit will become larger. 11. Place fruit under the leaves during their growth to increase their size. 12. Apply to young fruits a solution of sulphate of iron (272A 8 ) only when the fruit is cool. Repeat three times: When fruits are one-fourth grown; when a little larger; and again when three parts grown. 13. To increase size inarch a small shoot on the fruit spur, to which fruit is attached when a third grown.

F. The yearly extensions of wood should be shortened more or less, as the branches approach a vertical line, or the contrary.

273. Construction of walls and fences.-J. Cheal* gives some excellent advice upon the construction of walls and fences upon which

* Practical Fruit Culture, London. 
to train fruit trees. Paragraphs (273 to 278) are quoted from lis work. The arrangement and position of walls will depend on the size and the nature of the surroundings, etc., but they should always be arranged, if possible, in a square, with the principal wall facing south, or as nearly so as practicable. Where it is possible, place the walls so the outside as well as the inside borders may be used for fruit, thus making use of the whole wall space. Bear in mind that upon the north side many useful fruits may be grown.

The height of the walls should be 8 to 15 feet, according to circumstances. In most cases the south wall may be lower, to admit more sunshine into the garden; and in the case of large gardens, one or more cross walls may also be introduced. They should be built without piers. Architects have generally a great fancy for piers, and in many instances insist upon having them; but walls can be built without them, and they are always a great difficulty and nuisance to the gardener. They frequently interfere with the arrangement of the trees when planting. In training they are a great trouble, and often cause much damage to the trees. Provide a good permanent coping of tiles or stone, projecting at least 6 inches from the face of the wall. These should in all cases be provided independently of any further coping for the protection of the trees at the time of flowering.

274. Removable glass copings are very useful for peaches, nectarines and apricots. These are required for only a few weeks in spring, at the time of blossoming and setting the fruit, and should be removed when no longer required. Fixed glass copings are very objectionable, as they keep off all rain, encourage red spider and other vermin, and necessitate constant syringing.

In all cases it is a great saving of labor to wire the walls or fences. The vines should be placed in lines not exceeding 9 inches apart and 2 inches from the wall. Galvanized hold-fasts, tighteners and all needful appliances are easily obtainable.

275. Tying to the wire is much more quickly done than nailing to the wall, and does not afford the same shelter to insect pests, while it preserves the wall from injury due to constant nailing, and allows the wood to ripen more thoroughly and evenly. The branches are also enabled to form fruit spurs and buds all around. Frequently the inside or back blossoms escape injury from frost, which damages the outer ones, and a crop is thereby saved.

In the case of all fruits, however, and especially that of peaches and nectarines, it is needful to be very careful in tying in order to prevent the branch coming immediately in contact with the galvanized wire. Many instances have occurred of disease and decay resulting from this. There is, however, no danger if the precaution is always taken in tying to cross the tie between the branch and the wire, so the branch may be held firmly in position without coming in actual contact with the wire. And the danger may be still further lessened by painting the wires and hold-fasts after fixing. 
276. Espalier fences generally may be placed to advantage in a kitchen garden, as they occupy but little space, and produce an abundance of fine fruit. They may be used as a border near the paths, or at the back of the flower border, which is usually arranged on either side of the central walk, but there are also other positions outside the kitchen garden where they can be placed to advantage. If the fruit is well grown such fences present an artistic appearance (Fig. 300), and are admissible even in the ornamental garden, or may be used as a division between the ornamental and the kitchen garden.

The fences themselves are usually formed of galvanized iron posts, with wires stretched between. They require at each end a strong post of angle iron with anchor feet and stays, to bear the strain of tightening the wire. The intermediate posts need be only flat iron with anchor feet. For the ordinary horizontal form of training, 5 to 6 feet in height will be sufficient, but if made high enough-say 7 to 9 feet-these fences are very good for training cordons upon. Gooseberries may also be trained upon low espalier fences of 3 to 4 feet in height, and when trained as double cordons, or as palmettes with 3 to 5 branches, they produce the finest possible fruit; and this mode is strongly recommended for growing the choice dessert varieties.

277. Wire arches may sometimes be suitably introduced into the kitchen garden, spanning some of the paths. They occupy but little ground space, and afford excellent means for the training of cordons. They give a pleasant shade to the path, trees are well supporteil, and the fruit spread out to the full effect of the sun. In some respects they are better for training the cordon trees than ordinary espaliers. The turn at the top gives the gentle check to the upright flow of sap so desirable for securing fine fruit at the base of the tree.

278. Wooden fences sometimes are so placed as to be available for fruit. A wooden fence is in no case so good as a wall, as in the best of them there is always some draft, so the same uniform temperature is not maintained as in the case of walls which. from their greater substance, retain warmth during the night. Nevertheless, wooden fences are very useful for fruit. They should always be wired before planting the trees, as it is difficult to nail to the wooden fences, while wire also possesses other advantages.

Many wooden fences surrounding the gardens of suburban villas might be turned to very useful account, and would afford the overwrought brain-worker healthful and interesting employment in cultivating fruit trees, as well as enable him to supply his own tab'e with the freshest of fruit. There are also numberless wooden fences, as well as walls, in many of our farms and homesteads, which could be turned to profitable account hy covering them with fruit, trained as above described.

279. The pyramid* is an old and good form, suitable especially for pear trees. Its advantages are, that it can be cultivated in

\footnotetext{
*D. Bois, "Le Petit Jardin," Paris, 264 (279 to 284).
} 
borders, where it takes up relatively little room; that it allows free circulation of air and light; that it casts little shade; and that it bears abundantly. It consists of a principal or vertical stem, covered with lateral branches from a point an inch or so above ground to the top of the tree. The branches, which grow somewhat obliquely, are separated from each other by a distance of about 10 inches, diminishing gradually in length from bottom to top, thus forming a cone, the largest diameter of which is about one-third of the total height.

280. The column or spindle.-This form, adapted to pears and apple trees, has the advantage of taking up less room than the pyramid and of bearing more quickly. On the other hand, it is not so long-lived, and is suitable for less vigorous varieties only. The column differs from the pyramid only in its shorter lateral branches.

281. The vase.-Around a central stem, and at a distance of about 5 inches above the ground, arise branches which grow first horizontally and then vertically, in such a way as to give to the entire tree the form of a vase. The branches must be separated from each other by a distance of about 10 inches, and they are maintained in this position by tying them to hoops fastened to stakes inscrted in the ground. This form is justly much esteemed. It allows a free circulation of light and air through all its parts.

282. The horizontal cordon is suitable especially for apple trees grafted on Paradise stock, and to the less vigorous varieties of pear trees grafted on quince stock. This form is especially to be recommended for the borders of walks. It consists of a stem which first grows vertically, then bent at a certain height, and is maintained in this horizontal position by attaching it to wire. The trees are planted at a distance of 6 to 10 feet apart and their stems, when meeting, form a long, unbroken garland or wreath, which makes a very pretty effect.

283. Espalier training, to be especially recommended, is suitable for all kinds of fruit trees. It allows the cultivation of varieties the fruits of which would not ripen at all, or would ripen incompletely in a more exposed situation. When trained against walls. they receive an amount of heat sufficient to produce fruit of a superior quality. These include peaches, grapes, certain kinds of apricots, apples, pears, etc. The simplest form of espalier is the vertical cordon, which allows the trees to be planted very near together, which soon brings in a moderate return, and in a few years covers the wall. Like the column, this form is suitable for only the less vigorous varieties. It must be trained against a moderately high wall, for its growth is considerably stimulated by the suppression of its lateral branches, so the principal stem has a tendency to grow rapidly. Whenever it is necessary to cut them back very much, it produces an excessive development of wood, to the detriment of its productiveness. A form like a $U$ is frequently employed. It-is certainly one of the best.

284. The candelabrum is formed by several lateral branches, from 
three to six, distributed regularly along the principal stem. The simple palmette or palm leaf has a larger number of lateral branches. The Palmette Verrier differs from the preceding only in the fact that after a certain distance its branches grow vertically. Palmettes are formed with $6,7,8,10,12$ branches, and even with more.

285. The horizontal cordon in detail.*-When grown in a simple horizontal cordon, the pear tree consists of a stem bent at a distance of 15 inches above ground, then trained horizontally and covered with fruit-bearing branches. The cordons are trained as much as possible toward the strongest light. If the plantation is established on a slope, it is necessary to train the cordons toward the summit of the slope. Only pears grafted on quince stock, and apple trees grafted on Paradise or Doucin stock, can be thus grown.

Pear trees and apple trees grafted on their own stock are too vigorous, as they require (for otherwise they would remain sterile) more room than the horizontal cordon allows. One-year-old apple cions grafted on Paradise stock must be planted at a distance of 10 feet from each other. One-year-old apple cions grafted on Doucin stock, and pears on quince stock, must be planted at a distance of 12 feet from each other.

The first year they are cut at a distance of about $2 \mathrm{r} / 2$ inches above ground, and near a bud located on the side toward which the stem is to be inclined. In the autumn or in the following spring, these cions are gradually bent. But if the part beyond the bend must be strictly horizontal, it is necessary that the extremity of the cordon be slightly raised, in order to facilitate the flow of sap and consequently the elongation of the cordon.

From this time, the yearly growth of the cordon must be cut in such a way as to preserve two-thirds or three-fourths of its length. It is soon covered with branches, some of which are fertile (that is, bearing fruit-producing buds), while the others, or sterile ones, must be cut away. This kind of treatment prevents them from obtaining too large a growth, thus still more destroying their fertility.

286. Cherry growing in orchard houses. $†-T h e$ method of growing cherries in Rivers's orchard houses is given below in detail. Most of the trees are grafted on cherry stock, except the Duke cherries and Early Rivers and Governor Wood, which are grafted on mahaleb stock. They are never lifted nor replanted before potting.

Early in autumn one and two-year-old trees are taken up, their roots shortened so they can be put into the pots without breaking, and planted in 8 or 12 -inch pots. This potting must be done carefully and the trees must be set so deep the big roots near the surface will be covered with an inch of soil. Cover the bottom of the pots with a good, thick layer of drainage. The soil used in potting is a light, sandy loam, enriched with one-third of welldecayed fertilizer. It is important to firm the soil well around

* G. Ad. Bellair, “Les Arbres Fruitiers," Paris, 1891, Page 164 (285).

i: A. K. Anderson in "American Garden," XI1I, 594 (286). 


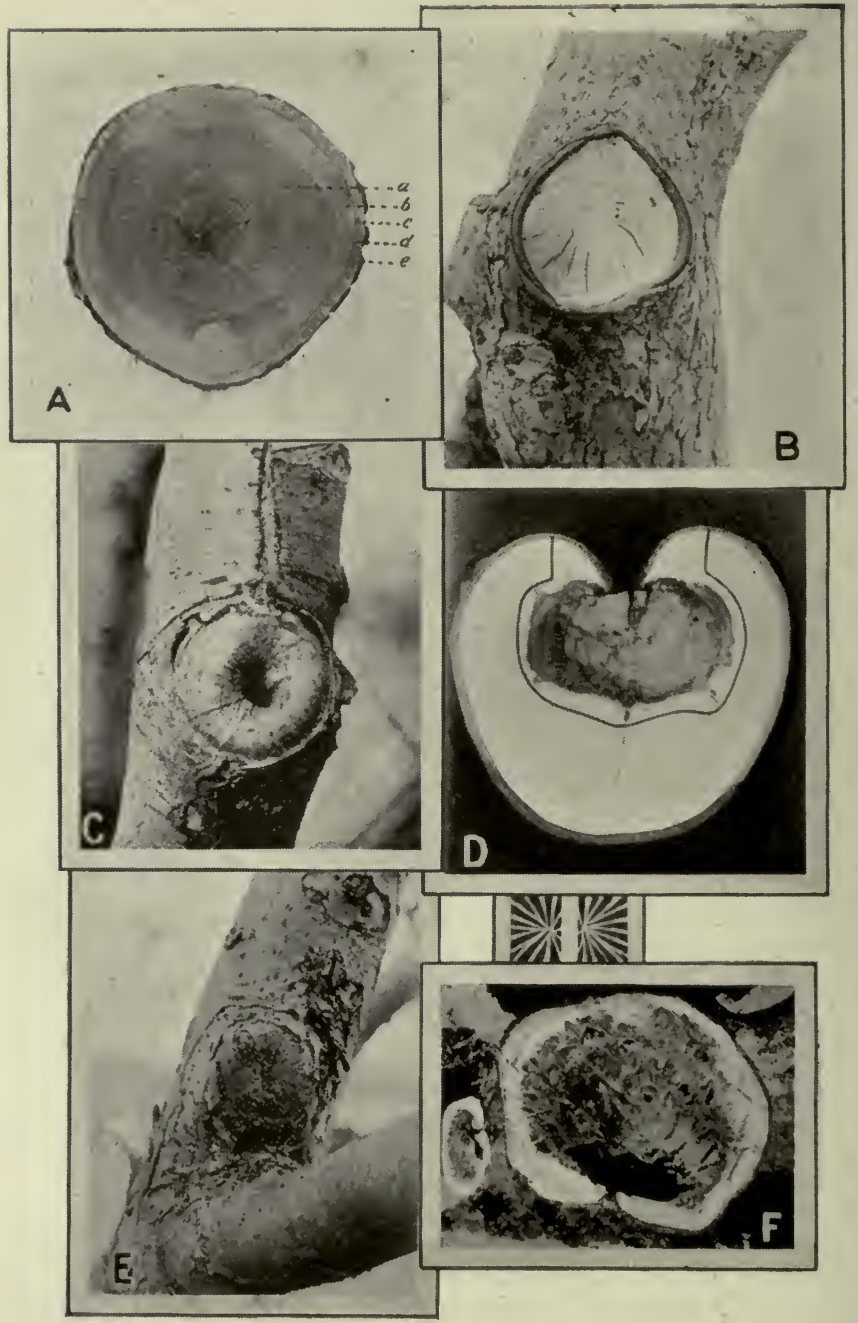

FIG. 301-TREATED INJURIES NORMALLY HEAL; UNTREATED ONES DECAY

A, Cross section of trunk, showing parts; $a$, heart-wood; $b$, sapwood; $c$, cam. bium; $d$, bark; $e$, corky outer bark. B, Scar beginning to heal rapidly at the sides. C, Scar three-fourths healed. D, Cross section of "blaze" on quaking aspen. Note decay at ax cut. Line indicates proper shape of cavity to excavate. E, Scar from cut limb fully healed. F, Opening to decayed area in log. Only a shell of sound wood. 
and among the roots. Fill it in by degrees and beat it down firmly all through the pot, taking care not to injure the roots. After potting, the trees are set.in a sheltered place outdoors, the pots being covered with leaves. If the soil is moist enough when the trees are potted, they will not need watering.

When spring comes the tree must be thinned out and the pots plunged one-third their depth in the earth. The trees remain here all summer, are watered carefully every morning when the weather is bright and dry and syringed with pure water if the green fly is troublesome. In July when the trees are well rooted, a topdressing of stable manure and kiln-dust in equal parts is given them. A few days before it is used it is spread out in thin layers outdoors and soaked several times with liquid manure. It is applied to the soil in the pots, in layers 2 inches thick near the rims, but thinner near the stems of the trees. This top-dressing greatly improves and strengthens the trees for the coming year. After growing in pots one summer, trees are fit to be sold the following autumn or spring. Old cherry trees that have been cultivated in pots for years are kept during winter in one of the orchard houses. When

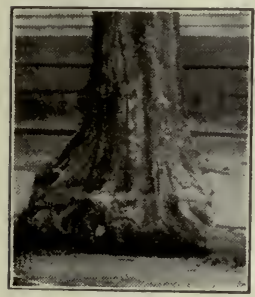

FIG. 302-MUTILATED TO LAY A spring comes and their buds start, the pots are plunged up to the rim in the ground in the cherry house.

The pyramidal form is best and most used for potted cherry trees. Pruning is not often necessary the first year after potting, for the strength of the tree goes to form short fruit branches; but after the trees are well rooted, strong shoots are sent out in summer. Summer pruning consists mainly in pinching back these strong shoots to six or seven leaves each. If after this first stopping they grow out again, they are again pinched back. On the leading branches, side shoots that are not needed to fill empty spaces or make new leaders are stopped at the third leaf. The sour cherries, which form young buds better on the side shoots, might be pruned less.

Much winter pruning is not needed for trees that have been well stopped in summer. Winter pruning must be done as soon as leat and bloom buds can be distinguished. It is done upon the same principle as outdoor pruning, but as the room in orchard houses is limited, all growth must soon be pruned into fruit branches.

After the cherries are all gathered, the trees are plunged outside in a sunny, sheltered place and left there until repotting time in October or November. Trees that have been potted but one year seldom need larger pots at this time, so 2 or 3 inches of the top soil in their pots is taken out and replaced with fresh. Larger pots are given in after years when these young trees become root-bound. Cherry trees ought to be repotted every other year. 


\section{CHAPTER XVIII}

\section{PRACTICAL TREE SURGERY*}

287. Object of tree surgery.-It is well known that trees are subject to all sorts of injuries, from sources too numerous to mention. In a great majority of cases these injuries are allowed to remain untreated-often for years. Rot-producing fungi commonly gain entrance at these places, and eventually the original inconspicuous or unobserved injury develops into a comparatively large area of decay. The real aim of tree surgery is to repair the damage resulting from such neglected injuries and rotted areas.

288. Principles involved.-In most tree-surgery work a few fundamental principles must be observed to secure good results. These may be summarized as follows: (1) Remove all decayed, cliseased or injured wood and bark. When on sinall limbs, this can often best be done by removing the limb. On larger limbs or on the trunk it may at times mean the digging out of a cavity. (2) Sterilize all cut surfaces. (3) Waterproof all cut surfaces. (4) Leave the work in the most favorable condition for rapid healing. This will often mean the filling of deep cavities. (5) Watch the work from year to year for defects. If any appear, attend to them immediately.

289. Qualifications of workmen.- Tree surgery, or, more properly, as some interested persons would have tree owners believe, tree repair work, is not a mysterious art known to only a favored few who alone are fitted to undertake it. It can be undertaken by any careful man who has a good general knowledge of the structure and life history of a tree, its normal manner of covering wounds and how insects and decay organisms cause clamage, provided he can handle the necessary tools and will apply in a practical manner his knowledge of the anatomy of a tree, together with a generous admixture of good common sense.

290. Types and scope of work.-In its simplest type, tree surgery consists in removing dead or decayed limbs or stubs from a tree and treating the scar with an antiseptic and waterproof covering to prevent decay while healing. Another type consists in cutting out the decayed and diseased matter in trees and filling the cavities with cement or other materials to facilitate the normal healing-over process. This is often referred to as "tree dentistry." a term which very aptly indicates the character of the work. Filled cavities do

* Paragraphs 287 to 311 have been excerpted and slightly condensed from J. T. Collins's article in the United States Department of Agriculture Year Book, 1913, Pages 162 to 190 . Only about half the article is herewith included, because the balance deals mostly with physiological and other features already discussed in this volume. 


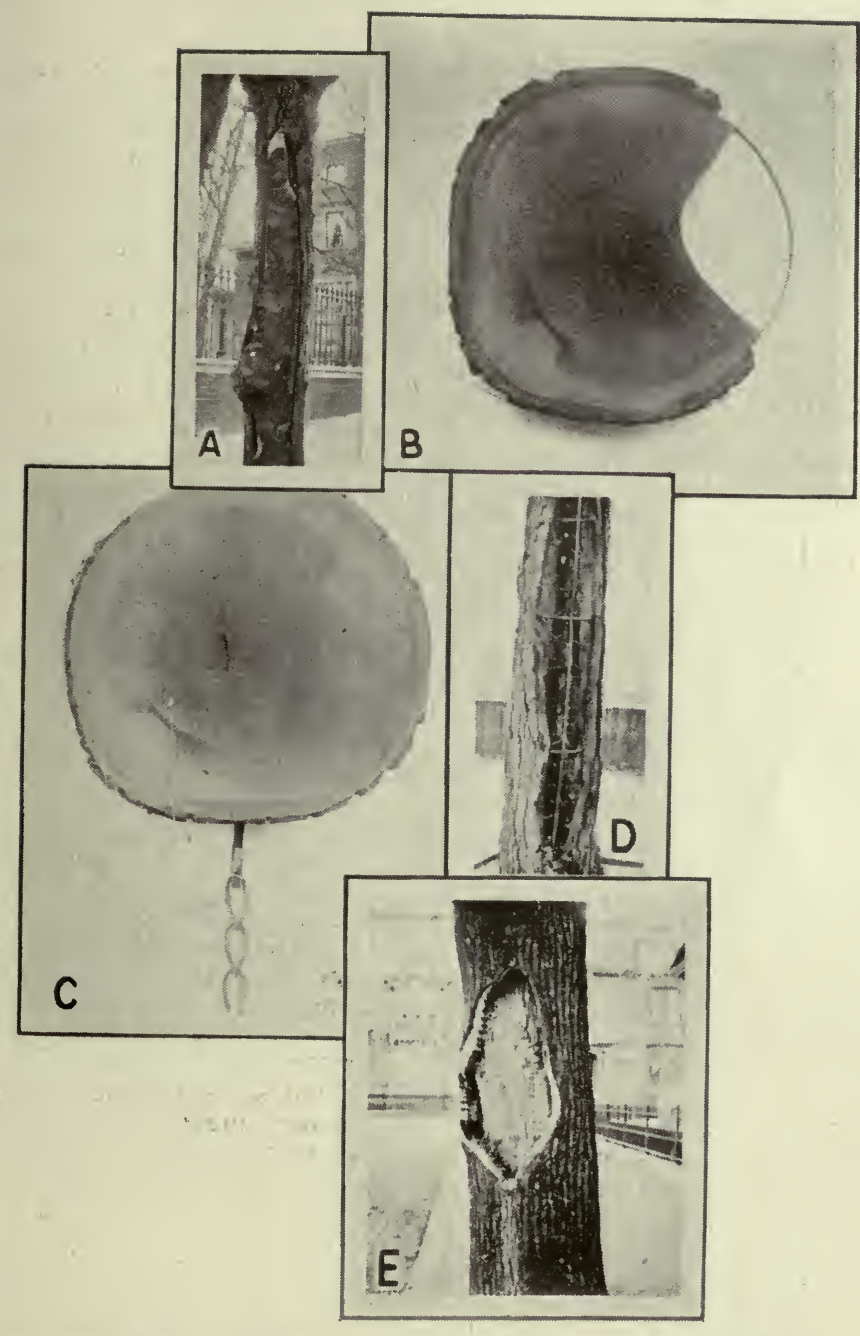

FIG. 303-CEMENT FILLINGS AND GUY CHAIN ATTACHMENT

A, Cement shattered by cold and swaying of tree. B, Section of trunk showing metal-covered cavities. C, Simple way to fasten guy chain to hook bolt. D, Nails and cement-reinforcing rods in place, for filling. E, Shallow cavity ready for creosote and tar, not usually cement filled. 
not increase the strength of the trunk or limb to the extent that is generally supposed.

291. Dead or diseased branches.-For the work of removing branches, the most essential implements are a good-sized saw with. teeth so set as to make a wide cut, a gouge, a chisel, a mallet and a strong knife. For cutting limbs near the ground these are the only necessary implements. For limbs situated elsewhere a ladder may be needed; also, at times, a rope.

292. Treatment of cavities.-During the last few years there has been widespread popular interest in the treatment of decayed places in old trees. This type of work comprises many inquiries addressed to the Department of Agriculture and refers solely to methods employed in cementing cavities. This is a logical result of the present extensive essential operations: (1) Removing all decayed and diseased matter, (2) sterilizing and waterproofing all cut surfaces, and (3) filling the cavity in a manner that will favor rapid healing and exclude rot-producing organisms.

The necessary tools for digging out decayed matter are two outside-ground socket-handled gouges (one with a curved cutting edge of about $3 / 4$ inch, and the other perhaps $1 \frac{1}{2}$ inches), a chisel, a mallet, a knife and an oilstone for ordinary work. The gouges, chisel and knife should never be used near the cambium when they lack a keen edge, as dull tools will injure it. In cutting out deep cavities, longer interchangeable handles for the gouges may be necessary. A ladder or a stepladder will be required if the viork is more than 5 feet from the ground.

293. Excavating.-Usually an old decayed spot may be partially or wholly covered by a new growth of wood and bark at the edges, and the visible decayed area be small as compared with that which is hidden (Fig. $301 \mathrm{D}, \mathrm{F}$ ). In such cases it is usually necessary to enlarge the opening with the gouges and mallet in order to make sufficient room in which to use the gouges in the interior. This opening should not be any wider than necessary, but it may be sufficiently long to reach all the decayed and diseased heartwood with little or no additional injury to the tree.

If the decayed and diseased wood extends some distance above or below the external opening, it is a common practice to cut one or more holes above or below the main opening in order to facilitate the removal of the diseased wood (Fig. 305 A). This results in one or more bridges of wood and bark spanning the long interior cavity, a practice of doubtful value, partly because it is often impossible to see whether the diseased wood has been entirely removed from the under side of the bridges, but mainly because there is a strong tendency in most trees for the bark and the sap wood of the bridges to die and decay as a result of severing the sap-conducting tubes both above and below. If the holes are pointed above and below, there is less trouble from this source. A practice that permits a more thorough cleaning out of the cavity is to make a narrow opening; pointed at both ends and sufficiently long to include all the 
diseased wood. This ofter. extends some distance above and below the visible discolored area.

The most important feature of this stage of the work is to remove all the diseased and insect-eaten wood (Fig. $305 \mathrm{~B}, \mathrm{C}$ ). This excavating must continue on all sides of the cavity until sound uninfected wood is reached. All discolored or water-soaked heartwood should be removed, as this is the region in which the rotproducing fungus is most active. In decayed areas of many years' standing there may be only a thin shell of uninfected wood around the cavity (Fig. 301 F), in which case there is danger of the tree being broken by storms unless braced or guyed.

294. Drainage.-The bottom and all other parts of the cavity should be so shaped that if water were thrown into the cavity it would promptly run out and none remain in any hollow. This feature is commonly called "drainage." It is bad practice to have a deep water pocket at the bottom of a cavity with drainage through an auger hole bored from the exterior. An open hole of this sort often becomes a favorable lodging place for insects or fungous spores.

295. Undercutting.-Another important point in shaping a cavity is to have the sides undercut if possible, so as to hold the filling firmly in place. Care must be taken, however, not to have the wood at the edges of the opening very thin, as this promotes the drying out of the bark and sap wood at these points. Ordinarily the edges should be at least $3 / 4$ of an inch thick, and $11 / 2$ would be better (Figs.301 D, $306 \mathrm{~A})$. Inrolled bark at the edges of an opening should be cut back in nearly parallel radial planes, as a rule, to a point which will permit the surface of the completed cement filling to conform with and continue across the cavity the general contour of the woody part of the trunk (Fig. $306 \mathrm{~A}$ ). If it is not possible to under-

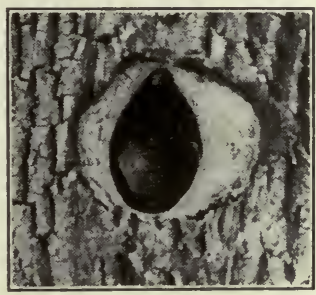

FIG. 304-GOOD HEAL-

ING OVER PROPER-

LY PLACED BOLT HEAD cut sufficiently to hold the filling firmly in place, the alternative method described under "Nailing" (297) may be adopted (Fig. 306 B).

Great care must be exercised in working around the cambium, and all cutting tools must be kept very sharp. The final cutting along the edges of the bark and the sap wood can usually best be made with a very sharp knife. This cutting must be followed immediately by a coating of shellac, which should cover the edges of both bark and sap wood.

296. Bolting.-Before cementing a long cavity it is advisable to place through it one or more bolts, so as to hold the wood and the cement more firmly in place. A cavity 2 feet or less in length will not usually require a bolt, but long cavities, as a general rule, should 


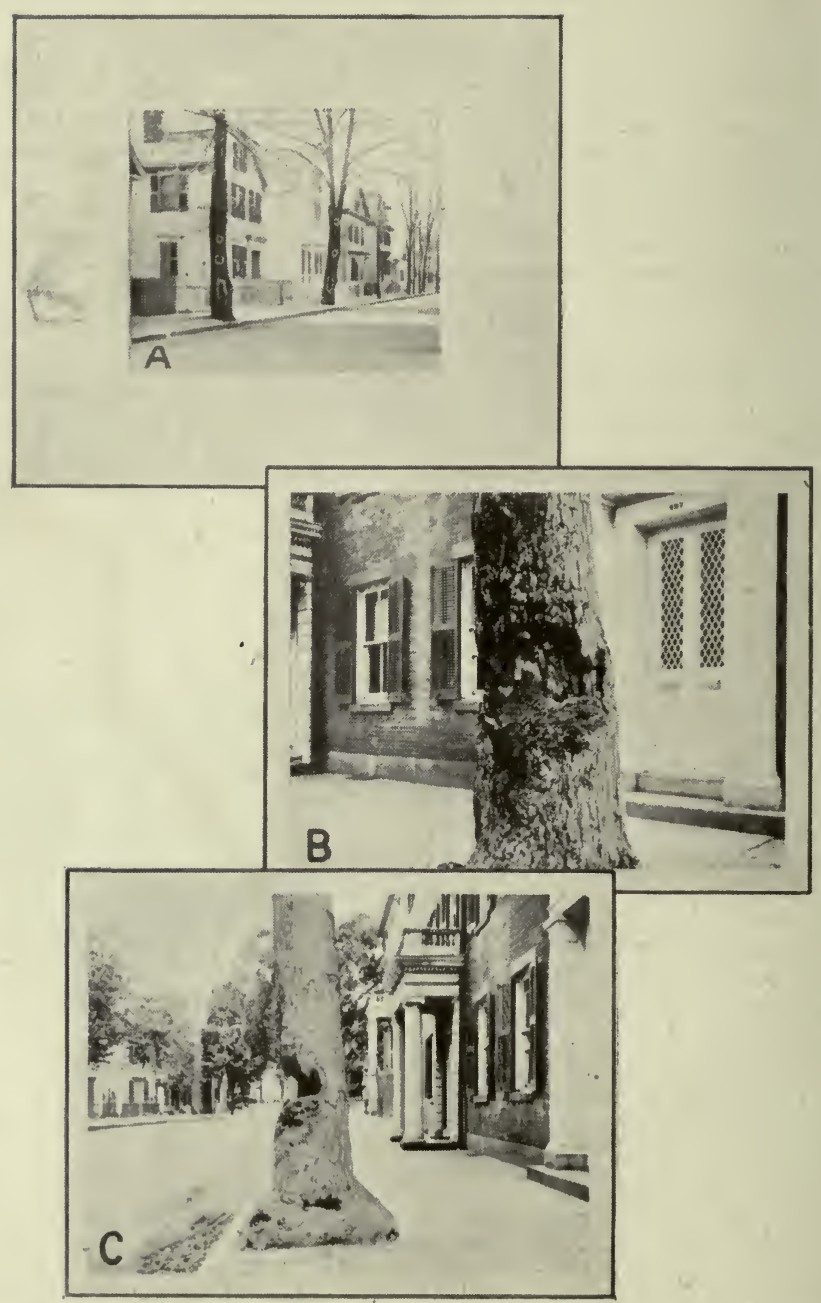

FIG. 305-LONG CAVITIES EXCAVATED THROUGH SEVERAL OPENINGS, AND A SHORT CAVITY EXCAVATED THROUGH ONE OPENING

A. Cavities in two trees excavated through small openings cut in the trunks. It would be better to make the openings oval and pointed rather than square or round. B, An old injury caused by horses gnawing the bark. C, The injury shown in $B$ excavated and ready for tarring prior to filling. 
be bol1306 B). The heads of the nails finally are completely embedded so as z cement (Fig. $306 \mathrm{E}$ ). If the cavity is already bolted, it may not be n'iecessary to use many nails, because the bolts help to hold the cas?nent in place.

le 298. Treating.-After the decayed and diseased matter has been scompletely excavated and the edges of the sap wood and bark shellacked, the next step is to sterilize the interior of the cavity in order that all germs of disease or decay may be killed and that any which may come in contact with the cut surfaces during subsequent operations may be destroyed. Creosote appears to be one of the best preparations to use. Every cut part of wood and bark must be creosoted. Over this a heavy coating of tar or hot asphalt should be applied before the cavity is filled.

299. Mixing the cement.-A good grade of Portland cement and clean, sharp sand free from loam (1 part of cement to 3 or less of sand) should be used. The mixing may be done in a mortar bin, : wheelbarrow, a pail, or in any other available receptacle sufficieníy large. A quantity of dry cement and sand sufficient to fill the cavit: should be thoroughly mixed before the requisite amount of water to make a rather stiff mortar is added, and the whole mixture worked to an even consistency. In large cavities fine gravel, free from loanı, is sometimes substituted for the sand.

300. Cementing.-For placing the mixture in the cavity a mason's flat trowel and an ordinary garden trowel with a curved blade will be found convenient. A tamping stick, 1 or 2 inches thick and 1 to 3 feet long, according to the size of the cavity, will be needed.

A layer of cement 2 or 3 inches deep may now be placed in the bottom of the cavity with the garden trowel and tamped firmly in place. This operation is repeated until the cement is 8 to 12 inches thick. Wet rocks of various sizes may be embedded in the cement provided they do not reach within an inch or two of its outer face. If the mixture is too wet, it will tend to run out of the cavity under the operation of tamping. If too little water has been used, it will not pack down promptly.

The top of the 8 .to 12-inch block of cement is smoothed with the flat trowel so it will slant slightly downward from back to front, in order to facilitate drainage. Over the top of this cement block a double or a single sheet of tarred roofing (or thinner) paper is placed after it has been cut so as to fit the cavity. On top of this another block of cement is built as soon as the first block is sufficiently hard to stand the weight and tamping without forcing any of it out at the bottom of the cavity.

If the interior of the cavity extends well above the level of the external opening, it may occasionally be necessary to bore or cut a downward slanting hole from the outside to the top of the interior cavity, through which a watery mixture of cement may be poured to fill the upper part of the cavity and the hole. The main opening of the cavity must be completely closed with the stiffer cement before this watery mixture is introduced. 
When a block of cement has partially hardened, it will be necessary to smooth carefully the outer surface or cut it down with the Hat trowel to the level of the cambium, taking great care that the latter is not injured in the operation. If the cement is allowed to become too hard to trim with the trowel, it can still, with more or less difficulty, be cut back to the cambium line with a cold chisel and a hammer. It is a rule with most tree surgeons to trim back the outer surface of the cement to $1 / 8$ inch or more below the cambium and then use a layer of stronger cement (one part of cement to one to two of sand) to raise it to the level of the cambium, after the filling has partially hardened.

The thinner mixtures of cement will set more firmly. If any mixtures thinner than the one already mentioned are used to fill a cavity, some sort of cloth or wire dam will have to be used to hold the cement in place until it is hard. For this purpose strips

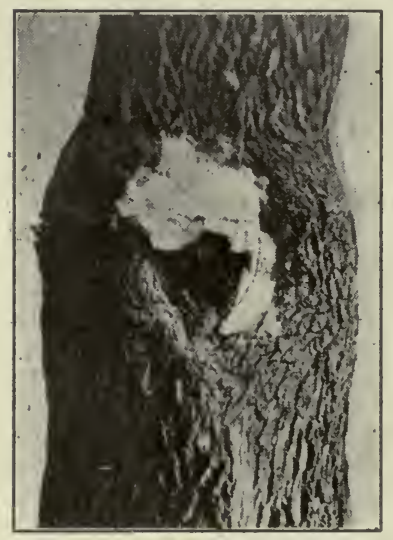

FIG. 307-HOW NOT TO COVER A CAVITY WITH CEMENT OR CONCRETE of burlap wrapped tightly around the tree so as to cover the lower part of the opening may be sufficient if the mixture is not very thin; otherwise, a more closely woven fabric, such as canvas or carpet, may be used. This dam at first should cover about a foot of the lower part of the opening. The cavity may then be filled with cement to the top of the dam.

The top is smoothed and covered with tarred paper, as already described, the height of the dam is increased and the operation repeated. Before the cement has become too hard, the dam is removed and the surface of the cement finished in the usual manner, either to the level of the cambium at once, or it may be cut a little farther back and a finishing layer of stronger cement applied to bring the surface to the proper level. The surface of the cement must be wet before the stronger finishing layer is applied.

A very large proportion of the cemented cavities seen in trees at present are made in one piece, without the use of tarred-paper partitions. Long cavities of this sort are particularly subject to defects, so one-piece fillings are not recommended except for short cavities, where these particular ohjections do not apply. The method employed is only a slight morlification of that already described, and will readily be understood by a study of Fig. 308 B, C, D, and the legends which accompany them. These figures show successive stages of work in the same cavity. 


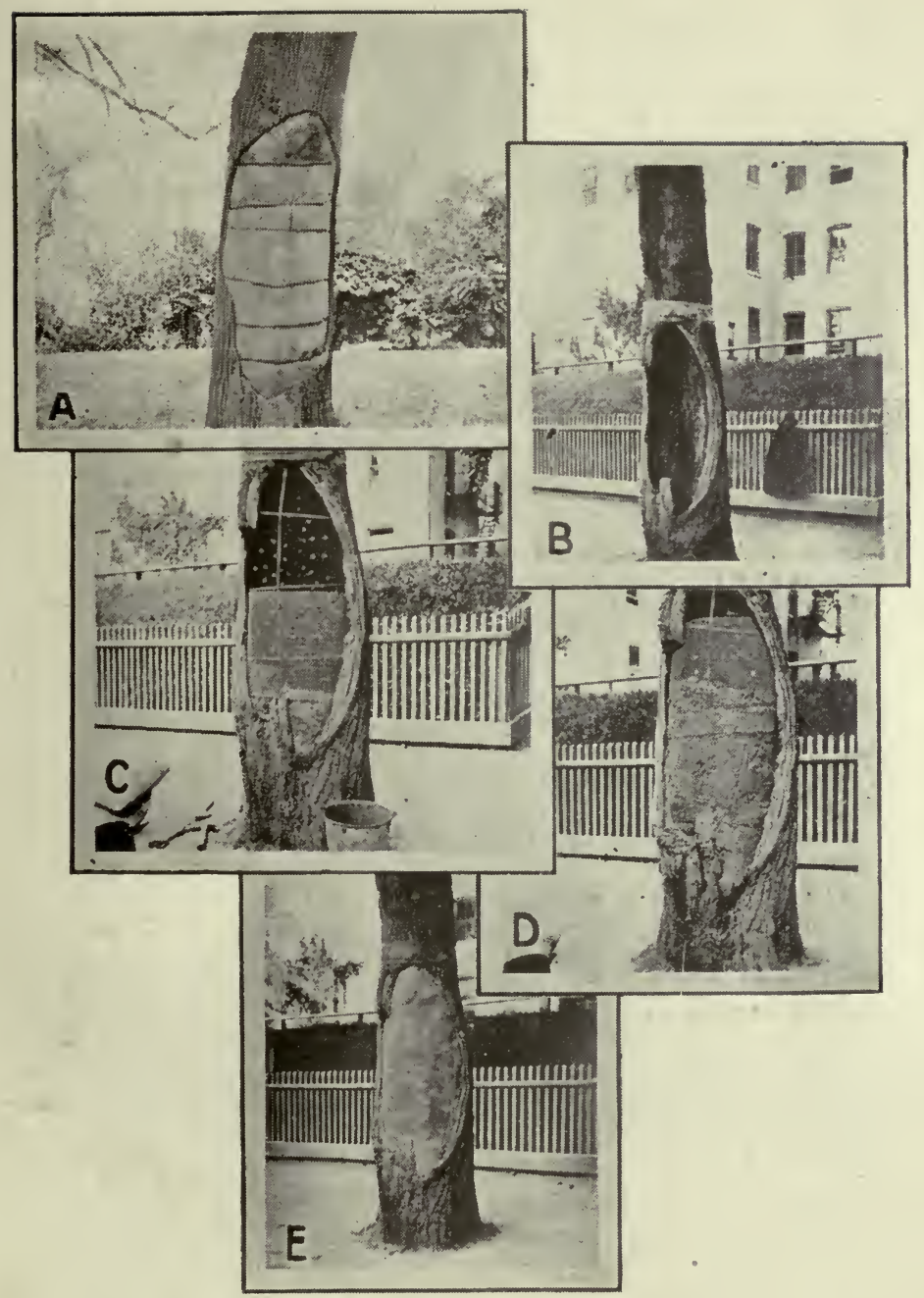

FIG. 308-CEMENT FILLING TYPES AND SUCCESSIVE STEPS

A, Cavity filled with cement blocks separated by tarred paper. B, Cavity ready for treating and filling. C, Cavity in B, nailed and partly cement filled. Ends of reinforcing rods sprung into shallow holes in wood. Wire dam, sometimes allowed to remain in cement, though usually removed when cement has partly set. D, Later stage of C, height of dam increased. E, Same cavity completed. 
The edges of cement fillings in the crotches of limbs are especially difficult to keep water-tight. Besides bolting the cavity and guying the limbs above it, the crevices at the edges of such cement fillings must be made as nearly waterproof as thick tar or asphalt can make them.

After the cement filling has become thoroughly dry, the outer face may be painted with coal tar or paint, especially around the edges where cracks are likely to appear. This should not be done for several weeks after the cement has been put into the cavity.

301. Defects in cement work.-Although fillings made with cement mixtures (cement mortar and concrete) have many, and often serious defects, this material is so cheap and so easily handled that no other at present is so generally used for the purpose in this country. The most serious defects in cement mixtures are directly due to the hardness and rigidity after the cement has become dry. This inflexibility results in cracks appearing across the cement of long fillings (where not put in in sections or blocks, as recommended here) as the tree sways back and forth in the wind (Fig. $303 \mathrm{~A}$ ). Rods for re-enforcing the concrete are often placed in large cavities to be filled in one block (Fig. $303 \mathrm{D}$ ).

During a cold period in winter, particularly one that has been preceded by warm weather, the wood of an unbolted cavity may draw away from the cement, often leaving a comparatively wide crack (Fig. $303 \mathrm{~A}$ ). Sometimes, by the contraction of the wood on a cold day, the tree itself will split above or below the filling, or even through the cement when the cavity has been nailed but not bolted. This cracking may be prevented to some extent by having nailed cavities with a vertical partition of tarred paper extending throughout the length of the filling.

On the other hand, the cement filling forms a surface over which new wood and bark can form during the growing season, and if the decayed and diseased matter in the cavity is entirely removed before the cement is used, it very largely, if not entirely, checks further decay. If cracks appear in the cement, or the wood draws away from the cement, or the work is not properly done, decay organisms may again gain entrance at the edge of the cement and cause further trouble.

302. Open cavities. - In a tree which is not considered of sufficient value to warrant cleaning and filling the decayed areas, these may be excavated, sterilized and waterproofed (Fig. $303 \mathrm{E}$ ). In this condition they may often be safely left for years if the waterproof covering is renewed as soon as cracks or blisters appear. Cavities treated in this way are probably as safe as ordinary cemented cavities and have the advantage of easy inspection from time to time. Shallow cavities in valuable trees may be very satisfactorily treated in this manner. The new wocd and bark produced by the cambium along the margins will form an inwardly rolled edge (Fig. $306 \mathrm{~A}$ ), as there is no cement across the cavity. 


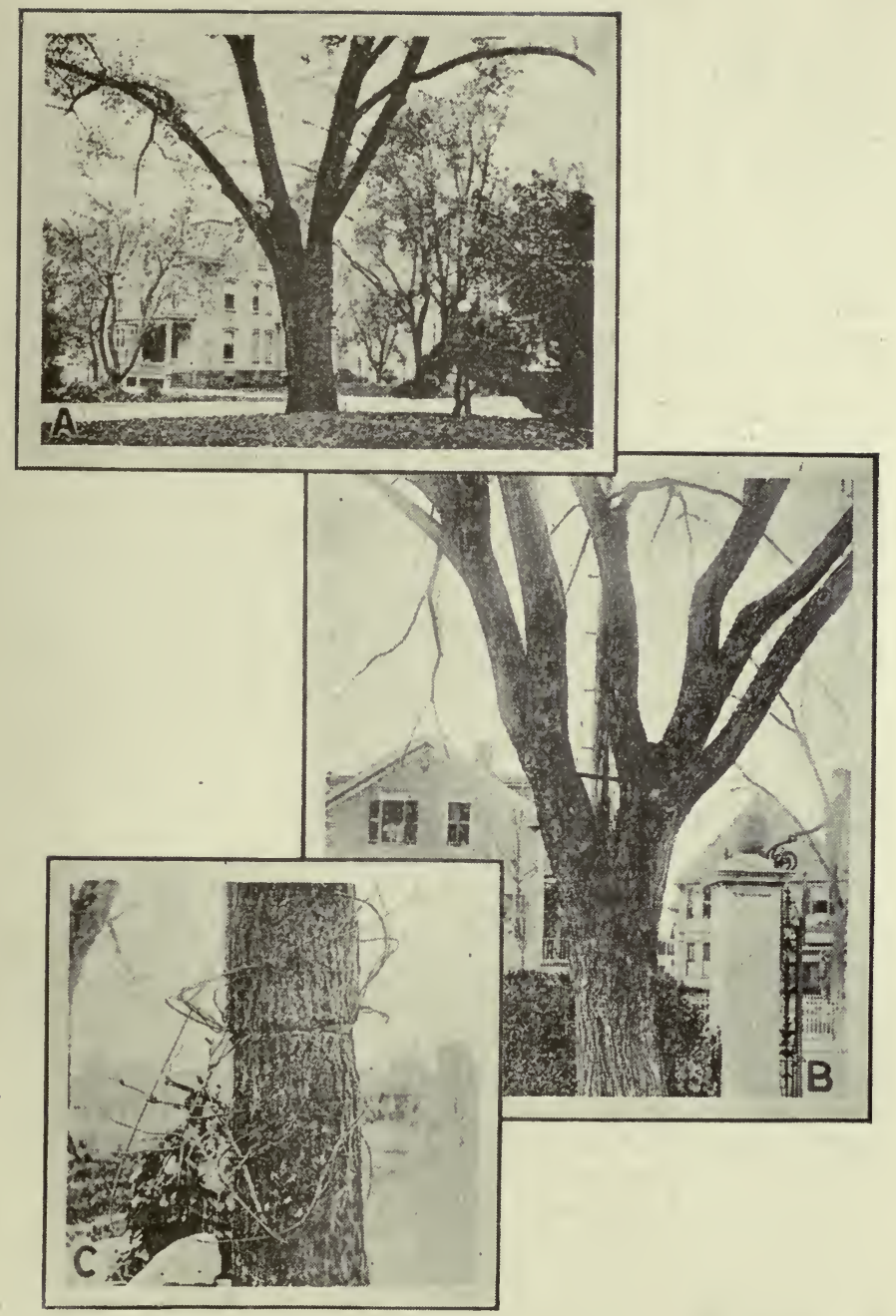

FIG. 309-PROPER METHOD OF FASTENING GUY CHAINS AND BOLTS, ALSO IMPROPER METHOD OF ATTACHING WIRES

$A$, Elm limbs guyed by several independent chains 15 feet ahove the crotches. B, Split crotch guyed by long bolt about 18 inches above the crotch. C, Tupelo tree nearly strangled by telegraph wires around the trunk. 
303. When to undertake tree surgery.-As a general rule, t"ce surgery may be safely undertaken at almost any time of year when the sap is not running too actively and the weather is not cold enough to freeze the cement. In most trees the sap will interfere with the work only from the time the buds begin to expand in the spring until the leaves are full grown. Cement work will be ruined if it is frozen before it is hard. It is not likely to be injured by frost after it has been drying for a week.

304. Guying.-Closely associated with the work of tree surgery proper, and often an indispensable adjunct, is the guying of limbs to prevent the splitting of the crotches or to check further splitting. The best place to put these guys depends largely upon the shape and position of the limbs to be braced. This varies so widely in different trees that it will be impossible to give very specific directions for this kind of work.

A simple method of guying a crotch is to place a hook bolt through each limb, with the hooks in the two limbs toward each other and from 3 to 10 feet or more above the crotch (depending upon the size, position and length of the limbs) and slipping the end link of a stout chain over one of the hooks (Fig. 303 C). While at the proper place in the chain to make a sufficiently taut guy a link is slipped over the other hook. The rest of the chain may then be cut away if desired (Fig. 309 A).

Modifications of this method may be used where three or more adjoining limbs are to be guyed collectively. A simple method is to place a hook bolt through each limb at the proper place and then hook a link of the chain over each bolt hook at any desired point, one of the hooks serving to hold the two end links of the chain. The precautions mentioned under "Bolting" (296) should always be followed, so far as they apply to boring and tarring the hole and countersinking the washers of the bolts.

A turnbuckle rod or bolt is much better than a chain when the guy is to be kept perfectly taut at all times. Furthermore, this rod permits a ready tightening of the guy within certain limits should it later become necessary. If for any reason the guy is to be placed within a foot or two of the crotch, a single long bolt may often be used to better advantage (Fig. $309 \mathrm{~B}$ ), and sometimes a single long bolt may be used in place of a chain or a turnbuckle rod where the guyed limbs are not likely to twist much as they sway in the wincl.

Occasionally it may become necessary to guy a whole tree in order to prevent the breaking of the trunk where an unusually large cavity leaves only a thin shell of sound wood, or to prevent the tree from tipping over. This may be accomplished by attaching four guy chains or ropes to the tree about half way from the ground to the top of the tree and having these siant downward at an angle about equidistant around the tree (e. g., on the north, east, south and west sides of the tree).

The method of attaching the guys securely to the posts is im- 
material. The method of attaching them to the tree is important. If the guying is for temporary purposes only, two broad bands of leather, stout canvas or other strong material, each long enough to make a loop at least twice the diameter of the trunk or limb to be encircled and 4 to 6 inches wide, may be passed around the tree or some favorably situated limb and two adjoining guys attached to each loose loop.

If a more permanent guying is needed, two eyebolts (or hook bolts) may be placed through parallel croosoted holes in the trunk or the limb about half way up the tree, one about 6 inches above the other. The eye of one bolt should be on the opposite side of the tree from the other. Two guys from two adjoining posts are attached to each eyebolt. The chafing of a limb against a guy may be prevented by padding the guy if this latter cannot be so placed as to clear the limbs.

Limbs or trees should never be guyed by passing wires, chains or ropes tightly around them. These may eventually strangle the portions beyond the encircling band. Encircling fence wires, telegraph wires, clotheslines, or guy wires will act in the same way, killing all parts of the tree beyond the wires if these remain tightly drawn around the limb or trunk for any great length of time-occasionally in less than a year (Fig. 309 C).

305. Trees worth repairing.-Most ornamental and shade trees having only a few dead limbs are unquestionably worth attention. Others which have many dead limbs or numerous decayed areas may not be worth the expense, particularly if they are naturally rapidgrowing, short-lived trees. No one can decide better than the owner of a tree whether it is worth the attempt to save it, because usually the actual commercial value of an ornamental or shade tree has little or nothing to do with the decision. It is generally a question merely of esthetic value, or historic associations, or rarity of the species. A man who has had experience in repairing mutilated or diseased trees may be able to say definitely whether it is possible to save the tree, but the owner, who pays the bills, is the one who will have to decide whether the tree is worth the price it will take to repair it. Often the owner will

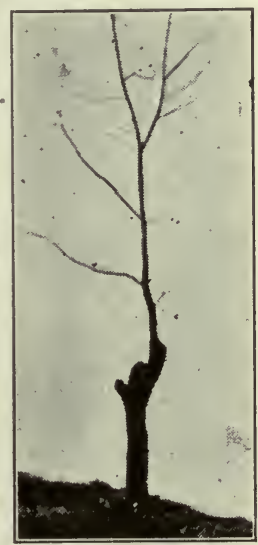

FIG.310-ISN'T THIS GHASTLY? realize a greater degree of satisfaction by having a badly diseased or mutilated tree replaced. In expert hands the moving of large trees is no longer a hazardous undertaking.

306. Commercial tree surgery.-The writer's observation of the workmen employed in commercial tree surgery leads to the conclusion that few have any knowledge of the manner of growth of 
fungi which caus a disease in trees, or, if they do know something about it, they apparently do not allow this knowledge to modify their methods appreciably. It is extremely important that special precautions be taken when a contagious disease, such as the chestnut bark disease, is infecting a tree [because through ignorance disease may be spread by infected tools, as in the case of pear blight, 196].

307. Ignorant workmen and fakers.-Unfortunately for tree owners and the trees themselves, many men who are set at work by an unreliable contractor know little or nothing of the fundamental principles concerning the life history of a tree. In their ignorance, such workmen are likely to make serious blunders through neglecting to do certain important things, the reason for which they do not understand. The faker will always slight any stage of the work, no matter how important, if evidence of his neglect can be effectually obliterated or hidden by subsequent operations.

There are few more favorable opportunities for practicing frauds of this nature than in the operation of filling cavities in trees. The decayed and diseased wood may be only partially removed, improper or ne antiseptic coatings used in the cavity, or no proper

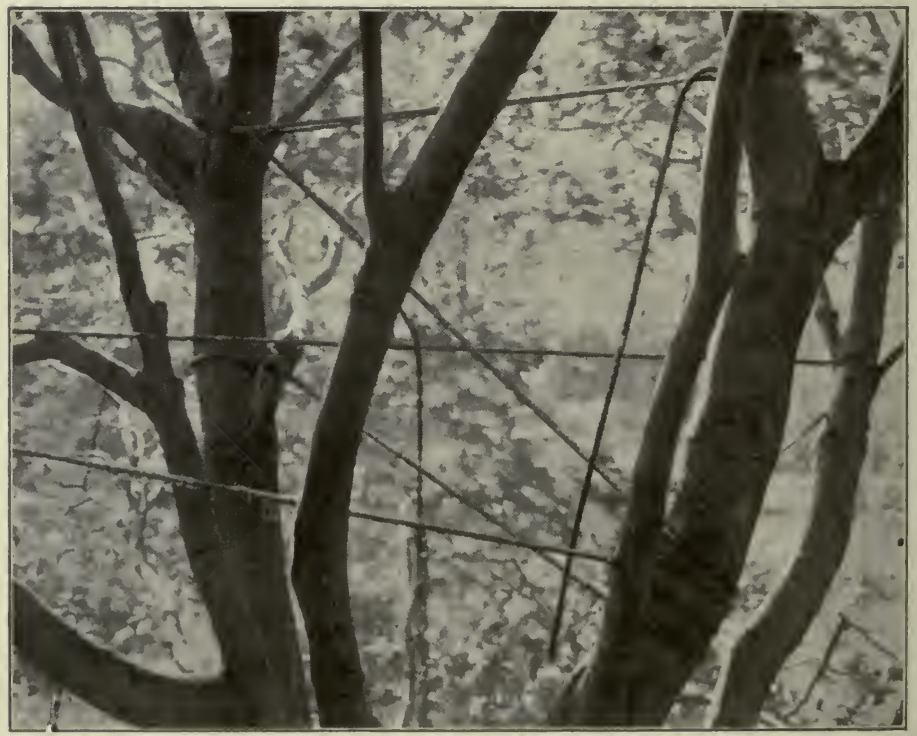

FIG. 311-ROPING A TREE PREPARATORY TO BOLTING $T$ ropes in this case were left for several months during the growing soason.
So began to girdle the large limb at the rlght. 


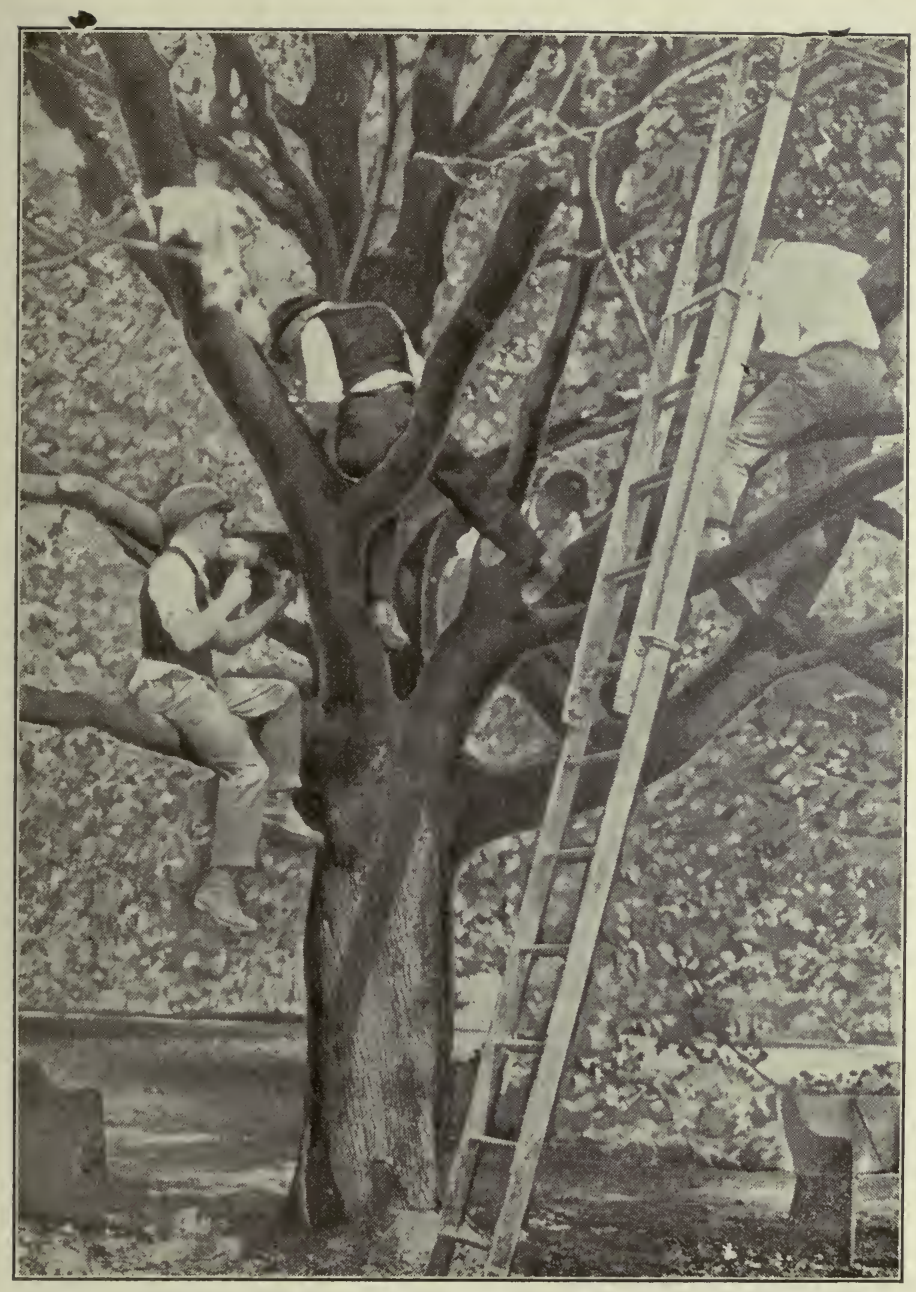

FIG. 312-STUDENTS AT WORK IN TREE SURGERY 
drainage provided, yet no one can tell the difference after the cavity has been filled or covered unless the filling or covering be removed. A cavity filled with cement or other material before the decayed and diseased wood has been wholly removed is nearly comparable to a tooth from which the decayed matter has been only partially removed by the dentist before it is filled.

308. Misuse of the pruning hook. - Too commonly the ordinary workman will get into the top of a tree and use his long pruning hook to break off the small dead branches, in the same manner that he would use a club for a like purpose. When so used, the pruning hook will inevitably cause many injuries to the young bark of adjoining branches and make wounds through which disease and decay germs may enter. In this manner many new openings for the possible entrance of disease may be created in addition to the one already existing in the dead branch, for it must be remembered that merely breaking off the branch does not prevent decay from continuing at this point, while every new bruise or wound may furnish a new point for decay to enter.

309. Climbing devices.-On various occasions we have seen workmen in the employ of well-known tree surgery firms repeatedly jab their climbing spurs into the bark on horizontal limbs where it would have been much easier for them to move about without using spurs at all. The use of climbing spurs on trees should be avoided, or at least severely discouraged. It would be best if they were never used. Every wound made by one of these spurs may become the center of a new region of decay if conditions favorable for the growth of decay organisms exist. The use of spurs should be strictly prohibited on all parts of a tree subject to a contagious disease above ground, especially if the disease is known to exist in the vicinity. A man who uses spurs on the trunk or on limbs that may readily be reached by a light ladder should never be allowed to work on trees. Firms which permit their workmen to do this should be classed as undesirable or dangerous firms to deal with and accordingly avoided. Many trees have been irreparably damaged and left in far worse condition after ignorant or indifferent workmen equipped with climbing spurs and pruning hooks have worked in them than if nothing had ever been done to them. The edges of the soles and heels of leather shoes, to say nothing of protruding nails, commonly cause considerable injury to soft and tender bark. Probably the best and safest footwear, from the point of view of preventing injury to the tree, is some form of rubbersoled shoe, such as tennis shoes or "sneaks." All properly equipped firms of tree surgeons have ladders that will reach 40 or 50 feet or more into a tree. Ladders, ropes and rubber-soled shoes will allow a man to reach practically every part of a tree that can be reached by climbing spurs.

Reliable estimates indicate that it takes somewhat longer (perhaps 25 per cent on an average) to do the required work on a tree fitcen ladders, ropes and rubber-soled shoes are used instead of 
climbing spurs. Consequently, it may be expected that contractors will have their workmen use spurs unless these are specifically prohibited.

310. Responsibility of tree owners.-Owners who contract with a firm of tree surgeons to attend to their trees are occasionally quite as much to blame for the resulting poor work as the men who do it. This statement refers to those owners who get an estimate for having their trees repaired in a proper manner by men who make a business of caring for trees and then say, in effect, "I've got only half that amount of money for the work; and you will have to do it for that or I will get someone else to do it."

The reliable man who has named a price that will insure at least reasonably good work has to do one of two things under those conditions; either he must decline to do the work or he must lower his price. When these conditions arise the work is often undertaken at a reduced price. This generally means that the work has to be of a cheaper grade, possibly done by inexperienced men, in order that a profit may be realized. A wiser course for the owner would have been to put his available money into repairing in a proper manner the more valuable of his trees, leaving the less valuable ones untreated.

With the completion of tree surgery work, owners usually fail to realize the importance of keeping close watch of their trees, in order that defects which appear in the work may be remedied promptly and that new injuries elsewhere on the tree may have immediate attention. If a tree is considered by its owner of sufficient value to warrant having it properly and carefully treated by a tree surgeon, it certainly is worth the slight expense of subsequent annual or biennial inspection and the immediate repair of newly discovered injuries at a time when the expense necessary to keep the tree in good condition will be comparatively small.

311. Contracts.-In order to secure better results in the future than have generally been attained in the past, and to put commercial tree surgery on a basis that will tend to eliminate the fakers, owners are urged to have a definite written contract with tree surgeons whom they employ to take care of their trees. The best results can generally be attained when payment is to be based upon the amount of work done plus the cost of materials used. Probably most persons, however, will prefer to have the trees examined and a definite price agreed upon before any work is undertaken. In either case there should be a definite written understanding concerning at least certain important phases of the work, in addition to price and methods of payment. The following is suggested as a model for such contract:

(1) No climbing spurs shall be used on any part of a tree. (2) The shoes worn by the workmen shall have soft rubber bottoms. (3) Ordinary commercial orange shellac or other specified dressing shall be applied to cover the cut edges of sap wood and cambium 
within five minutes after the final trimming cut is made. (4) All cut and shellacked surfaces shall be painted with commercial creosote, followed by thick coal tar. (5) All diseased, rotten, discolored, water-soaked, or insect-eaten wood shall be removed in cavity work and the cavity inspected by the owner or his agent before it is filled. (6) Only a good grade of Portland cement and clean, sharp sand in no weaker mixture than one to three shall be used to fill cavities. (7) The contractor shall repair, free of expense, any defects that may appear in the work within one year.

Tree owners are urged to remember at all times the axiom: The need of tree surgery 15 or 20 years hence may be very largely obviated by promptly attending to the fresh injuries of today.

312. Electrical injuries to trees. - According to G. E. Stone* most of the injury to trees from trolley or electric light currents is local; i. e., the injury takes place at or near the point of contact of the wire with the tree. This injury is done in wet weather when the tree is covered with a film of water, which provides favorable conditions for leakage, the current traversing the film of water on the tree to the ground. The result of contact of a wire with a limb under these conditions is grounding of the current and burning of the limb due to "arcing." The vital layer and wood become injured at the point of contact, resulting in an ugly scar and sometimes the destruction of the limb or leader. In a large number of tests made by the aid of sensitive instruments with guy wire and other connections of wires to trees we have never found any leakage during fair weather, or when the surface of the tree is dry.

313. Preventing injury to trees from wires.-The constantly increasing use of electricity for various purposes makes necessary a more extensive use of wires. These have become a great menace to shade trees. The appearance of streets is also hardly improved by the increased number of poles and wires, and the legal restrictions as to the height, distance apart, etc., of the wires of the telephone, telegraph, trolley and electric light companies make the problem of maintaining shade trees on the same street with public serviçe corporations a serious one.

Of all the troubles with which tree wardens have to contend the wire problem is often regarded as the worst. Notwithstanding the strict laws which some states have adopted in regard to injuring shade trees, the agents of some public service corporations often have little regard for trees or the laws respecting them. Where 40 -foot poles must carry the wires of three or four public service corporations there can be little or no opportunity to preserve the natural symmetry of shade trees, especially when low-branching trees are planted on the same side of the street with the wires.

The best solution of the wire problem lies in burying the wires. This has been done a good deal in large cities, especially in the business sections. It is an expensive system, however, and those who

\footnotetext{
* Massachusetts Agricultural Experiment Station, Bulletin 165.
} 
so strenuously advocate its adoption do not always consider that in the end it is the patrons who have to pay for it.

Another method of preventing injuries is the erection of high poles to bring the wires over the trees. This is sometimes done, especially where the trees are young or of a species that naturally grows low, when a very high pole would be sufficient to clear them for many years. The cable system may be used for telephone wires, and much injury to trees prevented. Large cables are rather expensive to install, but what is termed the "ring construction" system may be used to advantage in many instances, particularly in the suburbs. In this way it is possible to run a line through avenues of fine trees in the country districts without necessitating pruning or disfiguration.

Rights of way for poles on private property back of residences are sometimes secured, and by this means the poles and wires may be removed from the streets, much to the advantage of the trees. But such rights are often difficult to secure, and are not always satisfactory either to the public service corporations or the owners of the property. The former naturally do not care much for these rights of way unless they are legal and permanent, and the owners in granting permanent rights run a risk of lowering the value of the property. Most of the very high-tension transmission services, however, are at present on private property, and seldom interfere with trees. High-tension lines are affected seriously merely by close proximity to trees; therefore, these rights of way have to include broad strips of land-of course expensive.

On general principles it is not wise to allow wires to be attached to trees, although this is often done. Trolley and electric light wires are frequently guyed to trees, but they are a source of danger, since injury is likely to occur from the crossing of the wires, and lightning discharges occasionally pass from the wires to the tree, causing damage. It is, however, often better to allow this than to endure the erection of ugly poles; but proper insulation of the wires should be insisted on, although ordinary insulators have little effect on lightning discharges.

The lag-bolt system in common use for guying wires to trees is not the best method, for sooner or later the wire and the bolt become embedded in the tree and cause injury. Moreover, a direct metal connection with a tree is objectionable. The block system is butter, although it may not in all cases be free from objections. In no case should a wire be allowed to pass tightly around a tree, as it will girdle it in time. When live wires come into contact with limbs, some type of insulator should he employed. There are various types, some being effective in preventing injury from low-voltage lines.

Wires often accidentally come into contact with trees by the displacement of poles, particularly on curves, where the strain is very great, but much of this injury may be prevented by embedding the 
poles in Portland cement. It should be pointed out that the necessity for guying poles to trees may be obviated in this way.

Better methods of handling this vexatious question of wires and shade trees should be forthcoming in the future, and even at present there must be a compromise between the tree warden or city forester and the companies as to the best method of wiring through tree belts and the amount of pruning allowed. Conditions at present favor the corporations, as they are furnishing valuable and necessary facilities for business, etc. In towns they obtain their franchises and location of poles from the selectmen with little difficulty. The selectmen notify the abutters of any contemplated installations of poles and wires or of changes to occur in the systems, and the abutters are given a hearing. However, they usually wake up to their duty only after the installation of the lines, when the tree warden must assume all responsibility for injury to the trees. He has to choose between two courses-prevent the pruning or permit it. In either case the companies can erect the poles and install the wires, allowing the wires to burn their way through the trees, although this, of course, of ten causes trouble to the corporation as well as to the consumer. In case of injury to trees the warden has access to the courts, but nost companies are willing to put up with a few moderate fines for the sake of the right of way through a tree belt.

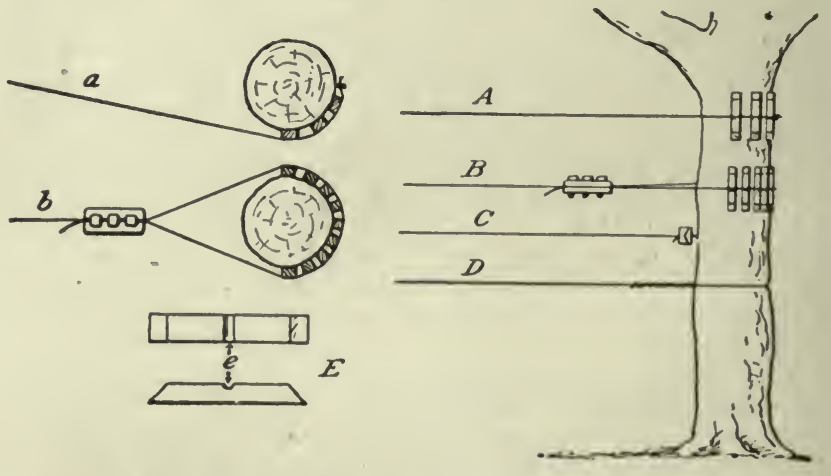

FIG. 313-METHODS OF FASTENING WIRES TO TREES

$A$, Wire attached to lag bolt and protected from tree by blocks; $a$, cross section. B. Loose wire loop fastened with clamp and separated from tree by blocks: $b$, cross section. C, Attachment of trolley guy wire. D, Wire toop tightiy placed around trunk will produce girdling. $E$, Blocks used in $A$ and $B$, showing groove at $c$. 


\section{CHAPTER XIX}

\section{REJUVENATION OF NEGLECTED TREES}

314. Will it pay to renovate neglected trees?-To answer this question satisfactorily depends on the answering of many other questions which no one is better able to answer than the owner of the trees. Doubtless many

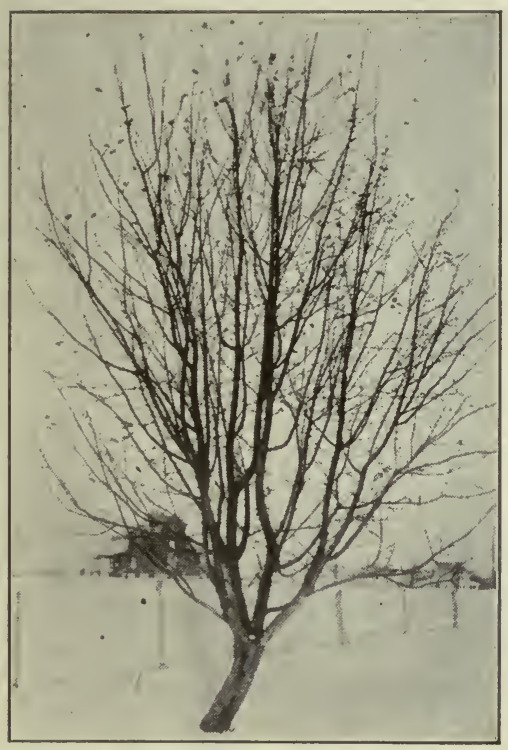

FIG. 314-NEGLECTED TREE HARD TO SPRAY AND HARVEST

Trees like this should be pruned to open the head and remove superfluous branches. trees that it would not pay financially to renovate might be saved without difficulty, as discussed in the chapter on tree surgery (Chapter X V I I I), when the question of cost to do the work and cost to maintain the tree in after years are set aside. As a ge n e r a 1 proposition, however, it will not pay to renovate neglected orchard trees for such reasons as the following: The cost of filling cavities and the risk of breakage after such work has been. done are too great to wa r r a n t the outlay; the number of vacant spaces in a neglected orchard due to the loss of trees beyond profitable repair may be so large that the amount of time required to cultivate the whole area, with perhaps 
50 per cent or more of the tree positions vacant; would be too great to make the venture profitable; the trees may have grown so tall and become so bare below from close planting and improper pruning that their tops cannot be lowered with reasonable assurance of success, even when the removal of each alternate tree would leave the balance spaced properly. Such points as these can be determined only after examination of the trees and the orchard area they occupy. To fill vacancies with young

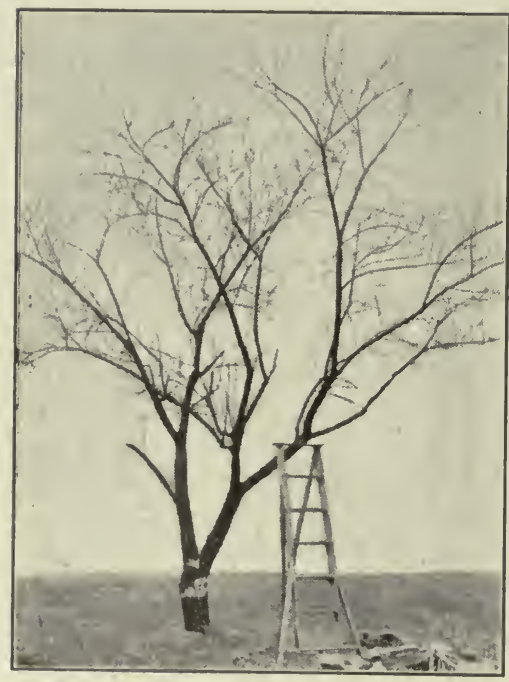

FIG. 315-OLD PEACH TREE BEFORE trees is by no means a sane practice in all or even in many cases; for the combination of old and young trees in a given area is sure to be unsatisfactory-the old trees will die or will have to be cut out at irregular intervals, and if their places are filled by new trees the $\mathrm{m}$ a $\mathrm{n}$ a $\mathrm{g}$ e ment of the orchard will be difficult, to say the least. Far better choose a new area, as a rule, and start afreshwith young trees.

315. Renovation problems other than pruning.-Besides the mere pruning and handling of the trees themselves, several questions must be considered in orchard renovation. Among them are the general thrift and health of the trees as affected by insects and diseases. Examination will show whether trees are affected by borers, San Jose or other scales, fire blight of pear and quince, black 


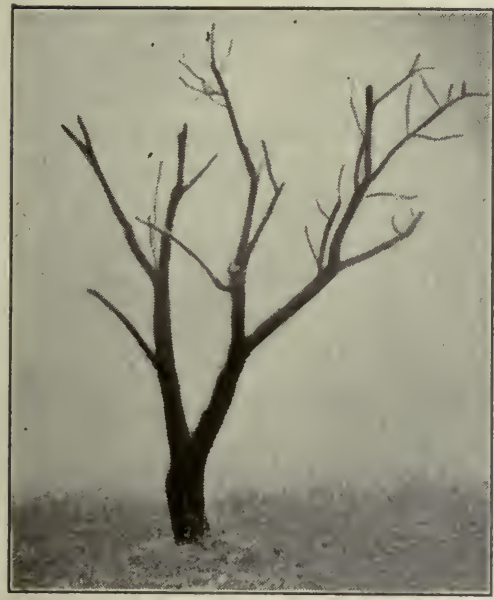

FIG. 316-OLD PEACH AFTER CUTTING BACK SEVERELY

knot of plum and cherry, yellows or rosette of peach, etc. In some cases the , whole tree should be burned, in others only the affected branches; in still others spraying will be $\mathrm{s} u$ ffi $\mathrm{c}$ i en t. How to make cuts, what wood to leave and what to remove, how to recognize "blind" wood and "fruiting", wood, etc., are points already discussed in previous chapters.

316. How to determine the health of the trees.-Trees often fail to thrive even when no disease or insect, such as those just mentioned, have played havoc with them. Something ails them. It may be lack of moisture in the soil, nearness of hardpan to the surface, lack of fertility in the soil, "bark binding" of the trunk and bra n che s (114), or some other cause that affects the nutrition. Careful examination should discover the cause. In most cases one of the surest signs that the roots are in good condition, though the top is in trouble, is the abundance of suckers

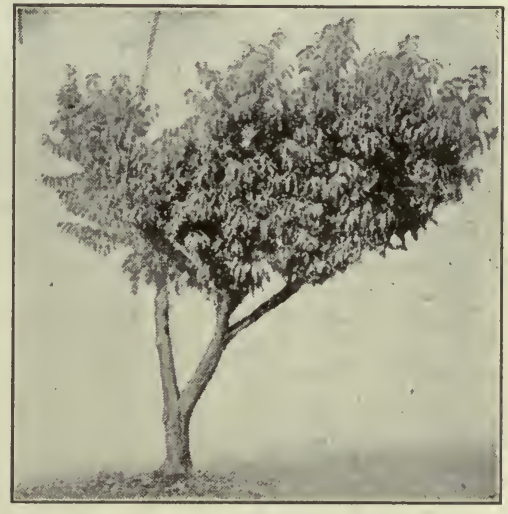

FIG. 317-OLD PEACH TREE REJUVENATED. FIRST SEASON'S GROWTH AFTER CUTTING 
around the base of the trunk and water sprouts on the main branches (Fig. 32).

317. Successful cases. - While it is a fact that because of such reasons as those given above, attempts to renovate or rejuvenate neglected orchards would often prove unremunerative, especially in the hands of an inexperienced fruit grower, it is nevertheless true that in the older settled parts of the country, where orchards were planted

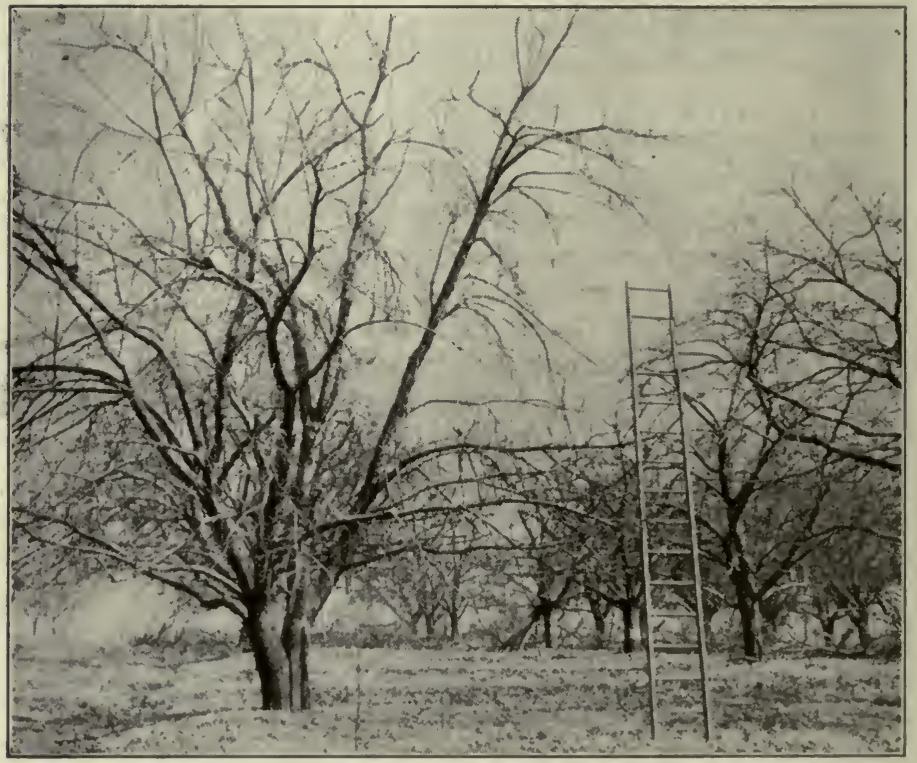

FIG. 318-ORCHARD BEFORE RENEWAL OR RENOVATION

by a former generation and neglected by the present one, countless orchards which for years had not merely been practically profitless to the owners, but had also been a menace to the neighboring plantations because they were breeders of insects and diseases, have been re-established on a profitable basis by judicious rejuvenation, soil fer- 
tilizing and cultural methods, and this often in only two or three years of vigilant attention.

The most notable cases of such work that have come under my observation are the half dozen or more rundown orchards bought up or rented for a term of years by $D_{i}$. Frank H. Lattin of Albion in western New York. In some cases the areas were so infested with undergrowth that the neighbors facetiously suggested that Dr.

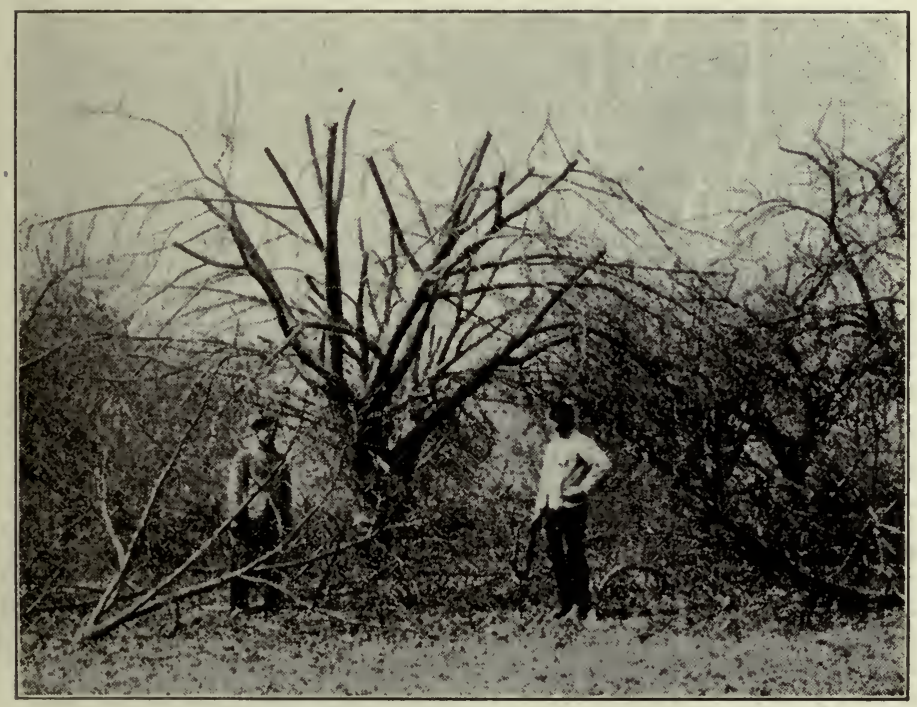

FIG. 319-CAUGHT RED HANDED!

Note the havoc both in the trees and on the ground. But see Figs. 4 and 321 for final judgment.

Lattin cut the trees down and rely for his profits on the raspberries and blackberries growing among the trees. the tops of which were veritable brush piles. But so easily and inexpensively was the work of reclamation performed, so profitable did the orchards become, and in so short a time, that these same neighbors said it made their heads swim! It must be remarked, however, that 
in these orchards the trees in most cases had merely been neglected; they had not been butchered (Figs. 61, 201 to 204) so that their trunks and main branches had decayed heartwood. No, they were mostly sound to the center.

318. Renovated orchards quicker to respond than young trees.-When conditions such as these exist, it is often if not usually possible to secure profitable returns in a shorter time (fewer years) than when a new orchard of the same kinds of fruit is set. Of course, the younger

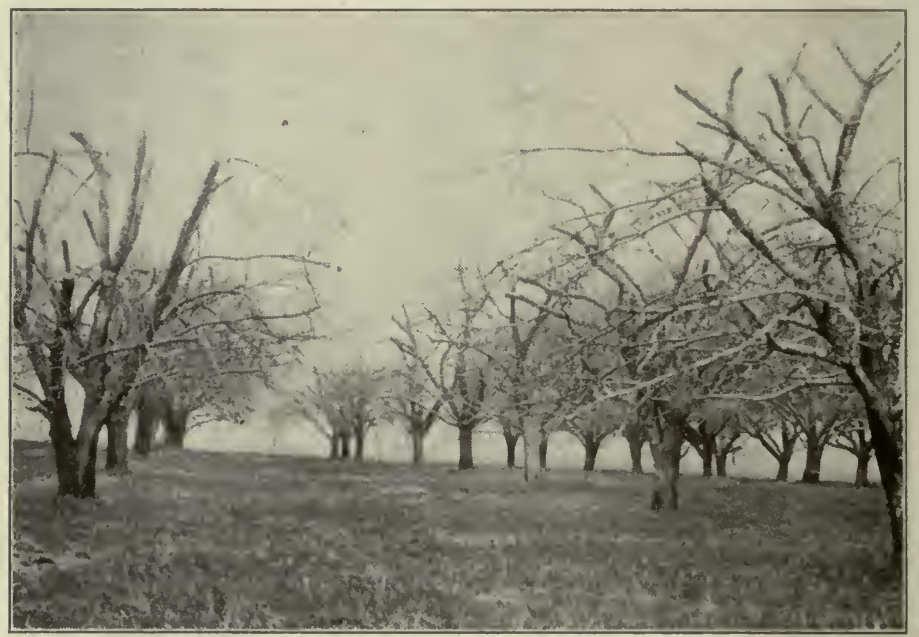

FIG. 320-TREES AFTER CUTTING. RUBBISH HAULED AWAY

the trees and the better they have been trained for the first few years, the more likely is success to be achieved and the longer are they likely to continue profitable under good management. With apple, pear and sweet cherry trees that are sound it is often well worth attempting to rejuvenate specimens fifty to seventy-five years old, or even older in exceptional cases; but if badly made wounds have resulted in rotting of the heart wood, trees may be worthless for rejuvenation when only fifteen or 
twenty years old. With peaches, apricots, nectarines, plums and sour cherries, which are considered shortlived trees and moreover are quick maturing, the chances are that in neglected orchards borers, San Jose scale, black knot and other pests may have weakened the specimens so seriously that it will be best not to attempt rejuvenation, but to destroy the trees and make a new plantation on land as far as conveniently possible from the neglected ones.

319. Vigor of tree is the important point to seek: age

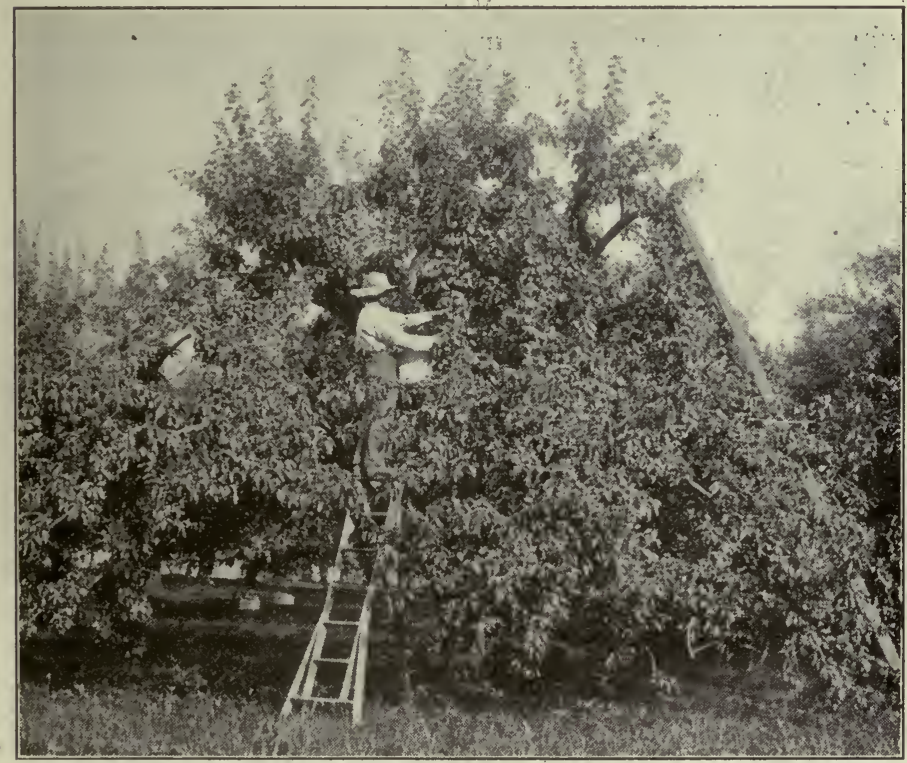

FIG. 321-FIRST SEASON'S GROWTH AFTER PRUNING. MEN THINNING FRUIT

Note new growth and height of tree.

is merely incidental. Vigor is indicated by the condition of the roots and the branches during winter and the color of the leaves during summer. Unless the roots are good, 
the case is very doubtful of success. Don't be disturbed by the small dead branches in the top. They have died probably for lack of light or because of pest injury. Pay special attention to the suckers and the water sprouts (Fig. 32). The former indicate the vigor of the roots, the latter of the branches and the trunk. Judicious spraying will exterminate most of the insect and disease enemies and give the trees a clean bill of health. Carefully save the water sprouts until after all dead and incurably diseased wood has been removed; then thin them out. exercising care to leave those that will fill in the blanks where limbs have been removed.

In every orchard each tree must be studied as an individual problem. Some specimens will need little pruning.

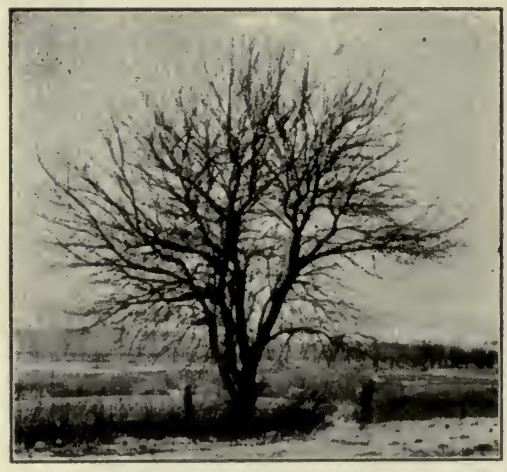

FIG. 322-ISOLATED APPLE TREE BEFORE PRUNING

but the majority will probably need a great deal. Just how much to do will depend upon the amount of dead and diseased wood in the top, whether or not the top must be lowered, and the number, size and position of the water sprouts. Trees in fairly normal condition and of a $1 \mathrm{readv}$ convenient height will need only normal pruning; those with abundant dead wood and excessive growths may have to be heavily pruned, and those too high for effective spraying, economical thinning and harvesting may have to be dehorned (Fig. 320).

When a high-topped tree with no water sprouts to fall back upon must have its head lowered, then to re!y on a light pruning would be a mistake, because it would not force the water sprout growths desired. A severe 
pruning of the top is indicated in such cases, the idea being to force the development of such adventitious growths. The needless stubs may be cut off two or three years later. It is not wise at once to cut off the limbs at the points to be chosen ultimately - "two or three years later"-because there are not enough water sprouts and small branches to utilize the plant food forced up by the roots.

On the other hand, when there are plenty of water sprouts placed well down on the trunk and the main

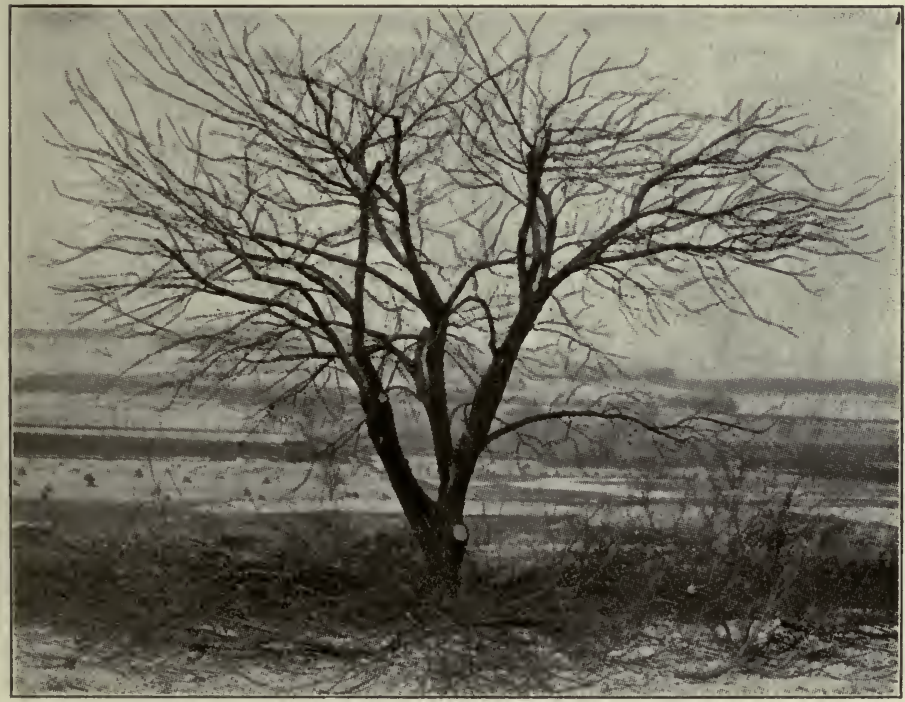

FIG. 323-ISOLATED APPLE TREE AFTER BEING PRUNED

branches, the tops may be dehorned. Here again good judgment is necessary. So many trees are needlessly dehorned that it seems necessary to say that when a tree has a fairly good top better lower it a little at a time, taking three to five years to do the work, by cutting out small limbs in the top each year. Thus the trees should 
not be thrown out of balance, and they should not only improve steadily, but yield more or less fruit during the process of rejuvenation.

320. "Dehorning" apple trees is a term used to describe the severe reduction of the tops of old and neglected trees by the removal of large limbs, especially in the upper parts of the top (Fig. 30). To a greater or less extent the proposition is the same, though less frequently practiced with other fruit trees (Fig. 31). Jarvis has so well handied this type of case* that his remarks are quoted as follows :

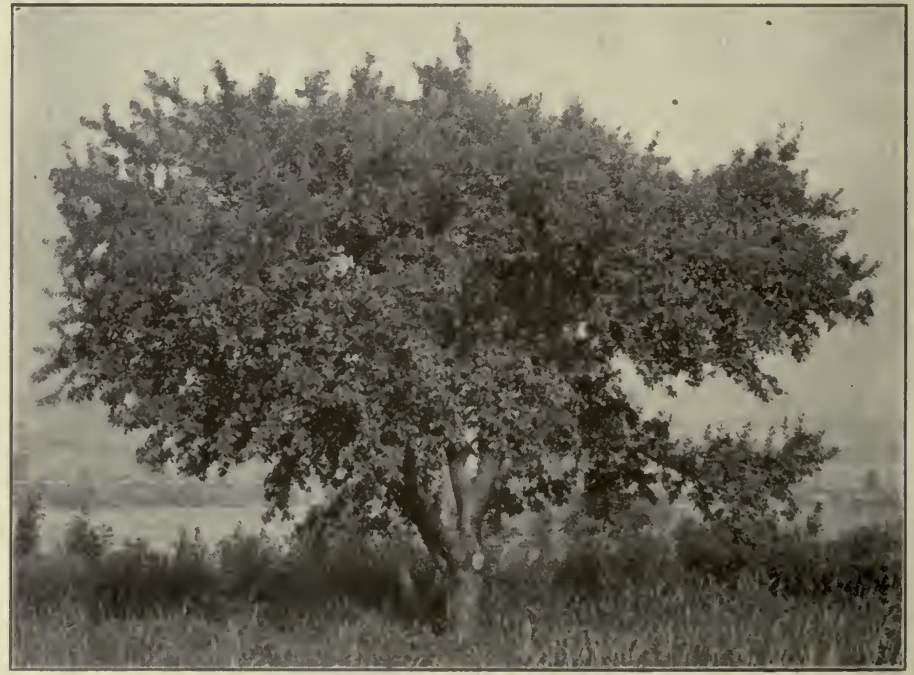

FIG. 324-SAME TREE AS IN FIG. 323 THE SUMMER AFTER PRUNING

"Most trees are too high and may be greatly improved by cutting back the upper branches. A tree that is 30 feet or over in height often may be shortened by 10 or 15 feet, and one between 25 and 30 feet often may be cut back to about 15 or 20 feet. The horizontal branches, as

- Connecticut (Storrs) Bulletin No. 61. 
well as the upright ones, may be cut back to advantage, especially with trees lacking in vitality, and also those infested with scale. In heading-back the upright branches, the cut is usually made just above a side branch that points outward. This tends to make the tree more spreading in habit. With trees that are naturally spreading, and where a more upright growth is desired, the cutting may be done just beyond an upright side branch. If this method is followed with all horizontal branches, a much stronger structure will be the result. The severity of heading-in will depend largely upon the vigor of the tree. Nothing will start a tree into renewed vigor like severe pruning during the dormant season. The cutting back, therefore, should be more severe with weakened trees. With moderately vigorous trees, there is danger of producing a rank growth in the form of watersprouts. If it is desirable severely to headback such trees, it is better to do it gradually, a little each year, and withhold all nitrogenous fertilizers. A still better plan would be to remove about half of the required amount of brush during the winter, and the remainder during the growing season. (The effect of summer pruning upon the vigor of the tree is just the opposite of winter pruning, and will counteract the stimulating effect of the latter.) With most of the neglected orchards, however, the vitality is so low that most of the pruning may be done, without fear of injury, during a single dormant season.

"The severity of cutting-back will also depend upon the presence of scale. The work of spraying is greatly simplified and the chances for success in controlling the scales are greatly enhanced by extreme methods of pruning.

"After the trees have been sufficiently headed-in, all dead and diseased branches should be removed, and also such other branches as are necessary to produce a condition favorable to the free circulation of air and the admis- 
sion of sunlight. While it is possible to overcio the pruning process, especially with the best of neglected orchards, the average man is more likely to err in the other direction." 


\section{INDEX}

Page

Age of shoot................ 53

Alderman, quoted................. 102

American Gardening, quoted..95, 381

Anderson, quoted............. 381

Ann. Ecole, Nat. Agr., quoted... 307

Annual bearing by pruning.... 118

Ann. Sci. Nat. Bot., quoted..... 117

Apple experiments in Netherlands 170

Apple fruit buds............ 57

Apple pruning ................ 242

Apple pruning experiments....89, 102

Apples annually ............ 118

Apples, pruning dwarf......... 369

Apricot fruit buds............. 63

Apricots, pruning mature....... 254

Arbor grape training.......... 329

Arches for trees .............. 379

Australian observations ......... 116

\section{B}

Bailey, quoted .............. 34

Baldwin bud studies............ 72

Baldwin orchard consecutive

bearing $\ldots \ldots \ldots \ldots \ldots \ldots \ldots . .118$

Baldwin pruning experiments..... 109

Bark-bound trees .............. 121

Batchelor, quoted ................ 117

Bearing affected by pruning...... 5

Bearing habit dictates style of

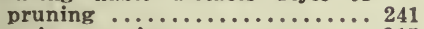

Bearing vs vigor.............. 215

Bedford, Duke of, quoted........ 116

Bellair, quoted............... 381

Blake, quoted............... 224

Bioletti, quoted.........296, 309, 331

Blackberry buds............. 76

Blackberry pruner.............. 148

Blackberry pruning............. 282

"Bleeding" of vines, etc...13, 14, 135

Blight, pear.............. 248

Bloom buds, ornamental........ 359

Boddy, quoted............... 165

Bois, quoted................ 379

Bolting ................. 387

Booth, quoted............... 7

Bramble buds .............. 76

Bramble pruning............ 279

Branch distribution and size...., 228

Branch length.............. 282

Bridge grafting............... 144

Bud, fruit, development........ 66
Buds affected by pruning, ringing,

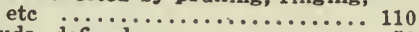

Buds defined.................... ${ }_{52}$

Buds, pome fruit............. 57

Buds, pruner must know where borne $. . \ldots \ldots \ldots \ldots \ldots \ldots \ldots . .62$

Buds, recognizing fruit.......... 64

Buds, resting................. 29

Buds, where borne.............. 52

Bundles, fibro-vascular......... 20

\section{C}

California bulletin, quoted

$296,309,326,331$

California citrus convention,

quoted .................. 238

California grape training.......... 331

Callus ..................... 127

Candelakrum training........... 380

Card, quoted................... 179

Castle's experiments............. 92

Cavities, excavating.............. 386

Cavities, open................ 394

Caywood grape training........... 328

Cell functions $\ldots \ldots \ldots \ldots \ldots \ldots \ldots, 6$

Cells $\ldots \ldots \ldots \ldots \ldots \ldots \ldots \ldots \ldots \ldots \ldots{ }^{6}$

Cementing cavities.............. 391

Cement defects............... 394

Chandler, quoted................ 258

Chautauqua grape training...... 325

Cheal, quoted................ 377

Cherries, pruning mature....... 251

Cherries, recommendations for. 218

Cherries under glass........... 381

Cherry fruit buds ............57, 64

Cherry tree, history of ........... 37

Chlorophyll ................... 23

Citrus Convention, quoted..........237

Citrus pruning.................. 235

Cleveland forester, quoted.......... 165

Climate, influence on pruning....88

Collins, quoted ................ 384

Colorado bulletin, quoted.......... 176

Columnar trees ................ 380

Compt. Rend. Acad. Sci., quoted

107,300

Constructions .............. 111

Contracts, surgery........... 401

Cook, quoted................ 160

Corbett, quoted $\ldots \ldots \ldots \ldots \ldots \ldots \ldots, 89$

Cordon, horizontal............ 381

Cordon, horizontal dwarf......... 38 n

Cordons, horizontal grape........ 346

Cordons, vertical, grape........ 346 
Country Gentlemen, quoted...... 159

Crab tree, history of .......... 43

Cranefield, quoted ............. 280

Cross-wise grape training........ 331

Crotch splitting prevented...... 40

Crotches, avoiding balanced...... 199

Crozier, quoted ............. 6

Cultura, quoted.............. 170

Currant buds................. 74

Currant pruning.............. 287

Custom based on principle...... 212

\section{D}

Defoliating grapes........... 307

Dehorning trees.............. 414

Dewberry buds................ 76

Dickens, quoted............... 116

Diffusion ................... 11

Disbudding grapes ............ 306

Double-headed vines .......... 345

Drainage, cavity ............. 387

Dressings, wound ............ 154

Drinkard, quoted....66, 106, 110,116

Drying, effect of ............ 227

Du Breuil, quoted........... 375

Duke of Bedford, quoted........ 116

Dwarf apple pruning.......... 369

Dwarf tree pruning.......... 364

E

Electrical injuries........... 402

English author, quoted........... 377

English pruning experiments

$89,92,116$

Espalier fences...........878, 880

Evergreens, pruning........... 362

\section{F}

Fakers, tree surgery. .......... 397

Fan grape training ...........326, 345

Farmers' Bulletin, quoted......... 282

Fences for trees.............. 379

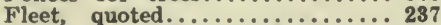

Forbes, quoted from Gardeners'

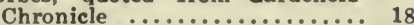

French investigator, quoted...... 299

French writer, quoted............375

Frame branches, choosing ........ 195

Fruit bearing vs season of pruning ................ 118

Fruitfulness affected by growth.. 56

Fruitfulness from shortening twigs ................... 115

Fungl in grape wounds........ 808

\section{G}

Garden and Forest, quoted....... 280 Gardeners' Chronicle, quoted....17, 18 Georgia Bulletin, quoted........ 170 Girdled trees...........17, 111, 138
Page

Gladwin, quoted............ 320

Goff, quoted................80, 95

Gooseberry buds............... 74

Gooseberry pruning............. 289

Gooseberry tree, big........... 293

Goumy, quoted........................ 117

Gourley, quoted............................... 72

Grafting, bridge ................ 144

Grafting $\operatorname{wax} \ldots \ldots \ldots \ldots \ldots \ldots \ldots \ldots 143$

Grape buds......................... 76

Grape, leaf area of........... 26

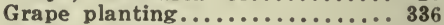

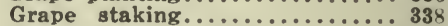

Grape, time to prune........... 299

Grapes under glass............... 352

Grape units................. 296

Growth relations and proof....26, 56

Guying ................... 396

\section{H}

Harper-Adams college experiments 92

Hawaii report, quoted......... 260

Head, height of ................. 224

Heading back effect on stockiness 103

Heads, low .................. 183

Head, time to form.......... 210

Heads, types of.............. 188

Health, determining tree...... 407

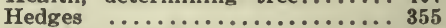

Hedrick, quoted.............107, 369

Herbaceous pruning of grape... 305

High renewal grape training.... 323

Horizontal cordon grape training 335

Horticultural Science Society,

quoted ................... 102

Howe, quoted..............107, 159

Hudson grape training.......... 327

Huxley, quoted............. 6

\section{I}

Ide, quoted................ 170

Injuries, electrical.............. 402

Injuries, kinds of .............. 138

Irons, climbing................ 400

Italian investigator, quoted..... 308

\section{J}

Journal of South Australia, quoted

Australia

\section{$\mathbf{K}$}

Kains' Propagation book, quoted $7,20,143,167,274,364$

Kansas Bulletin, quoted......... 116

Keffer, quoted...........79, 265, 311

Kentucky Bulletin, quoted...... 313

Kniffin modiflcations.......... 320

Kniffin training................ 314

Knives .................... 148.

Knots, how formed............ 125

Keuka grape training.......... 323 


\section{L}

Label wire injuries........... 138

Leader headed trees........... 190

Leader modifled............... 190

Leaf formation............. 29

Lemon pruning............. 237

"Le Petit Jardin"............ 379

"Les Arbres Fruitieres," quoted.. 381

I.ewis, quoted............... 186

Life in girdled trees........... 17

Light, relation of leaves to..... 31

Limbs, how to remove large.... 137

Limbs, when to cut big........ 134

Linemen damage trees.......... 87

Locality, influence on pruning.... 83

London Hort. Soc., quoted...... 293

Low heads................. 18 s

\section{$\mathbf{M}$}

Maryland, qunted............. 106 Massachusetts Bulletin, quoted

Michigan experiments, quoted.. 260 Mills, quoted............... 236 Missouri Bulletin, quoted....258, 261 Mules peel trees............. 18 Multiple cross-wire grape train-

ing ................... 329

Munson grape training......... 318

Muscadine grape "bleeding"..... 14

Muscadine grape training ........ 380

\section{$\mathbf{N}$}

Nailing ................. 889

Nebraska Palletin, quoted........ 157

Newman on vine "bleeding".... 14

New Hampshire Bulletin, quoted 72

New Jersey Bulletin, quoted..... 224

New York Bulletin, quoted

$107,159,320,369$

Netherland Pomological Society, quoted .................. 170

Nursery trees, trunk lengths of.. 172

Nursery trees, when to prune.... 171

\section{O}

Oaks, peeled............... 17

Ohio Circular, quoted...158, 162, 165

Orange pruning ............. 236

Oregon Bulletin, quoted.......... 186

Ornamentals bloom season....... 359

Ornamental trees and shrubs 354,357

Osmosis ................... 11

Overhead grape training....328, 829

Owners' responsibility.........4400

\section{$\mathbf{P}$}

Paddock, quoted ......... 107, 17

Parrales grape training......... 329

Peach fruit buds............. 57

Peach on Marianna stock....... 7
Peach pruning ..........256, 258

Peach pruning experiments......261

Peach rejuvenation............ 273

Peaches, recommendations for... 220

Pear experiments in Netherlands 170

Pear fruit buds............. 57

Pear orchard, old dwarf........ 366

Pears, pruning mature.......... 246

Pears, recommendations for...... 215

Pear tree barked ............. 18

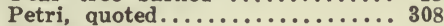

Phloem ................... 20

Photosynthesis .................. 25

Pickering, quoted ..........89, 116

Pit fruit buds............... 57

Planting methods.............. 178

Plant Propagation book, quoted

$7,20,143,167,274,364$

Plum fruit buds......... 57, 62 a

Plums, pruning mature........ 252

Plums, recommendations for..... 219

Pole pruners................ 148

Pome fruit buds............. 57

Poplar shoots............... 30

Poplars peeled by mules......... 18

"Practical Fruit Culture," quoted 377

Pressure, hydrostatic........... 13

Pressure, sap............... 13

Protoplasm ................ 6

Prunes, recommendations for.... 219

Pruning aims............... 81

Pruning a life saver........... 41

Pruning, defective........... 5

Pruning defined................. 1

Pruning effects............... 38

Pruning excessive.............. 40

Pruning in Bible times.......... 1

Pruning, injudicious, destroys

fruitfulness ............ 56

Pruning, season of............. 193

Pruning, summer experiments.... 117

Pruning systems and ideals..... 3

Pruning vs no pruning of grapes 79

Pyramids ................. 379

\section{Q}

Quality affected by pruning...... 5

Quince $\ldots \ldots \ldots \ldots \ldots \ldots \ldots \ldots \ldots \ldots \ldots \ldots 249$

Quince buds.................... 80

Quirn, quoted................... 116

\section{$\mathbf{R}$}

Raspberry buds............. 76

Raspberry, pruning black.......281

Raspberry, pruning red......... 279

Ravaz, quoted.............8. 307

Recherches sur les bourgeons..... 117

Rejuvenation, old orchard..... 405

Rejuvenation of peach.........273

Renewal, grape training........ 323

Renovation, vine.............. 348

Repairing, trees worth.......... 397

Revue de viticulture, quoted.... 299 
Page

Rhode Island report, quoted..175, 179

Ringing experiments.......... 106

Riviere, quoted............... 307

Root hair functions........... 8

Root losses in transplanting.... 9 9

Root pruning.............. 91

Roots, extent of............. 10

Roots, fibrous.............. 8

Roots, tap................ 8

Rotundifolia grape "bleeding"... 14

\section{$\mathbf{S}$}

Sablon, quoted.............. 107

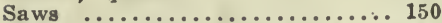

Scars, meaning of, on spurs.... 54

Selby, quoted................ 158

Shade trees.................. 354

Shears ..................... 149

Shoot, age of ................ 53

Simpson quoted from Gardeners' Chronicle ................ 17

Soc. Nat. Hort. (France) quoted 307

South Carolina Bulletin, quoted 14

Spacing frame limbs......... 195

Spacing plants.............. 33

Spindle-formed trees.......... 380

Sprouts on felled trees.......... 19

Spur grape training............ 327

Spur renewal grape training.... 324

Spurs, fruit............ 54

Staking grapes............... 338

Starns, quoted............... 170

Staz. Sper. Agr. Ital., quoted... 308

Stem extension............. 29

Stomata ................... 15

Stone fruit buds............ 59

Stone, quoted.............. 402

Stringfellow pruning........... 168

Stripping experiments......... 106

Stub pruning.............. 174

Stub-root pruning............ 168

Suckering grapes............ 807

Summer pruning.........337, 338, 343

Summer pruning experiments.... 117

Summer pruning non-bearing

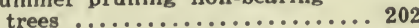

Summer pruning of grape...... 305

Surgery, when to do......... 394

\section{$\mathbf{T}$}

Taille Hative au Taille Tardive, quoted .................301, 302

Telephone linemen.............. 87

'Tennessee Bulletin, quoted

$79,265,311$

Texas Farm and Ranch, quoted.. 170

Thinning by pruning........... 118

Thinning grape shoots........... 306

Timber improved by peeling bark 17

Tools, pruning............146, 309

Tomato pruning............ 89
Page

Topping grape shoots........ 306

Top-worked trees............ 274

Transpiration of water........14, 15

Transplanting, pruning at....... 173

Transportation of water....... 16

Tree surgery............... 384

Trellis, grape................ 309

Types of heads............. 188

\section{U}

Umbrella grape training........831

Undercutting .............. 887

Unilateral grape training......... 335

Units of grape pruning.........2 296

Utah Bulletin, quoted......... 117

\section{V}

Vase-formed trees..........188, 380

Vase-formed vines............. 345

Venation, leaf.................. 22

Vidal, quoted................. 299

Vigor, determining tree.........4 411

Vine pruning, California....... 350

Vine renovation............... 348

Vine supports .............. 310

Virginia Bulletin, quoted..66, 106, 116

\section{W}

Walnuts, recommendations for.. 220

Washington Bulletin, quoted.... 85

Water, absorption of ........ 8

"Water branches"................ 19

Water, functions of ............ 7

Water-sprouting grapes............ 307

Waugh, quoted...........258, 259

Wax, grafting ............... 143

Wells, J. Q., orchard record..... 118

West Virginia Bulletin, quoted

89,102

Whip pruning............ 174

Whitten, quoted ..........170, 261

Winter pruning grapes $337,341,343$

Wire label injuries............ 138

Wisconsin Bulletin, quoted …80, 280

Woburn experiments........89, 116

Wound dressings............... 154

Wound healing experiments..... 157

Wounds, kinds contrasted....... 125

Wounds on grapes............ 308

Wounds, rational................. 128

Wounds, where to make large.... 133

\section{$\mathbf{X}$}

Xylem .................. 20

\section{Y}

Year Book, quoted.............384

Yeomans's pear orchard........ 366

$Y$-crotches, danger from......... 140 




\section{||||||||||||||||||||||||||||||||||||||||||||}

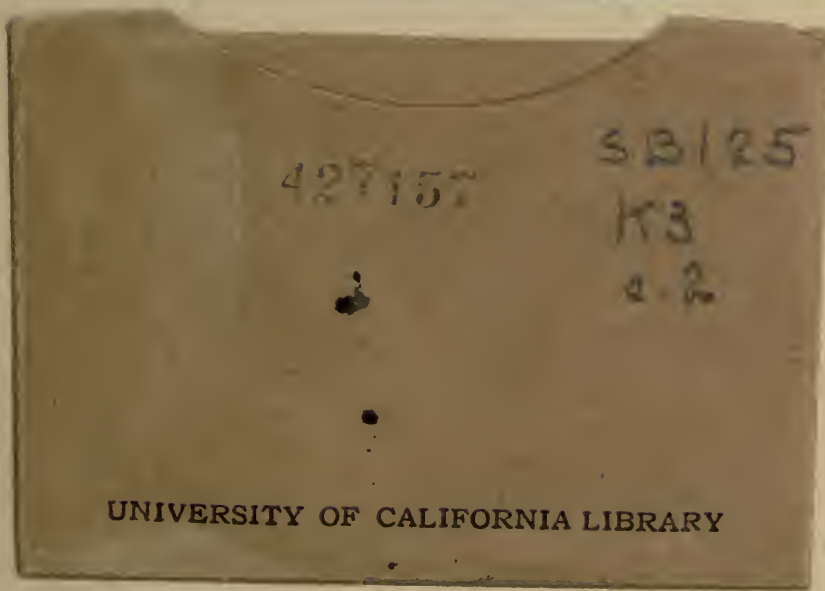

\section{UNIVERSITY OF CALIFORNIA LIBRARY}

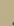


